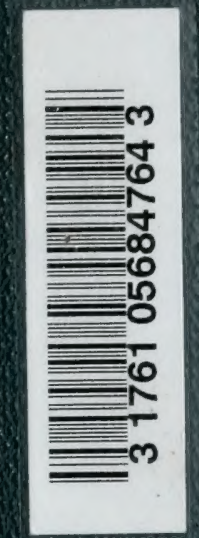



gohn C. Y ppord sinaca A.y. 


\section{WORKS ON AGRICULTURAL CHEMISTRY.}

AN Entirely New Edition.

\section{JOHNSTON'S ELEMENTS OF AGRICULTURAL CHEM-}

ISTRY. From the Edition by SIR C. A. CAMERON, M.D., F.R.C.S.I. Revised and rewritten by C. M. AIKMAN, M.A., B.Sc., \&c. Crown 8vo, 6s. 6d.

"We heartily commend this new edition of an extremely useful and able book."-Speaker.

"This popular treatise and text-book has been rendered as complete as the present position of agricultural science renders it possible to be."-Scottish Farmer.

"No farmer who desires to make the most of his holding should be without this well-tried and trusty companion."-Farming World.

\section{An Entirely New Edition.}

\section{JOHNSTON'S CATECHISM OF AGRICULTURAL CHEM-} ISTRY. From the Edition by SIR C. A. CAMERON, M.D., F.R.C.S.I. Revised and Enlarged by C. M. AIKMAN, M.A., B.Sc., \&c. With numerous Illustrations. Crown 8vo, 1s.

"Ought to enjoy a continuance of the popularity which has already carried it through previous issues."-Daily Telegraph.

"Can be confidently recommended as an introduction to a more elaborate study of the questions that are discussed."-Agricultural Gazette.

"Mr C. M. Aikman has considerably enhanced its value by many additions that bring the book abreast with the present advances of agricultural chemistry."-Scotsman.

"If every farmer in this country could be induced to read carefully this little book, and put the knowledge obtained thereby to practical tests, we venture to assert that there would be fewer complaints respecting the unproductiveness of the land, and the difficulty in making a farm pay."-Manchester Courier.

\section{MANURES AND THE PRINCIPLES OF MANURING.}

By C. M. AIKMAN, M.A., B.Sc., F.R.S.E., F.I.C., F.C.S., Professor of Chemistry, Glasgow Veterinary College; Examiner in Chemistry, University of Glasgow, \&c. Crown 8vo, 6s. 6d.

"A welcome addition to the literature of the more scientific side of agriculture........Mr Aikman has done his work carefully and well, and presented the results in a clear and readable form, which will commend itself to his readers." - Nature.

"This is perhaps the most comprehensive and generally useful work on manures that has ever been published."-Farmer and Stockbreeder.

"All persons interested in agriculture will find themselves improved by a careful study of Dr Aikman's work."-Chemical News.

"We welcome this treatise for its fulness and clearness....... We commend the work to all students of agriculture, including farmers, as one containing a vast amount of valuable information."-Agricultural Gazette.

\section{FARMYARD MANURE: Its Nature, Composition, AND}

Treamment. By the Same Author. Crown 8vo, 1s. $6 \mathrm{~d}$.

"The volume is a model of its kind. It is comprehensive yet concise. It is clearly written and admirably arranged."-Farming World.

"Must be strongly recommended for the general accuracy of its teachings, and the clearness and simplicity of its language."-Chemical Neros.

"Clear and incisive in style."-Bell's Weekly Messenger.

"It is a work every farmer should buy and read and make himself familiar with."-Irish Farming World.

WILLIAM BLACKWOOD \& SONS, EDINBURGH AND LONDON. 


\section{STEPHENS' \\ BOOK OF THE FARM.}

Detalling the Labours of the Farmer, Farm-steward, Ploughman, Shepherd, Hedger, FArm-Labourer, Fielid-Worker, and Cattlem-man.

Fourth Edition, Revised, and in great part Rewritten,

By JAMES MACDONALD, Secretart, Highland and Agricultural Society.

Assisted by Many of the Leading Agricultural Authorities OF THE DAY.

ILLUSTRATED WITH 40 PORTRAITS OF ANIMALS, PLANS OF FARM BUILDINGS, AND UPWARDS OF 700 ENGRAVINGS.

Handsomely bound in 3 Volumes, Royal svo, with leather back, gilt top, Price $£ 3,3$ s.

Also in 6 Divisions, bound in cloth, 10s. 6d. each.

\section{Standard.}

"The most comprehensive work on practical farming ever written."

\section{Scotsman.}

"Mr Macdonald has made the work what it was when first published by its author, the standard work on everything relating to the farm."

\section{Farmer.}

"In all matters relating to practical agricultural life, this work is, in the most comprehensive meaning of the term, encyclopædic, entertaining, and most reliable."

\section{Gloucester Chronicle.}

"The completed book literally constitutes a treasure-house for all engaged in our greatest national industry."

\section{Scottish Leader.}

"The one standard manual.......All that is good in Stephens' text has been retained, while an immense amount of fresh information has been incorporated."

\section{Agricultural Gazette.}

"The great merit of the book always was its attention to detail, and in this respect, we believe, it will be found more serviceable than ever."

\section{Farm, Field, and Fireside.}

"The most complete and important description of improved agricultural practice that we have."

Daily Chronicle.

"Mr Macdonald has performed his task with great ability."

WILLIAM BLACKWOOD \& SONS, EDINBURGH AND LONDON. 


\title{
THE FORESTER
}

\author{
LIBRARY \\ FACULTY OF FORESTRY \\ UNIVERSITY OF TORONTO
}


Digitized by the Internet Archive in 2010 with funding from University of Toronto 


\section{THE F O R ESTER}

A PRACTICAL TREATISE

ON THE PLANTING AND TENDING OF FOREST TREES

AND THE GENERAL MANAGEMENT OF

WOODLAND ESTATES

BY

JAMES BROWN, LL.D.

SIXTH EDITION, ENLARGED

Edited by JOHN NISBET, D.CE.

AUTHOR OF

'BRITISH FOREST TREES AND THEIR SYLVICULTURAL CHARACTERISTICS AND TREATMENT,

'STUDIFS IN FORESTRY,' 'PROTECTION OF' WOODLANDS,' ETC.

\section{IN TWO VOLUMES}

VOL. I.

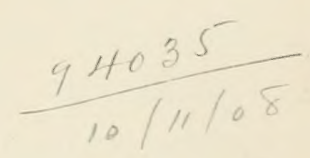

WILLIAM BLACKWOOD AND SONS

EDINBURGH AND LONDON

M D C.C C X C I V 


$$
\begin{aligned}
& 50 \\
& 371 \\
& B 76 \\
& 1894 \\
& 0.1
\end{aligned}
$$




\section{P R E F A C E.}

"Ask of the trees themselves how they should be treated, and they will teach you more than can be learned from books." - Pfeil. König.

"Sylvicultural knouledge has its only sure foundation in practical expcrience."-

Ix the present eclition of this work an eudearour has heen made to engraft the modern Continental science of Sylriculture upon the old British stock of Arboriculture.

In carrying out the task he was invited to perform, the editor lias found it necessary not only to rearrange and practically to rewrite the whole book, but also to prune away portions to a rery considerable extent. Where, however, the views of the author and of the editor have difficed greatly respecting any matters that appear to involre principles, then the latter has made a point of retaining the author's conclusions, though at the same time clearly and pointedly expressing his orn convictions. The object of this has been to allow the student of Forestry to see loth sicles of the yuestion, and to enable him to have the opportunity of testing both opinions by practical ohserration hefore coming to any deliberate conclusion for himself.

In subjecting the work to a thorough rearrangement, as well as revision and amplification, it has heen the aim of the editor to group all cognate matter's under their fropere 
relationships so ats to form chapters, and to make the sequenee of the latter assume something like a natural order.

Nearly the whole of the first chapter consists of new matter. Throughout the rest of the work the editor's amplifications have, so far as conrenient, leen placed in mediumsized type. This is certainly not intended to mean that they are of less interest or importance than the main text, but was a measure adopted in order to prevent the work becoming rery bulky and costly. Eren as it is, with about 150 pages of the former work excised, and with the frequent use of small type, the present edition is considerably larger in size than the last. But the editor trusts that his fulfilment of a task which has been by no means easy will prove of service to the struggling cause of Forestry throughout Britain.

As rearranged, the body of the work confines itself to Forestry as fractised in Britain, and to a description of the trees cultivated as well as of the rarious operations connected with the practice of Forestry; whilst the new portions in smaller type contain facts and hints culled from Continental experience. Finally, all the seattered references to Forestry in other parts of the globe have been collected in the form of an Appendix, for convenient reference.

Throughout the progress of the work the editor has receiverl kinkly assistance from Professor I. Barley Balfour, F.R.S., and also, as regards chapter iil., dealing with the description of the Conifers, from Dr Maxwell T. Master's. F.R.i., to loth of whom he takes this oplortunity of returning thanks.

This new celition hats been enriched by many illustrations olitainer from (reman wortis-more especially from Garer's

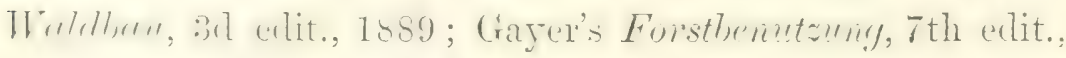
1888; and Hess's Forstschutz, 2 d edit. (vol. i., 1887 ; vol. ii., 1890) - and the editor would here return thanks to the 
authors and publishers concerned for the rearly courtesy with which clichés of the various illustrations were furnished.

During the last twelve years several works relating to scientific Forestry have appeared in English, all of which are either translations of, or else almost purely compilations from, French or German books. Of such, the chief are the following :-

1. Elements of Forestry. By Franklin Hough. Cincimnati, $18 \$ 2$.

2. Manucel of Sylviculture. By G. Bagneris. Translated by E. E. Fernandez and A. Smythies. London. Vol. i., 1876; vol. ii., 1882.

3. Organisation and Valuation of Forests. By J. Laird Macgregor. London, 1883.

4. Manual of Forestry. By W. Schlich, Ph.D. London. Vol. i., 1887; vol. ii., 1891.

5. British Forest Trees, and their Sylvicultural Characteristics and Treatment. By J. Nisbet, D.CEc. London, 1893.

6. Protection of Woodlands. By Kauschinger and Fürst. Translated by J. Nisbet, D.CEc. Edinburgh, 1893.

7. Stuclies in Forestry. By J. Nisbet, D.C.. Oxford, 1894.

But the present edition of The Forester is the first endearour that has been made to unite the scientific sylvicultural methods of the Continent with the less methodical and economical arboricultural practices that have hitherto obtained throughout the United Kingdom; and the editor hopes that his somewhat arduous task will be productive of substantial benefit both to the British woodlands and to those engaged in their formation, tending, management, and utilisation.

J. NISBET.

EDINBURGH, July $189 \%$. 



\title{
CONTENTS OF THE FIRST VOLUIE,
}

\author{
CHAPTER I.
}

INTRODUCTORY,--TREATING OF VARIOUS MATTERS CONAECTED BOTH WITH FORESTS IN GENERAL, AND WITH FORESTRY IN BRITAIN IN PARTICULAR.

Introductory remarks

The rise and progress of Arboriculture and Sylviculture in Britain . . . . 3

The requirements of Britain as regards timber and other forest produce . . 12

Climatic and national-economic influence of woodlands . . . . 15

The æsthetic influence of Arboriculture . . . . . . 15

Scientific investigations into the climatic and national-economic influence of wood-

lands . . . . . . . . . 17

Industrial or technical-economic importance of woodlands . . . . . . . . . . .

The physical capabilities of Britain for Arboriculture and Sylviculture . $\quad$ ?1

The influence of plantations throughout a country . _ _ . . . . . . . . . . . .

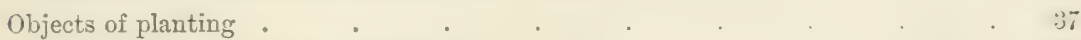

The financial value of sylvicultural crops . . . . . . . . . 39

Education in Forestry . . . . . . . . . 47

British woodlands . . . . . . . 61

State forests . . . . . . . . . . . . 66

Private forests . . . . . . . . . . . . . 67

Forestry in Britain . $\quad . \quad$. . . . . . . . . 68

Laws affecting private woodlands in Britain. . . . . . . $\quad 79$

The future of Forestry . . . . . . . . . . . 76

The British Sylva . . . . . . . . . . . . $\$ 3$

CHAPTER II.

Cupuliferex-

THE BROAD-LEAYED SPECIES OF TREES.

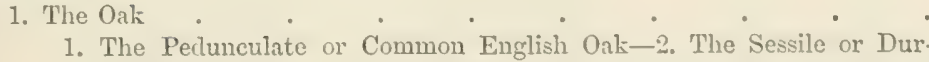
mast Oak-3. The White Oak-1. Holm or Holly Oak, or Erergreen Oak-5. The Scarlet Oák-6. The Turkey or Moss-cupped Oak. 
2. The Peech. . . . . . . . . . 110

3. The Sweet-Chestnut . . . . . . 118

Oleacese-

4. The Ash . . . . . . . . . . 123

Tlumerer-

5. The Eim . . . . . . . 130

1. Common English or Small-leaved Elm-2. Mountain, Scots, or Wych Elm.

Acorine -

6. The Maple .

1. Sycamore, Great Maple, or Scottish Plane-2. Maple or Norway Maple -3. The Soft or Bird's-Eye Maple.

Salicacce-

7. The Poplar.

1. The Italian or Lombardy Poplar-2. The Common Black Poplar-3. Canadian or Black Italian Poplar-4. The Abele-tree or White Poplar-5. The Common Grey Poplar-6. Aspen or Trembling Poplar-7. The Ontario Poplar.

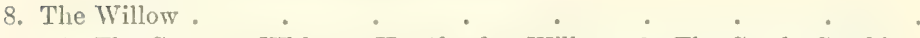

1. The Common White or Huntingdon Willow-2. The Crack, Cracking, or Redwood Willow-3. Russell or Bedford Willow.

Betulacece-

9. The Birch
1. The Common or Silver Birch-2. The Paper Birch-3. The Tall Birch.

10. The Alder.

Platanere-

11. The Plane-tree

1. Oriental Plane-tree-2. American or Western Plane-tree.

Carpincee-

12. The Hornbeam

Hippocastanece-

13. The Horse-Chestnut

Tiliacere-

14. The Lime-tree

Juglandece-

15. The Walnut-tree

Marnoliacea-

16. The Tulip-tree

A inmydalanen-

17. The Cherry .

\section{Pomacere-}

18. The Hawthorn

19. The Mountain-Ash .

Papitionacece-

20. The Iahumum

21. The False Acacia

lliriner -

22. The Holly 
CHAPTER III.

THE CONIFEROUS SPECIES OF TREES.

A-Conifere.

I. Araucarice-

The Chili Pine . . . . . . . . . 246

The Norfolk Island Pine . . . . . . . . 248

II. Abietinece-

1. The Pine

I. Pines having two leaves or necdles in each sheath.

1. The Scots Pine or Common Fir-2. The Black or Austrian Pine3. The Corsican Pine-4. The Taurian Pine-5. The Cluster or Naritime Pine-6. The Resinous or Red Pine-7. The Pyrenean Pine-8. The Calabrian Pine-9. The Mugho Pine-10. The Dwarf or Mountain Pine-11. The Jersey or Scrub Pine-12. Bishop's Pine-13. The Persian Pine-14. The Stone Pine or Umbrella Pine-15. The Aleppo Pine.

II. Pines having three leaves or needles in cach sheath.

1. Gerard's Pine-2. The Large-coned Pine-3. The Chinese Lacebark Pine-4. The Heavy-wooded or Yellow Pine-5. Bentham's Pine-6. The Stiff-leaved or Pitch Pine-7. The Radiated Cone Pine-8. The Remarkable Pine-9. Sabine's Pine-10. Jeffrey's Pine-11. The Tuberculated Coned Pine.

III. Pines having five leaves or needles in each sheath.

1. Cembran, Siberian, or Swiss Stone Pine-2. The Weymouth Pine -3. The Nepaul or Lofty Pine-4. Lambert's Giant-coned Pine -5. The Montezuma or Mexican Pine-6. The Five-leared Mountain Pine-7. Hartweg's Pine.

2. Spruce

1. The Spruce, Spruce Fir, or Norway Spruce-2. The Black Spruce or Black American Spruce-3. The White Spruce-4. The Menzies or Sitka Spruce-5. The Himalayan Spruce-6. The Oriental or Sapindus Spruce-7. Alcock's Spruce-8. The Red Spruce.

3. Hemlock.

1. The Common or Canadian Hemlock-2. The Californian Hemlock -3. Patton's Hemlock or the Californian Spruee.

4. The False Hemlock . . . . . . . 35

5. The Silver Fir . . . . . . . . 357

1. The Common Silver Fir-2. The Balsam or Balm of Gilead Silver Fir-3. The Lovely Silver Fir-4. The Leafy-bracted Silver Fir -5. The Great Californian Silver Fir, or Vancouver Island Pine6. The Mount Enos or Grecian Silver Fir-7. Low's Californian Silver Fir-8. The Noble Silver Fir-9. Nordmanu's or the Crimean Silver Fir-10. The Upright Indian Silver Fir-11. The Spanish Silver Fir-12. Webb's Indian Silver Fir.

6. The Larch

7. The Cedar d ' The Deodar or Indian Cedar-3. The Mount Atlas Cedar. 
III. Cupressince-

1. The True Cypress Epright or Italian Cypress-2. The Large-coned
1. The Common U

Cypress.

2. Dwarf Cypress or False Arborvite

1. Lawson's Cypress-2. The Nootka Sound or Alaska Cypress-3. The Obtuse-leared or Japan C5press.

3. The True Arborvitio

1. The Common or American Arborvitx-2. The Giant Arborvitx.

4. Chinese Arborvitio

5. The Incense Cedar

6. The Juniper .

IV. Taxodinece-

1. Japan Cedars

1. The Japan Cedar-2. The Elegant Japan Cedar.

2. The Mammoth Trees and Redwoods of California

1. The Mammoth T'ree-2. The Californian Redrrood.

3. The Deciduous Cypress .

B-Psetdodrupacei.

Taxacece-

The Yew

\section{CHAPTER IV.}

CONCERNING PURELY ARBORICULTURAT OPERATIONS, OR THE CULTIVATION OF TREES CHIEFLY FOR ORNAMENTAL AND ESTHETIC PURPOSES.

Pineta and Arboreta .

Arboriculture in cities and large towns . . . . . . . . . 447

Trees in towns . . . . . . . . . 453

Planting in order to hide objectionable objects . . . . . . 457

Arboriculture in residential parks . . . . . . . . 459

Physiological effects of transplanting _. . . . . . . 466

Best method of transplanting large trees . . . . . . . . 471

Nachines for transplanting large trees . . . . . . . 481

The Kingston Hall machine . . . . . . . . . 481

The French transplanting machine . . . . . . . 485

The raising of fallen trees . . . . . . . . . 487

Machines for transplanting smaller trees and slirubs . . . . . 488

Transplanting (continued frota p. 481) . $\quad . \quad$. $\quad . \quad$. $\quad . \quad 489$

Best season for transplanting _ . . . . . . . . . . 491

Stimulating the vigour of old trees . . . . . . . . . 492

Prevention of further decay in wounds and holes . . . . . . 494

CHAPTER V.

THE DISTRIBUTION OF TIALER CROPS ON LARGE ESTATES.

Extent of afforestation . . . . . . . . . . . . 497

Lajing out of plantations . . . . . . . . . . . 499

On the selection of trees for planting _ . . . . . 512

Should pure plantations be formed, or mixed woods? . . . . . 518 


\section{CHAPTER VI.}

SOIL-PREPARATION FOR THE FORMATION OF TIJBER-CROPS.

Object of soil-preparation

Advantages of drainage

Drainage of woodlands

Laying out of drains .

Drainage-ploughs

Closed or covered drains

CHAPTER VII.

THE FORMATION OF TIMBER-CROPS, - NATURAL REGENERATION, SOWING AND PLANTING.

Regeneration of woods

Natural regeneration by enclosure merely . . . . . . 563

Planting

Artificial regeneration

Choice between sowing and planting

Season for planting .

Nethods of planting-

1. Pit-planting .

2. Notching

3. Tumping or planting on mounds

Trimming of plants .

Hints concerning planting

Density of plantations

Conduct of planting operations . . . . . . . . . 584

Planting in mountainous tracts . . . . . . 596

Planting on hillsides and on the higher uplands . $\quad . \quad$. $\quad . \quad 599$

Planting on lowr-lying tracts . . . . . . . . 601

Planting of waste lands . . . . . . . 603

Planting near the sea-coast . . . . . . . 605

Planting on mossy land . . . . . . . 610

Coppice for powder-mood . . . . . . . 611

Planting of scrub-lands . . . . . . . 616

Replanting of woodlands . . . . . . . . 618

Hedgerow timber . . . . . . . . 622

Cost of planting

626 



\section{THE FORESTER.}

\section{CHAP'TER I.}

INTRODUCTORY,-TREATING OF VARIOUS MATTERS CONXECTED BOTH WITH FORESTS IN GENERAL, AND WITH FORESTRI IN BRITAIN IN PARTICULAR.

Introductory Remarks. - Wherever there have been vast stretches of "forest primeval" - that is to say, over by far the greater portion of the inhabited land of the globe-the clearance, and not the cultivation, of trees has occupied the attention of man from the earliest ages even down to the present day. In the very earliest times the clearance of woodlands for the purposes of agriculture was a work of merit; for the first instance in which anything at all relating to Forestry is mentioned in the Bible is in the 5th verse of the $7.4 \mathrm{th}$ I'salm, which says that "A man was famous according as he had lifted up axes upon the thich trecs." For thousands of years in the past the same work has been going on that is to-day being carried out in the direction of clearance in the remote jungles of Assam, Chittagong, Burma, and Siam, by dark-skinned tribes of nomadic habits; and which is also being carried ont very actirely by the white colonists and squatters throughout North America, Southern Africa, Australia, and other colonies. In tropical and subtropical districts having heavy rainfall, this clearance and destruction of the natural forests for purposes of temporary agricultural occupation is soon repaired again by nature: but where the occupation is permanent, as on the great plains of Hindostan, even in tropical countries the area of forest becomes restricted to those parts only whose soil is not good enough for permanent utilisation. In parts cleared by white settlers,

VOL. I. 
on the other hand, the first clearance is generally made with the express intention of a permanent occupation.

The lands that are cleared and permanently occupied are, first of all, those that offer natural advantages of one sort or another. Productivity or richness of soil, convenient situation on the banks of a limpe strean or at a ford which renders communication easy, a locality readily defensible anainst natural danger's like floods, or against enemies, are all matters that have received, and still receive, more or less consideration in clearing away the tree-growth that was at first one of the free gifts of nature.

Gradually, in course of time, this work of clearance has proceeded so far in certain countries that legislation has been required in order to frutect the existing areas still unler tree-growth against further encroachment; for it has been found that, except under unusually farvumalle conditions, the clearance of the natural forests has a very improtant influence on the ruming off of aqneons precipitations, on the motion of moisture within the soil, and on the amelioration of climates apt to vary from extreme heat in summer to excessive and intense cold in winter.

Although the Timber Ltilisation and Transport transaction, entered into between Solomon, King of the Jews, and Hiram of Tyre, in respect of Cedar and Fir from the forests of Lebanon (now almost totally devastated), details concerning which are to be found in 1 Kings chap. v. verses 6 to 16, is of considerably prior date (about 1000 B.C.), yet the first recorded instance of anything like Forest Arministration or Forest Conservancy is that mentioned in Nehemiah chap. ii. verse 8, where that prophet asked King Artaxerxes (in the twentieth year of his reign-i.e., in 384 B.c.) for "a letter unto Asaph, the liceper of the king's forest, that he may give me timber to make beams for the gates of the palace which appertained to the house, and for the wall of the city, and for the house that I shall enter into."

But of all the nations of antiquity the Romans were the greatest with regard to Sylviculture and Arboriculture: of this ample proof is derivable from the writings of Pliny. At an early period of their national history they found by experience the evil effects of the injulicions and excesive clearnee of wordlands, in the insalubity of swampy tracts, and in the reaction on the productive capacity of the agricultural lands. They were the first to introduce exotic trees into Britain; for many species can be traced back to their importatim, whilst many uthers that failed to acclinatise themselves and to beenne lenizens were intrulnced hy then first of all, although they had to be reintroduced later on. They were, in the common sense of the word, Foresters; for we learn, from both Pliny and Horace, that they plinted and reared coppice-woods for poles to supumt their vines, 
and for various other useful purposes, and that they planted Willows for basket-making and other wicker-work. It is also stated that they had forests on cheir hills, from which they ent timber for building purposes.

The Rise and Progress of Arboriculture and Sylviculture in Britain.-No reliable information exists as regards the particular period in the history of Britain at which tree-culture was first commenced; but there can be no reasonable doubt that the Romans were the first to introduce the art, at least to any important extent. To them we owe the English Elm, Lime, Sweet-Chestnut, I'oplar, and many other trees that failed, however, to establish themselves as forest-trees.

When any country is being opened out, the first clearances, as has above been indicated, are made at places offering special advantages of one kind or another. And when, in course of time, the natural forest gives place to fields and pasturage, the areas covered with tree-growth gradually become restricted to woodlands on the poorer qualities of land or in tracts that are inconveniently situated.

In the British Islands, where not even one of the highest mountain-peaks reaches an altitude of $4500 \mathrm{ft}$., there was nothing to necessitate the retention of wooled areas to serve purposes like those of the ban-forests of alpine countries, in obviatiug the formation of avalanches and the disturbance of agricultural tracts and vineyards by landslips; but love of the chase was the sole motive olject uring the early kings of England and Scotland to set apart tracts of woollands as forests or royal hunting-grounds.

Many such forests existed throughout England at the time of the Norman Conquest, but a great impetus was given in this direction by William I. and his successors: and the new forests created were not always confined to woodland tracts merely, but sometimes, as in the case of the great New Forest in Hants, included lands that hiul been cleared for permanent agricultural occupation.

The modern signification of the word Forest, however, has come to mean any woodland tract that has become an object of human care, with a view to the productive capacity of the soil being utilised to its fullest financial and economic advantage. The treatment of forests on sound, rational, scientifie, and financial principles constitutes the modern Art of Sylviculture, which is now struggling hard, especially in Scotland, for recognition and encomragement: whilst the cultivation of individual trees, or of small groups or patches, intended rather for ornament, beauty, shelter, or game-rearing, forms the minor Art of Arboriculture, whose wsthetic or game-protecting objects are comparatively indepentent of the exact financial demands 
that, in subordination only to the permanent maintenance of the productive capacity of the soil for the growth of timber-crops, forms the ruling principle in sylviculture. The differences between Sylviculture and Arboriculture are, in fact, precisely analogous to those existing between Agriculture and Horticulture. ${ }^{1}$

The first reliable account with reference to the planting of trees in liritain is that wiren by Holinshed in his Drseriptiun of Eritaine, who states that, in the reign of Henry VIII., "plantations of trees began to be made for purposes of utility." But it can be proved that the cultivation of the trees and woods of the New Forest was undertaken prior to the reign of Edward IV.- that is to say, about 450 years ago. In 1523, Fitzherbert wrote a book on planting, which is the first arboricultural work in the English language.

According to Gouch (Brit. Topo,, p. 61), it would appear that before the year 1597 Gerard had 1100 different plants and trees in cultivation.

From the date last noted up to 1664, when Evelyn first published his celemrated Silw, the Silver Fir, Maple, and Larch, among true forest-trees, and the Plane, Horse-Chestnut, and Rubinia, as well as many other ornannental trees, were introduced into England, and cultivated by private proprietors in their gardens and on their pleasure-grounds, and especially on those at Fulham Palace, the seat of Bishop Compton.

Considering the time at which it was written, Evelyn's Silva, or a Discourse of Forest-Trees, is a very interesting and philosophical work on the subject of planting and rearing trees. He was an authority on Arboriculture in his day, and in his writings he enters rery fully into the modes which were hy him adopted with reference to planting, pruning, and thinning. From the stimulus given by this work, the attention of many proprietors would no doubt be called to the advantages of planting trees extensively; and as he was a man not only of very considerable natural taste and ability, hut also occupied the high position of secretary to the lioval society. he would most probably be consulted personally on the subject of which he wrote so much. He seems to have been very fond of quaint Inteh arrlening or clipled specimens of everwretns, which were

1 The editor begs to draw particular attention to this distinction, which is, at the same time, a very important difference. In previous editions of this work, the treatment of the subject of Forestry has been arboricultural rather than sylvicultural: in the present edition howerer, an endearour is made to treat the subject as much as possible from a sylvicultural, as well as an arboricultural, point of view, but remembering always that, throughout Britain, Forestry is at the present moment in a transitional stage, and on the whole partakes more of the nature of Arboriculture than of scientific Sylviculture. 
greatly the fashion in his day; but, from his writings in general, it is evident that he was more a promoter of the planting of valualse timber plantations than of gardening or ornamental planting. And it is evident that the subject attracted a considerable amount of attention towards the close of the seventeenth century, for his Silin ran through three editions in little more than forty years. In fact, in the third edition of his work (1706) he hegins the celehrated Discourse by

"regretting the impolitic diminution of our timber, . . . caused through the prodigious havoc made" by those who "were tempted, not only to fall and cut down, but utterly to extirpate, demolish, and raze, as it were, all the many goodly woods and forests which our more prudent ancestors left standing, for the Ornament and Service of their Country."

From the fact of the Botanic Gardens at Edinburgh having also been founded by Dr Balfour in the year 1670, it seems much more than probable not only that about this time the formation of plantations was making extensive progress in Scotland, which we know to have been the case from timber felled and utilised during the present century, but also that a very considerable desire for botanical and arboricultural information had arisen in the country. From the catalogue of plants grown in these Gardens about the time referred to, and published by Mrr Sutherland, the curator, in 1683, it would seem that the Cedar of Lebanon was among the trees introduced in that year.

After the year 1700 a great stimulus seems to have been given to Forestry, for a large number of the great landed proprietors, both in England and Scotland, began to plant on a somewhat considerable scale; but it chiefly took the form of Arboriculture and the ornamentation of the residential portions of large estates. Perhaps Syon House, one of the seats of the Duke of Northumberland, may be specially mentioned as one of the most important cases of arboricultural adornment in point of variety of the species of trees planted. At this place there are still many fine specimens of old trees of all the important species known in the comntry at the time of their being planted.

From gleanings made from old writers on the subject of planting; it is certain that in Scotland Arboriculture was already practised to some extent about the middle of the serenteenth century. From Walker's Essays it appears that the Lime-tree was planted at Tarymouth in 1664, the Silver and the Spruce Firs at Inverary in 168?, the Black Poplar at Hamilton in 1696, the Horse-Chestnut at New Posso in 1709, the Weymouth Pine at Dunkeld in 1725 , and the Larch at the same place in $17 \pm 1$, the English Elm at I)almahor in 
1763 , the Norway Marle at Mountstewart in 1738 , and the Cedar of Lebanon at Hopetoun in 1743. These data prove that a taste for the cultivation of the varims species of trees had sprung up among the landed proprietors of Scotland at a comparatively early period.

In the year 1700 there were upwards of 1000 acres enclosed and planted in the New Forest, Hampshire. ${ }^{1}$

It would seem that in Scotland Thomas, Earl of Haddington, was among the first to plant trees in large masses for profitable use. He began to plant extensively at his seat, Tynninghame, in East Lothian, in 1705 . This nobleman wrote a treatise on forest-trees, and published it in 1733. In this work he says:-

"I will be bold to say that planting was not well understood in this country till this century began. I think it was the late Earl of Mar that first introduced the wilderness way of planting amongst us; and very much improved the taste of our gentlemen, who very soon followed his example."

The wilderness way of planting, referred to by the Earl of Inatdington, is simply a plantation with openings left through it, as vistas from some given point,--taken, no doubt, from the English style of the time.

About the year 1730 , the planting of trees in large masses began to be very generally practised all over the country, both in England and Scotland, as is evident from an examination of the still existing woods.

Shortly after that date many nurseries were established for the purpose of supplying the great demands that arose for young trees for planting. It is also to be inferred from Walker's Essays that between the years 1730 and 1760 public nurseries were established in Scotland for the rearing of forest-trees.

About this time Boutcher, an Edinburgh nurseryman, wrote a treatise on the rearing of forest-trees.

1 Previous to that date the plantations that were formed, and which still exist, amounted to 4500 acres. For convenience, the subsequent plantations may also here be noted. They are thus classifiable:-

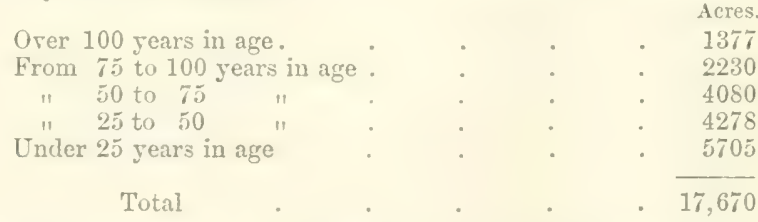

The New Forest aggregates about 92,395 acres, of which 27,658 acres are private property not included within the national forest. Deducting cultivated land, about 63,000 acres, parts of which are burdened with "rights of common," are comprised within the forest. Of this about 30,000 acres, or nearly one-half, were in 1849 described by an eminent firm of land-agents in England as being "unfit for cither agriculture, growth of timler, or pasturage." It might be well, in the national interests, to have this opinion reviewed in the light of our present sylricultural knowledge. 
The Kew Gardens were established in 1760 , and in them there were collected specimens of all known trees; lut a consideralile number of years previous to this date there were several extensive nurseries in England, in which were reared not only forest-trees, but also all the foreign plants known at the time.

As soon as public nurseries had become so plentifully and extensively established in the country as to canse competition, and consequently to produce a supply of young trees at a reasonable rate, proprietors commenced to plant on a large scale; and it will be found that a very large portion of the existing woodlands throughout Britain were planted in the latter part of the last, and the beginning of the present, century.

In England there are few extensive woodland proprietors who have not a large proportion of their older and mature woods of from eighty to one hundred and ten years of age, and of their younger crops from sixty to seventy years, from which it naturally follows that a large amount of planting must have been undertaken between the years 1777 and 1830 .

The same remarks are applicable to the age of the greater portion of the existing plantations in Scotland. For although the planting of trees for profitable purposes was undertaken at a much earlier date in England than in Scotland, still the proportion of plantations of this description was but small in England previous to 1777 , and it will generally be found to hold good that the larger proportion has been made since that date.

In the latter part of the last, and in the beginning of the present, century the chief planters in Scotland were the Duke of Atholl, Lord Breadalbane, and Sir J. Grant of Strathspey. No doubt others also planted extensively in a general sense; but the plantations of any one of those great landed proprietors far exceeded those of perhaps any other private proprietors in Britain.

From 1830 until about 1845, when agricultural returns were high, it would seem that plantations were formed to but a small extent comparatively. This circumstance in the listory of Arborienlture may perhaps also partially be accounted for from the fact that a large portion of the plantations which had been male previous thereto had not succeeded up to the expectations that had been formed; and that, consequently, not only the proprietors who had taken a decided lead in this respect, but also others who purposed to plant, were deterred from their praiseworthy exertions to improve the country, by seeing the generally unremmerative prospects which followed so great an outlay of capital. But it must also be recollected that it was just about this time that railways began to be leveloped very extensively; and no doubt this influenced the expenditure of 
many of the large landed proprietors, and diverted it for the time being to more tempting investments.

That partial fathe should have followed upon extensive planting, at a time when the alvantages of chainage and thinning were neither properly understood nor acted upon, is not to be wondered at. But nratually, and as experience was obtained on the subject, light was thrown on it, and a new era was entered on. This era may be dated from about the year 1845, as previous to this period few himi practised drainage to any important extent on land before planting trees upon it, and as few had understood the necessity and advantages of judicious and systematic thinning.

After the year 1845, when the partial drainage of waste and other lands began to be practised for the planting of forest-trees, and when even the imperfect system then adopted was found to operate in a beneficial manner on the health of the crop, many proprietors, especially in Scotland, commenced to plant largely.

Some time previous to the year 1845 the advantages of thinning young plantations in a decided and systematic way had become somewhat understood, but even then much remained to be learned by those who had the management of them. Within the last forty years, however, great improvements have been effected in this respect; and now, more particularly during the last ten to twenty years, the majority of those engaged in practical forestry in Scotland have learned to understand the principle of thinning, and to act upon it. Very much, however, still remains for them to learn regarding the art of Forestry in its four main branches of-i. Sylviculture, ii. Protestion of Woodlands, iii. Management and Valuation of Forests, and iv. Utilisation of Frorest Produce.

Within the last half-century considerable advances have been effected in the mode of cultivating trees, and in consequence of this proprictors aro now expending, with full confidence of realising profital)le returns, large amounts in the improvement of their properties by planting. And as, along with yearly increasing demands for timber and other forest produce, the productive area is rapidly being diminished, this sulject of the appreciation of timber and the supplying of our demands later on has now become one of the greatest importance to this country from a financial point of view, it is to be hoped, and it can hardly be doubted, that ere long very much greater attention will be brought to bear on it, and, consequently, that still greater advantages will arise from having sound instruction siven in the Principles and Practice of Forest Science.

Since the beginning of the present century, a large number of new species has leen alded to our arboricultural list of forest-trees, most of which are indigenous to the mountainous regions of India 
and America. Many of them, especially those of the Pine and the Fir tribes, are doubtless destined to become of very great importance to this country, both from a sylvicultural and a purely ornamental point of view; indeed, in this respect, the Ped or I ouglas Fir and the Menzies or Sitka Spruce have a value which is not yet properly appreciated.

Many public-spirited proprietors have planted collections of the newer sorts of trees upon their grounds, in order to test their lardiness and suitability to our changeable climate. Through these praiseworthy exertions a certain amount of experience has now been gained with regard to several of the characteristics of these new species; and by means of this, opportunities have been given for forming opinions as to such as have proved unsuitable for anything more than arboricultural adornment, and such as are likely to be of advantage for more extensive sylvicultural attention.

A great impetus was given to the study of Forestry, and to the development of Arboriculture, by the Forestry Exhibition held at Edinburgh in 1884 . It was hoped that a surplus would be secured, after paying all expenses, sufficient for the endowment of a Chair of Forestry in the Edinburgh University; but though in many important respects successful, the scheme failed to achieve this object. It, however, led to the consideration of the whole question of British Forestry by a committee of the House of Commons which sat in 1885, 1886, and 1887, and which, on 4th August 1887, submitted a Report, from which the following portions of more particular interest are excerpted:-

"The Committee was first appointed in 1885 for the purpose of considering 'whether, by the establishment of a Forest School, or otherwise, our' woodlands could be rendered more remunerative.' The Committee was reappointed in 1886 , when, in consequence of the general election, it had not time to complete its inquiry, and recommended that it should be reaplointed in the present session.

"The Committee has received evidence from persons representing various professions, occupations, and interests, connected with woodlands and forest management in England, as well as in Scotland and Ireland, and has especially directed its attention to the following points :-

"(1.) How far there is need of some means of giving instruction to those engaged in the cultivation and management of woodlands.

"(2.) How far the establishment of a school or schools of Forestry would meet such need.

"(3.) Whether a board of persons, representing various interests and associations comnected with Agriculture, Arboriculture, and Sylviculture, should be formed with the assistance of Parliament, for the purpose of examination, granting certificates, and generally promoting the improvement of our woodlands. 
"(4.) Whether by either or both of such means the cultivation of woodlands could be made more remunerative.

"The woodlands belonging to the State are comparatively small, though even, as regards them, the difference between skilled and unskilled management would itself more than repay the cost of a forest school. The woodlands in private hands, however, are far more considerable, and the total area of woodlands amounts, according to the agricultural accounts, to 2,788,000 acres, viz. :-

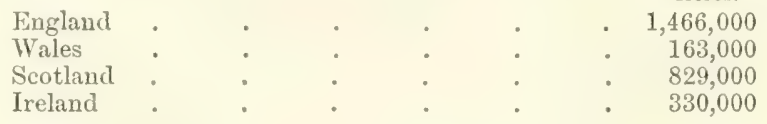

Moreover, strong evidence has been given before your Committee that large tracts of land in the United Kingdom, especially in Scotland and Ireland, might be planted with advantage. 'The forests in India and the Colonies must also be taken into consideration, and on the whole, the forest area in the British Empire is greater than that belonging to any other country. Your Committee are satisfied that, so far as Great Britain and Ireland are concerned, the management of our woodlands might be materially improved. Moreover, the present depressed values render economical and skilful management even more important than if the range of prices were higher, though it is probable that, with the waste of forests elsewhere, a brighter future is in store for home forestry, and that some considerable proportion of the timber now imported, to the value of $£ 16,000,000$, might, under more skilful management, be raised at home.

"Nearly every other civilised State possesses one or more forest schools. In this country, on the contrary, no organised system of forestry instruction is in existence excepting in connection with the Indian service.

"The witnesses examined before the Committee have been generally and strongly of opinion that the establishment of forest schools, or at any rate of some organised isystem of forest instruction, would be very desirable; but they have differed considerably as to the best mode in which this might be effected. There is a general agreement that the establishment of a Forest Board would be a wise step.

"As regards the formation of a forest school, more than one centre of instruction would be desirable; though in the first instance it might be well to establish one school only, in order to secure the most complete equipment, the best teachers, and a sufficiency of students. . . . This school would doubtless be situated in England, but a school for Scotland is also urgently needed, and your Committee are of opinion that it would probably be desirable to found another in Ireland.

"As regards Great Britain and Treland, the demand would be principally for instruction adapted to the needs of land-agents, foresters, and wood-reeves. ... Even as regards ordinary woodmen, your Committee consider that a certain amount of simple and practical instruction would be very useful.

"Apart from the question of actual profit derived from tree planting, its importance as an accessary to agriculture is shown by the effects which woods 
have in affording shelter and improving the climate; and your Committee are of opinion that, whilst on public and national grounds timber cultivation on a more scientific system should be encouraged, landowners might make their woods more remunerative were greater attention paid to the selection of trees suitable to different soils and to more skilful manasement after the trees are planted.

"Your Committee have had evidence that, apart from any immediate pecuniary benefits, there would be considerable social and economical advantages in an extensive system of planting in many parts of the kingrlom, especially on the west side of Ireland and in the Highlands of Scotland. This subject is one of great importance, and well worthy of early consideration.

"Your Committee also think it right to call attention to the present unsatisfactory condition of the New Forest. Mr Lascelles, the deputy surveyor, has expressed himself strongly on this question, and attributes it to the Act of 1877. 'There are to be seen by the student of Forestry,' he says, 'over 40,000 acres of waste land lying idle and worthless. But by clause 5 of the Act of 1877 no planting may be done there. He will see several fine plantations of Oak, which are not only ripe and mature, but which are going back rapidly, and he will wonder why the crop is not realised and the ground replanted, till he is referred to clause 6 of the same Act, by which he will see that the ground may not be cleared of the crop. Last, and worst of all, he will see some 4500 acres of the most beautiful old woods in the country, most of which are dying back and steadily going to wreck and ruin. But here again absolutely nothing can be done. . . . It is sad to see them dying out, when all that is required to preserve them for future generations is to imitate the wisdom of those who made them at first, and by simply protecting, by enclosing them and removing dead trees, leave it to nature to perpetuate them. .. Those who framed the New Forest Act of 1877 desired to conserve these old woods, but their zeal seems to have carried them so far as to defeat the object they had in view; and I cannot but think that had Forestry been a science commonly taught in the past, as I trust it may be in the future, owing to the result of this inquiry, no such clause could ever have found a place in an Act of Parliament dealing with woodlands.' The object of the Act of 1877 , no doubt, was that the forest should be maintained in a state of natural beauty; and as the effect now appears to be to defeat this very object, the present condition of the forest demands the serious attention of the Government.

"Your Committee recommend the establishment of a Forest Board. They are also satisfied by the evidence that the establishment of forest schools, or at any rate of a course of instruction and examination in Forestry, would be desirable, and they think that the consideration of the best mode of carrying this into effect might be one of the functions intrusted to such a Forest Board."

During 1893 an exhibition of Horticulture and Forestry was held at Earl's Court in London; but owing to the somewhat hasty manner in which it was projected and arranged, the Forestry portion was less complete and instructive than would otherwise have been the case. 
The Requirements of Britain as regards Timber and other Forest Produce.- Even since these figmes were put before the Committee on Forestry, there have been changes in the total of woodlands, for the Agricultural Returns of Great Britain, published for 1892 by the Board of Agriculture, show the following statement:-

\begin{tabular}{|c|c|c|c|}
\hline In the United Kingdom. & & Acres. & $\begin{array}{l}\text { Percentage of } \\
\text { total area. }\end{array}$ \\
\hline Total area of land and water. & . & $77,642,099$ & 100.0 \\
\hline Arable land . & . & $20,444,577$ & 25.5 \\
\hline Permanent pasture . & . & $27,533,326$ & 35.5 \\
\hline TVoodlands (and nurseries) & . & $3,005,670$ & 3.8 \\
\hline
\end{tabular}

Though not very extensive as compared with the forest areas of many of the countries on the continent of Europe, these 470 square miles of woodlands probably represent a capital value, in growing timber alone, of a sum greatly in excess of $£ 20,000,000$ as the actual cost of production, and with proper treatment they should have a prospective value of a very much greater amount.

In comparison with our woodland areas, the continental countries of Europe exhibit the following totals of forest lands: ${ }^{1}$

\begin{tabular}{|c|c|c|c|c|c|c|}
\hline \multicolumn{3}{|c|}{ State. } & \multirow{2}{*}{$\begin{array}{c}\begin{array}{c}\text { Forest area in } \\
\text { acres. }\end{array} \\
447,592,405\end{array}$} & \multirow{2}{*}{\begin{tabular}{|c|}
$\begin{array}{c}\text { Percentage of } \\
\text { the total area } \\
\text { of the State. }\end{array}$ \\
- \\
36.0
\end{tabular}} & \multirow{2}{*}{$\begin{array}{c}\begin{array}{c}\text { Acreage per } \\
\text { capita of } \\
\text { population. }\end{array} \\
4.94\end{array}$} & \multirow{2}{*}{$\begin{array}{c}\text { Percentage } \\
\text { owned by tho } \\
\text { State. } \\
57.4\end{array}$} \\
\hline Russia ? & . & • & & & & \\
\hline Finland & . & . & $50,359,471$ & 38.0 & 23.14 & 70.5 \\
\hline Sweden ? & . & 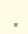 & $45,061,984$ & 44.4 & 9.50 & 31.0 \\
\hline Norway & . & . & $19,280,820$ & 24.0 & 10.67 & 13.0 \\
\hline Germany. & . & . & $34,353,743$ & 25.7 & 0.69 & 32.7 \\
\hline Austria \} & . & & $24,150,215$ & 32.6 & 1.11 & 6.5 \\
\hline Hungary $\}$ & . & . & $22,683,469$ & 28.3 & 1.53 & 16.1 \\
\hline France & . & . & $23,360,062$ & 17.7 & 0.61 & 11.3 \\
\hline Spain & $\therefore$ & & $20,955,480$ & 17.0 & 1.28 & 83.7 \\
\hline \multirow{2}{*}{$\left.\begin{array}{l}\text { Turkey (with } \\
\text { Bulgaria) }\end{array}\right\}$} & \} & & $13,919,685$ & 19.1 & 3.45 & $?$ \\
\hline & . & & $9,030,320$ & 12.0 & 0.32 & 1.6 \\
\hline $\left.\begin{array}{l}\text { Russia and } \\
\text { Herzegovina }\end{array}\right\}$ & \} & & $6,583,515$ & 51.0 & ? & 85.0 \\
\hline Roumania & ? & & $4,446,000$ & 13.7 & 0.38 & 52.3 \\
\hline Great Britain & $\mathrm{n}$ & & $3,005,670$ & 3.8 & 0.08 & 3.6 \\
\hline \multirow{2}{*}{$\begin{array}{l}\text { Servia } \\
\text { Switzerland }\end{array}$} & . & & $2,393,430$ & 20.0 & 1.43 & $?$ \\
\hline & . & . & $2,032,572$ & 19.9 & 0.71 & 4.2 \\
\hline Greece . & . & & $2,025,400$ & 15.8 & 1.21 & 80.0 \\
\hline \multirow{2}{*}{$\begin{array}{l}\text { Belgium : } \\
\text { Portugal : }\end{array}$} & . & & $1,205,830$ & 16.6 & 0.22 & ? \\
\hline & . & . & $1,165,346$ & 5.1 & 0.27 & ? \\
\hline Holland . & . & & 568,100 & 7.0 & 0.12 & ? \\
\hline & . & & 508,298 & 5.4 & 0.24 & 24.0 \\
\hline Luxemburg & . & & 380,380 & 34.8 & 1.77 & 71.4 \\
\hline \multicolumn{2}{|c|}{$\left.\begin{array}{l}\text { Total forest area } \\
\text { throughout Europe }\end{array}\right\}$} & 。 & $735,062,195$ & 30.2 & 2.51 & \\
\hline
\end{tabular}

1 Endres, article on Forsten, in IIandwörterbuch der Staatswissenschaftcn, Jena, 1892; but including corrections of figures for Britain. 
It will thus be seen that, with regard to woodland area and power of producing timber, Irritain occupies but a minor position among the countries of Europe. But our demands for forest produce are so enormous that the state of the British market practically regulates prices abroad. The important position which Britain thus assumes as a vast consumer may be more correctly gauged by the following quotation from an article by Professor Endres of Karlsruhe on The World's Timber Trade, and Tusation in Timber, in the Allgemeine Forst- und Jagdzeitung, March 1893, p. 82 :-

" England has only 4 per cent of woodland, and is, in consequence of its highly developed commerce and its intensive output of coal, the most absorptive country in the world. The English timber consumption influences the timher trade all over the world, and determines the level of the timber prices. In the beginning of the year 1890, when a serious crisis occurred in the English market in consequence of enormous imports, prices fell about 10 to 15 per cent throughout Central Europe. In 1890 the total import amounted to 9,983, $7 \mathrm{i}$ cubic metres $=5,990,244$ tons, valued at sixteen million pounds sterling. The total was supplied as follows:-

Sweden and Norway
Russia
British North America
United States :
Germany
British East India
Other countries.

Per cent.

37.4

21.5

19.3

6.5

4.7

0.6

10.0

Thus over 30 per cent of the timber is produced in non-European countries, and consists of kinds of timber that cannot possibly be grown in Europe. The timber export of England is almost zero, so that the new customs legislation relative to timber within the Central European countries does not affect England in the slightest degree."

During the year 1892 the imports of forest produce into Britain, as shown by the Customs Returns in the Accounts relating to Trado and Nurigation of the United Kingdom, published in December 1892, were as shown in tabular form on the next page.

From these returns it is impossible to eliminate the classes of timber which it would be a physical impossibility to produce in our climate, such as, for example, the Teak used in the lining of iron ships, the Jarrah and other Australasian Hardwoods used for street pavements, \&c. But, at the same time, the above return does not include the other similar articles that conld be eliminated from the customs accounts, such as Mahogany (56,315 tons $=£ 501,203)$, Cutch and Gambier (25,192 tons $= \pm 5 \pm 8,395)$, Ciroutchouc and Gutta-percha $(317,660 \mathrm{cwt} .=£ 3,501,923)$, \&c., supllies of which must of course, under all circunstances, be drawn from across the 
seas, although they certiinly might preferably be obtained from our own colonies and dependencies than from other countries.

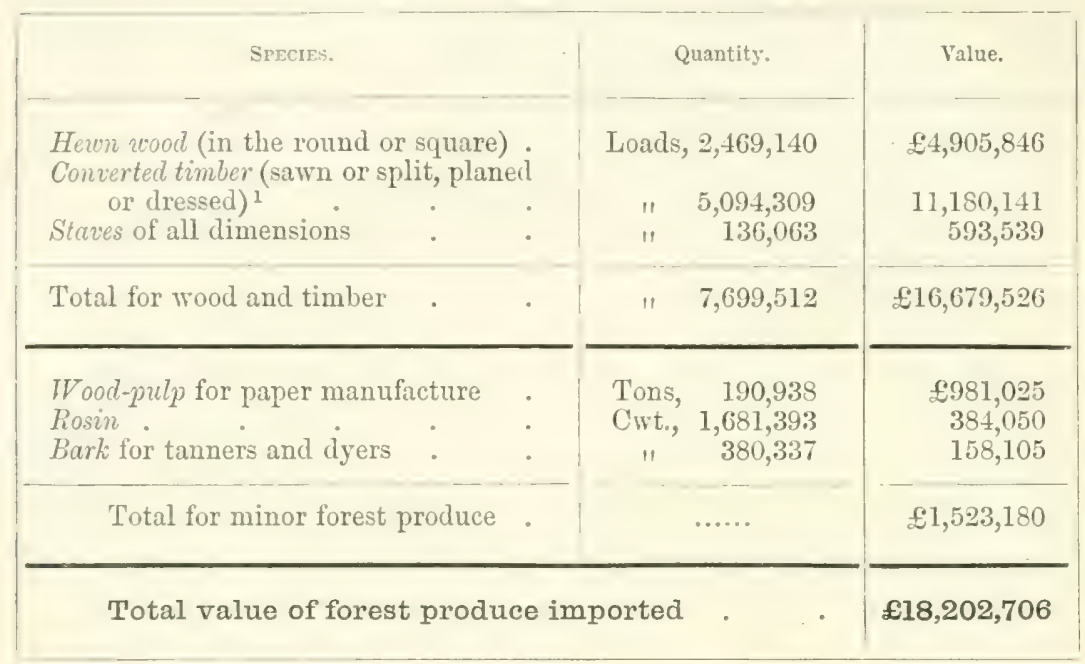

If our woodlands were better managed than they at present are, and if the landed proprietors could be made to study the importance of the steady appreciation in the value of timber, and the bright prospect existing for timber that may become marketable in about fifty years' time, home competition might easily be induced for the supply of more than the half of our total timber imports. For, taking the countries in which identically the same species of trees are srown that may he froduced sylviculturally in Britain, there still renain the following inports that may be regarded as utilised by us and not exported again :-

\section{Imported from Russia, Sweden, Norway, and Germany during 1892.}

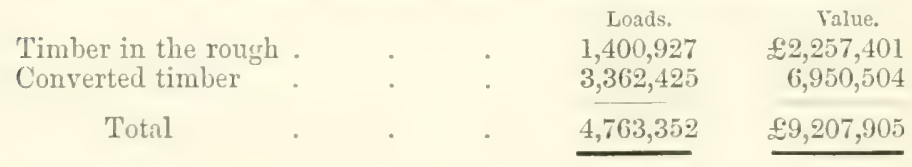

It may confidently be stated that if due attention were given to the selection of the proper species of trees for given soils and situations, if the principles relating to the most favourable density of plantations, or sowings, or natural regenerations, and to the operations of

\footnotetext{
1 Of this converted timber, 20,935 loads, valued at $\mathfrak{£} 72,860$, were exported; but all the other raw produce appears to have been actually consumed in the country, making the true figures for the year $\$ 18,129,816$.
} 
tending (clearing, thinning, \&c.) were properly understood and proctisurt. throughout Britain, there would not be the slightest necessity for the insertion (as at present olstains) of any clauses into Government contracts stipulating for the use of foreign wood in preference to home-grown timber.

But if woods be allowed to grow up so that a considerable portion of the energy of growth of the individual trees forming the erop is dissipated in branch development, in place of being utilised economically in the formation of a clean, smooth, full-wooded bole of high general technical quality, then no surprise need be felt at every person concerned with its utilisation giving a solid preference to foreign timber grown under more rational conditions, and therefore of higher technical and general value, owing to its comparative freedom from knots.

Climatic and National-Economic Influence of Woodlands.The present advanced state of agriculture everywhere demands a skilful and extended system of Forestry.

It is allowed by all who have given their attention to the improvement of lands in any country, that the judicious rearing of plantations, distributed equally over the face of the country, improves the general climate when the rainfall is not already so large as to make any increased humidity of the atmosphere undesirable. Not only may the climate often be improved to a great degree, but even the very soil upon which forest-trees grow may be very much improved in productive capacity by the gradual accumulation of nutrient soluble salts within it.

The Asthetic Influence of Arboriculture. - Trees are not only often profitable as a crop; they are also in the highest degree ornamental, and possess an asthetic influence of inestimable value. For what objects in nature are so grand and so effective as old trees, with their massive stems and spreading limbs, and their leafy crowns covered with foliage of different shapes and shades? MIany hillsides would be comparatively monotonous in appearance but for the plantations of trees of various shates formed upon them. And what would be the effect of the waterfall or the river without trees in their neighbourhood? A country without trees is uninteresting as comprued with landseapes in which trees are visible. What adds more heauty and asthetic effect to a noble mansion-house than ormamental grouns of fine-foliaged trees? Do not the woodlands constitute one of the greatest charms and pleasures of rural scenery in general? Does not a fringe or setting of graceful trees add beauty to, and enlance the resthetic effect of a cascacle, or a waterfall, or a lake ilotted orer with islands? Is it not in great measure owing to the noble timber-trees that the residential portions of large landed estates are belauded as 
"the stately homes of England"? Is it not the growing timber that remlers the home-parkis of our great landed proprietors so cheerful, so enlivening, so rich in beauty, and so much praised by the most cultivated minds? But trees are not merely to be admired on account of their beauty and their utility. They inspire a feeling of awe and respect, when we behold the gigantic stems that have stood the storms and stress of four hundred or five hundred years, and often longer, during which many generations of men have cone and gone, whilst they have remained in the pride of a beauty that increases year by year, and in the fulness and strength of their natural vigour.

Apart from the wanton destruction of the great pine-forests of Scotland, that were devastated by fire for political reasons, what is now the cause of so much waste land being found in the north of Scotland, and in many parts of England? Can it be denied that it is the want of trees to give shelter? Why is it that proprietors of land in these parts complain so much of great tracts of it being worthless, growing nothing but the inferior grasses, mosses, rushes, and heaths, upon which even one sheep cannot find food enough on two acres? Is it not because of the want of plantations to give shelter? Now that the art of agriculture has improved so much, forests and extensive plantations ought to receive an equal share of attention; for the full benefit will not be derived from a superior system of agriculture, if the fields be not sheltered from the evil efiects of uncongenial climate ly healthy plantations judicionsly situated. In the improvement of all waste lands a large proportion of these should be planted up in order to give shelter. Wherever this is not attended to, disappointment will often be the natural result. The land may remain comparatively unproductive; and when the owner finds that reclaiming does not pay him, he may very likely allow the wastes to fall back into their original state of unproductiveness.

It is a well-known fact that, both in Canada and in the United States, the yield of the wheat crop gradually diminishes as the forests are cleared, and that the heaviest crops of this cereal are found on land sheltered by woods.

Of course newly cleared land is more productive than land which has been some time in agricultural occupation; for there are large reserve-supplies of nutrient soluble salts that have been stored up in the soil if the canopy of the natural forest has been close enough to protect the soil from the deteriorating and inpoverishing influences of excessive exposure to sunshine, wind, and heavy rainfall. But even after these reserves have been consumed, the productive capacity of the soil is greater in tracts that are protected by woodlands against dry winds or floods. 
And if the population of a country doubles itself every fifty years, where is the supply of food to come from, in one hundred years hence, if the agricultural production be not stimulated by the planting up of the waste land? The influence of planting upon the general welfare of a country is, indeed, a question which demands serious consideration. If any piece of waste land, after being drained and ploughed, will yiehl 20 bushels per acre, in a state unsheltered by forest-trees, the same land may perhaps yield 25 or 30 or even 35 bushels per acre if judiciously sheltered by woods.

If the solution of such questions as the best utilisation of unproductive lands in the Highlands of Scotland, in England, Wales, and Ireland, and in a certain degree also local labour questions, can be helped by Forestry, the subject seems one well worthy of the attention of the Government. It must be borne in mind that many of the operations of Forestry can best be carried on at times of the year in which large numbers of able-bodied men are compulsorily thrown out of their regular employment.

For not only would the community at large be greatly benefited by an improved and extended system of Sylviculture throughout Britain, but every proprietor who lays out plantations judiciously, on scientific and financial principles, both gives shelter to his fields and at the same time greatly enhances the value of his estate.

Scientific Investigations into the Climatic and NationalEconomic Influence of Woodlands. ${ }^{1}$ - To Germany, the home of forest science, we owe the first steps taken to ascertain the climatic influences exerted by woodlands. It was not until the year 1867 that exact scientific observations were undertaken on any extensive scale to determine the actual influence which forests have in modifying the temperature of the air and of the soil within their own areas and over the surrounding tracts of country. Since then, however, meteorological observations have been carefully made at various forest and agricultural stations throughout Norway and Sweden, France, Germany, Austria, Switzerland, and the United States; but the results of these have not yet been fully collated and arranged for the deduction of the natural laws, to the better knowledge of which the investigations are expected to learl. So firr as information is yet available, the following conclusions have been arrived at:-

1. As regards Atmospheric Temperature. - The annual average temperature within forests growing in closed canopy is lower than in the open, although the crowns of the trees are on the whole a little warmer in winter. The difference is greatest in summer, least in winter, and about midray between these extremes in spring and autumn; the mean annual difference, however, seldom amounts to over $1^{\circ}$ Fahr. near the ground, and is scarcely $\frac{1}{2}^{\circ}$ 
in the cromns. The prevention of insolation of the soil during the long hot days of smmer, and the raphl transpintion taking place through the foliage, exert a greater influence on the atmospheric temperature than can be ascribed to shelter from wind and to decrease of nocturnal radiation.

The observations made prove (1) that the variations between the temperatures of the trees themselves and the air in the open exceed those between the woodland air and the latter except during winter; (2) that they are largest during the most active period of vegetation in summer; and (3) that they are greater in spring, when the circulation of sap begins, than during the autumn months, when vitality becomes sluggish and dormant.

In the crown of the trees, where insolation by day and radiation by night make their full infiucnce felt, the difference in the daily average over the whole year is less than it is near the ground. In winter it averages little either abore or below $0^{\circ}$, and in summer usually about the half of the reading at $5 \mathrm{ft}$. above the ground.

Observations made in Southern Germany establish the fact that in the forests it is cooler during the day and warmer during the night than in the open.

During the night the trees interfere with the radiation of heat, and in the daytime the shade afforded by the crowns keeps the air from being rapidly warmed by the sun's rays. These influences are naturally strongest during spring, summer, and autumn, when foliage is most abundant, whilst in winter the coniferous forests with evergreen foliage are milder than deciduous forests.

Owing to these differences in temperature, beneficial currents of air are induced between the forests and the open country, which follow the same law as obtains in regard to land and sea breezes. During the day the cooler and moister air of the forest sets outwards to take the place of the heated air ascending in the open; at night the current sets in from the open, cooled by radiation, torrards the forest.

The statistics, upon which these conclusions are based, prove that the immediate action of forests is to modify the daily maxima and minima of atmospheric temperature, whence it may be deduced that a comparison of the absolute extremes of temperature during the year must exhibit definitely the sum-total of the influence exerted by forests on the temperature of the atmosphere. This modification of the extremes of temperature, which are bad alike for man and beast, and also for agricultural operations, is of immense importance from a national-economic point of view, since many places that were once fertile are now little better than barren wastes in consequence of the reckless denudation of forest.

Oring to their dense foliage and complete canopy, Beech-forests in summer exert a considerably greater influence in diminishing the extremes of temperature than forests of Spruce or Scots Pine; but after defoliation their influence is very similar to that of the Pine-forest, and only half so great as that of the more densely foliaged Spruce.

2. As regards Soil-Temperature.-The influence exerted on the soiltemperature by forests growing in close canopy is of considerable importance, especially with regard to the soil-moisture. Obserrations have made it clear, therefore, that the mean annual temperature of the soil in the forest is at all depths of observation (extending to $4 \mathrm{ft}$.) cooler than in the open, and that 
the differences are greatest in summer, about the mean in spring and autumn, and very small in winter. In countries with warm summers this reduction of the soil-temperature over large areas by means of forest growth has a decidedly beneficial result. According to observations made in Wiurtemherw, the difference between the maxima of snil-temperature in forests and in the open can extend so far as up to $14^{\circ}$ Fahr.

The daily differences in soil-temperature were found to vary according to the season of the year, but throughout nearly the whole year the uliner layers of soil in the open were warmer in the afternoon than in the forenoon, whereas in the forest the variations were inconsiderable.

As with regard to the atmospheric temperature, the influence of the forest-trees in equalising the soil-temperature throughout the year is also greatest in the case of trees whose foliage is densest, Siruce heading the list.

3. As regards the Degree of Atmospheric Humidity.-Olsservations throughout Central Germany show that as resards the alsolute humidity of the air, forests have no appreciable climatic effect. The differences between the relative humidity of the air in forests and in the open are, as might be expected, greatest in summer.

The results of the various observations, corrected in order to eliminate, so far as possible, local differences due to altitude and to other physical dissimilarities of the meteorological stations, show that the mean ammal relative humidity of woodland air is from $3 \frac{1}{2}$ to 10 per cent greater than that of air in the open, but that the difference varies greatly according to the season of the year, being greatest in summer and autumn, and least in winter and spring. They show, too, that large areas covered with Spruce will be moister, as well as cooler, than those under woods less densely foliaged. In Bavaria it was found that in summer, in consequence of the density of the foliage in Beech-forests during the most active period of growth, the difference eren amounted to 13.6 per cent of saturation over the relative humidity in the open.

4. As regards the Precipitation of Aqueous Vapour.-It has been shown above, not only that the atmosphere within the forest is cooler than in the open, but also that the temperature of the trees themselves is lower, especially in summer, than the air surrounding them; hence, when a current of air is wafted from the open into the forest, and comes in contact with the cooler trees, its temperature is reduced, and it is brought nearer to the point of saturation-i.e., its relative humidity increases. But if this air was already in the open at or near the point of saturation, then the effect of the cooling process is that a certain amount of surplus moisture beyond the aqueous vapour that can be held by the air up to the point of saturation at its reduced temperature must be released and precipitated in the form of dew. Woodlands, therefore, act as condensers of atmospheric moisture, and clecrease the absolnte humidity of the air whilst increasing its relative lumidity: and in adclition to this, they add to the hmility of the air hy transpiration from the leaves, whilst the sap is heing made arailable for stmetural purposes, and the work of assimilation is proceeding.

Endeavours have been made to establish, by means of careful obserrations, the effect of forests in regard to the precipitation of aqueous vapour in the form of dew or rain, but the results are often of so conflicting a nature that, up to the present, safe deductions cannot be drawn. In order to compare 
observations made in the forests with those made at the usual meteorological stations in the open, a correction would in each case be necessary to reduce the localities to the same sea-level, as air cools in rising and increases in relative humidity-i.e., it approaches the point at which it must precipitate some of the aqueous vapour held by it. Hence rainfall generally increases with the height of a locality above the sea-level, although no direct proportional increase can be proved. It fluctuates with the geographical position and the varying physical conditions of each point of observation, whilst variations in the direction of the moist winds of the locality also militate against the collection of reliable data for comparison with readings made in other localities.

The mean statistics of readings made at 192 points of observation in Germany, corrected as carefully as possible with reference to these causes of difference, seem capable of yielding no general inference, except that at high altitudes large extents of forest may considerably increase the local rainfall. As regards the quantity of rainfall and snowfall which is intercepted in forests by the leaves, branches, and stems of the trees, the observations made in Switzerland, Prussia, and Bavaria prove that nearly one-fourth of all the precipitations of aqueous vapour is intercepted by the forest-trees, and is given off again by evajoration, or is gradually conducted down the stems to the soil. In lofty forest-clad regions the mechanical action of the rains on the surface-soil is thus very much modified.

By means of their lower temperature, their greater relative humidity, and the mechanical obstruction they offer to the movements of currents of air, extensive forests act decidedly as condensers of the aqueous vapour contained in the atmosphere, and their influence in this respect is more marked at high altitudes and in mountainous districts than on plains or near the sea-coast, where other plyysical factors come into competition with and modify it. But further data are still requisite to enable us to determine with anything like certainty that forests directly cause increase of precipitations irrespective of such local considerations as the ruling direction of winds and peculiarities of situation; the generally accepted dictum is, however, that in the vicinity of extensive forests rainfall is greater than at other localities under otherwise similar physical conditions.

In portions of the Russian steppes, planted up nearly fifty years ago, the inhabitants assert that the summer rainfall has considerably increased, and that the danger to crops from drought is not so great as formerly, whilst the villages are also protected by the forest from the violence of the winter storms.

In summarising and criticising this point, Prof. Endres of Karlsruhe remarks as follows : ${ }^{1}$ -

"The data furnished from tropical countries must be accepted with the greatest caution, and in any case they afford no conclusive deductions for European circumstances. Blandford reports from India (Meteorological Journal, 1888) that in an area of 61,000 square miles, which was formerly denuded of woodlands, but has been planted up again from 1875, the rainfall has increased 12 per cent since then. But H. Gannet (Weather, 5th vol.) arrives at exactly the opposite conclusions for America, as his observations in the prairie region and in Ohio go to prove that the re-wooding of a tract

1 op. cit., p. 608. 
exerts no perceptible difference on the amount of the arquenss precipitations. Lendenfeld also tries to prove that the clearance of woodlands in Australia has resulted in a better climate and an increase in rainfall, as the soil under Eucalyptus remains hard as stone and inahsonptive, whilst it is rendered lighter and more porous by grass."--(Petermann's Geog. Nittheilungen, vol. 34).

5. As regards Evaporation of Soil-Moisture.-The low temperature and the high relative humidity of the atmosphere in forests are unfavomrable to rapid evajoration, which is still further reducer by the protection afforterl to the soil against direct insolation and the action of winds. From olservatioms extending over ten years (1876-85) in various parts of Germany and Austria, the following relation is shown between evaporation in the forests and in the open in the vicinity of the forests; the differences would probably be greater if comparisons had been made with places in the open that were far removed from the modifying influence of the woodlands :-

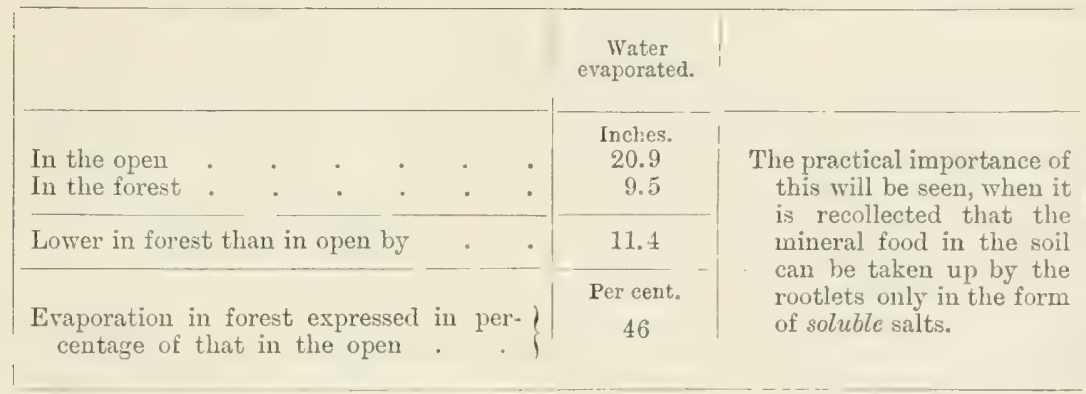

The action of forests, therefore, is to retain in the soil a large proportion of the rainfall or of the moisture arising from the melting of snows, which, by percolation to the lower layers and the subsoil, tends to feed the streams perennially, and to maintain a constant supply of moisture, without which trees could not derive their requisite food-supplies from the soil.

The nature of the soil-covering below the forest-trees exerts also considerable influence on the amount of moisture evaporated. From experiments conducted during five years in Bavaria it was found ${ }^{1}$ that a good layer of fallen leaves, and of humus or vegetable mould formed by their decay, diminishes the evaporation by more than half, or reduces it to less than one quarter of that in the open, and thus adds very considerably to the surplus amount of moisture retained in the soil.

6. As regards the Feeding of Streams and the Protection of the Soil.-From the above data it seems evident that the effect of extensive forests, more especially of those situaterl at high altitudes, is, by cooling the air and reducing its capacity for retaining aqueous vapour, to increase the precipitations. Whilst these precipitations are taking place the crowns of the trees intercept a large proportion of the total, and by brealing the violence of the rainfall protect the soil from the danger of being washed away during heavy storms. By the decomposition of fallen leaves and twigs a strongly hygroscopic soil-covering is formed, capable of imbibing and retaining moisture

1 Ebermayer's Gesammte Lehre der Waldstreu, 1876, p. 183. 
with sponge-like capacity. Rapid evaporation of the soil-moisture is counteracted through the junterion afforded hy the foliage against direct insolation during the day, and by the mechanical hindrance offered to currents of wind. The crown of foliage likewise prevents the soil cooling rapidly at night by ratiation. 'The hoter' the smmmer, the more markel are these beneficial etfect. of the woodlands.

When, therefore, large tracts of country are denuded of timber, increase of temperature during the days of summer, rapid radiation of soil-warmth by night, diminished precipitations (especially in the spring and summer), and mehecked eraporation of moisture, due to complete insolation of the soil by day and absence of any protection from winds, must be the inevitable consequences.

Examples of such actual results can be pointed out in many parts of continental Europe, in Western Asia, and throughout India. In Great Britain and Ireland the effects of the wholesale clearance of woodlands have not been so marked, in consequence of the favourable influences exerted on our climate by the Gulf-Stream.

In localities having no protective roodlands, heary rains wash away the surface-soil, torrents and freshets run down the water-courses with great violence, laden with detritus and discoloured with the soil held in mechanical solution, whilst streams and rivers often overflow their banks in consequence, derastating large areas of low-lying tracts under cultivation. Forests, on the other hand, tend to break the violence of the rainfall, and retain for the time being about one-fourth of the total amount on the foliage and branches; the roots of the trees and of the undergrowth help to bind the soil firmly; the rainfall is retained by the regetable mould and by the spongy growth usually found on the surface-soil, and thence gradually percolates to the deeper layers, where it is held in reserve, to be finally parted with in being utilised for the feeding of perennial streams having their sources on the wooded slopes.

Thus arose in the alpine districts of Southern Europe the necessity for maintaining ban-forests as a protection against landslips, avalanches, ic. ; and legal measures were early adopted for safeguarding them, in order to protect the lower tracts from erosion of the soil when sodden with rainfall or melted snow.

7. As regards General Hygienic Effect on the Atmosphere.-It is well known that on the one hand when large tracts of forests are cleared for cultivation, especially in tropical and sub-tropical countries, ferer and ague are frequently the consequence; and on the other, that the planting up of notorious ferer districts-such as the Campagna di Roma, the Tuscan marshes, and the Russian steppes-has decidedly diminished the insalubrity of these localities. But the causes are very probably rather due to the degree of direct insolation of the soil, freely afforded in the one case and counteracted in the other, than to any hygienic property inherent in tree-growth. In the latter case, too, stagnating surplus of soil-moisture may have been got rid of by transpiration through the foliage, and this would of itself go far towards remoring causes of insalubrity and improving the climate.

It is generally accepted that ozone kills miasma in the air and purifies the latter-at any rate, impure air contains little or no ozone; the proportion of ozone is therefore usually taken as the measure of atmospheric quality. 
The belief that the woodland air is, like sea-air, very rich in none, has not yet been satisfactorily prover. Experiments in Pavaria shower that in the forests the percentage of ozone, though greater than that in town; was slightly: less than in the open in the vicinity of forests, and that there was no perceptible difference in this respect between coniferous and deciduous forests.

The woodland air was found to contain most ozone in winter, which shows that its production could not be due to any chemical action of the foliage ; for there are no leaves on decidunus trees at that season, whilst Conifers transpire merely, and do not assimilate. It also inclicates that the excess is probably due to the comparative freedom of air in the forest from the smoke, carbonic acid, and many other impuritics with which air in the vicinity of towns is contaminated and defiled, and to the withdrawal of enormous supplies of oxygen from the air, which takes place for the sulport of animal life at all populous centres.

Sunlight, however, has the power of decomposing carbonic acid in the presence of chlorophyll, the green colouring matter contained in foliage, - the carbon being absorbed by the plant for its growth, and the oxygen set free. During darkness a contrary action takes place, oxygren being consumed by the foliage, and carbonic acid given off. As, howvever, particularly in the case of deciduous trees which are in leaf only from April till October, the hours of light far exceed in number those of darkness, the general hygienic effect of trees in cities and towns-apart from their invaluable resthetic influencetends decidedly towards the purification of the atmosphere from excess of carbonic acid.

Ozone is an allotropic modification of oxygen obtainable by passing a series of electrical discharges through it; hence it is more than probluble that in forests in exposed localities, more especially those at high altitules, where storms and electrical disturbances of the air are most frequent, a greater quantity of ozone may be generated in the atmospliere than in localities less subject to such powerful ozonising influences.

8. As regards the Agricultural Productive Capacity of Neighbouring Tracts, and the National-Economic Effect on the Soil generally.-From an agricultural standpoint, a dry season is much preferable to a low temperature and excessive rainfall. In the former case the fruits of the earth, although they may be somewhat scanty, are invariahly of smerior quality. A wet season may produce abundant crops, but they are generally of low quality.

With regard to the influence of forests on the aqueous precipitations throughout Central Euroje, Prof. Endres makes the following renarkis: ${ }^{1}$ -

"The question whether woodlands can influence the rainfall is one of the most important from a national-economic point of view. Even if this could be distinctly affirmed, the beneficial action of forests would only he estahlished in the rarest cases, for throughout Central Europe at present the number of too wet years exceeds that of dry years. In districts where the rainfall is over 40 in., any increase is undesirable." For agriculture, very dry

1 Op. cit., p. 607 .

2 This is a point of vast importance, that should not be overlooked by those who are now advocating the formation of large plantations throughout the Highlands of Scotland. For rainfall statistics of certain parts of Britain, see Whitaker's Almanack, 1893, p. 575. 
years are on the whole less disastrous than extremely wet years. The precipitations of any district are influenced mainly by the position of the mountain ranges with reference to the cardinal points of the compass, by its elevation above sea-level, and its distance from the sea."

Even so early as in Roman times it was recognised that too great a clearance of woodland areas brought undesirable changes in the physical conditions of Italy, and affected the welfare of the inhabitants.

Early in the present century, for example, the Agricultural Society of Marseilles reported that in consequence of the reckless destruction of the forests after the Revolution of 1789

"The winters are colder, the summers hotter, and the beneficial spring and autumn showers no longer fall; the Uveaune, flowing from east to west, rushes down in flood with the least rain, carrying away its banks and flooding the richest pasturage, while, for nine months of the year, its bed lies dry owing to the drying up of the streams."

To a similar cause also Prof. Geffcken (in the Speaker of 6th January 1893) attributes the Russian famine of 1892 in the following terms :-

"We surak of the deficit [in the liussian Budget] of 1r.9:3 as certain, and it is easy to show that it will be so. The principal cause of the mesent dearth is the drought during the last spring and early summer, and this absence of rain is greatly due to the devastation of the forests. The area formerly covered with timber was enormous, the woods belonging to the Crown, to the great landed proprietors, and to the village communities. But the means of transport were then so imperfect and costly that only in the neighbourhood of large rivers did the felling of timber pay. This changed with the construction of railways and the abolition of serfdom; the former gave the possibility of selling with profit, and the peasants abandoned their woods to speculators for what they thought a good price, little thinking of the future; the larger proprietors followed their example; the purchase-money was spent in drink and luxurious living, and no one thought of replanting. Too late has the Govermment issued a law for the protection of forests. Such a devastation going on for twenty years not only exhansts a source of wealth, but has also other bad consequences. When the country is deprived of its trees, the earth is dried up and crumbles from the hills; the water coming down from heaven cannot be kept back as is the case with the woods, which act as a sponge, but rushes in torrents into the rivers and disappears in the sea, and the consequence is a gradual diminution of the fertility of the soil and the disappearing of numerous brooklets and small rivers, to help the larger ones show a low water-mark, which proves prejudicial to the navigation."

This view is confirmed by the special correspondent of the Times (vide article Through Famine-stricken Russia in issue of 18th April 1892), who writes :-

"I have now travelled over most of the famine-stricken provinces, and I have been struck by the sameness of the picture. Everywhere reckless extravargance meets the eye, the forests have been cut away wantonly, the rivers are neglected, the climate is ruined."

Such also appears to have been the opinion of Major Law, Commercial Attache to the British Embassy at St Petersburg, as expressed in his Report on Agriculture in the South-Eastern Provinces of European Russia, commented 
on in a leading article of the Times of 17 th September 1892 , from which the following is excerpted :-

"It is said that this gigantic natural tillage farm-i.e., the "black-soil" region-was formerly hedged in by belts of forest, which served the twofold purpose of sheltering it from the desert winds and of increasing the humidity of the climate. It is certain that these forests do not now exist, and that the back-soil country is often scourged by devastating blasts from the stepue, and not infrequently baked by prolonged droughts. The desert winds pile the snow into drifts in winter, which become the source of destructive torrents in the spring. In summer the same winds are so fierce and arid that in the space of a few hours they wither the corn as it stands, while, when they are laden with sands, they smite the soil itself with perpetual barrenness."

Indeed, all writers who have recently published views on this subject seem agreed as to the main causes of the recent Russian famine.

That the destruction of the ancient forests throughout Great Britain and Ireland, to such an extent that, incluling all ornamental plantations, only 3.8 per cent of the total area can now be classified as woodlauds, was not followed by such disastrous climatic clanges as were occasioned by similar causes thronghout Southern France and the Landes, Syria, Asia Minor, Greece, Russia, and many parts of India, we owe entirely to our insular position with its moist climate, and to the happy effects wrought by that portion of the Gulf-Stream which reaches our western and southern shores.

Industrial or Technical-Economic Importance of Woodlands. -The cultivation of woodlands is of great importance to the welfare of every country from the technical and industrial point of view; for many trades are essentially dependent on forest-produce as a portion of the raw material without which their work cannot be carried on. In any country thinly inhabited by man, natural forests generally prevail in great abundance; often, indeed, to such an extent that the new settlers find forests of timber-trees to be a mere hindrance, and are very frequently obliged to destroy them, in order to have the land put under a crop' more profitable for their purpose for the time being. This is the state of things in many districts of a newly settled country. But it is ultimately a very unprofitable way of going to work, even in a country where natural forests prevail; for, were Forestry maintained as an art among settlers in a new country, much profitable and useful timber might be retained upon the newly improved lands, which might prove of great adrantage to generations coming after, as well as to the settlers themselves. An example of this is to be found in the scarcity of useful wood in a great part of the United States of America at the present day. The inference is, that the raising of artificial forests in any newly inhabited country is not of primary importance to the settlers; lut the retention of a part of the nutural forests is of great ultimate importance to them, and 
provision should the mate hy law for preserving a proper proportion of the natural forests for ultimate good. But the case is altogether diflerent in an oll-estallishel country, where the natural forests have for the nust part disinpleared, and where the inhabitants must either buy timber from other countries, or raise it on the land in the form of sylvicultural crops.

In most civilised countries the management of forests forms a most important part of their economy. From the timber of trees houses are constructed, and implements, as well as furniture, are manufactured; while we, as a nation, depend greatly upon it for the support of our mines and railways. Although the fruits produced in this country by trees are more a luxury than a necessary article of food, yet the fruit of the Palms, and of many other trees of hot climates, are really as necessary to the inhabitants as the cereal crops are to us. 'Trees, therefore, either in the form of timber or in respect to the fruits they produce, form a necessary and a profitable crop in all countries that are advanced in civilisation.

Thus, for example, in the forests of Germany, in addition to $\mathfrak{\&}, 150,000$ annually spent in the management, protection, and regeneration of the forests, and in the felling, preparing, and handling of the produce before it is delivered into the hands of the buyer, the timber and other produce of the woodlands directly affords employment to 583,000 persons (or 9 per cent of all the industrial classes throughout the empire), who are engaged in industries dependent on the forests for the raw material requisite for their various trades. ${ }^{1}$ These 583,000 bread-winners probably represent about 3,000,000 souls, or nearly one-sixteenth of the total population. And in addition thereto, there must also be taken into account the enormous sums whose outlay is necessitated for transport by land and water after the raw produce has come into the hands of the buyer.

Again, in the State Forests of Austria and those that are under State management, amounting to a total of 2,205,317 acres, or rather more than two-thirds of our British woodlands, employment is provided for 18,336 workmen, whilst members of the families of these are employed to the number of 39,060 persons. ${ }^{2}$

In his Rectorial Address before the University of Munich in 1889, Prof. Gayer stated that the annual out-turn in timber from the forests of (iemany amounted to alout $601,000,0000$ enlic metres (about $2,160,000,0000$

1 Prof. R. Weber in Lorey's Ilandbuch der Forstwissenschaft, 1886, vol. i. p. 85. The importance of the forests as raw-produce industries is even greater than this according to Prof. MI. Endres (Handwörterbuch der Stactswissenschaften, Jena, 1892, rol. iii. p. (16), who states that "the total quantity of labour employed in the management

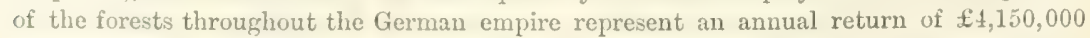
according to Danckelmann, or of $£ 8,000,000$ according to Lehr. Altogether from 190,000 to 230,000 families throughout Germany obtain their livelihood from work in the forests."

"Endres, ibid. 


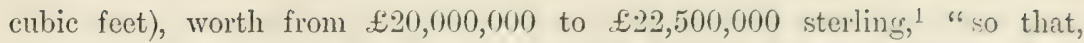
reckoning 2 per cent as the rate of interest yielded, the cap ital value of all the German forests may be assessed at about $\mathbb{E} 1,000,000,000)$ sterling." It therefore follows that, if only our l3ritish woodlands, which extend in area to about one-eleventh of those of Germany, were as economically and as well managed as the German forests, they would amually yicld very nearly $\mathscr{E}: 000,000$, and would have a capital value of $£ 90,000,000$, arlopting 2 per cent as the rate of interest yielded, or at any rate about $£ 50,000,000$, even adopting only twenty-five years' purchase as their value, and presuming that they yielded as much as 4 per cent per annum on the capital value of the soil plus the growing stock of timber. And it is of great importance to note that these actual returns from, and estimated capital value of, the German forests would be immensely higher if the domestic fuel of the nation were not wood. For a large proportion of these 60 millions of cubic metres consists of fine timber, which is split into fuel-pieces, although in every respect quite suitable for high technical purposes, so far as its quality and dimensions are concerned.

But want of scientific and sylvicultural knowledge, both on the part of landowners and of the great majority of land-agents and foresters, leaves much to be achieved in technical education before the natural capabilities of our island can be utilised to their best extent for the production of timber.

No accurate or even approximate data can be obtained with regard to the returns available from private forests; but from the Budget statements of the various Gemman States it appears that the State forests of Saxony vield a net profit of 19s. 9d. per annum per acre, those of Baden 12s. $7 \mathrm{~d}$., of Würtemberg 11s. 9d., and of Bavaria 6s. per acre per annum. It must be recollected that these include very poor classes of mountainous land that would otherwise be unproductive, and also that a great deal of the timber must be cut up into fuel for the supply of domestic requirements.

But if we wish to have a complete idea of the enormous importance of forest produce with regard to the industrial life of a nation, we must turn to the United States of America. The following extract from Bulletin No. 5 of the Forestry Division, U.S. Department of Agriculture, gives a capital idea of the importance of forests from a purely industrial point of view : ${ }^{2}$

"No more convincing argument for the importance of this resource in a nation's economy can be offered than to state the value of the forest product

1 Der Wald in Wechsel der Zeiten, 1889, p. 15.

2 B. E. Fernow, Chief of the Forestry Dirision, What is Forcstry? 1891, p. S. In connection with the above extract, the attention of thinking men is called to the following short excerpts made from the lieport of the Secretary of Agriculture, 1892 (U.S.A.), p. $304:-$

"We have now less than $500,000,000$ acres in forest growth; but eren that is neither in good condition nor well managed. We have, therefore, long ago begun to use more than the annual growth, and are cutting into the capital which we inherited at a rate which must sooner or later exhaust it unless we adopt recuperative methods. While there are still enormous quantities of virgin timber standing, the accumulations of centuries, the supply is not inexhaustible. Even were we to assume on every acre a stand of $10,000 \mathrm{ft}$. B.M. of saw timber-a most extravagant average-we would, with our present consumption, have hardly one hundred years of supply in sight,the time it takes to grow a tree to satisfactory log size. Certain kinds of supplies are beginning to give out. Even the White Pine resources, "which a few years ago seemed so 
in the United States. The total annual product of wood material of all sorts consumed in the United States may be valued in round numbers at $\$ 1.000 .1000 .000$, repesenting, mughly speaking, 2.5,000.000,000 culuc ft. of wood, or the annual increase of the wood-growth of $500,000,000$ acres of forest in fair condition. This value exceeds ten times the value of our gold and silver output, and three times the annual product of all our mineral and coal mines put together. It is three times the value of our wheat crop; and with all the toil and risk which our agricultural crops involve, they can barely quadruple the value of this product yielded by nature for the mere harvesting.

"If to the value of our total mining product be added the value of stone quarries and petroleum, and this sum be increased by the estimated value of

great that to attempt an accurate estimate of them was deemed too difficult an undertaking, have since then become reduced to such small proportions that the end of the whole supply in both Canada and the United States is now plainly in riew.'

"The annual product of this Pine from the sawnill has reached the enormous total of over $8,000,000,000$ B.MI., which, if we assume a Pine stumpage of $5000 \mathrm{ft}$. to the acrea high average-would require the cutting of $1,600,000$ acres annually of their White Pine supplies. Since the three White Pine states (Michigan, Wisconsin, and Minnesota) have a total reported forest area of altogether $60,000,000$ acres, it is evident that, even if we allow two-thirds of that area to be in the White Pine belt, and consider this area fully stocked-which it is not-twenty-five years would suffice to practically exhaust the supplies. These figures, crude though they be, leave no doubt that the end of this staple is practically much nearer than we have supposed. All opinions to the contrary may be set down as ill founded."

Our imports from North America during 1892 were as follows :-

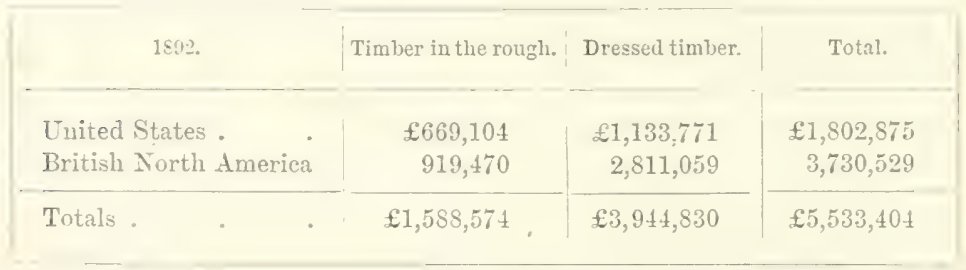

If these supplies are within measurable distance of becoming exhausted, then, taking into consideration the actual economic fact that during the whole of the present century timber is, along with gold, almost the only article that has steadily, all over the world, appreciated in exchange value relatively to other articles of commerce, it should require no very subtle argumentation to point out to the State and to landowners the advisability of now forming plantations, on sound sylvicultural principles, that may reach maturity from seventy to one hundred years hence.

And the following still more recent data, from Gardening World of 20th May 1893, are worthy of deep consideration :-

"American Forests.-From statistics presented to the Forestry Congress at Philadelphia it appears that the woodlands of the United States now cover $450,000,000$ of acres, or about 26 per cent of the area. Of this not less than $25,000,000$ acres are cut over annually. It was also stated that while the wood growing annually in the United States amounted to $12,000,000,000$ of cubic $\mathrm{ft}$., the amount cut anmually is just double that enormous quantity, besides a rast amount destroyed b5 fire, and not included in the estimate. 'The country's supply is being depleted, therefore, twice as fast as it is being reproduced, which clearly goes to show that a timber famine in America is approaching quite rapidly.' 
all the steamboats, sailing-vessels, canal-hoats, flat-hoats, and harces plying in Anerican waters, and belonging to citizens of the Lnited States, it will lue less than the value of the forest product by a sum sufficient to purchase at cost of construction all the canals, buy up at par all the stock of the telegraph companies, pay their bonded delst., and construct and equip all the telephone lines. The value of the annual forest product exceeds the gross income of all the railroad and transportation companies. It would suffice to pay the indebtedness of all the States, if we leave out New York and Pennsylvania, including that of all counties, townships, school districts, and cities within those States (in 1850); and it would more than wipe out the remaining lublic debt of the United States. In fact, ranking manufactures of all kinds and agriculture as respectively first and second in importance, as far as production of values goes, the forest product occupies the third place. This was the case according to the census of 1880. It is claimed that since then the lumber industry has enlarged to such an extent as to make its product second, if not first, in value.

"The capital employed in merely milling this product, aside from that employed in the harvesting, is roughly estimated at $\$ 650,000,000$, and there are more than 300,000 people occupied in the direct manufacture of forest and sawmill products alone, not to count the employment atforded by its transportation to centres of consumption and its re-manufacture.

"It would lead us through all phases and employments of human life were we to attempt an enumeration of the uses to which forest products are put.

"Not only does the forest furnish the material for the construction of dwelling and other structures, our railway consumption of $.500,000,000$ ('ubic ft. of timber included, but countless articles of domestic economy and implements necessitate its use. Not only does it yield to two-thirds of our population the fuel to warm their houses and to prepare their food, but it gave us the first means of using our mineral resources, and even now 600,000 tons of the iron product depend upon charcoal. Not only does the wood in its natural form serve our needs, but our ingenuity has invented methods by which we can transform it into all sorts of useful materials, like cellulose, paper, and even silk; while lately it has become possible to prepare from the brushwood a feed for cattle more nutritious than straw and equal to hay."

So far as the interests of private landowners are concerned, woodlands may often, in the first instance, be managed only as sources of profitable products; and in this case the higher the returns obtainable without 1rejulicing the productive capacity of the soil, the better for the owner. But from a national-economic point of view, woollands form a basis of material prosperity, both directly and indirectly affecting various industries, and their proper management is a matter worthy of national interest.

The mining operations of our country demand extensive woodlands to support them; the maintenance of railways as urgently calls for this; the present advanced state of agriculture demands the same thing; and it may be truly said that the general welfare of any 
highly civilised (m)ntry cannot be maintained without an extent of woodlands suitable to its circumstances and demands.

The policy of depending upon foreign countries for the supply of timber for national industries is a short-sighted one, and more particularly when there is so much waste land in our own country, of fair quality for the growing of timber, but the greater part of which is inaccessible or worthless to the plough of the farmer. The planting un, wi these would, therefore, by no means clininish the availalle quantity of land which might be improved for the increase of food for the population.

Many argue that there is no need for planting waste lands with trees so long as a full supply of timber can be had from foreign lands. But those who say this have not considered that in nearly every country upon the face of the globe the forest area is being diminished, whilst the demands for the world's supply of timber are gradually increasing. It is well known that, as civilisation makes progress, and as arricultural pursuits extend, the natural forests dininish, and eventually incone comparatively exhauster and often clemolished, as has been the case throughout Great Britain for about two hundred years; and at the same time, as civilisation increases, the demand for timber increases also. The very obvious inference from this is that each country, as its population increases, and as demands for forest produce become greater and greater, will have at least enough to do with its own home timber, and will require to encourage Forestry in order to maintain its own supply.

With the march of civilisation new methods of utilisation of forestproduce are developed, which were previously of no industrial importance. Thus about forty years ago the first wood-pulp factory was started in Saxony, whilst the first opened in Sweden began work in 1857; but in 1890 there were 531 wood-pulp factories in Germany, 211 in Austria, and 120 in Sweden. Again, the first cellulose factory was started only about twenty years ago, and in 1890 there were 63 in Germany and 28 in Austria. The annual consumption in the German pulp-factories alone is $5 \pi, 128,400$ cubic ft. of wood.

It must be borne in mind that these are merely comparatively new industries, capable of enormous expansion, and that the supply of raw material requisite for this new industry alone will in time exert great influence in enhancing the price of comparatively young crops of soft-wooded species of trees, like Willows, Poplars, Birch, Lime, and the softer Spruces and Firs.

Even at the present day some of the United States are dependent upon the wooded regions in Canada to eke out the supply of their useful timber; and in that country, where so much wood is necessarily consumed for fuel, the supply cannot continue to meet the demand for many years. It is therefore the opinion of many who 
are well acquainted with the sulject, that in a few years wood will not only be very scarce, but at the same time very dear-much beyomit any price we can form an arleruate iden of at the present rlay. But it is to be hoped that these mattress will receive serious consideration, in order that measures may be taken for forming and storing up) useful crops of timber against the time of failing supulies. The only available remedy, of course, lies in an improverl and extencled systen of Forestry throughout the whole of the civiliser cruntrics of the worle.

The Physical Capabilities of Britain for Arboriculture and Sylviculture. - There are few countries situaterl within the tenperate zone so well adapted as Great Britain for the growth of a large variety of valuable timber-trees.

Our soil is variable, and is consequently cenerally artapted to the healthy development of very many different species of trees introducel from all the temperate regions of the globe. There are sambly tracts for those that thrive best on silicious soils, and clays, limes, marls, loams, and lumose soils for those whose natural requirements are best met by one or other of these descriptions of land.

Our climate is, thanks to our insular position, and to the genial and equalising influence of an off-set from the great Gulf-Stream, milder than that of continental inland regions under the sane parallels of latitude; hence the temperature at London is lower in the summer than at Paris, and higher in winter, although the former is situated $2 \frac{1}{2}^{\circ}$ to the north of the latter. From our winters being generally milcler than those of many continental comntries considerably lower than our latitude, many sorts of useful plants, which are not found to stand the winters of the continents of North America and central Europe withont artificial means being used, mar here le cultivated without any artificial protection. The comparative nearness of all the parts of our island to the softening influences of the sea is no doubt the cause of this; for the ocean invariably preserves a more uniform temperature than the land.

The climate of the western seaboard of Great Britain and Ireland is in general milder than that of the eastern parts under the same parallel. For example, on many places on the west coast even of the

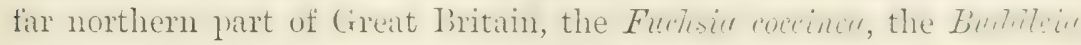
globosa, the Hydrangea Hortensia, the Lippia citriodora, and the Nyrtle stand the winter without any protection, and form large and very ornamental bushes in gardens and other sheltered situations; while on the east coast parallels these plants are generally injured by frosts if not protected during the winter. Even as far north as Glenelg; in the county of Inverness, at about 5 ' ${ }^{\circ} 12^{\prime}$, the Fuchsia coccinea stands the winter withont protection, and in sheltered gardens forms a bush of from 5 to $6 \mathrm{ft}$, in height. 
The uniformity of the temperature of our climate is very remarkable as compared with that of other parts of the world, and gives us, if care be taken to utilise it properly, an undoubted advantage over most other nations as regards the cultivation of non-indigenous trees. There are no violent extremes, such as are indicated by Humboldt in the following passage:-

"At New York we find the summer of Rome and the winter of Copenhagen. At Quebec grapes sometimes ripen in the open air, whereas the winter is that of Petersburg, during which the snow lies $5 \mathrm{ft}$. deep for several months, and travelling is performed in sledges, frequently on the ice of the St Lawrence. At Pekin, in China, where the mean temperature of the year is that of the coasts of Brittany, the scorching heats of summer are greater than at Cairo, and the winters as rigorous as at Upsala."

But apart from mere deductions regarding the mildness of our climate, a more convincing proof is obtainable from the results of practical arboricultural experience; for there are not many countries in the world from which plants have not been brought and cultivated, either for use or ormament; and a large portion of these need not be confined in an atmosphere raised artificially, but may be planted out in the open, and exposed to all the changes of our climate. For example, from the south of Europe we have the Sweet-Chestnut, English Elm, Lime-tree, and the Black Poplar; from Corsica and Austria, the Black Pines; from Germany and Switzerland, the Common Larch; from Persia, the Horse-Chestnut; from northern India, the Deodar; from Canada, the Hemlock Spruce and the Silver Poplar; from the eastem portion of the United States, the IIagnolic grandiflora, the Robinia, and the Tulip-Tree; from California, the Red or Douglas Fir, the Menzies or Sitka Spruce, and many useful Pines; and from Chili, the Araucaria or so-called Chili Pine. These few examples, out of very many more that could be adduced, are enough to show that both the soil and the climate of Great Britain are admirably adapted to the growth, not only of those which are indigenous to Europe, but also of such as are natives of the temperate regions in all other parts of the world.

But although the soil and climate of our island are thus generally suitable to the healthy growth of a great variety of useful trees introduced from foreign countries, yet all parts of it are not alike physically endowed in this respect; for throughout the length and breadth of Great Britain there exists a very considerable diversity with regard to both soil and climate. This is, of course, only what minlit be expected from the varying nature of the dilferent serlogical formations, as well as from the different degrees of latitude (ranging from about $50^{\circ}$ to $59^{\circ}$ ) and the relative elevations of land (ranging 
up to $\$ 406 \mathrm{ft}$. above the sea-level in the case of Ben Nevis) emluraced between Land's End and the Pentland Firth.

The great central and eastern plains of England, and the Talley of the Severn, may be classed as offering the most farouralile conditions for the growth and finest development of the more valualle species of forest-trees in this country; whilst the plains throughout Torkshire and Cheshire rank second in this respect. In comparison with these others, the table-land situated to the south-west of these districts can only be reckoned somewhat inferior for the growth of sylvicultural crops of trees of the broad-leaved species. The lofty platean occupying the north of England and the south of scotland, and embracing the whole of the tract from the river Tees on the south to the Firth of Forth on the north, is, both with respect to soil and to climate, even a less favourable portion of the island for sylvicultural and arboricultural operations.

There is a narrow central plain in Scotland, lying partly on the north of the Firth of Forth and partly on its south side, and stretching from Glasgow along both sides of the river Forth to Edinburgh, and thence northwards as far as Montrose, which, for sylvicultural and arboricultural purposes, may be clissed still lower in the scale, as it is apt to be swept both by east and west winds for the greater part of the year.

With the exception of the low-lying lands situated on the sides of the Moray Firth, which may perhaps be classed as only of sixthrate capabilities for the growth of trees, the greater part of the country situated to the north of the central plain of Scotland is, generally speaking, both from its geological formation and from its relative altitude, unsuitable to the cultivation of any trees other than those belonging to the Pine, Spruce, and Fir tribes; but on this portion of the island these attain even more valuable dimensions than in milder southern localities. It may, therefore, be aptly termed the coniferous region of Britain.

The artificial Larch-forests of the Duke of Atholl at Dunkeld, and those of the Marquess of Breadalbane at Taymouth, may be cited in illustration of the suitalility of the soil and climate of those districts in particular, and of the Trest Highlands in general, to this most valuable tree; and the Pine-forests of Glenmore, Rothiemurchus, Glemmorriston, Abernethy, Duthill, and Initemar supply evident proofs of the suitableness of the soil and climate of these inland tracts of Britain for the growth of the Scots Pine to its most valuable dimensions. The promising results attained by the Douglas Fir on Lord Powerscourt's estates in Ireland should also call the attention of landlords to the important sylvicultural and finamcial advantages that may be realised in a comparatively short

VOL. I. 
space of time by planting selected species of rapid-growing and

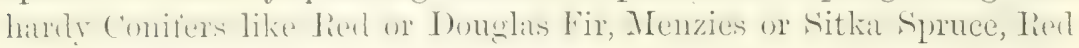
Pine, and, in fact, all the better classes of Californian Conifers, which give promise of producing large quantities of excellent timber in this climate.

The Influence of Plantations throughout a Country.The first, and perhaps the greatest, effect of judicious planting is that of shelter to the country in its neighbourhood; for, as has already been stated, in portions of the Russian steppes that were planted up nearly fifty years ago the climate has been ameliorated, and danger to agricultural crops is now less than was formerly the case, whilst villages are also protected from the fury of the wintry storms,

A second, and not always a less important, influence of planting trees in masses is that of ornament or resthetic effect.

When the agricultural and picturesque advantages of any part of the country which is judiciously clothed with trees are compared with those of a locality which has either been stripped of its crop of timber, or which has never borne any woodland covering at all, the difference is very striking. In the former all kinds of crops are sheltered, and consequently grow luxuriantly; while in the latter the crops are subject to extremes of cold in winter, as well as to excessive heat in summer.

The benefits derivable, from the purely agricultural point of view, by the formation of plantations, are well exhibited in the following short extract from Stephens's Book of the F'arm, 4th edit., 1893, vol. iii. p. 214:-

"Shelter from Plantations.-The benefits derivable from plantations in improving land are far more extensive and important than from stone walls. 'Previous to the division of the common moor of Methven (in Perthshire) in 1793,' says 'Thomas Bishop, 'the Iate venerable Lord Lynedoch and Lord Methven had each secured their lower slopes of land adjoining the moor with belts of plantation. The year following I entered Lord IIethren's service, and in 1798 planted about 60 acres of the higher moor-ground, valued at 2s. per acre, for shelter to 80 or 90 acres set apart for cultivation and let in three divisions to six individuals. The progress made in improving the land was very slow for the first 15 years, but thereafter went on rapidly, being aided by the shelter derived from the growth of the plantations; and the whole has now become fair land, bearing annually crops of oats, barley, peas, potatoes, and turnips; and in spring 1838 , exactly 40 years from the time of putting down the said plantation, I sold 4 acres of larch and fir (average growth) standing therein for $£ 220$, which, with the value of reserved trees, and arerage amount per acre of thinnings sold previously, gave a return of $\mathcal{L} 67$ per acre."

The drying effects of the absence of trees are exemplified on a large scale in North America at the present day, wherever the axe of the settler has been in operation for any considerable length of time. The beds of former water-courses are now often being plomelerl, and are only distinguishable as such by their hollow lines 
rumning through the farms. Settlers may often be fommel who can describe how, when they first came into the forest, a never-failing supply of water ran down these hollow lines, and how they rrarlually becinne dry as the woods were cleared for the plough, and the land was piece by piece exposed to the hot rays of the sun. Hundreds of families in British North America have been obliged to clamge the sites of their original holdings, simply lecause the streans, on the sides of which they had settlerl at first in confinlent expectation of having an unlimited supply of water, had gradually dried up as the land became cleared of its beneficial covering of forest.

But there is no need to go out of Britain for proof of the drying effects of injudicious clearing of forests on the land. Practical experience every now and again shows that after a large tract of wood has been cleared from a hillsicle, springs completely dry up which have previously yielded a constant supply of water while the land was covered with trees; for there are many who can attest cases of this description from their personal observation and knowledge.

On the other hand, it is often surprising to find, on examining woods which may have been formed some ten or twelve years previously on land considered dry at the time the plantations were made, that wet spots are to be observed here and there, which spread wider and wider every year, and some of which may even be beginning to throw out tiny rills of water. This proves that under the shade of the trees the larger portion of the moisture of the land is retained, and that it therefore accumulates in spots according to the nature of the subsoil.

The general effect produced hy high hills and mountain-ranges on the maisture of the air can be utilised for the benefit of the lower-lying and the level parts of a country by careful attention to the distribution of its forests. Woods and plantations, in all cases, cool the air, and increase its relative humidity. The roots of the trees loosen the soil, and assist in its decomposition; while the herbage growing uncler the shelter of their branches prevents the rain-water, even on sloping hillsides, from running quickly off. Plantations in all cases check the currents of air passing over a country, and from this cause the carrying off of its moisture ly drying winds is greatly lessened. The shade of trees prevents the rays of the sum finding their way to the soil, so that but little of the moisture in it can be evaporated and carried off to the upper air by warm currents of air.

The water imbibed from the earth by the roots of trees is transpired through the foliage in the form of aqueous vilpour: hence the air in plantations is always found moister and cooler than it is in the open country, where the land is destitute of trees. It therefore follows 
that while the warm air is rising upwards from the dry land of the open country, the cooled and moister air must fall again to the still cooler surface of the woodland; and consequently, in the neighbourhood of large plantations, there will be less chance of fields being robbed of their soil-moisture, than when warm dry air is wafted over the land, and robs it of water by evaporation.

When soft winds, highly charged with aqueous vapour, blow over dry ground heated by the sun, no precipitation of moisture usually takes place; on the contrary, any low clouds that are formed sink down into the warm air below, and are soon dissolved and vanish. The warmth reflected from the dried and warm soil diminishes the relative humidity of the air, and increases its power of holding aqueou. vapour, thus preventing the formation of rain. It is not so, however, where the temperature of the atmosphere is reduced by the influence of neighbouring woods. There the air, being saturated with moisture from the constant transpiration, soon becomes overcharged, and then rain follows.

For when evaporation is stimulated in this manner, the moisture rises in the soil by reason of capillary attraction, in place of remaining in the lower layers and tending to enhance the productive capacity of the soil by the formation of soluble nutrient salts, in which form alone the food-supply of plants can be absorbed by the suction-rootlets and root-hairs.

From a consideration of these facts, it appears evident that, within certain limits of course, by the distribution of plantations of such extent as may be suited to the particular circumstances of each case, it may be in the power of man to modify certain local climatic conditions, so as best to suit the various kinds of crops he cultivates in different localities. Attention is, however, again called to the fact, already noted on p. 23, that where the rainfall of any locality is on the average already over 40 inches a-year, the formation of forests to such an extent as to increase the rainfall is not a desirable measure with a view to the improvement of the agriculture.

Judicious planting has not only a very decided influence on the improvement of the climate of a country, but also exerts a direct and beneficial influence on the productive capacity of the soil; and on this branch of the subject it may not be too much to state that however good any piece of land-not properly agricultural soil, but merely land suited only for the growth of sylvicultural crops-may be previous to its being put under a crop of trees, it gains in productive capacity whilst it is kept under the shade of close-canopied forests, and must thereby be rendered more suitable for any subsequent agricultural purposes than if it had remained without any woodland cropping. 
These results are mainly due to the thorough protection afforderl by the dense crown of foliage against the drying and exhausting influences of insolation and winds, and against the washing ont of the soluble nutrient salts from the soil by heavy rainfall, which also scours away the finer layers of surface-soil. And at the same time, the work of decomposing the mineral soil itself, and of forming increased supplies of soluble salts for futire use, is stimulated ly the large amount of vegretable matter which trees ammally deposit on the land occupied by them, and which decomposes to form humus or leaf-mould. This general work of gradual decomposition of the soil is further aided greatly by the roots penetrating deep into the latter, and consequently dividing its parts and opening it up for the circulation of air and the percolation of water.

In proof of this the very rich soils of the American continent may be alluded to, as these have been formed for the most part by the deposits of vegetable matter from successive crops of trees that have grown spontaneously on them. But compare with these the sterility of such parts of a country as have never been covered with woodlands. From such a comparison it will at once be evident that, in the great economy of nature, forests perform a very important part in improving the land on the surface of the globe, and in rendering it serviceable for cultivation by man. It is not necessary to go far in search of proof of this fact, for on our own island abundant evidence is given that trees vastly improve the land on which they grow. Everywhere on the flats and hollows of this country the land bears evident proof of having been occupied by trees at an early period; and it is chiefly owing to these, and to their having decayed and rotted upon them, that the soil is now so fertile. And besides this, during the present century large tracts of waste land have in many localities been planted up, which, previous to their having been brought under forest, had only a poor and thin soil, but which have now gradually become transformed into comparatively good land, owing to the beneficial ellects of the sylvicultural crops in protecting the soil against sum and wind, and manuring and improving it through the annual fall of leaves, and their transformation into humus.

There can be no doubt that judicious planting on an extensive scale is destined to be the great means of improving the soil and climate of all countries which at present suffer from the ill effects of drought.

Objects of Planting.-When planting trees on his estate, nearly every proprietor has some definite object in view for the work. This may perhaps be to give shelter to his farms, to shut out some unpleasant object from his dwelling-house, or merely to produce a general ornamental effect in the landscale; and in either case 
it may be correctly termed Arboriculture. But the chief ultimate object of such operations on a large scale is undoubtedly the cultivation of crops that are profitable from a purely financial and monetary point of view; and in this case the proper name for the art practised is Sylviculture. The former object is more usually resthetic than utilitarian, although very frequently both aims are combined; whereas sylvicultural crops are reared entirely with a view to personal or national-economic advantages, and any resthetic and utilitarian features combined therewith are fortuitous rather than studied, except in the case of large woodlands formed for the improvement of the climate of tracts suffering from excessive dryness of the atmosphere, or from the effects of shifting sands or dunes.

On properties situated in naturally level, fertile, and sheltered parts of the country, where arable land is more immediately remunerative to the proprietor than woodlands, the owner can have no object in planting trees other than for their purely xsthetic or ornamental effect, unless he may, perhaps, desire to increase the relative humidity of the neighbourhood on a small scale.

The case, however, is somewhat different with regard to the proprietors of estates consisting partly of level and partly of hilly land. On such properties it is not infrequently advisable to plant on the higher districts, with a view to the amelioration of the local climate of the lower lands, as well as for the improvement of the soil on the hillsides, and for the enhancement of the general value of the property by means of the timber-crop.

But with the proprietors of estates including extensive hilly tracts, the great object in planting must usually be the rearing of a crop of trees on land which is otherwise unfit for profitable cultivation.

Such land is mostly totally unfit for arable cultivation, and at the same time not always worth much for pasturage; and unless it be utilised for the growth of timber, it is often classified as unproductive, both from a nationaleconomic point of view and from the standpoint of the private owner.

With the recent shrinkage in agricultural values, there has been a continuous tendency for the poorer classes of arable land to be transformed into permanent pasturage, and for the inferior pasture-lands to be thrown out of occupation. Unless, therefore, these latter be utilised sylviculturally, they must remain unproductive and unprofitable, which is deplorable both from a national-economic and a private point of view. In the Board of Agriculture's Agricultural Returns for 1891 (p.x) Major Craigie, the statistical secretary, remarks that-

"Turning to the details of the cultivated area, it is again necessary to note the remarkable changes which have been taking place in the ratio of arable to pasture land in Great Britain. The two great divisions of arable 
and pasture now claim for the first time an almost exactly equal share of the surface. Twenty years ago the arable land was to the grass as 3 to 2 . It exceeded l,y li,000,000 acres the surface of the permanent gran, there licing $18,430,000$ acres returned as arable to $12,435,000$ acres of pasture."

And in the Agricultural Returns for 1892 (Pp. x, xi, and xxi) he has the same sad story to tell:-

"The arable land, as has been the case in every year but two since 1872 , again shows a reduction. .. Between 1872 and 1882 about 936,000 acres were apparently withdrawn from arable tillage, and reappeared in the opposite category of the cultivated area in the form of permanent pasture. ... In the later ten years a similar process has continued. Betreen 1882 ant 1,592 the arable land has again diminished, and this time 1,y 1.16,5.000 acres. . . The more important alterations between 1891 and 1892 occurring in the entire United Kingdom may be summarised in the accompanying table :-

\begin{tabular}{|c|c|c|c|c|}
\hline \multirow{2}{*}{ ACREAGE. } & & \multirow{2}{*}{$\begin{array}{l}1891 . \\
\text { Acres. }\end{array}$} & \multicolumn{2}{|c|}{1892 compared with 1891.} \\
\hline & Acres. & & $\begin{array}{c}\text { Increase. } \\
\text { Acres. }\end{array}$ & $\begin{array}{c}\text { Decrease. } \\
\text { Acres. }\end{array}$ \\
\hline Total cultivated area. & $47,977,903$ & $48,179,473$ & $\ldots$ & 201,570 \\
\hline Total of permanent pasture & $27,533,326$ & $27,567,128$ & $\ldots$ & 33,802 \\
\hline Total of arable land . & $20,444,577$ & $20,612,345$ & $\cdots$ & $16 \overline{7}, 768^{\prime \prime}$ \\
\hline
\end{tabular}

Surely, when these figures are studied, the desirability of relaxing the existing rating on woodlands, and of amending the laws relating to the utilisation of timber on entailed estates, ought to be brought before the notice of Parliament.

The foregoing remarks are only applicable to the subject when viewed from a broad and comprehensive standpoint; for each point of view may diverge into many branches or different vistas, each of which may be desirable to owners, and expedient in practice, according to the given circumstances of each case. For example, a proprietor desiring to plant trees for shelter to his farms may at the same time wish to treat them as hedgerow timber, as belts of plantation, as coppice, as hop-pole woods, or merely as omanental timber, according to local circumstances, and accorting to the nature of the land he may have to deal with. All of these different arboricultural and sylvicultural systems will be treated of in their proper places, and under their respective headings.

The Financial Value of Sylvicultural Crops. - The ralue of wood as a crop upon any given piece of land depends very much upon the treatment it may have received in its cultivation. Trees, like every other useful product of the soil, may be considerally deteriorated in value by unskilful and careless treatment: and 
they may also he greatly enlanced in value hy skilful tenting and careful management. Although, to a certain extent, sylvicultural crops vary in marketable value according to the nature of the land planted, and also according as the locality may or may not be conveniently situated with regard to the disposal of the timber or other forest produce, yet their technical, and consequently their finumcial, ralue is to a rery great derree depentent on the treatment accorded to the timber throughout all the stages of its growth.

There is no climatic reason why a very considerable portion of the

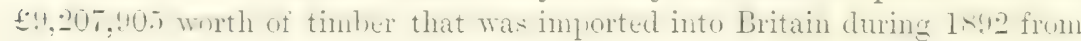
Russia, Scandinaria, and Germany should not in future be supplied of homegrowth, when once the crops raised have been subjected to rational treatment from the time of their formation onvards. This latter condition is essential; for woods that are crowded at thirty, forty, or fifty years of age may not have been of sufficient or normal density at ten or fifteen years of age; but may have become crowded in canopy through excessive and uneconomical ramification and coronal development. When, however, the woods have been properly tended during the early stages of growth, their subsequent tending, by means of thinning out, determines their economic value to a considerable extent. This has been very well put, by one of the greatest German authorities on Sylviculture, in the following words : ${ }^{1}$

"It must, however, be expressly stated that the youthful development of timber crops can afford no reliable indication for the future quality of the mature fall. Expectations, anticipations, and suppositions in this respect have no justification; for the whole matter depends most essentially on the l:ater treatment of the crops (whether formed hy sowing or hy planting) during the operations of thinning out."

It may be stated as a general rule, based on, and verified by, actual practical exprerience both in England and secotland, that land which is from various causes unfit for arable occupation will, if brought under sylvicultural crops, and subjected to rational and careful management, at the end of seventy years pay the proprietor nearly three times the sum of money that he would have received from any other crop upon the same piece of ground.

This assertion will doubtless, by many proprietors, be considered extravagant. But although it may be very much beyond what they have themselves experienced as to the profits, or want of profits, arising from their plantations, yet in all cases where good management has been introduced, what is above said will be found not to be incorrect. In order to support this statement a few examples may be given, without going into details, most of which are based upon the author's personal experience in dealing with woods in different parts of the country.

\footnotetext{
${ }^{1}$ Gayer, Wraldbau, $3 d$ edit., 1889, p. 384.
} 
On three estates that he had to deal with in the north of sicotland, where the woods are chiefly Larch and Scots Pine, and where regular accounts of the sales of the produce had been liept for a period of nearly forty years previous to his visiting them, he found that the older classes of the Pine woods harl yielded, on the average, ahout $13 \mathrm{~s}$. per acre per annum for thinnings throughout the forty years during which accounts had been kept of sales from them; and that where clear fellings had been made of the mature crops, these had realised, on an average, about $£ 70$ per acre, after the removal of all the thinnings that had from time to time been taken from them.

The Larch crops on these estates realised about one-half more than the Scots Pine. That is to say, the average annual value realised from the thimnings of the Larch was, during the forty years referred to, $20 \mathrm{~s}$. per acre; and where clearances had been made of the mature crops of Larch, these had yielded $£ 106$ per acre on the average.

The annual rent of the land upon which those plantations grew was reckoned at 4s. $6 \mathrm{~d}$. per acre on the average; and the crops, when mature, had occupied the land for a period of about seventy years. Now, had it been occupied by tenants for the purpose of grazing, the proprietors would have received only $£ 15,15 \mathrm{~s}$. per acre during the whole period of seventy years; but whilst the land was under timber crops they received, when the crops were cleared at the end of the period of seventy years, no less than $27 \mathrm{~s}$. $6 \mathrm{~d}$. per acre and per amnum throughout the whole period occupied by the Scots Pine crops, and about $41 \mathrm{~s}$. $6 \mathrm{~d}$. per acre and per annum for the land oceupied by the Larch. Even after deducting every necessary expense the proprietors were put to, and after also deducting compound interest upon the original outlay and rent, progressively, during the time when no return was received, it will be found that such land, when utilised sylviculturally, will pay fully tinree times the amount of money that it could do in the hands of farmers. And the obvious conclusion therefrom is that sylvicultural crops, even when managed in an ordinary way, may be highly profitable to the proprictor, and may add greatly to the capital value of his estate.

The editor does not feel justified in cancelling the above; but he must at the same time exhibit what he considers the proper methoul of reckoning in such actuarial calculations regarling the comparative remunerativeness of sylvicultural and agricultural utilisation of the soil. Sylvicultural oreugration of land is in many cases far more profitable than agricultural oecupation; but it is essential to apply correct actuarial methods in solving the rarious problems that present themselves. All sums of money invested in, or received as returni from, woodland crops must be treated as increasing at compound interest. 
The agricultural returns from the land are to be found by the formula-

$$
\text { Total value }=\frac{£ 0,4 \mathrm{~s} \cdot 6 \mathrm{~d} \cdot\left(1.0 p^{n}-1\right)}{0.0 p}
$$

If $p$, the rate per cent which the annual rent of the land yields on its capital value, be $=3$ per cent, then the actual monetary value of all the annual rentals received by the landlord, capitalised annually to the end of the term of seventy years, would be-

$$
\begin{aligned}
\text { Total value } & =\frac{£ 0,4 \mathrm{~s} \cdot 6 \mathrm{~d} \cdot\left(1 \cdot 03^{70}-1\right)}{0.03} \\
& =\frac{£ 0,4 \mathrm{~s} \cdot 6 \mathrm{~d} \cdot(7.9178-1)}{0.03} \\
& =£ 51,17 \mathrm{~s} .8 \mathrm{~d} .
\end{aligned}
$$

The sylvicultural returns from the land, if discounted and converted into an annual rental, would be as follows, using, of course, the same percentage, 3 per cent, as one of the essential data for the calculation:-

$$
\begin{aligned}
& \text { In the case of Scots Pine-Annual rental }=\left(\frac{\mathfrak{E} 70}{1.03^{\tau 0}-1}\right) 0.03 \\
& =£ 0,6 \mathrm{~s} .03 \mathrm{3} \text {. per acre. } \\
& \text { In the case of the Larch-Annual rental }=\left(\frac{£ 106}{1.03^{70}-1}\right) 0.03 \\
& =\mathfrak{E} 0,9 \mathrm{~s} .2 \frac{1}{4} \mathrm{~d} \text {. per acre. }
\end{aligned}
$$

If the dates were given at which the various thinnings were conducted, as well as the actual costs of the thinnings and the net surplus derived therefrom as profit, the additional transmuted annual value, ultimately paid as rent by the sylvicultural crops, could likewise be calculated. But, per contra, it must not be overlooked that the rating of the woods for land-tax must either be deducted from their annual rental value, or else capitalised up to seventy years and deducted from the sum obtained for the mature crops; whilst at the same time the rental received from the tenant of the pasturage was a clear sum freed from any costs of protection on account of fire, or risks from windfall, dre., and this is very difterent in the case of standing crops of immature timber. And further, the sums obtained for the crops of Scots Pine and Larch, above referred to, were not derived without an initial, and in some cases often a considerable, outlay on the plantations; hence the mrofit derivable from the roods in question should be calculated on the net price (free from all costs of harvesting) obtained from the mature crop, minus the capitalised value of the costs of the formation $\left(=\operatorname{costs} \times 1.03^{\circ}\right)$, but reduced in a proper actuarial manner by the net returns available from time to time by thinning operations. And if, as is often the case, additional cultural costs are incurred for filling up blanks, or for clearing and weeding before the material cut out is marketable and can cover the outlay thereby involved, then in all justice they must be added to the cost of the formation of sylvicultural crops, just in the same way as net income from thinnings may be applied in reducing the capitalised value of the costs of formation.

It must also be noted that if $3 \frac{1}{2}$ or 4 per cent be adopted as the rate of interest which the proprietor gets or expects for his land, this not only greatly 
enhances the cipitaliserl vilue of the pasturage rentals ealculaterl at mompond interest for seventy yenr's, but at the sime time greatly diminishes the present annual value of the woods, discounted from a sum due seventy years hence, and commuted into a present annual rental.

These actuarial problems in Forestry are not so simple as the above method of reckoning employed by the author would suggest. But at the sime time, practical experience, both at home and ahroad, shows that, for the prorer classes of land, sylvicultural occupation is on the whole much more advantageous than any other system, even for private owners; whilst, with regard to the national forests, there is no continental country of Europe in which the administration of the State forests is conducted in so laissez-faire a manner as in some cases in our own country, with the practical result that the woods do not pay as they otherwise would and should.

Again, in the south of Scotland and the north of England mature crops of Larch have sometimes heen sold at prices ranging from $£ 1.50$ up to $£ 380$ per acre, irrespective of the value of thimnings that had heen removed from them during the earlier stages of their development. The land on which these crops grew was valued at rates varying from $10 \mathrm{~s}$. to $15 \mathrm{~s}$. per acre per annum, and the crops when cleared were of from sixty-five to seventy years of age.

At 4 per cent, or twenty-five years' purchase, the value of 15 s. per acre at compound interest for seventy years would be $£ 273,4 \mathrm{~s} .4 \mathrm{~d}$.; at 3 per cent, however, it would only be $£ 172,18 \mathrm{~s} .10 \frac{4}{5} \mathrm{~d}$. It is impossible to balance the true actuarial facts of the case between Sylviculture and Agriculture on such rague generalisations as have here been given by the author. But, as has already been said, the editor also maintains that it is a fact, which has often been proved, that, on poor classes of land, woodland crops often pay fairly well, when the land is worth little or nothing for agricultural occupation.

It may also here be mentioned that, according to details received from a well-informed forester, who lives in the neighbourhood of the estate where this high sum was realised, and whose information is to be relied on, in the north of Englind a crop of matured Lareh was sold ahout twelve or fifteen years ago at the rate of $£ 500$ per acre. This crop was grown on a sloping bank unfit for the plough.

In the south of Scotland and the north of England crops of matured

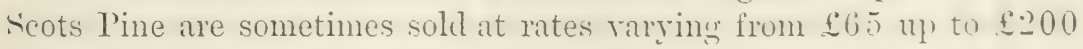
per acre. The ages of these are probably about seventy-five years on the average, and the rent of the land would be about $15 \mathrm{~s}$. per acre.

In the same parts of the country matured crops of mixed plantations of broal-leared species of trees are often sold at rates rarring from $£ S 0$ up to $£ 170$ per acre, and in one or two cases even as high as $£ 220$ per acre. 
Again, in the same localities, mature crops of Oak are sometimes disposed of at prices varying from $£ 200$ up to $£ 400$ per nere.

In these last five instances referred to, it must be kept in view that no account is taken of the thinnings which had been removed from the several crops while they were in the growing state, and before they became matured, as no information could be obtained with regard to that source of income.

But it must also be more particularly borne in mind that nothing has been said about the initial costs of the formation of the plantations. And for accurate reckoning, it is absolutely essential that such figures should also be taken into account, otherwise the results obtainable cannot be strictly correct from an actuarial point of view.

What has been said above refers to the value of a crop of wood when trained up as timber-trees. There are, however, many proprietors who cultivate a large portion of their woodlands as coppicewoods, which are growths from the stocks or stools of trees formerly cut over. From a financial point of view, erops of this class do notaccording to the author's experience-pay nearly so well as crops of timber growing in high - forest. Sylvicultural crops of this minor nature, growing in different localities throughout the west and the south of Scotland, and in the central and northern counties of England, are seldom found to pay their proprietors over $15 \mathrm{~s}$. per acre per annum for the land occupied.

The author's experience seems here to be at variance with the editor's, and with that of the majority of Continental sylviculturists. For it has been frequently proved that, on hillsides of rather a shallow description, but otherwise favourable as to soil and exposure, Oak coppice-woods are often by far the most remunerative form of sylvicultural crop, when there is any favourable market near at hand for the disposal of the bark to tanneries. Again, mixed coppices of Ash, Maple, Sycamore, Sweet-Chestnut, Hazel, and the like are also exceedingly remunerative throughout southern England, when near favourable markets for saplings and poles, such as hop districts. Throughout the Cambridgeshire and Lincolnshire districts, also, osier-holts yield such favourable returns that the Board of Agriculture issued a special pamphlet on the Cultivation of Osiers during 1893 ( $\mathrm{A} \frac{3-9.3}{1}$ ), "with a view to direct the attention of agrieulturists and others to a special industry for which there would appear to be some room for development in certain parts of this country."

Alder-coppice is likewise often a more remunerative form of crop than almost any other on land that is suited for the Alder, but which cannot be conveniently drained to serve higher purposes.

These examples may be considered quite sufficient for present cousideration. Many others might be given in illustration of the same 
point; yet as they wonld only swell this work, without altering the facts stated, it seems preferable not to detail them. But it is not alone the simple valne of the timluer that makes plantations of so great an importance upon a large landed estate. There is the shelter that they atford for all agricultural purposes, and the heneficial influence they exert in tending to regulate the climate: for where no shelter-woods exist, there is often only an inferior crop of grain upon the fields, as well as an ill-fed live-stock on the farm; and these points should all be taken into account. Upon almost any landed property, indeed, well-managed plantations are incaleulably of more value than an equal area of land in the hands of a farmer, but without trees to give shelter; and it is well known by-every proprietor of land that he receives by far the, highest rent for those parts of his estate which are most sheltered by his best plantations. And further, whatever agricultural value land may have when unsheltered by woodlands, its productive capacity is very much enhanced, and its rental value considerably greater, when it is properly sheltered ly plantations or natural woods.

Sylviculture or Forestry differs from no other science in its fundamental principle,--search after knowledge and truth. It would, therefore, be unfair not to point out that evidence was given before the Parliamentary Committee on Forestry of 1887 to prove that planting could not in Britain promise remunerative returns, owing to the fact of the timber marts being glutted with foreign timber, to the general depression in trade which was then making itself felt, and to the use of substitutes for many purposes for which timber was formerly employed. Mr Dundas of Arniston, a large colliery proprietor and estateowner, who deponed that he preferred to purchase Baltic timber for the supply of all his requirements, and sold his own forest produce at whatever it would fetch, made the following statement:-

"1435. . . P People go about, and they see woods that are neglected, and it is put down at once to want of scientific knowledge on the part of the foresters; but the fact is, that the bulk of the woods we see neglected nowadays is due to the unremunerative nature of wood-growing, and because the owners cannot and will not throw away good money after bad in keeping them in order: that is really the cause.

"1421. Your opinion is, that on land which is worth more than 3s. an acre it is hardly worth growing timber in Scotland?-No. I have a very strong impression of the uselessness of trying to plant timber on bad land. It used to be an old idea a century ago, and I have seen in old plans certain pieces tinted brown, and marked 'wet land, to be planted.' I am certain it is throwing away money to grow wood on such land: timber-growing requires good land and a fair climate.

"1422. Land that you could let, probably, for more than 3s. an acre?Yes.

"1423. Then it does not become profitable to grow timber? -No; it does not become profitable to grow timber. I think there is great exaggeration 
in the talk there is about the number of acres which might be profitably planted; I do not think, from the soil and climate, they could be; and then the distance from a large market always is fatal. Baltic wood is brought over so very cheap that Highland wood, which is the only wood that could be planted on a large scale, is at a disadvantage, because, although the distance is much shorter, the expense of carriage becomes so heavy. In Norway they get it on board ship at once.

" $1 \pm 47$. With regard to your own woods, I suppose we may assume that they were planted more for the purpose of shelter and ornament, and for unremunerative purposes, than for commercial purposes?-Quite so. But taking it along with what I have stated, that I am much more a woodpurchaser than a wood-grower,-at the price I am buying at, I cannot see how Highland proprietors can grow to a profit."

But at the same time it does not follow that these plantations are managed as well as they might have been. It is important to note that among Messis Thompson, Macgregor, and M'Quorquodale, at that time the able practical head-foresters in charge of the Strathspey, Athole, and Scone Forests, there was a consensus of opinion that properly managed woodland crops are undoubtedly profitable even with the low rates ruling for home-grown wood. The late Mr Macgregor's evidence may be quoted briefly on this point:-

"1122. Then you think the forest area in Scotland might be largely increased?-Very largely; it can be very much extended.

"1123. With profit?-With profit.

"1124. Why is that not done now? - I camnot tell. It is expensive to some proprietors to do so; and perhaps they would not be very able; that may be one reason.

"1125. Would you attribute that to popular ignorance of the value of woods and forestry?-No.

"1126. I suppose the largeness of the capital required is a consideration? - Yes, very much so; and it does not make immediate returns: that is another consideration."

"107\%. Have the great plantations on the Duke of Athole's property been successful as a commercial speculation?-I think so.

"1078. But at present prices they are not?-Even at present prices they are better than if left as moorland in their original state."

'There was one point frequently brought out in the evidence before the Committee that is shameful if it be still true-viz., that for the freight of foreign timber a lower preferential rate is charged by railway companies than is levied on the conveyance of home-grown timber. If this still be the case, it certainly should be stopped by Act of Parliament.

But even in spite of these hindrances the evidence of experts went to prove that woodlands may pay. The evidence of Mr Evan Powell, a Welsh land-agent, on this point was as follows:-

"2058. Is it your opinion that, in spite of the drawbacks that you mention-namely, the rating of woodlands and the preferential rates of railways-home-rrown timber can still be produced at a profit?-Yes, I think so; at least certain classes of timber." 
Education in Forestry.-It is trite and commonplace to say that a surgeon cannot practise successfully on the human subject unless he has been trained to his work by a thorough acquaintance with the human anatomy, physiology, amel pathology; or that it veterinary surgeon cannot practise with any hope of success on the diseases of any animal muless he has stndied its anatony, physiology, and pathology; or that every man who means to be a good, intelligent farmer must learn the art of farming, not only practically, but theoretically, in all its branches. If in such cases training to the end in view is so necessary to success, it reasonably follows that foresters should undergo a certain course of training before they can he safely and profitahly intrusted with the rearing of plantations. Further, it is admitted as a general rule in all professions that in this age of general improvement, whatever department a man may take up as his particular business, he should, before entering into it, whether upon his own account or as agent for another, make himself acquainted with such branches of science as have a direct bearing on it, and the knowledge of which will the better qualify him for it. For if he has not the requisite knowledge as a basis for practical work, he cannot possibly succeed to the mutual satisfaction of himself and of his employer.

Admitting these points-and their practical importance cannot well be disputed-it must be confessed that, although the erlucation of foresters has advinced considerably of late years, still very much that is desirable remains to be done before a knowledge of sylvicultural science can be said to be easily obtainable. There are several cognate sciences which have a direct bearing on the art of Forestry; and without a knowledge of these it is all but impossible for a man to be a sylviculturist or an arboriculturist in the true sense of the term, or at least to such an extent as to enable him to carry out improvements in the art with profitable results. Hence it follows that among the men who are now engaged in Forestry, and who have the management of British woods, there are comparatively few who have received such a training and education as is necessary to equip them thoroughly in all respects for their duties. This is equally important both to foresters and proprietors; for on the proper qualification of foresters depends much of the future sneces: in the twin arts of Sylviculture and of Arboriculture.

Forestry, like Agriculture, must adapt itself to the peculiar conditions and requirements of the country, and even of the particular part of the country, in which it is to be practised. A forester, trained in Continental methods of Sylviculture, would not be alle to alply, as a matter of course, the same practical rules and methols to Scottish woodlands that may have been found to yield the best 
practical results in France or Germany; and still less would he be able, as a matter of course, to apply them to the forest conditions obtaining in Brazil, for example, or in the Southern States of North America. In the latter case he would find kinds of trees different in most respects from those which he had been accustomed to deal with in Europe; and when he began sylvicultural operations, whether with resard to planting, clearing, thiming, or utilising, he would see that his former education in Forestry could not, in all respects, be bronght to bear successfully on the works he had taken in hand, and that he had still much to learn in order to adapt his former forest experience to suit the different circumstances of each case.

But the scientific principles of Forestry-whether acquired only by practical work in the woods, or preferably by a combination of theoretical instruction and practical woodcraft, as is insisted on ly the Continental Governments, which have either liberally endowed Chairs of Forestry at many of the universities (Switzerland, Hesse, Baden, Wuirtemberg, Sweden and Norway), or else formed national schools of Forestry (as in the cases of France, Italy, Spain, Prussia, Saxony, and Russia), or have even done both (as in the case of Bavaria and Austria) - remain the same throughout every condition of soil and climate, and vary only with regard to their practical application in the art of sylviculture. The fundamental principles or truths of Forest science are constant and unvarying, like those of all other sciences; and the only differences between the management of forests in the tropical, the subtropical, and the temperate zones, or in different parts of any of these regions, consist in the practical application of those principles so as to utilise the linowlenlge of the plyysiological laws resulating the growth of woodland crops to the best advantage of the individual, or of the general community.

This incontrovertible truth applies equally to foresters trained in Britain, or France, or Germany, or anywhere else, when they go to America, India, Africa, or Australia. In all these countries there is much that is peculiar to their respective climates, and which the European forester has to master ere he can properly deal with the necessary improvements in their woodlands respectively. But the scientific principles remain the same, no matter how greatly the concrete factors of soil, situation, climate, and species of trees may vary. From this it is evident that foresters should be well educated in all the respective hanches of science which have any learing on the art of Forestry. For if not, they are almost certain to arrive at unsound conclusions when brought face to face with such actual concrete conditions of woodlands as they have not previously been acquainted with.

Although very considerable improvement has of late years been 
made with regard to the erlucation of foresters, still there is only a small proportion of them who may be said to be really well-rqualified men, and capalle of conducting their charges in a highly intelligent and really trustworthy manner. Many of them are mere overseers or workmen, whose only qualification is that they can plant trees in the usual way, and cut them down with the axe when local circumstances require the operation; and the resnlt of this want of knowledge is, that the crops under their charge have not succeeded so well as they would have done had they been under the inspection and control of men properly trained to the management of woods. This may be considered by some (see the extract from the evidence of $\mathrm{Mr}$ Dundas of Arniston, given before the Parliamentary Committee on Forestry in 1887, and quoted at p. 45) to be somewhat of the nature of an exaggeration. It is really by no means so; it represents the simple truth of the case with regard to the general capabilities of the great majority of the men who at the present time have the management of plantations in this country.

It would indeed seem inconsistent in the managing committee of any hospital to appoint a man who had no skill in medicine and surgery to act as doctor to the patients of the institution; and yet this would only be very much similar to an appointment in the Department of Woods and Forests and Land Revenues of the Crown, made by Government, and to the short-sighted policy adopted by many landed proprietors in appointing comparatively unskilled men to the management of their woodlands. Many still seem to look upon trees as things that can take care of themselves, and that require no particular attention after they once have been put into the ground. There can be nothing more erroneous, however, than this idea; for when once plantations are formed, unless they are carefully and skilfully tended, and cleared, and thinned, the trees can no more grow up spontaneously, and as a matter of course, into a profitable crop of timber, than turnips can attain their largest bulk if not properly thinned.

It is indeed very singular that a proprietor should appoint a comparatively uneducated and mitrained man to the management of his woods, while he is generally much more careful in lis choice of a man to take the management of his home-farm. And yet in the former appointment there is generally, acre for acre, more capital at stake than in the latter, seeing that woodland crops take so long to mature in comparison with agricultural crops harvested amually. l'roprietors employing men to take the charge of their wooks msually do not care to pay the price necessary to secure the services of a highly yualified and really competent man; for muless the woodlands are very extensive, good men cammot be obtained for such a smitl salary as the profits

VOL. I. 
from their woods would admit of the owners paying. This is quite true in the case of the small proprietor; but it is wrong in principle. Intinectly, however, it is the fault of the proprietors themselves that their woods do not pay much better than they do ; for the majority of landuwners appear unwilling to contribute towards the establishment of any course of sound instruction in Forestry, which would help to ynalify land-agents and head-foresters for the better management of woodlands. The more qualified the forester, the more likely are the woods under his charge to be remunerative to the proprietor; and if the woodland area on any estate be too small to allow of the proprietor engaging the entire services of a trained sylviculturist, yet, with technical opportunities such as would be secured by the establishment of Chairs of Forestry at university centres, it might in a very short time be possible to have professional sylviculturists, whose time and services could be secured for a number of estates, in precisely the same way as land-agents' and lawyers' services are given to more than one estate without prejudice to the interests of any one individual proprietor.

This subject may briefly be summed up as follows:- Speaking generally, foresters in Brituin are not at present prossesserl of sufficient technical education to enable them to be intrusted with the management of large woodland estates; and until we have a better educated class of men, trained in a thorough professional manner, a large portion of our woods must continue to be less profitable than they otherwise might, and in all probability would be. Many proprietors have not gone the right way to ensure their plantations being so profitable to them as they are capable of being made. They too often appoint unqualified and unskilled men to undertake their management, from a mistaken notion that a saving on the forester's salary is an economy; whereas, in point of fact, from want of skill he may yearly be losing much more than the amount of this saving by bad management of the woods under his charge. And as there is no throrough training yet available for land-agents and highly educated men who may wish to become scientific sylviculturists, there is no body of men who may be engaged as experts for consultation regarding the formation of working-plans, and for intrusting as a matter of business with the supervision and control of the sylvicultural operations on landed estates. Of course, for these two distinct classes of men, the practical forester, wood bailiff, or plantation overseer, and the scientific sylviculturist, a different standard of education and a different course of training are requisite to fit each for his respective duties, and to entitle them to their different scales of remuneration.

Were proprictors to look to their own interest, they would upon 
no account employ men to take charge of their woorls who would do so at a low salary, as such men invarial,ly want alility and skill to manage profitally; and besides, they should never employ men who have not undergone proper training, and received an education fitting them for their charge. Were this attended to on the part of proprietors themselves, the right class of men would soon spring up, a class which would be able to advance the art of Arboriculture to the standing that its importance demands for the future welfare of the country.

The Practical Forester, Wood Bailiff, or Plantation Overseer should possess a good ordinary board-school education of the higher standard in rural districts. He should be a good arithmetician, su as to enable him to enter into all sorts of calculations, and to keep correct accounts. He ought also to be a fair grammarian, and acquainted with the construction and composition of the English language, so as to fit him for keeping up correspondence with his employer, and for describing his views on any subject in writing, when necessary. In order that he may be able to draw plans of plantations, and measure land and wood, he should be well versed in all the common branches of elementary mathematics. These are the ordinary branches of erlucation, which every man now has an opportunity of enjoying. But it will be of great advantage if he be also able to read either French or German, so far as to be able to study some of the great works on Sylviculture in one or other of these languages; for this will not only add to his own knowledge of nature and his own personal satisfaction, but will also increase his usefulness in many ways.

A forester should be able to recognise plants and trees of any sort when he happens to see them, and to describe them accurately when he may have occasion to write concerning them. Without botany he cannot do this; he should therefore study this science, as, without some knowledge of vegetable physiology, it is impossible for him either to think, to speak, or to write correctly regarding the growth of trees.

Of all the cognate sciences which are necessary for a forester, and which bear directly upon his professional work, there is perhaps none so important to his success as that of Botany. Without a very finir knowledge of regetable physiology, he camnot be consilered it Sylviculturist, or a first-rate Arboriculturist, any mure than a smreen would be fitted for practice without a knowledge of anatomy. No proprietor should engage a man to manage his wookls who has not at any rate a fair knowledge of the bearing of regetalule pliysiology on his everyday work.

As different sorts of trees grow better upon soil of one mineral or physical description than upon that of another, and as it is neces- 
sary that every forester should know the general peeuliarities of the land of one district from that of another, he should have some acquaintance with (ieology and the rudiments of Sylvicultural or Agricultural ('hemistry, combined with a lnowledge of the physiological requirements of the different kinds of trees. Without this he cannot possilily distinguish between soils best adlapted for the growth of Larch, or Spruce, or Pine, \&e., and those more suitable for the growth of certain broad-leaved species of trees; neither can he describe intelligently the precise local contitions of the soils and situations on certain districts.

Sylvicultural or Agricultural Chemistry is just as useful and as necessary to the forester as it is to the farmer. Unless possessed of a certain amount of sound elementary knowledge on this subject, neither the one nor the other can form correct judgments as to the nature and productive capacity of different classes of soils. This, therefore, should form a part of the education of every man who would be an intelligent practical forester.

As has long been well known, not a few of the diseases of trees are attributable either to unfavourable climatic conditions, or to unsuitable soils, or to the attacks of injurious insects, or to infection with parasitic fungoid spores, the natures of some of which are as yet very imperfectly understood. In order to enable the forester, therefore, $t$ o make intelligent olservations and suggestions regarding such matters, he should also endeavour to make himself acquainted with Entomology, and with the Pathology of trees.

With a sound elementary knowledge such as is above described, any man of intelligence may enter upon the practical managenent of woods, however extensive they may be, with reasonable hope of a successful administration; but, without a certain amount of theoretical knowledge, it is very improbable that his stewardship and treatment of any sylvicultural crops that may be intrusted to his management will be to the credit of himself, or to the best interests of his employer and of the community at large.

It must not, however, be understood that only the elementary theoretical knowledge described is necessary in order to make a man a good forester; for without a course of practical training at the same time, he cannot become fitted to be trusted with the management of woods. A student fresh from college might just as well pose as a consulting physician without any other preparation as a practitioner. Besides a thorough training in the practical work of Forestry, which can always be obtained on one or other of the comparatively few estates where some attempt is made to manage the womls on sylvicultural principles, a certain amount of somul elementary knowledge of the cognate sciences above clescribed is absolutely 
necessary in order to make a man capalle of thinking correctly for himself, and of carrying on imporovements on such rational lines as will probably lead to desirable results.

In recommending to practicai foresters the sturly of Sylviculture and of its cognate sciences, no attempt need be made to prove that a deep course of study is requisite, because such is not the case. But it is imperative that they should have a sufficient acquaintance with the fundamental principles of Forestry to enable them to aprly the latter to their business, under whatever varying comlitions of concrete factors they may find themselves called upon to act. Elementary knowledge of a sound scientific nature is far more to be rlesired than a wide extent of shallow and discursive reading. And, within the last decade, the means have now been given for obtaining a better, though still only a partial, insight into the laws of nature which regulate tree-growth, as several scientific. works have of late years been published in this country on the different branches of Sylviculture, from which an intelligent man may teach himself (see list of works recommended in the Preface).

An important event in the history of Forestry in Scotland occurred on the 17th November 1892-just one year before the great north-east storm of 1893, which, disastrous as it was, may perhaps ultimately be productive of good, if its results can draw the attention of landowners to the necessity for, or the advisability of, encouraging the study of such branches of Forestry as relate to the Protection of Forests against storms and other inimical influences, whether of an organic or an inorganic nature.

On the evening of 17th November 1892, a Course of Free Instruction for Practical Foresters and Gardeners was begun at the Royal Botanic Garden, Edinburgh, for which a temporary grant of $£ 150$ a-year was obtained by Prof. I. B. Balfour from the Board of Agriculture. The nature and scope of the course of instruction may be gathered from the following résumé of the proceedings; and it may be noted that the number of applications received from young practical gardeners and foresters for the benefit of the scheme was sixty-seven, of whom forty-four were admitted to the course. Some of these were taken on at a weekly wage as gardeners in the Arboretum, whilst the others received employment in the various nurseries around the city.

In his introductory remarks, Prof. Bayley Balfour said that it was not intended to teach them in the class-rooms to be practical foresters or gardeners. 'That must be learnt elsewhere. But if they wanted to know the secrets of Forestry and of Horticulture, they ought to have a sound knomledge of the scientific basis upon which these arts rested. It was meant, therefore, to give them some insight into the sciences that underlay their work. During the winter they should have three courses-one on chemistry and one on physies, and, in addition to that, they should have a course on mensuration and landmeasuring. This last course would be begun in winter, hut more would he done at it when the long evenings came. They would then go out into the garden, where surveying instruments would be provided. They would be taught to use 
these instruments, to survey land, and to draw out plans. After these subjects had been gone through, they should then proceed to deal with botany, which treated of the actual plants they would handle; of geology, which treated of the soils in which the plants grew; they should also have a course of meteorology, giving them the application of physics to the study of climate; and a course on entomology, which would work into the course of botany, and would show them how insects affected forest and garden plants in health and disease. After that they should hare lectures on Forestry and Horticulture, treated by experts from a practical point of view; and he hoped it would be possible to arrange for excursions to neighbouring estates and gardens. The scheme, he believed, was fitted to equip a class of men who were needed not only in Great Britain but also in her dependencies. Remarks had, he said, appeared in the newspapers that might lead to the notion that there was some sort of rivalry between this course of lectures and the teaching in the University; but there was really no competition or rivalry between this course and that of the University. They were devised for entirely different classes of men. They were really different branches of one scheme which had the approval of the Royal Scottish Arboricultural Society.

The Bavarian system, one of the best on the Continent, of training lads for the subordinate forest service of the State, is begun when they are from fourteen to sixteen years of age. It extends over two years, during which the young lads go through a course of practical instruction, and receive tuition in the principles of Forestry, Arithmetic, Book-keeping, \&c. There are five such elementary Forest Schools in different parts of the country, and the results attained have proved most satisfactory.

The Sylviculturist, or Scientific Head-Forester, requires, first of all, a practical training in the operations of Forestry, and then a cumse of theoretical instruction, combined with opportunities of visiting forests in which the various operations of natural and artificial regeneration, the tenrling, and the utilising of sylvicultural crops may be seen as they should be done, and very often also as they should not be done. Such a course goes over all the ground covered in the instruction of practical foresters; but it should, of course, be much more thorough and more comprehensive, and therefore can only be successfully entered upon by men having a very good preliminary education. On the continent of Europe, throughout all the State forests and on the woodland estates of the nobility, the supervision of sylvicultural operations is, as a rule, only intrusted to highly educated men of this class.

I'he following curriculum may be taken as a fair analysis of Forest Science as taught at the great Continental Universities and national Forest Academies. ${ }^{1}$

1 Article on Forest Scicnec: its Aim and Scope, in the National Revicw for 1889, pp. 681-690. 
I. Introductory Studies in the Cognate Sciences, stating the aims and objects of Forestry from national-economic and proprietary points of view, and giving a concise account of its history, and of the forest laws from earlier times up to the present.

To this branch belong the general grounding in geology, botany, and zoology, the mathematical studies, and the application of mathematics to Forestry in surveying, levelling, and road-making.

1. Petrology and Sylvicultural Chemistry.--One camot conceive the growth of forest produce without soil; hence it is necessary that a good knowledge be acquired of what, for want of a better and more comprehensive name, is generally in England called "agricultural chemistry."

This subject, comprising not only geology, but also chemistry and meteorology, treats of the mineral constituents of the various kinds of rocks; of their decomposition and the formation of soil; of the various physical properties of soils and subsoils; of the mutual relations between soils, subsoils, and vegetation; of the influence of latitude, elevation, gradient, and aspect, on forest-trees ; of the influence of forests on temperature, atmospheric and soil moisture; of the effects of different atmospheric conditions (wind, rain, snow, frost) on forest vegetation, dxc.

2. Botany.-The natural step from knowledge of soils is towards a knowledge of the regetable covering they bear. The scientific forester on the ('ontinent is taught not only the general principles of veretable morpholngy, physiology, and pathology, but his special attention is directed to the classes and varieties of plants most important to his work, and to the fungoid and other non-parasitic diseases by whose attacks they are liable to be damaged or even destroyed. Many useful conclusions relative to the proper treatment of forests being deducille from the individual mosses, grasses, or plants found on the soil, he is taught to know most of these, whilst at the same time his knowledge regarding the forest-trees of Europe and the imported species of foreign growth is thorough.

3. Zoology.-Under this heading the student of Forestry is taught concerning useful and injurious birds and insects, and about the habits of the game and vermin that are to be met with in woodland estates.

II. Sylviculture is, in the broadest sense of the term, often used synonymously with Forestry; but, within its narrower limits, it is that branch of forest science which treats of the cultiration of useful forest products, and the formation, treatment, and reproduction of woods.

After preliminary instruction regarding the habitat and peculiarities of the timber trees in general cultivation, their relations to soils and situations, the various modes of rearing trees in high-forest, coppice, or coppice with standards, the adrantages of mixed forests, and the general rules regulating the prosperity of the different kinds of trees in mixed forests, this brinch may be divided into two main sections-(1) the Formation of Forests, and (2) the Tending of Woods.

The former teaches the various methods by which forests can be formed artificially by sowing or llanting, or naturally in refrolucing them hy means of seed from parent trees, shoots from the root, or layers and cuttings. In the case of artificial production and reproduction, the approred methods of preparing the soil for seed-reception, of sowing the different kinds of seed, or 
forming nurseries, or planting out young plants at various ages and under various circumstances, ifc., are all fully described; while, in the case of natural reproduction, attention is called to the special peculiarities of each kind of tree, for example, as regards the most advantageous age for commencing preparatory fellings, and the manner and extent to which the subsequent clearances of the seed-trees should take place.

The section relating to the treatment of existing forests sets forth the most advantageous methods of weeding and thinning out thickets or young plantations, and instructs generally in the normal treatment of various classes of forest during the usual periods of rotation. Theoretical instruction is also given as to the modes in which forests of inferior growth may gradually be improved, and brought into a good normal condition, or how one class of forest may be transformed into another offering greater advantages-e.g., coppice, or coppice with standards, into high-timber forest—often a matter of extreme difficulty in practice.

III. The Protection of Forests aims at shielding the woods-so far as lies in the power of the owner-from the manifold dangers (wind, fire, insects, \&c.) constantly threatening their existence or development. A knowledge of the forest laws of the country must certainly be classed as pertaining to the protection of forests, in order to check or punish such destructive acts of men as injury to boundary-marks, illicit appropriation of forest produce, or incendiarism. How important a chapter is formed by the protection of forests from fire is best known to those who are acquainted with tropical or subtropical countries, although even in the temperate zone-e.g., the great NorthGerman plain-costly and well-planned measures against fire are also an absolute necessity, and not always a success.

Apart from the actions of men, danger to forests may arise from inorganic causes, such as storms, excessive rain, snow, hail, frost, drought, or else from enemies in the animal and vegetable worlds. The damage done by goats, sheep, pigs, deer, mice, squirrels, and birds is on the whole of minor importance to that perpetrated by insects. Protection of forests teaches all that can be taught in the way of preventing, minimising, and repairing damage caused by such enemies. In this respect the aid of zoology is greatly needed with reference to the study of birds and of insects, but especially of insects.

During the first years of existence many weeds (including trees or shrubs out of their proper place) threaten the development of young forest growth, and against such dangers also defensive measures are requisite. Young seedlings, as well as growing timber, are often liable to attacks from various kinds of spmarlic and eprlenic funfi and other parastic plants, with the life-history of which the scientific forester must be acquainted, in order to be able to combat them, and to grow timber free from the effects of such deteriorating influences. It is only of comparatively recent years that this particular branch of study has received the attention now admitted to be necessary; but those acquainted with the ravages of Peziza Willkommii and Trametes pini in Larch and Pine plantations, and those whose pockets have to suffer in consequence, best know how desirable such knowledge is in those to whom the management of forests is intrusted.

Dangers arising from the inorganic causes previously mentioned cannot indeed be totally prevented; but it is the object of this branch to set forth the 
practical treatment within our power to obviate or repair damage, and a thom mh knowledge of the suhject is perhaps more immediately productive of alparent beneficial results in this thin in the other hranches of the seience.

IV. The Utilisation of Forest Produce.-It will be rearlily admitted that those engaged in the production of timber ought to be thoroughly ar quitinted with the technical properties of what they produce-for instance, with regard to timber, its specific weight, hardness, toughness, flexibility, contraction and expansion, durability, effects of various kinds of flaws, \&c.; for to some extent these are dependent on, or may be affected by, the treatment accorded to the growing timber. By way of example it may be mentioned that, after years of hot dispute and acrimonious paper war, it has in Germany come to be generally admitted that timber grown by means of natural regeneration is in many technical respects superior to that grown artificially from seed or in plantations; for in the latter case the poles early begin to show a tendency to forked growth, that is not usual in natural woods.

To be in a position to satisfy customers, and to classify timber for disposal in the most advantageous lots, the controlling forester must be also acquainted with the uses to which various sizes and qualities are put. Shipbuilders, miners, railway contractors, furniture manufacturers, \&c., all make different demands for timber; and all can best be satisfied when their requirements are properly known and studied.

A sound practical knowledge of all the tools, implements, and machinery used in the felling and extraction of timber is also essential. Timber transport by land does not merely include dragging by oxen, horses, buffaloes, or elephunts, but necessarily involves road-making; the formation of draggingpaths as feeders, the construction of sledge-ways as in western France, of shoots and timber-slides as in southern Germany and Austria, of wire cableways as in Switzerland, and of tramways as in northern India. Knowledge in this branch often makes the whole difference between having large foresttracts practically unremunerative, or making them yield handsome returns. Timber transport by water demands a knowledge of the various methods for utilising, in the most advantageous manner, limited supplies of the carrying power, as well as of the best measures to be adopted when an enormous carrying power cannot be brought under control.

As forest produce is not confined merely to timber, the minor products also require study. Turpentine, resin, rubber, cutch, and other gums and oils are ritulble forest products in different parts of the world; hence it is necessury to know how they may best be won, and how the sources of supply may be properly conserved and improved. The same applies to the utilisation of tanning barks, so extensively cultivated here and on the Continent.

The technological education further includes a knowledge of the conserration of wood by impregnation and other methods, of charcoal-burning, of the preparation of peat, of the collection of tree-seeds and their transport and preparation for sale, of the fabrication of cellulose in paper-making, of the manufacture of potash, dc. Last, and not least, instruction is necessary about saw-mills, for it not infrequently happens that one is called upon to work saw-mills, either by water-power or steam, in the vicinity of the forests, in order to enable the produce to be farourably disposed of by reducing to minima the costs of transport to the available markets. 
V. Management of Forests and Valuation of Timber Crops, constituting the fourth and last great branch of forest science, treats of the most adrantageous arrangement and conduct of all business connected with the management of forests.

1. Organisation of the executive staff, arrangement of the forest areas into estates or divisions under the control of the same, subdivisions of estates or divisions into blocks and compartments for convenience of working, and directions regarding office business and the maintenance of cash and other accounts, are requisite in the case of very extensive owners, such as the State. In these cases rules are generally laid down in a codified form for the guidance of those concerned.

2. Valuation of Forests forms the second section. The introductory part, involving a certain knowledge of algebra, gives a thorough grounding in the various methods of calculating the probable future value of different kinds of forests formed, or yet to be formed, on different situations, under varying circumstances, with different ultimate objects and periods of rotation, with different initial costs and costs of maintenance, and yielding varying returns at different periods; in discounting, for comparison with initial and progressive outlays, the probable values of different crops of forest produce, with different periods of rotation, and yielding various returns at different periods of their growth; in estimating what is likely to be the best age for reproducing existing forests so as to have, without allowing the soil to deteriorate, the highest net percentage of profit on the past, present, and probable future outlays for formation and maintenance; and in ascertaining generally what are likely to prove the most remunerative timber crops for any land under consideration.

3. Timber Mensuration includes not merely the measurement of stems felled, stacked timber, and the like, but also the computation of the cubic contents of growing trees individually by means of various methods with or without instruments, or en masse by means of trial areas, or by the use of average-tables, based on past results, arranged for the different kinds of timber, at different periods of their growth, and on the various qualities of soil and situation. It further teaches the methods of estimating the age of trees individually, or their probable average age collectively, and - which is of immense importance in calculating the financial value of a forest, and enabling the best working-plan to be formed for its future treatment-explains the most approved and reliable methods of ascertaining the annual or periodical increase of growth in height, girth, and cubic contents, either for trees individually or on the arerage for whole forests or portions of forests, and of arranging such data in the most practical form of reference tables for guidance elsewhere or in the future.

4. The Formation of Working Plans is the last section of this branch, and indeed forms the key-stone in the whole science of Forestry. Its object is so to arrange work in a forest, with regard to areas and to periods of time, as best to effect and ensure the ends desired.

The data requisite before this arrangement of work can be made, necessitate a survey and plan of the whole area, the determination of the qualities and capabilities of soils at different parts of the area, a complete catalogue and description of the whole stock of growing timber, an estimate of the annual rate of increase of each portion, detailed information relative to the mutual 
relation between stock and annual increment, and a statement of the past history of the forest as to outlays and returns. These data having been carefully studied, the "working-plan" can now be framed for whatever period is consiclered most advantageous or convenient; and this, correcterl by periorlical revisions, forms the basis upon which operations are conducted. It usually consists of -

(a.) An introductory or general portion exhibiting the results ascertained in collecting the above-mentioned data.

(b.) The plan of fellings, aining at procuring equal supplies of produce yearly or periodically, and, so far as possible, of nearly expul amual value, and from nearly equal areas.

(c.) The plan of cultivation, dealing with the reproduction of timber cleared, or the sowing or planting up of areas not yet under forest growth.

Such are the special subjects forming the curriculum at the great forest schools on the Continent.

In the Bavarian Forest Service only students who can produce their Asofutorium from the highest class of schools, which entitles them to matriculate at any university, can enter the Forest Academy at Aschaffenburg. Here they have a two years' course of theoretical and practical instruction, which is followed by a two years' course of lectures at Munich University, and by three years of practical work, of which the first and third are in the State forests, and the second in the Forest Secretariat, in order to learn official routine. In Prussia the students have one year's practical work as apprentices first of all, and then proceed for two and a half years to one of the two great acadenies (Neustadt-Eberswalde and Münden). After two years' practical work they have to attend a miversity for one year, and are thereafter employed on practical work till they receive their appointments as Oberförster.

It may be considered by some that, with such an amount of education as is here inferred, a man might do better than be a sylviculturist. This may indeed at first sight seem correct, but in reality it is not; for any one possessed of the above theoretical and practical knowledge can command a fair salary even in these days of excessive competition in most walks of life. It is not probable that any one having the requisite amount of knowlenge will at the present time find difticulty in obtaining a situation as a leaulforester, at a salary equal to the income of most rural clersmen ame country practitioners of medicine. Probably one of the very reasons: why there are so many foresters in situations at extremely low salaries is, that they are unscientific men, who are not entitled to look for the same remuneration as a good sylviculturist might expect. Let practical foresters try the experiment of educiting themselves as ahove suggested, and the prohithility is that they will fincl it to their material advantage. No far-seeing proprietor of extensive woods will hesitate about paying a gool salary to a govel man, when he cin foresee that the result will be an improvement in the anmul returns 
from his woodlands, ami an enhancement in their market ralue as an investment of capital.

Many foresters in Britain obtain salaries from $£ 70$ to $£ 300$ per ammun; and great difficulty is often found in getting men of practical ability, combined with the necessary training, to fill vacancies. Proprietors are now too well aware of the value of a really good and intelligent practical forester not to employ him, although at a high salary. And there can be little doubt that if there were any body of scientifie sylviculturists whose services could be procured for the general supervision and superintendence of sylvicultural operations on lirge estates, their services would be appreciaterl by large landed proprietors, and would be in good demand professionally.

In no other art or science has the Anglo-Saxon race displayed such decided neglect and indifference as with regard to Forestry. Even the word Sylviculture is not commonly found in the most recent dictionaries of the English language, or in the glossaries of technical and scientific terms. And jet Britain and America own the largest and the most valuable timber tracts in the world.

It was not until 1866 that the necessity of having any of the servants of the State trained in forest science had practically made itself felt in Britain, and then only in so far as her Indian forests were concerned. In that year was held the first competition for appointments to the Indian Forest Service, and of the quality of the work done by the men trained in Germany (1867-75) and in France (1*ij-x.j) high testimony has very frequently been borne l,y the Indian Government. The Continental system of training for such candidates has now ceased, and their education is being conducted at the Indian Engineering College, Cooper's Hill, Surrey, by two professors lecturing on the various branches of Forestry, assisted by teachers of the cognate sciences. The course of training, however, still includes a term of residence, an apprenticeship, and a prolonged tour in forests in southern Germany and France, in order to give the students opportunities, not at present to be had in this country, of seeing the results of forest management and operations on a large scale.

It is indeed humiliating to Britain that-except at Cooper's Hill College, where a three years' course, at a cost of $£ 183$ a-year for board and tuition alone, is essential-there is not in the country any school where young men can acyuire an efficient grounling in the principles and practice of Forestry. This want has very frequently been felt by young men who wish to improve themselves, and to study this branch of rural economy; but up till the present perhaps the best thing they cau do is to put themselves under some practical forester of experience, where the woods under his charge are considered to be well managed, and at the same time to study the best works on the subject of Sylviculture, and see if such managenent is in accordance with the principles of sylviculture. 
But for any thorough and systematic training in Forestry on a large scale, there is no other course open at present than for the student to proceed to the Continent; and for preference he should hetake himself to one of the great schools of Gernany, the home of Forest Science.

There are in this country no opportunities for the education of those who wish to learn Forestry in all its branches. In France there are good schools for the training of foresters, and also in Germany; but of course few students are able and willing to go to the Continent in order to learn what they very properly think they ought to have facilities for learning at home.

The conclusions which the Parliamentary Committee on Forestry arrived at in 1887 have previously been quoted (see p. 10) in part; and as the remaining portion of their report has special reference to the question of education in Forestry, it is here continued in extenso :-

"Your Committee recommend the establishment of a Forest Board. They are also satisfied by the evidence that the establishment of Forest Schools, or at any rate of a course of instruction and examination in Forestry, would be desirable, and they think that the consideration of the best mode of carrying this into effect might be one of the functions intrusted to such a Forest Board.

"As regards the Board of Forestry, the Committee submit the following suggestions :-

"1. That the Board should be presided over by a responsible official (an expert by preference) appointed by the (foremment, and reporting amnally to some department of the Government.

"2. That the Board should be so constituted as to comprise the principal agencies interested in the promotion of a sounder knowledge of Forestry, especially the various teaching and examining bodies, as well as the professional societies. Board :-

" 3 . That the following bodies should be invited to send delegates to the

The Royal Agricultural Society of England;

The Highland and Agricultural Society of Scotland;

The Royal Dublin Society;

The Office of Woods and Forests;

The Linnean Society;

The Surveyors' Institution;

The English Arboricultural Society;

The Scottish Arboricultural Society;

and, that the Director of Kew Gardens should be a member ex officio.

"That the Board should also comprise three members of each House of Parliament, amd at certain number of owners or mantagers of litrge woodlands, a preference in the latter case being given to those who are in a position to afford facilities for study in their woods. 
"4. That the functions of the Board should be-

(a.) To organise Forest Schools, or, at any rate, a course of instruction in Forestry.

(b.) To make provision for examinations.

(c.) To prepare an official syllabus and text-book.

"5. That the examiners should be required to examine in the following subjects, namely :-

(a.) Practical Forestry.

(b.) Botany.

(c.) Vegetable Physiology and Entomology, especially in connection with diseases and insects affecting the growth of trees.

(d.) Geology, with special reference to soils.

(e.) Subjects connected with land agency, such as land drainage, surveying, timber-measuring, dc.

"The expense of secretarial staff and examiners need not, in the opinion of the Committee, exceed $£ 500$ a-year, and the cost might be considerably reduced by fees for diplomas.

"The fact that the Indian Government already incurs some expense in promoting the education of Forestry students for the Indian service, suggests the adoption of the Royal Indian Engineering College at Cooper's Hill as a nucleus for the proposed Forestry instruction.

"Inducements might be offered to the agricultural colleges and the Surveyors' Institution to send their students for examination, by a system of exemption from examination in certain preliminary subjects in respect of which the candidates could produce a certificate of proficiency."

Nothing has yet leen done towards the establishment of this Board of Forestry, as the following extract from the parliamentary report in the Times of Friday, 24th March 1893, will show:-

"Nr Collings, for Sir J. Lubbock, asked the President of the Board of " Agriculture whether he proposed to take any, and, if so, what steps to carry out the recommendations of the Select Committee on Forestry.

"Mr Gardner. As was stated by my predecessor in reply to the similar question put by the right hon. baronet on the 6th of March 1891, the statutory powers of the Board of Agriculture are strictly limited, and we have no means and no power of giving effect directly to the recommendations of the Select Committee either as regards the establishment of a school or schools of Forestry, or the creation of a Board of Forestry. I am, however, in full sympathy with the desire to promote the development of education in Forestry, and we are, I think, doing all that we can in that direction. We have continued to make a substantial grant towards the cost of lectures in the University of Edinburgh under the auspices of the Royal Scottish Arboricultural Society, and towards the cost of the chair which has been established in the Durham College of Science to include the teaching of Forestry. A course of free instruction to practical foresters and gardeners in connection with the Royal Botanic Garden at Edinburgh, to which we have devoted the sum of $£ 150$, is now in progress; and in view of the fact that a course of lectures in Forestry has been started in connection with the Glasgow and West of 
Seotland Technical College, we have increased our grant to that institution. We also propose to continue to give the statistical information as to woods and plantations which was supplier for the first time in 1891. I shall always be glad to receive and to consider any suggestions for the increase of sound technical knowledge on this subject."

And yet, when the editor of the present work offered, in 1892, to translate gratuitously, sulject of course to the consent of the respective authors, one of the leading German works on each of the four main branches of Forestry - i. Sylviculture, ii. Protection of Forests, iii. Management of Forests and Valuation of Timber Crops, and iv. Utilisation of Forest Produce-on condition that these works on The Science of Forestry should be published on whatever terms the Board of Agriculture might consider reasonable, the offer was declined, on the plea that, as the Government of India were paying the cost of textbooks in course of preparation for students at Cooper's Hill, the British Treasury need not be asked to incur any expense on the matter, for the funds would probably not be sanctioned.

At present the highest certificates (first and second class) that can be obtained in Forestry are those granted by the Highland and Agricultural Society of Scotland, whose examinations in I'ractical Forestry, Botany, Chemistry, Land and Timber Measuring, Forest Engineering, Arithmetic and Book-keeping, are held anmually in March.

The practical steps that have been undertaken in consequence of this Committee on Forestry consist first of all in the following cliuses of the Board of Agriculture Act of 1889 :-

"2.-(2.) The Board of Agriculture shall also undertake the collection and preparation of statistics relating to agriculture and Forestry, and may also undertake the inspection of, and reporting on, any schools which are not public elementary schools, and in which technical instruction, practical or scientific, is given in any matter connected with agriculture or Forestry, and the aiding of any school which admits such inspection, and in the judgment of the Board is qualified to receive such aid and the aiding of any system of lectures or instruction connected with agriculture or Forestry, and the inspection of and reporting on any examinations in agriculture or Forestry.

"(3.) The Board of Agriculture may also make or aid in making such inquiries, experiments, and research, and collect or aid in collecting such information as they may think important for the purpose of frometinu auriculture or Forestry.

"4. It shall be lawful for her Majesty the Queen in Council from time to time by order to transfer to the Board of Agriculture such powers and duties of any Government department as are conferred by or in pursuance of any statute, and appear to her Majesty to relate to Agriculture or Forestry, and to be of an administrative character; 
"Provided also, that nothing in this Act contained shall in any respect affect the exclusive control of the Secretary of State in Council of India over the candidates for the Indian Forest Department at Cooper's Hill College or Hewhere."

Under the powers thereby conferred, the Board of Agriculture pay one-half of the stipend, or $£ 250$ a-year, towards the support of the Chair of Arriculture and Forestry instituted at the I) mhan Collene of Science in 1891, $£ 100$ a-year since 1891 towards the Lectureship of Forestry instituted (temporarily) in $18 s 9$ at Eanlum University, $£ 150$ a-year towards the free instruction of foresters and gardeners at the Royal Botanic Garden, Edinburgh, and similar aid towards instruction at the Craserow Technical Institute in the Thest of Scotlanil.

It would not cost very much to form schools of practical Forestry at woodland centres like Lyndhurst in the New Forest and Coleford in the Forest of Dean for England, as well as at Dunkeld in Athole and Cirantown in strathisey for Scotland, where lisds could he trained as foresters and overseers, as at the elementary sylvicultural schools of Bavaria. Nor would it involve any great annual outlay to endow a Chair of Forestry at Oxford or Cambridge, at Edinburgh, and Aberdeen or St Andrews, and at Dublin or Belfast, in order to afford students, going through the ordinary Arts course, opportunities of obtaining sound instruction in Sylviculture or the modern science of Forestry. The total annual outlay for the establishment of six Chairs of Forestry at different universities, and the maintenance of four

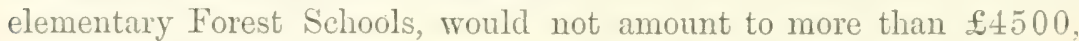
which is surely a small price to pay for the national benefits derivable from the better management of woodlands which we know to have cost more than $£ 20,000,000$ to form, and which, if properly tended, should have a present value of probably more than $£ 50,000,000$ (see p. 27).

British Woodlands. - The forests and woollands of this conntry consist of two distinct classes, National or State and Private. According to the report of a Select Parliamentary Committee, appointed in 1889 and 1890 to inquire into the Administration of the Department of Woods and Forests and Land Revenues of the Croun, which was pullisherl in 1890 , it appears that the national woollands are as follows:- -

"1. The woods, forests, and land revenues of the Crown consist of the following particulars :-

"In England.-Land situate in twenty-three counties, containing 69, 627 a. 2 r. 27 p., producing a rental of $£ 82,081$.

"Windsor Park and woods, containing 15,175 acres. 
"The New Forest, containing 64,834 acres.

"The Dean Forest, containing 18,710 acres.

"Other woods and forests in Cheshire, Gloucestershire, Hampshire, the Isle of Wight, Northamptonshire, Surrey, and other counties, containing 16,574 acres."

The evidence adduced before the Committee showed that the status of these national woods was as follows:-

"Windsor Forest.-Windsor Forest and Park comprises 15,175 acres; of this 5355 acres are maintained as the domain attached to Windsor Castle. The remainder is not regarded as part of the residential property of the Sovereign.

"The Ranger is appointed under the powers reserved in section 135 of 10 Geo. IV., and he has the sole control of the deer, game, fish, and herbage.

"The entire expenses of Windsor Park and the contiguous property in 1887-88 amounted to $£ 23,237$. Of this sum $£ 4227$ represents the salaries and allowances of the Riangers' Department and the Commissioner of Woods Department; $£ 8650$, the cost of repairs and maintenance of roads, drives, fences, and care of plantations, \&c. ; $£ 3 \& 22$, repairs and maintenance of lodges in Windsor Great Park, Ascot, and Bagshot; and $£ 1088$ for rates and taxes. The entire income in the same year was $£ 4442,4 \mathrm{~s} .6 \mathrm{~d}$.

"The New Forest.-The income of $£ 10,777,5$ s. 2d. derived from this large tract of land appears to be relatively small, but it must be considered that the profitable rights of the Crown in this estate are very limited.

"The surface of the soil in the open forest is subject to the rights of common, the timber in the recent inclosures has not reached maturity, and even in the older woods the rights of the Crown are greatly restricted by the provisions of the Act of 1877 .

"The method of dealing with this estate was at that time carefully considered by a Committee. The policy then deliberately adopted by Parliament was, that the New Forest should be administered principally with regard to the preservation of its ornamental character, and not with an exclusive view to the profit to be derived from it.

"Your Committee have not thought fit to reopen this question, as they concur in the policy then adopted. They have found nothing in the evidence adduced to show that there has been any departure in the arministration of the forest from the principles laid down in the Act of 1877 .

"The Forest of Dean.-The Committee are of opinion that, having proper regard to the rights of commoners and the convenience of those engaged in mining industries, the best available income is obtained from the surface; whilst, as in the New Forest, regard is paid to the preservation of the natumal beauty of the woods.

"Possibly a larger income might be obtained by the sale of the surface and the reinvestment of the proceeds; but a difficult question would have to be dealt with in the purchase of the right of commonage enjoyed ly tenants and freeholders of certain parishes. This would be detrimental to the welfare of, and repugnant to the feelings of, the inhabitants of the district; whilst the destruction of the forest would be most regrettable.

VOL. I. 
"It is doubtful whether an 'Assistant to the Deputy Surveyor' is required for the surface of Dean Forest, consiclering the large number of wood foremen and keepers.

"The Committee have taken evidence as to the peculiar conditions under which, by customs confirmed by Act of Parliament, the mineral properties in the Dean Forest (both coal, ironstone, and quarry stone) are 'galed' (leased) to freeminers only on perpetuity leases, which are in almost all cases alienated by the original 'galees.'

"They have not considered it within the scope of their inquiry to examine to what extent these peculiar conditions are, or are not, conducive to the further development of the mineral field, nor as to the desirability or feasibility of purchasing or extinguishing the interest of freeminers in the undeveloped properties. Evidence was, however, taken as to some modifications, under existing conditions, which ought to be made in the laws which direct the conduct of the Commissioners.

"In the Forest of Dean sites have been granted by the Crown for churches and church schools, while Nonconformist bodies for their places of worship, and the ratepayers for their board schools, have been compelled to pay a full competition price for their sites. Contributions in money also have been made towards the purposes of the Church of England. The Commissioners are advised that they are entitled only to make such contributions to the Churches of England and Scotland."

Among the recommendations made by the Committee it was determined that-

"The allotments set out and allotted to the Crown in severalty in Alice Holt Forest, Bere Forest, and Parkhurst Forest were by the Acts devoted to the growth of timber for the Royal Navy. As no timber is required by the Admiralty from these properties, the restriction as to their being devoted to the growth of timber, and also any similar enactments affecting the New Forest and the Forest of Dean, should be repealed."

The grave mismanagement of these properties as woodland estates was pointedly referred to in the report from the Committec on Forestry in 1887, which has previously been quoted (see p. 10).

The Private Forests include 98 per cent of the 3,005,670 acres returned in 1892 as under woodlands and nurseries throughout the United Kingdom. These include all the ornamental woods and game-preserves belonging to the landed gentry, in which sylvicultural crops are reared either for shelter or for ornament to the estates, or purely as sources of private income to their holders. With regard to each of these classes a few remarks, descriptive of their general condition at the present time, will not be out of place here.

State Forests.-Out of a total of 115,293 acres, only 57,304 acres are actually under timber-crops in the several forests named as belonging to Government. The crops cultivated are chiefly Oak, with 
a small proportion of the other kinds of trees, usually planted on spots of land considered unsuitalle for the growth of Oak. These cropss are of various ages, from mature growth down to plantations formed but a few years ago; the majority of the crops may, lowever, he said to consist of pole-forests and young tree-crops.

Previous to 1852 nearly all the crops in these forests had been so much neglected as regards thimning and draining, that their healthy and normal development had been arrested; lut since that date great improvements have been effected in dealing with them. Systematic thinning is now carried out, and some attention is paid to endeavouring to keep the land in a dry and healthy condition. So far as the nature of the soil is concerned, there is no reason why much better crops should not be raised in these forests if they were put under the executive charge of competent officers trained in Sylviculture, whose hands should not be tied by senseless enactments.

Private Forests.-With regard to the woods and plantations of private proprietors in this country, both in England and Scotland, a very considerable improvement has taken place within the last forty years. Previous to 1850 the greater part of the woods and plantations on private properties, in all parts of the country, was in a most unsatisfactory condition, but since that date rast improvements have been effected with respect to drainage, thimning, and tending; and now, on most estates, draining, planting, and thinuing are being carried out systematically. This not only promotes better health among the older classes of plantations, but also enalles sounder proposals to be made regarding the better conduct of planting operations. Before planting is mulertaken on any piece of land, the fitness of its condition for the growth of trees should be duly considered, and only those kinds of trees selected for planting which are likely to succeed best on the given soil and situation; whilst at the same time the most advantageous density of the crop should also receive careful consideration.

On examining the older class of plantations upon private properties, it is at once evident that a very large number of these have been formed of species of trees for which the land was not naturally suited. In consequence of this, a large proportion of them have had to be cleared of late years, in order to permit of the land heing replanted with crops hetter suited to its productive cilpicity. The process of clearing the unhealthy portions of the crops has, in many cases, been judicionsly undertaken and well carried out; hence the acreage under such unhealthy plantations is gradually hecoming less and less, while the extent of land under young and healthy crops is annually on the increase.

With the dissemination of better knowledge among practical 
foresters, the younger class of plintations, those under about thirty years of ace, are realping the advantages of more rational treatment: most of these are in a fair state of management, and promise to yield valuable timber in due time.

A greater degree of intelligence is now brought to bear on the general management of plantations on most properties than seems to have been the case more than thirty years ago. And if only better opportunities were given by Government for sound instruction in forest science, this encouraging circumstance would entitle us to expect that the woodlands of Britain would soon become greatly improved, and be in a much more promising condition than they now are. There is good reason to hope that, now the tide of improvement has fairly set in towards advancement in this department of rural economy, the Art of Forestry will shortly receive a more open recognition at our universities, and a more liberal share of the public money now being invested in the encouragement of technical education, than is at present the case.

Forestry in Britain.-The art of Forestry is still in its infancy in Britain. From the nature of sylvicultural crops, which require a considerable number of years to elapse before the many experiments and practical operations bear fruit, the final results of the sowing, and planting, and tending, are not so quickly liarvested as in the case of agricultural crops. 'To this cause, and to the comparatively small area of our woodlands, are attributable the very slow progress which has hitherto been made in Sylviculture, as compared with agriculture, throughout Britain. Every man of ordinary powers of observation will readily admit that when any land is planted with timber-trees the crops will ordinarily require at least fifty years in order to attain gool marketal,le dimensions, even in the case of most species of conifers; whilst with broad-leaved species of trees a longer time must generally pass by before the main crop can he utilised, and more particularly in the case of Oaks, which take longest before they attain their full technical and financial maturity.

Practical Forestry, ${ }^{1}$ as at present generally seen in operation thronghout britain, seems to the classifiable under nine headings:-

1. The sowing and schooling of the young plants in the nursery previous to their being planted out in their permanent sites ;

2. Fencing the lands to be planted, in order to separate them

1 The attention of the reader is here called again to the vast difference between Forestry-i.e., Sylviculture - as taught and practised on the Continent; and Forestry -i.e., Arboriculture mainly-as practised in Britain. The above classification of Practical Forestry should be compared with the sylvicultural curriculum gone through by students at the German academies and universities (see p. 55). 
from the agricultural portions of the estate, and to prevent cattle from getting into the plantations;

3. Drainage of wet portions, and soil-preparation of the land intended to be planted;

4. The planting out of the young trees intended to form the crops ;

5. The pruning or trimming of such trees as seem of a branching and rough habit of growth;

6. The thinning of woods for the promotion of the growth of the better portion of the respective crops;

7. The stripping of bark from such of the trees as can yield a supply suitable for tanning purposes;

8. The utilisation, or felling and disposal of the mature crop of timber; and,

9. The conversion of timber.

With regard to the mode of sowing and schooling young plants in the nursery, great improvements have been effected within the last twenty or thirty years. Previous to that date, the usual method was to sow the seeds of the different sorts of trees very thickly in the beds, so as to raise as many plants as possible from a small piece of ground, and to allow the young plants to stand two years in these seed-beds before beginning to school them by removing them to the nursery-lines. Now, however, the majority of arboriculturists agree that the young plants are much improved in health and strength by sowing thinly in the seed-beds, and by removing the young seedlings into the nursery-rows when they are yearling plants. Besides this improvement, another has been effected by attention to a judicious system of rotation in cropping. This was not attended to by the oller class of nurserymen, and the consequence was that their young plants became unlealthy from the sime sorts being repeatedly grown on the same piece of ground, without any intervening crop; for as one particular class of seedlings extracts precisely the same kind of mineral food from the soil as the preceding crop of the same species, a rotation of seedling crops was found advisable as in agriculture.

Any difficulty on this score could, however, in the editor's opinion, easily be got over by manuring, provided the disease among the seedlings was not due to parasitic fungi.

With regard to fencing, the chief improvement that has been effected within the last half-century consists in the nse of wire and of iron straining-posts. And this is a very great improvement indeed; for it is not only more ormanental than any other description 
of fence, hut is also infinitely more durable than the old system of fencing with wood alone, and is therefore by far the cheaper method in the long-run.

Drainage and soil-preparation, in the proper sense of the term as applied to woodlands, may also be said to be an improvement of our own day. Formerly it was not only little applied, but, even where practised, was done on such a shallow principle as often to be quite inoperative. For leading off surplus moisture from wet parts of woodlands, simple cuts of some $12 \mathrm{in}$. in depth were, at a comparatively recent date, considered quite sufficient. Now, however, experience has shown that open trenches of from 3 to $4 \mathrm{ft}$. in depth are often absolutely necessary. Owing to the more thorough application of the principles of drainage and soil-preparation, crops of good timber can now be grown on land which was formerly thought quite unfit for the production of timber.

As regards the formation of mixed forests or plantations, much experience has also been gained within the last twenty or thirty years. And from the practical knowledge that has thus been gained, particular kinds of trees may now be grown on certain descriptions of lankl, which were formerly consilered unfit for planting, with any hope of success, with these special kind of trees, or indeed often with any sort of tree at all. Sylvicultural chemistry and regetable physiology have given us much insight into this branch of forestry; for by a knowledge of these we can now understand not only the nature of soils and of their component parts, but also the requirements of the different species of trees as to mineral food imbibed by the suctionroots in the form of soluble nutrient salts. And with such knowledge at disposal, we are now in a better position for utilising given soils to their utmost capacity in producing marketable crops of timber.

Pruning was, generally speaking, one of the branches of arboriculture which was even less understood by the older class of foresters than by those of the present day, imperfect enough as the knowledge of the latter often shows itself to be. Fifty years ago, the system that was practisen consisted chiefly of lopping off all large branches from the stems, without respect to age, size, or kind, and simply leaving the bare trunks standing like so many May-poles. The science of vegetable physiology has, however, become somewhat better known since then, and pruning is now done very sparingly; for it is well-known that the removal of large branches from trees deprives them, according to the extent of the operation, of the organs with which nature has provided them for the assimilation of the food they take in by their roots. In this branch of Arboriculture, 
therefore, important improvements have taken place of late, owing to a slightly better linowledge of the laws which regrulate the healthy growth and development of trees.

Thinning plantations for the promotion of the growth of the better classes of individual stems is a branch of Forestry still either imperfectly understood or inadequately practised. It is not economy to allow trees in a plantation to stand so long unthinned as to become crowded, as the struggle for individual supremacy on the part of the dominant stems, and for existence itself on those that are becoming dominated, is thereby needlessly prolonged; the productive capacity of the soil becomes dissipated in the strutgrle, in place of being at once available for the enhanced increment of the dominating trees, a portion of which will ultimately form the mature crop.

Although Arboriculture, or the growth of ormamental timber, is well understood in Britain, the backwardness of Sylviculture is very extraordinary; and more especially is this the case, when the great improvements that have been attained in the other branches of rural economy are taken into consideration. Nutwithstanding the general high standard of intelligence among our landed proprietors, who usually exhibit a far-sighted policy in the improvement of the agricultural portions of their estates, it cannot be denied that many of them are generally short-sighted with respect to the sylvicultural branch of their estate management; although by proper attention to it, and by endeavouring to understand the natural laws of tree-growth, they might be gainers financially to a considerable extent. Fortunately, however, within the last twenty or thirty years a great number of proprietors throughout England and Scotland, as well as in Ireland, have adopted a mode of thinning, on a regular and systematic principle, ly which the crops are kept, at all stages of their growth, in a regular state without crowding, and therefore at all times in an equally healthy conlition; whilst they are never allowed to become crowded before thimning, as used to be the case on most estates.

The importance of thinning as a cultural operation has previously been adverted to (see page 40). But one most important point, not referred to above, is the density of the crop at the time of the formation of plantations. As compared with Continental plantations, those formed in Britain are generally wanting in density. Owing to the smaller number of plants per acre, the costs of formation, of filling blanks, of weeding, and of clearing during the earlier stages of development, are undoubtedly less; but thick low branches get formed, whose snags become embodied in the bole, and ultimately lessen its technical and monetary, value very considerably. 
The stripping of the bark from Oak and other sorts of trees, for the purpose of taming, is an important branch of Forestry in many parts of the comntry, and especially in those localities where Oak forms the chief woodland crop. In this branch but little improvement has been effected of late years, although a better mode of drying the material might well be adopted than the present rather primitive method of seasoning it unprotected in the open air.

The utilisation of crops of mature trees - that is to say, the felling, the transport, and the selling or conversion of the timberis now, from the use of machinery by steam-power, a comparatively easy process compared with what it was previously, when only horse and manual power could be applied. But although in this branch of Forestry very considerable improvements have also been effected of late years, yet very much may be easily learned from Continental experience. The formation and the working of timber-slides, for conveying Ings from clistant hillsides to public roads, floating streams, or lines of railway, are matters that should receive far more attention in woodland tracts than has ever yet been paid to them in Britain.

Laws affecting Private Woodlands in Britain.-There can be no doubt that the legal questions, apart from merely annual rating, connected with the utilisation of timber on entailed landed estates, have got a great deal to do in preventing the formation of large plantations. The following appear to be the main features of the case with reference to estates in tailzie under Scots law (Bell's Dictionary and Digest of the Lav of Scotland, 1890, pp. $1078,663,1059):--$

Growing Timber.-Questions regarding the right to use growing timber may occur between the fiar and the life-renter, the landlord and the tenant, and betreen the heir in possession under an entail and the next substitute.

"With regard to the rights of a life-renter, it was decided in MFacalister's Transactions, 27th June 1851, (1) that though a life-renter is entitled to ordinary windfalls of wood, he is not entitled to cut for sale any growing timber, or to sell trees blown down by an extraordinary storm; but he is entitled, at the sight of the fiar, to cut grown timber, or use blown-down trees, for repairing the fences and other purposes of the estate; (2) that he is not entitled at his own discretion to thin plantations, but he is entitled to do so at the sight of the fiar, to whom the cuttings belong; (3) that he is entitled to cut down copse-wood, which was in use to be cut down at intervals of twenty-two years, provided he is in possession when the usual period of cutting arrives; but he is not entitled to anticipate that period. . . .

"Life-renters are entitled to the fruits and annual produce of the subject life-rented; and they may possess by themselves, their servants or tenants; but the trees planted for ornament cannot be cut down by the fiar during the currency of the life-rent. The life-renter must leave the subject in as good condition as that in which it was at the commencement of the life-rent. In 
general, he has no right to cut growing timber, even though planted by himself. But there are exceptions to this rule in the case of (1) underwood, and ordinary (but not extraordinary) windfalls; (2) timber requiren for the maintenance of the estate; (3) sylva cædua, or coppice-wood, which is cut periodically, when it comes to maturity.

"Fiar, as contrasted with life-renter, is the person in whom the property of an estate is vested, burdened with the right of life-rent. . . He cannot cut the ornamental timber, though he may make the necessary thinnings, not hurting the amenity.

"Sylva cadua is a wood which, on being cut, stoles out again for another cutting, so as, by proper management, to yield a yearly profit, which may be turned to account by a temporary usufructuary, as a life-renter or wadsetter on a good title, but not by a mere tenant, unless his lease expressly so provide.

"Woods are reserved to the landlord ex lege. And even a lease of lands with 'woods' gives only the power of cutting wood for repairing or building houses upon the ground, but not of selling or otherwise disposing of the wood. The tenant in such a case may cut willows, when young, as a crop, but he is not entitled to cut willow-trees of a large size. A tenant selling or destroying the timber on his farm renders himself liable to a claim of damages, or to certain statutory forfeitures.

"An heir in possession under an entail is entitled to cut the timber as long as his possession lasts. In one case in which an heiress of entail, who was eighty years of age, quarrelled with the next heir, and advertised a sale of all the planted timber on the estate, the court refused to grant an interdict, although the heir offered the value of the whole if preserved. The court have, in a few instances, granted interdict against the sale of unripe timber, or ornamental timber, necessary to the amenity of the mansion-house; but it has been remarked that it requires a strong case to authorise judicial interference. There has been some fluctuation in the decisions on the question, whether the heir in possession can give a right to cut timber, to last beyond his own life; but it would appear that he cannot."

Under English law the timber is in general regarded as part of the estate, and the money arising from its sale is treated as capital, the interest thereon being paid to the owner in possession. The word timber includes, as a rule, only Oak, Ash, and Flm; but it extends to other trees which are comprised in the term by local eustom.

An important case as to the right of limited owners of landed estates to cut timber and retain the proceeds was decided in 1891. From 1862 onwards Lady Dashwood was tenant in life of large estates, mostly in Buckinghamshire. A great portion of them was under Beech-woods, and it was customary for the owner to cut down mature trees annually, and dispose of the rood to chairmakers. By the custom of the county of Bucks, Beech-trees are timber; ; and after Laly Dashwood's death the next heir contended that, in alpropriating the proceeds of the sales, she had been taking what legally belonged to him and his successors. In granting the decision the court held, having regard to the actual practice on the estate rather than to the strict rule of law, that 
Lady Dashwood, in following the custom of her predecessors, had acted within her right (see IIazell's Annual, 1892, p. 678).

But there can be no doubt that the present Rating of Woodlands also acts as a deterrent against planting; for although the rates must be paid annually, and therefore increase at compound interest like all other investments of capital, yet long periods of time must elapse before the owner of woodlands can recoup himself either for the costs of the formation of the plantation, or the rental derivable from the ground, or the annual rates, or the outlay for weeding, clearing, tending, and protecting before even the early thinnings yield the slightest return. Considering the nature of woodland crops, how long they take to mature, and to how many dangers they are exposed from storms, insect enemies, fungoid diseases, and other organic and inorganic causes, woodlands should not, as at present, be assessed on a par with the surrounding arable and pasture land. Such a rating is absolutely unfair. Even if it be retained at the same rating per acre, however, the owner of woodlands might easily be allowed an easement, in comparison with arable and pasture land, by not being called upon to pay the amount of the simple total of annual ratings (free from accumulations at compound interest) till the year in which the sylvicultural crops on any given area are being utilised. This would help to encourage planting operations on poor land, and would entail no really substantial loss to the Treasury from year to year. (See also Note on page 85.)

During the very year in which the duty was taken off foreign timber, rates were first imposed on British woods. A double blow was thus dealt at one and the same moment to the extension of an industry, or, to speak more correctly, an enterprise, that was far more in need of being bolstered up than of being strangled. It is a fact that waste land, after lying bare for decades, and becoming so deteriorated as not to be worth $1 \mathrm{~s}$. an acre for any pastoral purpose, has been known to produce more than $f 1$ an acre under wood; whilst at the same time the timber crop, by protecting the soil from the deteriorating effects of sun and wind, and the scouring and impoverishing action of heavy rainfall, considerably enhanced the productive capacity of the land, and raised its immediate future productivity either for subsequent woodland crops or for a better growth of pasture-herbage.

This system of rating, and the most iniquitous system of railway lines granting preferential rates for the haulage of foreign timber as compared with the carriage of home-grown wood, have militated against the extension of woodlands. The evidence given on these points before the Committee on Forestry in 1887 was as follows:- 
By Mr Clutton, Crown Receiver of the Midland Counties, and a past President of the Surveyors' Institute :-

"1932. From your experience do you think that the present system of rating woodlands has a prejudicial effect in preventing landowners planting as much as they otherwise would do ? - It is very difficult to say; lut everything that weights woodlands, or the srowth of woods, of course is an olstruction to a certain extent: moreover, the clause under which they are rated is so indefinite that it is very difficult to rate woods justly.

"1973. I will ask you the question generally. Do you think for a series of years, calculating the loss of rent and the loss of interest upon the rent, timber can be said to pay ? - I think so, if it is judiciously planted and judiciously managed. With regard to a subject ujon which the chairman asked me a question just now, the subject of rating, I quite admit that the accumulation of rating is very much against the paying of woodlands.

"1974. That is a necessary expense, however, which must be taken into consideration, is it not? - It has only been imposed in modern times. Under the Act of Elizabeth there was no rating on woodlands.

"1975. But it is now an expense which must be taken into consideration?-Quite so."

By Mr Powell, a Welsh law-agent:-

"2056. Could you give the Committee what you consider to be the reasons for the diminished amount of planting, and of the general growth of timber at present? - The diminished amount of planting is caused first, no doubt, by the scarcity of money and the depressed times, and also by the long period which the proprietor has to wait for a return of his money. I think also that the rating of woodlands has had a deterring effect on planting. I think it was a most injudicious law to pass; it was just the last straw that broke the camel's back. Other countries are endeavouring to extend the planting of timber. In the United States, for example, as an encouragement to planting, all land planted is exempted from taxation; and not only that, but a premium or bounty is offered for planting. It seems to me England is taking less care for the conservancy of her woodlands than any other country.

"2057. Do you think that the railway preferential rates given to foreign timber have affected the prices of home-grown timber? - Yes, that has affected the prices, and consequently the inclination to plant. I think the rates at present are most unequal and unfair. Foreign timber landed at Hartlepool, for example, comes from Hartlepool to Wales at a less rate than that for which we ean send British timber half the distance. And then, again, the rates for the conveyance of timber in England contrast most unfavourably with the rates in America. We can send timber for 700 miles in America for less than we can send it 100 miles in England.

"2108. As regards the question of rating woodlands, we have had it in evidence that judicious planting gives a considerahle anount of shelter, and also benefits all the district round. Would that be a reason for treating woodland differently in the matter of rating from arable or pasture land ?The advantage gained by shelter would show itself in the increased ralue of the arable and pasture land, and the increased rating should come in there. For instance, I have planted a very large extent of land in Deronshire, and 
also in Wales, for shelter. To give shelter has been the main object of planting there, because it was too high to expect timber to grow profitably. I consider in many cases the value of the shelter has been equivalent to $2 \mathrm{~s}$. $6 \mathrm{~d}$. an acre upon the whole land; that is, it would increase the rating value of the land round it by 2s.6d. an acre. That is one reason why land which is planted should be exempted from rating, because the ratable value of the adjacent land would be increased.

"2116. Do you think that before woodlands were rated there was a larger amount of planting than since? - It would be a very difficult thing to say. But I am sure of this; that the rate has had a deterrent influence upon planting. I am certain, from my own knowledge, that the very fact that the woodlands would be liable to be rated has deterred people from planting so extensively as they otherwise would have done."

Similar evidence, which need only be referred to without quoting, was also given respecting the preferential rates of railway haulage for foreign timber, by Mr Britton, of the firm of Richard Shelton \& Sons, timber merchants, Wolverhampton; Mr Thomson, head-forester on the Seafield estates in Strathspey; and Mr Gilchrist, head-forester on the Powerscourt estates at Enniskerry.

Until the passing of the Improvement of Land (Scotland) Act, 1893, owners of land in Scotland were only able, with the sanction of the Board of Agriculture, to charge their estates for the planting of woods and trees in cases where the planting was for the express purpose of providing shelter. But by the Act in question this limitation has been removed, and applications may now be made to the Board for sauction to charge estates, under the provisions of the Improurment of Land Act of 1864 , with the cost of planting, whether for shelter or otherwise. This amendment should pave the way for the extension of Sylviculture on a purely financial basis.

The Future of Forestry.-The ameliorating effects of Forests on the climate and soil of tracts whose average annual rainfall is below 40 inches, are beginning to be acknowledged by all who give attention to the subject; whilst their technical and material value may be gauged by the fact of our importing forest produce to the extent of over $£ 20,000,000$ annually, about one-half of which might quite easily be grown in Britain. Intelligent and thinking men of all ranks will be found to admit that woodlands are of infinitely more importance in the economy of any nation or country than they have hitherto been acknowledged to be. Seeing this, therefore, and noting the fact of the derressed state of agriculture, it is to be hoped that the time is rapidly approaching when the re-formation of the woods that can be proved to have once existed naturally in Britain, and the planting and distribution of trees, will be undertaken with due regard to well-defined natural laws, and when the art of Sylviculture will be elevated to the position of a Science, and will 
he taught at our universities in such fitting manner as its importance demands. Great improvements have taken place in most departments of Rural Economy within the last fifty years; but it is to be hoped that the advances to be made in the immediate future will be greater still. Hitherto the improvements that have been effected in Forestry and Arboriculture have been mainly brought about by practical foresters, without the application of even much or sound elementary scientific knowledge. But now that foresters in general are becoming better acquainted with Vegetable Physiology and the many other laws of nature, and are being zealously assisted in their observations loy a large number of men of science, it is only reasonable to expect that even by the end of the present century the Science and Art of Forestry will be very much better understood than it is now, and that it will have emerged from the mists and clouds which have hitherto obscured it in Britain, and will be brought out into such a degree of prominence, that a clear light may be cast on this page in the book of nature.

The indiscriminate clearing of forests, which has been going on continuously and unchecked in most parts of the civilised world, is now being watched and condemned. For the last quarter of a century the attention of Continental scientific men has been drawn to the effects of these clearances, which are found to lessen the regular supply of moisture within the soil, and consequently to render it very much less fertile to the agriculturist, as well as to have other undesirable effects that have already been noted. It therefore follows that a greater or less proportion of every country, varying according to its climatic conditions, requires to be kept under woods or forests, in order to obviate too much dryness, and to retain a due amount of moisture for the thriving of agricultural crops. In connection with this, a great and very important question at once suggests itself. What proportion of a country should be kept under woollands regularly dispersed over it; and what proportions should be liept as arable land, and as pasturages, with a view to maintaining the highest possible degree of fertility in the cultivated portions of the lancl, and at the same time to regulate the humidity of the air to that condition which is most conducive to the health of the inhabitants and the live-stock? This is a question which cannot yet be answered satisfactorily. Before a correct answer can be given. extensive investigations will still have to be made on the subject. It is a problem towards the solution of which scores of trained scientific men are now diligently engaged in recording meteorologieal and ayronomic observations in many different localities thronghout most of the countries on the continent of Europe, as well as throughout the United States of America. Although the lead in this respect was taken by 
France, the activity has become greatest in Germany. In France, Prusia, Wiirtemherg, Bavaria, Switzerland, Italy, and Austria, forest meteurological stations are located where diumal observations as to the temperature and humidity of the soil and atmosphere are recorded, both within the forest and away out in the open. It seems unworthy of the great position which Britain occupies, to find her stancling aluof from such investigations; for the peculiarity of her insular position would yield results that might be of great service from a scientific point of view.

In carrying out any system of experiments for ascertaining the proportion of land that should be kept under trees in any particular country, and in each particular part of the same country, the investigations require to be conducted under the superintendence of scientific men, who have in different parts of the country agents prepared to carry out their instructions with proper instruments, and who would receive from these agrents, and present to the public, at regular stated intervals, the results of their observations on the subjects of the barometric, thermometric, hygrometric changes, winds, \&c., \&c. Such observations require to be made in woodlands, on open lands, on dry lands, on wet lands, on marshy lands, on water, by the sides of rivers, by the sides of lakes, and at all the various elevations embraced in the country, so that deductions might be drawn from the results, when collated and corrected for comparison. The extent and particular character of each district experimented on would require to be carefully noted, together with the geological character of the land, and the aspect of the same. Until the results of such experiments, carefully conducted in every part of the country, are available, no sound opinion can be formed as to the exact extent of plantations which should be formed on any particular part of the country, with a riew to its being put into the best possible state for the health of men and cattle, and for the rearing of agricultural crops to the best advantage. This is a branch of rural economy having a very direct bearing on the national welfare, and is a subject to which every one interested should give the benefit of his influence and support; for it is only by united and continuous appeals to Government that any practical steps are likely to be arrived at. At present the subject is comparatively little understood by the great majority of the landnwners, who are most of all pecuniarily interested in the matter; and it is not altogether to their credit that they do so little towards the furthering of scientific instruction and research as regards Forestry.

It must always be kept in view, however, in carrying out investigitions on this sulject, that even when correct conclusions may be arrived at with respect to the amount of planting repuired for any particular country, such conclusions must always remain liable to be 
subseruently affected by the altered condition of neighluouring tracts. Fven our own peculiar climate appears to have undergone great changes within the memory of man, and account has to be taken of this.

Without a judicious distribution of trees, no country can be cultivated by the farmer to the fullest productivity of the soil ; therefore Forestry may be truly said to be the pioneer of agricultural improvement. Look, for example, at the state of farming on the prairies of North America. Many settlers have there been obliged to abandon their farms or holdings through the excessive dryness of the climate, and in consequence of storms of wind destroying their crops and withering the pasturage, after once the- surrounding forests had been cleared away, owing to the want of trees to protect their crops from storms, and to maintain a due humidity in the air. This state of things, on plains that have become treeless wastes, attracted the notice of the United States Government about twenty years ago, when the I'imber Culture Act of 1873 was passed to encourage the growth of timber on the western prairies. Any person planting 40 acres of timber trees on Government land thereby became entitled to 160 acres at the expiration of ten years.

The Timber Culture Act of 1873 was amended in 1874 , so as to confine the privilege of entry to heads of families, or persons over twenty-one years of age, and to citizens of the United States, as well as to restrict the amount to be entered to 160 acres for one person. It also allowed homesteaders to obtain the patent by planting one-sixteenth of the homestead with trees. It was again amended in 1876 , to allow an extension of time for perfecting the title in case of the destruction of the trees by grasshoppers ; also to permit of seeds and nuts being planted instead of trees. And in 1878 the number of acres required to be planted was reduced to 10 for every quarter section, and in the same proportion for smaller quantities,-but requiring closer planting-viz., 27,000 trees per acre. Five acres were to be broken in the first year, and five in the second, and planted with trees in the third and fourth years. This Act also repealed the homestead provision of the Act of 1874 .

It is Forestry, therefore, that is to render those vast plains habitable for men, and profitable to the American nation. The American people are now quite alive to the great advantages of wools for the successful improvement of their vast prairie-lands, which possess soil naturally of a rich character; and in the hands of such an energetic people as they are, those territories which are now almost uninhabitable for man, owing to want of trees, will ere long become teeming with human industry and overflowing with wealth -all from a judicious encouragement of Arboriculture.

Since 1848 , in the thirty-six years ending in 1884 , no less than 
nine million acres of waste land have been reclaimed in France, the principal areas being approximately shown thus:-

\begin{tabular}{|c|c|c|c|c|}
\hline Prodtce. & & ]S48. & 1884. & Increase. \\
\hline $\begin{array}{l}\text { Grain } \\
\text { Various crops } \\
\text { Forest }\end{array}$ & : & $\begin{array}{c}\text { Acres. } \\
34,500,000 \\
23,000,000 \\
16,000,000\end{array}$ & $\begin{array}{c}\text { Acres. } \\
37,500,000 \\
24,5110,000 \\
20,700,000\end{array}$ & $\begin{array}{c}\text { Acres. } \\
3,000,000 \\
1,500,000 \\
4,700,000\end{array}$ \\
\hline Total . & . & $73,500,000$ & $82,700,000$ & $9,200,000$ \\
\hline
\end{tabular}

Sylviculture is perhaps ultimately destined to be equally efiectual in the improvement of the treeless regions of South America. for the amelioration of the deserts of Africa, and for the improvement of the vast wastes of Asia and Australia. Can any one doubt that, under a well-directed system of forest conservancy and of planting trees, those regions could not he made lighly profitalle for arricultural occupation? Might not the recurrence of such terrible famines as have hitherto been only too common in some parts of our Indian empire be, to some extent at least, checked by a wise and judicious system of planting, and hy the better conserrancy of the forests still existing throughout that great country?

A good system of Sylviculture night be the means of improving all those regions, and of rendering them better abodes for man, and for all his dependants and his industries. On vast tracts, which are now considered unculturable, there may yet be formed, by means of the assistance of scientific Sylviculture, productive land cilnable of supplying the requirements of populations for which the present culturahle area of the globe would not be able to provide the rerpisite space at the present rate of increase in the populations of civilised countries.

Sylviculture and Arboriculture may easily change the natural aspeet of every country in which forestry is practised. Take the case of our own island as an example. Trees brought from all the temperate regions of the globe are now cultivated here, and the result of this must be that in time the woods and parks will exhibit features of scenery of a more or less foreign nature. Another generation will see the dark forms of the noble Silver Fir (Picca nobilis) and the Inouglats Fir (I'sumtutsingr Domglesii) towering in majestic grandeur above the smaller trees of our woods and plantations; while the Mamnoth-tree of California (Hillingtonia gigunten) will in time stand out above all. These grand Californian species will, in the course of time, form fine contrasts to the many other foreign species spread around and under them. 
The sister arts of Sylviculture and Arboriculture are of vast importance both to the welfare and the pleasure of all nations; and no people can be said to be wise and economic which does not attend to their advancement. The future of Forestry is not confined to any one people or nation; it is a universal science, and an art capable of being cultivated so as to promote the comfort and the happiness of every people in every clime, and to secure rich harvests to the industry of all nations that will put its precepts properly into practice.

The future prospects of Forestry in this country are more promising now than they were a quarter of a century ago. Then practical Forestry was but little understood, even lyy those who painl most attention to it; but now landed proprietors, scientific men, ani practical foresters are beginning to see that unless in the future a well-applied and judicious system of Sylviculture is adopted in this country, the effects of our neglect will certainly be felt when the present surplus supplies of other countries are no longer available for the satisfaction of our demands for timber:

The only safe manner in which the future benefits derivable from a system of Sylviculture, based upon natural laws and carried out with well-directed judgment, can be securely realised, is by the thorough education of practical foresters and sylviculturists. Upon these must chiefly depend the planning, the carrying out, and the supervision of all the operations in connection with the formation, tending, regeneration, protecting, utilising, and general management of the forests of the future-not only in this country, but in our colonies and depentencies as well. Care should he taken, therefore, that in the near future we may have a class of foresters who have received a sound general education in all the theoretical knowledge of their profession, combined with a good practical training, in which they may have proper opportunities of testing the soundness of the scientific teaching they receive. It is extremely undesirable that foresters should be men of theory alone. It is essential that they should be practical men; but they can only be well equipped for practical work when they have become thoroughly acyuainted with the fundamental principles of scientific Forestry.

So long as no well-organised system exists in this country for the education of foresters, the alvancement of Sylviculture must be slow; for no art can flourish so long as it feels the want of a sure scientific foundation. From a purely mational-economic point of view, therefore, it would appear to be the duty of Government to establish, from national funds, such means of education for foresters as will be for the future benefit not only of this country, but also of all her colonies and dependencies.

VOL. I. 
And among foresters themselves, at the same time, well-concerted and mited action is also requisite, in order to further the interests of their technical education. To a certain extent this object is attained in the case of the Royal Scottish Arboricultural Society, which has as its aim the advancement of Forestry in Scotland. But hitherto the action of this society, though decidedly useful in some important respects, has certainly not been quite so vigorous as might have been expected from a body of really zealous men earnestly striving after what they view as an important object. This society is now, along with the Highland and Agricultural Society, taking a leading part in endeavouring to raise funds in order to establish a Chair of Forestry in the University of Edinburgh. But up to the present the efforts on this behalf have only realised subscriptions to the extent of $£ 2250$ out of $£ 5000$ required to be collected before the Board of Agriculture can be approached with a request to grant other $£ 5000$ in order to provide the university authorities with the minimum sum of $£ 10,000$ for the endowment of a professorial chair. When the requisite sum has been obtained, it is to be hoped that the University authorities will give their high sanction to the admission of such a chair within their Faculty of Science; and that when the first Professor thereto is elected by them, he may be a thoroughly trained sylviculturist, and one in every way properly qualified to further the adrance of the science of Forestry, and the arts of Sylviculture and Arboriculture, throughout Scotland.

Despite the fact that our British woodlands amount altogether to three million acres only, the British empire contains at the present moment more extensire and more valuable timber-producing tracts than are owned by any other country in the rorld.

Even to confine our attention to home conditions entirely, it has very recently been urged by Mr Munro Ferguson, MI.P., ${ }^{1}$ that in the planting up of the Highlands of Scotland will be found the true and practical solution of the crofter question and the settlement of the deer-forest difficulties. This conviction on the part of certain members of Parliament led to the following question being put to the Secretary of State for Scotland in the House of Commons, on 13th November 1893:-

Waste Lands in the Highlands._- "Dr. Macyregor asked the Secretary for Scotland whether the Government, in framing the measure for Local Government in Scotland, would consider the desirability of giving to county or district councils power and facilities for planting waste and unproductive moorlands in the Highlands, where there were millions of acres unfit for arable or pastoral purposes, but well suited for afforestment.

"Sir G. Trevelyan. This is a large and interesting question, which, as the hon. member is no doubt aware, was raised before the Select Committee

${ }^{1}$ Contemporary Reriex, October 1893, pp. 521, 522. 
on Colonisation in 1890 by the hon. member for Leith Burghs (Ir Munro Ferguson). I observe that it has recently been brought under the notice of the Highlands and Islands Committee, and I can only at present say that I shall be grlad to give careful consideration to any scheme which may he lair before me for the development of the waste lands of the Highlands by Forestry."

And again, on 12th December 1893, in the House of Commons, attention was drawn to the subject in the following terms:-

Afforestation in Scotland.-- "Dr Macgregor asked the Secretary of State for Scotland whether in connection with the Local Government Bill for Scotland the Government would consider the expediency of enabling county councils to acquire waste moorlands in the Highlands at prairie value for the purposes of forestry, at the same time empowering the county conncils to assess the ratepayers for the necessary operations of planting and maintaining such lands, - thus not only improving the climate but creating work for the people and shelter for stock and game; the whole to be the property of the community in each county respectively.

"Sir G. Trevelyan. I have already answered the hon. member in reply to a question on the same subject. I have as yet received no communication from County Councils on the matter, implying that they are desirous of having powers for dealing with afforestation, and in any case the question must be answered irrespective of the Local Government Bill."

Reafforestation in Ireland.- " $\lambda r$. Field asked whether the Government was preprared to grant, out of the funds roterl for reattoresting in Ireland, a sum sufficient to start the planting of Willow and Osiers in suitable localities; and whether instructions will be issued to the Congested Districts Board to immediately promote the reproductive industry.

"MIr Bryce for Mr J. Morley said: The Congested Districts Board have already planted about 2 acres of land in the county of Galway with Osiers as an experiment, and are willing to consider any scheme submitted to them relative to the development of Osier cultivation, and-having due regard to other claims upon the Board's resources-to assist in developing any such schemes which, in their opinion, may reasonably he expected to be successful."

And a week later, on 19th December 1893, attention was once more called to the same matter as under:-

Afforestation in the Highlands.- " I), I Iacfrew, $r$ asked the First Lorl of the Treasury if the Govermment would consider the desirability of encouraying local authorities, by means of loans and otherwise, to plant the waste moorland in the Highlands and other parts of the country, therely creating work for thousands of the unemployed, besicles the future alvantages of profit and improvement of climate, \&c.; and would the Government, with as little delay as possible, initiate legislation for this purpose?

"IIr Gladstone said this important subject had been taken special notice of by the Commission now sitting on Lands in the Highlands, and that being so, it was obviously the duty of the Government to wait and see what was reported on the subject by the Commission."

The British Sylva. - The forest trees which are indigenous to Great Britain and Ireland are also of spontaneous growth through- 
out the neighbouring countries on the continent of Europe, such as in France, Belgium, and Germany. This is easily accounted for when the weneral similarity of the climatic conditions is considered, as well as the probability that the British Isles at one time formed part of the continent from which they are now separated as islands. Nuch controversy has always existed among our botanists as to the kinds of trees which may be considered truly indigenous to our islands among all those now found growing spontaneously in the woods. This, however, is excusable when the fact is taken into consideration that probably some of the species introduced by the Roman invaders many centuries ago have now become acclimatised within these islands, and consequently have by some been considered entitled to rank as indigenous to the country. It cannot be surprising, however, to find that the really indigenous trees of the country are but few in number compared with those of most other countries. This follows partly from the small extent of land embraced, and partly also from the fact that there is not much probalility of tree-seeds being brought from the Continent and deposited here in the excreta of birds after a long flight across the German Ocean.

The following list may be considered as embracing not only the principal timber-trees, exclusive of their varieties, recognised by hotanists as heing really indigenous to the British Islands, but also as including some kinds that are now of spontaneous growth, although concerning many of these doubts are entertained as to their being truly indigenous or being merely denizens that have in course of time become acclimatised :-

Small-leaved Lime-tree, Tilia parvifolia. Broad-leaved Lime-tree, T. platyphylla. Common Maple, Acer platanoides.

Sycamore, A. Pseudo-platanus.

Common Holly, Ilex aquifolium.

Hawthorn, Cratcegus oxyacantha.

Common Cherry, Prunus cerasus.

Mountain Ash, Sorbus aucuparia.

Common English Elm, Ulmus campestris.

WYych Elm, U. montana.

Sessile-fruited Oak, Quercus sessiliflora.

Common Oak, Q. pedunculata.

Common Beech, F'agus sylvatica.

Common Hornbeam, Carpinus Betulus.
Common Birch, Betula alba.

Dwarf Birch, B. nana.

Black Poplar, Populus nigra.

White Poplar, P. alba.

Aspen Poplar, P. tremula.

Grey Poplar, $P$. canescens.

Scots Pine, Pinus sylvestris.

Common Yew, Taxus baccata.

Common Ash, Fraxinus excelsior.

Common Alder, Alnus glutinosa.

Willows many, chief timber kinds-

White Willow, Salix alba.

Bedford Willow, S. Russelliana.

Cracking Willow, S. fragilis.

From the above list it will be seen that of the many kinds of trees at prescut cultivated in the British woods and plantations, only a suall funportion are really indigenums to, or of spontaneous growth in the comintry, and that the greater number has been introduced from 
time to time. This becomes more apparent when it is considererl that there are believed to be, at the present time, considerably upwards of 300 different kinds of trees growing in our woods which attain to the dimensions of timber-producing trees. Even some of the kinds named in the above list as being of spontaneous growth are certainly recognisable as not originally belonging to our islands; but so far as the practical purposes of Sylvicilture are concerned, they may now be considered as trees of native origin. Besides, so little is known about the earlier introduction of exotic trees into these islands, that only assumptions can be made on the subject of whether the doubtful trees are indigenous or not.

And from the point of view of practical Forestry it does not in the least matter whether any of the doubtful kinds of trees were, or were not, originally and truly indigenous to Great Britain. What is of far more importance is that, from long experience, they are known to thrive in our climate, and to reproduce themselves naturally from seed-i.e., they have long ago become denizens or naturalised trees in Britain. In the case of some species, however, like the English Elm and the Lime, the fact that seed-production is dependent on an unusual degree of warmth during spring and summer, as in 1893, distinctly points to exotic origin in a warmer clime than ours.

Note on Rating of Woodlands.-In Scots Law, under the Valuation of Lands Act, 1854, $\S 6$, in estimating the yearly value of lands and heritages, the same shall be taken to be the rent at which, one year with another, they might in their actual state be reasonably expected to let from year to year.

Where they consist of woods, copse, or underwood, the yearly value shall be taken to be the rent at which they might in their natural state be reasonably expected to let from year to year, as pusture or yrasiny lands (Bell's Dictionary and Digest of the Law of Scotland, 1890, p. 1106). 


\section{CHAPTER II.}

\section{THE BROAD-LEAVED SPECIES OF TREES.}

Tine broad-leaved linds of trees usually planted for cultivation as timher, or for the ormanentation in our woods, plantations, and parks, are comprised within the following list:-

\begin{tabular}{cl} 
Cupuliferce, & 1. Oak, Quercus. \\
\multicolumn{1}{c}{ 2. Beech, Fagus. } \\
"1 & 3. Sweet-Chestnut, Castanca. \\
Oleacece, & 4. Ash, Fraxinus. \\
Ulmacece, & 5. Elm, Ulmus. \\
Acerince, & 6. Maple and Sycamore, Aces. \\
Salicacece, & 7. Poplar, Populus. \\
" & 8. Willow, Salix. \\
Betulacece, & 9. Birch, Bctula. \\
" & 10. Alder, Alnus. \\
Platance, & 11. Plane-tree, Platanus. \\
Carpince, & 12. Hornbeam, Carpinus.
\end{tabular}

Hippocastance, 13. Horse-Chestnut, Esculus. Tiliacece, 14. Linden or Lime, Tilia. Juglandec, 15. Walnut, Juglans.

Magnoliacee, 16. Tulip-tree, Liviodendron. Amygdalacere, 17. Cherry, Prunus.

Pomacece, 18. Hawthorn, Thorn, or Quick, Cratogus.

19. Rowan or MountainAsh, Sorbus.

Papilionacece, 20. Laburnum, Cytisus.

$$
\text { "21. Acacia, Robinia. }
$$

Ilicine, 22. Holly or Holm, Ilex.

The above list contains all the generce of broad-leaved trees that are usually in cultivation in our plantations; and it is purposed to devote the various sections of this chapter to a full description of these, giving to each genus a separate section, in which will be described the distinctive character, habits, and peculiarities of all the species of it that are cultivated. At the same time particular reference will be made to the mode of cultivating them to the best advantage, so as to attain the highest economic qualities in their timber.

For the sake of convenience the species will be grouped together in their natural families, although otherwise not arranged with any attempt at classification according to one or other of the natural systems of botany.

\section{CUPULIFERA RICH.}

This family of the great order of Amentacece or catkin-bearers is characterised by having the fruits surrounded by a cupule or cup formed of 
aggregated bracts, and is now represented in Britain by two indigenous genera, Oak and Beech, and one acclimatised genus, the Sweet-Chestnut.

These three genera are distinguished botanically as follows: ${ }^{1}$

I. Female flowers singly or in clusters in the axils of the leaves or in axillary shoots (forming loose spikes), and each surrounded by a cupule, which finally becomes (cip)-shitgerl, and surrounds the nut from below. Oak . . . . . . . Quercus.

II. Female Howers in terminal bunches, or chintererl at the base of the male catkins; each covering-bract encloses 2 or 3 of the flowers, which develop into 2 or 3 nuts enclosed within the one cupule, that finally bursts open for the shedding of the seed.

(a) Female flowers in separate terminal bunches; male catkins with a long petiole, and hanging down from the side; cupule covered with short, soft prickles; nuts three-cornered and sharply pointed. Beech . . . . . . 2. Farjus.

(I) Female flowers clustered at the base of the longs spike-like male catkins; cupule covered with long, thin, interwoven prickles; nuts large and plano-convex. Chestnut . 3. Castanea.

\section{THE OAK, Quereus (Livxeax System, Monecta Polyaxdria).}

Character of Genus.-Flowers, unisexual. Males, disposed in long, slender, pendulous catkins, in mroups. Each flower consists of 8 or more stamens, and these are attended by $6-8$ bracteas, that are coherent at the base, and resemble a 6-8-parted calyx. Fomale flowers, erect on axillary peduncles, a few upon a peduncle. Each flower consists of a pistil, whose ovary and the basal part of whose style are invested with an adnate calyx toothed at the tip. Style, short. Stigma, 3-lobed. Fruit, an acorn; its lower part having an imbricate cup (Loudon, Trees and Shmibs, 1875, p. 846).2

Apart from doubtful species, A. de Candolle enumerates no less than two hundred and sixty-one distinct species of the Oak, the majority of which inhahit the northern hemisphere between the 30th to 60 th degrees of latitude. Only six of these need, however, be referred to-viz., the two British kinds, the Common English Oak, Quercus pectunculata, and the Durmast Oak, Q. sessiliflora, as they are preferable to all other sorts for the quality of their timber; the Turkey Oak, Q. ccrris; the Holm Oak or Evergreen Oak of the south of Europe, Q. Ilex; and the two American kinds, the Scarlet Oak, Q. coccinca, and the White Oak, Q. alba-as these are hardy, and calculated to produce a lighly ornimental effect in our plantations.

1 Willkomm, Forstliche Flora von Deutschland und Ocstcrrcich, 2d edit., 1SST, pp. $382,383$.

${ }^{3}$ All the generic and specific descriptions contained in this chapter hare been corrected in accordance with the above work. 
These six species of Oak are distinguishable as follows:-

I. Bracts of the eupule convex, broad at the base, and then suddenly contracting, grey. Shell of the acorn thin, smooth inside, and without any trace of internal divisions. Seed ripens within one year.

1. Foliage deciduous annually. Leaves with wavy-edged lobes or pinnatipartite.

(1) Leares with more than 5 pairs of primary side-veins, of an elongated oval form, and with many wavy-lined indentations; glabrous, at any rate when fully developed.

(a) Leaves with short petioles, and a broad, crinkled, heart-shaped base. Flowers arranged sidewards on peduncles . . 1. Q. pedunculata Ehrh.

(ל) Leaves with rather long petioles, and somewhat wedge-shaped at their base. Flowers sessile, often clustered in racemes . . 2. Q. sessiliflora $\mathrm{Sm}$.

(2) Leaves with 3-5 pairs of primary side-veins and lobes; the under-surface mostly pubescent . . . 3. Q. alba L.

2. Foliage persistent (evergreen). Leaves small, leathery, stiff, somewhat shortly oval, and with a greyish pubescent or downy undersurface; edge entire, or with sharp pointed crinkles 4. Q. Ilex L.

II. Bracts of the cupule broad at the base, and then narrowing gradually, brown. Shell of the acorn thick, downy inside, and with three false dirisions. Seed only ripens in the second year . 5. Q. coccinea L.

III. Bracts of the cupule loose and recurvate. Shell of the acorn thin, and without trace of any internal division. Seed only ripens in second year. Leaves thin, coarse, unequally serrately dentated or pinnatifid

6. Q. cerris L.

\section{(1.) THE PEDUNCULATE or COMMON ENGLISH OAK, Quercus pedunculate Ehrh.}

Srxonsms-Q. Robur L.; Q. Robur I. pedunculata DC.; Q. pedunculata Willd.

Specific Character.-Leaves on short footstalks, oblong, smooth, dilated upwards; sinuses rather acute; lobes obtuse. Stalks of the fruit elongated. Nut oblong (Loudon, op. cit., p. 849).

Distribution.-The Q. pedunculata is a native of nearly all parts of Europe, from Sweden in the north to the Mediterranean in the south; and it is also said to be found in the north of Africa, as well as in-Asia Minor and the Caucasian districts. It is the prevailing (jak in all our British woodlands, and in the forests of France as well, but is said not to be more common in Germany than the Sessile Oak. Its northern limit is below $58^{\circ}$ in Scotland and below $63^{\circ} 26^{\prime}$ on the west coast of Norway; but it sinks to $60^{\circ}$ in Sweden, and still further as it trends eastwards. Its southern limit for Emme is latrlly astignalile, as its special characteristies would often appear to become interchangeable with those of $Q$. sessitiflorc. Its total distribution may le assesed as commrising altogether about $26^{\circ}$ 
of latiturle and $66^{\circ}$ of longitude, and its finest development is attainer in the south-eastern part of Central Europe, more especially throughout Inungary and Croatia. ${ }^{1}$ As compred with the Sessile Oak, the Common Oak is rather a tree of the plains and mplands than of the hills and lowel mountain ranges, or of lofty plateaux. In general more is done throughout England for the artificial distribution of the latter as a timber-tree; but, in the rapid production of wood and bark on coppice-luags, the former deserves more favourable attention, and in high-forest it also undoubtedly forms a better bole than the Common Oak.

The spontaneous growth of this species in Central Spain, as well as in Western Russia, clearly proves that it can endure not only great summer heat, but also great winter cold; during May, however, its young foliage is sensitive to late frosts, and it is liable to suffer from drought when the summer flush of leaves appears during August, although this is to a far less extent the case in our damp insular climate than throughout the drier regions of Central Europe.

Description of Tree.-The Q. pedunculate, generally speaking, forms a large, massive-stemmed, and spreading-topped tree, naturally disposed to throw out large limbs, and to become what may properly be termed a ramifying and flat-topped tree. The appearance of the tree is, however, very much influenced by the soil and situation upon which it grows. When growing on a high, exposed site and a poor soil, it becomes of a stunted, low-stemmed, flat-topped character, whereas on a low-lying situation, with a deep strong soil, it assumes a more npright habit; and this again is, of course, moditied by given circumstances, according as the trees are drawn up through being close together, or have a freer growing-space from standing far apart. In the former case their crowns become comparatively small, whilst the boles are tall, and drawn up; but in the latter case they attain that full development, both of stems and branches, which renders the Oak so much admired as an ornamental tree in landscape scenery. It necessarily, however, follows that the farouring of ramitication for cesthetic purposes is entirely inconsistent with the procluction of a maximum of timber in the stem or bole for purely utilitarian and technical purposes. This, in fact, constitutes the great difference between Arboriculture and Sylviculture. This species is asily distinguishable from the Q. sesiliflore by its leaves having very short petioles or foot-stalks, as compared with those of the leaves of the other kind (see Figs. 1 to 4 ), and by the stalks of the fruit being elongated. Even during their leatless winter condition they mily be easily distinguished, as the buds of the Common ()alk are shorter, 
thicker, and blunter than the longer and more pointed buds of the Sessile Oak.

Economic Uses of Timber.-Although Oak timber is not now so much required as formerly in the construction of large oceangoing ships, still it is largely used for the building of small coasting vessels; and a very large quantity of the smaller sizes of trees is used annually in mining operations.

This technical fact, that crooks and ribs of iron are now used in shipbuilding in place of Oak-pieces of natural curved or crooked growth, is one of which the importance cannot be overlooked from a sylvicultural point of view. All the Oak plantations made throughout Britain during the greater part of the last two hundred years in the State forests (New Forest, Alice Holt, Parkhurst, Forest of Dean, icc.), as well as by private landowners, were
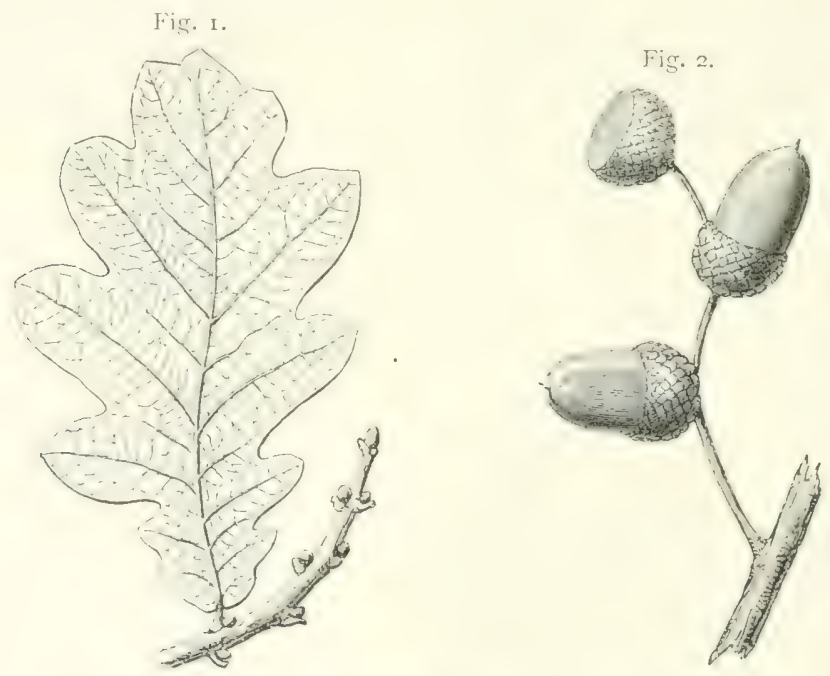

Leaf, buds, and fruits of the Common Oak (Q. pedunculata).

formed with the express intention of growing wood suited for the purposes of shipbuilding. Ramification, favoured by free-growing space, was therefore advantageous as well as highly æsthetic. But now the best prices are obtainable for long, straight, full-wooded, clean boles, free from knots and branches; and these can only be obtained by growing the trees in woods in such a manner that ramification and crown-development are confined merely to the normal healthy limit, so long as the stems are still capable of being stimulated in the direction of growth in height.

Oak timber is also used for a great variety of purposes in connection with house-building, carpentry, cabinet-making, furniture, agricultural erections and implements, \&c. In short, the uses of Oak timber are so numerous and so well known that it would be superfluous to attempt to enumerate all of them here. In point of 
durability generally, the timber of no other tree grown in Irritain takes equal rank with it; hence it assumes the first place among our hard-wooded sorts for general economic purposes. From a purely financial point of view, the only tree that may be said to surpass it in paying value as a high-forest crop for the sake of its timber is the Larch.

It belongs to the very heavy class of woods, having a sp. gr. of over 0.75 ; its sp. gr. is 1.04 whilst still green, and 0.76 when seasoned in the air. That is to say, when stems have to be floated in order to arrive at a convenient market, some amount of seasoning will have to be provided for in the forest, such as ringing or girdling the stems to a depth of 3 or 4 in. almost a year before felling them. In Hanover the stems are often barked, and allowed to stand thus for one year.

Soil and Situation.-The rate of growth and the quality of Oak timber, like those of all other trees, depend very much upon the nature of the soil and situation upon which it is grown. Throughout Britain the best-grown Oak-trees are generally to be found on somewhat heavy and deep clay soils, or on argillaceous loams of considerable depth, into which the roots can penetrate well and ramify freely, without any check from a change in the character of the subsoil. The Oak will, however, thrive well on all soils, even on those of a very light and sandy nature, provided they are not wanting in depth and freshness; though in the majority of cases the largest trees and the best quality of timber are usually to be found on deep lands of an argillaceous and heavy character.

Where such description of land is still given up to timber crops, the pedunculate Oak thrives excellently on flat or undulating stretches of deep soil formed by alluvial deposit; and in such cases far less depends on the argillaceous, or the loamy, or the sandy consistency of the soil, than on its depth and other generally favourable physical properties. Such land, however, is nowadays seldom to be found unutilised for agricultural purposes. For marshy tracts the Common Oak is better suited than the Sessile Oak.

On light loams and sandy descriptions of soil individual trees of the Common Oak may attain a girth of from 12 to $18 \mathrm{ft}$. near their base. But they are then generally short of stem, ramify excessively, and are accordingly large-crowned in proportion; while trees of anything like the same girth growing on deep heavy land usually develop very much longer and cleaner boles, and therefore form better proportionate and more valuable stems. On high-lying and exposed situations the Common Gak will grow, and even become timber of useful size, although the soil be but poor; but for all such localities the cultivation of the sessile Oak seems 
preferable. In order, however, to produce timber of the best description, whether as to dimensions or quality, this common species of Oak should preferably be planted on rather low-lying or merely undulating tracts, and on a soil that is not wanting either in depth or in moisture.

As a matter of actual practical fact, and despite differences in sp. gr. and other similar tests, the durability of Oak timber in general depends less on the specific kind of timber of these two principal species than on the general quality of the soil upon which it is grown. The height attainable by the stems depends, however, mainly on the depth and the general quality of the soil.

Propagation and Culture.-When grown in high-forest, the Oak is usually raised from acoms, as the fruits are named. Seed-production may begin about the twentieth year in coppice-woods, but does not set in until about the fiftieth to sixtieth year in trees raised in the open from seed, and not until about the seventieth or eightieth year in timber-crops growing in close canopy. The acorns generally ripen in the months of October and November, and germinate during the following spring. So soon as they are ripe, they should be gathered and either sown immediately or else stored carefully, because they are very apt to lose in germinative capacity by being long kept, more especially if measures be not taken to ensure that they are being kept dry and in a cool place. Only good sound acorns should be collected, and not those that are worm-bored or below the normal size. If kept perfectly dry and cool, however, the acorns may easily be preserved all winter and sown in the spring; but as they are extremely apt to be injured by careless keeping, the better way is to sow them at once when gathered, except where voles, squirrels, and other vermin are troublesome, or where late frosts in spring are to be feared.

Winter Storage of Acorns.-The main points to be kept in view in storing acorns are (1) to prevent them from germinating too early, or from becoming overheated, in which latter case they decidedly lose in germinative capacity, and (2) at the same time to avoid drying them so far as to cause them to rattle in their shells. The danger of premature germination is less in the case of the British than the Durmast Oak, whose smaller acorns are more difficult to store safely through the winter months. The best procedure that can be adopted is as follows: The acorns should be spread out on dry airy places, and frequently turned by means of the rake, or the shovel if in high heaps-a measure that should be attended to in the case of acorns to be despatched to other parts of the country in autumn, as well with regard to those that are to be stored throughout the winter. When frosty weather begins to make its appearance, they should then be stored in broad ditches about one foot deep, made in dry airy places, the output from which is ranged round the storing- 
place in order to prevent rain from entering it. Above this a roof is erected of thatch, straw, furze, reeds, dc., just high enough to let a man get underneath to turn over the acoms with rake or shovel occasionally to jrevent their getting overheated. In order to facilitate this operation the ditch and the roof-covering should be made somewhat longer than is afsolutely required for the quantity of acorns when filled up to a depth of about a foot. The shifting in the position of the vacant space at each end at the same time forms an excellent means of control when orders have been given for airing the acorns. So long as there is no hard frost, the ends of the roof-covering may remain open for the circulation of air; but in very hard weather it is advisable to close them up with straw or material similar to that of which the roof is composed, and if necessary the roof itself should be thickened. When warm spring weather sets in before it is deemed prudent to sow the acorns, the doors or coverings at the end may be closed again, and ventilation effecter principally by means of small holes in the roof, which must of course be closed during wet or very cold weather. Before sowing the acorns in spring, their quality should be tested; this can easily be done by making transverse sections of a few of them. If steeped in water before being sown, those that float on the surface should be put aside, as not likely to yield satisfactory results (Burckhardt, Säen und Pflaxzen, 1893, pp. 52-55).

In sowing the acorns in the nursery in autumn as soon as they have been gathered, it is best to place them in rows upon the surface of the ground, after it has previously been dug and prepared, and to cover them with about $2 \mathrm{in}$. of earth; for spring sowing a covering of only 1 to $1 \frac{1}{2}$ in. is sufficient, as the thicker the covering of soil, the longer will germination be delayed. In sowing them the rows should be marked off about 15 in. distant from each other. The breadth of the seed in the row may be about 5 in., and the seed may average 1 to every 3 sq. in. In covering the seed, the earth should be gathered up from the ground upon each side of the row that is sown, until it is of the desired depth upon the acorns, care being taken not to come too near the seed upon the sides of the row, but to keep the earth rather heavier there than above; for it is generally upon the sides of the rows that vermin make their attacks upon the seed.

Acorn Poisoning.- It may not be out of place here to note the fact that in years with warm dry spring and summer weather like 1893, during which a much larger number of fruits come to maturity than in ordinary years, there is often considerable danger of cattle being poisoned by eating largely of the acoms, which they consume with avidity. Considerable mischief was done from this cause during the autumns of 1868,1870 , and 1874 , the greatest sufferers being young cattle muler two years of age, whilst mileh-eows and cattle over three years old were seldom affected. For those specially interested in this matter, it may he remarked that a leatlet on the subject was issued by the Board of Agriculture during September ls!l: (marked A 1:3-0.3), 
in order to give timely warning to graziers before the rich harvest of the acorns of 1893 ripened and fell. Where any strong head of deer is maintained, the acorns form good feeding-material for the herds during the winter months.

After the acoms have been sown, fair attention must be given to see that vermin do not devour them. In the winter season, if mice or rats are in the neighbourhood, they will be certain to attack them; and if they do, traps must be used in order to destroy them. And in the spring months, if pheasants or any other birds commence upon the acorns, nets may be used in order to cover and protect the rows; or if these be not easily obtainable, the rows may advantageously be covered somewhat closely with the branches of trees, which will keep back birds, and at the same time allow a free circulation of air to the surface of the earth. As soon as the young plants appear above ground, which will generally be about the end of May, the branches should be removed in order to give the seedlings the full benefits derivable from free exposure to light and air.

In localities apt to be visited by late frosts, however, caution should be exercised in this respect; and if this can be conveniently arranged for on small areas without incurring any prohibitive expense, it will be best to remove the branches each morning, and replace them towards nightfall.

Attention should be paid to keep the seedlings clear of weeds, as rank growth of grass and other herhage greatly entangers their early wellbeing.

As a rule, the seedling plants should only stand one year in the seed-rows; when left longer, they are apt to become drawn up and comparatively weakly. It therefore seems preferable to adopt the plan of planting them out in rows when one year old; for when the plants thus treated have stood three years in the lines, they are usually very much superior to others that have been left for two years in the original seedling state, and have then stood for other two years in the mursery rows, although both are of the same age. They should, therefore, be transplanted into the nursery-ground, in rows about $2 \mathrm{ft}$. apart, keeping the plants in the rows about $4 \mathrm{in}$. from one another; and in this state they may remain for any length of time, according to the size that the plants may be required. That is to say, if the transplants are not required to be large, two years in the rows may be enough, though in no case should less be allowed; but if the transplants are required to be sturdy and large, then three and even four years may perhaps be no more than sufficient.

On good nursery soil a height of 3 to $3 \frac{1}{2} \mathrm{ft}$. may be attained within two to three years after transplanting; but in order to attain a height of 9 to 12 ft., other four to five years are requisite. Before then, they will be standing 
too thick in the transplant-beds, an evil that may be remerlied hy removing every alternate plant, and either planting it out, or else setting it in other special transplant-beds, with a reasonable amount of growing-space.

The Oak, during the first year after being transplanted, makes very little progress in growth, but merely establishes its roots in the ground. During the second year it begins to send out new shoots, and from the third year onwards it usually grows vigorously.

It would be superfluous to enter into detail of the many fine specimens of the Q. pedunculata that are to be found in the parks of the landed proprietors of Great Britain, and more especially of those in many parts of England. There are, indeed, few great estates of long standing in any part of the country that cannot boast of some fine old specimens of Oak-trees in their home-parks; and it would here be out of place to make reference to any historical trees or to others celebrated on account of their dimensions.

Sylvicultural Characteristics of the Oak.-The Oak is one of the essentially light-demanding trees which can ill brook any interference with its full enjoyment of light and air, or, in other words, that demands for its normal development a comparatively large growing-space. This natural tendency becomes more marked as it increases in age, after once its main growth in height has been completed. And as, at the same time, high periods of rotation are requisite before the timber acquires its best dimensions and highest marketable value, it therefore follows that, unless it be either grown along with a more densely foliaged tree like the Beech, or be underplanted in order to protect the soil against the deteriorating effects of sun and wind, the soil is apt to lose in productive capacity under the somewhat sparse and usually insufficient leaf-canopy of the Oaks alone.

The modern Continental system of Oak cultivation consists, therefore, in the formation of Oak crops, ${ }^{1}$ - either pure on good, deep, fresh soils, or else in admixture with other species like Beech; and on moist soils, even along with Ash, Elm, Maple, Sycamore, or Alder,- - and then afterwards, when the chief growth in height has been attained ahout the 70 th to s0th year, in cutting ont these other kinds of trees, and either allowing them to shoot from the stool so as to form a natural undergrowth, or else sowing or planting some soil-protecting species of underwood like Beech or Hornbeam. During the whole of this earlier period of its existence, it is of course essential that the Oak, which is to form the ultimate crop, must be constantly protected during all the operations of weeding, clearing, and thinning, so as to remain growing in advance of any competitors for light and air. The freer enjoyment of light and air which is thereafter accorded to the standard Oals either by thinnings or by partial clearances, conducted every ten to twenty years for the express purpose of stimulating their increment in girth, is accompranierl, as

1 A more detailed account of the Continental methods of growing Oak will be found in the editor's British Forest Trecs, 1893, pp. 193-211, and Studies in Forestry, 1894, chapters vii., s., and xi. 
experience in the State forests of Germany has abundantly shown, by rapid and material improvement both as regards the quantity and the quality of the timber produced. It attains, in fact, to a very great extent and in an improved form, not only the practical advantages regarding light and air formerly obtained by growing the Oak as standards over coppice in the old form of copse, but also combines therewith special advantages of its own in the formation of the longest possible bole, having the maximum of fullwoodedness at the top end as compared with the girth near the butt end.

After being stimulated from time to time by partial clearances, the Oak then usually attains its material and financial maturity about the 140th to 160 th year, when it is at least equal in dimensions to stems of considerably greater age that are merely treated by the ordinary method of thinning.

When such Oak-forests come to be regenerated, this can generally be effected very easily by natural means, for the soil is usually of anything but inferior quality, else it would not be so profitable to grow Oak as to cultivate mixed coniferous crops upon it. A certain amount of soil-preparation, either in strips or patches, will generally be sufficient to yield a crop of young seedlings; but, if desired, the dibbling in of acorns, more or less regularly over the area, may in many cases be carried out at a comparatively small cost. When once the seedlings have made their appearance, the standard trees require to be cleared away soon, for the Oak, being a light-demanding species, suffers even under the broken shade of the parent trees; although on good, fresh soils, of course the risk of damage being done to the young crop by overshadowing is not so great as where the soil is poor and dry, and the night dews are necessary for the wellbeing of the seedlings. As the standards are being cleared, blanks may be filled either by planting, or by sowing acorns, or else by introducing other kinds of trees, of which, on all soils that are not of a distinctly good class, and more especially if they have a tendency to be deficient in moisture, the Beech is to be most recommended. On better and moister classes of soil a larger choice of species is open, most of which hold out financial promises exceeding any that may be predicted for the Beech. But wherever there can be any danger of the soil deteriorating under the lighter shade of the Oak, Ash, Maple, Sycamore, drc., an admixture of some shade-bearing and soil-improving species is essential in order to safeguard the land against exhaustion and loss in productive capacity, for the maintenance of the continuous productivity of the soil is the first fundamental principle in Sylviculture.

Throughout the whole of the Rhine district, and the neighbouring parts of France, Belgium, and Holland, Oak coppice-woods occur very extensively, and yield high returns. They are worked with a rotation of sixteen years usually; but this varies locally from about twelve to eighteen years, according to the nature of the soil and situation, and the age at which the young bark begins to lose its smoothness and become fissured,-for the quantity of tannin contained in it diminishes when the cortex becomes rough and rugged. When Oak coppice-woods are being formed for the first time, planting is greatly preferred to sowing, as leading more quickly to the attainment of the object in view, and as being safer on the whole, although more costly. Sometimes the seedlings are put in whole, as in the ordinary method of planting, and afterwards cut back close to the ground when they have established them- 
selves firmly in the soil; but at other times the stems are lolped off with a clean cut against a wooden block, and only the roots are planted in the ground. The chief points to be kept in view in such coppice-woods are to see that the clearing and weeding operations are carefully performed, so that the Oaks remain in undisturbed tenancy of the soil. The regeneration of the annual hags takes place spontaneously by shoots from the stool, which, besides being vigorous, often inprove their hold upon the soil by forming root-systems for themselves independently of the jarent stool, when the felling of the poles takes place low down, just over the ground.

The shoots thrown out by the Sessile Oak are straighter and somewhat more vigorous than those of the Common Oak, so that they yield more wond and bark; the quality of the bark of the former stands also in slightly higher esteem than that of the latter, more especially when the woods are formed on hilly slopes at any considerable elevation.

Good, although not necessarily deep, soil and a warm southern exposure are requisite for the satisfactory growth of Oak-bark collices. And though, with the increased and still increasing use of other tanning materials, the growing of Oak-bark may not on the whole pay so well as it once did, before ocean-communication was so good and cheap as it now is, yet the fact that a great deal of such bark is still annually imported from the Continent proves that if the proper localities be chosen, and proper methods of treatment of the woods be adopited, our home sylviculturists ought surely to be able to hold their own in open market against foreign-grown bark handicapped with varions handlings and freightage. There are many thousands of acres along railway cuttings and embankments that might thus be utilised very profitably, besides helping to provide useful employment for many thousands of the poorer cla:ses who are usually unemployed during the early spring, when the sal begins to flow and the harvesting of the bark takes place.

For the private landowner this form of crop has the great advantage of locking up far less capital, and yielding substantial returns much sooner, than most other woodland crops; hence, wherever there seems fair prospect of the hark being disprosable at remunerative rates at any neighbouring town, this method of utilising shallow but otherwise good soil, having a wam exposure, is worthy of consideration.

(2.) THE SESSILE or DURIVAST OAK, Quereus stsitiflore im.

Synonsus-Q. Robur L.; Q. Robur II. sessiliftora DC. ; Q. sessilis Ehrh.; Q. scssiliflora Sal.

Specific Character.-Leaves on longish foot-stalls, leciluum: oblong, smooth; sinuses opposite, rather acute: lohes oltuse. Fruit sessile. Nut oblong. Leaves, when young, pubescent beneath (Loudon, op. cit., p. $8 \tilde{2} 2$ ).

The above are the distinguishing characteristics of this species from the scientific point of view of the botanist; but as it might not be sufficiently distinct for the recognition of it from the other species, Q. pedunculata, were the two descriptions laid before a person unacyuainted with botanical terms, the subject may well be

VOL. I. 
illustrated by reference to woodcuts (see Figs. 1 to 4). It will be observed that the two most distinguishing characters of each of the two species of our indigenous Oak which have been referred to are that the leaves of $Q$. pedrnculata have very short petioles or leaf-

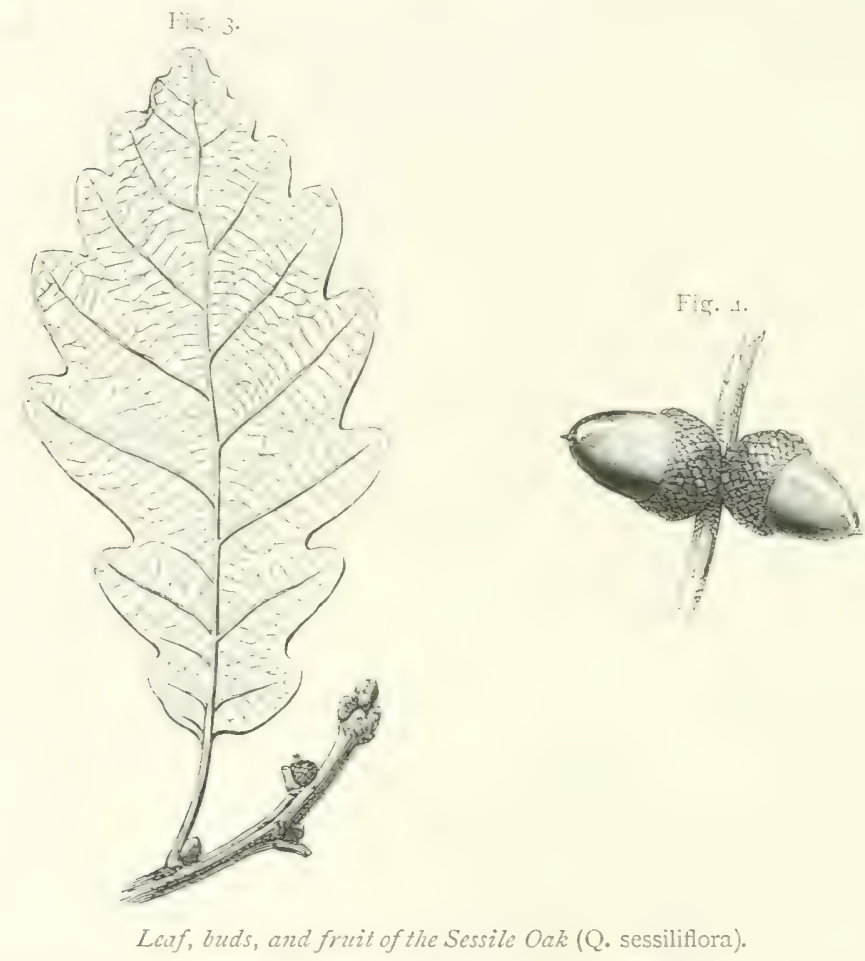

stalks (Fig. 1), while the fruit has comparatively long peduncles or flower-stalks (Fig. 2); Q. sessitiflora, on the other hand, has comparatively long petioles (Fig. 3), whilst the fruits are entirely sessile or without stalks, and are also frequently clustered in racemes (Fig. 4).

Young foliage of the Sessile Oak is generally more or less pubescent on the under side, and even the older leaves usually show traces of this pubescence at the angles formed by the side-veins; but in the Common Oak the leaves are quite smooth or glabrous. In the former, again, the side-veins alrrays end in the lobes; whereas in the latter they may also terminate in the indentations (Burckhardt, op. cit., p. 15).

These constitute the chief macroscopic or most prominent distinguishing characters of the two species. But they are not always to be relied on; for even in examining a number of leaves upon the same tree, some of them may perhaps be found to answer to the 
descriptions of both species. Generally speaking, however, these differences between the two linds do hold good to a very great extent; and any experienced person who has been long in the habit of examining the leaves of each species can at once, even from the forms as alreadly explained, distinguish the different species. And besides this, for use during the leafless winter period of rest, there is mother mark of distinction, which is perthaps even more decided than the differences noted between the fruit and the leaves-riz., the difference between the buds upon the young shoots. The buts of the 2 . sessiliflore are more prominently brought out upon the wood, and more sharply pointed, than those of the 0 . pertunculates and in the former the wood at the base of the buds is also more fully developed than is the case with the latter. See Fig. 3, where a piece of the young wood is shown; and compare the buds as shown there with those upon the young shoot in Fig. 1, which represents a piece of the young wood of the ?. pectunculata. As exhibited in Fig. 1, the young wood swells but slightly at the base of the buds in the case of Q. pechunculata; but as shown in Fig. 3, the young wood swells boldly at the same point in the case of Q. sessitiflore. The distinguishing characters that have been pointed out are, however, by no means constant, for they may very often be found blended together in one tree. But this is easily accounted for by the fact of the two species being indigenous, and being often fomnd growing together, from which circumstance many trees may have been produced which are no doubt what may be termed hybirits, anil which throw back more or less completely to one or other of the parent forms. When, however, the trees distinctly develop their own true characters, the differences above noted will hold goou, and will serve to point out to which of the original species they belong.

So far as lybrids are concerned, sometimes they approximate nearer to the one species, and sometimes to the other, without any apparent preference upon which to establish a rule.

Distribution. - The Q. sessiliflort is dispersed over nearly the same range of countries as the (. pedunculuta, and they are generally found growing together from sweden sonthwards to the Mediterramean. It is found largely in Britain, in France, and in Germiny, where it often forms rery extensive forests, along with the Common Oak, Beech, and other trees.

Its distribution is, however, somewhat more restricted than that of the ('ommon Oak towards the north and the east. Its northern limit is below 59' in Scotland, below 60 $11^{\prime}$ ' on the west coast of 'Torway, and below 58 ' $30^{\prime}$ in Sweden, whence it trends east across central liussia to about $5 f^{2}$ towards the southern portion of the Ural Mountains; from there its eastern limit prasses 
across the Crimea to Asia Minor, where its southern limit begins about the 40 th degree of latitude. It can, however, at the same time ascend vertically considerably beyond the elevation attainable by the common Oak. The explanation of this seeming anomaly must be that whilst the Sessile Oak can bear less winter cold than the Common Oak, yet it can thrive with less of summer warmth (Willkomm, op. cit., pp. 406-409).

Wherever there are extensive natural forests of Oak both species will usually be found growing together, although on lowland tracts the Common Oak will vastly outnumber the individuals of the sessile species. According as the woodlands stretch, however, to the higher uplands and the hilly tracts, the trees of the latter species will gradually increase in number. From natural spontaneity of this sort useful hints may be gained by the sylviculturist, and as a rule it will be advisable to propagate that species chiefly which seems to form the majority of the old crop. Throughout Central Germany in old coppice-woods, and in Oak forests that have been reproduced naturally, the Sessile Oak is more numerous than the pedunculate, which would point to its frobal,ly heing able to hear shade somewhat better than the Common Oak; lut in younger forests raised artificially by sowing or planting, a preference seems to have been given to the latter species, probably on account of the somerwhat larger size of the acorns (Burckhardt, op. cit., p. 14).

Description of Tree.-The two species grow nearly alike, so far as the dimensions attainable by the trees are concerned; but it may be generally observed, with respect to the $Q$. sessiliflora, that it assumes a more open and upright habit of growth than the Q. pedunculcta. The limbs of the former are not generally so crooked or knee-bent and gnarled as those of the latter; whilst trees of the former kind have a cleaner hole and in all respects a lighter aspect than those of the latter. It is usually about ten to fourteen days later in breaking into leaf than the Common Oak.

Economic Uses of Timber.-For all purposes to which Oak timber is arplied, that of the Sessile Oak is used as plentifully as that of the Common Oak, and in old buildings its duralility has practically been found to be almost equal to the timber of the latter kind, although it is somewhat softer and easier to work. And what is of even more importance to the landowner, the wood of the one kind fetches the same price as that of the other, for buyers do not differentiate between the two species. When young, the timber of the Durmast is of a more open texture than that of the Common Oak of the same age; but as it becomes older, it is found nearly as compact and solid as that of the latter.

Its sp. gr. is just a very little lower than that of the wood of the Common Oak, being 1.01 when green, and 0.74 when seasoned. Seasoning to some extent, either by means of girdling, or barking, or of letting the logs lie in the forest, will therefore be requisite before they can be safely floated down streams to convenient sale-depots. 
Soil and Situation.-These are in general the same as have been stated with reference to the Common Oak, except that the Sessile Oak is more frerpuent on hilly land, whilst the Common Oak is the chief species on low-lying tracts. Both demand, in order to thrive in high-forest, a fair depth of soil, and more especially a consirlerable amount of freshness, or even moistness, in it. It may be remarked here, however, that the Durmast Oak makes a much better hedgerow tree than the Common Oak does; because in such a situation it maintains more of an upright liabit of growth than the latter, and is more easily kept from spreading out its branches over the land, and injuring the field-crops by the heavier shade it thus casts.

Propagation and Culture.-For this species these are the same as described with reference to the Common Oak.

\section{(3.) THE WHITE OAK, Quercus alba L.}

Specific Character.-Leaves oblong, pinnatifidly serrated; pubescent underneath ; lobes linear-lanceolate, obtuse, entire, attenuated at the base. Fruit pedunculated. Calyx somewhat cup-shaped, warty, and flattened at the base. Acorn oval (Loudon, op. cit., p. S62).

Distribution.-The White Oak is plentiful in Canada, and in the Northern States of America generally, especially in the western portions of Pennsylvania and Virginia, where it grows to large dimensions on most of the better parts of the land, and more particularly where the soil is rich, light, and dry. The tree is very plentiful in the upper parts of the valley of the Madawaska river, a tributary of the Ottawa in Canada West: it is always to be found there on the rich lands, and but seldom on the poorer soils.

Description of Tree.-In looking at a well-branched specimen of the Q. alba, it resembles very much the British species? scssiliflorc, but on good land the leaves are larger, and the hollows along the edges of the leaf are deeper. The bark of this tree is of a whitish colour, and from this circumstance the tree has derivel it.s name "White Oak." The colour of its bark is a feature in the alpearance of the tree sufficient to enable any one to distinguish it from all other Oaks. In its native forests the Q. albe forms a gramel tree, attaining a height of 75 to $90 \mathrm{ft}$, and is considered the best of all the American Oaks with respect to the technical value of its timber. On the valley of the MIadawaska specimeus of this tree may often be seen measuring from 60 to $70 \mathrm{ft}$. of stem clear of branches, and having a cliameter of $t \mathrm{ft}$. at $30 \mathrm{ft}$. from the ground. Some of these trees, when standing, measured abont $110 \mathrm{ft}$. high, and when cut down were found to contain each upwards of 500 
cubic ft. of timber. On examining the cross sections and counting the annual rings, they were found to be upwards of 400 years old. It was introduced into Britain in 1724.

Economic Uses. - As already stated, the White Oak is one of the most valuable trees of the genus in America. It is largely used in housebuilding, and in fact it is in use for most purposes, from shipbuilding to handle-making. A large quantity of it is exported from Canada to Europe, and here it is well known under the general name of "American Oak."

Soil and Situation. - In order that this tree may have a fair chance of developing well in the British Isles, it requires to be planted in a rich, deep, light loam, and in a sheltered part of the country, as it will certainly not prosper either on a poor soil or in an exposed situation. It is perfectly hardy, however, and will grow on most soils and sites neither too poor nor too much exposed; but to grow it to any size of timber it must be placed on a good soil and warm site, where it may have a fair chance of overcoming the unfavourable differences of our climate, as compared with that of its native habitat.

Propagation and Culture. - Like our own two indigenous Oaks, the White Oak ripens its acorns during the autumn of the same year in which it flowers. This species is for the most part propagated from seed brought from America, and as this can now be easily obtained, it is found of easy propagation. The seed, as soon as brought home, should be sown in all respects in the same way as has been described with respect to the propagation of the Common Oak. This species, however, is not prolific in the production of acorns, and therefore the seed is always high-priced. In after cultivation the White Oak is dealt with in all respects in the same way as the British Oaks. This tree has hitherto perhaps been too little grown in this country; and looking at the matter from the point of view of the technical utility of its timber alone, independent of its ormamental qualities, it deserves to be more extensively introduced than it has been, arboriculturally at any rate, though perhaps not sylviculturally, for in general utility and adapitability to our climate, and to the available soils and situations forming our woodlands, it could not compete with our two native species of Oak.

On many places in Britain, and especially in the midland and sontlem counties of England, many fair specimens of this tree are to be found; and even in Scotland the tree seems to thrive well, attaining in many cases dimensions equal to the British Oaks in a given time. 
(4.) HOLM or HOLLY OAK, or EVERGREEN OAK, (uerrus Il. I.

Specific Character. - Leaves ovate-oblong, acute, coriaceous, entire or serrated; hoary beneath. Bark even. Nut ovate (Loudon, op. cit., p. 880). Figs. 5 and 6 will assist the inexperiencel in hotanical terms to a recornition of this species. This kinrt is also apt to run into varieties, and of these there are many in cultivation to which reference need not here be made.

Distribution. - The Holm Oak is a native of the Mediterranean districts, of the south of France, of Spain, and of Italy.

Fig. 5.

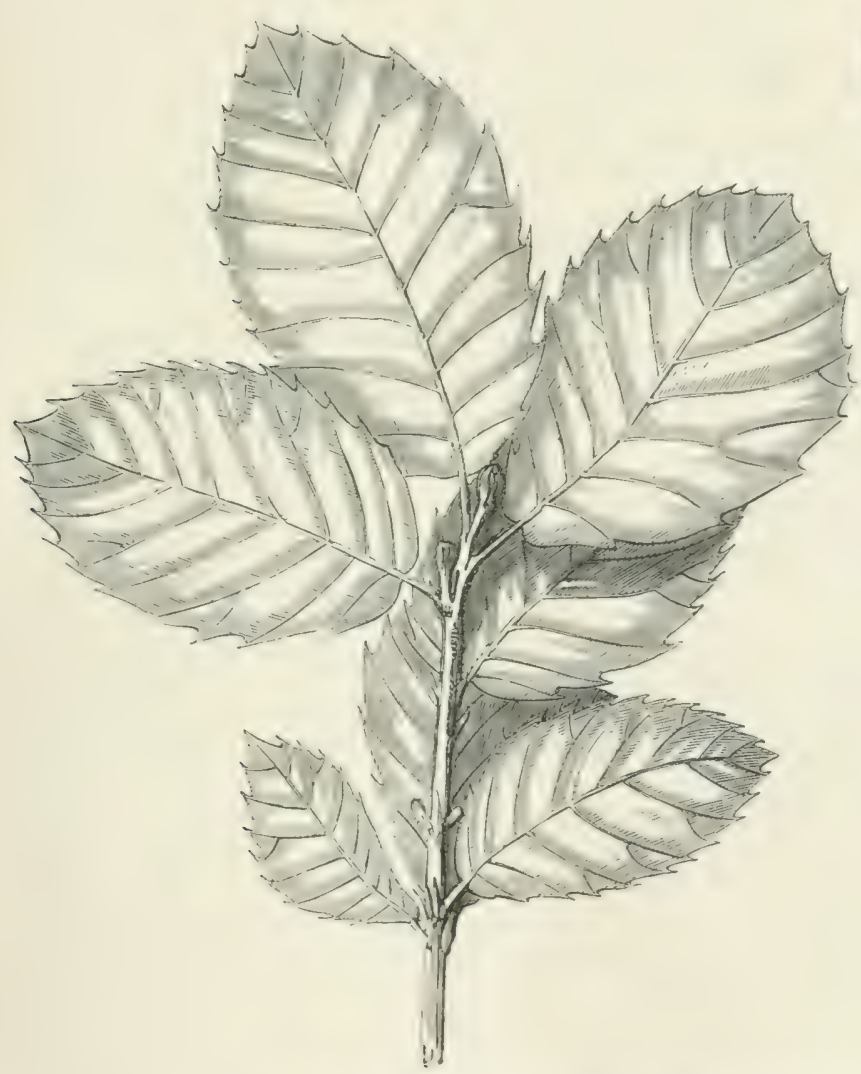

Leaves and acom of the Evergreen or Holm Oak (Q. Ilex).
Iig. 6.

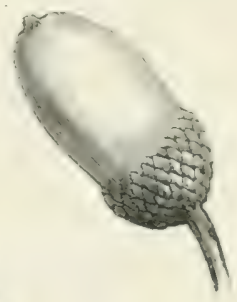

It is also indigenous to the different islands of the Mediterranean, on some of which it ascends to over $4000 \mathrm{ft}$. above the sea-level. Its northern limit trends from ahout Lake Garda across the northern part of the Ailiatic to Trieste, where it is usually found only as a shrub on the mountain-sides; for it cloes not attain the lofty dimensions of tree-growth further north than the island of Quarnero (Willkomm, op. cit., p. 416). 
It is said that this tree does not, in its natural state, grow in masses, lut in for the most part dispersed here and there among other trees. It is frepuently to be found of true forest growth among the woollands throughout siain and P'ortugal, on the islands throughout the westem half w the Meditermean Sea, on the hills in sicily, and all along the coast; it ascends Mount Etna as high as $3200 \mathrm{ft}$. above the l.rel of the sea, and to within about $800 \mathrm{ft}$. of the elevation at which 2. cerris is found. As might almost be expected from this, it has likewise shown itself to be a hardy tree in our somewhat similar, but coller, damp insular climate; for in Britain it is fouml to be rennarkably hardy, and to grow well even close to the sea-shore, where no other European species of Oak will thrive.

Description of Tree.-In favourable situations in its native countries this tree attains a height of 35 to $60 \mathrm{ft}$; but in Britain and Ireland, generally speaking, it fonms at hest merely a lare hush, and only in a few cases attains what may be called the dimensions of a timber-tree. But it has one advantage in point of ornament, viz., that it becomes thickly clothed from the ground to the top with a lene mase of hranches and of leaves, which wive it a peculiarly striking and handsome ornamental effect. This is when it stands alone and unencumberen, revelling in the free enjoynent of an unrestricted s.mwing space; for, from having to strive with other individual trees for a sufficiency of light and air, it forms a clean stem of fair height when confined among other trees. The leaves of this tree vary much in shape and size, thus giving rise to varieties that have received special

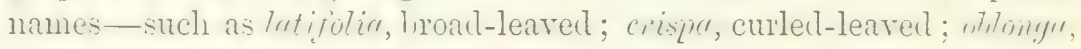
long-leaved, \&c., \&c. The colour of the leaves is a dark green; and fron their leing convex above, and quite smooth, they give a rich, full, shining appearance to the tree as a whole. In favourable parts of I)ritain, as in the warmer southern tracts of England, trees raised from seed grow very rapidly, often attaining a height of $20 \mathrm{ft}$. in twelve years; but in Scotland they grow much more slowly, seldom attaining over $10 \mathrm{ft}$. in as many years. This tree is said to live to a great age, and to continue in a healthy growing state for several centuries.

Economic Uses. - The matured heart-rood of the Holm Oak is of a dark-brown colour, has a very close grain, and is very hard and heavy-so much so as to be very difficult to work. The young wood is, however, comparatively soft, and easy to work. In Britain it has not been made much use of, being grown more as an ornamental tree only; but from several sample trees of it, cut down at about sixty years of age, the wood formed seems to be very hard. The imner obtained from these was used for furniture purposes; it was found to take a very fine polish, and had every appearance of being of a very durable nature. On the Continent, where it grows 
extensively, it is said to be much used for furniture-making and for charcoal.

Soil and Situation.-The Holn Oak thrives best in a light, dry, deep soil, whether of a limy, marly, or sandy rlescription. Indeerl it will not succeed unless the soil is deep, free, and open; and if it be at all wet in the subsoil it will become sickly, and fail to grow satisfactorily. The soil on which it grows best is one of a sandy nature rather than a clay or a loam; and where it is wished to have the tree of a good size, it should be planted in rather a warn, sumy; low-lying, and sheltered part, so that the climatic conditions may approximate, as nearly as is possible in our higher northern latitude, to those obtaining at about the same altitude in its native habitat.

Propagation and Culture.-The acorns are generally procurel from the Continent, as the tree is propagated chiefly from seed. The rarieties are extended by grafting and layers. As the plants run very much to tap-roots, and are diflicult to transplant safely, nurserymen generally rear them in pots. By this method the roots are at the command of the cultivator, and the plant can be easily transported and safely transplanted at any time. No tree appears to be so difficult to transplant with success as the Holm Oak; for the roots go down so deep into the subsoil, and are so badly supplied with fibres, that the operation seldom succeeds without a very careful and systematic previous preparation. And of course anything that tends to prevent displacenent or disturbance of the mother-earth around the root-system will at the sime time help to make the transplanting more sure of successful issue.

Seed production begins very early with this species of Oak, for from alsout the twelftli or fifteenth year onwards acorns begin to be formed. It flowers in April or May, and the acorns ripen during the October of the same year. The fruits formed in Britain, even in warm seasons, cannot be relied on to have good germinative capacity and to be capable of regenerating themselves energetically.

(5.) THE SCARLET OAK, Quercus coccinea Willd.

Specific Character. - Leaves smooth, oblong, deeply and widely sinuated, on long stalks; lobes divaricated, acute, sharply toothed, bristle-pointed. Calyx of the fruit turloinate, half as long as the nut (Loudon, op. cit., p. 869).

Distribution. -This Torth American Oak has been long eultivated as an ornamental tree in this comtry, and is well known from its beautiful shining green leaves, which in early autum become of a brilliant scarlet. Its indigenous rimge extends from Florida and Texas to Missouri, Massachusetts, and Nora Scotia (Willkomm, 
op. cit., p. 418). This tree is very abundant in the State of New Jersey, United States, where in the autumn it forms a perfect glow of scarlet, giving a character to the foliage of the woods which is indescribable, and can hardly be imagined unless it has once been seen. It is also to be found in Canada along the shores of Lake Ontario, but it is not nearly so common there as in the Northern States of the Union. It was introduced into Britain in 1691.

Description of Tree.-The Scarlet Oak in America grows to a large size-sometimes, under favourable circumstances, to $8 \mathrm{U}$ and $90 \mathrm{ft}$. high, with a stem from $2 \frac{1}{2}$ to $4 \mathrm{ft}$. in diameter, according to the soil and situation. The bark is generally of a dark colour and very thick, and the wood, when cut up, is of a coarse description, and open in the texture. The leaves are generally of a large size, and vary much in shape; sometimes they are nearly entire, but may in other cases be very ragged. The latter form of the leaf is more generally to be found when the trees begin to grow old; whilst the former shape prevails throughout the foliage on young trees. The tree is of an open habit of growth, and is highly prized on account of the beantiful scarlet of its leaves in autumn. It is perfectly hardy in Britain, and on some favourable situations even forms stems of very considerable dimensions.

This species is very apt to be mistaken for another very closely allied North American species, the Red Oak (Q. rubra L.), the leaves of which also turn a bright red in autumn. The Scarlet Oak may, however, be recognised from the Red Oak by its deeply indented pinnatipartite leaves, whereas those of the latter are broad, with shallow sinuosities, and with pointed and coarsely toothed lobes. This latter variety is said to be very rapid of growth, to coppice well, to retain its bark smooth for a long time, and to be very rich in tannin; hence it might be worthy of introduction into Oak coppice-woods.

Economic Uses.-The wood of the Scarlet Oak is almost of no economic value: it is so porous and open of texture, even when old and grown in America in its natural soil, that it is not esteemed for any purpose except that of making staves for dry-goods barrels. It does not even make a fair firewood. This tree is therefore only cultivated as an ornamental object, and it is admirably adapted for this, as no tree can well be more effective in the autumn when its foliage takes on its scarlet hue.

Soil and Situation.-In Britain this tree thrives best on a rather light dry soil: on heavy cold clays it does not succeed. In America it grows on a great variety of soils,-even on the débris of rocks it may be found as a tree of fair size; but the best specimens are generally found there, as here, on deep, light, dry soils, with a warm and sheltered site. 
Propagation and Culture.-Like the Q. cerris, the fruit of the Scarlet Oak only ripens in the second autumn after the flowering. The acorns of this species are importerl from America, ancl raised in the same way as those of the British Oak. As stated above, this cannot be said to be a tree worthy of cultivation for the sake of its timber; still, as an ornamental tree, there is not any other that can even compare with it-except perhaps its own nenr relative the Red Oak-in the beauty of its foliage, and for this reason it may be recommended to the notice of arboriculturists.

\section{(6.) THE TURKEY or MOSS-CUPPED OAK, Quercus ceris L.}

SrNonxMs-Q. austriaca Willd; Q. crinata Lam.

Specific Character. - Leaves on very short stalks, oblong, deeply and unequally pinnatifid; hairy beneath; lobes lancenlate, acute, somewhat angular. Stipules longer than the foot-stalks. Calyx of the fruit hemispherical, bristly (Loudon, op. cit., p. S55).

In order to make this description more readily intelligible to the reader, Figs 7, 8, and 9 are given to represent the forms of the leaf, of the seed with its bristly calyx, and of the stipules on the young wood.

Distribution.-The Moss-cupped or Bitter Oak is a native of south-eastern and southern Europe, of Spain, France, Italy, lower Austria, and as far east as Turkey. It was introduced into Britain in 1735 .

Its northern limit of spontaneous growth has not been accurately determined, but probably extends from lower Austria to Moravia, and thence to the north-west part of the Jura in France (Willkomm, op. cit., p. 423).

Description of Tree.-This species is, like the common British Oaks, a deciduous tree, growing to about the same height-viz., from 50 to $100 \mathrm{ft}$., according to soil and situation. It is, howerer, a much more rapid-growing tree than either of these other two species, and is found to endure the climate, and to grow well in Britain. Standing singly in a park, it forms a fine spreading tree, with somewhat fendulous branches that droop slightly. It offers, therefore, an agreeable change, and is decidedly ormamental among other trees of a more upright habit of growth; but it does not resist storms or high winds well, and under such circumstances is rery apt to have its limbs injured and broken.

The Turkey Oak breaks into leaf, along with the Common Oak, about the beginning of Xay, and sheds its foliage towards the end of Oetolver. Its growth in height is completed much sooner than is the case with our two 
indigenous species, and as regards longevity it takes a much lower position than they occupy. It possesses a strong capacity for reproducing itself by means of shoots from the stool; but as the bark on these shoots soon begins to get rough and fissured, it is not so suitable for copprice-growth as the Common and the Sessile Oaks.

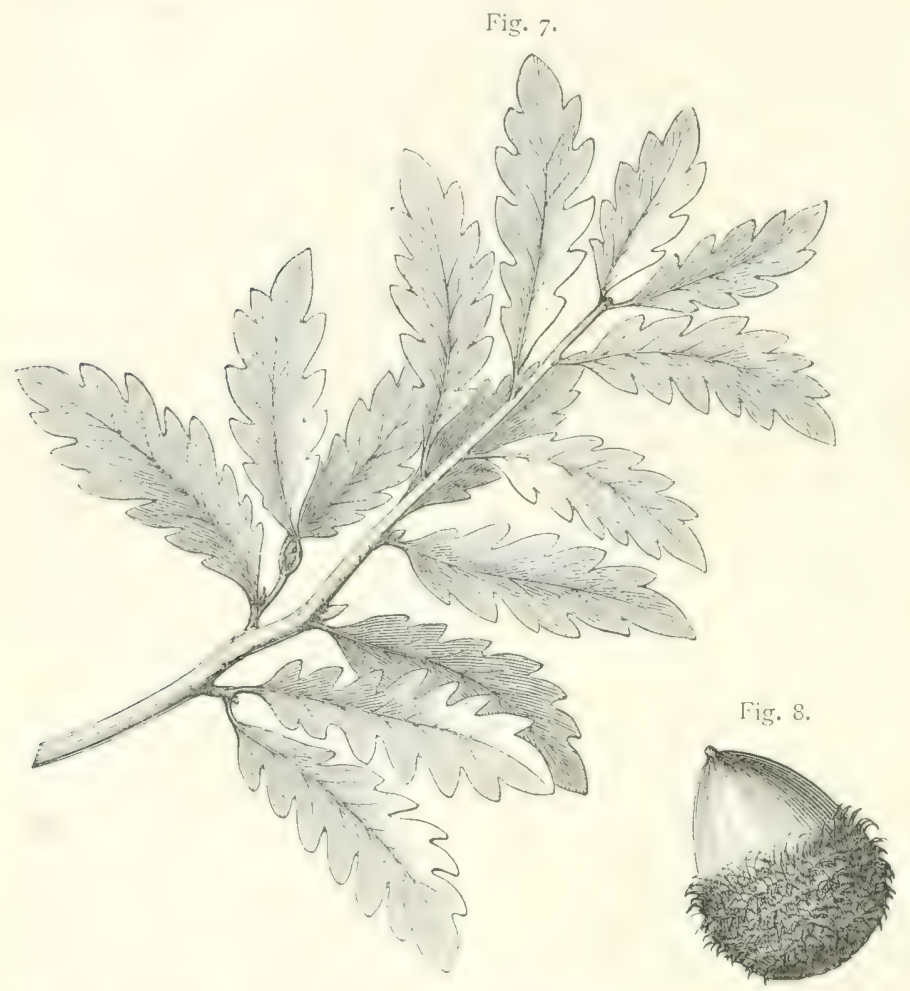

Foliage, fruitand antipules of the Turkey, Bitter, or Moss-cupped Oak (Q. cerris).

Economic Uses of Timber.-The Turkey Oak has not been long enough nor extensively enough cultivated in Britain to furnish a sufficiency of matured specimens of the wood for economic purposes, and therefore as yet practical experience can say but little as to its general technical qualities.

The timber yielded by it in central and southern Europe has Firs 0

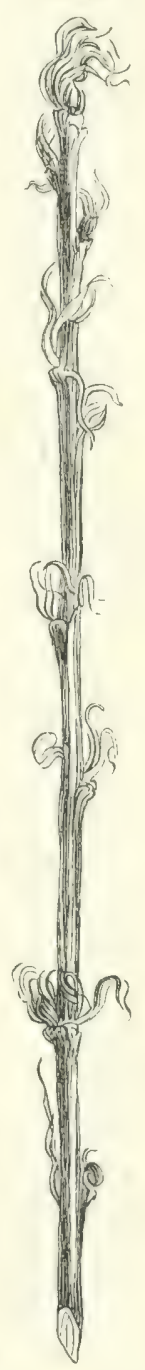
a sp. gr. of 1.10 when green, and 0.85 when seasoned, so that it is considerably heavier than that of either of our two British Oaks; indeed, with the exception of the Holm Oak, it is the heaviest of all native European woods, being on the average even heavier than the Yew. Experience throughout northern Germany is not in favour of the cultivation of this species of Oak in woodlands, for neither in quantity nor in quality of timber can it rival 
the Common and Sessile Oaks; and the same appears to hold good so far aBritish woodlands are concerned.

Experiments made with 'Turkey Oak, eut down in the work of thinning plantations in different places, and eut up and used for various purposes in connection with fencingr and other estate works, have in all cases shown the timber to he inferior for such purposes to that of our own indigenous species. It is said, however, that the maturerl timber of 0 . cerris is much finer in the grain than the wood of either of the British oalss. It is also said to take a better polish, and to be much more beautiful than those in the graining. It is adnitted, however, by most people who have seen the wood in its matured condition, to be inferior in strength to that of the British Oak, and when the tree attains old age the wood is very apt to get heart-shake. In Turkey the timber of this Oak is largely used in shipbuilding and in house-fitting. But so far as British Forestry is concerned, this tree can only be considered as of Arboricultural or itsthetic value; for Sylvicultural purposes it is of absolutely no practical importance as compared with our own native Oaks.

Soil and Situation. - The Q. cerris thrives well in most dry loamy soils; but in all cases, to grow the tree well, the land on which it is planted must be deep and dry. It thrives best on rather sheltered and warm districts, and worst on bleak exposures with a poor soil. In the comntries in which it is indigenous, the localities upon which it grows best are sunny exposures and deep stifi' soils, such as those formed of argillaceous loams and clayey limes; and though also by no means infrequently to be found on rocky ground and on sandy soil, yet the former situations are more essentially its true habitat.

Propagation and Culture.-The tree ripens its seeds, on the average of years, fairly well in Britain, and especially in the warmer midland and southern counties of England, where a supply may generally be had, and from which plants can be easily raised in the same way as those of the common British Oak. Plants raised from the seed are very apt to sport - that is, to run off into varieties somewhat different, either in leaf, in seed-calyx, or in the general hathit of the whole tree; and when a certain variety is wanted to be extended, it is generally increased by grafting either on stocks of the same species, or on the common British Oak. In fact, it is principally by grafting that this tree is propagated, as by this mode nurserymen and arboriculturists find they can produce the exact variety wanted: there are many of these grafts now in cultivation.

The Turkey Oak attains the power of reproducing itself from seed at an earlier age than either of our indigenous species, but does not seed so regularly. The moss-cupped acorns, however, do not ripen until the second 
autumn after the flowering. During the first autumn the young acom is about the size of a pea, and is enclosed completely by the cup or cupule.

On most estates of any importance in Britain the Turkey Oak is to he found planted in the parks, where, from its free exposure to light ant air, it generally attains a considerable size in the course of a few years. In England the tree is common not only in the parks, but also in many of the woods and plantations, where it thrives rapilly, and hecomes a tree of very considerable size within a period of forty years. In height and general dimensions at forty years it far surpasses the British Oaks of the same age, growing on the same land along with it; but notwithstanding this, it can never rival them in seneral or technical utility in woodlands formed and managed on a sound sylvicultural basis resting upon financial considerations.

\section{The BeECH, Fagus (Linnanan System, Moxecia Polyandria).}

Character of Genus.-Male flowers in stalked drooping heads or capitate catkins, 3 or 4 in each, attended by minute deciduous bracteas. Each flower consists of a 5-6-cleft bell-shaped calyx, and 8-12 stamens, that arise from the bottom of the calyx, and extend beyond its mouth. Female flowers borne 2-6 together,

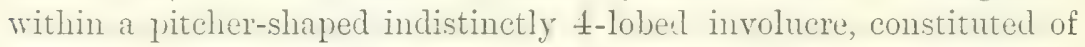
mmerous unequal bracteal scales, and interior scales, grown together. Each flower consists of a calyx, lengthened into a laciniate limb, and investing the ovary. Fruit, nuts (Loudon, op. cit., p. 905).

Ten species are known of the genus Fagus, but of these only one, the Common Beech, $F$. sylvatica, is indigenous to Europe. Three of them are natives of South America, one of North America, one of Japan, and four of New Zealand (Willkomm, op. cit., p. 435).

Of these ten species there are only two- $F$. sylvatica $L$. and F. fermuginea Ait.-described in our catalogues of trees, the former being the Common Beech of our woods, and the latter a native of Anerica, which is easily distinguishable from the European species by its leaves being larger and in shape rather like the leaf of the siweet-C'hestmut, from which argain it differs essentially by being pubescent or downy on the under surface. But there are also several varieties of the former in cultivation in our nurseries, of which the Copner Beech, F. sylutine utropurpuren, is best known, and mos frequently to be met with in parks and ornamental plantations. For sylvicultural purposes, however, reference need only be made here to the Common Beech, for it is the only species cultivated as a timber-tree in this country. 


\section{THE BEECH (Fagus syluatica I.}

Specific Character._Leaves ovate, glabrous, olsoletely dentate; ciliate on their margins (Loudon, ibid.)

Distribution. - The Beech is a native of most of the ternperate parts of Europe, from Norway southwards to the Mediterranean, and from Britain eastwards even to the Caucasian districts and northern Persia. It is plentiful in the southern parts of Russia. In Great Britain it is of native growth ouly in the southern portion of the island. Though not indigenous to Scotland or Irelant, it was extensively introdueed about the beginning of the eighteenth century. Its northern limit of spontaneous growth now lies in Scotland between latitude $56^{\circ}$ and $57^{\circ}$, whence it extends to $60^{\circ} 31^{\prime}$ on the west coast of Norway, and thence trends in a south-easterly direction. Its southern limit extends from Asia. Minor, through Greece, and along the Mediterranean coast to France and Spain. It is still to be found in a natural state of forest growth on many parts of central and southem England, particularly in Dorsetshire and Berlishire, and more especially where the land is of a limy description, such as on the chalk-hills in Wiltshire and Hampshire. Even in Scotland, the tree prospers well in all the southem and central parts of the country, and also attains very considerable dimensions in some of the milder more northern parts.

Description of Tree.-Except as regards late frosts in spring, the Beech is a very hardy tree-one of our hardiest; for in Devonshire, where some parts are much exposed to severe west winds, no tree appears to stand the storms so well, and that eren in high exposed situations and upon a poor, thin, gravelly soil. In mauy highlying parts of Scotland, too, where even the Scots Pine has failed upon a thin soil, the Beech can often grow and make an excellent shelter if growing within the vicinity of the sea-shore,-for an essentially insuliur climate seems very favourable to its levelopment. Hence it is an excellent tree for planting along the sea-shore as a protection for other more valuable forest-trees.

Besides the useful property of being a hardy tree, the Becch is also a very highly ormamental species, and is often found of dimensions far surpassing the Oak. When growing in the forest it rises generally with a clear stem; but in the open, although growing to a good height, it throws out many branches spreading almost horizontally, and drooping down to the very ground. When in full leaf, the tree has, owing to the leaves heing extended in the same plane as the shoots, and notwithstanding the actual density of the foliage, a somewhat light and airy appearance, which contrasts well with the rather heary and sombre aspect of the Sycamore or the Horse- 
Chestnut. In point of longevity, the Beech decidedly ranks below the Oak, the Chestnut, and the Elm, although under favourable circumstances it may attain an age of about three hundred years.

The Beech is a tree easily known from any other in the forest

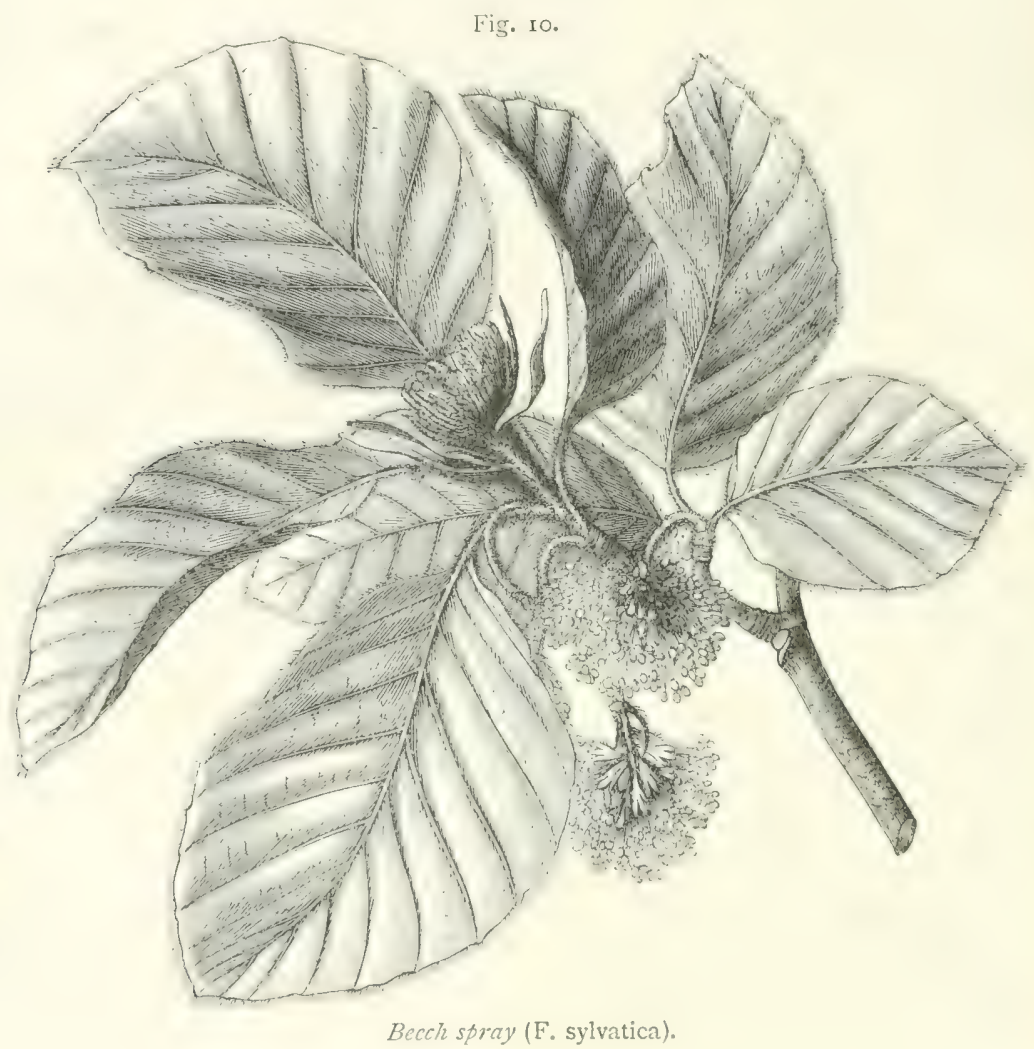

by its smooth grey bark and its light-green silliy leares (see Fig. 10). The leaves are what is termed ovate and obsoletely dentate, and whilst still young and soft are ciliated or fringed on the margin, although when fully developed the foliage loses all trace of this delicate fringe. The Beech in its young state generally retains its foliage all winter; but when it attains an age of from fifteen to twenty years, the leaves drop like those of any other deciduous tree. If the Beech be kept cut down in the form of a hedge, however, it retains its dead russet leaves all winter, so long as the plants flourish in a healthy state. This remarkable capacity for retaining its dead follirge thronghout the winter months characterises the Beech as the best of all plants for a hedge where shelter or privacy is the object, for it can easily be grown to a height of 10 or $12 \mathrm{ft}$. 
The young shoots of the Beech are numerous upon the larger branches; they are rather slender in appearance, and of a somewhat brittle texture (see Fig. 11). It breaks into leaf in April or May, about fourteen days in advance of the Common Oak, and flowers at the same time, the fruits or "Beech-nuts" ripening in the following autumn. It sheds its foliage about the end of October or in November; but until the fall of the leaf takes place, the Beech is one of the handsomest trees in the woods in autumn, when once its foliage has assumed its warm russet hues.

Economic Uses of Timber.-The Beech is not considered a timber of much value, as the wood is very brittle and short-grained, and not well adapted for purposes where strength and durability are required. Durability is, in fact, not its strongest point, except it be utilised in dry situations or entirely under water. If exposed to alternation of moisture and warmth, its wood soon becomes attacked by insects and by saprophytic fungi. At one time the wood of the Beech was much used for machinery, particularly by mill-wrights; but since the extensive use of iron in all machinery, the Beech is very little used for that purpose. When young, the wood of the Beech proverbially lasts for but a short time. Beechwood, however, when kept constantly wet, is remarkably durable, as is the case when it is made into water-wheels. But even if it be kept constantly dry, as in the case of roofing in a house, it lasts only a short time in comparison

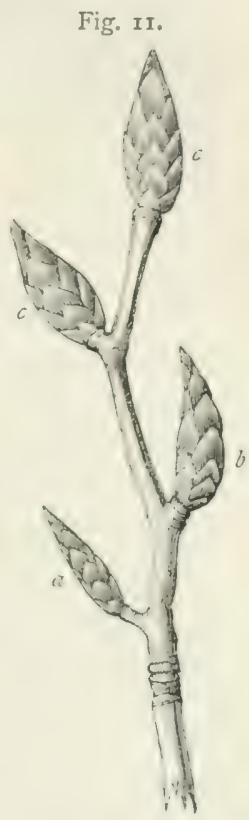

Young shoot of the Beech. a. Simple leaf-bud; $b$. Male flowering - bud ; $c$. Fenale floweringbuds. with many other sorts of timber. Beech, nevertheless, is still much used for the following purposes: framing for certain kinds of household furniture, panels for carriages, carpenters' planes, wooden bowls, granary shovels, and many small articles in turnery. It is also much used for making charcoal for colourmanufacturers, and large quantities of it are often utilised in this way.

On the Continent it is also used for carpentry work on stairs, parquetflooring, railway-sleepers, wood-pavement, bent-wood furniture (Austria), carts, and many parts of agricultural implements. It is also very extensively used as fuel for domestic heating, as its heating power surpasses that of most other woods. It has a specific gravity of 0.90 when green, and 0.71 when seasoned; hence if floating operations lave to be carriel out, some little time of seasoning will be requisite in order to obviate any risk of its getting waterlogged and sinking.

Soil and Situation.-The Beech will grow well on most dry or VOL. I. 
merely fresh, light soils occasionally refreshed by rainfall, or of a sandy nature, more especially if these rest on a subsoil of a loamy or marly nature; but it naturally attains its highest perfection on soils of a sumewhat limy description, without their being pure lime. On these classes of soil it often thrives well, even when they are so aryillaceous that they may be classified as heary and of a stiff nature; but in the humid insular climate of Britain, in which transpiration is not so great as in the drier climate of central Europe, it does not succeed so well on land at all of a wet character in either soil or subsoil. Shallow land or very rainy tracts are not the favourable soils for it to occupy. This tree assumes large dimensions on most kinds of land; lut the best and largest crops are usually to be found on a dry and rather light description of soil, haring a considerable proportion of lime or chalk. However, although this is the case in regard to the Beech, it is often found luxuriating, and forming excellent specimens and good quality of timber, upon lands of an opposite character-that is, upon a stiff clay land. From an arboricultural point of view the Beech is of a very accommodating nature with regard to soil, as may be seen from the many old Beech-trees about the seats of proprietors both in England and Scotland. But from the sylvicultural point of view this can hardly be said of it. In order that it may attain good density, and may continue in close canopy, so as to improve the soil with a rich fall of leaves annually, a decidedly better quality of soil is requisite than will sustain most coniferous crops.

Ebermayer's chemico-physiological investigations (Forstlich-naturwissenschaftliche Zeitschrift, 1893, pp. 230, 234) prove conclusively what is coincident with sylvicultural experience all over the Continent-viz., that the Beech, althnugh not making anything like the same demands amnually on the soil for mineral nutrients as the Ash, Italian Poplar, Elm, Lime, HorseChestnut, Maple, and Sycamore, nor even quite so much as Aspen, Willow, and Oak, yet can by no means be considered as being so easily satisfied as Birch, Alders, and the majority of Pines and Spruces. ${ }^{1}$

As to situation, although the Beech may be said to be one of the hardiest of our forest-trees, with respect to withstanding the blast of storms near the sea-const, still it does not develop itself to anything like large dimensions unless it is planted on sheltered tracts.

Throughout central and western Europe the Beech is to be found forming large forests in the lower hilly tracts beneath the various regions devoted to Silver Fir, Spruce, Scots Pine, and Larch. There it thrives better on the cooler northern and eastern aspects than on the warmer southern and western exposures. For, in the essentially dry Continental climate, freshness in the

1 Detailed information concerning the present state of knowledge regarding the FoodSupplies of Forest-trees will be found in Studies in Forestry, 1891, Chapter IV. 
soil is necessary to its best development, whereas in our more humid insular climate a dry soil is not prejudicial to its development so long as occasional showers may be relied on.

Any long-continued excess of soil-moisture is inimical to its thriving. Hence moist flat tracts on which the perlunculate Oak srows luxuriantly are not well suited for the Beech; and, fortunately cnough, the Beech is not usually required there for sylvicultural purposes, as the soil may be more arlvantageously utilised in cultivating mixed crops of Oak, Eln, Ash, Maple, and Sycamore, which may be underplanted later on, if necessary.

In localities exposed to frost, young seedling growth of Beech is apt to suffer a good deal unless protected either by parent standards or by nurses. Where, however, the soil is dry, the parent trees must be removed early, in order not to intercept the formation of beneficial dews at night.

Propagation and Culture.-Although it is endowed with a fair reproductive capacity of shooting from the stool, the Beech is usually propagated only from the seeds, or nuts, as they are commonly called, which are gathered when they fall from the trees in the mouths of October and November. Some nurserymen sow the nuts immediately in beds when they are gathered; but this is not the best plan, for when sown in the month of November, and lying in the earth all winter, the seeds are exposed to the attacks of mice and other vermin, which thin them very much, and of course cause a great deal of extra trouble in preserving them unhurt. A preferable method is, to mix the seed, when gathered, with a quantity of dry sand, previously prepared, and allow it to lie in that state till the month of March, when it may be sown upon a light soil, and covered with about one-half to three-fourths of an inch of earth; in this state the seeds will vegetate quickly. It is better to sow in rows than in beds. When in beds, the plants become so much crowded as to injure each other before they are ready for remoral; whereas in rows they have always room on either side, and may therefore remain strong and healthy until the time of removal. The plants should remain two years in the seedling beds before being transplanted into the nurseryrows, which latter operation may be carried out cluring any time from Norember till March when the weather is mild and open. When put out without shelter or murses in places that may be risited by late frosts in May, it is well to delay planting till the spring, as this interference with the normal action of the root-system delays the flushing of the new foliage, and consequently diminishes the danger from frost. The distance between the rows in the nursery may he about $1 \mathrm{~S}$ in., and the plants may he put in about $\pm \mathrm{in}$. one from another. When the plants have stood for two years in the mursery-rows, they will answer well for all purposes. While the Beech is in the nursery no pruning of the branches should be allowerl, as the plant does not 
stand cutting well in its young stages. I'ractically, no pruning should be performed on the Beech till the plants have become well estallished in their permanent sites. MIuch injury may be caused hy injulicions pruning of either roots or branches when the transplants are being removed from the nursery and planted out in the open ground.

Pruning of Beech.-Where some diminution in the number of foliagebearing shoots is requisite in order to maintain a due balance between the nutritive organs (roots) that have been more or less disturbed during the change of soil, and the assimilative and transpiratory orcans (leaves), then it is best to shorten the leading shoots. The lower side-branches should, however, be carefully preserved intact, as by shading the ground and tending to keep it cool and moist, they are important for the growth and thriving of the plants. Indeed, this curtailment of the leading-shoot is advisable in nearly all cases, except those introlving the use of large sturdy plants, and the pruningknife should be applied just immediately above a well-developed bud, in order that it may soon replace the leading-shoot removed.

Sylvicultural Qualities and Importance of the Beech.-During the present esseritially arboricultural state of Forestry in Britain, the true sylvicultural importance of the Beech can neither be immediately noted nor accurately assesised. Leaving out of consileration the mountainous regions of the Highlands of Scotland, where the summer is too short, and the total amount of warmth from May till October is too small to enable this tree to be of any sylvicultural importance, it can hardly be denied that throughout central and southern England the small seattered tracts maintained-more frequently for ornamental or sporting purposes than for timber-production based on financial principles alone-under woodland do not consist merely of the true forest-land,-- that is to say, of land that is only of such quality as to yield better permanent returns from woods than from arable or pastoral utilisation. On many of the existing tracts of woodland formed on fairly good soil, the ersential sylvicultural characteristics of Oak, Ash, Malle, Sircamore, and other light-demanding species of forest-trees are not so accentuated, nor indeed so clearly recognisable, as they are in the rast and excellently managed forests of France and Germany. The dampness of our climate generally, and the frequent showers that fall throughout the summer months, no doubt exert a considerable anom of influence in enabling these slecies of trees to maintain better canopy in England than in the dry climate of central Europe; but the difierences between the good fresh soil of ornamental frantations and helts of cover for game, and the less fertile soil of the higher uplands, and hills, and momitainous tracts, are punhahy of far more influence in obliterating important sylvicultural differences between the various species of timber-trees, and in obscuring our recognition of them. But whenever the day comes-and it may be close at hand on prudently administered estates of large acreage-for the poorer tracts of land returning to their original condition of woodlands, then these various sylvicultural differences are actual facts, the knowledge and recognition of which must be of exsential influence from the sylvicultural and financial ninciples which form the basis of modern scientific Forestry. Had 
the sylvicultural characteristics of the Beech been known, alyreciated, and utilised as they might have been, the Oak-tracts of the English State Forests in Hampshire and Gloncestershire, ic., would to-day undoubtedly possess a far higher monetary value than they at present actually represent.

Even in England over a century ago the anonymous author of Planting and Ornamental Gurdening; a Practical Treatise (London: Dorkisey, 17 s.t.), 1. 167), arrived at a practically correct estimate of the Beech as a sherte-loraring and sril-pirturting species when he wrote as follows, in the jart now printed in italics :-

"In point of actual use the Beech follows next to the Oak and the Ash; it is almost as necessary to the cabinet-makers and tumers (especially about the metropolis) as the Oak to the shipbuilder, or the Ash to the plough- and cart-wright. . . . The natural soil and situation of the Beech is upon dry, chalky, or limestone heights. . . . In situations like those, and where it is not alrealy pirevalent, the Beech, whether as a timber-tree or as an underumorl, is an object worthy the planter's attention."

All modern sylviculturists throughout the great home of Forestry, Germany, are agreed on the importance of the Beech in woodland tracts in which the productive capacity of the soil may be ultimately endangered by the free play of sun, when once the more light-demanding trees begin to show signs of broadening their crowns and lessening the density of their canopy after having completed their main growth in height. Only one quotation need be given as an example of what has been unanimously accepted on the Continent as a scientific sylvicultural truth with reference

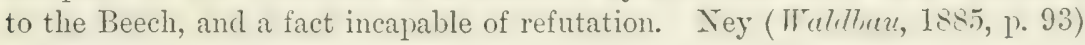
expresses only the general consensus of opinion in the following words:-

"Grown in pure crops, the Beech merely belongs to the more valuable class of trees through its natural power of protecting the soil; but in mixed woods this capacity of overshadowing the soil, and of improving it by a rich fall of leaves, becomes of very great importance. A suitable admixture of Beech enables all species of forest-trees to attain a much greater energy of development than when they are grown in pure forests. It conserves and protects the productive capacity of the soil better than any other species of tree, and may therefore well be termed the mother of the woods."

This fact of sylvicultural experience is accounted for by botanical and chemical specialists as due partly to the symbiotic action of root-fungi or Mycorhize (Frank), and partly to the great capacity of its root-system for contributing to the circulation of air throughout the soil, combined with its undeniable shade-bearing capacity, and its rich fall of leaves of an easily decomposable nature, yielding the very best quality of hum or leaf-mould (Ebermayer, op. cit., 1. 235; Ramann, Furstliche Budenkunde und strindertslehre, 1893, pp. 108, 302).

This indirect value of the Beech seems in Britain either to have remained umrecognised, or at any rate to have hitherto received less practical recognition than it really deserves for ultimate technical and financial considerations.

The Beech is usually grown from seed, or regenerated from parent standards, as its power of shooting from the stool is not so great as in many other species of trees. When grown along with Oak, it is usually cut out at about seventy to eighty years of age, being then reproduced from mast as an 
underwool for the protection of the soil until the standard trees attain their maturity about seventy or eighty years later on. When Ash, Elm, Maple, and Sycamore are grown along with it, they are generally utilised a few years before the regeneration of the Beech takes place; their removal stimulates seed-production in the Beech, and makes the natural reproduction of the latter easier than it otherwise might be, besides also in some cases obviating the necessity for artificial formation of underwood by means of sowing or planting.

As in all such mixed woods the introduction of the Beech is merely a means towards the better production of the more valuable species of trees in larger quantity, and of higher technical and monetary value, than they could attain if grown without its aid, it of course follows that throughout the whole of their life-period these species must be favoured during all the successive operations of weeding, clearing, and thinning. It is best to regenerate the Beech first of all, so as to form a matrix, and then to plant the different kinds of trees in small patches here and there, wherever the soil is best suited to their natural requirements. The means are thus given for securing for these more valuable species several years' growth in advance of the Beech; and during the natural process of development of the woods towards maturity, the axe must be frequently brought into play to protect those, whenever their ultimate value seems likely to be jrejudiced by encroachments of the latter, tending to restrict their enjoyment of a sufficient growingspace and of the requisite supplies of light and warmth.

For coppice, or underwood in copse, the Beech is only well suited when the soil is of a limy description, and the rotation falls between twenty and thirty years. But in the majority of cases in our existing woodlands, on good fresh soil and warm sunny situations, other kinds of coppice will yield better monetary returns than this species, for the market-value of Beech is unfortunately its weakest side. (See also British Forest Trees, 1893, pp. 162-185.)

The Beech attains a large size on suitable soils. In the chalk districts of England there are many Beech-trees of very large dimensions, especially in the parks of landed proprietors-some of them measuring upwards of $110 \mathrm{ft}$. in height, with stems from 4 to $6 \mathrm{ft}$. in diameter at $5 \mathrm{ft}$. from the ground. In many places in Scotland there are also fine specimens of the Beech, some measuring from 80 to $100 \mathrm{ft}$. in height, and having stems equal in diameter to most of those found in England.

\section{THE SWEET-CHESTNUT, Castanea (Linjean System, Monecia Polyandria).}

Character of the Genus. - Male flowers, each consisting of a 6-parted calyx, and 10-15 stamens, affixed to its bottom, and extended beyond its mouth. Flowers sessile, and disposed in groups along axillary stalks; each group consists of many flowers, and is involucrated by a bractea and a bracteole. Frmale flowers, consisting 
each of an ovary tapering to the tip, clothed with a calyx, and crowned by its $6-7-8$-cleft limb, and bearing as many styles, and having as many cells, with two pendulous ovules in each. The flowers are disposed 2-3, or more togrether, within a bell-shaped and externally bristly involucre. Fruit, $2-3$ nuts, included in a 4-valved involucre (Loudon, op. cit., p. 911, 912).

There are four known species of Chestnut, two of which belongs to North America, one to Japan, and one to Europe. Of these only two species are named in our catalogues of plants-viz., the Common Chestnut (C. vulgaris), a native of Europe, and the Dwarf Chestnut (C. pumila), which belongs to North America. The former species is much cultivated in many varieties on the continent of Europe, and especially in Italy and France, for the sake of its fruit. Reference need here only be made to that kind. It is a very ormamental tree, grows to large dimensions, and is very frequently to be found in coppice-woods throughout southern England. The other species is only a large bush, found in the Southern States of North America; and as it is of no sylvicultural importance, it need not be described.

\section{THE SWEET or SPANISH CHESTNUT, Castanea vulgaris Lam.}

Srnonyus-Fagus Castanea L. ; C. vesea Gaert.; C. sativa Mill.

Specific Character.-Leaves oblong-lanceolate, acuminate, mucronately serrate; glabrous on each side (Loudon, op. cit., p. 912).

Distribution. - The Sweet-Chestnut is found in the east and west of Asia, in the north of Africa, and also occurs plentifully in the woods of North America. It is found of true forest growth in some parts of Jtaly, France, and Spain; but it is evidently not a native of Britain, although it has been cultivated in the comntry from time immemorial.

According to Pliny, it was originally introduced into Europe from Testern Asia about 504 B.c. But so far as anything authentic is known, it appears to be indigenous to all southern Europe from Spain to Portugal, where it forms extensive forests eastwards along the Mediterranean lands and to the Caucasus. In the warmer regions throughout lower Austria, Croatia, and Dalmatia, it also forms large timber-forests. In the extreme southern lands of Europe it is a tree of the mountains, and has there a lower as well as an upper limit.

Description of Tree.-This is a tree which, in a favourable situation, attains large dimensions, and frequently surpasses the Oak in this respect. When grown in an open park or lawn, it is a highly ormamental tree, its general appearance at a distance very much resenbling that of the Oak. In the autumn, when its leares take on a rich golden yellow colour, it has a beautiful effect among other trees 
of darker foliage. Cultivated under these favourable circumstances, it also lives to a great age. As a timber-tree, growing in close forest canopy, however, it falls far short of even some of our secondary trees. It does not usually attain large dimensions, unless it has the advantage of a good loamy soil and a sheltered situation; it is therefore not generally adapted for planting out as a forest-tree in any exposed situation or upon an indifferent soil.

The foliage of the Sweet-Chestnut is full upon the young wood, and has a very fine effect in the early part of summer, as well as

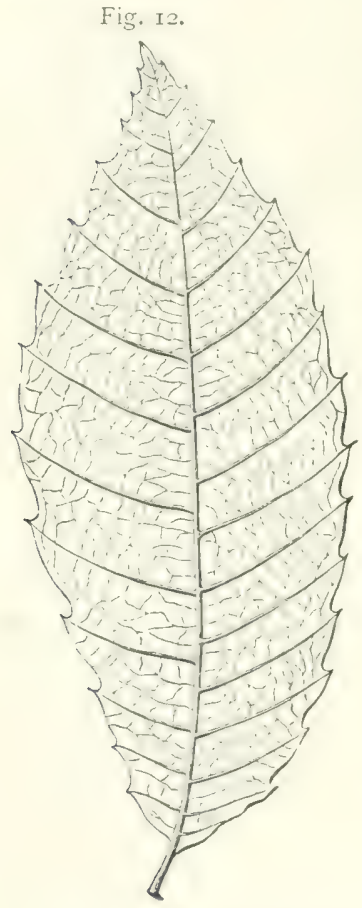

Leaf of the Sweet-Chestnut (C. vulgaris). in the autumn, when it begins to take on the yellow tinge. The leaves are by botanists termed oblongo-lanceolate, acuminate, and mucronately serrated (see Fig. 12). When young, the tree grows very rapidly, and soon attains a large size; but it seldom arrives at the age of sixty years without becoming ring-shaken in the heart-wood, and consequently almost useless for any technical purpose. It is, however, excellently adapted for coppice-woods; and in all districts where there may be a demand for hop-poles of various sizes, the Sweet-Chestnut pays well in the form of coppice. It readily throws up a succession of young shoots from the stools when cut over, which grow very rapidly for the first eight or ten years, frequently at the end of that period producing shoots of from 4 to 5 in. in diameter, and from 20 to $30 \mathrm{ft}$. in height, and these, too, are very numerous round the stoles.

Economic Uses of Timber.-The wood of the Sweet-Chestnut is generally found good and sound, and available for many useful purposes, up to the age of about

sixty years; hence it is well adapted as a secondary tree, or one which is grown for a time among others which may be meant to stand as the ultimate crop upon the ground. The rood of the Sweet-Chestnut is undoubtedly very durable. For gate-posts and general fencing purposes it answers excellently; and even for cart and waggon shafts it answers well when from thirty to forty years' old, besides being useful for many other purposes. In North America, where this tree is plentiful and of large dimensions, the wood is much used for fencing and house-building, and for these purposes no other wood is better suited. In Canada fences may be 
seen made of this wood, which, after having stood exposed to the weather for upwards of twenty-five years, appear as goorl as they were at the time when they were put up.

Throughout central Europe the wood of the Chestnut is principally used for the manufacture of staves for casks, and large cuantities of it are thus utilised in the warmer wine-districts along with Oak.

It ranks along with the more durable classes of timber, and when used as posts in the ground is said to be more durable than even Oak or Acacia. It has a mean sp. gr. of 0.99 when green and 0.66 when seasnned, so that with regard to weight it stands on about the same level as the Sycamore and the Birch. In England, however, its timber-producing capacity is of far les. importance than its suitability for coppice-growth. Whilst the stronger growtlis of coppice-poles will yield good material for hop-poles and the like, young shoots yield very good hoops for casks, drc.

Soil and Situation.-The Chestnut requires a deep and dry sandy loam in order to thrive well. It does not succeed on stiff clays, nor on any cold-bottomed lands; but it grows well on most dry-bottomed lands, if they are well sheltered, although not rich. Excellent crops of Chestnut timber may even be seen on lands of a stony and gravelly nature, which are poor but well sheltered and warmly situated. In Britain, a sheltered site and a dry-bottomed soil is certainly the class of land that is required for the profitalile growth of the Sweet-Chestnut.

Continental experience shows that the soils most favourable to the Chestnut are those of a light, deep, fresh, or moist character, which need not be possessed of any great amount of mineral strength, but must not be wet. Warmth of climate is essential to its normal development; hence its cultivation will be most remunerative in the central and southern counties of England, particularly as underwood beneath crops of Oak that are being held orer to thicken in girth. It thrives best on soils rich in potash, but according to Fliche's investigations (Annales de la Stution agronomique de l'Est, 1878), even a very slight percentage of carbonate of lime throughout the soil affects its development. Lands of a sandy or loamy character are therefore better suited for Chestnut than those of a limy nature, where Becch, Maple, and sycamore find specially favourable conditions for thriving as underwood.

Warm southern exposures or undulating ground best answer its undoubted demands with regard to temperature. Toung plants are apt to be damaged by late frosts; but, with the strong reproductive capacity of this species, the damage done is not permanent.

Propagation and Culture.-The Sweet-Chestnut is propngated in exactly the same manner as the Oak. What has been said relative to the Oak is therefore generally applicalule to the Sweet-Chestnut; but with this exeeption, that the C'hestnut is usually, when young, of more rapid growth than the Oak, and is 
therefore ready for transplanting out into the forest after having been two years in the nursery rows. It may be remarked here that the nuts of this tree are procured from America, and from France, Italy, and Spain, as they seldom ripen in Britain so as to attain good germinative capacity. As the nuts are large, they should be sown more thinly than the acorns of the Oak, and should also lie covered rather more deeply, say not less than fully $1 \frac{1}{3}$ to $2 \mathrm{in}$.

Sylvicultural Characteristics and Importance of Sweet-Chestnut. -Although in general the Chestnut has much in common with its close relative the Oak, yet it can thrive with less light, and in this particular respect it certainly has more in common with the Beech than the Oak. Thus, if grown in high-forest, it remains long in close canopy; but the stems only assume a large girth when grown in the compratively free enjoyment of light, air, and warmth.

But in Britain its sylvicultural importance is entirely confined to its favourable characteristics as coppice-growth or underwood. In power of producing shoots from the stool it is equalled by no other forest-tree, as stools of any age up to 100 years yield a good flush of strong shoots. As is also the case with the English Elm, the Chestnut is thus compensated by nature for its poor production of seed in our climate, by being enabled to throw out stoles and root-suckers as well as stool-shoots, the former of which can easily be transplanted, and can develop normally into sound trees caprable of attaining a great age.

On somewhat poor soil the Chestnut yields as coppice perhaps higher returns than any other kind of sylvicultural crop. When pure coppice of this species has been formed by sowing or planting, it should be cut over for the first time at ten years of age, in order to strengthen the stools; and if worked thereafter at a rotation of fifteen years, it yields a good return in stout poles, where such can be favourably disposed of. Where smaller material finds a good market, there is less danger of the soil deteriorating under this than under most other kinds of coppice-crops; for it yields a good annual fall of foliage forming good leumus, shoots vigorously from the stool, and keeps the soil cool and moist by its thick canopy of foliage. For climatic reasons, however, the Chestnut can only be expected to yield its best results in the warmer tracts of England, where its cultivation should receive much more general attention than has hitherto been paid to it by landowners.

Sowing of the seed should take place only in spring, in order to minimise the danger from mice, birds, dc., and also to obviate damage by late frosts to a certain extent. For the formation of underwood, dibbling in of the nuts at $2 \mathrm{ft} . \times 2 \mathrm{ft}$. or $3 \mathrm{ft} . \times 3 \mathrm{ft}$. is often a cheap method. But except when large supplies of fairly good seed can be got near at hand (as, for example, during 1893), planting has in many cases decided advantages over sowing: In order to effect the operation as cheaply as possible, yearling seedlings and two-yearold plants are often put out into the woods, whilst older material must first be transplanted into nursery-beds for two or three years.

The seed is sown in rills about $1 \mathrm{ft}$. apart in the nursery-beds, each seed being inserted point downwards at a distance of from 3 to $4 \mathrm{in}$. in the rill, and 
covered up with about $1 \frac{1}{2}$ in. of earth. At one and a half, two, or two and a half years of age, these seedlings are removed and put out in the forest. Owing to the early movement of sap in spring, many prefer that the planting out should take place in autumn; but where late frosts are to be feared, early planting in spring is preferable. Owing to the higher costs entailed, the use of transplants, that have been put into the nursery-beds at one or two years of age, is confined to the filling of blanks in young plantations, or to the rearing of material for ornamental plantations. Care should be tiken not to plant Chestnut too deep.

The reproductive capacity of the stools may be stinulated by felling low, and by heaping up earth on them.

It would be superfluous to name the dimensions of this tree on particular places, as there are few old wooded parks in Britain which have not their fine ornamental specimens of this species as well as those of the Oak. Under favourable circumstances of soil and situation the tree attains an average height of $70 \mathrm{ft}$, with stems of from 4 to $6 \mathrm{ft}$. in diameter. There are many specimens of much greater dimensions in various places; but these figures may be taken as about the average growth attainable by the tree under farourable circumstances.

\section{OLEACEA LINDL.}

To this comparatively small family belong the Ash, the Lilac (Syringa), the Privet (Ligustrum), and the Olive-tree (Olea).

\section{THE ASH, Fraxinus (Linnean System, Polygama Drecta).}

Character of Genus.-Flowers polygamous. Calyx none, or 4-parted, or 4-toothed. Corolla none. Stamens 2, in the male flowers. Anthe's sessile, or on short filaments, dehiscing outwardly. Female floxcers the same, except that they have no stamens, but liave each a pistil that has a bifid stigma. Fruit, or samara, 2-celled, compressed, winged at top. Cells 1-seedeci (Loudon, op. cit., p. 639).

There are about twenty-five to thirty distinct species of the Ash, the greater number of which are natives of North America, though many of them are chiefly to be found in Central and Western Asia and around the basin of the Mediterranean Sea; but of all of these, only one is indigenous to our country, or throughout Central and Northern Europe generally, the Common Ash (Fracinus cucclsior). The others attain, even under the most firourable circumstances, very inferior dimensions as compared with our own indigenous Common Ash, which, besides being a native of Britain, is one of the most useful of our hardwood timber-trees for general purposes. And only that species need be referred to here, as mone of the other sprecies is adapted for the cultivation of useful and profitable timber in our climate. 
It may be remarked that the leaflets of the pinnate leaves are borne on small petioles or leaf-stalks in most of the North American species; whilst they are sessile in all the European species.

\section{THE COMMON ASH, Fraxinus excelsior L.}

Specific Character.-Leaflets almost sessile, lanceolate-oblong, acuminate, serrated, cuneated at the base. Flowers naked. Samara obliquely emarginate at the apex. The leaves have generally five pairs of leaflets, but sometimes six. The flowers are produced in loose spikes, from the sides of the branches. On some there are only female flowers: on others, hermaphrodite ones; and on others, male ones; while on some trees the flowers are found in two of these states, or in all of them (Loudon, op. cit., pp. 639, 640).

Distribution.-The Common Ash is indigenous to Sweden, Norway, Russia, and the south of Europe, and is said to be found also in the north of Africa. In Britain it is found growing naturally over the whole length and breadth of the country, from the north of Scotland to the south of Eugland; and though it only thrives well as a timber-tree on good deep soil, it is far from seldom to be met with on exposel sites and poor soils, throughout tracts like the Highlands of Scotland.

According to Willkomm (op. cit., p. 66t), the northern limit of its spontaneous distribution extends from $63^{\circ} 10^{\prime}$ in Norway to $61^{\circ}$ in Sweden, and $62^{\circ}$ in Finnland, trending thence to the south-east across central Russia to Rjäfan, whence it strikes north-east again to Kasan, where its eastern limit begins, and continues in a south-westerly direction across the steples and by a circuitous curve to the Crimea, where its European limit ends; but in the Transcancasian districts it begins asain, and continues eastwards into central Asia. Its southern limit runs from Asia Minor to Turkey, thence across the Adriatic, Italy, and southern France to the Pyrenees and northern Portugal. This proves that, so far as climate is concerned, the Ash must be a species that can stand not only extreme winter cold, but also a very high degree of summer warmith, although in low-lying moist localities it recuires nurses to protect it against late frosts, and in this respect is very sensitive.

Description of Tree.-The Common Ash is undoubtedly one of the inost graceful and beautiful of our forest-trees, whether it be found in a plantation, or along hedgerows, or only in a park. Many object to the Ash being introduced into modem landscape on account of the lateness of the tree in coming into leaf: this generally takes place about the end of May or the first week of June, by which time most other trees are in almost full leaf, whilst the Ash is standing alone bare, and apparently lifeless. This objection seems to be superficial, anl comparatively trivinl. This rery peculiarity might rather 
serve to rive the tree an additional interest which is nort to be found in any other species; for what is more pleasing to the eye, and sugrestive to the thinking mind, than to see, at a time when all other trees are in full leaf, the Ash first swelling its large black burls, and unfurling its leaves to the summer's sun? Another objection formed against the introduction of the $A$ sh into the park is, that it is the first tree to lose its leaves in the autuinn. This is indeed true; for the first touch of frost at night brings down all the leaves at once. But even when the tree is newly stripped of its leaves, its appearance here and there as a leafless naked tree contrasts picturesquely with the masses of more or less witheren and sickly looking foliage upon the neighbouring trees. Apart, however, from the lateness of the tree in coming into leaf, and its being suddenly stripped of its foliage early in the autumn, the Ash is to be admirerl as a stately and graceful tree, and as one well wortliy of a place in every British landscape. The foliage of the Ash is pinnete,-that is to say, it has a compound leaf having leaflets arranged on each sile of a central stalk or midrib; and, as already remarked, these leatlets are sessile on the Common Ash (see Fig. 13), althongh petiolated in most North American species; whilst the young shoots are fluttened, of a very brittle texture, and are furnished with very prominent dark-coloured buds which deepen almost into black during the winter months (see Fig. 14). The foliage is of a very soft and heantiful light-green colour, with just a suggestion of blue in it, whilst the leaves are still young.

The natural habit of the Ash is that of a tall tree of first-rate magnitude, but inclined to run to height rather than to great girth of stem. In plantations of even a moderate density this tree is extremely apt to develop a great height, and to form a smooth, clean, cylindrical stem, though without assuming a girth proportionite to its height. But even when the plantation in which it grows is liept rather thin and airy, any excessive formation of side branches may easily be checked, and excellent tall timber be formed; for the Ash is one of the essentially light-demanding trees which are impatient of side-shade. When growing in a park or open lawn, the Ash forms a large-headed tree of imposing effect; and in this case a large stem is generally formed, quite in proportion to the massy top.

One of its very distinctive characteristics as compared with the senerality of other forest-trees is its tenlency to forked growth, time after time, as may easily be seen hy following along the main branches from their hase towards the youngest growth of twigs. This arises from the fact that the shoot within the terminal bud often gets nipped by frost, whilst the buds which olen later are spared. Its growth in height is most energetic between the twentieth and fortieth year, and its increment in girth greatest during the succeeding twenty 
year's; its sylvicultural maturity is reached about the age of sixty to eighty years, after which its increment is unsatisfactory from a financial point of view, and undesirable also for purely sylvicultural reasons.

Economic Uses of Timber. - There is, perhaps, none of our forest-trees the wood of which can be applied to so many different useful purposes as that of the Ash. As to its toughness and elasticity, no timber grown in our woods can be compared to it.
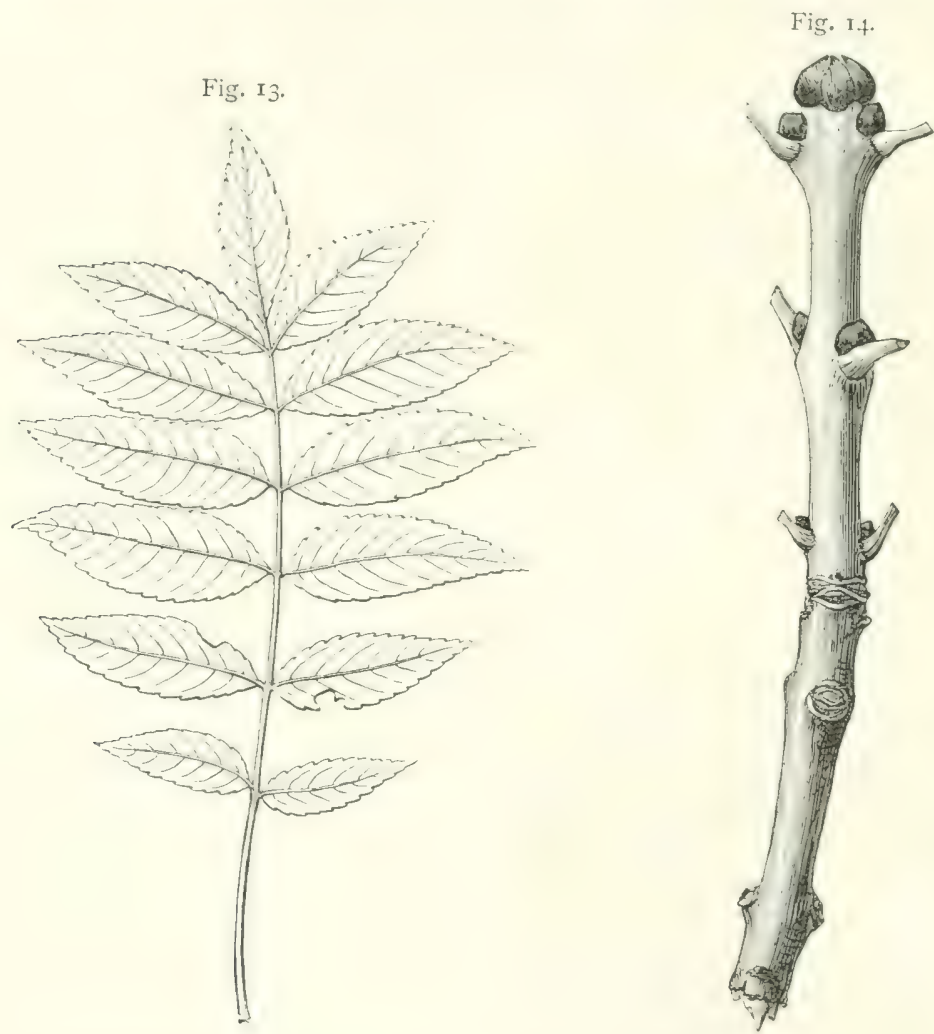

Pinnate leaf of the Common Ash (Fraxinus excelsior), and twig showing the buds.

As an example of this property, it is only necessary to look to the articles made from it by the sievewright and the basket-maker, in whose hands Ash-wood bends like a piece of wire. The value of Ash timber is always increased by the rapidity of its growth; and there can be no doubt whatever that the late flushing of its leaves in slring, though objected to hy some from the arboricultural point of view, adds greatly to the compactness and general quality of the timler; for loy being delayed until warm weather has thoroughly set in, the processes of absorption, assimilation, nutrition, and formation 
of woody-fibrous tissue are carried on more energetically, and more thoroughly, than could possibly be the case with a less degree of warmth and a less favourable intensity of light. Its highest technical utility is attained whilst the tree is still comparatively young-ie., not much over sixty years of age. It has rather a high sp. gr., as it loses but little weight in seasoning. According to Gayer (Forstbenutzung, 1888, p. 27), its sp. grr. is 0.88 when green, and 0.75 when seasoned. It will therefore float easily, even immediately after being felled, but is ultimately of practically about the same weight as Oak. The timber is much in use by the conchmaker and cartwright, and in many parts of agricultural machinery $A$ sh is still much used. It is particularly valuable, in its young stages, for hoppoles, hoops, crates, handles, and for fencing-purposes; and in many parts of England Ash-coppice is cultivated to a large extent for crate-wood, for packing up articles manufactured at the potteries. On the Continent, where it is grown in high-timber forest to a greater extent than in Britain, it is also used largely for cabinetmaking; because, owing to its forked growth, this tree often supplies wood with a very beautiful grain.

Soil and Situation. - As might be expected from its extensive spontaneous distribution, the Ash is in all respects a hardy tree, and accommodates itself to most soils and situations not too high-lying and exposed. But to grow it so as to attain to large dimensions of timber, and to have the wood of good quality, the tree should be planted in a rather low-lying situation, and on a strong loamy soil, though not of a retentive character. Nor is any situation favourable which has a wet subsoil; for although the Ash thrives with a considerable degree of soil-moisture, still the land on which it grows best is in all cases found to be porous, deep, and free from stagnant water in the subsoil.

In other words, in order to attain its highest development, it should, if possible, be planted out on a fresh, deep, light, loamy soil ; and it will thrive all the better if the soil contains a fair admixture of humus, or leaf-mould formed from the dead foliage annually cast to the ground. On binding argillaceous soils, or on dry porous sand, it is apt to develop indifferently, and to show early signs that the situation is unfarourable to its normal requirements in nutrients and moisture. Recent investigations made by Elyermeyer (Forstlich-neturmissenscheftliche Zeitschrift, 1893, 1. 2.30) have shown that is regards mineral food it is the most exacting of all our forest-trees. With regard to the quantity of water required to maintain a normal rate of transpiration through the foliage, it also exhibits far higher demands than the majority of our woodland trees; and it is in consequence of this, that the foliage dries ur and falls off more quickly in autum than is the case with most other trees.

There is no situation so well fitted for the profitable growth of 
the Ash as the sides of ravines where there is a good strong loamy soil, and where a constant supply of water for the roots percolates gradually downwards from the ground above; and even in such cases the best and largest trees will be found on the lower parts, where there is most shelter and the strongest soil. In damp lowlying localities it is anything but hardy with respect to late frosts, being one of the species most apt to suffer injury therefrom. In such situations it may even require the aid of nurses for the first few years; but when it is planted out in fresh uplands, where the circulation of air is freer, its lateness in bursting into leaf usually affords it ample protection against late frosts about the middle of spring.

Propagation and Culture.-The Ash is propagated by seeds, and varieties are extended by grafting and budding on plants of the same species. From about the fortieth year onwards, and earlier in trees growing in the open, the Asil seeds freely and almost annually. The seeds are enclosed in what is termed samaras, or winged dry fruits, forming bunches of "keys," which are generally ripe for gathering about the end of October.

If left on the tree they often hang there throughout all the winter, until the following spring, or even into the summer months. If sown in autumn, they sometimes germinate in the following spring; but if left to fall from the tree, they usually remain for a whole year or longer before being called into germinative activity. Hence it is generally advisable to store them for a year, so as to increase their chance of germinating soon after being sown.

When gathered for the purpose of being stored, and then sown out in the nursery, the seeds should be mixed with a quantity of dry sand or light dry earth, in which they should be kept for about eighteen months, so as to rot off the outer coat; and in order the more effectually to ensure this, the whole mass of seeds and sand should be turned once every three months. This mass of sand and seed should not be much over $1 \mathrm{ft}$. in depth, as, if more, it will be liable to become heated, in consequence of which the vitality of the seed would be injured. In the second March after they are gathered, the seeds should be sown rather thinly in rows, and upon any moderately well-pulverised soil. They are then almost sure to come up thickly, and perhaps even to interfere with one another, if not sown thin-say one seed to every 3 sq. in.; the covering of earth given to them should not exceed $\frac{1}{2}$ to $\frac{3}{4}$ of an inch. In the following spring the plants will be ready for being transplanted into the nursery-rows; these should be about 15 in. apart, whilst the distance from plant to plant in the rows should be about $4 \mathrm{in}$. When the plants have stood two years in the nursery-rows, they may be removed and transplanted wherever required; but if wanted of a 
larger size, they may he left a year longer. Though the growth in height during the first year is slight, it hecomes rapid from the second year onwards.

The Common Ash can hardly be classed as one of those species of trees which attain any very great longevity. Yet, even in this respect, it excels several of our other indigenous trees. For there are many instances of it having attained an age of over 300 years in several parts of the country; and upon many estates there are Ashtrees known to be upwards of 200 years old, and yet apparently still in healthy growth. In England there are many fine specinens of Ash; for example, at Longleat, in Wiltshire, there are several trees having clear stems of nearly $50 \mathrm{ft}$., and measuring from 10 to $14 \mathrm{ft}$. in circumference. In many other places, both in England and Scotland, there are fine specimens of old Ash-trees, some of them measuring from 15 to $20 \mathrm{ft}$. in circumference, and bearing a proportionate crown of foliage.

The leading Sylvicultural Characteristic of the Ash is emphatically the great demands it makes with regard to the undisputed enjoyment of light - a characteristic plainly exhibited in the thinness of its foliage and the lightness of its crown. Hence it is little suited for the formation of pure forests, or even for forming large groups or patches of trees of its own species, whether raised from seed or from stool-shoots or suckers. This characteristic is lerhapss not so strongly marked in Britain as on the Continent, from the fact that this tree is most frequently to be seen under the circumstances highly farourable to its growth - that is to say, on moist tracts, or as a hedgerow-tree on good soil at the edge of fields (where, however, it robs the agricultural crops of a good deal of nutriment with its network of shallow surface-roots ramifying throughont the up'per layers of the soil); but it is nevertheless a sylvicultural fact, which will have to be reckoned with wherever woodlands may ultimately be formed on rather poor qualities of land, that have been thrown out of agricultural or pastoral occupation. And there are now in Britain many such tracts that may soon revert once more to their original form of forest land, in order to bring in any revenue at all to the owners.

On the whole, the normal demands made by the Ash for light are greater than those made by the Oak; but as it is generally cultivated only on better and fresher soil, these are, as already remarked, not always so easily distinguishable, for under such favourable circumstances all light-ilemanding species of trees are less intolerant of shade. Its proper position is therefore that of a subordinate tree scattered simply throughout a matrix of other trees of somewhat slower growth, and hetter ahle to protect the soil against deterioration. On hillsides there are many places near the small water-courses where a good and profitable growth of Ash may be encouraged; whilst on good, but rather moist, low-lying soil it can often give fair returns when grown along with Oak, Maple, Sycamore, and Elm, or even with Willows and Alder on land of a wet description. In such localities the trees not only lave a thicker cromn of foliage than on land containing a less amount of soil-moisture, but at the

VOL. I. 
same time there is less danger of the soil becoming deteriorated through the evaporating action of sun and wind. When grown along with the Oak on fresh soil, the Ash should be cut out about the sixtieth or seventieth year; for just about that age its sylvicultural maturity is attained, whilst at the same time it is usually necessary that underplanting should be carried out with a riew to the future development of the Oaks. Not infrequently on such tracts - and more especially if there be a good fall of dead leaves covering the soil-the Ash, Sycamore, and other trees, being cut out and utilised, throw up a sufficient crop of stool-shoots and stoles or root-suckers to obriate any necessity for the artificial formation of an underwood of Beech, Hornbeam, and the like; these, however, are signs of the better classes of soil only, and not many such tracts are utilised to their best advantage if still retained under woodland.

The Ash is in every way suited to be grown as standards or overwood in copse, and in such situations soon attains good development. Among the underwood, when not overshaded heavily, it also yields good returns, and reprotuces itself easily by shoming from the stoul, or less frecunently by throwing out stoles or suckers from the surface-roots.

On wet soils, where the common Alder forms the ruling species, the Ash can often be treated in very much the same manner as Oak grown along with Beech, and can then often be introduced in larger numbers than would otherwise be prudent on soils of a drier nature. On such marshy land the Alder may be coppiced, whilst the Ash remains as a standard, to thicken into dimensions of greater technical and monetary value. In other classes of forest formed of broad-leaved species of trees, the Ash should merely be sprinkled individually among other trees more capable of protecting the productive capacity of the soil. In such cases, and in fact wherever it is intended to allow it to derelop into the larger dimensions of timber, it is advisable to introduce it of seedling growth only, as stool-shoots or suckers, though soon developing their independent root-systems, culminate earlier in growth than plants raised from seed. At first young seedling transplants require careful protection against rank growth of grass and other weeds; but as they rapidly shoot up when once they have established themselves in the ground, weeding and clearing operations are soon no longer requisite. Endowed with a strong recuperative powrer, the Ash quickly outgrows injuries received from cattle, dc.

\section{ULIIACE E MIRB.}

This family consists of eight genera; but only one of these is represented in Europe, as all the others belong to tropical lands.

\section{The Elir, Ulmus (Linx.eax System, Pextaxdria Digyxia).}

Character of Genus.-Flmips in lateral groulss, proceeting from leculiar lumis, and protruded lefore the leares; bisexual; moncecions. Calys reddish, distinct from the ovary, top-shaped or bell-shaped, of one piece, but having 5 or 4-8 segments, which imbricate in xstivation; remaining until the fruit falls. Stamens as many as 
the segments. Style, short or wanting. Stigmas, 2, acuminate. Fruit, a samara, with a membranous wing (Loudon, op. cit., p. 715).

There are several species of Elm, from the dwarf sort, Ulmus pminila, a native of Silheria, which grows only to about $t \mathrm{ft}$. in height, to the Clmus compestris, or English Elun, which often grows to the height of $100 \mathrm{ft}$. There are also several species, natives of North America, which in their native climate form large trees, but which are not suited for cultivation as timber-trees in Britain, though occasionally to be met with as ormamental specimens of their kinds in our pleasure-grounds. In the Continental forest literature there is a great want of unanimity in the nomenclature of the Elms, and, indeed, no small amount of confusion about the matter. But, as Purkyne conclusively proved, only three species of this genus occur of spontaneous forest growth, and all the others are mercly varieties or hybrids. These three species are, $U$. campestris Sm., $U$. effusa Willd., and $U$. montance Sm., all of which appear to have been originally comprised within the species $U$. campestris L. And as it not infrequently happens that certain of the characteristics of these three species are interchangeable, it seems of more practical utility to confine our attention to the hroader generalisation of two species only in Britain showing anything like more or less constant and characteristic differences. Hence reference need here be made to two species only-(1) the Ulmus campestris Sm. and (2) the $U$. montenu sm.-as these are certainly the only two incligenous species of anything like sylvicultural importance in Britain.

\section{(1.) COMMON ENGLISH or SMALL-LEAVED ELM,}

Ulmus campestris Sm.

Specific Character.-Leaves doubly serrated, rough. Flowers nearly sessile, 4-cleft. Samara oblong, deeply cloven, glabrous. . Flowers brownish; March and April. Samara yellow; ripe in May (Loudon, op. cit., p. 716).

The English Elm is easily distinguished from the $I^{2}$. montanu, or Sicots Elm, by having the young shoots of a slencler form, and those of the last year springing alternately from each sicle of the preceeling young shoots (see Fig. 15). The leaves also all spring from the roung shoots in an alternate mamner; and when these are off in the winter season, the slender and irregular appearance of the young wood contrasts beautifully with the rugged appearance of the bark upon the old wood, and gives the branches altogether a light and airy appearance. The leaves (Fig. 16) are small as comprared with those of the $C$. montance (Fig. 1S): they are iloully serrated, rough and hard to the touch, of a beautiful dark-green colour, and usually more 
unequal at the base, although such inequality is a particular characteristic of all the different species of the Elm.

Distribution. - The $U$. campestris is indigenous to the central and to the southern parts of Europe, in which latter localities it is said to be the only indigenous species, and where it certainly attains its highest development. It also occurs spontaneously throughout the whole of southern and south-eastern Europe around the Mediterranean, in Spain, in Algiers, and in Asia Minor, whence it extends eastwards into southern Siberia and the regions drained by the
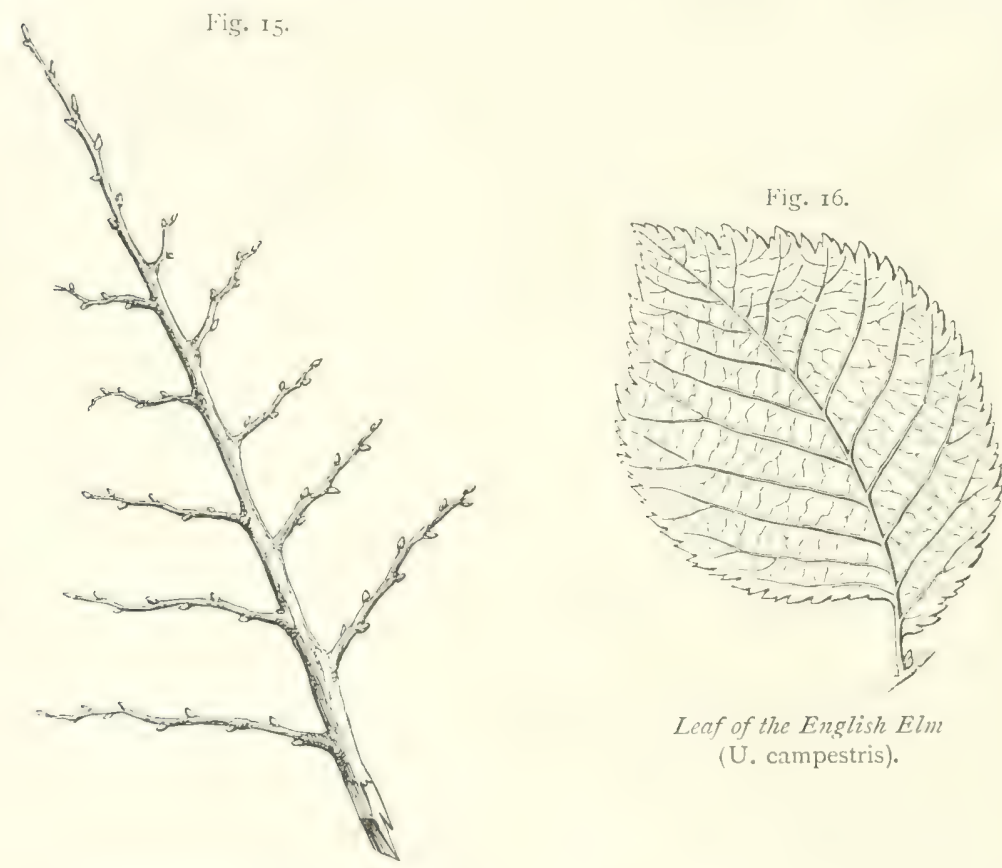

Leaf of the English Elm

(U. campestris).

Young shoot or spray of English Elm in winter (U. campestris).

Amur. In southern Europe it is not only the favourite tree for avenues (as may also be said with reference to southern England), but is also to be found forming large forests. Even so little to the north as Hungary, however, it ceases to become a tree of true forest growth, but gradually gives place to the northern species, $U$. montana. There can hardly be any doubt that this common Elm of England was introduced by our Roman conquerors; for except in very exceptionally warm years like 1893 , when it seeded abundantly, it is unable to produce seed of germinative capacity. That it has been able to maintain itself so securely through all these long centuries is earily explainable in its strong reproductive capacity by means both 
of stool-shoots, and of stoles or root-suckers, which develop good root-systems for the maintenance of their own individual stems.

Description of Tree.- This tree is, next to the Oak, that most generally cultivated for ornamental purposes in England, where it is found in great perfection as an avenue-tree, as well as adorning in individual stems, or in groups of trees, the parks and lawns of landed proprietors. It is also a very common hedgerow tree in many parts of England; as, for instance, in the valley of the Severn and throughout many of the southern and eastern counties, where it may be seen in great perfection. It is generally admitted to be one of the tallest and finest of our European timber-trees for park scenery, and lives to a very considerable age: some of the Elm-trees in central Germany are known to be over 500 years in age. In favourable situations this tree grows rapidly, sometimes attaining so much as $25 \mathrm{ft}$. in height when only ten or twelve years planted. The general character of the tree favours a tall, upright habit of growth, with a straight stem, generally from 3 to $5 \mathrm{ft}$. diameter when of mature age, while the branches are slender in proportion to the diameter of trunk. During gales and high winds, particularly after heavy rainfall, the large branches are apt to get torn away from the trunk and thrown to the ground.

Economic Uses of Timber.-The timber of the $U$. campestris is particularly strong in what is termed lateral fibre, but is deficient in longitudinal adhesion of fibre. Its strength in lateral fibre fits it admirably for the making of blocks and dead-eyes for the rigging of ships, and for this purpose it is much used. It is very much used also in the shape of naves for wheels, and a large quantity of it is used in furniture-making. In short, the timber of this tree is used in England for a great variety of purposes in connection with rural economy-such as troughs for conveying and retaining water, and for supporting the banks of water-courses, \&c.

It has a sp. gr. of 0.95 when green, and 0.69 when seasoned, so that it will be floatable immediately after felling. When grown on warm southern exposures, it yields a very durable wood, ranking not far behind Oak; but when grown on less favourable situations, durability is not always the strongest characteristic of its timber. Its many excellent technical qualities, and its fine texture and colour, as well as its rapid growth, claim for it a fair share of the sylviculturist's attention on land favourable to its growth.

Soil and Situation. - This tree attains its largest dimensions on warm, sunny exposures, having a deep, rich, and fresh loam - not necessarily of the character of clay, nor of that of sand or gravel, but rather of a free, open loam.

Like the $A$ sh, the Elm requires a considerable amount of freshness in the 
soil in order to supply it with the requisite amount of water for transpiration through its foliage. Ebermayer's recent investigations, already referred to in dealing with the Ash, have proved that the Elms generally are not only decidedly exacting with regard to the amount of mineral nutrients withdrawn from the soil, but also require a large quantity of soil-moisture to replace the water transpired rather freely through their foliage. These characteristics may not appear so markedly in Britain, where the trees are treated merely arboriculturally in the vast majority of cases; but they will undoubtedly have to be taken into consideration whenever woodlands on poorer qualities of land are treated sylviculturally, and on a purely financial basis. Though often to be seen thriving well on what appears to be light and rather dry land, Elms in reality require no small degree of soil-moisture; and it is only because the general quality of such apparently rather dry land is good, and because trees can draw the requisite supplies of water from the lower strata entered by their deep-going heart-shaped roots, that Elms are to be found developing so favourably. In general, like the Ash, Elm grows best on fresh or even damp soils; and although it naturally prefers light sandy loams, yet Elm can even thrive when the soil is somewhat too binding for the former. A warm, sunny exposure is, however, under all circumstances, essential for producing the best quality of timber. The Elm is rather a tree of the plains and of undulating uplands than a denizen of the hilly tracts, where other species yield better sylvicultural results.

Propagation and Culture. - In the southern parts of Europe the $U$. compostris is raised from seeds, and plants are often produced from these, more especially in the south of France. But in this country, where the seeds seldom ripen, the seed has usually to be imported; or else the tree may be propagated by means of stoles or suckers from the roots of the old trees, which are formed in abundance, and may easily be detached and transplanted; or finally, it may be regenerated by means of layers, the method by which plants of the true kind are mostly procured, and which is the plan still adopted in many public nurseries in Britain for the propagation of this tree.

Even where indigenous, this Elm produces seed having a low germinative capacity of only about 40 per cent, and this becomes lower still by storage, or by packing and transport even for a very short time. Hence the method of regeneration by means of layering has much to recommend it. When seed is procurable, as during the warm dry spring of 1893 , it should be sown at once, for it germinates within about three to four weeks after ripening. Seed that has been stored over one winter, besides having a very low germinative capacity, is apt to remain inert in the soil for a year before the seedlings come up at all.

The Sylvicultural Treatment of the Elm in many respects closely resembles that of the Ash, Maple, and Sycamore, as it is in reality one of the exintially light-demanding trees, although this natural characteristic is often not so distinctly apparent in English Arboriculture as in scientific 
Sylviculture. It is, however, a fact, and one that will certainly have to be kept well in view if ever timber-growing should be-as seems only reasonable from an agricultural point of view-more or less abolished from the hedgerows and confined to woodlands consisting of the true natural forest tracts, i.e., the poorer classes of soil on the higher uplands and the hilly and mountainous tracts.

It is just as little suited, sylviculturally, for the formation of pure woods, or of large groups of trees, as the other light-demanding species of forest-trees. When once it has completed its main growth in height, increase of growingspace is requisite for the expansion of its crown; and long before its technical and financial maturity is attained, the light canopy of foliage is insufficient to protect soils that are in any way exposed to deterioration through the action of sun and wind.

It should, therefore, in general be sprinkled individually throughout mixed crops in which the Oak, Ash, Maple, and Sycamore are interspersed throughout a matrix of Beech, or other shade-bearing tree suitable to the soil and situation, and may then hy abont the eightieth year yield stems of gool marketable dimensions. On the better classes of soil, where the proportion of Oak is larger, and where it is intended to have a full crop of Oak on the land by the time this species attains its maturity, it may he introduced along with Ash, Maple, and Sycamore, and then cut out and utilised between the sixtieth to eightieth year, so as to permit the Oaks to have the undisturbed enjoyment of a larger growing-space and fuller supplies of light and warmth. Such woods will often in Britain, and in the more genial climate of southern England especially, require no artificial formation of underwood, as on the better descriptions of soil frequently to be met with under such woods these species exhibit a strong power of copluicing, and a capacity of bearing shade which at first sight seems strangely at variance with their true sylvicultural character as light-demanding species of trees on all merely average or inferior classes of soil.

Young Elm plants suffer but little from late frosts, in which respect they are decidedly hardy. But as the sap begins to rise early in spring, planting operations should be carried out in autumn rather than in spring. The growth of the young plants is rapid, a height of $10 \mathrm{ft}$. often being attained in six years. As they are endowed with considerable recuperative power, large plants have little difficulty in establishing themselves satisfactorily after being transplanted. To make up for their deficiency as regards seed-production in our climate, they possess very considerable power of reproducing themselves slontaneously by shoots and stoles, as well as artificially by layering. The production of stoles or root-suckers is stimulated by felling very low down, as close as possible to the ground.

As a standard tree in copse the EIm is not so rrell suited as Oak or Ash, for its shade is often heavy, and at the same time it does not hold out promise of such remunerative returns as these species.

Among coppice-growth the Elm is well able to maintain itself. But as it is of rapid growth, and at the same time has a tendency to spread itself out at first, and then afterwards to reduce the number of its shoots considerably, its natural efforts for possession of the soil often require to be restrained in favour of more remunerative species like Oak, Ash, Chestnut, and the like. 
As a coppice-wood under standard trees in copse it can, on good fresh soil, bear a larger amount of shade than might be expected, judging from its unmistakable requirements regarding light when growing in high-forest on poorer and drier qualities of true roodland soil.

Layering.-The process of layering consists in having a piece of arnumd first of all planted up, at ahout $6 \mathrm{ft}$. aprart, with plants of the Ennlish Eln, or of any other tree that it may be desirable to propagate in this particular way. When these have stood for three or perhaps four years, in order to gain sufficient strength, they are cut over to within three or four eyes of the ground, in the same manner as a bed of osiers. When the eyes have pushed out shoots of one year's growth, they are in the autumn, when these shoots are ripe, fit for layering. In layering the shoots which are meant to become young plants or trees, all the ground about the plants is dug and made perfectly clean from weeds, all stones being also taken out. When the ground has been thus prepared, the young shoots are bent down regularly round the parent stool (see Fig. 17) into the earth, and are kept in their places by small

Fig. I7.

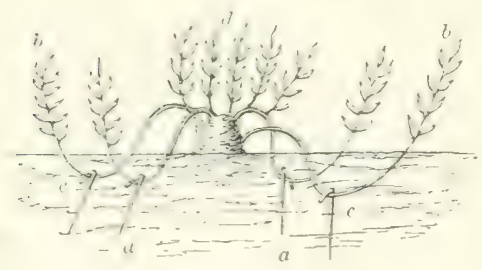

Method of Layering. wooden pegs $a$ a, and covered with soil about 4 in. deep at the part bent into the ground. The top portion of each shoot $b b$ is turned up in an upright direction out of the soil, and in a fer months the part which is buried in the soil c $e$ takes root, when of course each shoot becomes a perfect and independent plant in itself, which may be remover in the autumn following with all the fibrous roots attached. When removed, they are put out in nursery-lines, in order to gain more strength before being planted out into the forest. Great care must be observed in cutting away the young and newly rooted plants from the parent stem; and before the spade is put into the ground in order to loosen their roots from the soil, they should all be cut away from the parent by using a sharp knife, care being taken not to pull up the shoot in the act of cutting. When all the young plants have been removed, the stools Should have all the stumps of the lranches, which were cut olf, taken away; young shoots will then proceed from the cut parts during the following spring, which will again answer for layers in the autumn, as at $d$. This process may go on successively. Each summer's shoots as they rise upwards are in the autumn laid down in order to become new plants; and while these are in the act of making roots, the parent stool is again busy in the reproduction of a new supply of shoots to succeed them. When a severe drought sets in, 
the ground should be liberally watered in order to encourage the rooting of the young plants.

The Dutch Method of Layering is slightly different, for plants of it or $6 \mathrm{ft}$. in height are put out in autumn, at distances of 8 to $12 \mathrm{ft}$. apart, in light, well-prepared, manured soil, and then cut off close above the ground. Is soon as the shoots have shed their foliage in the following autumn, they are carefully bent down or layered in rills of about $1 \mathrm{ft}$. deep, that are lined with good mould before the earth is filled in again and trodden down. The tips of the shoots come for about 2 to $12 \mathrm{in}$. (according to circumstances) out of the soil, and are assisted in attaining an upright develolment by having tufts of turf laid below them. If these main-shoots should have side-shoots, they can also be layered at the same time; but any shoots in excess of those that can be conveniently layered are eut away. In the following autumn-that is to say, after being layered for just one year-the young plants are separated from the parent stool. Not much stress is laid on the retention of numerous rootlets, for the new plant is cut through in such manner that the rooted end forms the straight continuation of the stem; and it is only when the rootdevelopment has been poor, that jart of the crook is included along with the detached layer. The stem of the new individual plant is then severed with a slanting cut made about 4 to $6 \mathrm{in}$. above the rooted portion, which is next put out in rows on prepared manured land trenched to a depth of 16 to 20 in.; the rows are usually $2 \mathrm{ft}$. apart, and in these the plants stand about $15 \mathrm{in}$. distant. No further transplanting is necessary ; but in the following antumn they are cut back again close to the ground, and during the next spring only the best of the shoots is left to develop. In the course of the next five or six years this develops into a stout young stem ready for transplanting wherever required. The only tending consists of keeping the beds free from weeds, though sometimes the lower shoots are cut away in order to allow the workmen to move about more freely during the weeding operations. Such Dutch Elms, nearly all of the species $C$. compestris, are characterised by straight and rapid growth, smooth bark, and good deep root-system. As they increase in age, the parent stools produce more numerous and better shoots than at first. When they become too high to permit of the shoots being layered easily, they are simply sawn through close to the ground-care being, however, taken to smooth off the ragged surface with an adze or similar instrument (Burckharelt, '1,. rit., 1'l'. 200-202).

In England this tree attains large dimensions. For example, at Syon House, Isleworth, in the neighbourhood of Lonclon, there are specimens upwards of $100 \mathrm{ft}$. high, with stems from 5 to $\mathrm{S} \mathrm{ft}$. in diameter, forming large and spreading tops of grand and imposing aspect. In Kensington l'ark also, in the immediate neighbourhoud of London, there are many handsome specimens of this species, several of them being upwarls of $100 \mathrm{ft}$. high, and with stems from 5 to $6 \mathrm{ft}$. in diameter. At Longleat, Wiltshire, there is a specimen $120 \mathrm{ft}$. high, with a circumference of $20 \mathrm{ft}$. at $4 \mathrm{ft}$. from the ground. 
Some of the most celebrated Elms in Europe are in Germany. The largest is that on the village green at Schimsheim near the Rhine, in Hessen, which is said to be between 500 and 600 years old, and which is still flourishing, although rotten and hollow in the bole. It is $100 \mathrm{ft}$. in height, and has a girth of $44 \mathrm{ft}$. at $31 \mathrm{ft}$. above the ground. At Gölbheim, in the Rhine Palatine, the Elm is still vegetating under which the Emperor Adolph fell in battle in 1:2s:

(․) IMOUNTAIN, SCOTS, or WYCH ELM, Ulmus montene, Sin.

Specific Character.-Leaves pointed, rough, broad, and doubly serrated. Flowers on longish peduncles, loosely tufted, 5-6-cleft. Samara somewhat orbicular, slightly cloven, naked. Branches drooping at their extremities; their bark smooth and even. Flowers reddish, April and May. Samara brown; ripe in June (Loudon, op. eit., p. 720 ).

The Wych EIm is easily distinguished from the $U$. campestris by

Fig. 19.

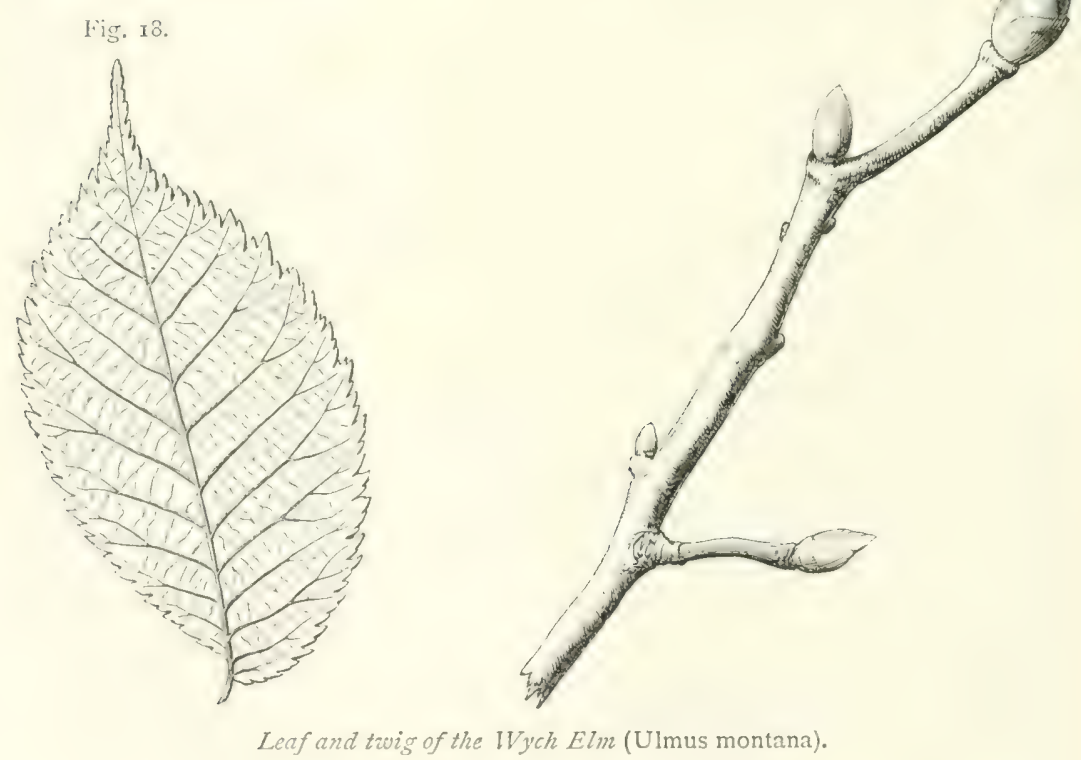

the greater size of its leaves. In comparison with those of the Common Elm, the leaves of the Scots Elm may be termed rough and broud (see Fig. 18); they have also a longer point, and are more deeply serrated than is the case with the leaves of the other species.

The young shoots of the Scots Elm (see Fig. 19) are much stronger, and altogether more massive, than those of the English Elm; further, they are slightly pubescent or downy in their first 
stages, which may help, along with the other difference in the formation of the twigs, to distinguish between them during the leafless period of winter rest. Another distinctive characteristic of the $\mathrm{Wych}$ Elm is its incapacity for producing suckers from its roots, and by this it may easily be known, independently of any other specific peculiarity.

For the English Elm, on the other hand, seems in our climate to be endowed with the power of throwing out stoles or root-suckers, as well as shoots, in order to compensate it for the want of a sufficient amount of early spring warmth to enable it to ripen its seed during ordinary years.

Distribution.-The $U$. montana is a native of Britain and of other parts of Europe, and is cultivated in Scotland more than the English Elm is, for which latter species the average amount of summer warmth seems hardly sufficient. It is cultivated extensively in Ireland as a timber-tree; but in England, and on the continent of Europe, it is not much cultivated, the $U$. campestris being preferred in those parts.

Description of Tree.-The Wych Elm forms a large-crowned and spreading tree, with strong and diverging limbs, which give it a magnificent appearance among other trees of a stiffer and more rigid character. When the tree has arrived at full maturity, the branches, from their great weight, incline to hang down in a drooping position at the extremities, and form rich festoons when in full leaf. This is the habit of the tree when grown to form avenues, or in an open park, with a free growing-space for the unrestricted development of its branches; but under such circumstances it seldom attains its greatest height and magnitude as a timber-tree. When grown in the forest, or wherever it has not so much free room to extend its side branches, this natural diverging habit is checked; and in such a position it may almost always be found to contain the greatest quantity of marketable timber, and to form a tree of first-rate magnitude. The Scots Elm is of much quicker growth than the English Elm. It is generally of a very rambling or straggling habit in its young stages, until its leader becomes fairly developed; but after that it assumes a more upright habit of growth, and soon attains a considerable height. This tree, when left to itself in an open park, forms an extremely picturesque and heautiful object in the lindseape. It may, indeed, often be surpassed by its close relative the English Elm with regard to height and cleammess of stem; but it camnot he surpassed in the general picturesque effect and grace of its outline. It in all cases stands umrivalled upon the lawn, its appearance being altogether natural, light, and graceful. The English Elm lias somewhat of a stitf, unbending outline; whereas the scots Elm is deciledly elegant, and has neither a hard nor a rigid contour. 
Economic Uses of Timber.--In Scotland the rood of this tree is much sought after for all country purposes- such as cart and waym shatt., plough swing-trees, cart-naves, wheel-barrow and cart framing, \&c., \&c. Indeed there are few purposes to which Ash is generally applied, for which Elm is not used instead when that wood cannot be got conveniently and of good quality; and for all these different uses it is well adapted, owing to the toughness of its loneitudinal fibre. Large quantities of this kind of Elm timber are nsed for railway purposes, and especially for handles for implements used by the workmen in connection with them. In England the timber of the Scots EIm is not much used, that of the English Elm being generally preferred: where toughness of fibre is required, however, the Ash is decidedly preferable to either of them, when it is easily obtainable.

Soil and Situation.-Whilst the English Elm is a tree of the plains and uplands, the Scots Elm is more the tree of hilly tracts. It thrives well in deep glens and ravines, on a deep open-bottomed soil, where it can get its deep side-roots easily down into the subsoil, and where fresh moisture is constantly percolating downwards; but it does not succeed if its roots get into stagnant water. The largest trees of this kind are usually to be found near the sides of a running stream, where the roots have ample supplies of water without its lodging about them; and where the soil is a sandy loam, of an open and porous nature. The tree grows better in a heavy soil than in a light one-that is, it will grow much better on a stiff or argillaceous loam than on land of a very loose sandy or gravelly character; but on the whole it prefers soil of a medium description, and on such land the best trees are almost always to be found.

Propagation and Culture.-The Wych Elm is propagated from seed, which is generally found very plentiful upon old trees from the end of May to the middle of June. Even when trees are growing in the open, the power of producing seed of germinative capacity is seldom attained before about the thirtieth year; but from that time onwards it seeds freely almost every year. At all times, however, its germinative capacity is small, 45 per cent being a very good yield in experiments to test the quality of the seed.

The flowering takes place in March and April, before the flush of foliage occurs in spring; and the seed ripens about the end of May or the beginning of June. It is shed at once, and soon germinates if it happens to alight on favourable soil. If gathered and sown out in the woods directly, the young seedlings may attain a height of from about 6 to 9 inches before entering the period of winter rest in the autumn.

The seed being very light, and easily blown about by the wind 
when fallen, it should, when ripe, be gathered by the hands from the tree, and not allowed to fall; and when it is sathered it should be sown immediately, as it will not keep long. It should be sown in rows $15 \mathrm{in}$. apart in the nursery, upon a fine light soil, and should not be covered to a greater depth than $\frac{1}{4}$ of an inch at the very most, although anything like so much is not repuisite. The seedlings spring up very freely and quickly, and will be ready for planting out into nursery-rows in the following spring. In planting them into rows, these may be about 20 in. apart, and the plants may stand in the rows about $4 \mathrm{in}$. distant from one another. When they have stood two years they will be ready for planting out into the forest.

Fine specimens of the $U$. montana are to be found in many places These are, indeed, so common in all parts of the country that it would be superfluous to refer here to any trees in particular. It need merely be said, that specimens from 80 to $90 \mathrm{ft}$. high, with stems from 3 to $5 \mathrm{ft}$. in diameter, are common in most parts of the country.

\section{ACERIN DE DC.}

\section{The Maple, Acer (Linnean System, Polygania Movecia).}

Character of Genus. - Sexes hermaphrodite, or monceciously polygamous. Flowers with a calyx and corolla. Calyx divided into 5 parts, or some number between 4 and 9. Petals the same in number. Stamens 8, or some number between 5 and 12 . Anthers 2-lobed. Carpels 2, very rarely 3, each a samara-that is, a fruit which is called in Britain, vernacularly, a key (Loudon, op. cit., p. 79).

There are altogether about 81 species of Maple, most of which inhabit the temperate zone of North America, and of which 8 occur in Central Europe; but of these the only species worthy of sylvicultural or even arboricultural attention in Britain are-(1), Sycamore or Great Maple (Accr Psculo-platanus); (2), the Norway Maple (A. platcnoides); and (3), the Sugar Miple of North America (A. saccharinum). The Field Maple (A. campestre), a shrub or minor tree, is common in hedgerows throughout central and southern England, where its 3 - to 5-lobed leares form a beautiful piece of colouring in the early autumn.

These three species are easily distinguishable as follows (Willkomm, op. cit., p. 746$)$ :-

1. Flowering occurs after the complete flushing of the foliage in spring. Leaves 5-lobed. Flowers in pendulous racemes A. Pseudo-platanus.

2. Flowering occurs simultaneously with, or shortly lefore the flushing of, the foliage in spring. Leaves with five or seven lobes.

(a) Young shoots and leaf-stalks exude a milky sap when broken. 
Samaras or winged carpels of the fruit extending far apart

A. platanoides.

(b) Sap of young shoots and leaf-stalks not of a milky nature.

Samaras upright or close together A. saccharinum.

Nome of these are indigenous to Britain, but the two first-named have long ago become thoroughly naturalised.

\section{(1.) SYCAMORE, GREAT MAPLE, or SCOTTISH PLANE,} Acer Pseudo-platanus L.

Specific Character.-Leaves cordate, smooth, with 5 acuminated, mequally toother lobes. Liacemes pendulous, rather compound; with the rachis, as well as the filaments of stamens, hairy. Fruit smooth, with the wings rather diverging. Flowers greenish yellow, mostly hermaphrodite; May and June. Keys reddish-brown; ripe in October (Loudon, op. cit., p. 86).

Distribution. - The Sycamore is indigenous to all parts of central and southern Europe except the extreme south-east or south-

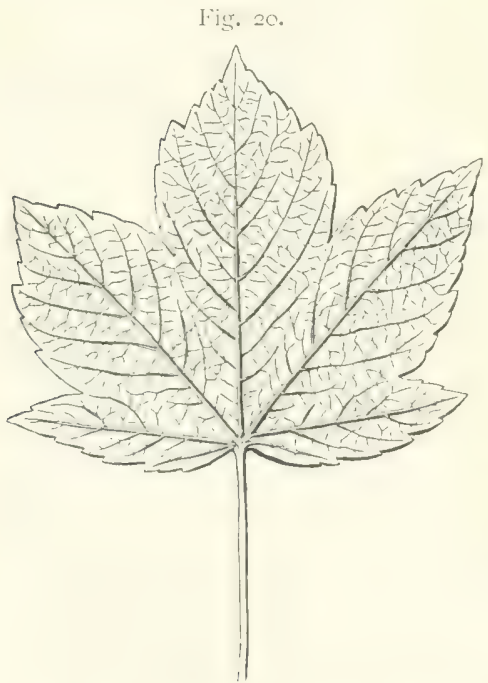

Lcaf of the Sycamore (A. Pseudo-platanus). west portions, and attains its finest development more particularly throughout the central area occupied by Germany, Switzerland, Austria, and Italy, where it is found chiefly on the hilly tracts. It is not a native of Britain, but was introduced during the fifteenth century: it has, however, found climatic conditions highly favourable to its requirements, and certainly is as hardy as any other tree we have-and, indeed, is as well fitted to withstand our climate as the Ash or any other indigenous species.

Description of Tree.-The Sycamore is very easily distinguishable by its beautiful 5-lobed, bluntly pointed, and broadly toothed leaves; or, as botanists describe them, heart-shaped, with 5 acuminate, unequally toothed lobes (see Fig. 20).

It is easily distinguishable from the Maple in summer by its foliage (compare Figs. 20 and 22), and in winter by its having yellowish-green buds, whilst those of the latter are of a reddish-brown,-likewise by its scaly trunk, which often closely resembles in apyearance the stem of the Plane-tree (whence 
its common name of "Plane" in Scotland); but it is then also readily distinguishable from this latter species of tree by its buds being arranged opposite to each on the twigs, and not alternating as in the true Plane.

It is a tree of first-rate magnitude, and lives to a great age. It is of rapid growth; and from its leaves being large, it always presents a heavy mass of foliage as compared with most other trees. From the latter feature in the appearance of the tree, many comsider it of a heavy and gloomy aspect, and not suitable for introduction into particular parts of landscape,-especially, they say, where a lively natural effect is desired. There seems room, however, for quite the opposite opinion to this. Only let the fine effect that this tree has upon open lawns and parks about the end of April and beginning of May be considered, for it is then that the Sycamore appears to best advantage. Its light-green leaves have then both freshness and lightness, so that its foliage gives the park upon which the tree stands somewhat of an oriental appearance. The very circumstance of the Sycamore flushing its spring foliage with a lower temperature than the majority of other forest-trees, and coming into leaf earlier than almost any other tree upon the lawn, makes it a favourite with the lovers of natural scenery; and even in the midst of summer the tree presents a grand mulroken mass of foliage, which contrasts pleasantly with other trees of a more airy character, particularly if the situation be a prominent one. As compared with many other forest-trees, unless grown in close canopy, the sycamore camnot be said to carry height along with its girth; and this tendency towards almost horizontal ramification and large demand for individual growing-space is particularly noticeable when it is found growing free in an open park or lawn. In such a situation it forms a rather short massive stem, with a spreading head, frequently of very great magnitude. When introduced into Beech - woods it soon shoots ahead in growth, but later on requires to be protected agaimst the latter. Though not absolutely a light-demanding tree, it can hardly be truly classed along with the Beech and the Hombeam as a species capable of bearing shade well on soils that are not moist and fertile. Although it presents a dense mass of foliage to the eye, the leaves in the interior of the crown are not nearly so numerous as in the true shade-bearing species. And in our British woods, mostly on good fresh soil, it bears more shate thin it possibly could on true forest land of indifferent quality only.

Economic Uses of Timber. - The Sycamore, when of large dimensions, is a very valuable tree, often being suld at rites rarving from $2 \mathrm{~s}$. to $3 \mathrm{~s}$. per cubic ft. The timber is reckoned of excellent quality if used in dry places, and when well matured and of linge dimensions it is sure to sell at a gool price; but when of small sizes 
it is not reckoned of much value. There is not a large quantity of Sycanore timliex of large dimensions lrought into the market; hence, when a few good trees are offered for sale they always bring a high price. Sycamore wood enters largely into the manufacture of household furniture, wooden dishes, and certain parts of fixed rural machinery; and a considerable quantity of it is used by turners and toy-makers. It is somewhat finer in the grain than the wood of the Maple. It is also much used in the making of ends for herringbarrels, and for this purpose large quantities of the smaller-sized timber are used. It has a sp. gr. of 0.93 when green, and 0.66 when seasoned, so that it is safely floatable very soon after being felled and logged.

Soil and Situation.-Few of our forest-trees succeed on a greater variety of soils and situations than the Sycamore. It is, without doubt, one of the most accommodating trees we cultivate, as fair specimens of it are to be found on all sorts of land, from stiff clay to light sand, and in all kinds of situations, from muchsheltered to much-exposed, and from low-lying to high-lying. In no case, however, do we find it in health and of fair dimensions of timber on a wet soil. It must grow on land free from stagnant water; for if not, it will become stunted, and die off at an early stage.

The circumstances which are found most favourable to the healthy growth and development of the Sycamore are-a dry sandy loamy soil, porous and open in the subsoil, with a free exposed situation, as in the open parks about gentlemen's home-grounds.

In Scotland the foliage is very liable to be damaged and rendered unsightly by a fungoid disease due to Rhytisma acerinum, which, however, exerts no direct influence on the quality of the wood formed. As it is infectious, and a blemish from an arboricultural point of view, all those blackspotted autumn leaves should be swept together in heaps and burned, in order to prevent the spread of the disease.

The above remarks in the text may be quite true for British plantations formed generally for ornamental or game-cover purposes on soil rather above the average in quality. But they do not agree with the experiences of Sylviculturists having to deal with absolute forest land-i.e., land not capable of being utilised more profitably for arable or pastoral purposes, as so much of the existing and more or less ornamental English woodland might be. And the researches of scientists agree wonderfully closely with the facts of sylvicultural experience. Thus, from his analyses of leaves, Ebermayer (op. cit., pp. 230, 232) has proved that both the Sycamore and the Maple are classifiable as trees which make very considerable demands as to the amount of mineral nutrients (especially potash and phosphoric acid) which they annually withdraw from the soil. In this respect they are more exacting than Beech, Willow, or Oak, although not so exacting as Elm, and considerably less so than Ash, the most exacting of all. And at the same time their 
actual requirements with regard to water for transpiration are lirese, like those of all other deep-rooting suecies of trees; whilst, as might he expected, they are greater in the case of the Sycamore, with its more pronounced taproot, than of the Maple.

Sylvicultural experience has proved that the Sycamore must have either a deep soil, or a fissured subsoil, for the normal development of its deetr-going root-system. With a favourable subsoil, however, the quality and nature of the upper soil is of comparatively little:importance. It is more essentially a tree of the hilly tracts than the Maple, which is rather the tree of the plains and uplands merely; and whilst the former thrives well on moist soil, fringing the water-channels on hillsides, it is less able than the Ash and the Maple to develop normally where the movement of moisture within the soil is somewhat sluggrish and little better than stagnant. Dry light soil is not really suiterl to its normal requirements; nor does it find the most favourable conditions of srowth in heavy, binding, or very wet land, although merely temporary excess of moisture does it no permanent injury. Though it may often be found of good growth on flat land along with Oak, Maple, Elm, drc., yet whenever anything but the better classes of soil are being dealt with, it will be best to select the Sycamore in place of the Maple for planting out on hilly tracts, and the Maple in preference to the Sycamore on lower lying localities, on which the latter is apt to suffer from late frosts in spring during the earlier period of its development. A fair amount of lime throughout the soil is favourable to the growth of both species, but more especially of the Sycamore.

Whilst the Sycamore can ascend to higher elevations than the Maple, the latter can be cultivated with success and profit further north than the former, as it is able to thrive with a less degree or total of summer warmth.

The Sycamore, from its being easily checked in the side branches, is well adapted as a nurse for other more valuable trees in a forest. It also, as may likewise be said of the Maple, coppices freely on being cut back to the stool for the first time, the young shoots growing exceedingly rapidly from the stock, and making flushes or growths of from 3 to $5 \mathrm{ft}$. in length during one season.

But in order to maintain its reproductive capacity in coppice-woods or as the undergrowth in copse, it is necessary to fell close to the ground, otherwise the stools soon rot. And after being coppiced once or twice its reproductive capacity becomes weakened, so that it is not really one of the species of forest-trees naturally adapted for permanent utilisation in copluice-woods or for coppice under standards.

Being an exceedingly hardy species (except as regards frost on low-lying localities), and of a peculiarly stiff and mubending hathit, it is well adapted for hedgerow timber; and, moreover, as a tree which comes very early into leaf in the spring, it has the alvantage of producing considerable shelter to the fields by its larege leares, as well as giving a healthy and clothed appearance to the comntry. Miany, indeed, object to it as a tree adapted for hedgerow timber, upon 
account of its wide-spreading branches; and no doubt it must be confessed that these will, under careless management, cast a great shade upon the land on each side of the hedgerow. But if it be furoprly trained by judicions and enrly pruning, it may be made to assume a tall and closely branched habit of growth, of the best du-cription possible for producing shelter to the aljoining fields. ${ }^{1}$

Propagation and Culture.-The Sycamore is propagated entirely ly seeds, excepting, indeed, the variegater and other varieties, which are reproduced by budding or grafting.

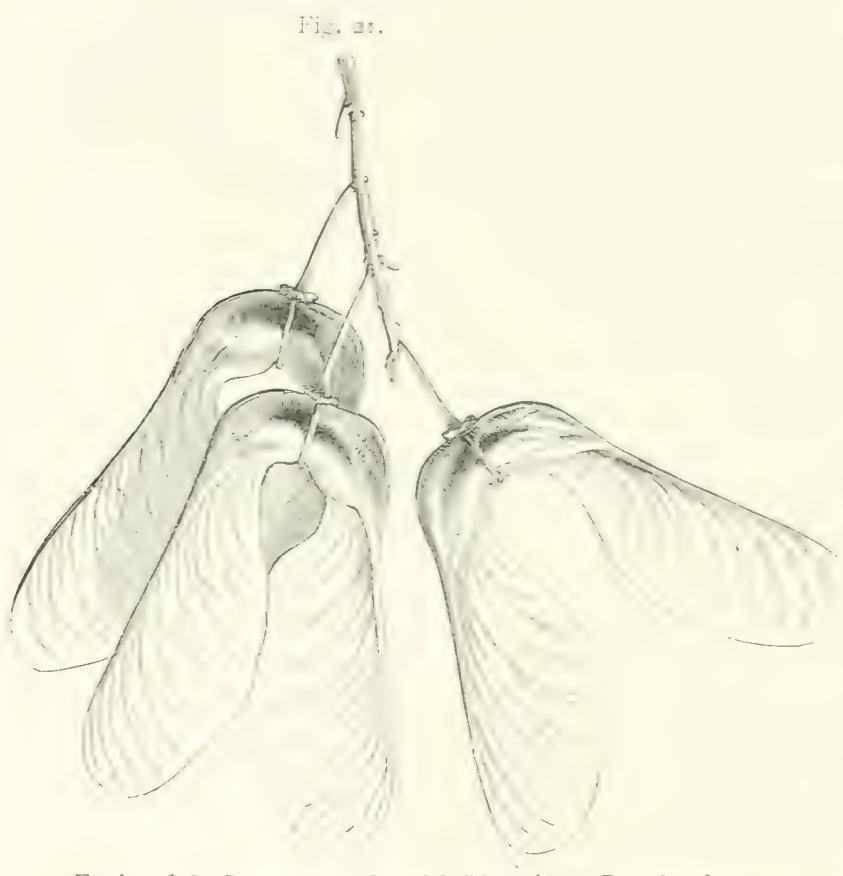

Fruits of the Sycamore or Scottish Plane (Acer Pseudo-platanus).

Seed-production begins about the 25th to 30th year on trees in the open;

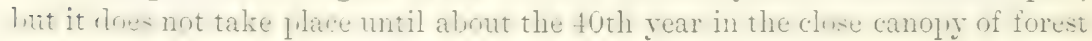
crops, except on coppice-shoots, when it is attained very early.

When the seeds ripen in September or October (see Fig. 21), they should le sown immerliately after being gathered, because they

1 As a lover of natural beauty, the editor is an admirer of hedgerow timber; but as a sylviculturist and economist, he objects to it vers strongly. Although Euglish rural scenery would lose one of its greatest charms if the hedgerow timber were remored, jet the growth of trees along the edge of fields is a direct interference with the productive capacity of the soil, by overshadowing the crops over considerable areas. Any benefits possibly derivable from shelter are more than counteracted by the interruption of the sun's rays during the summer months. (See also the remarks under Hedgerow Timber in a later chapter.) 
are extremely apt to lose their vegetative powers. This may be done about the middle of October; or if it seem preferable to keep the seed till spring, it should he mixed up with a quantity of rlry sand, and sown as early as possible in the spring.

Seed thus stored through the winter is, however, apt to lose about the half of its germinative capacity, and even then a mood deal of it may fail to germinate until the following spring, in place of the seedlings springing up about five or six weeks after the seeds are sown. If kept stored over a second winter, the seed loses its germinative power entirely.

When the seedlings are one year old, they should be planted out into the nursery-rows, where they should remain two years before being transplanted into the forest. The distance at which the plants should stand in the nursery-rows is the same as that already given for the Ash (see p. 128). During its young stages of growth the Sycamore is very apt to throw out rather strong side-branches. Hence, in its cultivation in the forest, this tendency should be checked to a certain extent by judicious pruning; for it can heal wounds easily, although its recuperative power is not so great as that of the Ash. With regard to such pruning, however, it should be remarked that if the young trees be cut and pruned in the winter or spring months, they are sure to bleed profusely at the wounded parts, and may not improbably remain stunted for a year or two afterwards. When it is foml necessary to prume the Sycamore, therefore, it is preferable to let this be done in the summer months, or at some time during the regetative season, when, instead of being injurious, judicious pruning becomes beneficial to it; because at this season the sap is quickly utilised by the foliage and assimilated for structural purposes, so that the wound heals up in a very short time, without much "bleeding" or unnecessary loss of sap.

Sylvicultural Characteristics and Importance of Sycamore and Maple.-On fresh good soil Sycamore and Maple can, like most other trees which are not truly shade-bearing species, stand a considerable degree of overshadowing before being suppressed as underwood; and in the same way they can maintain in high-forest a better leaf-canopy than Oak, Ash, or Elm. But they in reality occupy a sort of position midway between the essentially lightdemanding trees and those shade-bearing species which are undoubtedly caprable of also thriving with a less degree of intensity of light,-although this latter class of course attains its finest development only when in the free enjoyment of light and warmth. In many English plantations on fresh umelulating lands both species would scem capable of bearing a high degree of shade; but this apparent promise would be belied on the poorer and drier soils on hilly land, where they wonld indeed maintain hetter canogy than Oak or Ash about the 70th or Soth year, but, if not cut out then, would also in general require special measures to be taken with a view to preserving the 
productive capracity of the soil against deterioration, or, in other words, would require underplanting.

With regard to their general sylvicultural treatment Naples have much in common with the Ash and the Elm, except that they are not so emphatically light-demanding as is the former especially. On fresh deep soils they may very adrantageously be grown along with Oak, Ash, and Elm in mixed woods with or without the Beech; but on indifferent classes of hilly soil a matrix of Beech is almost essential to their wellbeing. Here they should be planted out as sturdy transplants on the moister patches of ground, and favoured by the cutting back or thinning out of the Beech wherever this threatens to eatch them up and interfere with their normal development. They may be advantageously utilised about the 80th or 90th year; but when they have been originally planted in patches, these may be kept until the 100 th to 120 th year for the production of large timber, if the soil is not likely to deteriorate under them, or if underplanting be adopted. When Maples are being regenerated in high-forest, planting is preferable to any attempt at natural reproduction, for the seed will only germinate on prepared soil; and when planting is adopted, a better distribution of the individuals can also be attained.

There are many fine specimens of the Sycamore both in England and Scotland, most of them being from 70 to $100 \mathrm{ft}$. high, and with stems varying from 6 to $8 \mathrm{ft}$. diameter, and some of them even very considerably larger. It completes its growth in height about the Soth to 100th year in close forest, though much sooner in the open, after which it expands in diameter.

\section{(2.) MAPLE or NORWAY MAPLE, Acer platanoides L.}

Specific Character.-Leaves cordate, smooth, 5-lobed. Lobes acuminated, with a few coarse acute teeth. Corymbs stalked, erectish, and, as well as the fruit, smooth. Fruit with divaricated wings. Flowers rich yellow; April and May. Keys brown; ripe in September and October (Loudon, op. cit., p. 83).

Distribution. - The Norway Maple, as its name indicates, is a native of Norway, and is, in fact, an inhabitant of all the northern half of Europe up to near the polar limit of tree-growth. But besides being indigenous to that part, it is found also in Germany, in Switzerland, and France, and from the last-named country eastward to the eastern boundary of European Russia. It is a very common tree in all the woods of Russia. It is not indigenous to Britain, but was introduced during the year 1683. It is now one of our most hardy trees, and is well deserving of a place in most plantations, both with respect to the value of its timber, and to its ornamental effect from an arboricultural point of view.

Description of Tree. - The Norway Maple is a tree of first-class magnitule, calrable of attaining nearly equal dimensions 
with the Sycamore in a given period. It is by far too little cultivated in Britain. As a lawn tree, it is perhaps not surpassed by any other. A particular recommendation of it is, that it comes very early into leaf; for it is one of the first species to flush in spring. And in the autumn its leaves certainly produce an extremely rich and raried effect, their hright yellow colour contrasting well with the dark-green and russet tints of most other trees. The form of the tree, although much resembling that of the Sycamore, is nurre open and light, and it does not present so heary or so massive an appearance. It is easily distinguishable from a distance by an outline more natural, easy, and light than that of the Sycamore. The leaves resemble those of the Plane-tree (hence its botanical name) very much more than they do those of the Sycamore, in having an entire edge and being more acute at the points (see Fig. 22). They are also fully as large as those of the Sycamore, but of a lighter green, and more transparent in the texture. One particular characteristic of the leaves is, that they are not apt to be eaten or injured by insects, as is the case with most other trees; hence the foliage of the Maple always presents a sound healthy appearance. The young shoots of this tree are at first of a greenish colour; but as the season advances, and the rood

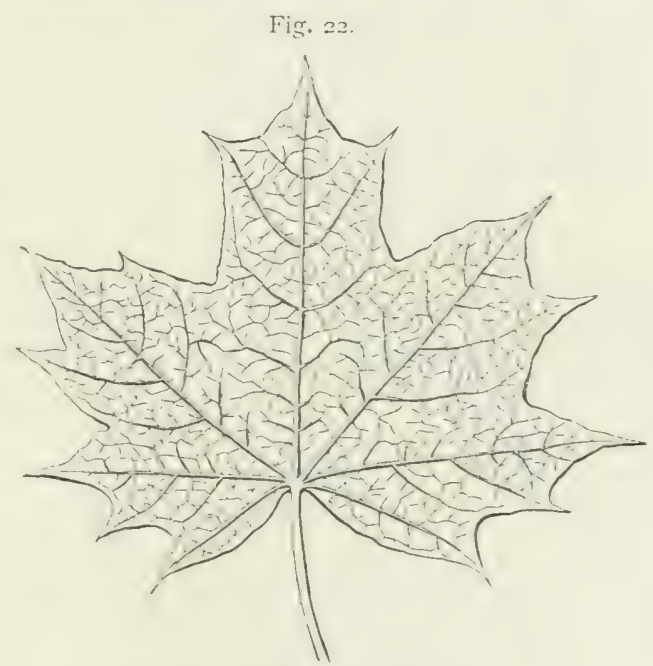

Leaf of the Maple (A. platanoides). becomes more ripened, they then assume a brown colour, with white spots upon the surface of the bark. The leaves of the Maple are easily distinguishable from those of the Plane-tree, in heing of posite and in having 7 ribs or main nerves in place of 5 in the Platanus orientalis and 3 in the $P$. occidentalis. In the winter season the Maple is easily distinguishable from the sycamore by the bark upon the old wood or trunk of the tree, for it is of a brownishgrey colour, and does not peel off' in flakes to a like extent, whilst the buds are of a deep red, and very prominent and large.

Economic Uses. - Home-grown wood of the Norway Maple is by no means plentiful enough in Britain to admit of its being used for common purposes, as is the case with the Sycamore; but 
from various specimens of trees that have been felled and manufactured into articles of clifferent kinds, it appears to produce a wood in all respects equal to that of the Sycamore. And although the grain of the wood is somewhat finer in the latter, yet the Maple appears to be somewhat closer and heavier, and therefore to take on a better polish. It is well adapted for many of the purposes to which the wool of the Sycamore is applied, and no dould it may be employed in all the purposes for which that sort is generally used.

It has when seasoned a sp. gr. of 0.75 , being thus as heavy as the Ash, and between the sessile and pedunculate Oak. Seasoning will therefore be requisite before it can. safely be floated in the log to favourable markets.

Soil and Situation.-The soil most favourable for the growth of the Maple is found to be a free, open, sandy loam, with an admixture of lime; but although under such circumstances it does no doubt grow most rapidly, and develop itself to greatest advantage, it will nevertheless thrive freely upon soils below the average in quality, provided that such be fresh and have no tendency to stagnating moisture.

In comparison with the Sycamore, it is rather a tree of the plains and the lower undulating hills; but though it cannot ascend to the same elevations as the former, yet it thrives further to the north, being content with a less degree of total summer warmth. Hence for the planting up of flat stretches of good land in Scotland it is deserving of very particular attention.

Being a native of the colder regions of Europe, and a useful timber-tree, the Norway Maple is well adapted for British plantations. It is met with growing in Norway down to the very sea-shore, and is there found to stand the blasts of the sea excellently--so much so as to become timber of considerable dimensions. It is therefore remarkable that it has not been more cultivated in this country, particularly upon estates along our sea-coasts. Upon the west coast of Scotland it thrives well; and judging from specimens that are to be seen growing there, especially on some parts of the shores of Galloway, it seems probable that, were its cultivation extensively carried on, the Norway Maple would there prove more remunerative than crops of most other trees. Instead of that barrenness of appearance which so generally characterises the west coast of Scotland, a beautiful woodland aspect might then be given to the greater part of it, were this valuable tree introduced there to the extent that its various merits suggest.

The Sylvicultural Characteristics of Maple are in general like those of the Sycamore (see p. 147), save that it can thrive further north than the latter, 
althongh it cannot ascend the hillsiles to the same elevation. It suffers less from late frosts in Apuil and the early part of May than the Sycamore, l, ut is not really a hardy species in damp localities exposed to dangers of this kind. As it is able to thrive with a less degree of warmth than the Sycamore, it is perhaps better suited for being introduced in large numbers as the matrix of mixed woods of broad-leaved, light-demanding species of trees on land of such quality that underwood may easily be formed if there be any signs of deterinration setting in under the light canopy of foliage. It may even on such favourable localities be utilised as an underwood beneath Oak standards, as in Holland; but it is not in reality one of the true slade-bearings species nyon whose utility the sylviculturist may depend, even on soils that are not of the best order. The Maples are not naturally fitted for the formation of extensive pure forests, but are best capable of being grown either individually or in small patches among Oak and Beech along with Ash and Elm. They may be cut out and utilised about the T0th to 80th year, when consiclerations regarding the ultimate crop and the soil call for the Oak being allowed a larger amount of growing-space, and for an underwood being formed of Beech or Hornbeam in preference to any other species. On good fresh soil, however, the underwood formed by the different kinds cut out of the canopy is often in our damp climate capable of forming a sufficiency of underwood to safeguard the soil against deterioration; and in this case Maple, Sycamore, and other hardwoods of course form a more valuable crop than Beech or Hornbeam.

Propagation and Culture.-The Norway Maple is propagated by seeds in the same manner as the Sycamore; and in every respect the method of culture stated for the Sycanore is aplicable to this tree. It usually begins to bear seed at a very early period, often five to ten years in advance of the Sycamore in close forest canopy, and produces it even more freely and abundantly than that species. Crood seed may frequently be gathered from trees of thirtyfive to forty years' growth; it ripens towards the end of September and the begimning of October. Yeither sowing nor planting onerations are opposed by the slightest difficulties. But if stored over winter the seed of the Maple is very apt, like that of the Srycamore, to lose greatly in germinative capacity. As, however, it fruits anmually, there is seldom any occasion for attempting to store the fruits. When it is sown in autumn, and at the same time it is not desirable that the seedlings should come up too early on aceumn of danger from late frosts, the germination of the seed may be retarded by giving it a slightly thicker soil-covering than usual.

Neither in height, nor girth, nor in the age attainable by it, does the Maple quite equal the Sycamore. There are some fair specimens of the Norway Maple on the island of Bute. Several of them are upwards of $70 \mathrm{ft}$. high, and with stems of from $2 \frac{1}{2} \mathrm{ft}$. to $3 \mathrm{ft}$. in diameter. There are some good specimens of this tree at rarious places in England, and especially at $K$ ew and at Syon House. 
(3.) THE SOFT or BIRD'S-EYE MAPLE, Acer sacharinum L.

Specific Character.-Leaves cordate, smooth, glaucous beneath, palmately 5-lobed; lobes acuminated, serrately toothed. Corymbs drooping, on short peduncles. Pedicels pilose. Fruit smooth, with the wings diverging. Flowers small, yellowish, and suspended on long, slender, drooping peduncles; April and May. Keys brown; ripe in September (Loudon, op. cit., p. 85).

This tree is easily known from the Norway Maple by the leaves being whitish on the underside in summer, and by their becoming reddish early in the autumn, instead of yellowish, as those of the Norway Maple do. The bark of the Sugar Maple is of a whitish colour, while that of the Norway Maple is of a light brown. From these specific characteristics the trees may be easily distinguished.

Distribution. - The Soft Maple is a tree indigenous to North America between the 30th to 50th degrees of latitude. It is to be found occurring frequently all over Upper Canada, on most of the richer portions of the lands, where it forms nearly one-third part of the natural forests. In Lower Canada it is plentiful, and also throughout the better parts of the country; but it is not nearly so abundant there as in Upper Canada, where the soil is generally of a deeper and richer character than in the lower province. It is also to be met with in many parts of the Northerm States of the Union, especially in New York and Pennsylvania; but as by far the greater portion of the natural forests has now been cleared away, it is only to be found in patches that remain here and there; and from this it may be deduced that the tree must once have formed a large part of the crop of the natural woods, as it still does in those of Canada. It was introduced into Britain in 1735.

Description of Tree. - At first sight the leaves of the Soft Maple very much resemble those of the Norway Maple, as they are nearly of the same shape and general size; but on a closer. examination of the two kinds, and especially on comparing the under sides of the leaves, it is found that those of the Soft Maple are whitish, while those of the Norway Maple are not. In the American woods, even under the ordinary conditions of soil, the Soft Maple becomes a large and handsome tree, seldom under $90 \mathrm{ft}$. in height, and generally having stems of from 2 to $4 \mathrm{ft}$. in diameter. Trees of this kind may very often be seen having stems fully $\check{5} \mathrm{ft}$. in diameter, and with a bole rumning clear of branches to a height of 60 or $70 \mathrm{ft}$., while the total height is over $120 \mathrm{ft}$. high. It is this tree that gives the well-known splendid effect to the American woods during the "Indian summer" in the months of September and October. Then the leaves put on all shates of colouring from a bright orange 
to a dark crimson; and these, mixed with the still green leaves of many other trees, give an effect to the woodland scenery of America which is probably not equalled in any other part of the world. The splendour produced by this colouring of the leaves of the Soft Maple is greatly heightener through the trees being lacked by the dark foliage of the I'ine; and it is where these two kinds are found growing together that the grandest effects are produced. The tree is, in an ornanental point of view, well worthy of extensive cultivation in Britain, where, however, it is never likely to assume the sane sylvicultural importance as both the Sycamore and the Maple deserve. Those who have not seen this species in its native labitat in autumn can form but a very imperfect idea of the beauty it gives to woodland scenery. If planted along the margins of woods, or on the sides of roads and walks running through plantations, and on prominent sites here and there over large estates, the pleasurable effect produced in the autumn by the various colourings of its leaves will amply repay any little cost and trouble involved in these operations.

In order to ensure its giving the best effect, the Soft Maple should be planted with an intermixture of trees having a darkcoloured and evergreen foliage; for these, properly mixed, will produce a colouring of foliage in the autumn that will bafle description, and produce a picture which no painter's art dare imitate.

Economic Uses.-In America there are few trees applied to more general uses than the Soft Maple. Where it is plentiful, the timber is used as fuel in preference to any other kind. In housebuilding it is in much demand; and it is also employed very extensively for furniture. Perhaps the most beautiful of all household furniture is that made of the well-known wood called "bird's-eye Maple." Considerable quantities are brought from Canada to Britain for the purposes of cabinetmaking. That the salp of this tree produces large quantities of sugar is perhaps not necessary to be referred to here.

Soil and Situation. - The Sugar Maple is not so harly in the climate of Britain as the Norwiy Mriple or the Common syeanore, but in all cases requires a rather sheltered situation, and a dry, open-bottomed, rich, and rather light soil, to develop well on. It will thrive well and attain fair dimensions as a tree on parts of the country not over $400 \mathrm{ft}$. above sea-level, when it has the shelter of other plantations, and when planted on the sonthern sides, or in openings in these; but it will not grow on bleak or exposed parts, nor on a cold-bottomed soil, especially if it have a northern exposure.

According to the results of the experiments conducted by the Prussian Government in the State Forests of Xorthern Germany (Schwaprach, Zcit- 
schrift für Forst- und Jagdwesen, 1891), the Soft Maple thrives best on a fresh, and somewhat loamy, sandy soil. It is of slower initial development than the Maple and Sycamore, but soon exhibits considerable energy in upward growth. Like them, it is at first somewhat sensitive to late frosts in spring, and therefore requires some kind of protection. The wood produced is said to hold out very considerable promise of high value, so that its cultivation has been recommended on suitable situations. The use of good stout transplants of 3 to $4 \mathrm{ft}$. in height is advisable.

Another North American species, the Silver Maple (A. dasycarpum), is also well deserving of the attention of arboriculturists. It attains good dimensions, is little sensitive to late frosts, hardy in exposed windy situations, and very quick in growth, besides being an object of great beauty in woodland landscape. Not only is its foliage in itself beautiful, but as it throws out very many short shoots, these appear to hang around it like a pendulous veil or fringe. These numerous qualities seem strong recommendations for its cultivation in woods, as well as in parks and avenues.

Propagation and Culture. - This tree is raised in Britain from seeds imported from America, and in the culture of the plants they are dealt with in the nursery in all respects as has been recommended for the cultivation of the Sycamore. Young plants are, however, often imported from America.

\section{SALICACEA RICH.}

This family, which is almost entirely confined to the northern hemisphere, and chiefly inhabits the temperate zone, contains only the two genera, Poplar (Populus) and Willow (Salix).

In the Poplars the buds are enclosed within several bracts; the catkinscales are cleft or toothed; the stamens are numerous ( 8 to 30 ), have short filaments, and are, along with the ovary or base of the pistil, surrounded by a cup-shaped receptaculum; whilst the leaves have long petioles or leafstalks, and are mostly large and broad, or frequently lobed. They are all trees, and none of them mere shrubs.

In the Willows the buds are enclosed by what is apparently one bract (but which is in reality merely the concrescence of the two lowest bracts); the catkin-scales are entire, being neither cleft nor toothed; the stamens $(2,3$, or 5 ; seldom more) are prominent, the anthers being supported on long filaments, and instead of the stamens and pistil being enclosed in a cup-like receptaculum, two glands are situated below the ovary (one on each side; one of these usually withers or becomes deformed); whilst the leaves have short petioles, and are always whole and unlobed. The majority of the species are shrubs merely, and not trees.

\section{THE POPLAR, Populus (Lixxeax System, Diceda Octandria).}

Character of Genus._- Bractea to the flower of each sex laciniated on its terminal exlse. Mule glum, consisting of a calyx, and $\mathrm{S}$ stanens 
at ferest, in many instances many more. Female florcir consisting of a calyx and a pistil (Loudon, op. cit., p. 819).

There are several species of this gemus which are well adapted for forest timber-trees. Alout twenty linds of I'oplar are enumerated in the last edition of De Candolle's Prodromus, but of these only seven are of arboricultural or sylvicultural interest in Iiritain. The species which are most worthy of our notice here are the Hlack l'uplar, Populus nigra; the Abele-tree, or White Poplar, Populus alba; the Grey Poplar, $P$. canescens; the Lombardy Poplar, P. pyramidcitis; the Canadian, or Black Italian Poplar, $P$. canadensis; the Ontario Poplar, P. candicans; and the Aspen or Trembling Poplar, $P$. tremula. With the exception of the last-named, these are all rapidgrowing trees, which attain very large dimensions when planted in a soil congenial to their nature.

These different species of Pollar are distinguished botanically as follows (Willkomm, op. cit., pp. 515, 516) :--

I. True or Black Poplars.--Leaves with translucent edges, coloured nearly alike on both surfaces, and never lobed.

1. Crown consisting of upright branches, narrow, and conical in outline. Lombardy Poplar . . . P. pyramidalis.

2. Crown broom-shaped, consisting of very numerous long shoots and but few short shoots, long shoots when young without corky bark; ovary oval and consisting of two divisions, stigma divided. Black Poplar . . . . . P. nigra.

3. Crown diffuse, consisting of compratively few long shoots and very numerous short shoots; long shoots of no great length when young, but thick, and ribbed with corky bark; ovary pumpkin-like, with 3 or 4 divisions, often having depressions between them; stigma simple. Canadian Poplar

P. canadensis.

II. Aspens.-Leaves mostly wavy - edged, or coarsely toothed, and occasionally lobed.

4. Leaves with snow-white pubescence or felty down on the lower side, and of two different shapes, those that are formed first on shoots of young growth being round and somewhat waryedged, whilst those formed later on older shoots are much larger, and have 5 more or less distinct lobes; stigma dividing into 2 ends. White Poplar . . . . P. alba.

5. Leaves with greyish-white pubescence on the lower side, and always of the same shape; stigma dividing into \pm ends. Grey Poplar

P. conescens.

6. Leaves of the short shoots nearly round, and with bluntly notehed or toothed edges; stipules linear-lanceolate. Aspen

P. tremula.

III. Balsam Poplars.-Leares green to the extreme edge of the upper surface, but of a whitish-green colour on the lower side, and never 
lobed. Crown diffuse, as there are fer long, but many short shoots.

7. Leares triangularly or ovally cordate, and almost as broad as long (resembling the leaf of the Lime in shape). Ontario Poplar

$P$. candicans.

Except the Aspen, none of the Poplars is indigenous to the British Isles.

\section{(1.) THE ITALIAN Or LOMBARDY POPLAR, \\ Populus pyramidalis Roz.}

Srronms - $P$. dilatata Ait.; $P$. fastigiata Pers.; P. italica MIönch.

Specific Character.-Petiole compressed. Disk of leaf deltoid, wider than long, crenulated in the whole of the edge, even the base: glabrous upon both surfaces. Leaves in the bud involutely folded. A fastigiate tree. Flowers red; March and April.

This is by some botanists (e.g., Willkomm, op. cit., p. 528) recognised as probably merely a variety of the following species, the Black Poplar, although it has been classed as a separate species in the latest edition of De Candolle's Prodromus.

Apart from its peculiarly fastigiate growth, and its long, conical crown, formed by the thin branches striving strongly upwards, it exhibits no botanical differences from the Black Poplar. In their wild state, trees producing female flowers have only been found on the Himalaya Mountains (by Royle) and throughont the northern part of the Punjal, (loy various forest officers), although some occur cultivated in southern Germany and in Austria. All the trees of this species throughout Britain are of the male gender. But as propagation can be very easily effected by means of slips or layers, this want of natural regenerative power is practically of no consequence arboriculturally.

Distribution.-This tree, as its name indicates, is a native of Lombardy in Italy, and it is said to be found growing naturally on the banks of the Po. It was introduced into Britain about the year 1758 .

Description of Tree. - This species is easily distinguished from all other trees of the genus by its tall, narrow, fastigiate form, and by the entire absence of horizontal branches. In this respect its habit very much resembles that of the Irish Yew. It is not a tree suitable for sylvicultural purposes, but rather for arboricultural attention merely. It is excellently adapted to stand as an ornamental tree on certain situations in a park among other sorts; for its tall and upright form has an imposing effect among trees of a lower and spreading habit.

Throughout the whole of the northern portion of continental Europe-in France, Germany, Denmark, Holland, and Belgium - it is one of the kinds of trees most frequently to be found forming avenues along the roadsides or 
chaussees. But its use in this manner is not to be recommended; for it throws long shadows over crops lying behind it, and, like the Ash, has a tendency to rob the soil of its nutrients through its long, shallow, stragrgling surface-roots. It also becomes monotonous, depressingly monotonons, along roads.

Economic Uses of Timber.-From the stem of this species being generally deeply furrowel, and seldom attaining great dianeter, it is not valuable as timber, but chiefly prized for ornamental effect. In England trees of this sort, of not more than fifty years of age, often attain a height of $100 \mathrm{ft}$. The timber is, however, even when of large size, only used for purposes for which lightness is more important than durability; and even then this wood is generally rejected when the timber of either the Black or the White Poplars can be had.

Soil and Situation.--In order to enable it to grow so rapidly as it is capable of doing, the Lombardy Poplar requires a strong loamy soil, and at the same time a low-lying and naturally sheltered situation; without these it grows comparatively slowly, and becomes merely a tall, densely branched bush. It is admirably adapted for planting in the streets of towns, as it takes up but little space with its closely-drawn-up branches, and is very little affected by the smoke, in which many other kinds of trees would languish. When these Poplars are planted closely in a line, they form an excellent tall hedge in a remarkably short time, giving shelter to more tender plants for a considerable distance behind them.

From Ebermayer's investigations and analyses (op. cit., p. 230), the Italian Poplar makes demands for mineral nutrients exceeded only by those of the Ash; and at the same time it seems able to transpire larger quantities of water per unit of dry substance of its foliage than any other species of woodland tree.

Propagation and Culture.-This tree is propagated chiefly by slips or cuttings of the young wood, which in light open soil root freely, and are fit to plant out when one or two years old, according to the height of plants wanted.

\section{(2.) THE COMMON BLACK POPLAR, Populus nigra L.}

Srnonrurs-P. viminca Du Ham.; P. vistulensis ct polonica Hort.

Specific Character.-Petiole somewhat compresserl. Disk of leaf deltoid, pointed, serrated with glanded teeth, glahrous on both surfaces. Catkins lax, cylindrical. Stigmas 4 , simple, spreading. Flowers dark red; March and April. Seed ripe in Mary (Loudon, op. cit., p. 824).

Distribution.-Although the Black Poplar is now to be found throughout the greater part of Europe, from sweden in the north to 
Italy in the south, it is unquestionably indigenous only to the southern parts of the C'ontinent, Wmdering on the Mediterranean Sea. It is a tree of true forest growth only in the low-lying tracts throughout Spain, Southern France, Italy, Austria, Roumania, and Greece. Thence it stretches eastwards into Southern Siberia. It is said to be found also in some parts of the north of Africa.

Botanists are agreed that it is not probable that this tree was indigenous to Britain, or to any part of north-western Europe; but it may have perhaps been introduced as early as the Roman occupation, for it appears to have been found growing wild from time immemorial.

Description of Tree. - The Black Poplar is a tree which attains large dimensions of timber in a very short time; but frequently it does not endure long when it has arrived at maturity, which may be reckoned at about fifty years of age. When planted in a low-lying moist situation, even without having the advantage of shelter, it forms a very graceful and prominent tree in the landscape :

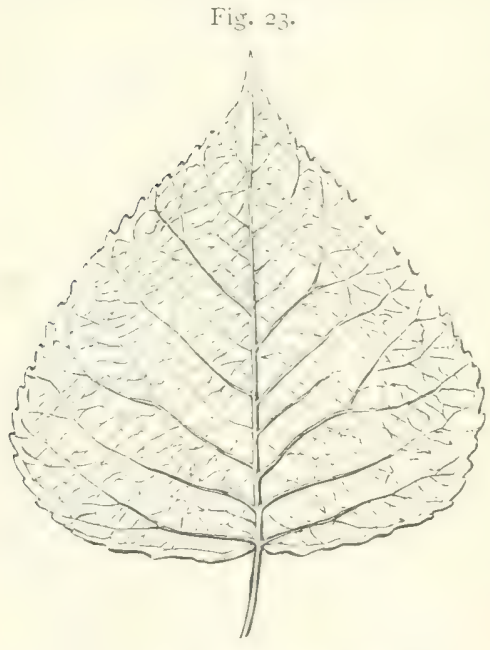

Leaf of the Common Black Poplar (P. nigra). but if planted out among trees of slow growth it soon overtops all the others, and then has by no means a fine arboricultural effect. When it is planted in a situation adapted to its rapid growth, it forms a magnificent tree, having a large spreading top, and forming an extremely massive trunk. The great rapidity of its development is very remarkable; it is the quickest-growing of all the European species of timbertrees. Young trees of only thirty years of age may attain a height of about $80 \mathrm{ft}$., and may contain upwards of 60 eubic $\mathrm{ft}$. of timber. This proves the remunerativeness of the tree when planted on a suitable soil and site. Within each of the three main subdivisions of Poplars, many of the species much resemble one another in the appearance of their leaves. But the Black Poplar is easily distinguished from most of the others by having its leaves of a pale-green shining colour; their shape is by botanists termed deltoid, or trowel-shaped; they are pointed and serrated, and smooth on both sides (see Fig. 23). The leaf-stalks of this species are thin and slender at their insertion upon the leaf; this gives them a vibrating motion upon the tree with every breath of wind. 
The name Black Poplar has reference to the bark, which soon fissures longitudinally and (in contrast to the White Poplar and Aspen) loses its smooth light surface. The colour deepens as the stems increase in age.

It is easily recognisable at a distance from its very close relative, the Canadian or Black Italian Poplar, by the crown being somewhat thinner and more open, owing to the branches leaving the stem at a wide angle; whilst in the latter they form a smaller angle with the stem, and also curve in slightly near their extremities.

Economic Uses of Timber.-The wood of this tree is much sought after by cartwrights for bottoming, and is likewise used for many purposes in turnery. It is also much in demand on the Continent, and in some parts of England as well, for sabots or wooden shoes.

It is soft and light, hence may be very well adapted for the manufacture of packing-cases or similar articles where lightness is a consideration, and no great demands are made on the durability of the wood used; and of late years there has on the Continent arisen a very considerable demand for Black Poplar timber for the construction of railway waggons.

Soil and Situation.-In order to grow this species profitably, it should be planted in a good strong loam, rather of a moist and deep character, but not with stagnant water in the subsoil; for although the tree makes high demands with regard to the mineral nutrients withdrawn from the soil, yet it will not-nor does any of the genus-prosper if its roots get down into stagnant water. Black Poplar thrives best upon a deep sandy loam, and in a sheltered situation among other trees, where it has ample room to spread out its branches. Trees of very large size may, however, be grown upon a poor light soil, situated upon sloping banks, where water percolates freely down the slope. But none of the Poplars will develop profitably upon a dry, thin, high-lying soil. All the species thrive well

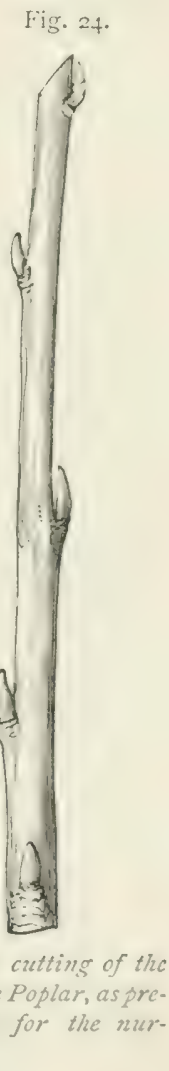
on the sides of rivers, where the land is well sheltered, and of a deep, open, and rather rich character: but even there they will not io well if the water stagnate about their roots.

Propagation and Culture. - This species is venerally propagated by slips or cuttings of the roung wool (see Fin. 24), which take root in the nusery-gromel with extremely little attention; and 
after remaining one year in the cutting state in the nursery, they are fit for transplanting out into the open.

The Black Poplar is plentiful on most alluvial parts of the country, often forming trees $80 \mathrm{ft}$. high, and with stems over $3 \mathrm{ft}$. in diameter.

\section{(3.) CANADIAN or BLACK ITALIAN POPLAR,} Populus canadensis Desf.

Symonyus $-P$. monilifera Ait.; $P$. virginiana Dum.; $P$. marylandica Bosc.; $P$. levvigata W. ; $P$. carolinensis Mönch.

Specific Character.-Young branches angled. Petiole compressed. Disk of leaf roundish ovate, deltoid, acuminate, subcordate at the base, where there are glands, serrated with unequal teeth, glabrous. The branches are angular, and the angles form whitish lines, which persist even in the adult age of the tree. The young buds are gummy. Flowers red; April and May. Seeds ripe in June (Loudon, op. cit., p. 825). In nurserymen's lists the Canadian Poplar is most commonly known as $P$. monilifera.

Distribution. - This species is a native of Canada and the United States, where it is to be met with growing naturally in ravines and on strong clay-lands, and there forming a tree of moderate size, but seldom of such dimensions as it attains in Britain. In its native habitat it is generally found growing along with other indigenous species of the same genus, and forming trees of from 60 to $70 \mathrm{ft}$. in height, and having a stem of from 18 to $24 \mathrm{in}$. in diameter near the ground. In the cultivated state in Europe, however, it often attains a height of $100 \mathrm{ft}$., and forms a stem between 3 and $5 \mathrm{ft}$. in diameter. When cultivated in the Western States of America, it also attains very large dimensions as a timber-tree. Introduced in 1769.

Description of Tree.-Like the other true or Black Poplars, this species is characterised by more rapid growth than any of the Aspens or Balsam Poplars. In habit it very much resembles its close relative the Common Black Poplar; but it is of somewhat more upright growth, and does not throw out its branches so widely: in this respect it seems to hold a position about midway between the Black and the Italian Poplar. In its younger stages this species is therefore easily known from the Common Black I'oplar by its growing more directly in the form of an upright stem, and by its branches being smaller as compared with the diameter of the stem.

The crown of foliage is somewhat thicker than on the Black Poplar, the branches are more upright, and the tips of the twigs bend in slightly towards the stem-distinctions that may often be recognised from some distance. The leaves are usually larger and of a darker green than the foliage of the Black 
Poplar; but these differences are comparatively slight and inconstant. When short stiff hairs can be detected with a magnifying-rglass between the teeth at the edge of the leaf, the tree is of the varicty known throughont the Lnited States as the Cottonwood, P. monilifera (Burckhardt, op. cit., p. 503).

Economic Uses of Timber.-The timber of this tree is very similar to that of the Black Poplar, and is used for the same purposes in all respects. Indeed many consider the wood of the Canadian Poplar superior to that of any other species. It generally assumes larger dimensions, and is therefore applicable to a greater number of purposes than any other of the Poplars; but so far as regards the durability and the general quality of the timber, it cannot be said to be superior to the wood of the Black Poplar. None of the tribe can, however, compare with this tree in the great length of its stem for available timber; for in this respect it often even surpasses the Black Poplar, which is the most rapid growing and most productive of all our European timber-trees.

Soil and Situation.-WTe Canadian or Black Italian Poplar, in order to attain perfection, requires a stroug loamy soil and a sheltered situation. When planted on an indifferent soil, or on any site much exposed to winds, it is inferior to the Common Black Poplar, both with regard to the quantity and the quality of its crop. As a timber-tree it is therefore only suited for land of good quality; but on such it may often attain extraordinary dimensions, even when comparatively young.

In the State forests throughout Northern Germany more attention is now being given to the cultivation of this species than to any other of the nonindigenous Poplars. For, besides standing the trying Continental climate well, it shows itself accommodative with regard to the soil, and is extremely rapid in growth; whilst its wood is considered of better quality than that of the Black Poplar. And although still essentially a light-demanding species of tree, its more restricted cromn gives it a sylvicultural adrantage over the latter.

Being a very hardy tree as regards frost, it thrives well in the far North. In Norway it is also the species of Poplar which now receives the greatest amount of attention in consequence of its rapidity in the production of light timber suitable for match-making, paper-pulp manufacture, and the like.

Propagation and Culture.-This Poplar is usually propagated from slips or cuttings of the young wood, which root freely in any moderately light land. Cuttings of one year's growth are not infrequently fully $4 \mathrm{ft}$. high, and quite fit to plant out into the forest, thus showing the rapid growth the tree makes, even in its first stage from the cutting.

This species is common in most alluvial districts of the country, where it attains very large dimensions, often reaching heights from 100 to $130 \mathrm{ft}$, with stems from 3 to $5 \mathrm{ft}$. diameter. 
(1.) THE ABELE-TREE or WHITE POPLAR, Populus alba L.

Specific Character. - Leaves lobed and toothed; somewhat heart-shaped at the base; snow-white, and densely downy beneath. Catkins of the female plant ovate. Stigmas, 4. Flowers dark brown; March. Seed ripe; May (Loudon, op. cit., p. 820).

Distribution.-The White Poplar is indigenons to many parts of southern Europe, and is found in the west of Asia and the north of Africa; but in the northern half of Europe it has only been produced artificially. It is cultivated to a considerable extent throughout Germany and France. In some of the forests of the latter country it is said to be now so plentiful in some places as to form the prevailing tree over large districts, where it is the principal fuel

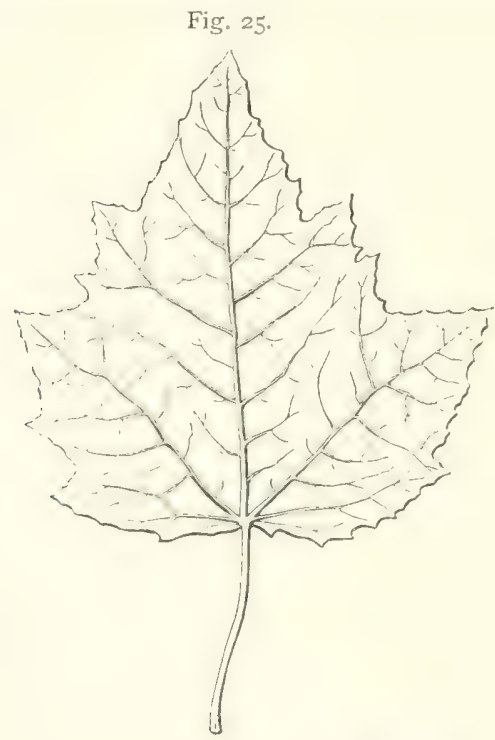

Fig. 26.

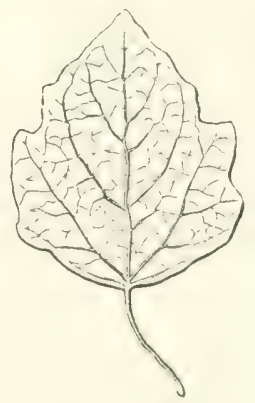

Leaf produced on an older shoot of the White Poplar.

Leaf produced on a young shoot of the White Poplar (P. alba).

of the inhabitants. This species has been long in cultivation in Britain, and has by some botanists been considered as one of the indigenous trees.

For climatic reasons this is extremely improbable; but it may have been introduced into England along with the Black Poplar at a very early date.

Description of Tree. - This is a tree of a well-formed upright habit, and upon a lawn or park it makes a very fine contrast by its white, waving, downy leaves and silvery branches glittering among others of a darker colour. The leaves of this species are upon 
young plants almost palmate or five-lohed, and are larger than those taken from an older tree (see Fig. 25, which shows a leaf taken from a coppice-shoot of the second year's growth). In the young state the leaves are covered with a white down beneath, and on the upper surface but slightly. Upon plants a few years old the leaves are much smaller, though also darkgreen, and smooth on the upper surface; but they are not palmate, being wavy-edged or merely with slight indications of lobes, and somewhat toothed (see Fig. 26). The young branches are also thickly covered with down, and are of a more spreading and ramifying habit than those of the last-mentioned species (see Fig. 27 ); they are also more slender and tough. This tree, wherever it is planted, throws out shallow surface-roots and sends up large quantities of suckers from the

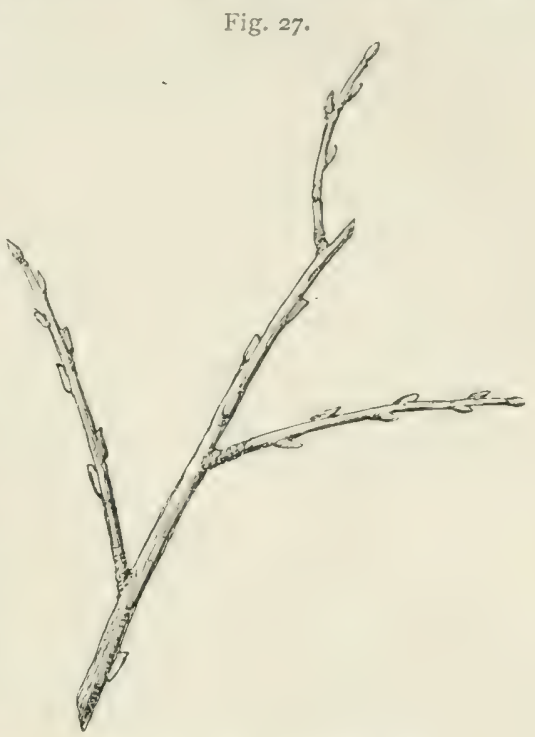

Branchlet of the White Poplar. roots all round, which often become troublesome on pasture. Therefore, where clean pasture is an object, it should not be planted on grazing land, but should be strictly confined to the woodlands.

Economic Uses of Timber.-The wood of this species is white, very light and spongy, but is as durable as that of the Conmon Black Poplar when cut up. It is, therefore, fairly well adapted for planking, which is used for flooring, cart and waggon bottoms, \&c., and it sells readily for these purposes. It is also used for packingcases, for turnery and cabinet-work; and the boards and rollers round which manufactured silk is wrapped are for the most part made of it, from its being soft and light, and not liable to injure the material.

It has a sp. gr. of 0.95 when green, and 0.48 after the wood has been seasoned. Along with Aspen and Black Poplar, its cultivation is wortlyy of attention wherever its wood may be disposed of to local match factories or cellulose mills, or any similar industry requiring a regular supply of soft timber. It resembles the Black Poplar in yielding markctable timber of good size at about forty to fifty years of age.

Soil and Situation.-Like the Common lilack Poplar, this tree thrives best in a sheltered situation, upon a moist loany soil, not of a binding description. When planted on low-lying grounds near 
the sides of water streams, where the soil is deep and open, it wrows ratidly, and in a few years attains large dimensions. On deep open land, and on sheltered situations, it is, next to the lilack P'oplar, the must rapid-growing of the genus, and is well worthy of extensive culture for many purposes. It is an excellent tree for coppice-rood, and on low-lying and favourable sites produces a crop very quickly. It thrives well in the neighbourhood of towns, and does not seem to be so much affected by the smoke from them as some other trees are.

Where it may be found springing up spontaneously near the banks of streams, the soil will generally be found to be of a sandy-loamy or humose description. Although not so exacting with respect to the amount of mineral food annually extracted from the soil, it is less accommodative than the Black Poplar to soils that are not exactly of the loamy-sandy description that suits it best; and on the whole it is not so rapid in growth as that species. On heary argillaceous soils it is apt to become dry in the crown ("stag-headed ") at an early period.

Propagation and Culture.-The young plants of this species are propagated by slips or cuttings, by layers, and by stoles or root-suckers. The latter rise freely from the roots wherever they are growing; and if put into the nursery-ground in the spring, they will be ready for transplanting out into the open during the following autumn or spring.

The slips or cuttings of this species do not, however, strike so readily as those of the Black Poplar; but the system is easy, cheap, and satisfactory. Planting of the slips, and the putting out of transplants in the open, should be undertaken in the spring.

This species on favourable soils and situations forms a large timber-tree, attaining a height of from 70 to $100 \mathrm{ft}$., with a bole from $2 \frac{1}{2}$ to $5 \mathrm{ft}$. in diameter.

\section{(5.) THE COMMON GREY POPLAR, Populus canescens Sm.}

Sxwonrms $-P$, alba aut canescens Ait.; $P$. alba-tremula Wimm.

Specific Character.-Leaves roundish, deeply waved, toothed; hoary and downy beneath. Catkins of the female plant cylindrical. Stigmas 8. It is essentially distinguished from $P$. alba by the stigmas, which are 8 , spreading in two opposite directions. The bracteas of the fertile flowers are, also, more deeply and regularly cut (Loudon, op. cit., p. 820).

Distribution.-The common Grey Poplar is a native of northern Germany, lower Austria, and Servia.

Throughout north-western Europe, in France, Belgium, Holland, and Britain, it has been introduced artificially. It is now by a good many 
botanists regarded as a hybrid between $P$. allure and $I$. tremulu, althourh it is able to produce seed in a specific manner. During the earlier period of its development the greyish-white, pubescent foliase somewhat resembles that of the White Poplar ; but later on it is more like that of the Aspen, - a similarity that is heightened by its flattened leaf-stalk, in which resprect it differs essentially from the former species. But in its general sylvicultural characteristics it resembles the White Poplar more closely than the Aspen.

Description of Tree. - The Grey Poplar very much resembles the White Poplar; but it is easily distinguished therefrom by its greater propensity to send up suckers, and that often at a great distance from the tree, as also by the branches being more upright and compact. The leaves are rounder, more conspicuously 3-ribbed, and less deeply or acutely lobed; they are not folded in the bud, and are without any gummy coating. They are downy beneath, but the down is chiefly greyish, and not so white or cottony as in $P$. alba; but in some instances the leaves are glabrous (Loudon, ibicl.) This species can at once be distinguished from the White Poplar by its leaves being less deeply lobed, and by the down being somewhat grey upon the under side of the leaf (see Fig. 2S). In favourable situations it grows as rapidly, and to as great a size, as the White Poplar, but its branches assume a more upright form of growth. It forms a very ornamental tree in a low-lying situation upon a soil adapted to its nature. It is a very hardy and accommodating species, and attains the dimensions of a timber-tree upon a greater variety of soils and situations than any other of the Poplar

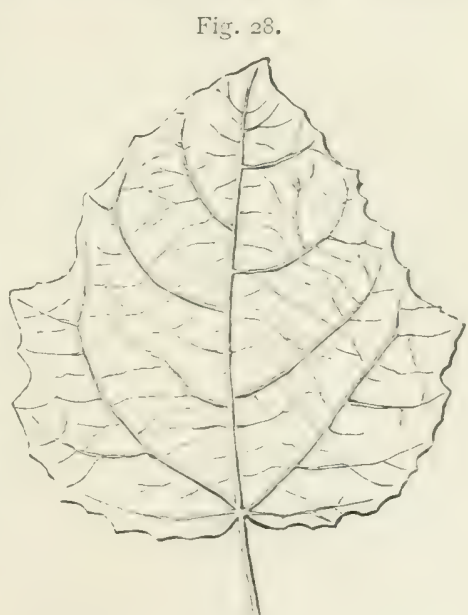

Leaf of the Grey Poplar (P. canescens). tribe. This species also makes excellent coppice, and is very productive of young shoots, which rise up freely even in a rather indifferent soil. This strong reproductive capacity might be utilised very profitably, and to a large extent, for the production of poles, fencing, \&c., \&c. As coppice it is very easily kept up, on account of the great tendency the tree has to throw up stoles or suckers all over the ground upon which it grows, - a capacity that it shares with both its nearest relatives, the White Poplan and the Aspren.

Economic Uses of Timber.-The wood of this tree is used for the same purposes as that of the White I'oplar. The timber of both species, when of large size and goou quility, is much sought 
after for musical-instrument making, and for carving purposes, as also for wooden dishes.

Soil and Situation.-The soil on which this species attains its greatest bulk of useful timber is a good loam with a fair supply of rumning water. As already stated, however, it attains the dimensions of a timber-tree upon a greater range of soils and situations than any other of the Poplar tribe. Still, it is only in a low-lying situation, and on a good, rather moist loam, that it develops itself normally; but under these circumstances it rapidly becomes a very lofty tree, frequently rising to $80 \mathrm{ft}$. in height, and developing a fine straight bole, surmounted by a large and spreading crown of light foliage.

Propagation and Culture.-The Grey Poplar is propagated in the same manner as the White Poplar, though less frequently from slips or cuttings than from suckers. For in all cases stoles or rootsuckers ultimately develop better and maintain themselves longer in healthy growth; hence they are usually given the preference for the production of a supply of young trees. When detached from the roots of the parent plant, they may be put into rows in the nursery for one year, when they will be ready for transplanting out into the open. As, however, a supply of plants from this source cannot always be had, nurserymen generally propagate them by layers from stocks cultivated for the purpose in their grounds, and in the same way as previonsly described with reference to the English Elm (see p. 136).

Generally speaking, the leading arboricultural characteristics of this species are its heavy-branched and widespreading top, and its greater diameter of stem in proportion to its height than any of the other Poplars. In many parts stems of this tree may be found upwards of $4 \mathrm{ft}$. in diameter, whilst at the same time its height may not rise much over $60 \mathrm{ft}$. The tree is common in all parts of the country, there being few estates without some fair specimens of it.

\section{(6.) ASPEN or TREMBLING POPLAR, Populus tremula L.}

Specific Character.-Young branchlets hairy. Leaves having compressed footstalls, and disks that are roundish ovate, or nearly orbicular; toothed in a repand manner, downy when young, afterwards glabrous on both surfaces. Stigmas 4 , erect, eared at the base. Flowers brown; March and April. Seeds ripe; May (Loudon, op. cit., p. 821).

Distribution.-The Aspen or Trembling Poplar is one of the comparatively few trees truly indigenous to Britain. It is a native uf most parts of the country, and is especially of frequent occurrence in the wet cold districts of the Highlands of Scotland. It is very 
plentiful in the valley of the Spey, and also in that of the Dee as far up as Braemar. It is likewise found of spontaneous growth in Ireland.

The Aspen has probably a larger range than any other species of tree, as it occurs from Lapland southwards into Africa, and from Ireland and Portugal eastwards through most of Asia, even to Japran. - Although its exact limits have not yet been determined, its range embraces no less than $35^{\circ}$ of latitude and $140^{\circ}$ of longitude. In eastern Prussia, Poland, western Russia, Galicia, and Hungary it forms extensive forests throughout low-lying tracts, where it is often to be found forming jure forests, although more generally associated with the Birch and the Common Alder in mixed forests. In other parts of Europe it is chiefly to be found in clumps or patches of various extent, scattered throughout forests of other broad-leaved or of coniferous species, and generally occupying low moist tracts. Its finest development is attained in Poland, and throughout the neighbouring parts of Prussia and Russia (Willkomm, op. cit., p. 525).

Description of Tree.-The Aspen is a very interesting species of the Poplar family, on account of its leaves being put into motion by the slightest breeze; and, indeed, few woodland phenomena are more attrictive than the fluttering of the Trembling Poplar on a calm evening. The leaves of all the Poplars are easily agitated by the most gentle breeze, but those of this species often become agitated while there is no breeze whatever to be felt; and it is this circumstance, due to the leaf-stalk being flattened or compressed and set on edge, that gives the tree an interest to most people who witness its foliage fluttering in a calm, wind-still summer evening. It is a rapidgrowing tree in its early stages of development; but it seldom produces timber of a large size, as it attains maturity at an early age. The trunk is generally straight, clean, and tall in proportion to its diameter, and has a smooth grey bark. The branches extend horizontally, and are for the most part thinly distributed along the stem; hence the tree assumes a drooping habit as it advances in age. This species has a strong tendency to throw up suckers from the roots, and these

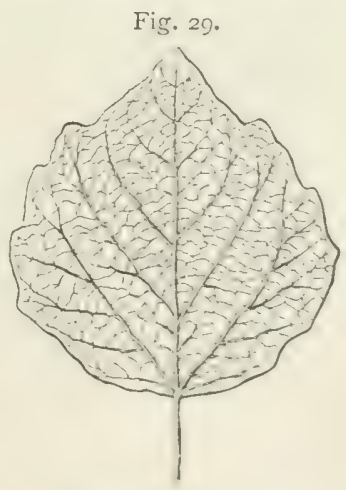

Aspen lcaf (P. tremula). are often produced so plentifully near the parent tree as to form an almost impenetrable thicket around it. The leaves very much resemble those of the Grey Poplar; but they are easily distinguished from them by being more nearly round, and also smooth on both sides, after the month of June (see Fig. 29).

Economic Uses. - Although this very interesting tree is worthy 
of a place in a properly chosen part of every park or plantation, on account of the peculiar trembling motion of its leaves, yet, as a timber tree, it is only of third-rate importance, for it does not produce timber of nearly so good a quality as the other species already described among the Black Poplars. The wood, when cut up, is in all cases short-grained, and very easily broken when applied to any useful country purpose.

As it has a mean sp. gr. of only 0.81 , which becomes reduced by seasoning to 0.51 , it is one of the woods that are easily floatable immediately after felling.

On the Continent its chief use at present is for the safety-match industry, and for the manufacture of wood-pulp for paper. In common with other soft woods it is well adapted for the latter purpose; but Aspen and Lime are preferred to Birch in these industries.

Soil and Situation. - This species thrives on any moderate soil, provided it is rather of a wet than a dry nature. The natural conditions of soil and situation for the Aspen are to be found in most extensive woods, such as prevail in many parts of the Highlands of Scotland. On low-lying meadows, or the edges of plantations, however, where the tree has a good depth of soil of a moist nature, and at the same time is well sheltered by the adjoining plantation, it can attain its largest dimensions, and may often be found containing as much as 40 cubic ft. of timber per stem.

It is a very hardy species of tree, and is therefore to be found of spontaneous growth in damp localities, even where late and early frosts are most frequent.

It is exceedingly accommodating with respect to the mineral character of the soil, and even ascends the hillsides to higher elevations than any of the other Poplars. But whenever planting operations on sylvicultural (i.e., financial) principles are under consideration, it can only be expected to yield good returns on fairly good soil; and in the majority of cases the land may be very much better utilised for the growth of other species of trees.

Propagation and Culture. - The Aspen is propagated chiefly from layers and suckers, the latter being found plentifully in every wood where the tree occurs. These have only to be dug up with their roots, and transplanted into rows in the nursery for a year or two, when they are fit for removing to where they are to be planted out permanently.

Sylvicultural Characteristics and Importance of Aspen.-The Aspen is not on the whole well suited for growth in high-forest along with other broad-leaved trees. For, being of more rapid growth at first, it is apt to hinder the development of other species; and although it may then be cut out, when once its roots have obtained a good hold on the soil they long 
remain capable of sending out quick-growing suckers that are hard indeed to suppress. This is the great drawback to its use as a nurse for less hardy species in low, damp localities exposed to danger from late frosts in spring, a drawback that is to a certain extent also chargeal,le against the Birch. And in moist tracts of coniferous woods, where it is often to be found growing abundantly, its presence is not always desirable. Its foliage is liable to a trifling disease occasioned by the fungus Melampsore tremule; but this stands, however, in generation with the far more serious fungoid disease of Sicots Pine caused by C'eome pinetorqun, which occasions deformities of the leadingshoots, and ultimately of course of the bole. That same fungus has also been proved to stand in generation with a disease of Larch foliage, caused by Cacoma Laricis (Jour. Royal Hort. Socy., vol. xiv., 1892, p. 133). In a great many cases, therefore, it is in reality more or less of a weed. And it is one that is exceedingly hard to get rid of, owing to its strong reproductive capracity in throwing up crop after crop of stoles or root-suckers long after the parent stems have been felled, and the stools or stumps of the trees have rotted away. Its demands for light are only slightly inferior to those of the Larch and the Birch, and if allowed an opportunity of developing its crown, it soon exhibits its natural requirements for a large growing-space. Hence, although easily suppressed by other trees, it interferes greatly with their growth if once it be allowed to get its crown free above them. Its root-system is shallow and far-spreading; and, as already noticed, the manner in which stoles spring up when mature crops of timber are cleared away, long after all the Aspen have been cut out, is remarkable. This often interferes with the rewooding of annual falls.

A humid atmosphere and a moist soil are alike favourable to its development. As its seed-production is large when male and female trees are standing in close proximity to each other, and as the seeds are light and have cottonlike filaments attached to them, they can easily be wafted far into neighbouring woods.

In well-managed woods its rôle is only that of a very minor species of tree, which should be cut out of the crop and utilised before it has passed the age of forty years; for even by that time its bole has often begun to be unsound. Its sylvicultural treatment corresponds very closely with that of the Birch (see p. 183), with this difference, that when only one of these two kinds of soft woods can be removed at any given time during any of the periodical operations of weeding or clearing, the Birch should have the preference and be retained, as being probably capable of developing into a more valuable stem ultimately.

Where once the Aspen has been introduced into woods, there will seldom be any necessity for regenerating it artificially; the sylviculturist will more often find considerable difficulty in preventing it from becoming a troublesome weed.

The Aspen, even under the most farourable conditions, seldom attains such height or girth as the other species already described. Its general dimensions, muler ordinary ciremmstances, may be said to be about 40 to $50 \mathrm{ft}$. in height, with a stem of about $14 \mathrm{in}$. in 
diameter. On very farrourable soils and situations, however, it may attain a height of 70 or even $80 \mathrm{ft}$., with a stem of about $3 \mathrm{ft}$. in diameter.

(7.) THE ONTARIO POPLAR, Populus candicans Ait.

Srnonyus- $P$. macrophylle Lindl.; P. latifolia MIönch; $P$. cordata Lodd. ; $P$. ontariensis Desf.

Specific Character.-Shoot round. Bud very gummy. Stipules gummy. Petiole compressed in its upper part, hairy in many instances. Disk of leaf heart-shaped at the base, ovate, acuminate; serrated with blunt unequal teeth; 3-nerved; deep green on the upper surface, whitish on the under one, on which the veins appear reticulate. Flowers purplish; March (Loudon, op. cit., p. 831).

Distribution.-This species is said to be a native of Canada and the Western States of North America, and to have been introduced into Britain in 1772. Even in America it is seldom to be found growing spontaneously, although it may often be met with about farm-steadings, or planted in towns along the sides of the streets, but always in the cultivated state.

Description of Tree.-The Ontario Poplar is of extremely rapid growth, and from this circumstance it seems worthy of being described and recommended for planting. It appears to be especially suitable for cultivation as a timber-tree on the sides of streams with a shallow soil, on which other sorts of trees may not succeed profitably. It is easily distinguishable from all the other species of the same genus by its very large heart-shaped leaves (see Fig. 30), some of which measure $10 \mathrm{in}$. from base to apex. They are generally from 6 to $8 \mathrm{in}$. in length, and of a beautiful deep green colour on the upper surface. It may be also easily distinguished from any of the other Poplars by its gummy or resinous buds, which, especially in the spring, have an agreeable balsamic smell. In this respect it resembles its close relative the Common Balsam Poplar (P. balsamiferc $\mathrm{L}$.), which is also a native of the same localities, and is not infrequently to he found in Britain in parks and public gardens. But the leaves of the Ontario Poplar are so very much larger than those of the Balsam Poplar, that the two species of trees are readily distinguishable.

Soil and Situation. - To grow the Ontario Poplar well, it recpuires to have a plentiful supply of unlerground water, as without this it will not attain even fair dimensions. It should be planted on lands only some 2 or $3 \mathrm{ft}$. above the level of a river or stream, and along its banks, as in such places it will attain large dimensions in a very short time. 
It is not so hardy as the Canadian Poplar with regard to frost, and this danger is heightened by the fact that it begins to flush its foliage rather earlier in the spring than the latter species. Otherwise it is often of extremely rapid growth, and (according to Continental experience) under favourable circumstances can send out shoots of over $7 \frac{1}{2} \mathrm{ft}$. in length during the course of the year; but as such shoots do not harden thoroughly before autumn, they are apt to be injured by frost in winter (Burckhardt, op..cit., p. 502).

Propagation and Culture.-This species is readily propagated loy slips or euttings, which make rapid growth during the first year,

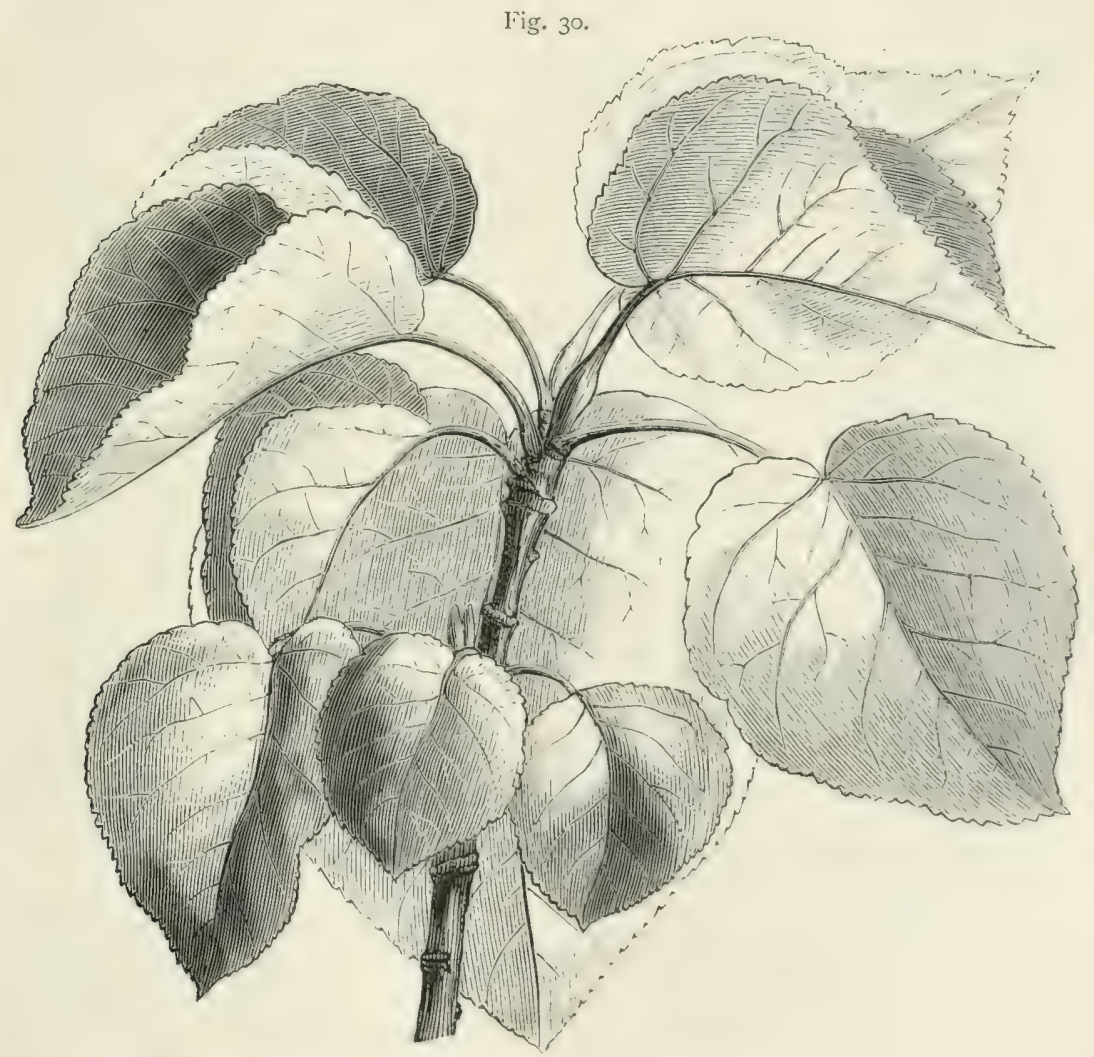

Cordate leaves of the Ontario Poplar (P. candicans).

and are fit to be planted out, on the land they are to occupy, when they are one or two years old, according as the plants may be wanted of a small or large size.

This Poplar, when planted on a suitable soil and site, attains a great height within a very short period. In some parts of the country it has been found to attain the height of $50 \mathrm{ft}$. in fourteen years. 
Like the White Poplar, it has a strong tendency to throw up stoles or root-suckers for some distance round about the parent stem; hence on pastureland it is not the most suitable kind of tree to plant, for its reproductive capacity in this respect is strong, and the stoles are ultimately difficult to suppress and get rid of. Similar trouble may also be experienced in nurseries where cuttings of this species may have been allowed to leave portions of their roots behind in the soil when the rooted slips were removed for transplanting into the open.

\section{THe Willow, Salix (Linneax System, Difcia Diandria).}

Character of Genus.-Bractea to the flower of each sex entire. Male flower consisting of 1-5 stamens, more in a few species, and of one or more glands inserted contiguously to the stamens. Female flouer consisting of a pistil that is stallied or sessile, or nearly sessile, and one or more glands inserted contiguously to it (Loudon, op. cit., p. 744).

There are many species of the Willow genus. Anderson (De Candolle's Prodromus, 1868) distinguished 160 species and 68 hybrids, of which 31 species and 57 hybrids occur in Europe. But comparatively few of these grow to a size yielding useful timber. At present, therefore, only the very few kinds need be described which really are, properly speaking, trees of the forest. And of these there are only two true species-viz., the common White Willow ( $S$. alba) and the Cracking Willow (S. fragitis), and also one hybrid, formed of these two species, the Bedford Wrillow (S. Pusselliunu)which on favourable soils and situations attain the dimensions of timber-trees of the first magnitude; but all of these are well deserving of a place either upon a lawn, or in woods managed purely on sylvicultural and financial principles.

These Willows are distinguished botanically as follows (Willkomm, op. cit., p. 463):-

1. Leaves covered with silky hairs, and whitish or greyish on the under-surface. Male flowers with 2 glands and 2 free stamens; female flowers with 1 gland . . . S. alba.

2. Leaves lanceolate, coarsely serrate and glandular. Branches and twigs easily broken off at the point of junction with the stem, and in mature trees bent upwards. Nale flowers with 2 glands and 2 stamens; female flowers also with 2 glands . S. fragilis.

It is believed that neither of these species is indigenous to Britain, but that both of them were introduced in the fifteenth century. The only species of this genus that seems to have been a true native of our island is the Saugh, Sallow, or Goat Willow (S. caprea L.), which, like its hardy relative the Aspen, is to be found over the whole length and breadth of Europe, and also stretches far eastwards into Asia. It is common in most moist low-lying tracts of woodland, and is easily distinguishable from any of the other species of 
Willow by its broad oval leaves, pointed and generally twisted at the tip, which are of a smooth dark-green colour above, but covered with greyish down beneath. It is, however, in general a tree of only the second or third magnitude, and is very frequently to be met with as a mere shrub on hillsides.

\section{(1.) THE COMMON WHITE or HUNTINGDON WILLOW, Salix alba I.}

Specific Character.-Leaves elliptic-lanceolate, pointed, serrated, silky on both sides; the lowest serratures glandular. Stanens hairy. Germen smooth, almost sessile. Stigmas deeply cloven. Scales notched. Flowers yellow; May (Loudon, op. cit., p. 761).

Distribution. - This species, although perhaps not truly indigenous to Britain, has at any rate maintained itself since the fifteenth century. It is found occurring frequently in most parts of Europe, from Sweden southwards to the Mediterranean, and is also said to be found in the western portion of Asia.

Hooker (Students' Flora, p. 337) considers it native.

Description of Tree. - The White Willow, in a situation favourable to its natural requirements, attains the dimensions of a first-class tree, and has an agreeable and elegant outline; hence it is a species well worthy of a place in any extensive park or lawn, where the soil is deep, strong, and somewhat moist, and the situation not too much exposed. Its growth is very rapid, and it is thus well adapted for planting in any situation in a

Fig. $3 \mathrm{r}$.

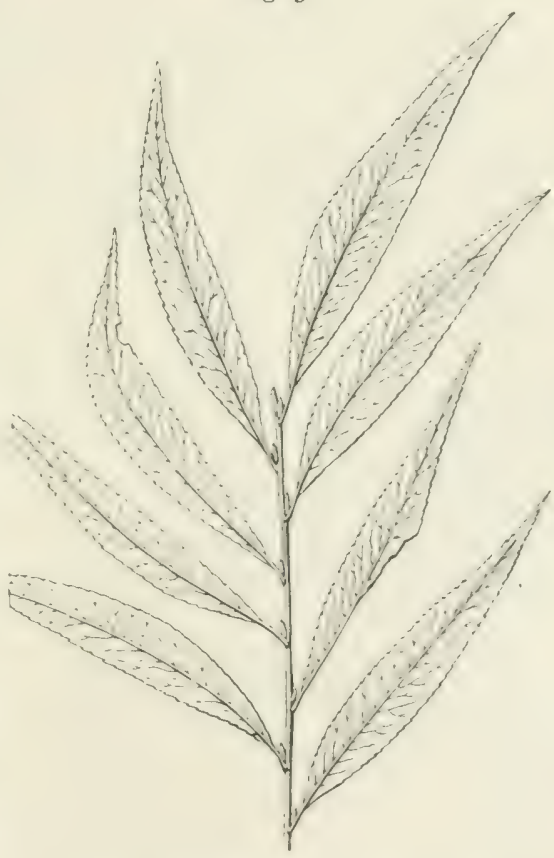

Foliage of the White IVillow (S. alba). park where it may be wished to hide a disagreeable object.

The leaves of the different sorts of IVillows have a close resemblance to one another; differences, indeed, cin only be detected and distinguished by a careful examination of their texture, more than by any conspicuous variations in shape. The White Willow has the leaves clliptic-lanceulute, or between oval and lance-shaped, and serrated, the lower serratures bearing small ylunds. Both sides 
of the leaves are covered with very fine silky hairs, which lie closely upon the bouly of the leaf, giving the leaves a whitish appearance, and cansing a beautiful effect when they are slightly moved by the wind. Fig. :I represents the leaves and young wool, as taken from a plant in the month of August. This Willow makes one of the best of all trees for the purpose of coppicing or pollarding, and forms a very profitable crop in coppice-woods when cut over at periods of from three to twelve years so as to yield poles of various sizes.

Economic Uses of Timber.-The wood of all the tree Willows is much sought after, and is preferred in all cases to that of the Poplar. It is reckoned more tough and durable than the latter, and is used for a great variety of country purposes. It makes excellent charcoal for porvder manufacturers, and is much sought after for this industry; but it is not easily procured in sufficient quantity. It is also particularly adapted for lining to stone-carts and coal-waggons, for which purpose there exists a fair market for large quantities of it. When struck by a stone or by any other heavy body, the deal produced from the Willow is not readily injured nor split, as is the case with deals made from the Fir and Pine trees; and it is this quality of toughness in the wood which makes it so valuable for technical purposes. As a paling-rail, it will last much longer than the young immature wood of the Scots Pine or Spruce Fir.

On the Continent all available kinds of Willow-wood are used as the framework or base for veneered furniture, for packing-cases, and as the raw material for match and wood-pulp factories. It would seem well adapted for the manufacture of railway trucks, as it would have the advantage of being tough as well as light. The sp. gr. of Willow wood in general is about 0.85 when sreen and 0.5.3 when seasoned ; hence it is floatable without requiring to be seasoned before being launched into the stream for conveyance to any distant mart.

Soil and Situation.--The White Willow requires a good deep and somewhat moist soil, such as that usually to be found on the banks of lakes and rivers, before it can grow as rapidly and profitably as it is capable of doing. The best and largest trees of this species are often, however, to be found by the sides of streams rumning through sheltered glens or ravines. In such a situation, if the soil be at all moderately good, the trees grow up very rapidly, and attain large dimensions in an astonishingly short time. The White Willow does well on most soils if these are not too light and dry, and if the situation be not too exposed.

It cannot be said to be anything but accommodating with regard to soil, so long as this contains the requisite quantity of moisture; but its finest dimensions are undoubtedly attainable on deep loamy or loamy-sandy riverine tracts of a marshy description. 
In order to have the Willow assume good dimensions and prorluce a clean bole of good technical quality, the trees should be planted in a mass, so as to he drawn up quickly in their struggle for light and air; and when this competition is being warged too keenly for healthy growth, thinning may take place as required, in order to allow them to have more growing-space for their development. This is particularly necessary with regard to the White Willow, which is rery liable to set off into large branches if left to itself in any open part without lateral confinement. But where planted somewhat closely together, or if mixed with a few Conifers, it rises to a great height before branching off; and when the thinning operations are carefully attended to, excellent timber is produced. As its wood is soft and open in the grain, the Willow, and indeed the Poplar too, should never be pruned except in the young state. If any branches of considerable size be taken from a full-grown tree, the wound never heals up; the weather takes effect upon the cut part very quickly; and soon rot is produced, rendering the timber near it useless.

Unless the wound-surfaces are small and can cicatrise easily and rapidly, the wood soon becomes infected with fungoid diseases occasioned by various species of Polyporus; for the soft porous wood of Willows and Poplars is little able to resist the penetration of the hyplue and the mycelium into the woody tissue when once the fungoid spores have lodged on the surface of the wound, and have begun to germinate.

Propagation and Culture.-No forest-trees are easier of propagation than the Willows. Indeed their characteristic in this respect is almost proverbial. All that is necessary is to put a cutting of young wood into the soil in the spring, and in the following autumm it will be ready for transplanting out into the open. Many even recommend the use of pieces of the older wood for cuttings in propagating the Willow; but though success be attainable in both wars, yet it will almost always be found that the cuttings from the last year's wood make the best plants, which ultimately develop into the most rapid-growing and the finest trees.

This species is very plentifully distributed over the country: Its general dimensions, under firvourable circumstances, may be said to range up to about $70 \mathrm{ft}$. in height, with a stem averaging about $3 \mathrm{ft}$. in diameter at breast height. Of such dimensions there are specimens to be found on most estates affording a farourable soil and situation for the tree. 


\section{(2.) THE CRACK, CRACKING, or REDWOOD WILLOW, Salix fragilis L.}

Srnonym-S. decipiens Hoffm.; S. fragilissime Host.; S. monspeliensis Forb.

Specific Character.-Leaves ovate-lanceolate, pointed, serrated throughout, very glabrous. Footstalks glandular. Ovary ovate, abrupt, nearly sessile, glabrous. Bracteas oblong, about equal to the stamens and pistils. Stigmas cloven, longer than the style. Flowers yellow; April and May (Loudon, op. cit., p. 759).

Distribution.- This tree was also not indigenous to Britain, but was introduced along with the White Willow in the fifteenth century, and has become very thoroughly acclimatised.

Description of Tree.-The Crack Willow is a tree comparatively more common in Scotland than in England, where the White and the Bedford Willows are the two species of this genus that chiefly occur as timber-trees. It is in all respects a more hardy species than either of these two other Willows; and on this account it deserves to be more cultivated in Scotland than they are. In

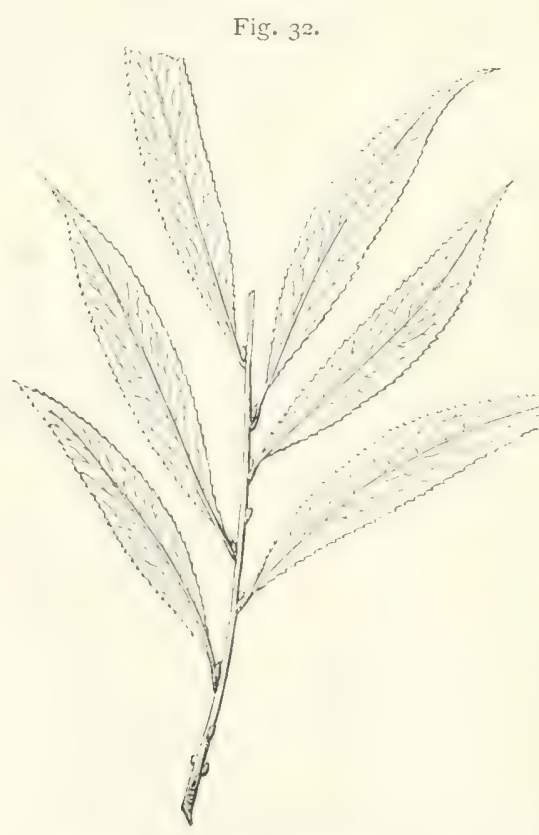

Foliage of the Crack Willow (S. fragilis). the north of Scotland especially it prevails largely, and is there known as the Red-Wood Willow, from the timber having a reddish tinge when cut up. It is much prized throughout Scotland for the usefulness of its timber; and, indeed, on many cold-bottomed lands in the north it produces timber of a good size, and this often too upon a very poor soil. This is also a very fast-growing tree. When planted on a good soil and in a sheltered situation, it may even attain about $70 \mathrm{ft}$. in height, and $8 \mathrm{ft}$. in circumference at $4 \mathrm{ft}$. from the ground, when it is only about thirty-five years of age.

The leaves of this species very much resemble those of the White Willow, being slightly downy when young. Fig. 32 represents the leaves and young wood. There is one peculiar feature in this tree that may here be noticed-viz., its aptitude to become what is termed stag-hacuded or dry in the top, when found growing upon a 
soil not naturally suitalle to its normal requirements. This is the principal reason that it is so much kept out of lawns and parks; for when stag-headed, it certainly hecomes rather unsightly. But as, when well grown, it is quite as fine and ornamental a tree as the White Willow, which is often to be found in parks, it would be unwise to attempt to keep this fine Willow out of all park scenery, provided the soil be capalble of nourishing it properly. Wherever it is planted upon a loamy soil, from which it can have a sufficient supply of nourishment, as will generally be the case in the lowlying parts of parks and lawns, experience shows that it not only grows rapidly, but will maintain its health thronghout both stem and crown as well as either of the other two species, the White and the Bedford Willows.

Economic Uses of Timber.-The wood of the Crack Willow is, in the practical estimation of country carpenters, somewhat more durable and tough than that of either of the other tree-Willows. And as a matter of practical experience in estate management, less difficulty is found in selling it for country purposes than any other wood of the Willow kind. Practical builders say that as a timber for flooring it can scarcely be surpassed, as it is extremely light, and lasts a long time. It is, generally speaking, used for all the purposes for which the timber of the other two kinds is utilised; and it would seem to have special recommendations for employment in the construction of railway waggons and trucks.

Soil and Situation.-The Crack Willow will attain fair dimensions on a greater variety of soils than either the White or the Bedford Willow can thrive on; still, in order to grow it well, and to obtain timber of large dimensions, it requires to be planted on a deep, rather moist soil, and in a sheltered situation.

Propagation and Culture.-This tree is, like the other Willows, very easy of propagation, and may be regenorated or multiplied by means of slips or cuttings in the same manner as has already been described with reference to the White Willow (see p. 175).

The average dimensions of this species, under moderately farourable circumstances, may be said to range up to $50 \mathrm{ft}$. in height, with a stem about $2 \mathrm{ft}$. in diameter. In many parts of the country, however, on very favourable soils and situations, it frequently attains 70 to $80 \mathrm{ft}$. in height, with a stem $3 \mathrm{ft}$. or more in diameter.

(3.) RUSSELL or BEDFORD WILLOW, Sulic Russellinu Furth.

Srnonyu-Salix fragilis var. Russelliana Hooker.

Specific Character--Leaves lanceolate, tapering at each end, serrated throughout, very glabrous. Footstalks glamdular or leafy.

VOL. I. 
Ovary tapering, stalked, longer than the bracteas. Style as long as the stigmas. Flowers yellowish; April and May (Loudon, op. cit., p. 760$)$.

Distribution. - This tree is of course a native of Britain, for it is merely the British hybrid or cross between the two former species, the White and the Crack Willows. It is to be found in most of the marshy woods and osier-grounds throughout England.

Description of Tree.-The Bedford Willow is another tree which is, arboriculturally, well worthy of a place in pleasure-grounds. It has a much better effect upon a

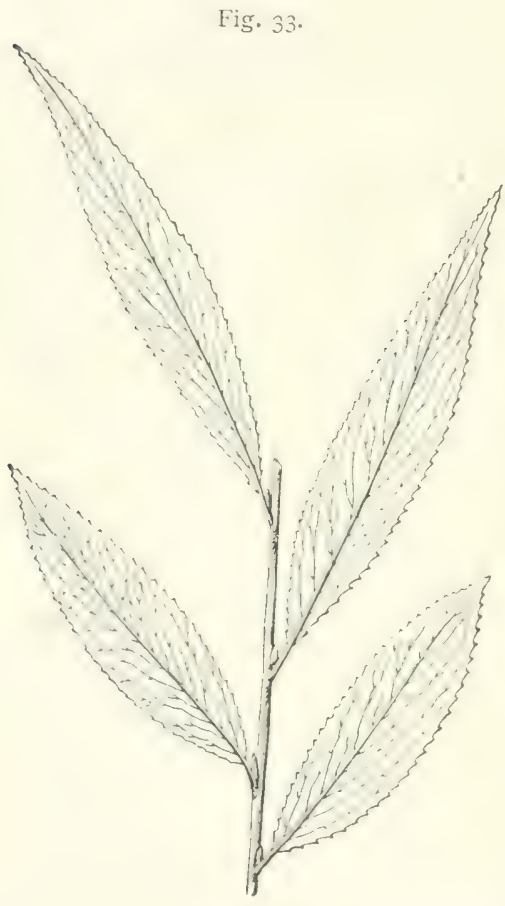

Foliage of the Russcil or Bedford Willow (S. Russelliana). lawn or park than any other of the Willow genus, having a bold outline and rather a rugged habit, which gives it, when viewed from a distance, the appearance of an Ash more than that of a Willow. As described in the specific characteristics, the leaves of the Bedford Willow are lanceolate, tapering, and scrrated; they are without hairs, and are smooth on both sides. Even by this difference alone the Bedford Willow may be readily distinguished from the White Willow; but there is the additional difference that the leaves are also larger than those of the latter. Fig. 33 is a representation of the leaves and young wood as in the month of August.

Economic Uses of Timber.The timber of this tree is used for much the same purposes as those stated with regard to the wood of the White Willow. There is, indeed, scarcely any difference in the quality of the timber of the two sorts, and both kinds of wood are employed alike for all the oljects stated with reference to the White Willow (see p. 174).

Soil and Situation.-What has already been said with regard to the soils and situations best suited to the White Willow is in every respect equally applicable to this species. Under somewhat similar circumstances, they both appear to attain about the same magnitude as timber-trees. When planted upon an exposed situation, the branches of the Bedford Willow are very apt to be broken 
down by high winds, a tendency naturally inherited from the Crack Willow. But in many other respects it may perhaps be considered a somewhat more hardy tree than the White Willow.

Propagation and Culture. - What has heen staterl with regard to the White Willow (see p. 175) nay be applied in all respects to this species.

There are many specimens of the Pedford Willow, both in England and Scotland, that are from 70 to $80 \mathrm{ft}$. in height, and have stems of from 3 to $4 \mathrm{ft}$. in diameter.

\section{BETULACENE BARTL.}

The family of the Betulacece consists of the two genera, Birch (Betula) and Alder $(1 \ln u s)$, the majority of the species of which inhabit the temperate zone of the northern hemisphere. These two genera are distinguished botanically (Willkomm, Waldbuichlein, 1889, p. 105) as follows:-

Buds sessile, and enclosed by several bracts arranged spirally; male catkins mostly in clusters at the top of the previous year's shoots; female spikes only appearing simultaneously with the foliage, and situated at the end of the short shoots consisting of but a few leaves. Under each bract of the catkin 2 or 3 flowers with 4 stamens, each of which is situated at the corner of a thin leaflet; anthers divided into two halves; under each of the 3-lobed bracts of the spike there are 3 ovaries, which produce a broad-winged nut. The cylindrical, petiolated, and pendulous catkins fall to pieces on ripening, leaving only the spindle. Flowering takes place after the flushing of the foliage. Birch . . . Betula.

Buds petiolated or stalked (except in the Aphine Aliter, 1. riritis, where they are sessile), and covered with 2 or 3 thick bracts. Male and female flowers on one branching stalk, on the upper part of which the catkins are situated, and on the lower part the spikes. Under each catkin-scale 3 distinctly separate flowers with 4 stamens and floral bracts crosswise ; under each bract of the spike only 2 oraries, from which unwinged (except in A. viridis), compressed, and angular nuts are produced. The spikes develop into long cones with thick woody bracts, which are at first cemented together with a kind of waxy resin, but which on ripening open and let the seed escape, without falling to pieces and detaching themselves from the spindle. The empty cones remain long on the tree. The flowering (except in A. viridis) takes place long before the foliage flushes in spring. Alder

Alnus.

Out of a total of 37 species of Birch, 8 are indigenous to Europe. Of these latter 5 are to be found in the central and north-western portions of the Continent, including Britain; but as they gradually merge into each other, it is impossible to determine any hard-and-fast lines of distribution for the rarious species.

Only one species is of true sylvicultural value, the Common Birch,

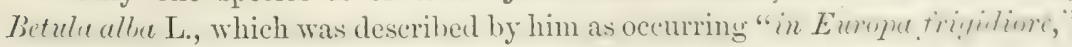
but which was subdivided by his pupil Ehrhart into the warty kind $B$. verrucosa, and the velvety kind $B$. pubescens. But though these may quite justifiably be ranked as separate sprecies, the more comprehensive specitic name of Linnæus may here be retained, as the sub-species exhibit only comparatively unimportant sylvicultural differences. The warty race extend. further to the north and east, whilst the jubescent goes further south. The 
latter is the Birch most frequently to be found in moist or wet, low-lying soil, and the former is the ruling kind on drier situations; but they are very often to be found growing together on the same soil. The warty race appears to be the more frequent in the Highlands of Scotland, where it thrives well in the humid atmosphere.

Of arboricultural interest there are two exotic species, $B$. lutea and B. papyraced, which were introduced into Britain from North America about the middle of last century. These three species, now to be described, are distinguishable (Willkomm, Forstliche Flora, 1887, p. 301) as follows :-

I. Outer layer of the bark of the stems white.

1. Leaves rhomboidal or ovate and long-pointed, entire at the base, but doubly, and often trebly, serrate along the upper edges; more or less velvety or pubescent on young shoots, but not on any of the foliage of the older twigs (B. pubescens and B. verrucosa, Ehrh.).

B. alla.

2. Leaves large, ovate, and shortly pointed; entire at the lower edge, but doubly serrate along the upper edges . . B. papyracea.

II. Outer layer of the bark of the stems brown or brownish-yellow.

3. Leaves large, ovate, and pointed. Young shoots pubescent and without waxy warts

B. lutea.

\section{THE BIRCH, Betula (Linndean Sýstem, Mongcta Polyandria).}

Character of Genus.-Barren flowers: Catkins cylindrical, lax, imbricated all round with ternate concave scales, the middle one largest, ovate. Corolla none. Filaments 10 to 12, shorter than the midlle scale, to which they are attached. Anthers roundish, 2-lohed. Fertile flowers: Catkins similar but more dense; scales horizontal, peltate, dilated outwards, 3-lobed, 3-flowered. Corolla none. Germen compressed. Styles 2. Stigma simple. Nut oblong, deciduous, winged at each sirle. Flowers whitish, in pendulous catlins (Loudon, op. cit., p. 838).

\section{(1.) THE COIMMON or SILVER BIRCH, Betula alba L.}

Srnoxyars-B. pubescens et B. vermecosa Ehrh.

Specific Character.-Leaves ovate, acute, somewhat deltoid, mequally serrated, nearly glabrous. Flowers whitish; in England, in February and March. Fruit brown; ripe in September and October (Loudon, ibid.)

Distribution. - This tree is a native of most parts of Europe, and especially of the northern and the mountainous tracts. In the extreme northern parts of the continent of Europe it occurs only as a small tree or large bush; while in the central portion, particularly in eastern Prussia and western Russia, it forms extensive forests along with the Alder and the Aspen, and develous into a tree of rery 
considerable dimensions-often attaining a height of 50 to $60 \mathrm{ft}$. It is indisputally a native of Iritain, and forms, even at the present day, considerable natural forests in the north of Scotland. In Strathspey, in Braemar, and around Loch Tummel there are natural forests of this tree, which give a most pleasing effect to many of the hill-slopes that otherwise might present rather a bleak appearance.

Description of Tree.-The Birch is one of the most graceful of all our native trees, and is in consequence grenerally found in all well-arranged landscape scenery. As compared with many of our forest trees, it attains at best but very inferior dimensions as a timber-tree; but it is not so much on account of the value of its timber that the Birch is generally a favourite, as on account of its gracefulness - in which respect no other forest tree surpasses it. This is particularly the case with the pendulous variety, known as the "Weeping Birch," which is also to be found growing wild in many of the higher districts throughout both England and Scotland. A particular recommendation of this variety is that it is of a more rapid growth than the common Birch; and on this account the generality of young plants are now raised from the seed of the weeping variety, which is easily known by the drooping tendency of its branches, and also by small white rough spots or verrucosities upon the bark of the young trees. The foliage of the Birch is small (see Fig. 34) and in spring it has a peculiarly sweet smell, particularly after a shower of rain.

\section{Economic Uses of Timber.-}

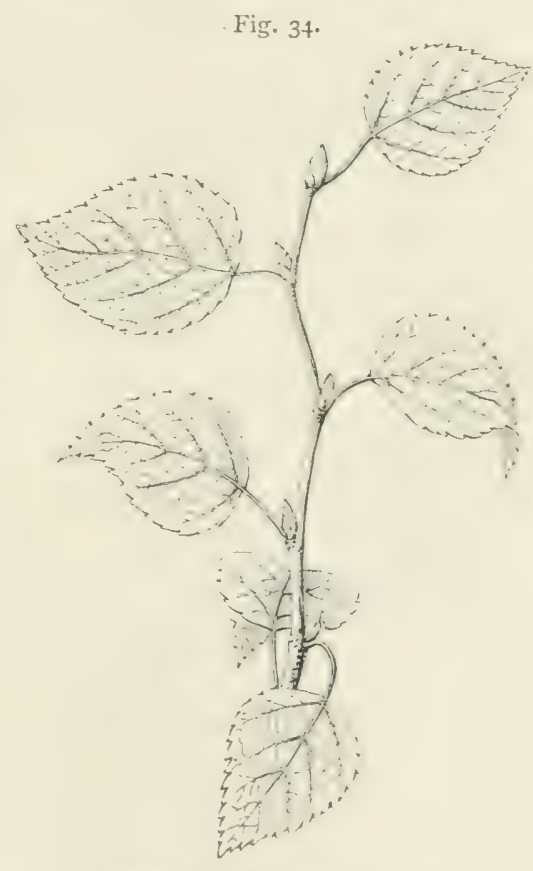

Foliage of the Birch (B. alba L.)

The wood of the Birch is by no means of great durability, in whatever situation it may be placed. It may, however, be utilised in a large variety of ways, both for outside and inside work; but for use in the open air, as in the case of a post in a fence, it is of very inferior durability, and does not last much more than three rears. In this respect the wool of the lirch resembles that of the Beech. Even when used for furniture, it is apt to be very soon affected by dry rot. It is much used for maling herring-barrel 
staves, for which purpose it suits excellently; and it is much sought after for making charcoal in gunpowder manufactories. But perhaps the most important use to which the wood of the Birch is applied is that of making bobbins for thread manufactories. Very large quantities are used for this purpose now, and the advantage of this to the grower of the wood is, that for bobbins he can dispose of even the branches down to $1 \mathrm{in.}$ in diameter.

One such bobbin-mill, situated about half-way between Pitlochry and Loch Tummel, carries on an extensive industry solely in the manufacture of bobbins. Throughout the whole of Strath Tummel the Birch grows luxuriantly, although the woods are only treated arboriculturally, and no attempt seems made to manage them on anything like sylvicultural and financial principles. The wood of the Birch has a sp. gr. of 0.96 when green, which decreases to 0.65 after seasoning. Hence, if floating operations require to be carried out before the logs can find their most favourable market, some little period of seasoning will be requisite to ensure their floating well. On the Continent the wood is used by cartwrights, turners, carvers, and cabinetmakers,- the blocks with gnarled excrescences commanding good prices for the better classes of furniture.

Soil and Situation.-In longevity as a tree the Birch is not to be comprared with the Oak or Sycamore; but, on a good dry soil suited to its requirements, it lives to a great age. The Birch is a species by no means particular as regards soil and situation-in fact, it is one of the most hardy trees we possess, being found to exist as a shrub or a low tree in the mountainous districts of Scotland, at an elevation of fully $3000 \mathrm{ft}$. above the level of the sea. Yet notwithstanding this hardihood, it does not attain good dimensions unless planted upon a fair soil, and at an elevation something under 1500 ft. above sea-level. The verrucose variety prefers naturally a dry sandy or a stony soil, which is generally of a poor quality; but the pubescent variety, which attains the largest dimensions, thrives best upon moist soils of sandy-loamy nature, even though they rest upon a subsoil that is by no means dry. Even a very considerable amount of soil-moisture is by no means prejudicial to this latter kind, provided always that this is not allowed to remain stagnant about the roots.

Propagation and Culture.-This tree is raised in the nursery from seed, which is generally ready for gathering before the end of September, or about the first week of October. When gathered, it should be kept in a dry and airy loft or room all through the winter, and should be sown in the month of March. In sowing it, care should be taken that the earth upon which it is sown be very finely wrought by the spade and rake. The soil ought to be light, and the surface made as fine as oatmeal before sowing; and even in the act 
of covering the seed, great care is necessary to see that it is not cmbedded too deep. In fact, the slightest covering of earth is sufficient: and this, too, should be of the finest quality. The seed is always sown on beds about $3 \frac{1}{2} \mathrm{ft}$. broad. When the soil cannot be got of a nature fine enough, a very good plan is merely to sow upon the prepared surface, and give the seed no coveringr at all, but merely a slight beat with the back of the spade, in order to keep the wind from blowing it about. By this plan excellent crops of young seedling Jirch may be raised in the nursery-beds.

About the first week of June the plants will be seen to come up abundantly and thickly all orer the beds; and as they are ensily interfered with by weeds, they should receive every attention in the way of keeping the beds clean.

One year after the seeds have been sown, the young plants may be lifted and transplanted into rows in the nursery-ground; and when they have stood there for two years, they may be put out into the opeu. But if wanted of a larger size, they should be allowed to remain in the nursery another year before being finally transplanted.

In the south of England, and on sandy soil with a warm exposure especially, the seed may sometimes be matured in August, and fall so as to germinate before the regetative season closes. Where such is the case, the young seedlings can easily be bedded in the nursery during the following spring, for seed that has been stored over the winter takes four or five weeks to germinate and loses quality generally.

The Birch is an excellent tree for planting on exposed parts of an enclosure where there is little soil, and that only of a poor and thin quality. For, on such lands, it will soon make a cover, and may perhaps ultimately become a more valuable broad-leaved crop than any other that conld be formed, although for these conditions Scots and Black Pine are very accommodating coniferous species.

As a coppice-wood, the Birch occasionally answers well. This form of treatment may sometimes be more profitable than Oakcoppice, as, for instance, when the small wood produced can be solil locally either for powder-wood or bobbin-making.

Sylvicultural Characteristics and Importance of Birch.-In many sylvicultural respects the Birch closely resembles the Aspen (see 1). 16is). It is the most essentially light-demendin! of the broad-leaved sprecies of trees. and, like all light-demanding trees, forms rather a deep root-ststem. From Ebermayer's analyses (op. cit., pp. 230, 235) it appears not only to make smaller demands for mineral nutrients than any other species of broad-leared tree except the Common Alder (which agrees with sylvicultural experience), but also to require rather larser quantities of soil-moisture for transpiration through its foliage than the sycamore neuls per unit of drr sulstanee: and, in this respect, it stands on almost the same level as the Fowan or Momntain- 
Ash, which is very often to be found growing along with it. When, therefore, the verrucose variety is seen growing on soil that is apparently dry at the surface, it still requires, and is able to draw, comparatively large supplies of water from the soil by means of its deep and wide-spreading roots. It is also endowed with the other characteristics of essentially light-demanding trees, rapidity of growth, and a lightly foliaged crown. As it is at the same time a hardy tree, it is therefore well adapted for acting as a nurse to less sensitive species like Oak, Ash, Sweet-Chestnut, Beech, or Silver Fir. But when once its period of useful service is at an end in this respect, it is often hard to get rid of the Birch; for on good soil it possesses great reproductive capacity, and this more frequently takes the form of throwing out shoots from the stool than of producing stoles or root-suckers. But its reproductive power in forming stool-shoots is not of continuous energy, and one of the best ways of keeping it down is to cut them out regularly for broom-making.

With its thin crown and light annual fall of foliage, the Birch is not naturally endowed with the qualities desirable in any tree forming pure forest; and though such crops are to be seen in some parts of Scotland, they are merely examples of that want of scientific knowledge of Forestry that may be notieed generally throughout Britain-for in those cases the soil is certainly not used to its best sylvicultural advantage. Where the Birch can thrive in pure woods, the soil will support better species if planted and tended rationally.

It attains its best development when growing in mixed woods along with other species like Aspen, Alder, and Hornbeam on moist localities, or with Scots Pine on drier situations. For admixture with Spruce or Douglas Fir it is less suitable, as its long whip-like twigs scourge and damage their leadingshoots. And it further resembles the Aspen by being the host upon whose leares the fungus Melampsora betulina has its change of generation for the production of Ceoma Laricis on the foliage of the Larch (Jour. Royal Hort. Socy., vol. xiv., 1892 , p. 133). Under favourable circumstances it can hold out a rotation of 80 to 100 years; but in the majority of cases it will have to be cut out at about forty to sixty years of age, when it begins to make demands as to growing-space that are incompatible with the financial promises it can hold out. When trees stand near areas about to undergo regeneration, they should be felled; for the seed production of the Birch is large, and the light seed is easily wafted to great distances, where it may perhaps spring up as a troublesome weed on areas undergoing regeneration.

At Aboyne Castle there is a Birch-tree $50 \mathrm{ft}$. high, with a girth of $9 \mathrm{ft}$. near the hottom; and in the forest of Ballochbuie, on the estate of Invercauld, Aberdeenshire, there is a tree of this species which measures $6 \mathrm{ft}$. 8 in. in circumference at $4 \mathrm{ft}$. from the ground.

\section{(2.) THE PAPER BIRCH, Betula papyracea Dryand.}

Srnoxrsis-B. papyrifera Mich.; B. lanceolata Hort.

Specific Character.-Leaves ovate, acuminate, doubly serrate; veins hairy beneath; petiole glabrous. Female catkins on long footstalks, drooping; scales having the side-lobes short, somewhat 
orbiculate. Flowers greenish-white; May and June. Fruit brown; ripe in October (Loudon, op. cit., p. 842).

Distribution.-This tree is also a native of North America, and was introduced into Britain in 1750 . In Canada specimens of it attain very large dimensions, not unfrequently from 90 to $100 \mathrm{ft}$. in height, with a diameter of stem exceeding $4 \frac{1}{3}$ feet; but in reneral it does not attain much over $70 \mathrm{ft}$. in height, with a stem of from $2 \frac{1}{2}$ to $3 \mathrm{ft}$. in diameter. It is plentiful on good land all over Upper Canada, and is generally found in the neighbourhood of the tall birch; but it prefers the drier soils, whilst the latter is naturally better suited for those of a moist nature.

Description of Tree. - The Paper Birch is easily known from the tall Birch by its leaves being smaller, and of a darker green in colour. Its branches are also more slender than those of the tall Birch, and its bark is more silvery and shining. It forms a beautiful object in the Canadian forests, furnishing, in those parts of them throughout which it grows, a lively contrast with the Limes, Maples, and other species of trees with which it is associated. The native Indians of Canada make their canoes from the bark of this species, for which purpose they strip the stems. It also forms a fine ornamental tree in a park, its beautiful white bark contrasting well with the dark green of its foliage, which is thick and plentiful on the branches of well-grown specimens. Both this species and the following are well worthy of cultivation in the parks and on the litwns of landed proprietors in Britain; they are quite hardy enough for most places at all favourably situated, and may therefore be confidently recommended to notice. They are as easy of cultivation as the common British Birch; and from being of stronger growth, they are calculated to produce an effect of a pleasing, though somewhat different, character upon the landscape much sooner than can be arranged by means of that species. The leaves being larger are more easily agitated by the breeze; and this circumstance produces a peculiar effect, especially when contrasted with the bright silvery hue of the bark on the stems.

This species, which is only a tree of the second magnitude, has a straight cylindrical bole, upon which the tough outer layer of bark, in fissuring, forms long rolls like paper (hence its botanical name). It is a very hardy species, and is little apt to suffer from frost. It posisesses, like the Tiall Birch ( $B$. luten), an arboricultural value only, and is of no account sylviculturally.

Soil and Situation. - In its native forests this tree requires a deep, dry, and humose soil. It is not to be found on soil of a wet character, such as that on which the Tall Birch generally oceurs, but oceupies gentle knolls and ridges having a dry subsoil. Like 
the latter, it will not succeed in any exposed site, but should have a low-lying situation, with the shelter of other trees.

Propagation and Culture. - The Paper Birch is chiefly raised from seeds imported from America. The seed of both this and the Tall species can easily be had cheaply from seed-merchants in New York; and any nurseryman in Britain could have no difficulty in rearing large cumantities of these trees at a cheap rate, provided he had orders for them from landed proprietors. As they have been very little inquired for, they have not been much reared; hence they are scarce and high in price. But were there any constant demand for them, nurserymen here could soon supply them at a very moderate cost.

\section{(3.) THE TALI BIRCH, Betula lutea Mich.}

Srnomis-B. excelsa Dryand.

Specific Character. - Leaves ovate, acute, serrated; petioles pubescent, shorter than the perluncles. Scales of the strobiles haviug the side-lobes roundish. Flowers greenish-white; May. Fruit brownish; ripe in October (Loudon, op. cit., p. 844).

Distribution.-This tree is also a native of North America, and was introduced into Britain in 1767. It is chiefly to be found on deep and rather moist lands throughout most parts of Upper Canada, especially in the valley of the Ottawa, where it occurs very plentifully in the natural forests.

Description of Tree.-The leaves of this tree are very much larger than those of the common British Birch, being generally from 3 to $4 \mathrm{in}$. long, and from 2 to $3 \mathrm{in}$. broad, and with sharp irregular teeth on their margins. In the natural forests of Canada it forms a tall stately tree, often rising up to a height of from 80 to $90 \mathrm{ft}$., with a stem of from $2 \frac{1}{2}$ to $3 \frac{1}{2} \mathrm{ft}$. in diameter. In some instances it may even be found attaining a height of $95 \mathrm{ft}$., with a stem nearly $4 \mathrm{ft}$. in diameter; yet generally speaking the trees are not so large, but more frequently measure only from 70 to $90 \mathrm{ft}$. in height, with stems of from 2 to $3 \mathrm{ft}$. in diameter. When this Birch stands alone, it forms a fine ornamental object, being clothed with branches, and thickly foliaged down nearly to the ground. Many specimens of this species to be met with on the sides of rivers and lakes in America are of a highly ornamental character, being well clothed with branches down to the water's edge, and presenting the most lerfect festoons imaginable. It may well, therefore, he recommended as an ornamental tree in parks and on lawns in Britain. In such situations it would make a fine contrast with many other of our common trees, as its habit is to grow upright, and to become clothed 
with branches from top to bottom when grown in an open part and on a suitable soil.

This species, which rarely assumes the dimensions of a tree of the first magnitude, possesses for Britain merely an arloricultural value. As a foresttree it cannot be compared to our own indigenous Birch. With its soft pubescent young shoots and its bronze-yellow bark, however, it forms a very agreeable and striking feature near the margin of ponds or streams.

Soil and Situation. - In order that it may thrive well, the Tall Birch requires a good, deep, and rather moist soil. Fine specimens of it may, indeed, be met with on dry ground in Canada; but in all cases the largest and best developed trees grow on the sides of rivers and lakes, and on the edges of swamps, where there is a sufliciency of moisture for their roots, without its being starnant about them. It requires also to be planted in a well-sheltered situation; for although it is quite hardy enough to stand the climate of Britain, still it will not grow to a good size unless on a low-lying site, and sheltered by other trees.

Propagation and Culture. - This tree is propagated by seeds imported from America, which may be had from any extensive dealer in foreign tree-seeds. The species is as easily raised from seed as the Common Birch, and the same treatment is necessary in rearing them both.

\section{THE ALDER, Almus (Livxfax System, Moxecta Tetraxdria).}

Character of the Genus.-Barren flowers numerous, aggregate, in a loose cylindrical catkin. Calyx a permanent wedge-shaped scale, 3-flowered, with two very minute lateral scales. Corolla composed of 3 equal florets. Filaments 4 , from the tube of the corolla. Anthers of two round lobes. Fertile flowers fewer, aggregate, in an oval firm catkin. Calyx a permanent wedge-shaped scale, -2-llowered. Corolla none. Styles 2. Stigma simple. Nut ovate, without wings (Loudon, op. cit., p. 832).

Of the fourteen species of this genus known to exist throughout Europe, Asia, and America, only eight are to be found in Central and Western Europe. These are all small trees, some of them scarcely attaining tree-size, but merely remaining shrubs and nune of them can be said to be ornamental. Perhaps the only species to which it is necessary to make reference here is the common Alder (A. glutinosa), as it is sometimes found a useful tree for planting on cold, wet sites, where few other trees can thrive so as to give profitable returns. 
From an arboricultural point of view it is rather a disappointing tree. Although during the summer months its thick dark-green foliage is of a pleasing colour, the outline of the tree is heavy and formal; and when the autumn comes it does not contribute much to the forest tints, for most of the leaves drop off without even temporarily changing their colour.

THE COMMON ALDER, Alnus glutinosa Medic.

Srronsms-Betula alnus L.; B. cmarginata Ehrh.; B. glutinosa Lamk.

Specific Character.-Leaves roundish, wedge-shaped, wavy, serrated, glutinous, rather abrupt; downy at the branching of the veins beneath. Flowers brownish; March and April. Fruit brown; ripe in October (Loudon, ibid.)

Distribution.-The Common Alder is found all over Europe, and always in moist places, such as swamps. Indeed it is found growing in situations which are too wet for either Poplars or Willows to thrive in. It occurs also along all the northern parts of Asia, and in the north of Africa. This is one of the comparatively few trees truly indigenous to Britain. It is found along the

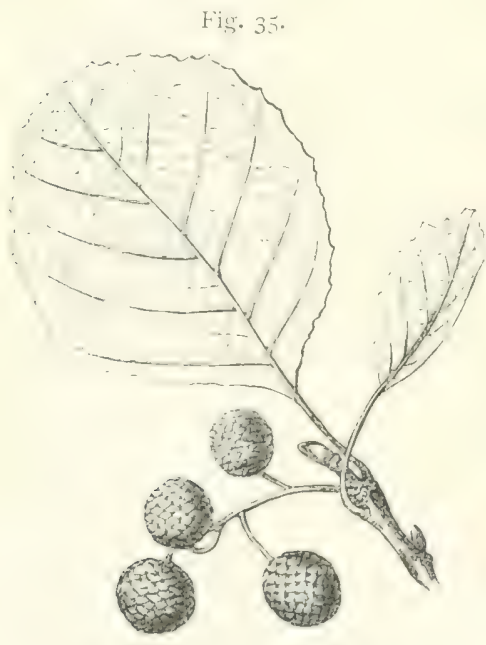

Leaf and fruits of the Common Alder (A. glutinosa). banks of our rivers, and on marshy parts of our waste lands. In these cases it is seldom to be met with of large dimensions, but generally as a small tree, somewhat prone to branching growth.

Its horizontal distribution concides to a large extent with that of its near relative the Common Birch. Although it does not stretch so far northwards towards the polar limit of growth, it reaches somewhat further south. But it lags far behind the Birch with regard to vertical distribution, for, even throughout central and southern Europe, it remains a tree of the plains and lowlying localities rather than of the hills.

Its finest development is attained in western Russia and eastern Prussia, where vast Alder-marshes are occupied by this species either in pure woods or in admixture with Birch and Aspen chiefly; but Oak, Ash, Elm, Maple, Sycamore, Lime, Pine, and Spruce are all often to be found associated with it there on the classes of soil best suited for their respective requirements. Under these circumstances it there attains a height of from 50 to $60 \mathrm{ft}$.

Description of Tree.-Fig. 35 represents the leaves of this tree, and also the catkins containing the seeds. When of spon- 
taneous forest growth, the Alder seldom attains a height of more than $40 \mathrm{ft}$.; but where attention has been paid to it arboriculturally, or when it has been drawn up in close canopy along with other forest trees, it frecuently, upon a good loany soil, attains a height of from 50 to $60 \mathrm{ft}$., with a proportionate girth. In no case will it, however, attain a large size unless it has a considerable degree of moisture for its roots, as may always be found by it upon the margins of rivers. The bark of the Cornmon Alder, in the case of trees approaching maturity, is nearly black, and is full of clefts. When they are still young, and the tree is in a state of vigorous growth, the branches have a triangular form; but when mature they are round. The Alder is well known all over Britain, as there are few wet parts by the sides of our streams and smaller rivers where it is not found.

When once the Alder enters into the stage of seed-production, about the 15th to 20th year, its hitherto rapid growth in height reaches its culnninating point, and is only inconsiderable thereafter. Hence, when worked as coppice with a rotation of twenty to thirty years, the soil can be made to yield more timber than if any longer period of high-forest rotation be tried.

Economic Uses of Timber. - The wood of the Alder is by no means valuable, nor is it generally applied to many purposes. It is reckoned one of the most lasting of all woods for any underground work, such as piles for bridges; and it is even admitted to last for a long time when protected against the effects of changes from dry to moist. But it is one of the least durable of woods for any common outdoor work, such as fencing; posts of this timber ofteu become useless in less than one year, as they rot at the part between the earth and the air. Still, both as a tree-crop and as a coppicewood, it is very valuable for making charcoal for powder, and for sawing up into herring-barrel staves. For both of these purposes it is much sought after, and sells readily in most parts of the country.

When used in places where it is nearly always under water, or kept wet and shut off from the atmosphere, it is endowed with considerable durability: but otherwise it is soon apt to become worm-eaten and rotten. Its chief use on the Continent is for the manufacture of cigar-boxes, for which its light, rechlish, cedar-like wood is well adaptenl. Even in such small matters fashion and habit are all-powerful; and white cigar-hoxes of Willow or Poplar, although equally good for practical purposes, would not command the same market-prices as those of the hitherto prevailing colour. Copnice-woods of Alder worked with a rotation of thirty to forty years often yield very good financial returns: but good soil suitable for Alder-woods is generally capable of being more profitably utilised as meadow-land. The wood has an average sp. gr. of 0.83 when green and $0.5+$ after seasoning. 
Soil and Situation.-The Alder is by no means particular as regards quality of soil, but moisture is indispensable. Throughout the Highlands of scotland, and in some of the northem hilly parts of England, large tracts may be found under this tree. It is always found arowing best in swampy low-lying grounds, and on the margins of rivulets; and this at once indicates the circumstances favourable to its growth. The Alder will, however, attain its normal dimensions as a timber-tree when planted on any low-lying site, having a strong soil with a moist subsoil, such as lands upon which the Poplar and Willow are also found to thrive well. On these situations it can easily attain a height of 50 to $60 \mathrm{ft}$., with a stem of from 2 to $3 \mathrm{ft}$. in diameter.

The localities offering the most favourable conditions for its development are tracts in which the atmosphere is humid and the soil moist. It is a tree of low-lying situations, and, when ascending hillsides to any considerable elevation, is almost entirely confined to the immediate vicinity of the brooks and streams, where it can obtain abundant supplies of moisture.

It does not form any decided tap-root, but develops a large number of thin strands, which gradually extend themselves deeper down into the soil, and produce large quantities of suction-roots.

Propagation and Culture.-The Alder may be propagated by cuttings and layers of the young wood, but is principally grown from seed. Although the former method is sometimes resorted to, the plants obtained by such means are of little real worth, and can never attain such good growth as those which are raised from the seed. The young plants ought, therefore, in all cases where healthy trees, and not mere shrubs, are desired, to be grown from the seed. Of course these remarks do not apply to the extending or propagating of the varieties of this genus, such as the A. laciniata, or cut-leaved Alder, and others, which must be propragated by slips or cuttings and layers, in order to retain their temporary characteristics.

The seeds should be gathered in the month of October, or at least as soon as the scales of the catkins or seed-vessels begin to open a little. When the catkins are gathered, they should be well exposed to the sun upon a sheet for a few days in the open air, when the scales will open widely, and allow the seed to he separated by a slight rubbing and turning with the hands. Many seedsmen, when they gather the seed of the Alder, simply lay it past in a dry room, and turn it frequently, till the seeds fall out of their own accord. ' It should be sown in the month of March and only slightly covered. When the seedlings have stood one year in the seed-beds, they should be planted out in rows in the nursery-beds, and there they may be allowed to remain one or two years, according to the height that the transplants may be desired. 
Sylvicultural Characteristics and Importance of Alder.-In many cases, soils suital,le for the best development of Alder may be drained so as to serve a higher purpose as meadow-land. When planted up with a crop of Alder, however, this grows rapidly, and soon attains marketalole rlimensions for the industries utilising its wood. It possesses strong reproductive power of shroting from the stool, although not endowed, like its close relative, the White Alder (A. incana), with any considerable capacity for throwing up stoles or root-suckers. Its foliage is not insensitive to late frosts; but when young shoots have been injured, they are soon replaced by a new flush. More damage is often done to it when floods occur at the time the burls are opening in spring.

Whilst, like all other trees, thriving best when its foliage is fully exposed to light and air, it is not so essentially light-demanding as many other species. But on inferior soils, containing less than the most advantageous degree of moisture for its thriving, it requires a large amount of growing-space, and has only a diminished productive and reproductive capacity. On good soils, however, it forms thick coppice-woods, and, worked with a rotation of about twenty-five to thirty years, can yield good financial returns if there is any market for its wood near at hand. When grown under standards of Oak and Ash, it can endure a considerable amount of shade; but under such circumstances the yield from the Alder is of course greatly diminished. Too low a period of rotation undermines the reproductive capacity of Alder coppice; for then the reserve supplies of nutrients stored up in the stools get exhausted, when the growth of stool-shoots becomes sparse, and the soil is overrun with grass of a rank description.

It fruits freely almost annually from about the fifteenth to twentieth year; and as the seed is small, it hardly requires any covering with soil on the seed-beds. The seedlings are slow of growth after germination, but before autumn can attain a height of about $1 \mathrm{ft}$. They bear transplanting well, and plants of even 6 or $7 \mathrm{ft}$. in height may be easily and safely removed and planted out. Natural reproduction of high-forest of Alder is not recommendable; for the wet localities on which its cultivation is profitahle have a natural tendency to rank growth of grass and similar weeds, which interfere with the thriving of the young seedlings. And for the same reason sowing is less reliable than planting.

\section{PLATANEE ClaRkE.}

\section{1. 'THE PLANE-TREE, Platanus \\ (Linnean System, Monecia Polyandria).}

Character of Genus.-Flocers unisexual, collected into glohose or oblong catkins of different sexes, involucrated or naked. Malo flocer having the perianth composed of numerous small linear pieces, intermixed with the stamens. Fimule florer with the sciles absent, or intermixed with the flowers; perianth adhering to the orimim, cup-shaped, or ending in small pilose bristles. Carpels 1 or 2 , 1-celled, hormed at apex, coriaceous. Sccls solitary in the cells, pendulous. Albumen none (Loudon, op. cit., p. 927). 
Five species of Plane are known to botanists, of which four belong to North America, but none to western Europe. Only two of these species of the genus need be referred to, as they are the best known, and at the same time the most ornamental-viz., (1) the Oriental Plane-tree, P. orientalis; and (2) the American Plane, $P$. occidentalis.

These two trees of this genus are by some of the Continental botanists considered as mere varieties of but one species, which has been termed $P$. vulgaris Spach. This may quite easily be the case, for the differentiating influence of climate may similarly be noted in the case of the Black Pines, i.e., the Austrian Pine (Pinus austriaca) and the Corsican Pine (Pinus Laricio). These are all over the Continent recognised as one species merely, but are distinctly kept apart as two independent species by British arboriculturists.

The plants possess a strong reproductive capacity of shooting from the stool, which would render them well adapted for coppicing and for pollarding; but, unfortunately, wound-surfaces are apt to offer little resistance to the entrance of fungoid spores, and soon become spotted. The wood is yellowishwhite and hard; it has large pores, and the annual layers are intersected by numerous medullary rays. For their best development they require a deep, light, moist, and humose soil, and are capable of thriving even with a higher degree of soil-moisture. For Britain they possess much more arboricultural interest than sylvicultural importance.

\section{(1.) ORIENTAL PLANE-TREE, Platanus orientalis L.}

Specific Character.-Leaves 5-lohed, palmate, werlge-shaped at the base; the divisions lanceolate, sinuated. Stipules nearly entire. Flowers greenish-yellow; April, May. Fruit brown; ripe in October; persistent great part of the winter (Loudon, ibid.)

Distribution. - The Oriental Plane-tree is a native of the Levant, Asia Minor, and eastwards as far as Persia, Turkestan, and Afghanistan. It seems to have been cultivated in Britain as an ornamental tree for the last 350 years. It is said to be found on Mount Etna at an elevation of $2000 \mathrm{ft}$. above the sea-level; but its true home is the mountainnus region of the Steppes, where it ascends the Taurus range to a height of $5000 \mathrm{ft}$. It occurs also of true forest-growth in Greece and on the outlying ranges of Mount Athos (Willkomm, op. cit., p. 539). It seldom attains its full dimensions as a timber-tree except in low-lying and level parts of the country, on a light deep soil, in the neighbourhood of running water.

Description of Tree.-The Oriental Plane is said to be one of the noblest trees of eastern Europe, where it grows to a height of 70 and sil feet, and, with widely spreading hanches and a massive trunk, forms altogether a majestic object. As an ornamental tree, no species which attains so large a size has a finer appearance when it stands 
singly or in small groups upon a lawn where there is room to allow its lower branches, which stretch themselves horizontally to a considerable distance, to bend gracefully towards the gromul, and turn up at their extremities. The tree is in all respects peculiarly adapter?

Fig. $3^{6 .}$

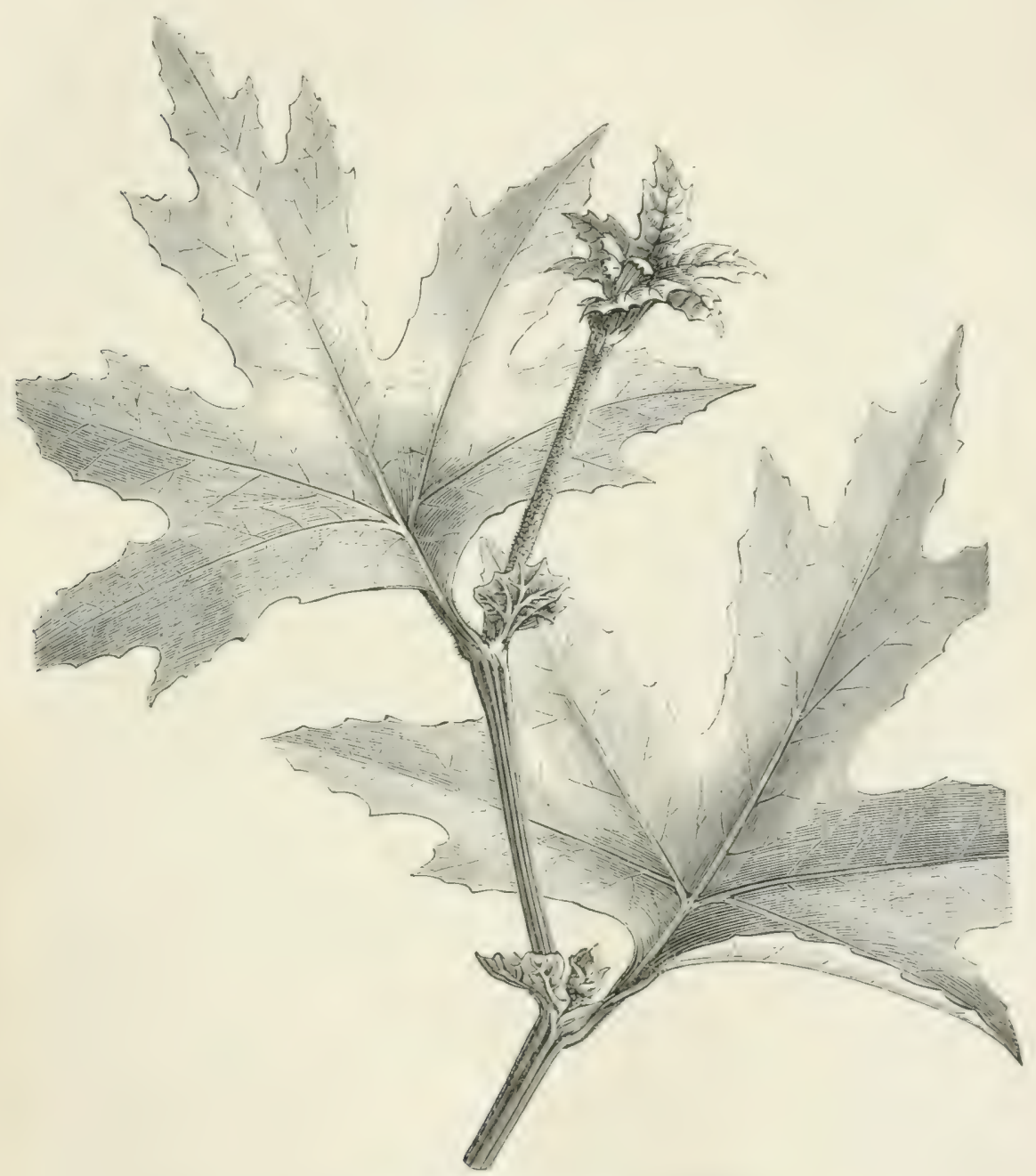

Spray of the Oriental Plane (P. orientalis).

for pleasure-orounds, and for growing in town warlens. It, and especially the variety accifolie, known as the "Lmolon l'lane." seems to be very little affected hy the injurinus action of smolie. This slecies thrives well in Britain, and attains very considerable dimensions, VOL. I. 
where sheltered by other trees, on parks and lawns. It is easily distinguisherl from the Maples - although the leaves of the Maple are somerhat similarly shaped, and the bark of the sycamore also scales off in flakes to a slight degree-in the winter season, by the alternating arrangement of its buds; or in the summer season, by its leaves having five main nerves or veins (not seven as in the Maple), and having stipules, and also by not being arranged in opposite pairs like Maple leaves. Fig. 36 represents a twig of the $P$. orientalis with its leaves and stipules. The leaf-bud is concealed in the hollow leaf-stalk.

Economic Uses.-In the native countries of this tree its timber is used for various purposes in furniture-making and carpentry. From some specimens of stems cut up in this country, the timber seems of about as good a quality as our Sycamore, and, we should say, might be used in all cases in which that is used. When seasoned it has a sp. gr. of only 0.58 , so that it is a very light description of timber, and would be easily floatable immediately after felling. It is not, however, as a timber-tree that it is cultivated throughout Britain, but only as an ornamental species; and in this respect few trees can rival it.

It deserves very special recommendation for the planting up of streets in towns and eities, as its foliage resists, better than that of any other species of tree, the clogging and disease-produeing effects of sulphurous acid, and of the carbonic and other impurities with which the atmosphere of densely populated and manufacturing centres is laden. It is easily distinguishable from the American Plane by its bark scaling off much more freely during the winter months, and by usually having 2 or 3 fruit-balls, whereas in occidentalis they are generally solitary.

Soil and Situation.-A light, deep, free soil, moist, but not wet in the subsoil, is that on which the $P$. orientalis thrives best; and the situation should be sheltered, but, at the same time, not shaded or crowded by other trees. It will scarcely grow in strong clay and on elevated exposed parts; nor will it thrive in places where the Lime-tree does not prosper, as it is somewhat more sensitive to late frosts than that species.

On the whole, it may be said to have a fair amount of accommodative power with respect to soil ; but situations that are either very dry or very wet are not favourable to its normal development, and soils containing a large percentage of lime are also not naturally suited for it. In this latter respect, howerer, it is not so sensitive as the Sweet-Chestnut and the Naritime Pine, un, whose growth and development carbonate of lime acts rery prejudicially.

Propagation and Culture.-This tree may be propagated by seeds, layers, or cuttings. The fruits, which ripen plentifully in 
Britain in fine, dry, warm seasons like 1893 , should be gathered in October or November, the balls being broken liy the hand or by threshing them with a light flail; the seeds may then easily be separated from the husks and cleaned by the usual process. The seed may either be sown ont immediately in the nursery, or else mixed with sand and preserved in a dry place, secure from frost, till Felsuary or March. The fruits may also be liept in the balls or catkins till spring, either by allowing them to hang on the tree, or by gathering them in autumn and spreading them out in a dry loft. The general practice is to sow the seeds in autumn, or as soon as gathered or received from the Continent. They should be sown on a moist rich soil and in a shady situation, and should only be covered as lightly as those of the Birch, Elm, or Alder. Or it may suffice if the seeds are merely made to acthere to the soil simply by beating them in lightly with the back of the spacle, and not covering them at all; but in this case it will be necessary to protect the seed-beds with litter of some sort, in order to prevent damage from the winter frosts. The plants will come up during the following spring. The tree is commonly propagated by layers, however, which root freely.

The general method of reproduction throughout Northern Germany is by means of slips taken from the one- or two-year-old wood. They are inserted, like willow-slips, about a foot apart, in good, light, nursery soil ; and when two or three buds are left above the ground, they soon shoot from these. The slips are planted in the nursery during the spring. Variations of this species are numberless. Even from the same fruits hardy and tender varieties may be produced simultaneously.

There are many gond specimens of the Oriental Plane to be found at various places in both England and Scotland, some of them rising to heights from 60 to $80 \mathrm{ft}$., with stems of from 3 to $6 \mathrm{ft}$. in diameter. Being of rapid growth, and affording a good shade in the open, it is eminently suited for the formation of avenues, \&c.

(2.) AMERICAN or WESTERN PLANE-TREE, I'lutums occidentulis L.

Specific Character.-Leares $\tilde{5}$-angled, olsoletely lobed, dentate. wedge-shaped at the base; downy beneath. Flowers greenish: May. Fruit brownish ; ripe in October and November (Loudon, (1p). cit., p. 9:31).

Distribution. - The American Plane is foumd orer a large extent of the North American continent, from the eastem seaboanl to the Westem States, and from the sonthern parts of Canculia sonthwards to the Carolinas. It is plentiful on the sides of rivers in the State of Pemsylvania, and also on the Crmol River in Camada: but is hardly ever found on dry inland parts far removed from the rivers. 
In Furope it is more extensively cultivated throughout Southern Germany and Austria than elsewhere. It is there frequently to be met with forming avenues. It is, however, capable of being cultivated everywhere throughout Britain, as it grows and flowers as far north as $58^{\circ}$ in Western Norway. As it is of rapid development, and yields a fairly good wood for many ordinary purposes, its cultivation is deserving of some attention.

Fig. 37.

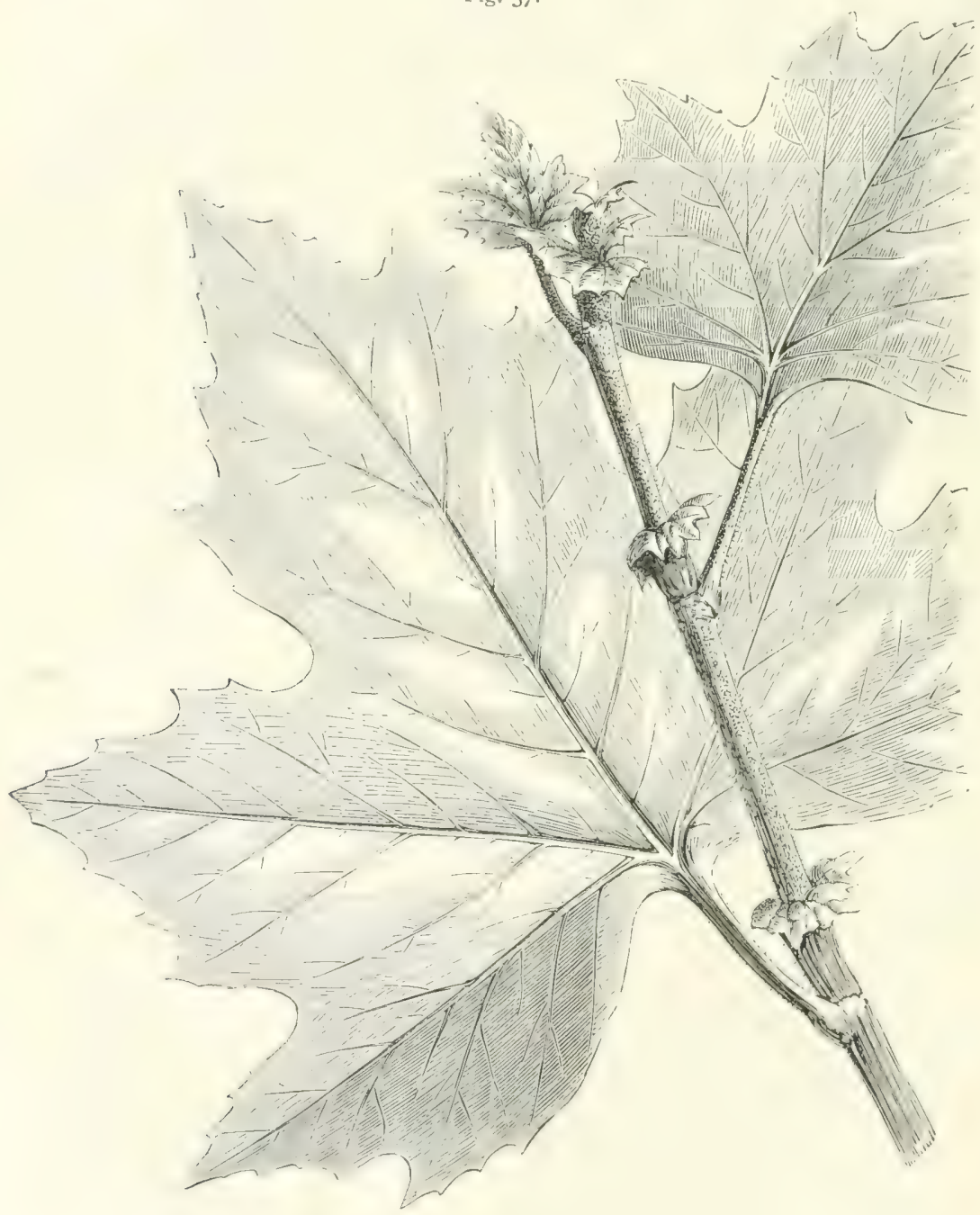

Spray of the American Plane (P. occidentalis).

Description of Tree.-This species is of much more rapid and "uriglit growth than the Oriental L'lane, alrenly referred to, and has broader and less deeply cut leaves (see Fig. 37). 
"Both species ripen seeds in Britain, in fine seasons. P. occidentalis is readily known from I'. orientalis, in the winter season, by its bark scaling off much less freely, or, in young or middle-sized trees, scarcely at all; and, in the summer season, by its leaves having red petioles, and being but slightly lobed, instead of being palmate, like those of the $P$. orientrelis, which have green petioles, and by its globular catkins being nearly smooth, while those of $P$. orientalis are rough" (Loudon, ibid.)

The leaves of the Western Plane are rounded off, and not usually heartshaped at the base, and have, as a rule, only three main nerves and three lobes; those of the Oriental Plane are either wedge-like or heart-shajed at the base, and have five main nerves and five lobes. The young foliage and leafstalks of the former are also usually covered with a yellowish-white primrose bloom, whilst the stalks are of a reddish-brown colour. In the latter the young leaves are jubescent or downy on the under surface only, and the leaf-stalks are shorter and mostly green. In the Western Plane the fruit-balls are usually solitary; whilst in the other species there are generally 2 or 3 seed-balls on each spike.

The American Plane is also ensily distinguishable at a distance from the Oriental Plane by its more upright habit and rapid growth, especially when placed on a low-lying level part, near to running water. On the whole, it is not quite of so ornamental a habit of growth as the $P$. orientalis; its outline at all stages of development is somewhat stiffer, and therefore rather less graceful, than in the case of the latter. But even making full allowance for this, it is a handsome tree, and well worthy of a place in any well-sheltered park on a site by a river-side, where its generally tall form and heautifully waving masses of leaves give it a character peculiar to itself, and add quite a foreign element to the scene.

Economic Uses of Timber. - In America the timber of this tree is not held in much estimation; and it is hardly ever used for any technical purposes when Maple can be obtained instead. It is sometimes, however, used for furniture-making, and for some parts of the inner work of house-building. It is rather a handsome wood when cut up, and beautiful pieces of furniture may be made from it; but it is short-grained, is easily broken, and does not last well. Like the wood of the Lime, its light timber is well adapted for being used as a base or frame-work in the manufacture of veneered furniture.

Soil and Situation.-In order to give the Plane a fiar chance of succeeding it must be planted on a deep, open, and porous soil of a cool nature, but not wet, as on the sides of rivers; and the situation must be a sheltered one, otherwise it will not thrive. Specinens of this tree growing on the sides of some of the rivers in I'ennsylyania attain a height of fully $100 \mathrm{ft}$, and form stems of from 3 to $6 \mathrm{ft}$. in diameter. In these cases the soil is generally of a deep, moist, sandy nature, and very rich in litmus or vegetable matter. 
Propagation and Culture.-This I'lane is often propagated in Britain from seeds imported from America. The seeds should be sown in a cold frane in February or March, and shaded from the sun till the plants have come up and gained some strength. Afterwards they should be gradually exposed till they are accustomed to the sunshine; and when they have become hardy enough the frame should be removed, and the plants left to themselves to mature their growth in the open air. During the following season they will be fit for transplanting out into lines in the nursery; this may be done in the same manner as specified for the Sycamore.

This tree may also be reproduced from slips or cuttings, which root quite freely and form excellent plants; it is as easily propagated in this way as the Willow or the Poplar. It may also be reproduced by layers, and by this mode a large proportion of the plants reared in Britain are propagated (see under Oriental Plane).

There are very fair specimens of this species in many of the streets and open spaces, and in most of the parks in the neighbourhood of London; and in different parts of England there are specimens even of larger dimensions than those of the Oriental Plane. In Scotland also there are many good trees of this species.

\section{CARPINEA DÖLL.}

The Carpinew, or Corylacew as it was named by A. de Candolle, is a family scattered throughout the temperate zone of the northern hemisphere, and especially frequent in central Asia and eastwards to Japan, which consists of 4 genera and 18 species, whereof 2 genera and 6 species belong to Europe, and occur of suontaneous growth throughout central and southern Europe. These genera are (Willkomm, op. cit., p. 355) distinguishable as follows:-

I. Carpinex. Nut $\frac{1}{4}$ to $\frac{1}{3}$ of an in. in length.

1. Nut encircled at the base by a large flat-lobed or indented toothed bract. Hornbeam

Carpinus.

2. Nut enclosed in a hollow, conical, net-veined bract. Hop-beech

Ostrya.

II. Corylece. Nut $\frac{3}{4}$ to $1 \frac{1}{2}$ in. in length, and either covered or hidden by the envelope formed by the bracts. Hazel . . . Corylus.

Of these only the Hazel (Corylus) is indigenous to Britain, whilst the Hornbeam (Carpinus) was introduced before the close of the fifteenth century. The Hop-Beech (Ostrya) is of more recent introcluction, and is almost solely confined to arboreta and botanic gardens; even in its own home throughout southern Europe it plays a comparatively unimportant part as a tree of true forest growth.

Hazel.-According to the scheme of this work, only timber-pro- 
ducing trees are here treated in retail; but the Hazel, thourgh only a shrub, certainly demands some little passing notice for its true sylvicultural importance in most parts of Britain. It possesses special value as colpice-wood, since storl-shots of three or four years of age can be very usefully and remumeratively disposed of as horps for barrels and all similar purposes. It has excellent reprorluctive capacity, and sends out numerous straight shoots from the stool whenever it is cut back. It can thrive on all kinds of soil, but attains better development and stronger reproductive capacity on fresh or moist limy, loamy, alluvial, or humose soils than on throse of an inferior sandy description; sour marshy land and heary stiff clays are not well suited for its growth. Even on shallow rocky hillsides it can often yield a fair return, when a mere handful of earth here and there enables it to establish itself, and in such situations its heavy fall of leaves amnually tends greatly to the enhancement of the productive capacity of the soil. It can be of considerable service in filling up blanks in Oak-coppice on patches of soil that are not good enough for the Oak, as it can be worked advantageously in the same rotation (14 to 16 years) as the main crop. Throughout southern England it often forms a large proportion of the undergrowth under Oak standards, and is by no means the least profitable part of the underwood, as the long straight stool-shoots can be utilised for a great variety of purposes, and yield fuel of no mean quality. And in addition to that, the revenue obtainable for the collection of the nuts is sometimes capable of yielding a very fair return.

The Hizel-stools retain for a long time their reproductive power, as the shoots coming up out of the ground from near the base of the stem often take root for themselves, and thereby give additional vigour to the parent stool. In Oak-woods with a sparse growth of underwood, any Hazel throughout the coppice-crop may advantageously be utilised by bending back a few of the stool-shoots and layering them, in order to increase the density of the crop: as these soon strike root for themselves, they do not draw their supplies of fool from the parent stool when once they have established themselves away from it. As most of the woods in England are not sufficiently dense to utilise the soil to its fullest degree, and at the same time to protect its productive capacity thoroughly, this methoul deserves a trial wherever it can conveniently be adopted; for it has the merits of being chenp and rational. When Hazel plants are required for filling up blanks in existing plantations, or for the formation of new coppice-wools or underplanting, the methou of layering will produce gool plints more yuickly than raising them from the seed; this latter methol, however, presents no difhenlties of any kind to be orercome, its only dratrack being that the seedling 
flint:s are of much slower initial development than those obtained by layering. The method of lavering has previonsly been described with regard to the Elm (see p. 136).

Despite its good thick foliage, the Hazel is rather a light-demanding species of shrub; hence its highest returns can only be expected from coppice in the free enjoyment of light and warmth, and not when it has to be content with a diminished supply under the shade of standards. Even when allowed to develop to its full extent, it forms only a minor tree of about 20 to $22 \mathrm{ft}$. in height.

12. THE HORNBEAN, Carpinus

(Lixyzax System, Monecta Polyandria).

Character of the Genus.-Male flowers: Catkin lateral, sessile, cylindrical. Bracteas imbricate. Flowers consisting of 12 or more stamens inserted at the base of a bractea. Anthers bearded at the tip, 1-celled. Female flowers in lax terminal catkins. Bracteas of two kinds, outer and inner: outer bracteas entire, soon falling off; inner bracteas in pairs, each 3 -lobed. Calyx clothing the ovary to near its tip, and adhering to it; toothed at the tip. Style very short. Stigmas 2, long, thread-shaped. Fruit not attended by the involucre; ovate, compresed, ribbed, clotherl, except at the hase, and tipped with the adnate calyx; woody; including one seed (Loudon, op. cit., p. 916).

Only one species of this genus need be referred to here-viz., the Common Hornbeam (C. Bctulus), as it is the chief timber-tree of the family, is very hardy, and under favourable circumstances attains a considerable magnitude.

\section{THE COMMON HORNBEAM, Carpinus Betulus L.}

Specific Character.-Bracteas of the fruit flat, oblong, serrated, with two lateral lobes. Flowers yellowish; May. Nuts brown; ripe in October or November (Loudon, ibid.)

Distribution.-The Common Hornbeam is a native of all parts of central Europe, being found in France, Germany, Italy, the south of Russia, and in the west of Asia. It is also a native of England, Ireland, and the southern parts of Scotland.

Description of Tree.-It is a singular fact in the history of the Arburiculture of this comntry, that althoun the Hornbean, when grown on a good loamy soil, often forms a stem of from 2 to $3 \mathrm{ft}$. or even more in cliameter, with a height of from 60 to $70 \mathrm{ft}$., and though, under such circumstances, it is a very ornamental tree with a thick and spreading cromn of foliage, yet it has not been much cultivated. It has been neglected, and reduced to the position of 
a mere liedge plant. This may have arisen from the great tendency that the tree has to ramify and remain short of stem, and thus not worth much as timber; whilst, of course, this ramification directly enhances its general fitness for hedging purposes. It is,

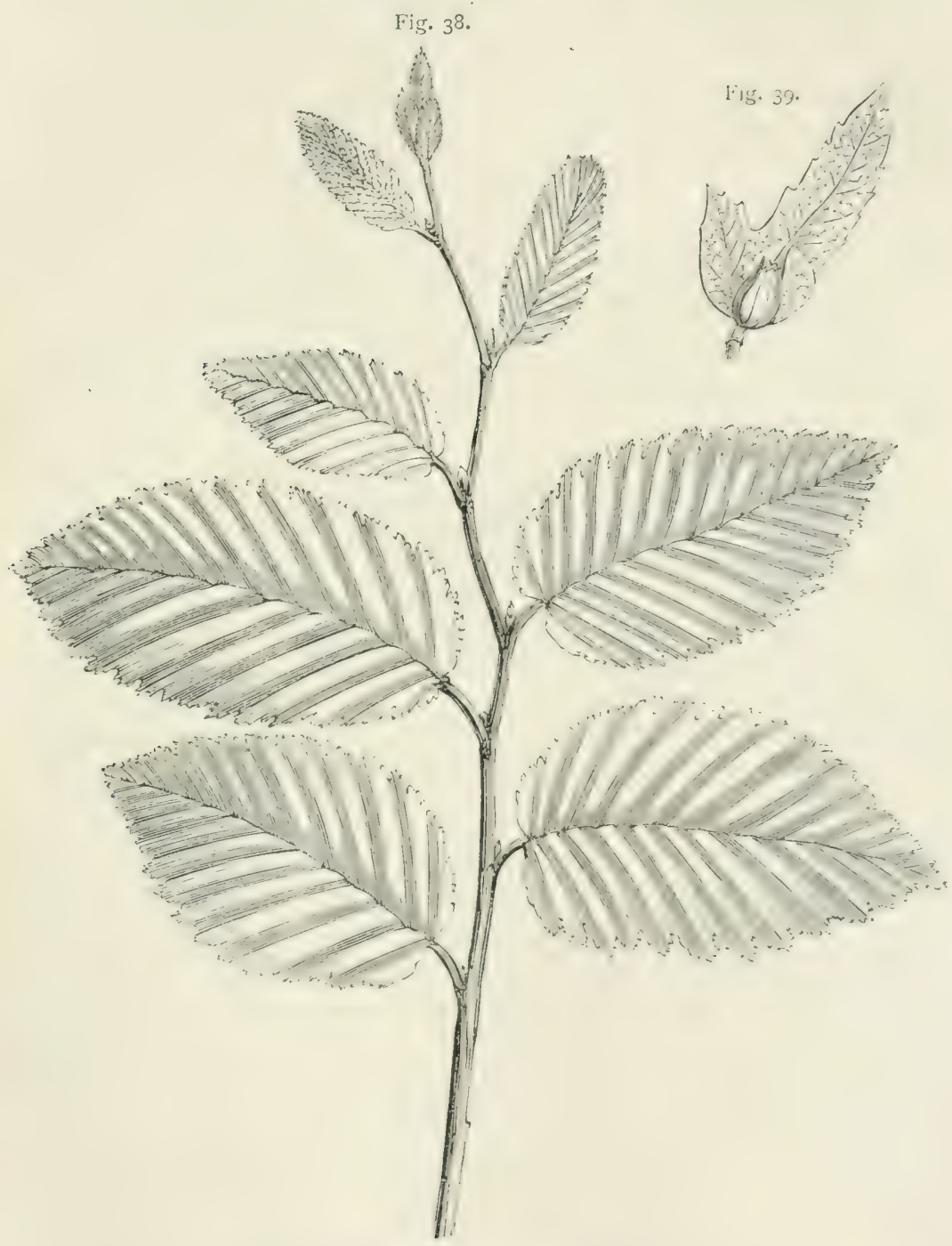

Leaves and fruit of the Hornbeam (Carpinus Betulus).

notwithstanding, a tree capable of being cultivated to very considerable timber size, as good specimens of it may frequently be found growing in plantations along with other trees, where it has its tendency to ramification checked hy standing in close canopy among 
them. In fact, the Hornbeam is so seldom seen of the dimensions of a timber-tree, that practical foresters of lons experience may even be excused for occasionally failing to recognise it, and for conceiving it to be merely a species of Beech. It certainly does much resemble the Common Beech; but it is very easily distinguishable by the feather-nerved and plaited appearance of the leaves, as well as by the difference in the seed or nuts, which have a flat, leafy, threelobed appendage (see Figs. 38, 39). Hornbeam is chiefly reared for hedging purposes; and as it stands pruning well, and has a strong reproductive power, it answers admirably for this purpose.

The Hornbeam is easily distinguishable from the Beech by the usual fluted growth of its stem, and although the leaves are ranged on the twig in the same manner and correspond as regards size and outline, yet there can be no mistake made about them, as the Beech-leaf has an entire edge, whilst the Hornbeam-leaf is doubly serrate. During winter the buds are smaller than those of the Beech, and the slightly bent side-buds are always pressed closely down against the twigs.

Except in western Russia, where it attains its finest dimensions, and takes the place of the Beech as a forest-tree, it does not usually grow to more than $60 \mathrm{ft}$. in height, with a stem of about 2 to $2 \frac{1}{2} \mathrm{ft}$. in diameter. Nor does it attain so high an age as the Beech, for after about its 100th to 120th year it is apt to become stag-headed and unsound in the bole. But it retains its reproductive capacity of shooting from the stool to about 95 years, like the Oak.

During the development of the buds annually large numbers of diminutive adventitious buds are also formed near the base of the bud-axis, and when the twigs are clipped or removed these attain development. It is to this fact that its special adaptability for hedging purposes is attributable.

Economic Uses of Timber.-The wood of the Hornbeam is white, of a very hard texture, and heavy as compared with many other kinds of timber; it is also a very cross-grained kind of wood, and therefore rather difficult to work up for technical purposes. It is, however, often used by country carpenters for many of the rural purposes to which the timber of the Beech is applied. It makes excellent firewood, and forms charcoal of very superior quality. It is seldom that the Hornbeam is to be found in this country of dimensions large enough to make it valuable as a timber-tree, for the great majority of the specimens remain comparatively small, and are really often only fit for firewood and charcoal.

On the Continent the wood of the Hornbeam is, owing to its extreme tonghness, jrized for cogs, ire., for machinery, and is also largely used for making carts, moulds of different sorts, boxes for planes, wedges, working-benches, flails, agricultural implements, wooden pegs for shoes, and the like. It can only be accounted durable when utilised in dry places. It has a sp. gr. of 1.05 when green and 0.74 when seasoned, so that it is on the whole at least as heavy as the Sessile Oak. It is difficult to split, and shrinks a good deal. 
Of all the European woods it possesses the greatest heat-producing jower as fuel, the list being headed by Hornbeam, Beech, and Birch.

Soil and Situation.-As a hedge plant, the Hornbeam will thrive on most soils, excepting those of a chalky nature. As a timber-tree, however, it attains its largest dimensions on lands of a stiff and rather clayey nature.

Continental experience of this tree has shown that it thrives best on a fresh or moist, deep, loamy-sandy or rich marshy soil, but that it also attains good development on fresh loamy or limy, and deep sandy soils. On shallow, dry soils, and warm sunny exposures, as also on soils that are constantly more or less wet, it does not develop beyond the dimensions of a large shrub; it can therefore in such circumstances only be utilised as coppice, whereas under more favourable conditions it ranks as a tree of the second magnitude.

It is essentially a tree of the plains and of low-lying localities, and can there often yield good service as underwood on soils that are somewhat too moist for the Beech.

Propagation and Culture. - The fruit does not generally ripen in Scotland, but in England it easily attains germinative capacity. It should be sown when gathered, in the month of October, as the greater part of it generally requires to lie dormant for one year in the ground before germinating; or the seed may be stored till one year after ripening and then sown out, when it germinates in the following spring. The plants should be planted out into nurserylines when one year old, and allowed to stand for two years before being put out to their permanent sites.

The Hornbeam can hardly be said to be of much sylvicultural Importance in Britain. Its chief claim to attention rests on its shade-bearing capacity, in which it resembles, but does not quite equal, the Beech, and in its undoubtedly strong power of reproducing itself by shoots from the stool. It is therefore sometimes of value for the underplanting of standards of Oak, where the soil requires an underwood of some shade-bearing and essentially soil-improving species in order to prevent it from deteriorating and losing in productive capracity, but where the land is somewhat too moist for the Beech to thrive. Throughout Britain, however, thanks to our damp climate, the same object can very often be attained quite efficiently by underwood of other sprecies: that hold out better prospeets of yielding fair monetary returns. But where an underwood of Maple and Sycamore, Sweet-Chestnut, Hazel, and the like, shows signs of failing to protect duly the productive capacity of the soil, considerations regarding the latter point to the introduction of Beech and Hornbeam to a greater or less extent; and whilst on the drier classes of land the former should be given the preference, on soil that is moist, or even has a tendency to wetness, Hornbeam will usually perform its duties more etticiently and yield the more satisfactory results. In coppice-wooks, when felling takes place deep down near the ground, this genus often throws out stoles or 
suckers as well as stool-shoots. Where firewood is in demand, coppice-woods of Hormbeam, worked with a rotation of 20 to 40 years, can yield good returns.

As it bears seed freely from about the age of 30 years, and as the long bract attached to it enables the seed to be borne far by the wind in autumn, all Hornbeam-trees should be cleared away from the vicinity of tracts in which crops of Oak or Beech are being regenerated naturally. For the Hornbeam springs np easily, and is often difficult to exterminate owing to its great reproductive power.

It is one of the hardiest species of trees against late frosts; and is therefore specially adapted for undergrowth in damp low-lying tracts, where less hardy species fail to thrive.

Underwood may easily be formed either by sowing or planting.

In many parts of England the Hornbeam is to be found $70 \mathrm{ft}$. in height, and with stems ranging from 30 to $36 \mathrm{in}$. in diameter. In Scotland it frequently attains a height of from 50 to $60 \mathrm{ft}$., with stems over $30 \mathrm{in}$. in diameter. It seldom attains an age of over 150 years, but usually begins to exhibit signs of senile decay about the 100 th or 120 th year.

\section{HIPPOCASTANEE DC.}

\section{THE HORSE-CHESTNUT, Esculus \\ (Linnean System, Heptandria Monogynia).}

Character of the Genus. - Calyx campanulate. Petals 4-5, expanded, with an ovate border. Stamens with the filaments recurved inwardly. Capsules echinated. Leaflets sessile, or almost sessile. Leaves palmately divided, with stalked leaflets, generally rough. Capsule rough (Loudon, op. cit., p. 124).

The only species of this genus that need here be referred to is the Horse-Chestnut (Asculus Hippocastanum). This is a tree of great magnitude and beauty, and therefore well deserves a place in any park, as it may be said to be the only flowering large tree we have upon our lawns. It is called the Horse-Chestnut from the fact that the Greeks and Turks used the seed medicinally for the cure of glanders or strangles and of pulmonary diseases in horses.

Through the whole of central and western Europe the Horse-Chestnuts are favourite trees for the formation of avenues and of ornamental lines of trees in towns, not only on account of the beauty of their flowers in early spring, but also of the fulness of their foliage throughout the summer. There are several kinds of Horse-Chestnuts, but in England the Common HorseChestnut is the only species that is to be met with frequently. These others include the Red Horse-Chestnut (A. camec Willd.) and the two American species (the genus Pavia of Boerh.), the Yellow Horse-Chestnut (Esculus flava Ait. = Pavia flava .Inch.) and the rarer Purple Horse-Chestnut (Esculus pavia L. $=$ P. rubra Lamk.) The first-mentioned is most probably merely a hybrid of the Common and the Purple Horse-Chestnut. 
THE COMMON HORSE-CHESTNUT, LEculus Hippacastanum I.

Sryoxys-IJippocastanum vulgare Gaertn.

Specific Character.-Lecuftets 7 , obovately cuneated, acute, and toothed. Flowers white, tinged with red; May. Fruit brown; ripe in October. Buds long, large, greenish-l,rown, covered with resin (Loudon, ibicl.)

Distribution.--This tree is a native of the mountains of Greece. It was introduced into Britain from Asia, however, by way of the continent of Europe, about the year 1629.

Description of Tree.--The Horse-Chestnut is of rapid growth,

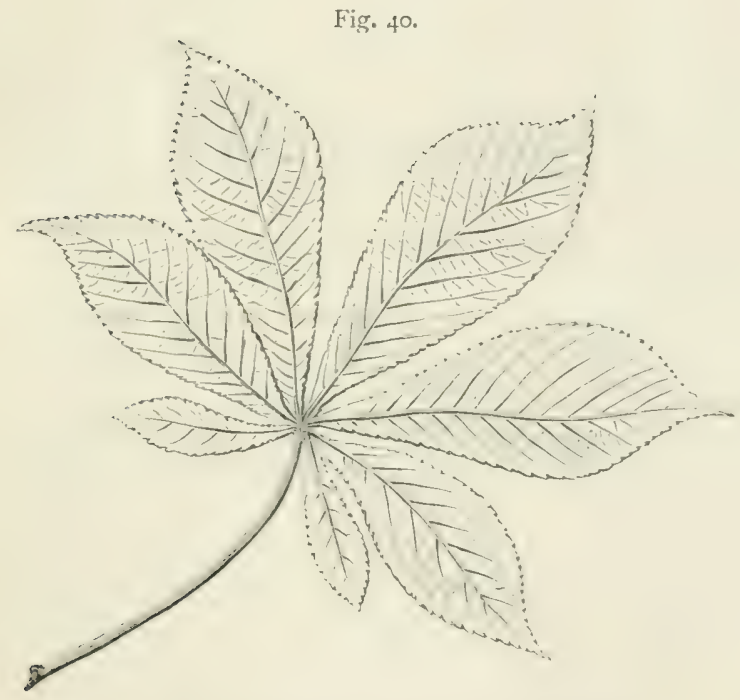

Seven-lobed digitate leaf of the Horse-Chestnut.
Fig. 4I.

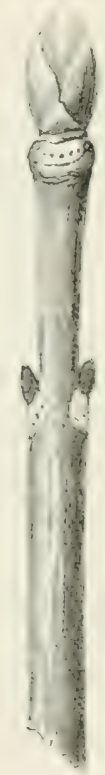

Shoot showing buds and lcaf. scars of the Horse-Chestnut (Esculus Hippocastanum).

and in a few years attains a very considerable size. It is by no means a delicate tree, although a native of countries having a much warmer climate than Britain. It is, in fact, a hardy species, so far as regards the degree of cold which it can bear; but from the shortgrained texture of the wool, which is brittle, it is not at all adapted for growth in an exposed situation. Though the crown has a somewhat formal outline, the leaves (Fig. 40) have a very fine massive effect when the tree is placerl among others of a more light and airy character: and as the foliage thushes early in the season, atcompanied 
hy the rich pinkish-white flowers, this genus is upon that account more worthy of a place upon the lawn. The naked tree is in winter of a stift and ungraceful character, the young shoots being large and not numerous (Fig. 41). The lower branches are usually pendulous, and with curving, upturned ends. The rapid growth of the young woul of this tree is remarkalule, the shoots of the year's growth being senerally perfected within one month from the time of the opening of the leaf-buds. The Horse-Chestnut, when standing in an open park, has, like all other trees, but in a more marked degree, a tendency to spread out massive limbs rather than to grow to height of stem; and in this form it is always most ornamental, being clothed from bottom to top with branches spreading out a large surface of leaves, which, with their accompanying flowers, produce an admirable effect in the month of May.

This tree was long supposed to be indigenous to Central Asia, until in $1879 \mathrm{Th}$. v. Heldreich proved it to be a native of the mountainous regions of northern Greece, Thessaly, and Epirus, where, at elevations of 3300 to $4.500 \mathrm{ft}$., it is found growing in association with Walnut, Plane, Ash, Maple, Oaks, and Holly. It has been said to occur extensively in the Himalaya Mountains; but the species occurring there is not the Eveulus Hiprocastanum-it is the Esculus indica, Colebr. = Pavia indica, Royle (Willkomm, op. cit., pp. 774, 775).

Economic Uses of Timber. - Although the wood of the Horse-Chestnut is soft, and by no means adapted for requirements in which durability and strength are objects, still there are many purposes for which it is useful, such as flooring, waggon-bottoming, turnery-work, and many of the similar uses to which the timber of the Poplar and Willow is applied. In Britain, however, the HorseChestnut is never cultivated with a view to its timber, but solely as an ornamental genus; and as such it is well known to every one. It is an excellent tree for planting on the sides of roads near towns, and in parks and public places, for the smoke does not seen to injure it much; but its spreading halyit must be repressed by trimming the lower branches when it is used for the ornamentation of the sides of streets in towns.

On the Continent there is a fair demand for its timber by turners and cabinetmakers, and it is of special value for the purposes of carvers; otherwise its durability is not sufficient to recommend it for general use. It has a sp. gr. of 0.90 when green and 0.57 when seasoned. Like other softwoods, its timber is well adapted for the manufacture of wood-pulp and cellulose.

Soil and Situation. - In order to attain large dimensions, and to have the full appearance which its massy foliage and heary limbs are calculated to produce, it requires to be grown upon a good rich loamy and dry soil, and in rather a sheltered situation; at least, it 
must be in a situation where it is not apt to be exposed to severe storms of wind, such as in a park among other trees, or on the sides of roads in plantations.

Where late frosts are frequent, the trees are apt to be very much interfered with in the setting of their fruits.

Propagation and Culture.-This tree is propnagated from the seed, which is termed a nut. These are generally ripe in the month of October, and they should be sown immediately when gathered, as they are extremely apt to lose their germinative power if kept long. They should be sown in rows, in the same way as has already been recommended for the nut of the Sweet-Chestnut. The young plants make vigorous shoots during their first year, and are fit for being planted out into nursery-rows when one year old. They may remain in the latter either for one year or for two years, according as the transplants may be wished to be small or large. It is perhaps unnecessary to remark that the nuts ripen freely in this country, and should be gathered before they fall from the trees, which they generally do in the month of November.

"The rearing of seedlings and transplants offers no special difficulties to contend with. The seed is usually put into the prepared seed-beds in autumn, being sown in rills with about 4 inches between every two seeds. Care must be taken to have the smooth side upwards and the grey scar undermost, otherwise malformation of the root-system and weakly seedlings are the results, as was proved by experiments in the forest-nursery at Carlsruhe." (Nisbet, British Forest Trees, p. 309.)

This tree also attains very large dimensions under favourable circumstances, being frequently found of from 70 to $80 \mathrm{ft}$. in height, and with stems of from 4 to $6 \mathrm{ft}$. in diameter.

\section{TILIACE JE JUSS.}

\section{THE LIME-TREE, Tilia}

(Linnean System, Polixandria Monogynia).

Character of the Genus.-Calyx 5-parted. Petals 5. Stamens numerous, free, or somewhat polyalelphous. Orury globose, villous, 1-styled, 5-celled; cells 2-ovuled. Nut coriaceous, 1-celled 1-2seeded, from abortion (Loudon, op. cit., p. 63).

London, in his Encyclopedia, originally distinguished and described 4 speeies of the Lime-tree as natives of Britain, 3 as nutives of North America, and 1 as a native of Hungary. The four sorts described by Loudon as species, and as natives of Britain, were the Common Lime-tree, Tilia mbra; the intermediate Lime, Tr. interinceliu; the 
small-leaved Lime, T. parvifolia; and the broad-leaved Lime, $T$. platyplylle. The specific characters of these four kinds were given by Loudon as follows :-

1. Leaves cordate, unequal at base; petioles and suckers hairy; axil of veins beard beneath; fruit globose, smooth . . . T. rubra.

2. Leaves cordate, acuminated, serrated, smooth, twice as long as stalks; axil of veins beard beneath; fruit membranous, oblong, deformed, 2-seeded . . . . T. intermedia.

3. Leaves cordate, round, acuminated, finely serrated, smooth, scarcely longer than stalks; axil of veins beard beneath; fruit round, very thin and brittle . . . . . T. parvifolia.

4. Leaves cordate, round, acuminated, finely serrated, a little downy beneath; fruit turb., woody, with prominent ribs. T. platyphylla.

Even although botanical differences exist with regard to these different kinds of Lime-trees, yet the whole genus Tilia is really of so little sylvicultural importance throughout Britain that it will best suit the purposes of the present work to class them all together (as was originally done by Linnæus), and consider them as merely varieties of the one tree-viz., the Linden or Line-Tree (Titia exropaca), or the common European Lime. Sylviculturally and arboriculturally there is really no difference worth mentioning in respect to the general habits and peculiarities of the trees, all requiring the same treatment in their general cultivation, \&c. Hence reference will here be made only to the species which are given as natives of Britain, for, whether as timber or as ornamental trees, they are very much superior to the others.

The majority of Linden or Limes are indigenous to the warmer temperate zones of North America and Asia, and the few species native to Europe were by Linneus classed as $T$, europaed. Strictly speaking, however, there are two distinct species indigenous to central Europe, which are thas distinguishable:-

1. Leaves smooth; upper side dark-green; under side dull bluish-green, with rusty-brown hairs in the angles of the ribs; cymes bearing many flowers (T'. ulmifolia, Scop.) ․ . . T'parvifolia, Ehrlı.

2. Leaves hairy; under side grass-green, shining, and with whitish hairs in the angles of the rib; cymes bearing three flowers ( $T$. platyphyllos, Scop.)

1'. grandifolia, Ehrh.

THE COMMON LINDEN or LIME-TREE, Tilic curopen L.

Synonyms-T. parvifolia and T. grandifolia Ehrh.; T. ulmifolia and T. platyphyllos Scop.; besides other synonyms for each of these two species.

Specific Character. - Petals without scales. Leaves cordate, acuminated, serrated, smooth, except a tuft of hair at the veins beneath, twice the length of the petioles. Cymes many-flowered. 
Fruit coriaceous, downy. Flowers yellowish-white; August and September. Fruit yellow; ripe in October (Loudon, T'rees and Shrubs, 1875, p. 64).

Distribution.- The Lime-tree is found in the Alps of Switzerland, in the north of Italy, and also in Spain and Portugal. It is likewise found in Russia, Sweden, and Gemnany. It was originally introduced into Jiritain by the Romans; but the large-leaverl species apparently died out, for it was reintroduced during the eighteenth century. Except in rare instances, it does not ripen seeds in this country, which is a proof that the tree is not truly indigenous to Britain. The short-leaved species has been cultivated in Britain from time immemorial (as may be proved by the derivation of many ancient names of places throughout both Scotland and England), and consequently, like some species of our other trees, has become a denizen-i.e., it is now so far naturalised as to be constitutionally as hardy as a native.

Throughout central Europe the small-leaved Lime occurs much more extensively than the broad-leaved species, which is that most frequently to be found over southern and south-eastern Europe and in south-western Asia. The former forms extensive woods throughout western Russia, Poland, and eastern Prussia, where it is often associated along with the Oak and the Elm.

The Limes are essentially trees of the plain, and do not ascend the hillsides to any great elevation.

Description of Tree.-The Lime-tree is one of the most beautiful and interesting of our ornamental trees in the month of July, when in full flower, with leaves in their freshest state. Many object to it as being of a stiff and formal outline with a clumsy habit, and as not presenting that light and shade which are required for picturesque scenery. This is no doubt true; but in well-chosen situations, such as along the sides of wallis or avenues, it is one of the most desirable of trees. Even when standing singly, freely exposed to the open air, and when in contrast among other genera, it forms a beantiful object when in full flower; indeed, as an ornamental tree, in almost any situation, few can object to its presence. This tree, under favourable circumstances, attains very large dimensions, often reaching a height of $100 \mathrm{ft}$., with a stem over $4 \mathrm{ft}$. in diameter near the ground. It also lives to a great age, and may often be found in a sound state of timber when upwards of 200 years old.

The leaves of the Lime are of a fine light green, and are deseribed by botanists as cordate, acuminated, and serrated (see Fig. 42, a). There is a peculiar appendage attached to the peduncle of each of the cymes of flowers of the Lime-tree, termed the flural leaf, out of which the flowers protrude, as it were (see Fig. 42,6 ).

VOL. I. 
As has already been noted, the cymes of the large-leaved Linden have only thre flowers. whilst those of the small-leaved species (shown in the above figure) have more than three flowers. They both do fairly well in the impure atmo-sibere of towns, and are well adapted for lopping and pollarding, as they easily develop large numbers of adventitious buds near their crowns.

Economic Uses of Timber.-CThe wood of the Lime is white in colour, and of a peculiarly cluse and soft nature, hence particularly well adapted for all kinds of turning-work. It is much sought after for boards upon which to cut leather. It is also used in the making of musical instruments, as in the case of sounding-boards for piano-

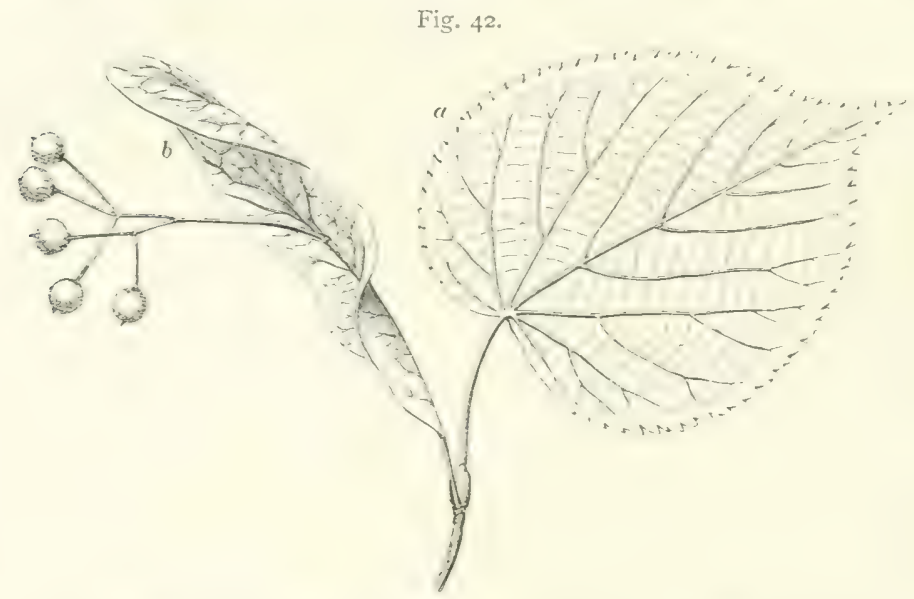

Leaf and fruit of the Small-leaved Lime (T. europæa L.=T. parvifolia Ehr.h.)

fortes, for which purpose large quantities of it are often disposed of. It is also used in the maling of charcoal for gunpowder. In Russia and ciwelen, the inner bark or bast of the Lime-tree is manufactured into the bass-mats which are so much employed in this country for various rough purposes.

The rood of the Lime possesses little durability, and even in dry places is apt to be attacked by insects. It is the lightest wood produced by any of the broad-leaved species of European trees, having a mean sp. gr. of only 0.74 when green and 0.45 when seasoned, so that it is no heavier than Sprucewood.

On the Continent it is used extensively for the fabrication of wood-pulp, for piano and organ manufacture, for coarse carving, and as the framework for veneered furniture. Owing to its lightness, it can be highly recommended for packing-cases and the like.

Soil and Situation.-The Lime-tree is found to thrive well on a great variety of soils, if not too poor and too dry, and if not exposed to heavy storms. It attains a large size on deep, rich, light loam, 
when well sheltered among other tall trees; but the best specinens may sometimes be seen growing upon a strong, deep, clayey loam, rather of a moist nature than otherwise in the sulsoil. In general it may be said to thrive best on a good strong loam, and in a lowlying and sheltered situation; hut it becones a fair and handsome tree on lighter lands, if the soil is deep and the situation shelterer. The Lime-tree is very easy to trinsplant with safety at a consideralle age and size. Hence it is also useful in filling up gaps, or for making groups so as to produce an immediate effect upon a lawn.

Both the large-leaved and the small-leaved Linden require a good deep soil, upon which they make much the same demands as the Beech. But the former makes higher demands than the other, both with respect to soil and to temperature; and, as it is at the same time the more handsome tree of the two, it should in general receive the preference for planting out in prarks and avenues in southern England. For Scotland, for poorer land, and for the smoky atmosphere of towns, the small-leaved Lime has decided advantages.

Propagation and Culture.- The fruits very seldom ripen thoroughly in Britain, and it is only during very fine seasons that the seed acquires good germinable capacity. The Linden is therefore generally propagated by layers, by means of which it is very readily multiplied. Being a soft-wooded tree, it ensily strikes root by layering. Nurserymen in Britain, however, sometimes get seeds from the Continent, where they ripen perfectly; but as the plants raised in this way take a long time to attain sufficient size for sale, and for transplanting into their permanent sites, the morle of rearing them by layering is most generally adopted, as by this method they ean be reared of a given size in half the time that is required to have plants of the same height by growing them from seed. In raising the Lime from seed, the seeds should be sown as soon as received, because, if they are preserved dry till the following spring, they will not come up equally - many of them not till the second year. Some, however, mix the seeds with sand, or very fine earth, which should not be so dry as to extract the natural moisture from the seeth, nor so damp as to induce rot in them. If kept in sand or fine, not too dry, earth, they should be sown in the following spring, and will come up equally in summer. For the reasons stated, however, layering is the mode by which the plant is generally propagated in our nurseries: and when the layers are one year old, they may with all safety be remored from the parent stock and planted out in the nursery rows, where they can remain for one, two, or even three years, according as the transplants may be wished to be small or large.

It may be remarked here, that there are no ferwer than fourteen varieties of the Common Lime-tree enumerated in the catalogues of 
British nurserymen, all of which can of course be reproduced by layering.

It would hardly be correct to speak of any sylvicultural characteristics of the Lime in Britain, for it is really only of arboricultural importance for the formation of avenues and as an ornamental tree in parks and open spaces, and along broad roadways in towns. This latter position, once largely occupied by the Lime and the Elm, has, however, in our huge modern cities been found to be perhaps more suitable for species like the Plane, that are even hardier against the action of injurious constituents, like sulphurous and nitrous acids, contained in abnormal quantities in the atmosphere. Wherever bee-keeping is largely in vogue, Lime-trees have a special value, as the honeybees visit them frequently during the time of flowering in July and August.

When supplies of seed may be had after warm dry seasons like 1893, it should be sown out in the seed-beds as soon as gathered in autumn, the rills on the beds being about $8 \mathrm{in}$. apart, and the seed being covered with about $\frac{1}{2}$ to $\frac{3}{3}$ of an inch of earth; and it is well to cover up the beds in spring with some sort of protection against early germination and simultaneous danger from frost. After they are planted out as yearlings into the nurserybeds, they require to be trimmed from time to time, as they often exhibit a decided tendency towards excessive lateral development.

The large-leaved Lime is of more rapid growth than the small-leaved kind, and at the age of seven or eight years transplants of the former are usually as large as 10- or 11-year-old plants of the latter. They are provided with strong reproductive power, and are therefore not much liable to permanent damage from late frosts, being endowed with a good capacity for throwing out fresh shoots or foliage when twigs have been nipped. This reproductive capacity, combined with a fair power of bearing shade, would suit them for coppice-growth as underwood were their market value equal to that of other species of woods.

The Lime-tree, on favourable soils and sheltered sites, attains large dimensions, there being few estates of any standing in Britain which cannot boast of trees of this species upwards of $70 \mathrm{ft}$. high, and with stems over $4 \mathrm{ft}$. in diameter. On many places, however, they are to be found of even from 90 to $100 \mathrm{ft}$. in height, and with stems of from 5 to $6 \mathrm{ft}$. in diameter.

\section{JUGLANDEA DC.}

\section{THE WALNUT-TREE, Juglans

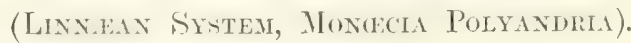

Character of Genus.-Flowers unisexual, monocious. Male flowers in cylindrical, drooping, solitary catkins. Calyx of 5-6 scales. Stamens 18 to 36. Female flowers solitary, or a few in a group, terminal upon a shoot developed in the same year. Calyx ovate, including and adhering to the ovary. Petals 4 . Stigmas 2-3, 
fleshy. Fruit a drupe. Covering of the nut a fleshy husk of 1 piece that bursts irregularly. Nut wooly, of 2 valves. Lcures compound, alternate, exstipulate, deciduous ; imparipimate, of $\check{\check{-}-19}$ leaflets, all but the terminal one in opposite or nearly opposite pairs; all serrate, and all spreading in one plane (Loudon, op. cit., p. 732).

There are many species and several varieties of the Walnut, chiefly natives of North America, but the only one that need be referred to here is the Common Walnut (Juglans regiu), which is known to have been in cultivation in Britain since 1562 at least.

\section{THE COMMON WALNUT-TREE, Juglans regia L.}

Specific Character.-Leaflets in a leaf, 5-9; oval, glabrous, obscurely serrated. Fruit oval, situated upon a short inflexible peduncle. Nut rather oval, rather even. Flowers greenish; April and May. Fruit with a green husk, enclosing a brown nut; ripe in September (idem).

Distribution. - The Walnut was formerly considered to be a native of Persia, and eastwards throughout northern India into China. But the investigations of Th. v. Heldreich have shown that, like the Horse-Chestnut, it is indigenous to the mountainous tracts of Greece, where it may frequently be found of true forest growth, along with Oaks and Chestnuts, in damp valleys and bordering the watercourses at elevations varying from about 2000 to $4000 \mathrm{ft}$. In Bosnia it is also to be found forming large pure forests, and from there it extends eastwards across the Caucasus (Williomm, op. cit., p. 806). This tree is cultivated in every part of Europe, as far north as Warsaw, both for its fruit and timber. In Britain it generally ripens its fruit in most parts of the country lying to the south of the river Forth, but to the north of this it may be said to do so only in fine seasons.

Description of Tree. - Under favourable circumstances, the Walnut in Britain becomes a tree of very considerable dimensions, producing a thick stem with an ample crown of foliage. When the tree begins to get old, it has a thick and deeply furrowed birk on the stem, but on the branches the latter generally remains of a lightish grey colour, and smooth. The leaves, especially when bruised, have a strong aroma, often very perceptible in the warm weather of summer. The leaflets, ranged generally in three or four opposite pairs with an odd teminal leallet, are oval in shine, smooth, and somewhat serrated (see Fig. 43).

Economic Uses of Timber.-The Walnut has hitherto been cultivated chielly for its fruit, but there can be no doubt that it might be turned to good accomnt for its timber also. Then the tree is young 
the timber is soft and white, and worthless as compared with that of most other young trees; but after it has attained an age of 50 to 60

Fig. 43 .

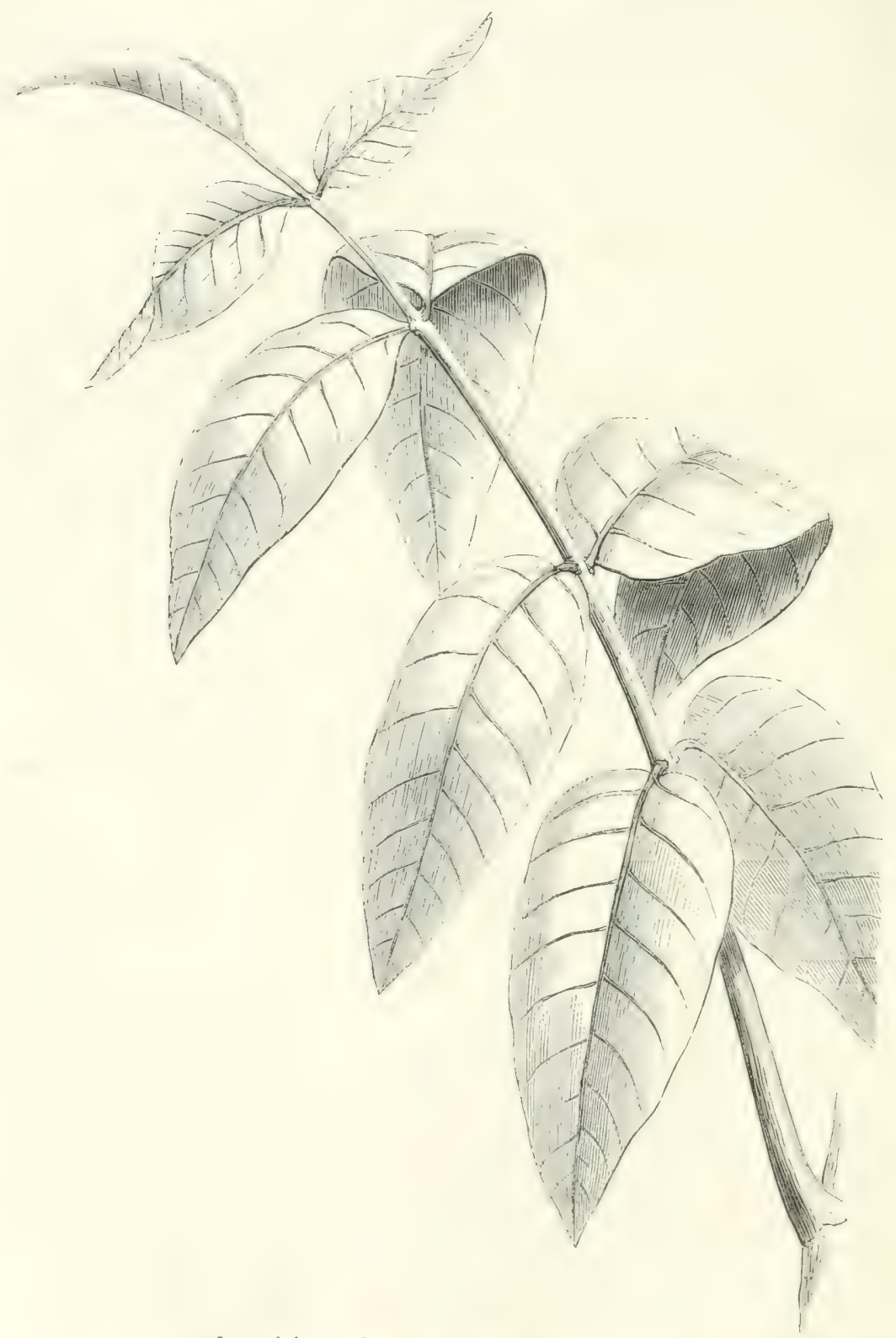

Imparipinnate leaf of the IValnut (Juglans regia).

Years, the duramen sradually becomes hard and solid in the interior of the tree, until at about eighty years of age it assumes a very close 
texture and a dark-brown colour, with heautiful markingss. It is very much sought after for furniture purposes, and for these it brings a high price when of really good and solid quality. It is also very largely used for gun-stocks, as no other description of European wood has been found so suitable for this purpose. In general, however, this tree is chiefly cultivated for its fruit, which is much in demand for the table in most parts of the civilised world. In its young and green state this is pickled and preserved, and when ripe it is used as dessert by all people who can afford it; while in the countries where it grows plentifully, the poorer classes use it as food.

Throughout southern Europe, where the tree attains an age of 300 to 400 years, and a diameter of about $40 \mathrm{in}$., the wood of the Walnut is rery largely used in the manufacture of furniture. In most parts of central Europe it ranks almost equally with mahogany for the purposes of furniture-making, and not infrequently fetches an equal price with that timber. But, in general throughout northern Europe, its importance is to a far greater extent arboricultural than sylvicultural.

Soil and Situation.-To grow the Walnut well, and to a really valuable size, it requires to be planted in a deep and strong loamy soil, rather light than henvy, and by all means deep and dry; for it throws out large and strong tap-roots, and if these get down into wet or bad subsoil the tree will not thrive. It may do well on a considerable variety of soils, if these are of a deep, light, porous, and dry nature; but it will not succeed on a heavy or cold-bottomed land.

Continental experience shows that even on light, deep, humose soil, the Walnut is an essentially light-dementing species of tree, and, in addition to free exposure to light and warmth, requires to occupy a situation not much exposed to cold bleak winds. It is apt to suffer damage from late frosts in May, just at the time when it breaks into foliage.

Propagation and Culture. - This species is always grown from the nuts, which are generally ripe about the beginning of October. They should be sown in rows, and covered to the depth of about 2 in. As they are very apt to lose their vitality if long kept, they should be sown as soon as possible after they have been obtained, whether they may have heen imported or collected near at hand. As the plants throw out strong tap-roots during the first year, they should be lifted when only one year old and plinted out in lines. This will cause them to become more fibrous in the root, and safer to plant out into their permanent sites. There are several varieties of this tree, and these are propagated by loukding, grafting, and layering. 
For sylvicultural purposes two North American species-the Black Walnut $(J$. nigra L.) and the Grey Walnut (J. cinerea L.) - are said to have yielded farourable results in Continental experiments. They are of rapid growth, appear to stand the climate of Europe well, and are not so liable to be damaged by late frosts. In America they are trees of true forest growth, as their fruits have little edible value. The Black Walnut is said both to be an ornamental tree and to yield splendid timber. It is said, also, to be much hardier than the common species.

The average dimensions of the Common IValnut, in favourable soils and situations in Britain, may be stated as about $60 \mathrm{ft}$. in height, and about 30 to $36 \mathrm{in}$. in diameter. It indeed sometimes attains the height of 80 and $90 \mathrm{ft}$., with stems over $4 \mathrm{ft}$. in diameter, but these are only very exceptional cases.

\section{MAGNOLIACEA.}

16. THE TULIP-TREE, Liriodendron

(Linxean System, Polyandria Polygyyia).

Character of Genus.-Carpels 1-2-seeded, disposed in spikes, indehiscent, deciduous, drawn out into a wing at the apex. Calys of 3 deciduous sepals. Corolla of 6 petals, conniving into a bellshaped flower (Loudon, op. cit., p. 36).

There is only one distinct species of this genus, the $L$. tulipifera, which is a free-growing tree, attaining a large size in this country, and especially in the southern and midland counties of England.

THE COMMON TULIP-TREE, Liriodendron tulipifera L.

Srzoxyss-L. procera Salisb.; Tulipifera Liviodendron Mill.

Specific Character.-Leaves smooth, truncate at the top; 4lobed, resembling a saddle in shape. Flowers large, solitary, terminal; variegated with green, yellow, and orange colour; fuxnished with two deciduous bracteas under flowers. Flowers greenish yellow without, orange within; June and July. Strobile brown; ripe in October (idem).

Distribution. - The Tulip-tree is foum growing unturally in the woods of Canada, and those of the United States as far south as Carolina and Georgia, and also very abundantly in Tennessee and Kentucky. It appears to be more frequent in the southern than in the northern parts of Upper Canada, and it is also plentiful in New York State, and in Pennsylvania, where it is called the Tulip Poplar.

It was introduced into Europe from North America either in 1663 or in 1688.

Description of Tree. - This tree is easily known by its 
leaves. These are quite characteristic, heings unlike those of almost any other tree, and in outline very much resembling a riding-saddle (see Fig. 44). In Americal beautiful specimens of the Tulip-tree may be seen growing naturally in the woods, and where they have space to develop their branches they form splendid oljects in the month of July, when in full flower. They may be found of from 90 to 100 $\mathrm{ft}$. in height, with stems of from 2 to $4 \mathrm{ft}$. in diameter, and straight

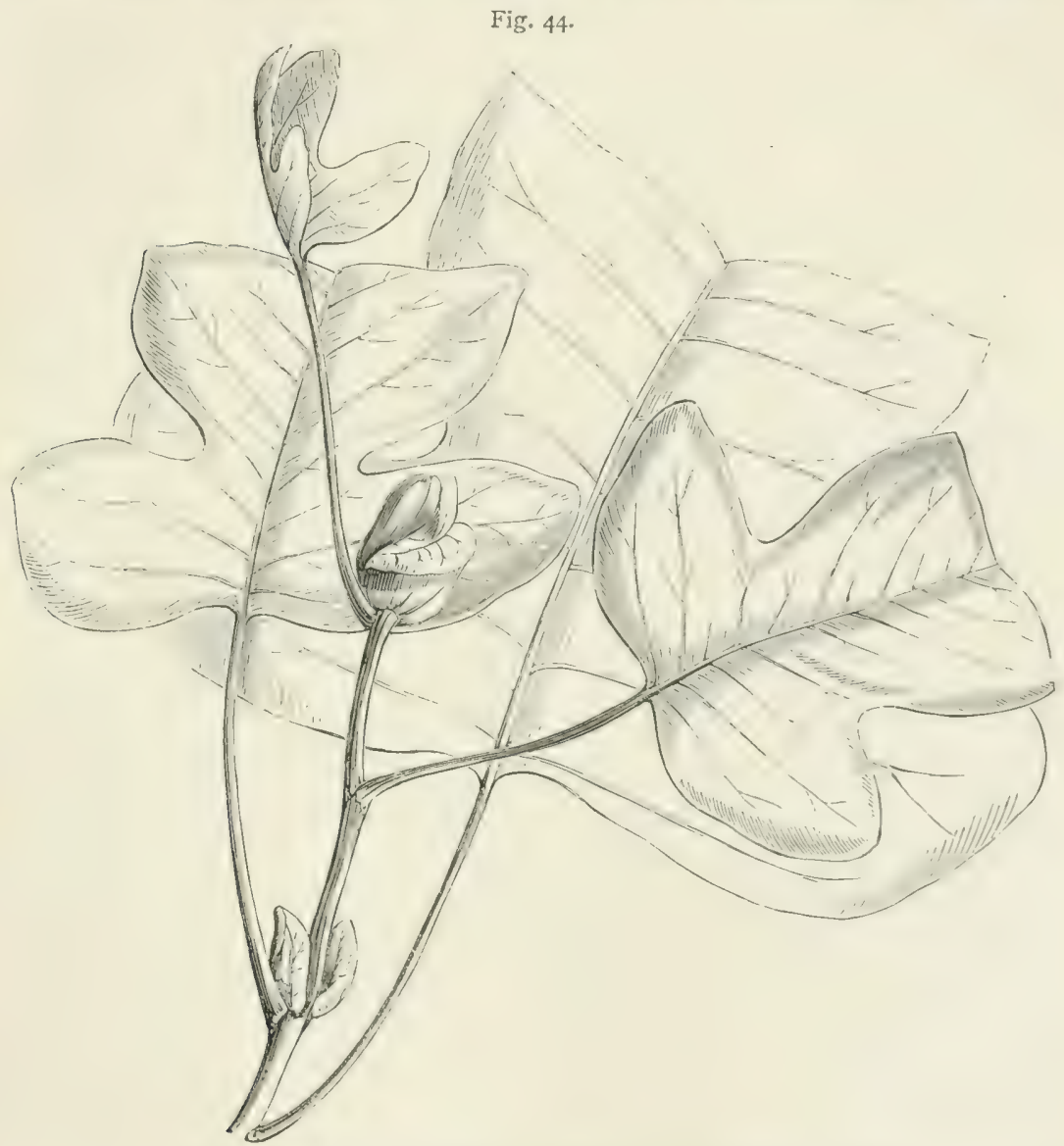

Truncated leaves of the Common Tulip-tree (Liriodendron tulipifera).

as an arrow, bearing spreading tops covered with their pretty creamcoloured tulip-shaped flowers. The foliage of this tree is of a very rich and peculiar character; the leaves are large, and of a beautiful light shining green, and have a tendency to more from side to side when acted on by a very slight breeze. Although often only classifiable as a tree of the second magnitude, this may well be considered one of the most ormamental trees introduced from 
Anerica : and it may lie strongly recommended for planting, more than has hitherto been the case, as an ornamental tree on the parks and lawns of proprietors' seats in Britain. It is perfectly hardy in most parts of the country, and when of some age forms a fine stem, with a spreading crown of foliage, and bearing flowers in great profusion in some seasons.

Soil and Situation.-Although this tree is, generally speaking, hardy enough to stand the climate of this country in favourable parts as far north as the southern slope of the Grampians, still it is comparatively tender, for it thrives only in well-sheltered situations, and on a deep, dry, loamy soil. The best specimens in Britain stand on lawns where there is a considerable degree of shelter from the presence of other larger and branching trees, and at the same time where they have full exposure to light and air, and are thus under the most favourable conditions for ripening their wood before early frosts occur in autumn. In America it is to be found growing on all kinds of soil and situation; but the largest specimens are usually to be met with on low-lying tracts of country, and on deep loamy land, rather inclined to be wet in the subsoil. Even in its native parts, it requires shelter to develop itself perfectly; and this should teach us how to deal with it here. In giving it a sheltered place, however, as already hinted, it should in all cases have a free, open growing-space, in order to admit the rays of the sun and permit a free circulation of air around it; for unless planted under these favourable conditions, it will probably fail to ripen its wood and huds perfectly, and consequently will not be able to flower. It is somewhat liable to be nipped by late and early frosts in spring and autumn; but it stands our winters thoroughly.

Propagation and Culture.-Although, generally spealing, the Tulip-tree grows well in the more favourable parts of this country, and flowers profusely, it ripens its seeds only in very favourable seasons, even in southern England. The supply of seed for the raising of a stock of plants has therefore usually to be obtained from America. The seeds should be sown as soon as they are received, which may generally be in the autumn. If this be attended to, the plants will come up in the following spring; but if they should not be sown till spring, they will in all probability lie dormant for one year, till the succeeding spring. The seeds should be sown on a very light and fine soil, or on a sandy loam. A very good plan is to sow them in a bed or cool frame, taking care to keep the earth rather moist than otherwise, and to shade the frame with a thin net till the llints have conte up, when the shading may be gimbully removed.

As the young plants are not well furnished with ramifying fibrous roots, they should not be allowed to stand more than one 
season in the seed-beds. At the end of the first year they should be planted out into lines in the open ground, as this tends greatly to encourage the development of fibrous roots, and therefore to secure success at the time of transplanting later on. From this disposition of the plant to run to a long tap-root, and not to ranify into fibrous roots, the plants should never be allowed to remain longer in the nursery than two years from the time of their coming above ground, as if they should be kept longer they will not transplant so safely afterwards.

In England this tree, under favourable circumstances, often attains the height of from 70 to $80 \mathrm{ft}$, with stems of from 2 to $3 \mathrm{ft}$. in diameter. At Longleat there is a specimen about $100 \mathrm{ft}$. high, with a stem $12 \mathrm{ft}$. in circumference at $4 \mathrm{ft}$. from the ground. In Scotland there are specimens of from 60 to $70 \mathrm{ft}$. high, with stems from 2 to $3 \mathrm{ft}$. in diameter.

Owing to its rapid growth, it is very often employed throughout the central and northern portions of the continent of Europe in the formation of avenues. The most celebrated of these is the avenue at Wilhelmshöhe, near Cassel (where Napoleon III. was sent after Sedan), consisting of 116 trees, the largest of which have a girth of between 7 and $8 \mathrm{ft}$.

\section{AMYGDALACEA JUSS.}

\section{THe Cherry, Prumus (Linnean System, Icosakdria Moxogivia).}

Character of the Genus.-Drupe globose, or umbilicate at the base, fleshy, quite glabrous, destitute of bloom, containing a smooth, rather globose compressed stone. Leares simple, alternate, stipulate, deciduous, or evergreen; when young conduplicate. Flovers white. Pedicels 1-flowered, rising before the leares, in fasicled umbels, from scaly buds; but sometimes rising after the evolution of the leaves, in racemes, from the tops of the branches (Loudon, op. cit., p. 276).

As almost all the species of this genus are cultivated chiefly either for their fruit or for ornamental purposes, and as only one of them is considered worthy of being planted as a timber-tree-riz., the black-fruited Wild Cherry-tree or Gean (P. arium), that is the only kind to which reference need here be made.

The majority of the family of the Amyedulucict principally inhahit the warmer temperate and the subtropical zones of the northern hemisphere, although some of them are indigenous to the tropical regions of Asia and Africa. Only three genera are represented in Central Europe-riz., the Almond (Amygdulus), the Peach (Persicu), and the l'lum, Apricot, and (herry (Prunus), which are distinguishable as follows (Willkomm, op. cit., p. 8s:) :- 
I. Drupe with tough, leathery pericarp or outer covering, free from sap and finally fissuring irregularly; putamen or interior shell mostly thickened, and with either a smooth, or a pitted, or grooved surface

Amygdalus.

II. Drupe with thick, fleshy pericarp, which does not dry and fissure; putamen or stone thickened, and covered with a tracery of wrinkled furrows and pitted indentations . . . . Persica.

III. Drupe with fleshy or sarcous pericarp, which does not dry and fissure; stone either smooth, or covered with wrinkled furrows, or a shallow network of indentations. . . . . . Prunus,

The genus Prunus is again divisible into three main classes of races, viz.:-

1. Apricots, having 1 or 2 flowers springing on very short stalks from the side, and a velvety skin to the drupe.

2. Plums, having 1 or 2 flowers issuing also from the sides, but on longer stalks, and having a smooth drupe with a bloom that can be wiped off:

3. Cherries, having numerous flowers ranged in racemes or simple corymbs, and smooth, spherical drupes without any bloom.

THE COMMON WILD CHERRY OR GEAN, Prunus arium L.

Srnonyss-P. nigricans and $P$. varia Ehrh; Cerasus avium Mönch; C. Duracina and Juliana DC.

Specific Character.-Flowers in subsessile umbels, not numerous. Leaves oval-lanceolate, toothed, glabrous. Flowers white; May. Drupe red; ripe in July (ibid., p. 278).

Distribution. - This species is indigenous throughout the whole of Europe, and eastwards into Asia Minor and the Caucasian districts. It is found in the wild state in many woods in Britain.

Description of Tree. - The Wild Cherry is well known in most parts of Britain. It is vely often found of spontaneous growth among woods or old hedgerows, in both of which it has a good effect in the spring when in flower, in the summer when in fruit, and in the autumn when the leaves become of a reddish-yellow colour. It is well deserving of a place in any plantations where ornament is an object, especially by the sides of roads running through them, as it comes early into flower, and gives an enlivening effect to woods at a season when most other trees are only beginning to unfold their buds.

Economic Uses of Timber.-The timber of the Wild Cherry is much sought after by cabinetmakers for furniture, and trees of good dimensions sell readily at a high price for this purpose, as it is comparatively seldom that a tree of any really useful size is brought into market.

The wood is rather light, but hard. The duramen or heartwood is of a beautiful brown or yellowish-brown colour, and takes on a fine polish, which 
shows up the structure of the timber. Unfortunately it is apt to shrink considerably; but notwitstanding this it is a favourite wood with furniture and instrument makers, and turners.

Soil and Situation.-This tree will grow well on any moderately good soil if dry, and developes rapilly without alnust any attention. It produces most timber, however, on a good, deep, rich, and rather light loam. On soils of this kind the Wild Cherry often attains upwards of $45 \mathrm{ft}$. in height, and can yield a considerable quantity of useful timber.

Continental experience shorvs that it seems to require for its best development a somewhat limy soil, or at any rate a considerable degree of mineral strength in other classes of land.

Propagation and Culture.-The Cherry is propagated from the seed or stone, so well known to every one that it requires no description here. The fruits ripen in July, and the seeds should be sown shortly afterwards, as they are very apt to lose their vitality if kept long. Most of the other species and varieties of the Cherry which are cultivated in gardens for their fruit are propagated by grafting on young stocks of this species, raised from seeds.

The Wild Cherry is only classifiable as a tree of the second magnitude; but when grown in close canopy along with other forest-trees, it can even attain a height of close on $70 \mathrm{ft}$., and may thus be made to form a good, straight, fullwooded stem, with an oval crown of foliage. It does not attain any great age, 80 years being about its normal limit.

It is the parent stock from which the various kinds of yellow, red, and black cherries have been obtained by cultivation, and forms a very good, useful, and vigorous stem ulon which to graft the nobler species in forming orchards.

In some localities it throws out stoles or root-suckers as well as stoolshoots; but under all circumstances its reproductive porver from the stool is good.

The Wild Black or Bird Cherry (Prumus Padus L.) is a close relative of the Wild Cherry, which deserves some little attention both arboriculturally and sylviculturally. Not only is it a beautiful object in parks during spring, when its branches are covered with long hanging racemes of white flowers, but it also adds considerably to the charm of park scenery during the autumn. It thrives best on fresh or moist land of good quality. It is suitable for admixture along with other species in ordinary coppice-woods, as it shoots freely from the stool, and often also develops stoles or suckers. As it can bear a fair amount of shade, it is also suitable for planting out along with Hornbeam on damp land as an underwood beneath standard Oaks. It is decidedly of quick growth, but does not attain any greater height than about $50 \mathrm{ft}$. Its heartwood is somewhat lighter in colour than that of the Wild Cherry, but otherwise resembles it elosely. The bark smells strongly of oil of almonds, owing to the cmyydulin stored up in it. The leaves and petioles of this species are in erery 
way smaller than three of the Wild Cherry, the two glands on the leaf-stalk of the latter being also more prominent and red; in the former the leaves are naked both above and below, whilst in the latter there is a hairy or woolly growth in the angles of the veins on the lower surface; the drupes of the former are bitter-street in taste, black, and not much larger than a pea, whilst those of the latter are rather sweeter, ruddier, and larger.

The Blackthorn or Sloe (Prunus spinosa L.), though merely a shrub, also deserves a lansing notice, as being one of the most charming growths in hedges and along country lanes in southern England during the early spring, before the other kinds of trees have done much to change the face of nature. The snow-white flowers, which appear before the flush of leaves takes place, are one of the characteristic features of English rural scenery, although even as milerwood the Blackthorn can only be classed as a weed from a sylvicultural point of view.

\section{POMACEE JUSS.}

The family of the Pomacece embraces various genera distributed throughout the whole of the temperate and the subtropical zones of the northern hemisphere. It is naturally divisible into two distinct sections-viz., Pomacea putaminiferce, having drupaceous fruits; and $P$. pomiferce, having their fruits in the form of a pome. To the former belongs, along with other genera, the Cratcegus or Hawthorns, and to the latter the Pirus or Pyrus, Pears and Apples, and the somtus or Service-trees, including the Rowan or Mountain-Ash.

\section{THE HAWTHORN, Cratagus}

\section{(Linnear Systemi, Icosandria Dipentagynta).}

Character of the Genus. - Calyx with an urceolate tube, and a 5-cleft limb. Petals orbicular, spreading. Ovarium 2-5-celled. Styles 2-5, glabrous. Pome fleshy, ovate, closed; the calycine teeth, or the thickened disk, containing a bony putamen (Loudon, op. cit., p. 352 ).

There are many species and varieties of the genus Cratogus; they are chiefly deciduous small trees or large shrubs, for only a few of them attain the height of $30 \mathrm{ft}$. The greater number of the species are natives of North America and Central Asia, whilst only a few of them belong to Europe. All are easy to grow, flower profusely, and are very ornamental. In a work of this kind, which professes to treat of timber-trees merely, reference need only be made to one of the menbers of this fanily-viz, the Common Hawthorn, Hawtree, Quick, or Thorn (C. Oxyacantha), which is not only well known, and useful for letering purposes, but also for its ornamental effect, both in summer when in flower, and in autumn and winter when in fruit.

Although they are somewhat slow in growth, most Thorns have a strong reproductive pinwer of shooting from adventitions: huls on the branches as well as from the stools. Hence their special value for hedging purposes. They 
form a very hard wood, but have little sylvicultural value as coppice, owing to their inferior rate of production of wood. Otherwise they would be suitable for underwood, as they can bear a considerable amount of shade.

\section{THE COMMON HAWTHORN, THORN, QUICK, OR HAWTREE, Cratregus Oxyacantha L.}

\section{Srroxyss-C. semitrigyna Wierzb. ; C. macròcarpa Hegetschw.; Mespilus Oxyacantha Willd.}

Specific Character. - Leaves obovate-werge-shaped, almost entire, or trifid or cut, glabrous, rather glossy. Corymls of several flowers. Sepals glandless, acute. Styles 1-3. Flowers white; May. Haws red or scarlet; ripe in September (ibid., p. 375 ).

Distribution. - The Common Hawthorn is, together with a very closely allied form, $C$. monogyna (Jacquin), found in most parts of Europe, but is more frequent in the northern than the southern portion of the Continent, where the latter species is more abundant. It is distinguishable from $C$. monogyna by being of a yellowish-green colour on the under surface of the leaves, whilst in the latter the under surface of the foliage is bluish-green; and it has the secondary nerves curved inwards (or at least the lower nerves are always inclined inwards), whilst in the latter they are curved outwards (at any rate in the case of the lower nerves). Both of these species also occur throughout eastern Europe, whence they extend eastwards into central Asia, as well as southwards to Syria and Northern Africa. It is found nearly all over Britain in the cultivated state, as live hedges, and often growing wild in woods and neglected fields.

Description of Tree.-The Hawthorn cannot, properly speaking, be considered in the light of a timber-tree, although, as is often to be observed, it may, by cultivation and attention to judicions pruming, be made to attain the dimensions of a tree of the third magnitude; still in this respect it holds but a low rank, and must be considered merely as an ormamental shrub, capable of being trained to the size of a small tree.

The great use of the Hawthorn in this country is for the formation of live or quick helges, for which purpose no other plant is so suitable. Not only is it easy to grow in a great variety of soils, but it also exhibits a considerable denree of density, and has strength to resist pressure when properly trained for the purpose. In the wilk state, the Hawthorn, when found in a loany soil with a dry bottum, grows very freely and often rapidly when under 15 years of age. I Sut after it once attains the height of from 15 to $20 \mathrm{ft}$., its yrowth in height ceases, its crown of foliage becomes extended laterally, and it assumes the character of a large and sprealing bush; and when once it has arrived at this state, it is much admired for its profusion 
of sweet-smelling flowers in the spring and its bright-red fruit during the autumn and winter. The flowers of this species are of a pinkishwhite colour; but there is also a well-known and beautiful variety of it called C. O. rosea, which has petals of a bright-pink colour, with white claws. When both kinds are planted in the same neighbourhood, and near to each other, so as to form a contrast, the effect is

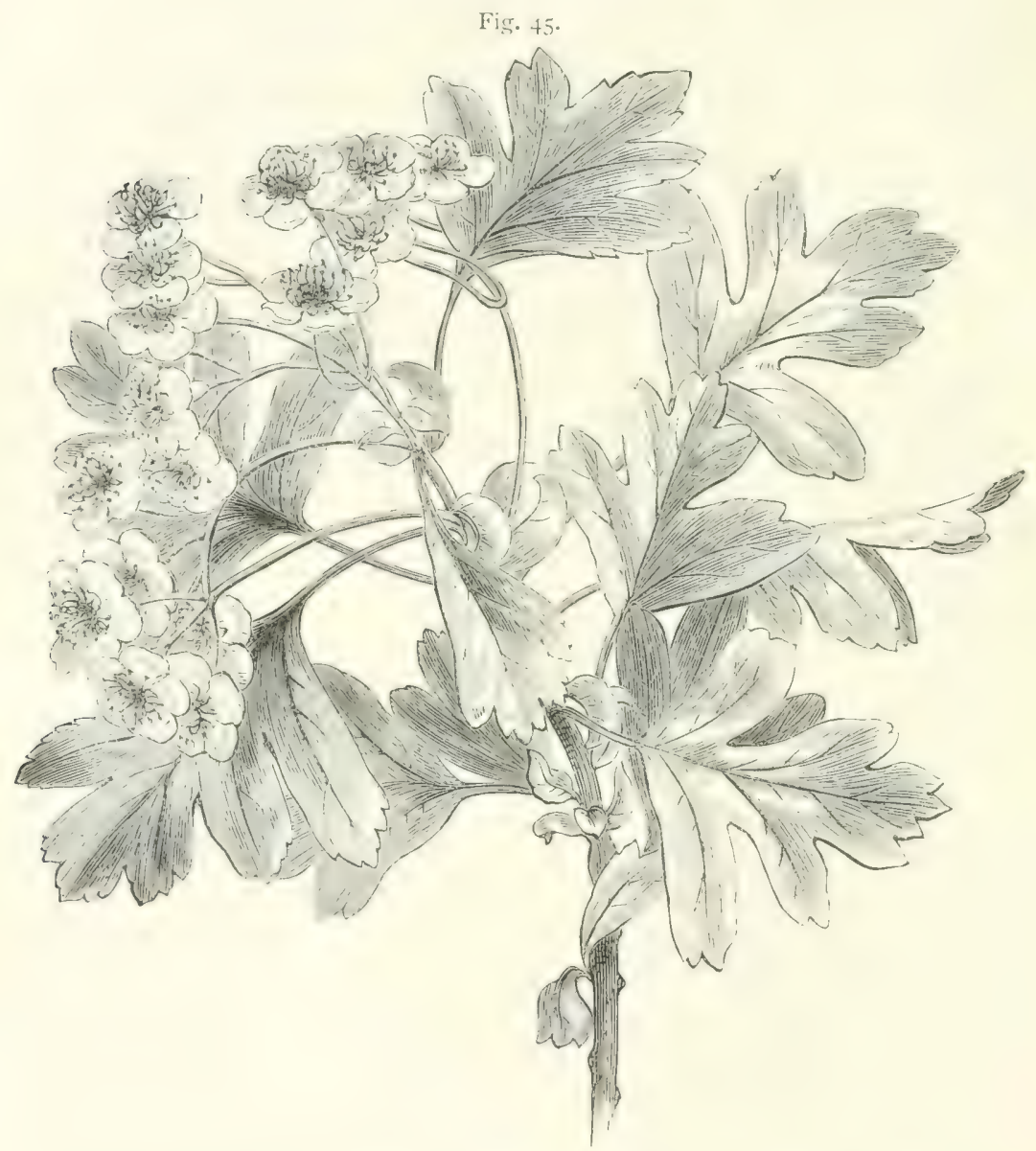

Flowers and fuliage of the Common Hawthorn or Whitethorn (Crategus Oxyacantha).

very pleasing, and cannot fail to be appreciated by every one, especially when the Hawthorns form a contrast with plants of a different shade of foliage in the background.

Economic Uses of Timber. - The wood of the Common Hawthorn is very hard. It is of a yellowish-white colour, is finely grained, and takes on a very good polish; but it is not much sought after for any purpose. It makes an excellent firewood. 
Soil and Situation.--To have the Hawthorn srow healthily and vigorously, it must be planted on a good, dry, and rather rich loam. It does not thrive well on a wet soil, nor on land of a poor and light description, hut grows more rapilly on a heavy dry loam, even although of a somewhat clayey nature. It seems to do best, however, on soils of a limy or marly nature. It is one of our hardiest plants, and will succeed well evèn on exposed places if the soil on which it is planted is dry and suitable.

Propagation and Culture.-The Hawthorn, in warm seasons favourable for fruit-production, generally bears a large and alundant supply of fruit, which are termed haws: these are ordinarily ripe and fit for sowing about the beginning of November. They should, however, never be gathered for sowing until they are perfectly ripe. Their arrival at this state may easily be known by their being of a dark-red colour and mealy, and by the fleshy pericarp separating freely from the stone of the fruit. If gathered before they are rize, the cotyledons of the seed are liable to perish from not having been perfected before gathering. The haws should be pulled from the bushes by the hand. When collected for the purpose of raising plants from them, they should be laid in a heap, so as to rot the pulp, and to separate it from the stones. This is best done by laying them down upon the ground in the open air, in long heaps of about $24 \mathrm{in}$. high in the middle and 48 in. broad at the base; or the ridge may be of smaller climensions if a small quantity of seecl is being operated with. To prevent the pulpy part or sarcous pericarp of the fruit from heating, and from thereby entangering the vitality of the seed, a good plan is to mix the haws with finely riddled soil, say in quantity equal to the bulk of the fruit or haws themselves. The whole should be intimately mixed together, so as to hasten the decomposition of the pulp, and should be turned orer now and then, say once every two weeks, so as to turn inwards the portion which lay most exposed to the air, and to bring to the outside the portion which was immermost. In this decomposing heip the haws may be allowed to lie for fifteen or sixteen months, when the pulp will be perfectly rotted, and the seed ready for sowing. Then, supposing that the haws were gathered and treated in this mamer from November 1894 , they would be realy for sowing in February 1896. They should be sown in beds on a good light mould properly prepared for the purpose. They should not he sown thickly but rather thinly, say at the rate of one seed to the square inch, and they should be covered with from about $\frac{1}{4}$ to $\frac{x}{2}$ an inch of earth. They will braird the same year, but should not be lifted till they have stood two years in the seed-bed. When they have arrived at this stage, they should be planted out into rows in 
nursery-beds, say at a distance of about $2 \mathrm{in}$. from plant to plant, whilst the lines should he about 12 in. apart. When they havestood for two years in the nursery-beds-i.c., when they are four years old - they will be quite fit for hedging or other purposes.

The varicties are propagated by ludcling or grafting on the stocks of the Common Hawthorn.

The Continental plan is to sow the haws, immediately after they ripen in autumn, in a limy or marly soil, marl being added to the seed-beds if the soil of the nursery is deficient in lime. Sometimes germination takes place in the following spring, but usually not until the second spring after the sowing. The rills are made about $4 \mathrm{in}$. broad and $8 \mathrm{in}$. apart, and the haws are covered with about $\frac{3}{4}$ of an inch of earth. In order to keep the soil warm, and thus stimulate germination, the seed-beds are covered with Pine sprays or dead leaves, which may be removed from time to time to see if germination has begun. Without such a warm covering germination does not take place till the second spring. When once the seedlings are two years old, their tap-roots are shortened and they are put out into the nursery-beds, and then transplanted two years later for forming hedges (Burckhardt, op. cit., p. 523).

\section{THE MOUNTAIN-ASH, Sorbus}

(Linnean System, Icosandria Di-Pextagyita).

Generic Character.-Calyx with an urceolate tube, and a 5-lobed limb. Pctals roundish, spreading, flat. Styles 2-5. Pome closed, ó-celled, globose, or top-shaped. Sceds 2 in each cell. Testa cartilaginous. Leaves imparipinnate, or pinnately cut. Flowers in branched corymbs (Loudon, op. cit., pp. 417, 438).

The genus Sorbus is closely allied to the genus Pimus or Pyrus, which comprises the most popular of our British fruits, pears and alples. Both cliffer from the wher European genera of the Primerew (Cotoneaster, Mespilus, and Cratagnes) by having pomes as fruits in flace of drupes, a diflerence which they share with the genera C'ytonin and Amclanchior. But the only genus and species of these Pomacces to which reference need here be made is the Rorvan or Mountain-Ash (of the $P$. pomiferce), one of the most beautiful of our comparatively few truly indigenous trees. It is a handsome small tree in our woods at all seasons of the year, and is perhaps better known by the local

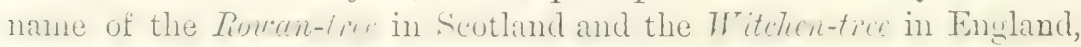
than by its rather misleading general name of the MIountain-Ash.

Apart from botanical differences, it can easily be distinguished from any of its close relatives, the T'ears and Alldes, through the foliage alone. In the latter (Pinus or Pymus) the leaves are always simple and undivided; in the former (Sorbus) the leaves are simple, and entire or pinnatifid, or less frequently imparipinnate (as in the Rowan). 
COMMON MOUNTAIN-ASH, ROWAN, OR FOWLER'S SERVICE TREE, Sorbus Aucuparia L.

Srxoxys-Pyrus A ucuparia Gärtn.; Mespilus Aucuparia Scop.

Specific Character.- Bucls softly tromentose. Ioaflets serraterl, slightly glabrous. Pomes globose. Flowers white; May. Fruit red; ripe in September (ibid., p. 439).

Distribution. - The common liowan or Mountain-Ash is one of the most wirlely distributed of trees, being found from the sci-level ul, to near the limit of eternal snow. It is a native of most parts of Furope, from Iceland on the north to the Merliterranean on the south. It also extends throughout the whole of north-western Asia, and occurs likewise in the northern parts of North America. It is iucligenous to Britain, and is common in our woods and hedges all over the country, where it is generally to be found growing on moist, coldbottomed lands.

Description of Tree.-The MIomtain-Ash, Porech, or Witchintree is too well known to require any particular or detailed description. It is readily distinguishable during the summer from all the other sprecies of the same genus by its beautifully pinurete or winged leaves (see Fig. 46), which very much resemble those of the Common Ash, and during the autumn by the buatiful rudity-yellow glow of its foliage and by its bright red bunches of berries, which are generally ripe, and give the tree a fine effect, about the besinning of October, when the birds begin to feed on them. It may perhaps not merit being classed as a timber-tree; still even in this respect it may be worthy of attention here and there, for, on good land, it frequently attains a height of $30 \mathrm{ft}$., and forms a stem of about 2 ft. in dianeter. But although, in point of fact, it can hardly claim to possess any sylvicultural value merely for the sake of its timber, it can sometimes do good service by way of protection as a nurse to hard-wooded species of trees on certain classes of soil upon which the Pine and the Larch would be apt to overgrow and perhaps suppress them. The Rowan may thus often be found an admirable nurse for hardwoods in small plantations or narrow beltings, as it never overtops other trees growing with it, but rather, from its straight mpright hahit of growth, permits them to have a fair amount of growing-space for their rimification and coronal derelupment. And besicles that, it is excellently alapted for sowing as coppice. Good reproductive capacity, both by stoles and stool-shoots, combined with its quick habit of growth when young, renders it alaptable for coppice-growth; for it makes strong shonts within the first four or five years after being cut clown, and these are found to suit well for hoops, and for all sorts of crates or rough basket-work. 
The Rorran is only a tree of the second magnitude, which does not usually attain a height of more than 35 to $50 \mathrm{ft}$. It forms a clean, full-wooded stem, surmounted by an oval crown of rather sparse foliage. It throws out long branching side-roots, from which stoles or root-suckers are freely developed.

Its mood is of a reddish-brown colour, and a soft and fine texture; it is highly prized for cart-making and for agricultural implements, owing to its extreme toughness.

Fig. 46 .

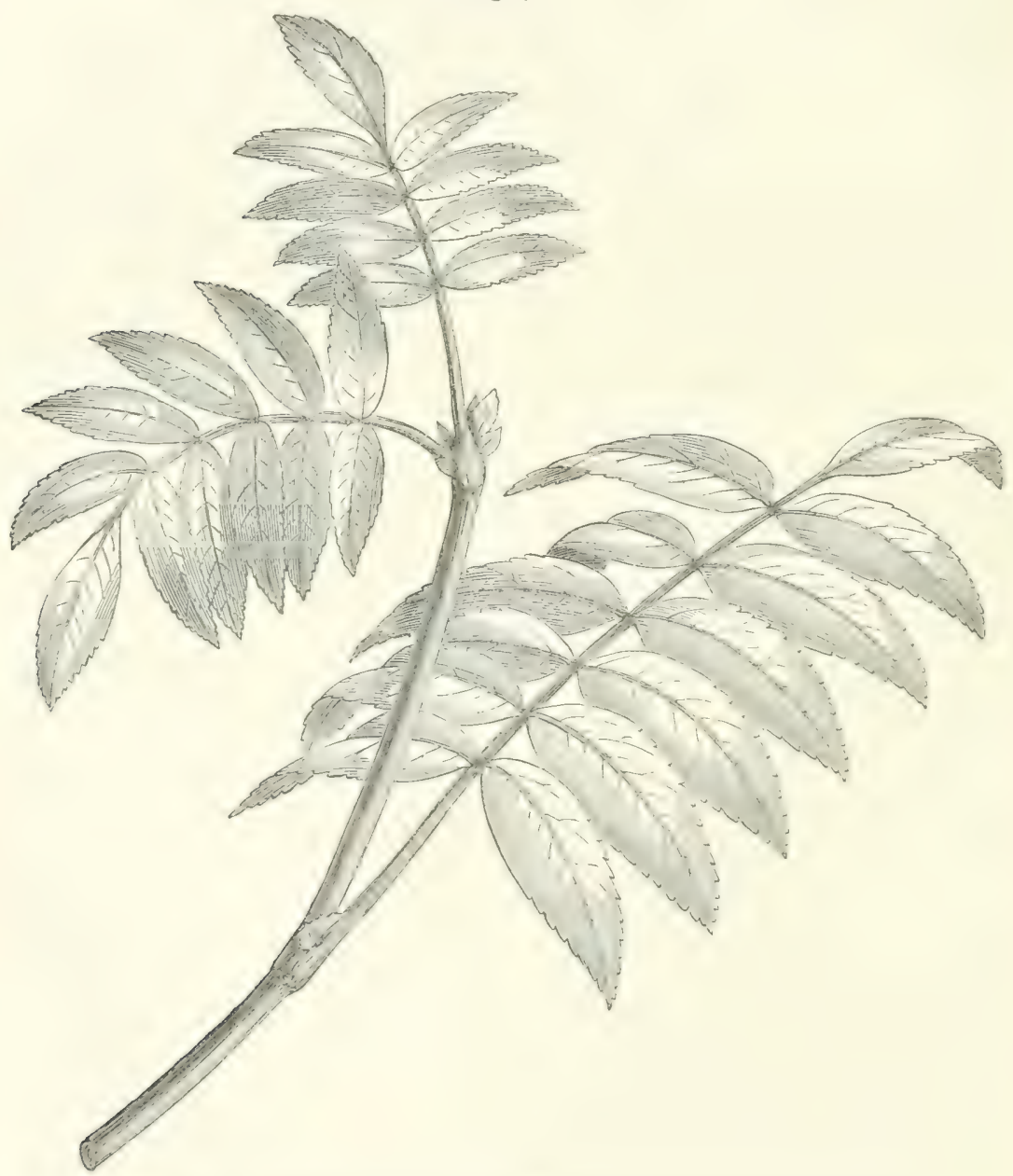

Imparipinnate leaves of the Rowan or Mountain-Ash (Sorbus Aucuparia).

Soil and Situation.-The Mountain Ash will grow well on very poor soils, and even in the most exposed situations; but where it is wanted as ornamental specimens it should be grown on a good soil, and in a somewhat sheltered though not confined situation. The 
proper locality for the Mountain-Ash is on the sides of roads in plantations; here it grows rapidly, soon develops a crown of moderate size, and becomes an interesting olject anong both decidurous and erergreen trees, especially in the autumn, when its foliage is changing colour and its fruit is in perfection.

As Ebermayer's investigations (op. cit., p. 230) have proved, the Rowan is classifiable as making considerable demands on the snil with respect to mineral food, being ranked midway between the Elm and Lime on the one hand, and the Acacia and Horse-Chestnut on the other; and it likervise makes considerable demands on soil-moisture, occulying in this respect a similar position to the Birch and the Sycamore. These scientific results may appear to be in conflict with what we know to be the case, that the Rowan is often found of good spontaneous growth on poor shallow soil, until the large development of widespreading surface-roots is taken into consideration.

Of all our British forest-trees it is the hardiest; and it is the best endowed with accommodative power in respect to soil and situation. To these natural capacities, to its power of reproducing itself from stoles, and to the distribution of seed by means of birds, are due its remarkably extensive distribution, hoth horizontally and vertically; for the pome, though not heavy, is not ap, to be carried far from the parent trees by the wind.

Propagation and Culture.-The fruit of the MInuntain-Ash should be gathered as soon as it is ripe; for birds, being very fond of it, congregate where it is, and soon devour it all if the crop of pomes be not very plentiful. After it is gathered, the seed for a crop of young plants should be dealt with exactly as has previously been described for the treatment of haws (see p. 225). The seed of both of these plants lies about eighteen months in the earth hefore it germinates; but when rotted in a heap, or mixed with earth for about fifteen months, and then sown out after all the fleshy pulp or sarcous pericarp has been decomposed, they come up in June if sown in the previous spring. The seed should be sown somewhat thinly, say one seed to every $2 \mathrm{in}$. by $2 \mathrm{in}$, for the leaves, even when the plants are young, are comparatively large, and if thickly sown, the seenllings would be drawn up and weakened by crowding. As the MountainAsh is of rapid growth when young, the seediings need not be kept in the seed-bed longer than one year. The seedlings should therefore lie planted out into the nursery-lines during the autumn of the vear in which they have sprung up in the seed-heds; and at this stage they will generally be found to have attained a height of from $\&$ to 12 in. In the nursery-lines they should be put in about 3 in. apart, with a distance of about $18 \mathrm{in}$. betreen the rows. When the plants have stood one year in the nursery-lines, they will nsually be about $3 \mathrm{ft}$. in height on the average, and are fit for transplanting for ornamental purposes. 
The Service-Tree (Sortus torminalis, Crantz. Synonyms: Cratcegus torminalis I.; Pyrus torminalis, Ehrh.) also deserves some slight passing notice. It is one of the old-fashioned trees, which was probably indigenous to central and southern England, and may have been of true forest growth formerly; but now it is only to be found in quaint old gardens and in parks.

Like the Rowan, it is only a tree of the second magnitude, but under favourable conditions may attain a height of over $60 \mathrm{ft}$.; it forms a somewhat rounder and more densely foliaged crown than the former. Its stem is covered with greyish-brown bark, furrowed by long fissures, between which the bark flakes off in patches here and there. Its wood is of a brownishyellow at first, but deepens later on into a ruddy-brown colour, speckled with numerous short medullary rays. It is specially prized by turners and cabinetmakers, as it is denser in the grain and heavier (0.80) than Pear-tree $(0.73)$ when seasoned: it is not infrequently offered to the public as Boxwood, in the shape of surveyors' scales, de.

It is a low-growing tree, which attains an age of over 100 years. Even although it has a considerable capacity for bearing shade, its slow rate of growth has doubtless been the cause of its having been gradually ousted from the forests; for as its fruit is heavy, it could not be wafted far from the parent trees by the wind; and as it is at the same time large, it could not conveniently be distributed naturally by means of any of our numerous small birds that convey the Rowan seed far and wide.

Like the Rowan, its foliage is an object of beauty in the autumn landscape; but its hue is golden, and contrasts well with the coppery sheen of the Mountain-Ash. It differs very greatly from the latter also with regard to its demands as to soil and situation; for it does not grow well on sand, but requires soil of considerable mineral strength, and certainly thrives best, like the Yew and the Holly, on land of a limy description.

\section{PAPILIONACEE L}

The Papilionaceous division of the great order of Legnminosce embraces a considerable number of sub-families and genera. To it belongs the family of Genistece, including Furze, Greenwood, and Broom, shrubs occurring throughout Britain only too frequently in the undisturbed possession of land that might (and should) be far more profitably and adrantageously utilised for sylvicultural purposes.

Apart from some flowering shrubs utilised for horticultural purposes, the only genera of arboricultural or sylvicultural importance are the Laburnum (Cytisus) and the False Acacia (Rotinia).

\section{THE LABURNUM, Cytisus}

(Linseay System, Moxadelphia Decaxdria).

Generic Character.-Calyx bilabiate. Upper lip usually entire; lower one somewhat tridentate. Vexillum ovate, large. Carina very obtuse, including the stamens and pistils. Stamens monadelphous. Legume compressed, many-seeded, glandless. Leares trifoliolate, 
alternate, stipulate. Flowers of nearly all the species yellow (Loudon, op. cit., p. 213).

The Cytisus forms a genus of ornamental trees and shrubs, of which the species called Lalumums are hoth well known and greatly admired; and to these alone reference need lue mate here. They are admirally adapted for ornamenting the sirles of roarls in our woorls, as they are hardy trees. There are five species of the Laburmum DC. throughout Central Europe, but of these muly two jossess any real interest for Britain - viz., the Common Laburnum (Luturmum irulgare) and the Scots Laburnm (L. alpinem), which are so much alike that their recognition as different species is often overlooked. They are cuite distinct, however, for though the inflorescence of both takes place in long pendulons many-flowered racenes, the latter species flowers much later in the season than the former, and has polls that are quite smooth, while those of the Common Lalumum are hairy. In describing them, however, they may conveniently be classed together as if they were but one species, for, with the exception of the differences stated, they have the same general appearance, they are propragated and cultivated in precisely the same way, they are of the same halit of growth, and, finally, they are both equally showy and hardy.

THE COMMON LABURNUIM, Labumum vulgare Gris. Rchb.

SrNovxir-Cytisus Laburnum L.

THE SCOTS IABURNUM, Laburnum alpinum Gris. Rchb.

Syronsm-Cytisus alpinus Mill.

Specific Characters of the two Laburnums.-Common Latburnum (Luburnum vulgare)-Lranches terete, whitish. Leaves petiolate; leaflets ovate-lanceolate, pubescent beneath. Tacemes penduluus, simple. I'edicels and calyxes clothed with closely pressed pulnescence. Legume linear, many-seeded, clothed with closely pressect pubescence (ilirl., p. 215). Scots Laburnum (L. alpinum)-Branches glabrous and terete. Leaves petiolate; leaflets ovate-lanceolate, rounded at the base. Racemes pendulous. Pedicels and calyxes puberulous. Legumes glalmous, few-seeded, marginate (itici., p. 2216).

Distribution. - The Laburnum is of spontaneous growth in forests throughout the mountainous parts of Germany, Anstria, Hungary, Switzerland, Italy, eastern France, and Spain; but, although it has been in eultivation throughout Britain since about 1596 , it is not indigenous to, but merely a denizen of, this country.

Description of Tree.-The Laburnum may not perhaps have any good title to be considered a timber-tree, for it sellom attinins 
either any great height or any large girth of stem; still, where left alone unencumbered, and when growing on a dry and good loamy soil, it frequently does reach a fair size. But putting out of view altogether any recommendations this tree may have as regards its timber, it can urge very great claims arboriculturally to our favour

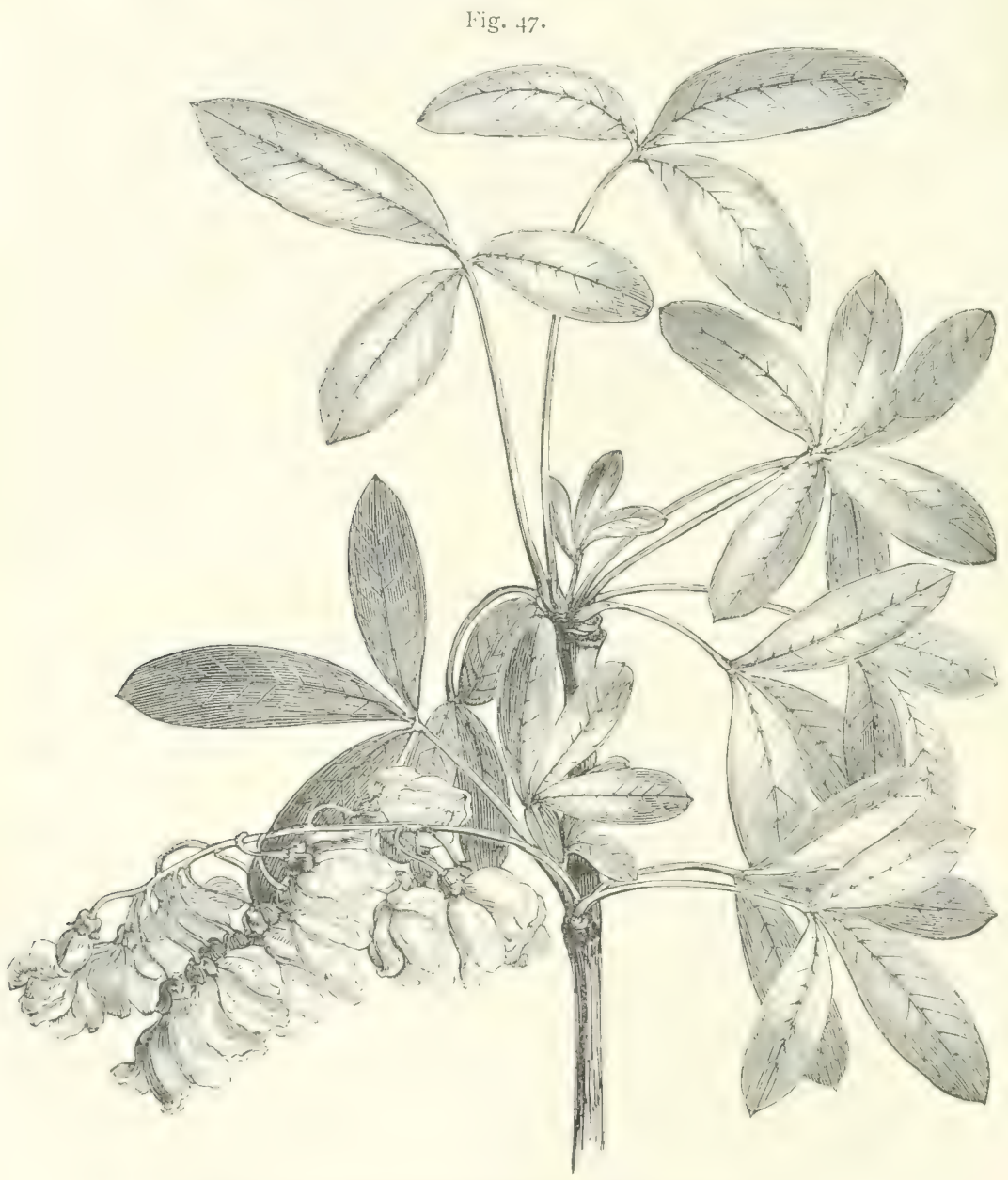

Flowers and foliage of the Laburnum (Laburnum vulgare).

on account of its highly ornamental effect. There is, indeed, no flowering-tree which is more worthy of being cultivated than the Laburnum. In the months of June and July its bright-green shining foliage, with which its pendulous branches of brilliant yellow flowers is mixed up, almost attains the perfection of beauty that may be looked for in a flowering-tree (see Fig. 47). And it is withal a graceful 
tree, notwithstanding its very showy exhibition of leaf and flower. The general outline of the whole shrub or small tree is somewhat irregular, and this characteristic adds much to its beanty and effect. What makes this tree so very showy in its flowering season is the smallness of its folinge as compared with the size of its bunches of bright, pale, golden-yellow flowers. The leaves are small, only three leatlets being on each petiole, whilst the flowers are numerous on one stalk, and as they are pendulous, each hangss down like a bunch of yellow grapes.

The Laburnum is worthy of a place in any arboretum or collection of ornamental trees; but its proper place is on the sides of roads and walks, whether in the park, the shrubbery, or the woods, for there it always forms an agreeable object when allowed to have full growingspace for the normal development of its branches and crown of foliage. Without a good coronal development the tree does not form so ornamental an object as it is otherwise capable of becoming.

Out of several varieties of the Common Laburnum two are largely cultivated by horticulturists. Of these the var. quercifolium has wavy-lined or lobed leaflets, whilst in the var. Alschingeri the racemes are ulmight instead of pendulous, and the vexillum of the flower is marked with a broad brown line.

The seed of the Laburnum is of a very poisonous nature.

Economic Uses of Timber.-The timber of the Laburnum, when of good size, and forming a stem of from 12 to $20 \mathrm{in}$. in diameter, is very valuable for furniture purposes, and may sometimes be disposed of at as high a rate as $7 \mathrm{~s}$. per cubic ft. It is much sought after by cabinetmakers.

The wood is hard, the alburnum yellow, and the duramen blackish-brown in colour. It takes on a very fine polish, and in many respects resembles ebony in appearance and texture.

Soil and Situation.-The Laburnum will grow in most soils; but to enable it to attain a large size, it requires a deep, loamy, and rather light dry soil, and a situation well sheltered hy uther trees. When planted with any view to timber-production, it should be put out on a strong soil; but if for ornament merely, it may be planted on any part where its presence may be wanted. It continnes longest in flower when lightly shated by other trees from the direct rays of the sun.

Propagation and Culture. - The seed of the Laburnum is generally ripe about the middle of October, when the seed-pods should be gathered. When collected, they should be stored in an airy loft and kept dry till they are required for sowing in early spring, towards the end of March. The seed may be sown in beels 
in any light soil; but the sowing should take place thinly, and the seed should not be covered with earth to a depth of more than half an inch. As the Laburnum is a rapid-growing plant when young, the sededings should be lifted from the seed-hed during the following spring, and planted out into lines in the nursery-ground, as previously directed with reference to the Mountain-Ash (see p. 229).

\section{THE FALSE ACACTA, Robinia}

(Linnean System, Diadelifila Decandria).

Generic Character.-Calyx 5-toothed, lanceolate, 2 upper ones shorter and approximate. Corolla papilionaceous. Vexillum large. Keel obtuse. Stamens diadelphous, deciduous. Ovaries 16-20ovulate. Style bearded in front. Legume compressed, almost sessile, many-seeded, with the valves thin and flat, marginated at the seminiferous suture. Leaves compound, unequally pinnate, alternate, deciduous; leaflets generally ovate or obovate, petiolate. Flowers white or rose-coloured, in axillary usually nodding racemes (Loudon, op. cit., p. 233).

Only one species of this genus of Asiatic and American trees and shrubs need here be referred to-viz, the Common Robinia, or False Acacia (Li. P'smeducteiur). It is a rapid-growing tree, with beautiful, fine, pinnated leaves, and pendulous, white, sweet-smelling flowers. This is in all respects a desirable tree for ornamenting lawns and shrubberies, besides possessing fair claims entitling it to it certain amount of purely sylvicultural attention.

\section{THE ROBINIA or FALSE ACACIA, Robinia Psendacacia L.}

Specific Character. - Prickles stipular. Branches twiggy. Racemes of flowers loose and pendulous; and smooth, as are the legumes. Leaflets ovate. The flowers are white and sweetscented; the roots creeping, and their fibres sometimes bearing tubercles. Flowers white; May and June. Legume compressed, dark purplish brown; ripe in September (idem).

Distribution. - This tree is a native of North America, whence it was introduced from Virginia into Britain by Robin in 1638. It is to be found of spontaneous growth in the forests of Canada, and also in those of the Northern States of the Union. It is not found growing in masses or clumps in these forests, but generally only as individual stems mixed with other trees, or in small grouns, and always on dry land of good quality. The liohinia is much cultivated by the American people, both on account of the great durability of its timber and its ornamental effect as a tree. In most 
of the older settled ristricts, especially in Upper Canada and in the, States of New York and I'emsylvania, the farmers have this tree, which they call the "locust-tree," planted about their garilens anr homesteads. Very old specimens may frepuently he seen standins here and there in fields; these, no doubt, constitute the last remuants left of the original forests which have been cleared away by the settler. This tree is perfectly hardy in most parts of Britain. In the warmer and milder portions of the country it attains a consirlerable size, and forms a highly ornamental tree, that gives a peculiar effect to the landscape by its beautiful pinnated leaves and its pendulous bunches of pinkish white tlowers, which it begins to bear in profusion from about its 20 th year onwards.

Throughout the arboreta and public parks of central Europe, with the exception of northern Prussia, where the climate is too cold in winter for this genus, two ormamental species of the Rolinia are extensively cultivated on account of their heauty-viz., the Red Acacia (R. hissiclu L.), a low-growing tree with small stipular thorns or spines and large rose-coloured flowers, and the sticky liobinia ( $R$. viscosa Vent.), a smaller tree with sticky leaves and roundish clusters or close racemes of reddish-white flowers. Both of these species have likewise been introduced from North America (Willkomm, op. cit., p. 931).

Description of Tree.-The value of the Robinia is not yet sufticiently recognised in Britain, whether for arboricultural or for sylvicultural purposes, and this opportunity may be taken of recommending it to the notice of landed proprietors; for it really is worthy of far more attention than has hitherto been bestowed on it. Even as a timber-tree it is deserving of cultivation. Its timber is of the most durable description, and is highly prized for many purposes in America. But, of course, for production on an extensive scale there are many other trees which may be more profitably cultivated for timber-production in Britain than the liobinia. Hence its greatest value is arboricultural rather than sylvicultural; and it is recommended chiefly as an ommental tree, to be planted on lawns, aloug the edges of plantations, and on the sides of roads leading thromsh woods, where its graceful foliuge is calculated to produce viriety anong the leares of our commoner trees, and where its racemes of beautiful flowers produce a charm quite unknown to thuse who are accustomed to look on trees as oljects whose flowers are not gencrally conspicuous.

In its native woods the Robinia or False Acacia may frequently be found attaining a height of from 70 to $80 \mathrm{ft}$, and hiving a trumk upwards of $2 \mathrm{ft}$. in diameter even at about 5 to $6 \mathrm{ft}$. above the ground; but it is only when growing in close canopy anong Walnuts, Lime-trees, and Maple that the tree attains this height. ()n the sicles of 
rivers and the maruins of lakes, where it hats free growing-space for the development of branches, it will generally be found to attain a height of only from 30 to $40 \mathrm{ft}$., and to form a short irregularly shaped stem, usually of about. $3 \mathrm{ft}$. in diameter. Under these latter circunstances it forms a highly ormamental tree, presenting a broad mass of light-green airy-looking foliage, with which large bunches of pendulous flowers are intermixed; and it is under such conditions that the tree should be cultivated in Britain. That is to say, it should not be planted intermixed with other troes in a plantation, as in this case its natural beauties would be lost; but it should occupy a free, isolated position on a lawn, or along the sides of roads in plantations, where it may have a free space to develop its limbs and branches all round, and may enjoy ample opportunity of developing a full crown of foliage, and of becoming stimulated by light and warmth to rich production of flowers and fruit.

The Robinia shoots rapidly upwards in its younger stages; but as it grows old the branches spread out horizontally, and very little growth is made in height. In this respect it bears no slight resemblance to the Mountain-Ash and the Laburnum. The branches of young trees are armed with strong hooked prickles, but these are not found on old trees. The leaves are imparipinnate, consisting of 11 to 21 leaflets, and the foliage is of a very fine and thin texture. It is an excellent tree for growing on the sides of streets in towns, and in that position has a graceful and agreeable effect in summer; but as it requires a very considerable amount of atmospheric warmth for active vegetation, it is late of breaking into leaf, and carly in autumn throws off its mantle of foliage. It is largely planted on the sides of the streets in the eity of Montreal, in Canada.

Economic Uses of Timber. - The wood of this tree. is very heavy and hard when matured, and is found to be very durable for all kinds of purposes, whether outdoor or indoor. It is even said to be a stronger and more lasting wood than the British Oak. In America the timber is prized for fencing and other outdoor purposes; and there it is also much used in house-building and for furniture-making. In slont, in all parts of Anerica where the tree is found, it is much sought after for various technical purposes; but it is nowhere so plentiful as to be commonly employed for many purposes in any one locality.

The wood of the Robinia is of a greenish-white, but gradually turns into a reddish-yellow in the duramen or heartwood. It is porous and easy to work, though in some cases apt to cause sores, owing to some poisonous secretion contained in it. With the exception of the Conifers, it is the most elastic of the woods now grown in Europe, and with the exception of shrubs like Dogwood, Hawthorn, and Sloe, forms also the hardest wood, although not belonging to the heaviest class of timber. It has a sp. gr. of 0.87 when green, and 0.73 
when seasoned, so that it is lighter than the Oak, Ash, or Maple, though heavier than Elm, Chestnut, Sycamore, or Birch. It belongs to the most durable class of timber, and may even rank before the Oak in this respect under favourable conditions. On the Continent it is extensively used for cartmaking, for agricultural inplements, and for props for training up the vines in vineyards. A very important and remunerative use of the wood is the manufacture of long wooden nails or pegs for shiphuileling, for which its unusual degree of elasticity and toughness makes it especially valuable.

Soil and Situation.-In the American woods this tree arows; for the most part, on deep light lands that are always lry, and are of a moderately rich character. In this country, however, the Robinia often grows well on very poor land; and even in Canada, especially in the neighbourhood of the city of Ottawa, it may be found on poor sandy soil, growing luxuriantly where the land had been so much exhausted as to he unfit for the profitable cultivation of farm crojs. With regard to soil, the tree grows well on most lands that are neither wet nor of a heavy nature; and as to situation, it should be always sheltered, lut not confined, as the Robinia will not prosper if it hare not an airy site, freely exposed to the rays of the sun, nor will it under any other circumstances develop itself so as to assume its proper character as a broad spreading tree, clothed with branches down to the ground.

The False Acacia is one of the most interesting of trees, for whilst, as above stated, it can thrive on very poor land, it, as a matter of fact (proved by Ramann's investigations, op. cit., p. 331, and Ebermayer's analysis, op. cit., 1. 2:30), withdraws very considerable quantities of mineral food and of moisture from the snil. With respect to the food-supplies annually withdraw from the soil it ranks next after Ash, Italian Poplar, Elm, Lime, and Fowan, and comes before Horse-Chestnut, Sycamore, Maple, Aspen, Willow, Oak, Silver Poplar, Hornbeam, Beech, White Alder, Birch, and Common Alder, in which order the decidnons trees are arrangeel by Ebermayer. And with respect to demands for soil-moisture for transpiration, it ranks next to the Italian Poplar, HorseChestnut, Ash, and Common Aller, and comes before Oak, White Hhler, EIm, Lime, Birch, Rowan, Syeamore, Willows in general, Maple, Aspen, Beech, Hombeam, and Silver Poplar. Sylviculturally, therefore, it oceupies a praraloxical position, like that which the variety of pulse called Lupine ocenpies andiculturally; for whilst analyses of its foliage and stem show that it withdraws from the soil large amounts of mineral salts and of the water in which they are held in solution, yet it apparently is content even with occupying poor sandy soils. But both with regard to the liobinia (which is assisted in this matter hy its extensive horizontal root-system) and the Lupine, this mystery is solved by the discovery that a fungus (Bacillus radicicola or Rhizobium leguminoserum) lends symbiotic aid in the formation of nitrogenons and albuminoin substanees, which are stored up in the tubercles or nodules on the roots, and within which the Bacteria are located. The common Hlater is also similarly assisted by a bacterial symbiosis on land of poor quality. 
Propagation and Culture.-The seed of this tree ripens well in Findind, and sometines in seotland; hut nurserymen generally procure their supply of it direct from America. Whether it be got from trees grown in this country or from America, it should always be preserved in the pods till sown; for if not, it is very apt to lose its vitality, and much of it will, in consequence, fail to germinate. The anels gut from America have a higher germinative power than those witherel from home-grown trees, and are therefore preferable. Early in spring, during good weather about the end of February or the beginning of March, they should be sown in rows about $15 \mathrm{in}$. apart, along which the seeds should be placed at distances of about 3 in. The soil should be light, rich, and well prepared, and the covering of earth may be fully half an inch. The seedlings will come up during the following summer, and be fit for planting out into nursery-rows in the succeeding spring. In the nursery-beds they should be planted at distances of $4 \mathrm{in}$. from plant to plant, the rows being not less than $20 \mathrm{in}$. apart. When they have stood for one Jear in the nursery-lines they will be about $3 \mathrm{ft}$. high, and are ready for planting out into their permanent sites. No difficulties whatever are connected with transplanting; for no other tree, when transplanted, establishes itself more readily and easily.

Sylvicultural Characteristies of the Robinia.-As a considerable degree of warmth is requisite for this tree, its cultivation on any large scale should only be attempted in the milder tracts of England. It is liable to be damaged by late frosts in spring, and heavy winds are apt to tear off the branches; hence it requires to occupy a sheltered position. Notwithstanding its very extensive superficial expansion of roots (which can often be of great service in binding light sandy soil), it throws down a deep tap-root into the soil; and like all trees developing a strong tap-root, it makes considerable demands for light and air, and therefore requires a large amount of growingspace for the unhindered development of its expansive, lightly foliaged, and irregular crown. It is well adapted for planting along the berms or slopes of steep railway cuttings or embankments with a view to fixing the soil, and for fringing, along with the Birch, tracts of Scots Pine-woods through which lines of railway pass, and where there is a constant danger of the soil-covering of dead needles being set fire to by the sparks of locomotives during the hot dry months of July and August.

The Robinia or Acacia does not attain any large dimensions as a timbertree in England, although in central and southern Germany, where it is often grown in pure clumps on warm situations, it reaches nearly $80 \mathrm{ft}$. in height and over $2 \frac{1}{2} \mathrm{ft}$. in diameter. But it is as coppice that its sylvicultural importance is greatest; when the stem is cut down, it possesses strong reproductive capacity both by means of stoles or root-suckers and stool-shoots. For underwood, however, it is unfortunately not adapted, owing to its pronounced characteristic as a light-demanding species. It is eagerly attacked by hares and rabbits, but where these enemies are not too frequent, or where they can 
conveniently and cheaply he kept off by wire-fencins, it can, when intermixed with less quickly growing species, yiclel very fair monetary returns in any colplicewoods, whether cut over in a short rotation of 10 to 1.5 years, or in anmal falls returning only after every 20 to 2.5 years. Its long, straight, and very durable poles are then copecially valuable for such purposes as hrop-poles ant the like; whilst with lower rotations it yickls gond withes and tongh horper for casks. It is well adapted as a stantard in copse, as it throws only a lifht sharle over the underwood. It then yields its best financial ruturns between to aurd (jo years of age, when it attains its full maturity as a tree in hoalthy develonnent. For warmly exposerl, sandy land thronghout southern Enchland, like the P'ine tracts of Surrey, the cultivation of the Acacia in a rational manner, based on a knowledge of its natural requirements, seems to offer good financial returns without having to wait very long for them.

In Germany the seed is collected in bags and threshed out of the pods. It germinates about fourteen days after being sown out in spring. As the Rohinia seeds freely every year, it is seldom necessary to stnre up the seed; but Continental experience differs from what is stated ahove, for the germinative capacity of the seed is there found to he retainable for sereral year.. On rery light soil, yearling scedling-plants are put out by the simple metlod of notching, but in other cases two-year-old plants are used generally.

\section{ILICINE E BRONGN.}

The various genera forming the family of Ilicince are mostly scattered throughout South Africa, the West Indies, and South America, whilst only a few are indigenous to Europe. Along with the fanilies of the Pimpernels

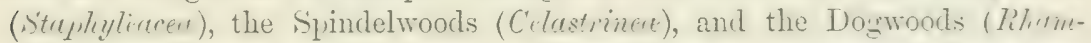
uncer), they form the natural order of Fronyuline as represented throughout central Europe.

\section{THE HOLLY, Ilex (Linnzay System, Tetrandria Temagria).}

Character of the Genus. - Calyx 4-5-toothed, permanent. Corolla 4-5-cleft, subrotate. Stamens 4-5, alternating with the segments of the corolla. Ovary sessile. Stigmas 4. Berry containing 4-5 one-seeded nuts (Loudon, op. cit., p. 156).

There are several species and varieties of this genus, some of them with spiny teeth on their luves and others without. mostly evergreens, and low trees or shruls, natives chiefly of central Europe and North America. The only species, however, that need be referred to is the prickly leaved or Common Holly (Ili Aquifulium).

\section{THE COMMON HOLLY or HOLM, Ilex Aquifolium L.}

Specific Character. — Leaves oblong, shining, wavy, spinytoothed. Peduncles axillary. Flowers nearly mubellate. Flowers white; May. Fruit red; ripe in september, and remaining on the tree 
all the winter. The lower leaves are very spinous; while the upper ones, especially on old trees, are entire (ibid., p. 157). See Fig. 48.

Fig. $4^{8}$.

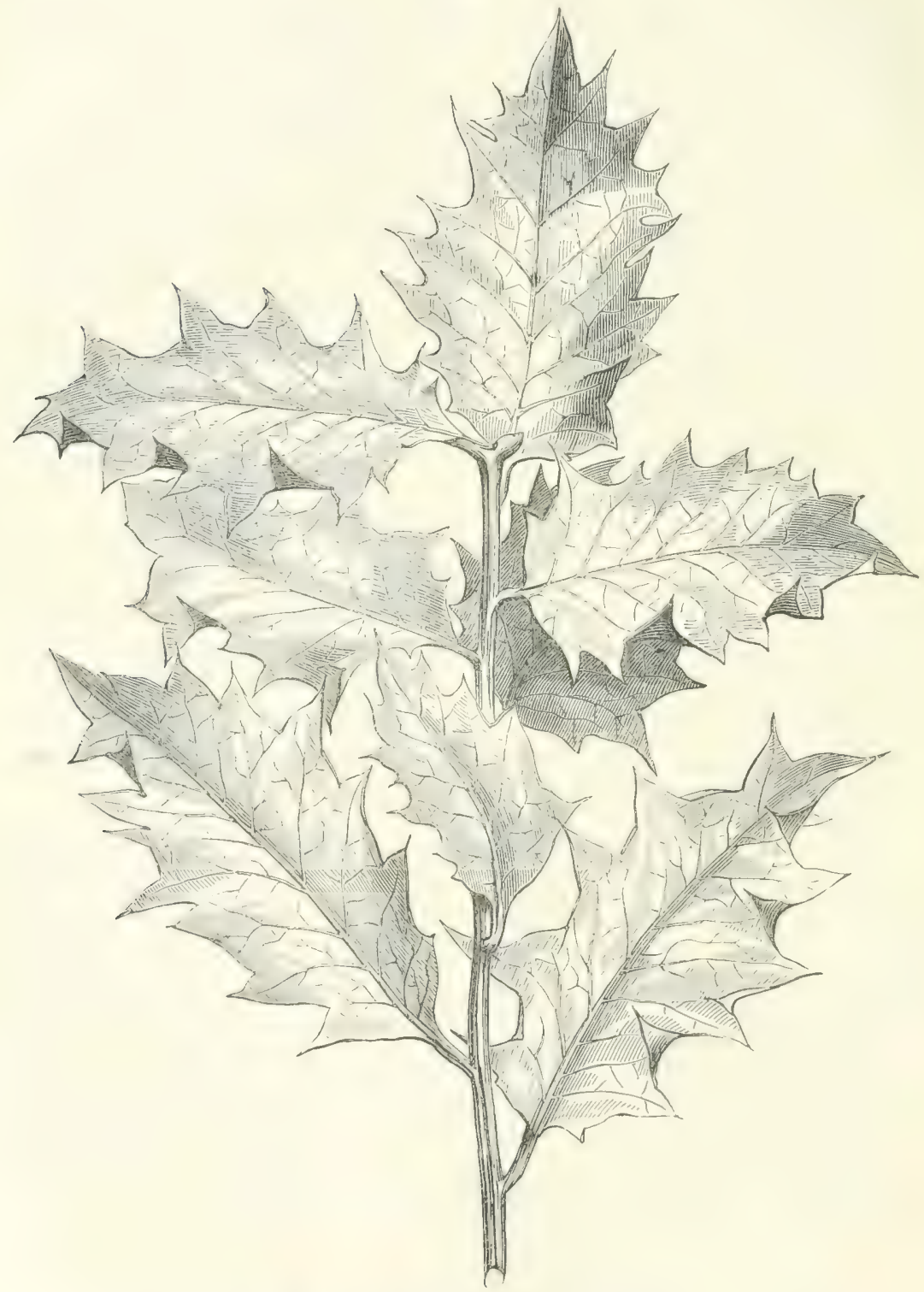

Spray of the Common Holly (Ilex Aquifolium).

Distribution.-The Holly is a native of most parts of the middle and south of Europe, and is frequently to be found of spon- 
taneous growth in woods and shady places, on light dry soils, having a large proportion of vegetable matter. It abounds laroely in many of the German and Swiss forests, particularly in those of the southern and middle states. In Engrland the plant is plentifully distributed in matural woods, especially in the New Forest in Hampshire, and the Forest of Dean in Gloncestershire. It is also plentiful in many parts of Scotland-as, for example, in Lord Seatield's words on the north side of Loch Ness.

Description of Treo.-The size attained by the Ifolly depends very much upon whether it grows in a cultivated or in a wild state. When merely of spontaneous growth it is seldom to be seen of more than $20 \mathrm{ft}$. in height, while in the cultivated state it may attain upwards of $60 \mathrm{ft}$., and may even contain a fair quantity of timber in its stem. The Holly, however, is not cultivated for its timber, but almost exclusively for its ornamental effect, which is beautiful at all seasons of the year, from its being evergreen, and from its enlivening effect in winter when clothed with its clustering berries.

Along with the Yew, it forms one of the best of our native evergreen hedges. When growing as a tree, its crown assumes a conical shape; and as, owing to the numerous adventitious buds which it develops, it has a strong reproductive power, it stands cutting and trimming well. This latter capacity was utilised to a great degree in old-fashioned gardening, the shrubs often being made to assume fantastic shapes.

Holly attains a great age; many trees are known to be several hundred years old.

For ornamental and horticultural purposes, several varieties are propagated, of which the chief are the white-and-yellow foliaged kind (var. variegatum), the prickly leaved kind (var. ferox), and the smooth, entire-edged kind (var. inerme). These varieties are extensively cultivated in gardens throughout Britain, Holland, Belgium, France, Southern Germany, and Switzerland.

Economic Uses of Timber.-When an old Holly-tree of some size is cut down, it may be very readily disposed of at a good rate to cabinetmakers for furniture. The wood is also utilised for various purposes by many other tradesmen, snch as turners and engineers.

The wood is of a dull greenish-white colour, hard, heavy, tough, and of a fine and equal texture, with plininly marked annual rings and fine medullary rays. In technical qualities and value its wood closely resembles that of the Yew.

Soil and Situation.-The soil on which Holly thrives best in Britain is a light dry loam, containing a good deal of humus or vegetable matter. Fair specimens of it and of its varieties may often

VOL. I. 
be found on soil of a heavy as well as on that of a poor character; but really healthy, thriving specimens are seldom to be met with on a soil that does not contain a large percentage of humus, such as is generally found in very old woodlands.

Like the Hawthorn and the Hornbeam, the Holly is largely made use of for hedging. Few shrubs are really so well fitted for quick hedges, for it forms an almost inpregnable fence, in addition to being evergreen. Not only is it desirable from the shelter it affords, but its appearance is at all times pleasant. Although the Holly is very hardy, and will sometimes grow to a good size on poor and exposed sites, still, in order to have it thrive well, it should be planted in rather a sheltered part, where it has the protection of larger trees to shield it from storms. It grows well even under the shade of other trees.

The Holly is a species of shrub capable of bearing a considerable amount of shade, although it is only when growing in full exposure to light and warmth that it can develop into a small tree. It is frequently to be found of spontaneous growth in cool, shady spots on fresh loamy, sandy, or limy soil, for, like the Yew, a certain amount of lime in the soil seems to be advantageous to its growth and development. On good classes of land it may sometimes be troublesome as a weed during natural regeneration of the crop. It possesses a very considerable reproductive capacity in sending out shoots from the stool, and is often to be found cropping up in coppice-woods; but when the period of rotation extends beyond about ten years, as is usually the case, it gradually disappears from the woods, as it is of slow growth, and gets suppressed by more rapidly growing species.

Propagation and Culture. - The Common Holly is always propagated from seed, but the several varieties of it are reproduced by budding and grafting, and sometimes by slips or cuttings. The mode of gathering and preparing the seed, as well as the method of sowing it, is in all respects the same as has already been described with regard to the cultivation of the Hawthorn. The seeds of both require about two years to germinate; hence the use of land may be saved for one year by storing the fruits for that time. That is to say, if the seed of the Hawthorn and the Holly be sown when it ripens in autumn, it will usually lie dormant for a year and a half in the ground before it comes up; but when stored either in or out of the ground (see p. 225), and not sown for sixteen months after the gathering, it comes up during the spring in which it is sown. The Holly is of slow growth at all its stages; hence it will be found advisalle to let the plants stand for three years in the nursery-lines before transplanting them into their permanent sites. By this method of treatment they form good spreading fibrous roots, and develop into strong plants-points which are necessary to be kept 
in view in order to ensure success in the cultivation of good hedgeplants. When Holly plants of a large size are wanted for putting out, they should be twice transplanted, anid allowerl to stand four or five years in the nursery-lines, - care being taken to give them rorm to develop themselves, and not to confine them in their young stages.

It would seem to be a preferable and much more practical plan merely to remove every alternate plant, and only transplant for the second time the alternate plants removed. By this means exactly one-half of the plants would obtain double the amount of growing-space, without any expense being incurred on their account, and, what is more important, without their root-system or assimilative capacity being in any way interfered with or disturbed.

As Hollies, even in their young state-say, when merely two-yearold seedlings, and just when they should be removed from the seerbed into the nursery-rows-always suffer to a greater or less extent by removal if the atmosphere be at all dry, care should be taken to transplant them only during wet weather. It is well to remove them from the seed-bed to the nursery-lines in wet weather about the end of April ; and even although the weather should be damp or wet, no harm is done by giving the roots a thorough watering, after the first spadeful of earth is put on them. This assists the plants in establishing themselves in their new home; for if they lack moisture they soon wilt, and many are certain to die off.

One of the largest-girthed specimens of Holly is probably that in Col. Lloyd-Terney's grounds in Llanidloes, Montgomeryshire, which has a circumference of $30 \mathrm{ft}$. and a height of $43 \mathrm{ft}$. 


\section{CHAPTER III.}

\section{THE CONIFEROUS SPECIES OF TREES.}

As this work professes to treat merely of such trees as are well known, and have been proved to be worthy of cultivation in our forests, plantations, and parks, only such genera and species need here be described as have shown themselves to be hardy enough for our climate, and as are suitable for leeing reared either for timber-production or for ornamental effect. The greater number of them will be found quite hardy enough for the climate of the milder parts of Scotland; and all of them are perfectly hardy and in other respects suited to develop into useful and omamental trees in the southern and central parts of Britain. Many of them, that but a few years ago were comparatively rare, have indeed already become well known and appreciated arboriculturally: whilst other's of them are also now comprised among the kinds usually cultivated in our plantations for the sake of their timber. All the kinds now about to be described are, therefore, well adapted for growing in our climate, and are carrable of being utilised either arboriculturally or sylviculturally.

\section{A-CONIFERA JUSS.}

The great natural order of the Coniferæ, of which, curiously enough, only the Scots Pine and the Common Juniper (together with the pseudodrupaceous and non-coniferous $\mathrm{YEW}$ ) are indigenous to Britain, is divisible into the following families and genera (Willkomm, op. cit., pp. 57, 58):-

I. AraUchrief.-Androceum or male organs with 6 to 20 anthers. Cone-bracts arranged spirally; outer scale (bract) and seed-scale united, or only separate at the apex. Ovule single, inverted, and attached longitudinally to the scale. Cone large, upright, and woody: the seed ripens only in the second autumn after flowering.

Diøecious evergreen trees having regular branch-whorls and naked buds. 
II. Abietine.玉-Anther scales with 2 anthers. Cone-bracts arranged spirally; outer scale (bract) and seed-scale seprarate, or only united near the base. Ovules dependent, 2 being situated at the base of each scale. Cones woody: in some cases the seeds ripen during the year of flowering, in others not till the second year.

Ifonecious and mostly evergreen trees and shrulss, whose branches ustually develop in regular whorls, and whose buds are usually naked.

III. CUPREsSINE...-Anther scales with 3 to 6 , and only seldom 2 anthers. Cone-bracts, 4 or numerous, ranged crosswise, singly, or in clusters of 3 or 4 ; outer bract and seed-scale indistinguishably united. Gemmula upright, with 2 or numerous ovules on each bract. Cones small in size, and either woody or having a pulpy sarcous development like a berry.

IIoncecions and diwcious trees and shrubs, mostly evergreen, with branches ranged irregularly round the central axis, and having naked buds.

IV. TAxodines.-Anther scales with 2 to 5 and seldom 9 anthers. Cone-bracts arranged spirally; outer scale (bract) and seed-scale united to form 1 bract, lut still plainly distinguishable. Ovules, 3 to 9, less frequently only 2 , and sometimes only 1 ; sometimes upright on the seed-scale, sometimes reflexed or even inverted. Cones woody: in some cases the seeds ripen in the year of flowering, in others not until the second year.

Trees either moncecious or diœcious, mostly evergreen, whose branches sometimes develop in whorls, and sometimes only irregularly around the central axis, and whose buds are naked.

The genera that are of value or interest in Britain are comprised within the following:-

I. Araucarie.e: 1. Araucaria.

II. Abietine玉: 1. Pinus, 2. Picea, 3. T'suga, 4. Pseudotsuga, 5. Alies, 6. Larix, 7. Cedrus.

III. Cupressinee: 1. Cupressus, 2. Chamacyparis, 3. Thuja, 4. Biota, 5. Libocedrus, 6. Juniperus.

IV. Thxodinee: 1. Cryptomeria, 2. Sequoia, 3. Taxodium.

For convenience of arrangement, the Taxus or Yew will also be considered along with the Conifers, after all these various genera have been dealt with; for, as its fruit is not a true cone but a false berry, or pseudodrupe, it has now been formed into a separate family, Turuces (Lindl.), forming the sole family of the natural order Psendodrupacece Willk.

\section{ARAUCARIEE.}

None of the genera of this fanily is indigenons to Europe. All belong to the tropical and subtropical zones of the sontherm hemisphere. It is one of the smallest of all the natural families of trees, as it consists of only one genus, trancoric, of which two species, the Chili Pine (A. imbiricate) and the Norfoll Island Pine (A. ckectsu), have been introduced into Britain for cultivation in parks and arboreta. 
Generic Character ${ }^{1}$ of Araucaria.-Lofty trees. Flowers diweions; males in spikes; anther-lohes 8-15, pendulons; pollen glohose. cones ulobulinr, scales very uumerous, spiral, deciduous, united with the bracts. Ovule 1 to each scale, more or less winged, inverted, and more or less united with the scale itself. Cotyledons epi- or hypagal (Masters, List of Conifer's and Tewads in . Tour. Fioyal IIvit. Socy., vol. xiv., 1892, p. 197).

THE CHILI PINE, Arancaria imbricata Pav.

(Linnean System, Diccia Monadelphia).

Specific Character.-Leaves in whorls of from seven to eight in number, ovate-lanceolate, spirally placed, rigid, concave, straight, smooth, shining, deep green, very pungent, closely imbrierted or placent so as to overlap each other like the tiles on a roof, and cartilaginous on the margin. They entirely cover the stems, and are persistent for several years, $\frac{3}{4}$ to $1 \frac{3}{4}$ in. long, very sharp-pointed, somewhat thickened at the base, but without any foot-stalk, and remain on the shoots for years quite green, though they get more separated, closely pressed down along the stem, and turned backwards as the tree increases in circumference (see Fig. 49). Its branches are horizontal, somewhat ascending at the extremities, regularly divided laterally, in opposite pairs, and quite straight, from five to seven in a whorl, diminishing in length as they ascend higher up the tree, until at the top they terminate in the leading shoot, and form a kind of pyramidal head. The lateral branches are long, straight, in opposite pairs, and regularly divided; whilst the branchlets are cylindrical, thickly covered all over with leaves, rather slender, undivided, and mostly bent downwards. The male and female flowers occur on separate trees. The male catlins are ovate-cylindrical, and in clusters of from six to seven at the ends of the branches; whilst the female flowers are solitary and erect. Cones very large, globular, solitary, and standing erect on the ends of the top branches. They are from 6 to $8 \mathrm{in}$. broad and from 6 to $7 \mathrm{in.}$ long, and are of a dark-brown colour, with the seales regularly and closely imbricated; but when ripe they are deciduous, and very soon fall to pieces (Gordon's Pinetum, 1858, p. 24).

Distribution.- This tree forms vast forests, at an elevation of 1600 to $2200 \mathrm{ft}$., on the slopes of the Andes, in that part of Chili

1 Throughout this chapter the generic descriptions given are those adopted by Masters, and published in the Report of the Conifer Conference of 1891; but as no specific descriptions are given in that list, the original descriptions, taken by the author partly from Loudon (as in the case of the broad-leaved species of trees) and partly from Gordon's Pinctum, 1858, have been revised and allowed to stand for the present edition. 
inhabited by the Arancanian Indians, a people who are said to pricle themselves on their name, its signification being frenti cend, free. It occurs also in southern Chili, on the western slopes of the Andes, often reaching the snow-line, but never more than poloo ft. below it. It is likewise found in great abundance on the mountains of Caramavida and Naguelbuta in Chili, and in the neighbourhood of Conception. It was introduced into Britain in 1796.

Description of Tree.-The Araucaria grows often to the height of $150 \mathrm{ft}$. in Chili, and female trees are said to attain a height of over 200 feet. Even in England, specimens have been known to reach a height of $50 \mathrm{ft}$, and a girth of nearly 20 in., at 35 years of age. Its appearance is altogether unique, and quite different from any other tree that has been introduced into this country. It is quite hardy enough to thrive in this climate, for Continental experience shows that it can grow in the open in all localities where the temperature does not sink below $-15^{\circ} \mathrm{C}$. (or $5^{\circ}$ Fahr.) during the winter (Willkomm, op. cit., p. 58). The stem is in all cases perfectly straight, and up to a considerable age it is covered from bottom to top with the hard and sharp-pointed leaves, while the branches droop at first, and again ascend, giving the whole tree a formal and peculiar aspect, somewhat suggestive of the arms of a candelabrum. This remarkable tree is now too well known

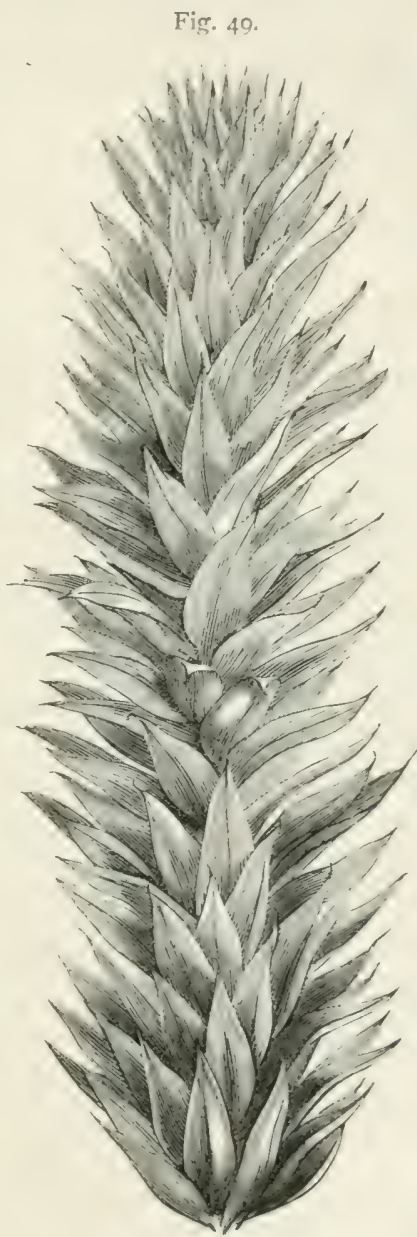

Shoot of the Chili Pine (Araucaria imbricata). and appreciated to need any special recommendation here. It is quite hardy in most parts of Britain, eren in the north of scotland, whenever it is planted on a suitable soil and situation. The Araucaria is, however, somewhat slow in the productinn of timber in Britain; hence it is net likely ever to be found of any sylvicultural value, but will merely remain of arboricultural interest for the decorating of our parks and lawns. It is, howerer, a handsome and 
highly ornamental tree, and deserves a place in all dry and airy parks, as it presents a striking aspect when contrasted among other trees. The seeds are about $1 \mathrm{in}$. in length, and have an edible kernel of an almond-like flavour.

Economic Uses of Timber.-The timber of this tree is said to be hard and of a very solid nature; but whether the wood produced in this country may be so or not still remains to be satisfactorily proved.

Soil and Situation. - The Araucaria is known to grow fairly well on most soils that are not wet in the subsoil. In order that it may really thrive, however, it should be planted out in a light soil, and not in heavy, argillaceous land, so that its roots can get down without hindrance. The tree will not prosper on low-lying or damp situations; on such localities it generally sickens and becomes unhealthy at an early stage, as also do most other of our non-indigenous kinds of trees. Besides a dry and deep soil, it prefers free exposure and an airy situation. It does not thrive if exposed too much; for it is little able to withstand high winds.

Propagation and Culture.-The Chili Pine is raised from imported seed, which germinates very freely and readily. The seed is generally sown in cold frames, and the young plants are planted out into the nursery after they are one year old; but seedlings need protection during the first winter. They require frequent transplanting within the nursery with a view to encourage the developinent of fibrous roots, in order to ensure their establishing themselves when once they are removed to the places which they are to occupy permanently.

Many fine specimens of this Araucaria are now to be found in all parts of the country, from the south of England even to the north of Scotland. Trees of it are common, of heights ranging from 40 up to about $60 \mathrm{ft}$., and nearly all appear healthy and seem still to be making progress.

The great Araucaria at Dropmore, which was planted in 1830, is now 70 $\mathrm{ft}$. high, and girths over $8 \mathrm{ft}$. at $5 \mathrm{ft}$. above the ground.

THE NORFOLK ISLAND PINE, Araucaria excelsa R. Br.,

I)iffers from the Chili I'ine in having bright green, slightly curved, blunt-pointed, compressed, and indistinctly four-cornered foliage nearly $\frac{1}{2}$ an inch in length, but broadening at the base, and covering the twigs thickly. The branches stand in regular whorls of five or six; the twigs are ranged in double comb-like rows along the branches. The cones are situated terminally on long stalks; 
they are almost spherical, but not so large as those of the Chili I'ine, being rather over $6 \mathrm{in}$. in length and rather under that in breadth. Whereas in the Chili P'ine the seed is large, minwinged, and edible, in the Norfolk Island I'ine it is large, broadly winged, of a blackishbrown colour, and not edible.

On the Noriolk Island, where it is indigenons, it is a magnificent tree, said to attain a height of consideralily over $200 \mathrm{ft}$. According to Continental experience, it is well suited for cultivation arboriculturally in all localities where the winter temperature dres not sink below $-10^{\circ} \mathrm{C}$. (or $14^{\circ}$ Fahr.)

\section{ABIETINE E RICH.}

From a sylvicultural point of view this is undoubtedly by far the most important group of trees so far as Europe is concerned. The seven genera into which the indigenous species and the denizens in Europe are naturally divisible are thus distinguishable (IVillkomm, op. cit., pp. 64,65):-

A. Cone-scales narrow, and more or less thickened towards the apex; seed only ripens during the second year after flowering; resin-ducts varying in number and disposition. Evergreen trees and shrubs, whose leaves, ranged spirally round the short shoots, are usually from the second year onwards divided into 2,3 , or 5 needles, contained within a membranous sheath. Pines .

B. Cone-scales thin, broad, and becoming thinner at the edges.

a. Needles (leaves) single, ranged spirally around the twigs, and persistent for several years. Seeds ripen in one year. Evergreen trees.

a. Older (defoliated) twigs rough, owing to the prominence of the adherent bases of the needles on the leaf-scars ; bracts of the female flower-spike smaller and shorter than the seed-scales; cones mostly pendulous, and with the scales persistent on the spindle or rachis.

(a) Leaves sessile, 2- or 4-sided, ranged along the upper and under sides, and with two lateral resin-ducts. Spruces. . . . . 2. Picea ${ }^{1}$ Lk.

(b) Leaves petiolated, 2-sided, with a single resin-duct running along the back of the leaf or needle. Hemlocks 3. Tsuga Endl.

${ }^{1}$ In accordance (1) with the acknowledged system on the Continent, to which he has always been accustomed, and which he has already adopted in his British Forest T'recs, 1893; (2) with Bentham and Hooker's Genera Plantamum; (3) with Masters' List of Conifers and Taxads, formally approved at the Conifer Conference, 1891; and (4) with the Index Kewensis, 1893, vol. i. pp. 2 and 3,-- the editor has here introduced the correct scientific nomenclature for Spruces and Silver Firs, in place of that fixed by Loudon, which has hitherto been generally accepted by nurserymen and arboriculturists throughout Britain. 
$\beta$. Twigs smooth, leaf-scars not prominent; bracts of the female Howering-spike considerably longer than the seed-scale.

(a) Leaves petiolated, 2-sided, with 2 lateral resin-ducts below the under surface; leaf-scars transversely oval; cones pendulous when ripe, with the scales persistent to the spindle or rachis. Douglas Firs 4. Pseudotsuga Carr.

(b) Leaves sessile, 2-sided, with 2 lateral resin-ducts near the edges ; leaf-scar circular ; cones erect, but with deciduous scales which fall away from the spindle on the ripening of the seed. Silver Firs . 5. Abies ${ }^{1}$ DC.

b. Needles (leaves) of the short shoots clustered in tufts, but occurring singly on the long shoots that develop later on.

a. Deciduous trees, whose cones ripen within one year from the flowering. Larches. . . . 6. Larix Lk.

$\beta$. Evergreen trees, whose cones only ripen during the second year after flowering. Cedars . . . 7. Cedrus Lk.

\section{THE PiNe, Pinus L. (Linnean System, Monecta Monadelphia).}

Generic Character.-True Pines are evergreen trees, with the adult leaves persistent, in tufts of 2,3 , or 5 ; the flowers are monocious, males in catkins; pollen cells winged; coṇes ripening in the second year, woody; scales (relatively) thin at the tips in $\S$ Strobus and $\$$ Cembra, thick in $\$$ Pinaster. Wing of the seed ultimately separable, dilated above, prolonged below into two clawlike processes which clip the wings of the seed. Cotyledons variable in number, 3-sided, usually entire, whilst the primordial leaves are denticulate (Masters, op. cit., p. 224).

The Pines are all evergreen trees, for the most part of large size, and indigenous to the hilly regions of Europe, America, and Asia. They are, in respect to economical purposes and to their general utility, perhaps the most useful of all trees to mankind. Nearly all the species flower in Britain in the months of May and June; and they generally ripen their cones within two years of the flowering. They all require a light, porous, dry soil for their normal development, and none of them grow healthily unless they live in a pure air, such as is always found on elevated sites, and at a considerable distance from the smoke of towns. They are all unfavourably influenced in growth by wetness in the soil, and they do not succeed on heavy land retentive of much moisture. They are in all cases found to develop more healthily, and to attain a greater age, on a soil that is rather poor than rich; and most of the species which have been introduced from America and Asia attain better development in Britain when planted on situations having aspects between the south-west and north, than when they are put out on easterly or southern exposures.

\footnotetext{
1 See footnote on previous page.
} 
The P'ines are of a gregarions habit of growth, and as they are at the same time light-demending rather than stude-herering sjeceses of trees, Pine-woods are comparatively thin as compared with woods of Spruces and Silver Firs. Even when growing in isolated positions, they throw off the majority of their lower branches, and form compraratively straight, full-woorled, and clean boles, the bark of which becomes thicker and more cortaceous and fissured with advancing age. The leaves or needles are persistent only from 3 to 6 years, although on inferior classes of soil they are of shorter duration; defoliation takes place in the autumn under normal circumstances. As they approach maturity the shoots of the branches forming the crown continue more vigorous than the leading shoots, and the crown consequently hecomes rounded off, in place of remaining more or less conical like that of Spruces and Silver Firs. ILost Pines have a well-developed tap-root, and a deel', as well as wide-sprearling, root-system, which enables them to offer consideral)le resistance to the violence of storms.

The timber of most of the species of Pines is usually rich in resin, and, like all trees which have a decided tap-root, they form a duramen or heartwood of a considerably deeper colour than the alburnum or sapwood.

The various species of Pines may conveniently be considered in the following order:-

I. Two Leaves or Needles in each Sheath-

(1.) Pinus sylvestris.

(2.) " austriaca.

(3.) " Laricio.

(4.) " Pallasiana.

(5.) " Pinaster.
(6.) Pinus resinosa.

(7.) " pyrenaica.

(8.) " Brutia.

(9.) 1 Mughus.

(10.) " Pumilio.
(11.) Pinus inops.

(12.) " muricata.

(13.) " persica.

(14.) " pinea.

(15.) " halepensis.

II. Three Leaves or Needles in Each Sheath-

(1.) Pinus Gerardiana.

(2.) " macrocarpa.

(3.) " Bungeana.

(4.) " ponderosa.

(5.) Pinus Benthamiana.

(6.) " rigida.

(7.) " radiata.

(8.) "1 insignis.
(9.) Pinus Sabiniaua.

(10.) " Jefireyii.

(11.) " tuberculata.

III. Five Leaves or Needles iN eAch Sheath-

(1.) Pinus Cembra.

(2.) " Strobus.

(3.) 1 excelsa.
(4.) Pinus Lambertiana.

(5.) " Montezumic.
(6.) Pinus monticola.

(7.) " Hartwegii.

According to Willkomm (op. cit., p. 166), there are at least 83 species of Pinus, with more than 170 varieties.

\section{PINES IIAVING TWO LEAVES OR NEEDLES IN EACH SHEATH.}

(1.) THE SCOTS PINE ol COMMON FIR, Pinu syllestri. L.

STronsu-P. mubce Mill.

Specific Character.-Leaves in pairs, rigid, from $1 \frac{1}{2}$ to $2 \frac{1}{2} \mathrm{in}$. in length, somewhat waved and twisted: slighty concive on the upper and conver on the under surface, of a light hluish-green or greyish colour; finely serrulated on the edges, sheaths jagged and 
slightly ringed. Cones, from 2 to $3 \mathrm{in.}$ long, and from 1 to $1 \frac{1}{4} \mathrm{in.}$ broad, terminating in an irregular 4-sided, projecting point, often recurved. Seeds, with the wing, from 1 to $1 \frac{1}{4}$ in. long; seed-leaves from 5 to 7 in number (Gordon, op. cit., p. 184).

Distribution.-This is the only one of the Pine genus which is truly indigenous to Britain; and in so far as regards the general utility of the timber produced by it, it is at least inferior to no other species which has yet been introduced. It becomes a tree of firstrate magnitude in favourable situations, and is one of the most hardy of our forest-trees, being found in Scotland growing up to $2000 \mathrm{ft}$. above the level of the sea. At one time this tree formed vast pure forests throughout the Highlands of Scotland, as well as in many parts of the Lowlands, as is evident from fossil records, and from the remains of forest yet existing. There may here be mentioned, in particular, the remains of the natural Pine-forests still to be found around Invercauld, Rothiemurchus, Glemmore, Abernethy, and Duthal, where there are by far the finest specimens of the Scots Pine to be found in Britain. Althongh this tree has in Britain received the name of the Scots Pine ${ }^{1}$ from the fact that it is our only indigenous coniferous tree of true forest growth, it is by no means confined mainly to this country. It is found growing naturally throughout most of the countries in the north of Europe and Asia, but has not yet been found of spontaneous growth in America. It abounds very plentifully throughout the great north German plain, as well as in Sweden and Norway. From these countries

1 The nomenclature of the Conifers in ordinary English is a vexed question, and just as great confusion exists about it as has hitherto existed with regard to the scientific names of the Picea, Abies, Tsuga, and Pscudotsuga.

Pinus sylvestris was the only tree of the Abictinece indigenous to Britain, and its name was Fin ; of that there can be no doubt. For it is directly traceable from the old AngloSaxon Fuhr, which still survives as Fuhre or Föhr, the common modern names of this tree throughout northern Germany (although the term hicfer or Pine is of more common occurrence in the north, and is usual throughout southern Germany). Its Gaelic name was Guithes, which still survives in a few place-names, e.g., Kingussie.

If, however, the different genera of the Abictinece are all to be called Firs, this cannot fail to produce immense confusion, as well as being most unscientific and very far from practical. The nomenclature is absurd, and badly in want of improvement, which calls Pinus Laricio the Corsican Fir, and Pseudotsuga Douglasii, Picea grandis, and Araucaria cxcelsa respectively the Oregon, the Vancouver Island, and the Norfolk Island Pines. It seems preferable to settle the matter once for all; and the following nomenclature is nccordingly suggested as a practical solution of the difficulty:-

All species of the Genus Pinus to be known always as Pines.

$\begin{array}{llll}\text { Picea (Link.) } & \text { " } & \text { " } & \text { Spruces. } \\ \text { T'suge } & \text { " } & \text { " } & \text { Henlocks. } \\ \text { Pseudotsuge } & \text { " } & \text { " } & \text { Douglas Firs. } \\ \text { Abics (DC.) } & \text { " } & \text { " } & \text { Silver Firs. } \\ \text { Larix } & \text { " } & \text { " } & \text { Larches. } \\ \text { Cadrus } & \text { " } & \text { " } & \text { Cedars. }\end{array}$


its timber is largely imported into Britain under the name of "Red Pine," as contrasted with the "Baltic deals" of slruce, and the "White Pine" of the Silver Fir, and is reckoned to be the best quality of Pine timber imported from those countries.

Although not enjoying such a large European distribution as the Suruce, the Scots Pine has a greater general distribution; for it is to be found throughout the major part of Europe, and also over a large portion of northern Asia. The area over which it occurs stretches from western Spain eastwards to the drainage of the Amur, and from Lapland and Arctic Riussia southwards to Upper Italy in Europe and Asia Minor and Persia in Asia. Both its polar and its equatorial limits form broken lines owing to climatic causes; but the total area of its distribution may be assessed at about $123^{\circ}$ of longitude and $30^{\circ}$ of latitude, or rather over one-third of the northern hemisplhere. From the climatic conditions obtaining in portions of this great area, it is therefore evident that it can thrive normally with a lower average annual temperature than the Larch; and the essential conditions for its srowth are thus summarised by Willkomm (op. cit., p. 208) :-

"The more essential conditions for the thriving of the Scots Pine are a period of winter rest for at least three months, with at least an equal period of active vegetation annually, during which the sky is not continuously obscured or darkened by misty clouds; a sunny situation, such as the southern slopes of mountain-ranges; protection against accumulations of snow and ice; and light, porous, sandy-loamy soil, with a continuously moist subsoil, or else a generally dry or fresh soil."

Description of Tree. - The Scots Pine is easily recognisable from any of the introduced species by its buds, leaves, and cones. The buds are what are called ovate, blunt, and pointed, and around the central bud, from which the leading shoot develops, there are generally from four to six smaller buds set closely (see Fig. 50). The cones are generally in pairs, and when ripe are of a redilish-brown colour.

In the natural forests yet remaining in Scotland specimens of the Scots Pine are to be found which have attained large dimensions. Some of them measure from 12 to $13 \mathrm{ft}$. in circumference near the ground, and have a height of about $80 \mathrm{ft}$; whilst many of them are between 300 and 400 years of age. When the Scots Pine is full grown and somewhat advanced in age, there are few trees that can be said to be more picturesque. The stem is comparatively smonth, though not so smooth as that of Spruces and Silver Firs, and is generally straight and clear of branches for a considerable way up: if in healthy growth, it has bark of a reddish colour on the upper portion of the bole, which is usually deeply furrowed, and from which the cortex scales off freely on the reddened upper portion. This reddening of the Pines is usually a sign that the locality is favourable to their development. 
The foliage of the Scots Pine is persistent for from 2 to 3 years ; but this, as well as the characteristic reddening of the stems and the size of the cones, depends to a very great extent on the general nature of the soil and situation. In the forests of the Continent, where it is treated sylviculturally, so as to stimulate it to the formation of a long bole during the period of most active

Fig. 50.

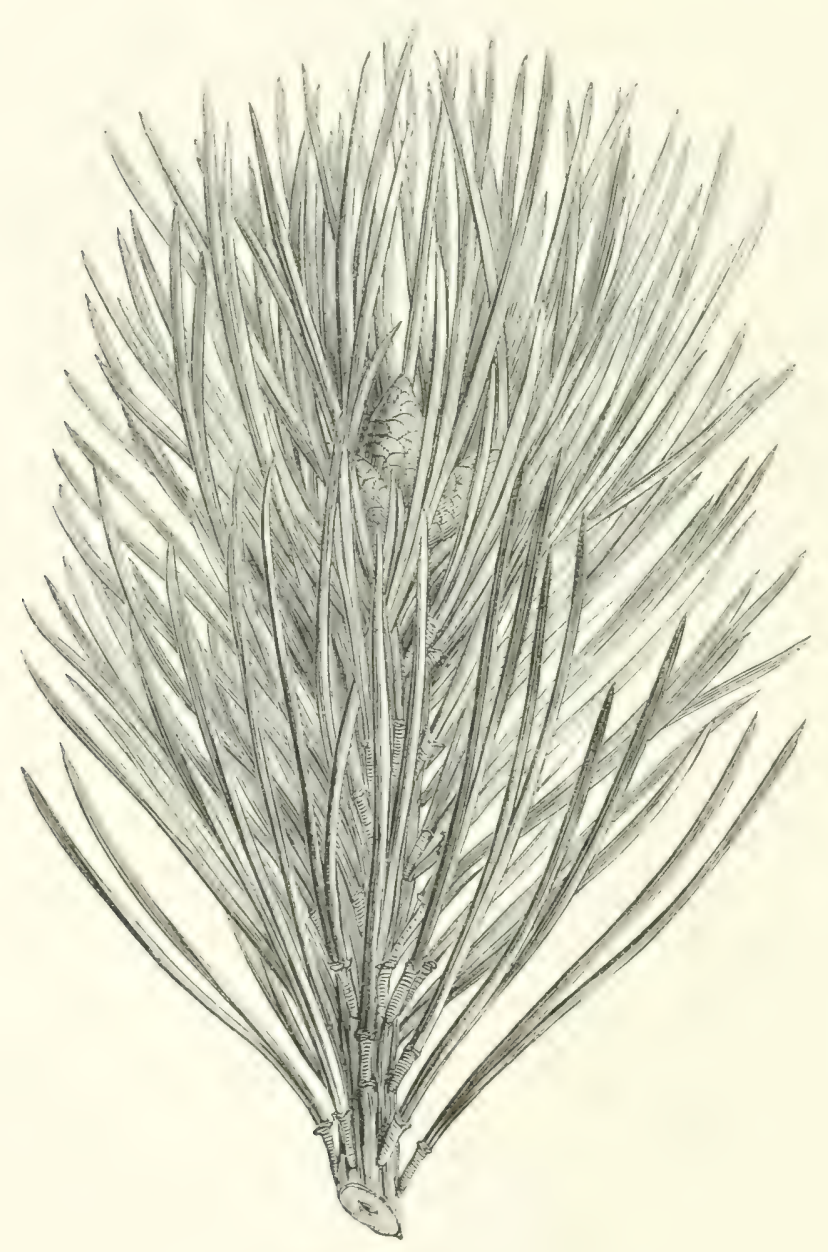

Spray of the Scots Pine (Pinus sylvestris).

growth in length, it can attain a height of 100 to $120 \mathrm{ft}$. in moodland crops at the age of 70 to 120 years.

The length of the foliage, the length and straightness of the bole, the persistence of the leaves or needles, and consequently the density of the crown and the capacity for maintaining close canopy as a timber-crop, depend most esientially on the general quality of the soil with regard to denth and freshness, and of the situation with regard to freedom from exposure to exhausting winds. 
The evergreen Conifers (including the pseurln-drupacents Yew for conventence) retain their foliage as under (Burckhardt, op. cit., p. 249):-

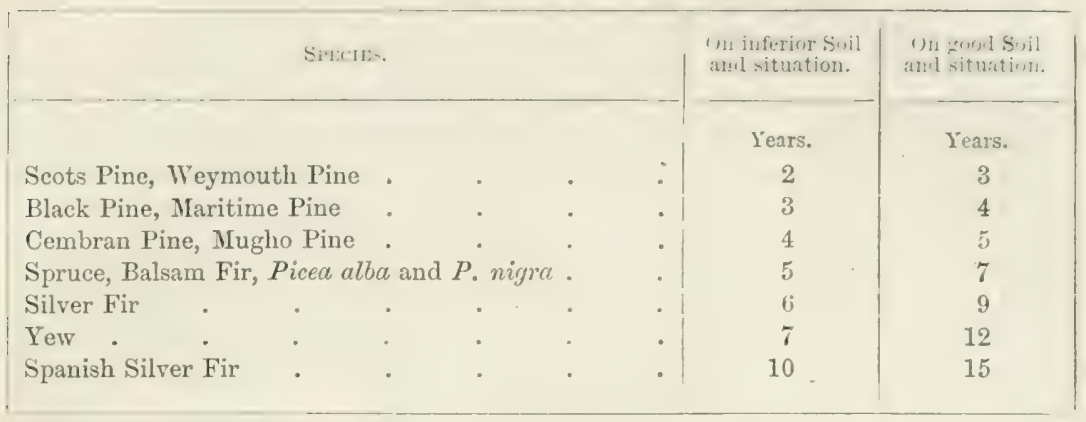

According to the Report of the Conifer Conference in 1891, p. 570, the largest Scots Pine reported on in Britain is at Studley Royal in Yorkshire: it has a height of $90 \mathrm{ft}$, and a girth of $11 \frac{1}{4} \mathrm{ft}$. at $5 \mathrm{ft}$. from the ground.

Economic Uses of Timber.-The quality of the timber of the Scots Pine is very much influenced by the nature of the soil and situation upon which it is grown, as well as by the age at which the tree is cut. The close-grained, highly resinous timber produced upon cold high-lying districts in the north of Scotland is found, when of mature age, superior to that imported from any part of Europe; while that which has been planted and reared in the Lowlands of Scotland, as well as in rather rich soils in many parts of England, is not nearly so good, although of the same age. The technical uses to which the timber of the Scots Pine is applied are almost endless, no sort of rood being so generally used for almost all kinds of purposes to which timber is applied. When of a fair size, but not quite of the dimensions of large timber-as, for example, when having a diameter of between 6 and $S$ in.-large quantities of the young trees thimned from plantations are used for making staves for barrels of dry goods, and for many other similar minor technical purposes. When of large timber-dimensions, and fully matured, the Scots Pinc enters largely into the general economy of the country, its wood being utilised very largely in the form of boarts and scantlings of various dimensions, as well as in the shape of beams, for building purposes. Vast quantities of Scots Pine timber are also used for railway sleepers. So great, indeed, is the demand for good and wellmatured Scots Pine timber for this purpose, that erery one who may have it to dispose of should be able to get it sold reallily at a noou price. Our home plantations are not able to supply lialf the clemand for this class of timber, and in consequence large yuantities are erery year brought from abroad. 
Considering that the world's demands for timber are growing annually, whilst the area of possible production is yearly decreasing, it should need no elaborate argument to point out to landowners the immense value that may be attachable to mature woods in the course of another half-century.

In mean sp. gr. the wood of Scots Pine ranks next to that of the Larch among European Conifers of extensive distribution (see table on p. 331). And as it only amounts to 0.82 when green and 0.52 when seasoned, it follows that Pine logs may easily be floated to distant marts, immediately after being felled.

It is not so elastic as Larch or Spruce, but more so than Silver Fir; but it shrinks to about 3 to 5 per cent of its volume when green, whilst these other woods only shrink from about 2 to 3 per cent. In general durability it ranks only below the Pedunculate Oak and the Larch among European timbers.

Soil and Situation. - The Scots Pine is not a tree that can be said to be particular with regard to the quality of the soil upon which it may be grown; in this respect, indeed, it is one of the most accommodating of forest trees. The best qualities of Scots Pine timber are, however, produced in Scotland upon a gravelly loam, resting upon a dry stratum of rotten rock; but excellent timber may also be formed upon a dry sandy loam. A thin light surface-soil, resting on a subsoil of gravelly till, has also often been observed to grow Scots Pine so as to yield an excellent quality of timber. The natural forests of Pine in Strathspey are generally growing on land that may properly be termed a sandy gravel; and on this description of land Pine timber of large size, and of the best quality, is produced. There, also, on sandy loam, the trees grow to large dimensions; and, even when allowed to stand to so great an age as 200 years, are found to yield timber of fine quality and mature healthy condition. In short, Scots Pine may be found of good growth on almost every variety of land; but a dry light sandy or gravelly loam appears, on the whole, to be the class of soil best adapted for the growth of large crops of this species.

And so long as the land on which the Scots Pine is planted be dry, it will prosper in any situation that is not too elevated or too exposed for tree-crops to thrive well in this country.

The investigations and analyses of Continental scientists have proved (see table on p. 332) that Scots Pine makes only moderate demands on the soil for mineral food, in which respect it ranks much below Silver Fir and Larch, and lower than Spruce; and with regard to the amount of water actually withdrawn from the soil for purposes of transpiration it ranks below Black Pines and Larch, but above Spruce or Silver Fir. This seems somewhat contrary to actual sylvicultural experience, until it is considered that by means of its deep tap-root it can imbibe large quantities of moisture from the subsoil of land that appears dry in the upper layers. On binding soils it neither grows so well, nor produces such good timber, as on lighter soils of any description. 
Propagation and Culture. - The Scots Pine is entirely propagated from seed. The three-leaver sprecies of I'ine are, like Larches and some of the Silver Firs, endowed with slight reproductive power of shooting from the stool and rooting from slips; lut this is of no sylvicultural importance whatever for copplice-growth, and is purely of an arboricultural interest. The cones ripen in the second autumn after the flowering, and the seed is shed during the ensuing spring; hence, for nursery requirements, the cones should be gathered during the winter, and preferably in December and January, as the scales afterwards open more readily with heat than when they are harvested in November (see also chapter ix., on the Management of Nurseries). When the desired quantity is collected, and the seed is wanted for sowing during the following spring, the cones should be placed on a timber-kiln made for the purpose. They may be laid on from 6 to $8 \mathrm{in}$. deep, and the heat in the kiln raised to about $110^{\circ}$ Fahr. ; but great care must be used by the operator not to raise the heat to more than $116^{\circ}$ at the utmost. Brick kilns, as well as metal ones, are very unsafe for this purpose, and should not be used. Even when the cones are heated on wood, very considerable care is necessary not to apply too great an amount of heat to them, as a very slight overheating will be certain to destroy the vitality of a large portion of the seeds, and this must be carefully guarded against. With a heat of $110^{\circ}$ to $114^{\circ}$, the cones should be fit for being removed in about eleven or twelve hours. They should be turned once every two hours during the time they are being warmed; and at each turning all the seeds that come out should be gathered up. At the end of twelve hours, all the cones will be opened up in their scales, and the seeds that remain in them will come out on being well shaken in a rildle. This is the plan adopted by nurserymen who have large quantities of cones to extract seeds from. But for a small quantity, the seeds may conveniently be extracted by exposing them to the heat of the sun; this will open their scales, and the seeds will fall out by gentle threshing with a light flail or piece of stick. When the seed has been extracted, it should be stored past in a dry cool place till required for sowing.

The following extract from Burckhardt (op. cit., p. 269), perhaps the greatest of all the practical sylviculturists of the present century on the Continent, may be compared with the above method of winning the secd, and with the remarks immediately preceling that description in the last edition of this work :-

"The harvesting of the seed from the cones is usually undertaken directly by the foresters and woodmen, although in some cases contracts are made with approred seeds. men for delivery of seed under certain stipulations as to quality, \&c. In many districts the harvesting of the seeds of Conifers forms an important branch of trade and industry.

VOL. I. 
"The worst quality of seed is delivered by peasants, who heat the cones in their" baking-orens, whilst the best quality is obtainable by exposing the cones to the sun's warmth; but care must in the latter case be taken to procure the seed only from trustworthy persons. When seed harrested by means of the sun's warmth is used, hardly two-thirds of the quantity of seed is requisite for the ordinary operations of sowing, and the most vigorous plants are produced; hence it can be strongly recommended for use in the nurseries. Although it is dearer in price, seedsmen buy it eagerly, in order to mis it up with older seed.

"The construction of seed-kilns has been considerably improved of recent years. The warming of the cones takes place with heated air, and a special contrivance admits of the seed falling down into a cooling-chamber as soon as it drops out of the cone. Whether the use of perforated trass ranged as shelres, or of wire crlinders that are kept turning round like coffee-roasting machines, deserves the preference, is a point not yet decided.

"When the harresting of the seed is completed, the cones are used as fuel for the kiln. The warmth that should be applied varies according to the nature of the kiln, but is in general greater for Scots Pine than for Spruce cones; it is usually kept at or below $127^{\circ}$ Falur. for the latter, but mas be somewhat higher for the former; and the Scots Pine seed is less likely to be damaged by the rapid change of temperature on falling into the cooling-space.

"The cleaning of the seed from the seed-wings or bracts takes place either by threshing in half-filled sacks, or by moistening it slightly with water, an operation requiring caution; but in both cases it has to be cleaned subsequently in sieves or winnowingmachines."

In sowing the seed, a piece of very fine light ground should be chosen as the nursery. It should be well prepared by digging and by repeated raking until the earth is fine enough. The ground being

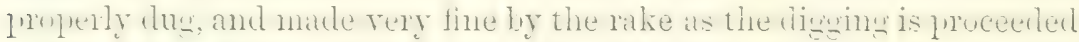
with, it should be marked off into parallel beds of $4 \mathrm{ft}$. in breadth, every two adjacent beds having a path 1 ft. broad between them. The seed should be sown at an average of about two sceds to the square inch. When sown, it should be covered up with about a quarter of an inch of very fine soil. The plants should be allowed to remain only one year in the seed-beds, at which stage they are termed yearlings or one-year-old seedlings. They should then be schooled by being transplanted into nursery-rows. When they have remained there one year, the plants are termed one-year-old transplants; if they stand for two years, they become two-year-old transplants, and so on. In forming plantations on high-lying parts of the country, Scots Pine may be put out either as yearling seedlings or as twoyear-old schooled transplants that have stood for one year in the nursery-lines. But if the transplants are wanted to be of about 9 in. in height before they are planted out, then in that case they would require to stand for two years in the nursery-rows.

Perhaps the best crops of the Scots Pine in Britain are to be found at Gordon Castle, Castle Grant, and at Invercauld. But throughout various parts of the country trees of this species are to be found ranging from 70 to $115 \mathrm{ft}$. in height, and with stems of from 3 to $5 \mathrm{ft}$. in diameter. 
The leading Sylvicultural Characteristic of the Scots Pine is unquestionahly its relation towards light and shade, for this furnishes the key to all the sperial characteristies peculiar to its growth as a forest-tree. Even thongh in our clamp insular climate it undenlitedly forms a better crown of foliage, and can therefore maintain itself longer in canouy as a forest cropl, than on the sandy soils and in the dry climate of the great north German plain, upon which it is the chief tree, yet there can. be no doubt that it must be classed as a light-demanding species of tree when compared with the more densely foliaged Conifers like Common and Menzies Suruce, Henlock, Jonnglas Fir, Silver Fir, Nordmann's Fir, and even the Black Pines (Austrian and Corsican).

Its growth is not usually so straight as that of the Spruces or Silver Firs, for its leading shoot is apt to be clamaged by numerous insects and lis fimgoirl diseases, nor are the boles formed so clear of branches and so full-worderl as in the case of those other trees.

Although the branches formed by the Scots Pine are somewhat thicker than those of the Spruce, yet they are sooner thrown off, owing to the inherent light-demanding nature of the tree. But of course this natural demand for light is not so distinguishable on good fresh land and on sheltered situations as under less favourable conditions of soil and climate. Under no circumstances, however, can it ever be utilised as a suitable species for underplanting, which is the special characteristic of the shute-lyering species having denser foliage. On the better classes of land Scots Pine will thrive well when intermixed with either coniferous or broad-leaved species of trees of slightly slower growth, so that it can keep, its crown compraratively freely exposed to the light and air: in such mixed crops it is less exposed to attacks from insects or fungoid diseases, and forms a better bole and a larger proportion of heartwood than when grown in pure crops. But on inferior land, not good enough for the profitable growth of other kinds of forest-trees, the best use that can be made of the soil is often to plant it up with Pines and afterwards to thin them out well, about the 25th to 35th year, when they hegin to exhilhit their natural tendency, thus reducing the number of trees per acre so as to have an increased individual growing-space for the survivors, and then to underplant them with some good shade-bearing species; for by the rich fall of needles, and the beneficial shade of the young crop, the quality of the land will usually have become greatly improved in the meantime. Cropss of ficots Pine treated thus will be found to yield fair returns at 50 to 70 years of age even from rather poor land.

Existing forests of Scots Pine may easily be regenerated naturally under parent standard trees on the better classes of soil: hut on the inferior kinds of land only artificial regeneration should he attempted. The formation of new woods may also take place, as in the latter case, either hy sowing or planting: but on the whole planting is usually lueferable, as it is rather safer, and, with the young classes of plants that may be utilised, need not always be much more expensive than sowings often prove before the filling up of blanks is completed.

Continental experience shows that the use of naked, well-dereloped yearling seellings or two-year-old transplants is preferalule to that of oliter transplants with balls of earth around them; for the plants can be put out without 
much dancer of the tap-root heing injurel. On light sandy soil, when planting can take place easily with wedge-like notching spades, the plantations can be formed at a very low cost per acre. 'Throughout the German forests, there are always temporary nurseries made near where planting operations are likely to be carrie! out in the immediate future, so that the plants may be ready at hand whenever required, without any special costs being incurred for material or for carriage. This also obviates the risk of the transplants sickening before reaching the area to be planted up. As a rule, the planting operations are carried out in spring; and with small plants, like yearling seedlings and two-year-old transplants, close planting at about $3 \mathrm{ft}$. by $3 \mathrm{ft}$., or else in rows, giving the same growing-space per individual plant, is favoured. It soon shoots ahead in upward growth, in which respect it is only excelled by the Larch among European Conifers. The young plants do not begin to form regular whorls until their third year.

Whenever cones can be conveniently collected, it is advisable to harvest the seed for home use, or at any rate, to obtain it only from trustwortlyy seedsmen, and under guarantee that it is not imported from Germany; for experience has shomn that young seedlings and transplants raised from foreign seed are much less hardy as regards late frosts and drought, such as occurred in England during 1893, and that they are also more liable to attacks from the "leaf-shedding" disease caused principally by the fungus Hysterium pinastri, although it may also result from drought and frost.

\section{(2.) THE BLACK o1 AUSTRIAN PINE, ${ }^{\circ}$ Pinus austriack Höss.}

Srxoxrys-Pinus Laricio austriaca Endl.; Pinus nigricans Lk. and Host.; P. pinaster Bess.; P. Laricio Pokorny., Heuff, and Schur.; P. maritima Ait, and Koch.

Specific Character. - Sheath with from 3 to 5 rings, at first of a clear ash-grey, then becoming reddish, afterwards darker, and at last black. Leaves in twos, from 2 to $5 \mathrm{in.} \mathrm{long,} \mathrm{seldom} \mathrm{and}$ but slightly twisted; when young, erect; when older, standing out, and curved towards the twig; outer surface half-romnd, dark, green, glossy, and with a sharply serrated margin; inner surface nearly even, but slightly dotted along the ridge; points prickly, of a yellowish-brown or fawn colour. Buds large, the leader often from 1 to $1 \frac{1}{4}$ in. long, ovate, with a long point. The cone does not arrive at maturity till October in its second year; it is conical, rounded at the base, 2 to 3 in. long, pointing horizontally, or nearly so; of a light-brown colour, polished, and shining. Seeds very closely re-

1 The Austrian Pine, the Corsican Pine, and the Taurian Pine are by Continental sylvicultural botanists now always included as mere climatic varieties of one species, the Black Plve (Pinus Laricio Poir.) But as they have long been treated by British arboriculturists as separate species, no attempt is here made to group them together as one great distinctive race of the Pine genus. For the information of the student it may here be noted that a monograph on the Black Pines (Austrian and Corsican) is to be found in the Transactions of the Highland and Agricultural Society of Scotland for 1876, fourth series, vol. viii. p. 220. See also Trans. Scot. Arbor. Socy., 1875, pp. 52-59. 
sembling those of the Corsican Pine ( $P$. Luricio); and the cotyledons from 6 to $S$ in number, as in that species. The bark of the shoots of the current year is of a greenish-yellow, regularly and deeply raised by the insertions of the leaves, furrowed, and shining (Loudon, op. cit., p. 959).

Distribution. - The Biack Pine grows indigenously in Austria, in the Breima Forest (Wienerwald), the Jianat, upon the Demoglet, near Mehadia, and in the neighbourhoorl of the Snowy MIountains, at higher altitudes than the Common Silver Fir. It was first introduced into Britain by Lawson of Edinburgh in 1835.

It is a characteristic tree of the Austrian flora, where alone it forms large natural pure forests thronghout lower Austria, Carinthia, Hungary, C'natia, Dalmatia, Bosnia, and the Herzegovina, as well as along the coast.

Its climatic requirements are a hot summer, a mean annual temperature of not less than $4.52_{2}^{\circ}$ Fahr., and a winter that is not exeessively cold (Willkomm, op. cit., p. 232).

Description of Tree.-The Austrian Pine is easily distinguishable from all the other l'ines introduced into this country by its very strong and robust habit of growth, by the stifiness and strength of the leaves, by their prickly points, and by the very decided dark appearance of the foliage over the whole tree. Any one having once carefully examined this tree can hardly afterwards mistake it for another species, as there is a natural robustness in its whole halit of growth which distinguishes it from all the other Pines. It is, without doul,t, a tree of great hardihood; in this respect, indeed, it is not exceeded even by the Scots Pine. In several localities throughout Britain woodland crops formed of this species are to be found growing luxuriantly at elevations of upwards of 1000 feet above the level of the sea; and not infrequently they appear to be making even more rapid progress than the Larch and Scots Pine growing along with them in mixed crops. Besides its hardiness as a forest tree, this Pine has the advantage, from an arboricultural point of view, of a somewhat irregular outline in the natural distribution of its branches; and from this fact it may be considered a tree well worthy of a place in any arboretum or ornamental plantation.

On favourable soils and situations it grows to a height of 70 to $100 \mathrm{ft}$., and forms a stem of 10 to $12 \mathrm{ft}$. in girth; but on rery proor, diry, limy land its development is often little better than merely to form a large shrub of upright pyramidal shape.

In Austria it is often to be found of enormous dimensions, and sometimes attains an age of over 500 years. One of the celebrated giant Pines in the Wienerwald near Tiemna is over $20 \mathrm{ft}$. in girth at breast-height (Willkomm, op. cit., p. 229). 
Economic Uses of Timber.-Although, in Britain, we have not yet any mature plantations of trees of this species from which to juil.... of the Anstrian l'ine as a timber-producing erop, yet it. general healthy appearance and its very thriving habit seem to indicate that it naty he destined to become of very considerable sylvicultural utility in this country. It is well known to be highly valued for general technical purposes in Austria, where it is of equal importance to what the Scots Pine is in Britain.

Its wood is somewhat heavier than that of the Silver Fir, the mean sp. gr. being 0.97 when green, and 0.51 when seasoned (see table on p. 331). In point of durability it ranks close to the Scots Pine. It is somervhat harder than the latter, but is not so elastic. Like the Scots Pine, it has a greater shrinkage ( 3 to 5 per cent) than Weymouth Pine, Spruce, Silver Fir, Larch, or Arborvitie (Thuja), whose loss in bulk is usually only from 2 to 3 per cent of the volume when green. The timber of the Austrian Pine is better adapted for utilisation in the ground, and for pit-work, than for general building and carpentry purposes.

To other resin is so rich in oil of turpentine as that of the Austrian Pine. In this respect it surpasses even the Maritime Pine; for $100 \mathrm{lb}$. of Austrian Pine resin yields from 14 to $20 \mathrm{lb}$. of oil of turpentine, and about. $60 \mathrm{lb}$. of colophonium or rosin (Gayer, Forstbenutzung, Tth edit., 1888, p. 501).

Soil and Situation.-With regard to soil, so long as this be neither stiff nor wet, the Austrian Pine is a species of tree that is decidedly of an accommodating nature. It attains good growth even upon dry sloping banks, where the soil is of a deep and porous, light, loamy description, and thriving plantations of it may also be seen on most kinds of land, provided that these have been made dry by drainage, if naturally inclined towards wetness. It is a tree well adapted for froducing a consideralle degree of shelter to less hardy species planted along with it; for its massy foliage forms a great protection from winds, and its rapid growth ensures this within a very short time after planting. It is said to attain large dimensions of timber in favourable situations; and from its general thriving habit of growth in Britain this expectation seems well founded. It grows well on sites near the sea-shore, and in this respect is nearly as hardy as the Cluster Pine.

Continental experience seems to indicate that the Austrian Pine develops best in a warm and dry climate, and that, although its best development is undoubtedly attained on a limy soil, yet it is one of the most easily satisfied trees with regard to the mineral nature of the land on which it is planted out. Accorling to Eluermayer's analyses (see p. 3:32), the Black Pine withdraws less mineral food from the soil than any of the other great coniferous timber-trees of Europe; but, though able to thrive on what seem dry sandy soils at the surface, it withdraws more water from the soil for transpiration through its foliage than any of these other Conifers usually grown on financial principles. 
Propagation and Culture.-The seer of this tree is easily procured from those localities on the Continent where it is inrligenous. The seeds are a good deal larger than those of the Scots Pine; hence in sowing them in the nursery they should be much more thinly distributed on the bed than those of the Scots Pine, and covered up a little more deeply with soil. In forming plantations of this kind of tree, whether for shelter merely or to grow up to maturity as timber crops, the plants do not require to be put out so close together as in the case of the Scots Pine; and yearling seedlings or two-year-old transplants need not stind closer than $t \mathrm{ft}$. ly $4 \mathrm{ft}$.

The Sylvicultural Utility of the Black Pine rests mainly on its great accommodative power on the poorer classes of limy or sandy soil, and on its undoubtedly greater capacity for bearing shade than the Scots Pine, although it can hardly be ranked among the class of sherle-lyeding trees like the Silver or Nordmann's Firs. By the hap'py combination of these natural capacitie: aided by the unusual length of the dark leaves or needles forming its foliage, it is possessed of great power in improving soils that have become deteriorated at the surface by injudicious exposure to the exhausting action of sun, wind, and rain; for whilst sun and wind rob the soil of its moisture by evaporation, violent downpours of rain wash away the soluble nutrient salts out of the upper layers of earth without their being utilised profitably for treegrowth.

Owing to its greater capacity for bearing side-shade than the Scots Pine, the Black Pine has a better crown of foliage; but it cannot be said to maintain any very much better canopy overhead, or to be content with a much less individual growing-s lace throughout all the stages of its development, for the Black Pine shows an ummistakable tendency to spreading growth and ramification.

With the above exception, its sylvicultural characteristics closely resemble those of the Scots I'ine. It is equally hardy as regards frost; but eren on sancly soils it can withstand the effects of long-continued drought better than the Scots Pine, as the experience of 1893 has proved in Southern England. I On good classes of soil the Black Pine may easily be regenerated naturally by removing all the stems except about 25 or 30 per acre as parent standards. But on the whole most attention is given to artificial regeneration; and in that case, as well as in the formation of new woods, planting is generally preferred to sowing. For light classes of soil in which notching or other simple methods of planting can take place, a preference is usually given to the use of naked yearling seedlings or two-year-old transplants: whilst when three- or four-year-old transplants require to be utilised in the planting

1 For example, in a young mixed plantation of Larch, Scots Pine, and Black Pine, in the Tudney woods belonging to Magdalen College, Oxford, that was formed tiro or three years previously on a light sandy soil below the average in quality, the drought of 1893 killed off most of the Scots Pine, and a good many of the Larch, whilst the Austrian Pine stood the trial much better, hardly any of the latter species being injured. 
operations, they are generally put out with balls of earth around the roots. In the schooling of plants in the nursery-beds, the yearling seedlings are usually put out at $6 \mathrm{in}$. from plant to plant, in rows about 10 to $12 \mathrm{in}$. apart; and in the course of a couple of years they develop into sturdy transplants.

Black Pine woods are most productive of good seed between the ages of 30 to 60 years. The cones should be collected in Narch or early in April, before the seed begins to be seattered during warm days.

In the State forests of Austria the seed is harvested by exposure of the cones to the sun's warmth; but kilns are also in use for the supply of seed to seedsmen. According to Burckhardt (op. cit., p. 462), these kilns are worked by means of air-chambers heated to a temperature of $101^{\circ}$ to $111^{\circ} \mathrm{Fahr}$, which are warmed from below, and have funnels or vents in the ceiling for permitting the escape of the vapour and gases formed by the heated cones. When the operation has been carefully conducted, the seed should have a germinative capacity of 75 per cent; for, in this respect, Black Pine seed is only second to that of the Spruce ( 75 to 80 per cent).

\section{(3.) THE CORSICAN PINE, Pinus Laricio Poir.}

Srvoxras - Pinus Laricio Poiretiana Endl.; P. L. calabrica Delam.; P. corsicana Poir.; $P$. sylrestris maritima Ait.

Specific Character.-Leaves two in a sheath, from 4 to $6 \mathrm{in}$. long, dark green, often twisted, and rather slender for its class, and with shorter sheaths (see Fig. 51). Cones solitary, or in pairs; seldom more than 3 or $4 \mathrm{in}$. long, and $1 \frac{1}{2}$ in. broad near the base, conical, straight, or sometimes slightly curved near the points. Buds ovate, with a long narrow point, and resinous. Seed-leaves from 6 to 8 in number (Gordon, op. cit., p. 168).

Distribution.-The Corsican Pine, a species of Black Pine, was first discovered in Corsica, hence its name. It is said to form large forests on the mountains of Sila in Calabria, and it has been found throughout most of the countries of southern Europe, in Greece, Crete, Italy, Sicily, Corsica, and Spain, as well as on the Caucasian mountains in Russia. It is said to have been introduced into Britain in 1759 by Vilmorin.

It attains its finest development on the island of Corsica, where stems of from 10 to $20 \mathrm{ft}$. in girth are still not uncommon. According to the estimates made by von Seckendorfif, some of the gigantic stems in the Valley of Trottalia are from 1500 to 1800 years of age (Willkomm, op. cit., p. 229).

Description of Tree.-The Corsican Pine is a rapid-growing tree, which attains a height of from 90 to 120 , and sometimes even 150 ft., with a proportionate girth of stem, according to soil, situation, and climate. It is a very hardy and accommodating tree, and is said to lue fround on Mount Etna at elevations between 1000 and $6000 \mathrm{ft}$. Even in this comntry its character for hardihood is fully established; 


$$
\text { Fis. } 5 \text { r. }
$$

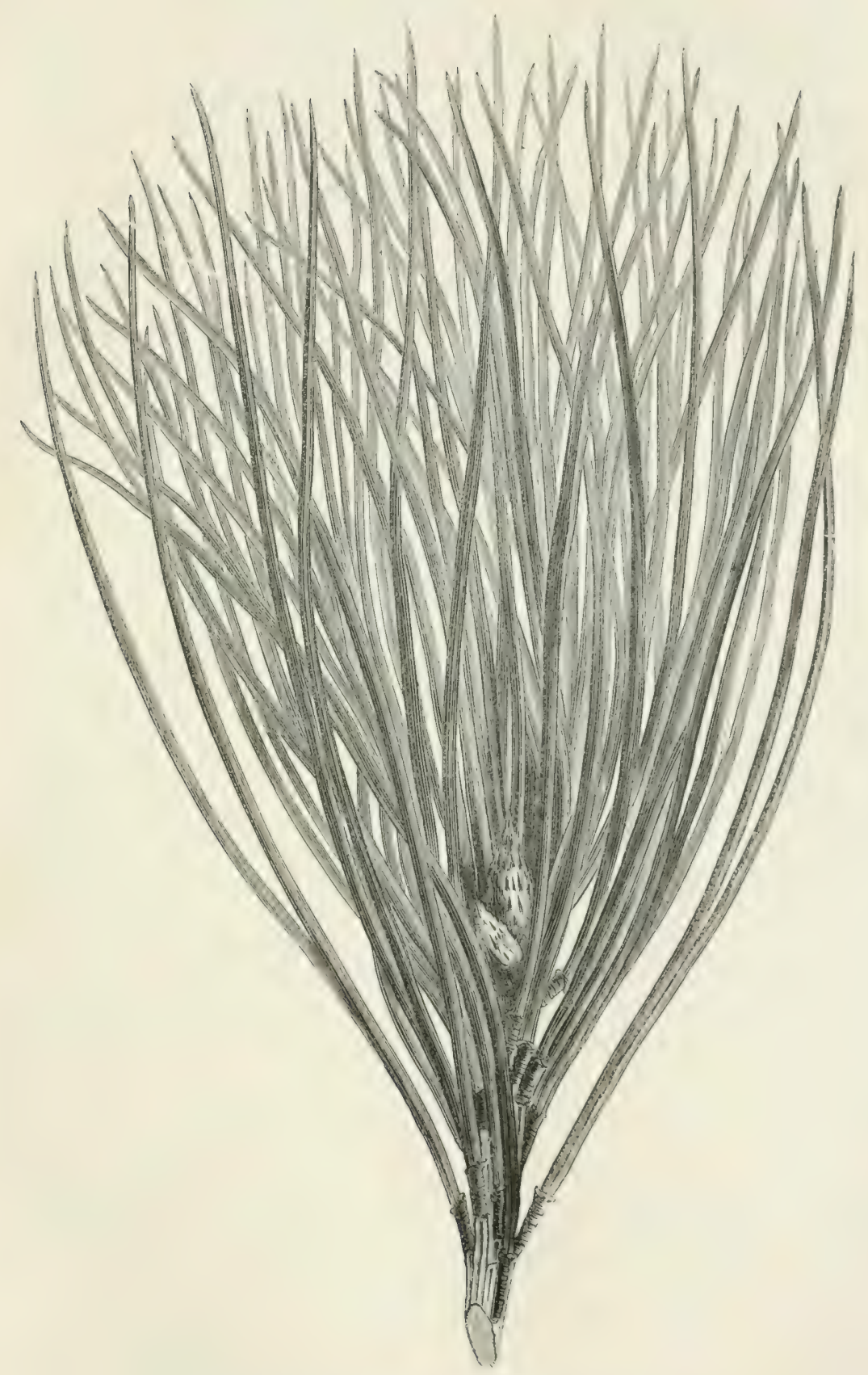


and it is acknomledged to be a tree in all respects adapted to become valuable in Britain for timber-production. From the very fact of this kind of Black Pine being indigenous to an insular climate, it is all the mere wrthy of attention throughout Britain from a sylvicultural point of view; for in the case of the Black Pines, as well as of other trees-e.g., the Pacific coast and the inland varieties of Douglas Fir - the best results are attainable with genera that are already by heredity accustomed to a damp insular or coast climate.

The Corsican Pine forms a handsome, open-branched, pyramidalshaped tree, growing very rapidly, and attaining maturity at a comparatively early age, generally within from 70 to 90 years after planting. From this species of I'ine having been introduced into this country over 130 years ago, and from its seed being abundant and cheap, it is now plentifully distributed over most parts of Britain; and it is a general favourite with all tree-growers, for it establishes itself readily, besides being both free-growing and ornanental in it: general character.

It is easily known from any other of the many exotic Pines by its very rapid and upright growth, for it often makes leading-shoots of from 2 to $3 \mathrm{ft}$. in height in one season, and indeed seldom adds less than $2 \mathrm{ft}$. per annum to its height after once its root-system has become well established in the soil. It is also easily known from other species by its branches being in regular whorls, and spreading out in an open, horizontal manner, which gives the whole tree that free, open, airy character so peculiar and graceful in this Pine. And it may further be readily distinguished by its leaves being wavy and set more loosely on the branches, and by their having shorter sheaths than most other Pines of the same class (Black Pines), by their being thinly dispersed over the shoots, and by the terminal buds of its shoots being comparatively long, and tapering to a point. Few of the Pines that have been introduced into Great Britain promise to become so useful as the Corsican Pine. Even in this country it grows much more rapidly, and, cateris paribus, attains a larger bulk of timber in a given time, than the Scots Pine. It flowers in May, and its cones ripen in the November of the second year.

From a purely arboricultural point of view, its full rich foliage, its deep root-system, and its great longevity (for stems of 1000 years are not rare in Southern Europe) should secure for it a welcome in ornamental woods and throughout the residential portions of large estates.

Economic Uses of Timber. - The timber of this tree is of a whitish colour, but brownish in the heartwood; it is coarse in the grain, but is well impregnated with resin. It is, however, of considerable elasticity; is fairly easy to work, and is said to be very 
durahle. Although no great practical experience has yet hecen harl of the quality of the woorl prorluced hy it in Pritain, yet, as there is at considerable extent of land under crops of it, ere many years linjse ample opportunities will le siven of forming a coorl estimate of the utility of home-nrown timler of this species. It holds out fair sylvicultural promise of being valuable as a timber-tree in this cruntry; and it may specially be recommended for the planting up of soils that are somewhat below the average in quality. It may be grown in pure forests if desired; but, in accordance with the principles of Sylviculture, it is preferable to grow it in mixed forests along witl other species of trees suitable for the given soil and situation.

Soil and Situation. - The Corsican Pine is by no means particular with regard to the quality of the land on which it srows, provided that the latter be porous, deep, and dry. Most soils, from a stiff clay loam to a sandy soil, are able to produce good crops of it: but, like all other Pines, it attains its most rapid growth in leight on a light, dry, sandy loam, with a deep, open subsoil. It makes the least progress on heavy, cold, moist, argillaceous land. The more sheltered the situation, the better are the trees enabled to develop. They do not thrive well on high-lying situations in this country; for the comparatively weak roots are not adapted to resist the influence of high winds acting with the leverage of a heavily foliaged top. The situations most farourable to its development seem to be low-lying or only moderately elevated localities, where it is not exposed to high winds. In all other respects it is as hardy a tree as even the Scots or the Austrian Pine.

Propagation and Culture. - The Corsican Pine is always in Britain propagated from seed, which ean be got in abundance from the Continent. The seeds should be sown thinly on the seed-beds, say not closer than one seed to the square inch; and as they are somewhat large, or about twice as large as those of the scots Pine, they should be corered with about three-eighths of an inch of earth, which is more than the covering of soil required hy Scots l'ine secel.

Its Sylvicultural Characteristics are practically illentical with thome already detailed with regard to the Austrian Pine, which also belongs to the Continental species of Black Pines.

The Corsican Pine is now plentiful on most estates throughout Britain, and many specinens may be found ranging from abut 60 to $80 \mathrm{ft}$. in height, and having stems of proportionate girth.

The two largest stems recorded by the Conifer Conference in 1891 were $79 \mathrm{ft}$. high and $5 \frac{3}{4} \mathrm{ft}$. in girth (at $5 \mathrm{ft}$. above the ground), and $69 \frac{1}{4} \mathrm{ft}$. high and $7 \mathrm{ft} .7 \frac{1}{2}$ in. in girth.

For monograph on the Corsican Pine, see Trans. Scot. Arbor: Socy., rol. xi., part ii., 1886, pp. 181-187. 
(4.) THE TAURIAN PINE, Pinns Pallasiana Lamb.

Srmoxras-Pinus Laricio Pallasiana Endl.; P. maritima Pall.; P. caramanica Oliv.; $P$. taurica et tatarica Hort.

Specific Character.-Leaves in twos, very long, sharp-pointed, erect, rigid, 5 to $6 \mathrm{in}$. long, and channeled above; smooth, crowded, and of a shining dark green; sheaths short, $\frac{1}{2}$ in. long, covered with scales, and tom on the margin; white when young, but dark-brown when old. Buds ovate, $1 \frac{1}{4}$ in. long, and resinous, with the sides hollow. Branches scattered irregularly along the stem, rohust, and incurved upwards; some of the lower branches are nearly equal to the stem in size. Cones, ovate-oblong, tapering to a point, without footstalks, often curved near the end, 4 or $5 \mathrm{in}$. long, and $1 \frac{3}{4} \mathrm{in}$. broad at the widest part near the base; horizontal or incurved downwards, mostly single, or in threes round the branches, and of an ash-grey colour. Seeds, middle size, with a broad wing (Gordon, op. cit., p. 175).

Distribution. - The Taurian Pine is, like the two preceding species, considered on the Continent a mere climatic variety of the comprehensive species Black Pine (P. Laricio Poir.) It seems to be confined chiefly to the central regions of the Crimea and of Asia Minor, where it forms forests of considerable extent on the western slopes of the chain of lofty mountains which runs along the coast of the Black Sea. Loudon says this species was first introduced into England by Messrs Lee \& Kennedy of the Hammersmith. Nursery, who raised a number of plants from seeds sent to them by Professor Pallas from the Crimea about 1790 .

Description of Tree.-The Taurian Pine is a large tree of spreading hal,it, which generally sends out numerous large, declining, and horizontal branches from the summit to the base, and whose lower branches often nearly equal the main stem in size. The bark becomes cracked, rugged, and brown, and then scales off. It is a rapid-growing tree, and is easily distinguishable from the other Black Pines by the huge knots formed along the stem, and by the large dimensions that some of the lower branches generally attain. The tree is perfectly hardy, and grows rapidly : it is well deserving uf a place in our parks as an ornamental object, but can hardly claim any attention from a sylvicultural point of view.

In the tracts to which it is indigenous it is to be found from the size of a small tree, hearing tiny cones, up to 100 feet in height, and bearing cones of 4 in. in length.

Economic Uses of Timber.-The timber of the Taurian Pine is said to be of a very durable nature, but, judging from the char- 
acter of the older specimens that have at times been utiliserl in this country, it must be an exceedingly dificult wod to work on account of its knottiness. Even if its rate of production were much greater, therefore, it could harlly be recommended for extensive introduction as a timber-tree, for many of the other Pines produce timlser that is equally durable, while it is rery much more easily worked up into planks.

Soil and Situation.-The Taurian Pine accommodates itself without difficulty to a considerable variety of soils, and in this respect must be allowed to possess a great advantage over many other Pines of more recent introduction. Specimens may sonetines he seen in excellent growth on poor, thin, gravelly sroils, and others again on a stiff loam; but in all cases it requires a dry and porous subsoil. It also grows well on limy soils and chalk lands, and thrives in situations near the sea-coast.

Propagation and Culture.--The seed of the Taurian Pine is easily procuralile from seedsmen on the continent of Europe, who import it from Asia Minor, and healthy plants may be reared liy sowing the seed in beds, very much in the same way as previously detailed for the common Scots Pine. Some prefer, however, to treat it in the mamer that will be nore particulinly detailed with reference to the Pyrenean Pine (see p. 277).

At varions places, both in England and Scotland, good specinens of this Pine are to be found, some of them now ranging up to over $50 \mathrm{ft}$. in height, and having a girth of over $7 \frac{1}{3} \mathrm{ft}$. at $5 \mathrm{ft}$. above the ground.

\section{(5.) THE CLUSTER or MARITIME PINE, I'inus Pincht, siland.}

Syxoxrus-Pinus maritima Lamk., Poir., DC.; P. Pinaster Loud., Link., Endl., Carr.

Specific Character.-Leaves in twos, dark green, 6 to $S$ in. long, rigid, lroad, and very stont, slightly serrated on the marnin. and thickly set on the branches in dense whorls; sheaths $\frac{3}{4}$ in. long, imbricated, and pale yellow when young, but turning nearly black when old; buds $\frac{3}{4}$ in. long, white, woolly, imbricated, and nonresinous, with the scales turned back at the points. Cones from 4 to $6 \mathrm{in}$. long and $2 \frac{1}{2}$ in. wide at the broadest part, which is below the middle, and of a light shining brown colour, and growing in clusters of from 4 to 8 , but sometimes more in number, in a horizontal direction, and without any footstalks. Seeds oblong, with wings $1 \frac{1}{2} \mathrm{in}$. long, and nearly $1 \mathrm{in}$. broad. Seed-leaves from 7 to 8 in number (Gordon, op. cit., p. 177).

Distribution. - The Pinaster is indigenous to the south of Europe and to both shores of the Mediterranean: from cireece it 
extends eastwards into the western portion of Asia. It is most abundant in Spain, and along the shores of the Mediterranean. It was introduced into Britain in 1596.

From Portugal to eastern Greece, and from Dalmatia to Algiers, its natural distribution extends over more than $30^{\circ}$ of longitude and $10^{\circ}$ of latitude. But it is principally to be found on islands, and upon stretches of country within the influence of a purely sea-board or insular climate, where it frequently forms almost pure woods, as well as mixed forests in association with the Black Pines and broad-leaved species of trees. Willkomm considers (op. cit., p. 235) that the climatic conditions for its growth are a mean annual temperature not below $53 \frac{1}{2}^{\circ}$ Fahr., and a mean winter-temperature of at least $43^{\circ}$ Fahr.

Description of Tree. - The Pinaster or Maritime P'ine is a lare and rather hamkinne tree, closely resmbling the black l'ines in general appearance, which attains in Britain a height of from 40 to 60 and even $70 \mathrm{ft}$., with stems of from 2 to $3 \mathrm{ft}$. in diameter. When standing alone, it forms a wide-spreading tree of massive appearance. The stem is clothed with a deeply furrowed coarse bark, which gives the tree at all stages of its growth a peculiarly rugged aspect. The branches are in regular whorls, and always turn somewhat upwards. The leaves are in pairs, and generally from 6 to 8 in. long, although sometimes they are found nearly $1 \mathrm{ft}$. in length (see Fig. 52). Groups of cones, varying from three to eight in number, point outwards in star-like clusters, and hence the name of Cluster Pine.

This tree has a decided tap-root, which goes deep into the soil, when that is dry and favourable for its development; but its lateral roots are generally weak in proportion to the size of the tap-root, and from this circumstance, as well as from the tree forming a heavy densely foliaged crown, it is generally found leaning over somewhat to one side, in place of being quite erect and perpendicular. It is a very hardy tree in all low-lying situations throughout Britain; but it is not suited for planting on exposed, highly elevated parts of the country. Yet no tree of the Pine genus is better adapted than the Cluster Pine for growth as a crop along the sea-shore. In such situations it can withstand the blasting influences of the strongest sea-breezes of our climate; and in this respect it is one of the most nseful trees we have. This Pine, named Pin maritime, has been much used in France in covering immense tracts of barren sandy grounds, especially the Landes or wastes situated to the south of Bordeaux, on the Gulf of Gascony. These Landes are composed of chittines sands, and have leen covered by thriving plintations of this tree, which are now said to be very valuable, both for the timber 
Fig. 52.

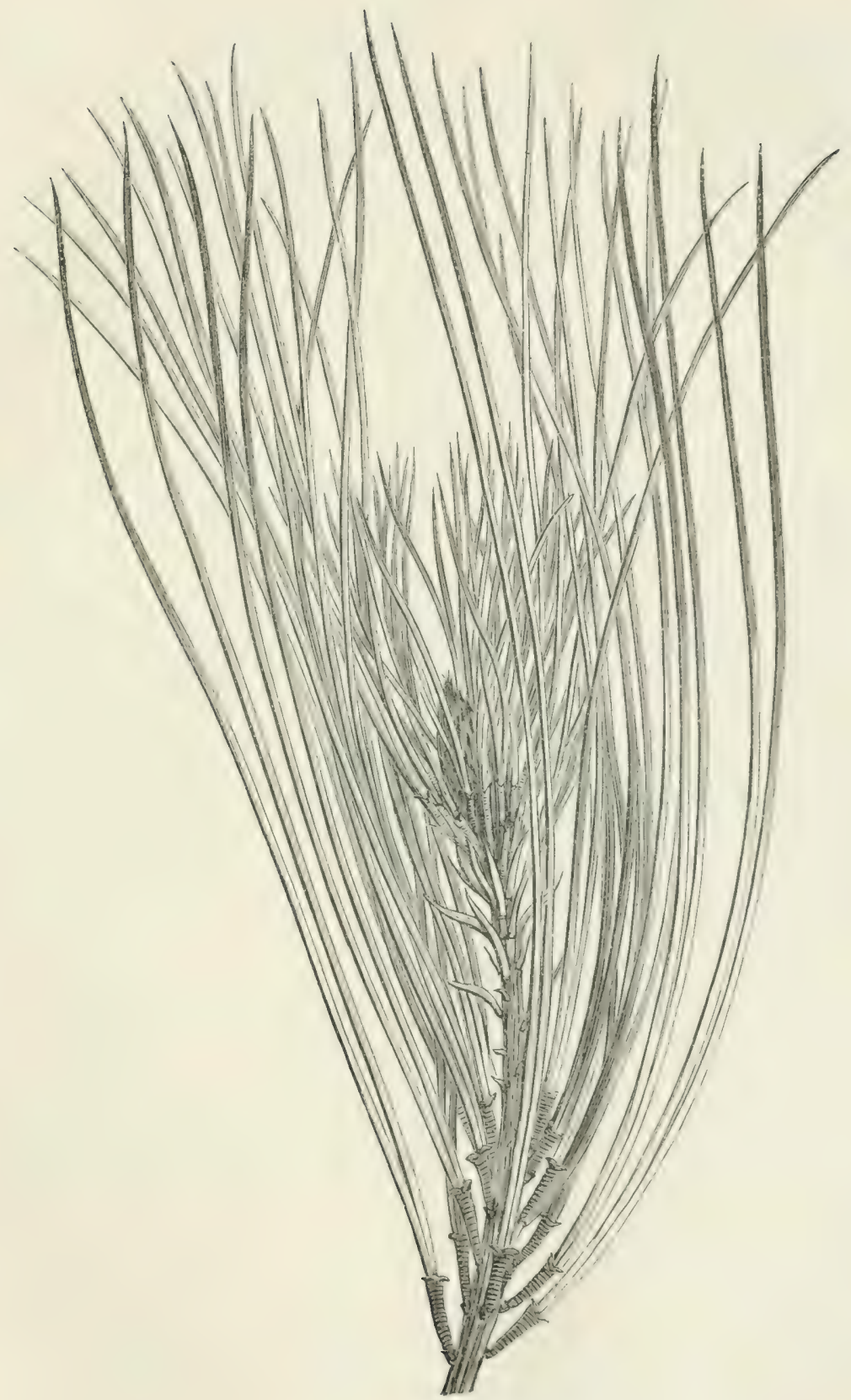

Spray of the Cluster Pine (Pinus Pinaster). 
they produce and on account of the resin and tar prepared from them, as well as for the shelter provided for agriculture.

The Maritime Pine is, at all stages of its growth, of a very. branching and spreading character. When it is planted along the sea-shore, and has plenty of room to develop its branching habit, it therefore forms the best possible protection for the rearing of more valuable and less hardy trees in the lee of this cover; but if the trees forming such an outer belt or fringe be confined in growth, or limited in individual growing-space, they show their natural tendencies as a distinctly light-demanding species, lose their branches very quickly, and soon assume a drawn-up and weakly appearance. Hence in the cultivation of the Cluster Pine great attention should be given to keeping the crowns of the individual trees clear of each other at all stages of their development.

In the regions where it is indigenous the Pinaster sometimes attains a height of over 90 to $100 \mathrm{ft}$., and a girth of 12 to $15 \mathrm{ft}$. It also has considerable longevity, although not so largely endowed with vital power as the Black Pines.

Economic Uses of Timber.-The wood of the Pinaster is soft and by no means of a durable nature; this species is therefore not to be recommended as a sylvicultural crop, seeing that in this respect it is far surpassed by the Black Pines, as well as by our indigenous Scots I'ine, which even in the comparatively early stages of its growth yields a better class of timber. In the south of France and in Spain, where it abounds, the wood of the tree is, however, much used for various purposes, such as for boards and scantling, and for the making of packing-boxes.

Over 125,000 acres of these barren Gascon Landes have been planted up with the Maritime Pine, which, besides improving the national-economic and agricultural capacity of the district, has given rise to a great industry in timber, and in the manufacture of "French turpentine." Its richness in resin is, however, dependent on a warm climate. Being of rapid growth, the wood has broad annual rings, but is coarse in fibre; the heartwood is reddish-brown, very resinous, and heavy, though of comparatively little elasticity or durability.

Soil and Situation.-A deep, dry, sandy soil, or even a light loam, that is always porous and dry in the subsoil, is most suitable for this tree. It does not do well on chalk, nor on any description of calcareous soil. With respect to situation, the nearer it is to the level of the sea, the more thriving will be its growth. As already stated, it will not thrive in Britain on any inland or lofty situation away from the sea: on such localities it invariably languishes and 
dies off prematurely; but near the coast, where the wintry cold is mitigated by the comparatively mild sea air, it is hardy enough.

Propagation and Culture.-The P'inaster begins to produce seed on the Landes as early as its fifteenth year. In Britain it is propagaterl from the seed, which is generally procured from the continent of Europe. The seeds are somewhat large, and when placed in the bed ought to be covered with about three-ryarters of an inch of fine earth. They should be sown about the middle of April; or, when the season is late or spring frosts may be apprehenderl, the sowing may even be delayed until the beginning of May. The young seerllings germinate quickly, and develop comparatively rapidly whilst of yearling growth. They should be transplanted out into nurseryrows when one year old, and after they have thus been schooler for one year, they should be lifted again in the following May, and then bediled for a second time, in order to stimulate them to make filmous roots. When they have been twice transplanted, and have attained three years of age, they will be ready for planting finally into the open.

The Maritime Pine possesses little sylvicultural interest for Britain, except as a means of forming woods for shelter along coast districts, so as to enable other species of crops to thrive better under their lee. For this purpose it can be advantageously utilised in admixture with Black Pines (see p. 262).

Good specimens of the Pinaster or Maritime Pine are to be found in most parts of Britain, and of course more especially on estates that lie near the sea-coast. But in exposed-parts its length of life is very short.

The largest stem recorded by the Conifer Conference in 1891 had a height of $68 \mathrm{ft}$., and a girth of $10 \mathrm{ft}$. at $5 \mathrm{ft}$. from the ground.

(6.) THE RESINOUS or RED PINE, Pinus resinosa, Soland.

Srnonxi-P. muba Mich.

Specific Character.-Leaves in twos, 5 or $6 \mathrm{in.}$ long, straight, stift, yellowish-green, thickly set on the shoots, compressed, and collected in bunches at the extremities of the branches; sheaths, nearly 1 in. long, white on the young leaves, but shorter, jagged, and darker with age on the older ones. Branches, rather maked, straight, open, and reddish-brown, the larger ones on the trunk more distant than those of the Corsican Pine (P. Laricio); buds, long, pointed, and very resinous. Cones, pale reshlish-hrown, shining, hard, ovate-conical, rounded at the base, 2 in. long, $1 \frac{1}{t} \mathrm{in.}$ lirual, and with rery short footstallis. Seenls small, with the wing $f$ in. long (Gordon, op. cit., p. 183).

VOL. I. 
Distribution.-The Red Pine is found in Canada, Nova Scotia, and the Northern States of the North American Union. It is never found growing to a large extent in any particular part of its native forests, but only in comparatively small patches as portions of the crop here and there, and never covering many acres in extent in any one place. It is seldom found intermixed with other Pines, or with any other kinds of trees, but is generally to be met with alone, and always on dry, gravelly, sandy, or rocky soil, never on flat land with a moist subsoil. It was introduced into Britain in 1756 .

Description of Tree.-The timber of the Red Pine, which must not be confounded with the Redwood jielded by the Sequoic sompervirens of California, is decidedly the best produced in the American woods; and besides the good quality of its timber, it is also a handsome tree when standing alone with its branches well extended. When fully developed, this tree has a distinctive character from all other Pines; for its leaves or needles are borne in dense bunches on the ends of the branches, which gives it a peculiar outline, differing from that of all the other trees of this genus. It should therefore be at once recognisable, even at a distance, when found growing among other Pines. In the American forests groups of the Red Pine may always, even as far off as about 400 or 500 yards, be distinguished from other Pines by the redness of their bark and by the tufted appearance of their leaves on the ends of the branches. This species never attains very large dimensions even in its native forests; it is there seldom to be found of more than $80 \mathrm{ft}$. in height, and with stems of from 18 to $30 \mathrm{in}$. in diameter at $5 \mathrm{ft}$. from the ground. Specimens are, however, occasionally to be seen measuring about $3 \mathrm{ft}$. in diameter at $5 \mathrm{ft}$. from the ground; but these are evidently very old parent stems, for other trees of the same species are usually to be found growing round about it, but with a diameter not aloove $15 \mathrm{in}$. to $2 \mathrm{ft}$.

The leaves or needles are thickly set on the ends of the young liranchlets, while ther are but thinly scattered on the ohler hranehe; and this circumstance gives the tree the peculiar character above mentioned. On examining the foliage, the needles will be found to have very much the appearance of those of the Corsican Pine; but they are much lighter in colour. The Corsican Pine is the only one of the Black Pines for which it may easily be mistaken; but it is

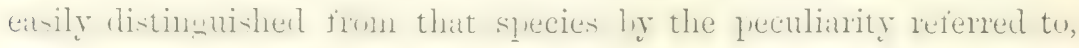
and by the tree being much more open and light in its whole aspect and habit of growth than the Corsican Pine.

The Red Pine has been but little cultivated in Britain as yet. Ije-inc l, bing of arhoricultural interest, it may even possess no mean 
value as a timber-tree, for its wood is of the first class; hence it may prove wortly of the attention of lander proprietors for planting on favourable sites in young plantations, not only with the ol,ject of oltaining goor timber later on, but also for ornamental effect anong other trees in parlss and throughout the resirlential portions of large estates. It is hardy in this climate, and is of a free habit of growth when put out upon a favourable soil.

Economic Uses of Timber. - The concentric circles of the wood of this tree are remarkably close, and present a fine compact grain, although unfortunately this also indicates a slow rate of growth: it is very heavy when newly cut up, and there is always a large quantity of resin in it. The timber is justly prized in Canada and the United States for its strength and durability, and it is well known in Britain under the name of Red Pine, large quantities of which are imported every year from Quebec. It is employed in inside house-finishing in America, for boat-building, and for numerous technical purposes. It cuts up into beautiful, clean timber. At saw-mills on the Ottawa stems upwards of $35 \mathrm{ft}$. long are often converted into planking without a single knot becoming exposed to view. For its useful qualities as timber, this tree cannot be too much extolled.

But the unfortunate evidence of its narrow annual rings unmistakably stamps it as a slow-growing species; and this is a matter that financial and scientific sylviculture must look to in the very first instance. It cannot, therefore, be expected to prefer such claims to the attention of the British landowner as species like the Douglas Fir and the Menzies Spruce.

Soil and Situation.-The lied l'ine attains its best derelopnent on dry, sandy, or gravelly land, or on good soil formed from rocky débris. In Canada it is seldom to be found on any other than sandy and gravelly soils, and on perfectly dry knolls and ridges. In plinnting this tree in Britain, it should therefore be put out on soils of a similar nature, and never in that or low-lying situations where there is any tendency to coldness or wetness in the subsoil. And in place of being used as an outer belt or fringe, it should be planted in the interior of plantations, where it may have shelter from the surrumeling trees; for, where indigenous, it is always found surromuled hy other trees, which afford it shelter.

Propagation and Culture.-The seed of the Teel l'ine is easily procurable from any seedsman in America. In sowing the seeds and transplanting the yearling seedlings into row in the nursery, the work should in all respects be carried out in the same way as hats already been described in respect to the propragation of the seots l'ine. What has previously been stated in detail with regard to the 
proparation and culture of that species for arboricultural purposes, is equally applicable as regards the Red Pine.

() this species there are many healthy and promising specimens in Britain: those at Kew in England, and at Castle Kennedy in sicutland, may be mentioned as probably including some of the finest.

(7.) THE PYRENEAN PINE, Pinus Laricio var. pyrenaica Loudon.

Specific Character.-Leaves in twos, rarely in threes, long, rather fine, stift, straight, and of a lright green colour, thickly set on the branches, and 6 or $7 \mathrm{in}$. long, channeled on the inner sides, and sharp-pointed; sheaths, $\frac{1}{2}$ in. long on the young leaves, smooth, entire at the margins, and dark brown, but on the old ones very short, shrivelled, rough, jagged, and nearly black. . . C Cones, $2 \frac{1}{2}$ in. long, $1 \frac{1}{4}$ in. wide, conical, tapering a little to the base, on short, slender footstalks, mostly solitary, and pointing horizontal. Seeds, rather small, with a narrow, pointed wing, $\frac{3}{4}$ in. long (Gordon, op. cit., p. 183).

Distribution. - The Pyrenean Pine seems to be confined chiefly to the Pyrenees, hence its name. It is found in the forests of both France and Spain, often occupying the highest ranges of the mountains in those countries, which accounts for its well-known hardiness in our climate, even in the north of Scotland. It is said to grow intermixed with other Pines at very lofty elevations on the Pyrenees, and to be found only in dry localities. It was introduced into Britain in 1834 .

This species, together with the Calabrian Pine $(P$. Brutia), seems very closely allied both to the Corsican Pine ( $P$. Laricio) and to the Aleppo Pine ( $P$. halepensis). The botanical distinctions between the two former are so comparively slight that Continental botanists regard them as mere climatic varieties of one species; and for a long time doubt existed as to their being anything but more or less constant varieties of the broad and comprehensive original species of Black Pines (P. Laricio).

Description of Tree.-The Pyrenean Pine is, without doubt, one of the handsomest species of the genus, forming, when well developed, a majestic tree, from 70 to $80 \mathrm{ft}$. high, and with a proportionate girth of stem. It is a highly ornamental tree when found stamling alone; ior its lense masces of foliage, of a clear, transparent green colour, gives the whole tree a noble aspect, and creates a very striking effect. It is very hardy, and grows to a considerable size in a comparatively short time; consequently it may be recommended for extensive planting in Britain as an ornamental tree, for which purpose it is well adapted. 
It is easily recognised from the other species of the coniferous family by the beautirul transparent colour of its bark and foliage, and by its cones growing for the most part singly on the young shoots. The leaves or needles are long and fine, but very strong and upright, and are arranged round the branches like the hairs of a camel-hair pencil. The branches are strut and of a bright orange colour, and the buds are conical, with a long tapering point, covered with downy scales, and full of resin. The tree when young resembles the Aleppo Pine (P. halepensis) in appearance; lut when it becones older it grows more rapilly, attains a greater height, and assunnes a more pyramidal form. The cones also resemble those of the Aleppo Pine in having strong footstalks; but instead of pointing downwards, they are always in a horizontal position. These distinctive marks should be sufficient to enable this beautiful Pine to be easily distinguished from all the others.

Economic Uses of Timber.-The timber of the I'yrenean Pine is said to be white and dry, and nearly without turpentine. It was in former days much used by the Spanish Government in the arsenals of Carthagena and Cadiz for decking ships; but, on the whole, it is of inferior quality as compared with the wood of many of the other Pines now grown in Britain. The place of this tree in British rural economy is therefore merely that of an ormamental species in arboreta, parks, and lawns, or along the sides of roads in plantations. For such purely arboricultural purposes it is as well adapted as any other species of Pine.

Soil and Situation.-The Pyrenean Pine thrives well and makes rapid growth on most soils that are of a fairly loamy character, and dry; but the best specimens are usually to be found growing on a light, deep, dry, sandy loam. Although the tree is perfectly hardy in our climate, still it requires to be sheltered by other trees in order to attain its full development to the majestic proportions to which it is capable of expanding.

Propagation and Culture.-The seed of the Pyrenean Pine is procurable from the Continent, and may he had from any respectable seedsman there at a molerate cost. It should be sown in beils, or in a bed, according to quantity, in the same way as has been already detailed with reference to the arboricultural treatment of the Scots Pine. The yearling seedlings should be planted out in the mursery-rows much in the manner recommended for the plants of the Common Pine, and shoukl be kept in the nursery-beds until large enough to be transplanted into their permanent sites. Some sow the seeds of this and other of the newer l'ines in cold frames, and in boxes in glass houses; but, where it can be aroiled, this mole of treatment should not be adopted, as by far the healthiest and hardiest plints of the 
coniferous species of trees are procured by sowing the seeds on the open ground, just in the usual way adopted with the Scots Pine.

In propagating all the newer Coniferæ, however, a good plan is to shade the beds by a cloth stretched over them, and fixed on iron or wooden pins made for the purpose. This cloth or canvas may be of any convenient kind, and should be stretched about $1 \mathrm{ft}$. above the surface of the beds. By being thus shaded, the seed germinates better than when fully exposed to the sunlight; but as soon as the seent has sprouted and the young plants appear, the sun-shades should always be removed during cloudy weather. (See also remarks on 1. : :12.)

At many places, both in England and Scotland, there are thriving and ormanental specimens of this tree to be found, especially at Dropmore, Hopetoun House, Keir, and Castle Kennedy.

The largest specimen reported to the Conifer Conference of 1891 was 35 $\mathrm{ft}$. high, and had a girth of $5 \frac{1}{3} \mathrm{ft}$. at $5 \mathrm{ft}$. above the ground.

(8.) THE CATABRIAN PINE, Pinus pyrenaica Lapeyrouse.

Srxoxrsis-Pinus Paroliana WTebb; P. Loiselouriana ct pyrenaica Carr.; P. Parolinii Vis.; P. hispanica Cook.

Specific Character.-Leaves or needles in twos, rarely in threes, from 6 to 8 in. long, very slender and wavy, glabrous, spreading, channeled above and convex below, serrulated on the margins, with a sharp point, and of a bright-green colour. Sheaths $\frac{1}{2}$ in. long, of an ash-colour, quite entire, and not falling off. Buds $\frac{3}{4}$ of an inch long, pointed, woolly, and free from resinous matter. Cones stalkless, cenerally in laree clusters, hut sometimes singly on young trees, ovate, and smooth, 2 to $3 \mathrm{in}$. long, and flattened at the base, of a deep-brown colour, and remaining on the tree for years. Scales depressed, umbilicate, and slightly concave at the apex (Gordon, op. cit., p. 164).

Distribution.-The Calabrian Pine is said to be found in Calabria, on the mountain of Aspero, at an elevation of from 2400 to $2600 \mathrm{ft}$.

It occurs also in Cyprus, Crete, Asia Minor, and Syria as well as in Southern Italy, and is by Continental botanists regarded merely as a climatic variety of the last species, the Pyrenean Pine (P. pyrenaica); whilst both of these were formerly taken to be but varieties of the comprehensive species Black Pine (P. Laricio).

Description of Tree.-The Calabrian Pine is a tree of only medium size, and not always even of the second magnitude. It has many large and spreading branches, thickly set with long, brightgreen folinge. The bark is of a greyish-brown colour, smooth, but 
covered with depresserl tubercles. It resembles the Alepur Pine ( $P$. heelepensis), but is easily clistinguishalde therefrom by its leaves or needles being of nearly doulble the length, and by its crnes lecing without stalks, and growing in large clusters. The habit of the tree somewhat resembles that of the Corsican P'ine ( $I$ '. Leteririo) at first sight; but a slight examination of the leaves shows the difference at once, those of the Calabrian Pine being very much nore slender and somewhat longer than those of the Corsican Pine. It is quite hardy in most parts of Britain, and forms a handsome, wary-leared, ornamental tree.

Economic Uses of Timber.-The timber of the Cilal,rian I'ine is said to be of excellent quality; but as there are 110 mature trees of this species in Britain, no judgment can be formed as to the cuality of the rood produced by it in our climate.

As compared with many other coniferous species of comparatively recent introduction, however, it has no claims to offer for sylvicultural attention on any large scale; its value is purely that attachable to a tree of some arboricultural interest.

Soil and Situation.-The Calabrian Pine thrives well on most soils of any dry light character, when it has the advantage of a mild, favourable exposure, and enjoys a moderate amount of shelter. It forms a fine ornamental tree, and is well worthy of a place in every arboretum.

Propagation and Culture.-The seed of this Pine is procuratle through seedsmen on the Continent. It does well when sown on any warm-lying piece of ground, of a light and fine description; but richness of the soil is apt to stimulate the seedlings to abnormal growth in height, which predisposes them to disease, and makes them over-sensitive. Otherwise, the young schooled plants are hardy and accommolating, and are fit for transplanting into their permanent sites in the third or fourth year, according to the size that may be wanted. Seeds of this Pine are now comparatively plentiful, and the plants are therefore not nearly so high-priced is they formerly were.

At IBicton, Devonshire, and at C'astle Kennedy in Wigtowushire, there are good specimens of the Calabrian Pine, ranging from 40 to $50 \mathrm{ft}$. in height.

(9.) THE MUGHO PINE, Pinus NIugho Poir.

Srxomrus-Pinus montana Du Roi and Mill.; P. Pumilio Mughus Loud.; P. Mughus Scop. and Forb. ; P. uncinata Gand.; P. humilis Link.

Specific Character.-Leares or needles two in a sheath, from 1 to $2 \mathrm{in.}$ long, twisted, rather liroul, stiff, and of a chll green colour. 
Cones $1 \frac{1}{2}$ to $2 \mathrm{in}$. long, ovate and stalkless, growing 2 or 3 together, rather erect, with hooked scales, more fully developed on the outer side, and full of resinous matter. Branches ascending and numerous, thickly covered with foliage, and with a greyish-brown bark (Gordon, op. cit., p. 172).

Distribution. - The Mugho Pine is found on the mountains extencling from the Pyrenees eastwards into the $A$ lps of central Europe. This particular Mugho kind is more especially to be found in the I'yrenees and the southern Alps, whilst the other species of Mountain Pine, the P. Prmilio, is more common in the colder northern Alps, in Bohemia, and in the Black Forest. The former is principally found on the drier localities, whilst the latter is more often in the occupation of marshy land. It was introduced into Britain in 1785.

Under the comprehensive specific name of Mountain Pine (Pinus montana Du Roi and Mill.) numerous varieties are now included in one species by Continental botanists and arboriculturists. These varieties include $P$. ILughus Scop.; P. Pumilio Hänke; and $P$. uncinata Gand., which, however, are usually kept distinct by British nurserymen.

Description of Tree.-The Mugho Pine is of a low, spreading, dwarfish habit of growth, seldom being found more than from 20 to $25 \mathrm{ft}$. high, and more frequently only from 10 to $15 \mathrm{ft}$. in height; in fact, generally speaking, it forms only a mere bush or shrub. This species is readily known from all other Pines by its numerous asconding branches, which are thickly covered with dark-green leaves or needles, forming, as it were, a large bush or scrubby, stunted tree, whose main axis has become lost, and whose place is taken by many side-leaders. It can assuredly not be considered in the light of a timber-tree, for it seldom has stem enough to make it valuable in this respect; but as a quaint, and in certain circumstances perhaps even an ornamental, specinen in plantations it is perhaps well deserving of a place, especially on any bare, exposed, and prominent point. Its great hardiness ensures its making a very ornamental cover on bleak treeless tracts; and even when contrasted with the lighter green of other Conifers, or with the foliage of broad-leaved trees, the very dark aneen of its foliage produces an anreeable change and a decinled effect. It is also well adapted for planting out in order to hide from view any undesirable object that may be visible from roads or walks leading through parks or lawns; for its very numerous and densely foliaged branches completely shut out from view any ohject immediately behind them.

Soil and Situation.-The Mugho Pine will succeed on any soil and situation on which the Scots Pine grows, as it is equally hardy, and is found of spontaneous growth on the same descriptions of 
land. With respect to the most suital,le soils and situations for this tree it may be remarkerl, however, that on low-lying parts of the comntry, and on a good deep sandy loan, it often develops into a tree of a fair size; but on high-lying tracts, where it is much exposed, and on a poor thin soil, it forms only a many-headed bush, or a dwarfish, stunted tree.

Propagation and Culture.-The Mugho l'ine is lmoprated from seed in the same way as the Scots Pine. The seed may le collected plentifully from the older trees growing in this comntry; lut if fresh supplies be desired from its Alpine home, they can, of course, be obtained from any respectable seedsman on the Continent.

The cones should be collected early in the autumn of ripening, as they often open and scatter the seed before the end of the year.

This tree is to be found in most collections of Conifers in Britain, the specimens usually attaining a height of from 15 to $25 \mathrm{ft}$.

The largest specimen reported to the Conifer Conference in 1891 had a height of $24 \mathrm{ft}$., and a girth of $2 \mathrm{ft} .10 \mathrm{in}$. at $5 \mathrm{ft}$. above the ground.

(10.) THE DWARF or MOUNTAIN PINE, Pinus Punilin Hünke.

Srronrus-Pinus montana Walth.; P. Mughus var. Pumilio Koch; P. sylvestris var. Pumilio Gand.; $P$. magellensis Schouw.; $P$. uliginosa Neum.

Specific Character.-Leaves two in a sheath, curved, short, stiff, somewhat twisted, thickly set on the branches, from 2 to $2 \frac{1}{2}$ in. long, with long, lacerated, woolly, white sheaths when young, but which afterwards, as they get older, become much shorter, and dark brown, or nearly black. Cones from $1 \frac{1}{2}$ to $2 \mathrm{in}$. long and $\frac{3}{4}$ in. broad near the base, two or three growing together, pendulous, of a dull brown colour, and bluntly egg-shaped. Scales about the size of those of the Scots Pine, but not so much elevated in the centre. Branches turned uptwards, and very numerous, forming a dense bush, with the lower branches creeping on the ground, but growing, in favourable situations, into a small tree from 20 to $30 \mathrm{ft}$. high, with a grey and rather smooth bark (Gordon, op. cit., p. 180).

Distribution. - The Dwarf Pine is found on the mountains of central Europe, on the southern slopes of the Alps towarls the east, and beyond the usual limits of trees, but scarcely lower than $\$ 000$ ft. of elevation, nor higher than $7500 \mathrm{ft}$., where it prefer's a swampy soil. It also grows on the northern slopes of the Alps, and is very common on the Carpathians, where it occupies a region above the Common spruce Fir; but at great elevations it becomes merely a stemless, spreading bush creeping along the ground. It was introduced into Britain in 1779. 
With regard to the distribution of this species, and to its relation to the Nugho Pine ( $P$. I Trgho), with which it forms the comprehensive Continental species Pinus montana, see the detailed description of the preceding tree.

Description of Tree. - This species of Mountain Pine assumes more the character of a handsome evergreen shrub than of a tree; and on this account it is very interesting as a variety among, and a contrast to, most other Pines or trees of a taller habit of growth. The aspect of the Mountain Pine, when it is seen among the giants of its tribe, can hardly fail to elicit admiration; for it relieves the monotony and sameness of character that the latter liesent when they are viewed as a whole among themselves. It forms a beautiful bush when planted in woods, or along the sides of roads running through them, and in such situations contrasts pleasantly with the outlines of the taller trees forming the background: it is in such positions that its use may be chiefly recommended. It closely resembles Scots Pine of low dwarfish growth (for which reason it received one of its synonymous botanical names, $P$. sylvestris var. Pumilio); but it is somewhat less glaucous or pale bluish-green in the general appearance of its foliage. The leaves or needles are also much more thickly set on the branches than with the Scots Pine, and the sheaths on the leaves of the current year are much longer and whiter, especially towards the extremities of the shoots. In short, this species is readily recognised. from all the others of the Pine genus by these detailed characteristics of the leaves and buds; but in order to assist the young forester still further in distinguishing it from other species, it may be added that the Dwarf Pine seldom makes long shoots of more than 4 in. in length in any one season. And it may further be remarked that, on breaking a branch, there exudes from the broken part a fluid resin which has a fragrant aroma, differing from the smell of the resin of other Pines even of this same Pinaster class.

Soil and Situation. - The Dwarf Pine is a very hardy species, and will grow on any soil and situation upon which the Scots Pine can maintain itself. It is by no means particular with respect either to soil or situation, and it is found to thrive well on most descriptions of land. Still, in order to enable it to attain its best development, it should be planted behind the shelter of other trees, or in such situations as along the sides of roads or of walks leading through plantations, as there the vigour of its foliage is increased by the shelter afforded it. When seen among hard-wooded trees, and especially in winter, when the latter are bare, it forms a dense, ormamental, and very large and spreading bush of rather pleasing appearance.

Propagation and Culture.-The Iowarf l'ine proluces its seeds 
at the same time of the year as the Common I'ine: in order to frocure the seeds, the cones should le gatherer and treated in very much the same mamner as has alrearly heen detailerl with regard tr that species (see p. 257). The seed should be sown in the nursery in the same way as the seerls of the Common l'ine: lut they should be covered up more lightly with soil, as they are smaller.

Along with the Mugho Pine (which equally deserves the name of Ifrentrin P'ine) this Dwarf species is of inmence national-econmic imprortance thronghout the Alpine districts, where it forms the upper linit of tree-growth in the "ban-forests" maintained as State property" for the preventim of the formation of avalanches, and for the protection of the agricultural lanuls lying far off in the plains below. In the Tyrol and Vorarlberg alone, more than $7 \tau, 000$ acres are stocked chiefly with these Mountain P'ines, whose sprealling, tough branches, and dense foliage, keep back the snow, and whose rootsystems bind the soil whilst it is sodden with rain or melted snow.

At Dropmore this species is found to grow to fully $20 \mathrm{ft}$. in height; whilst at Castle Kennedy specimens of the same age are only about 10 or $12 \mathrm{ft}$. in height. At various other places, both in Scotland and England, it is found varying from 12 to $20 \mathrm{ft}$. in height, and forming wide-spreading bushes, or dwarfish, stunted trees, of a very ornamental character.

\section{(11.) THE JERSEY or SCRUB PINE, Pinus inops Soland.}

Srxonras-Pinus variabilis Lamb; P. virginiana Mill.

Specific Character.-Leaves in twos, short, rigid, and sharppointed; from 2 to $2 \frac{1}{2} \mathrm{in}$. long, hright-green, and scattered equally all over the younger branches. Sheaths short, entire, and aljout $\frac{1}{4}$ in. long. Branches irregularly placed on the stem, twisted, with the more slender branchlets pendulous, and the young shoots corereil with a fine, violet, glaucous bloom. Buls blunt-pointed and resinous; the stem and larger branches emitting tufts of leaves or albortive shoots. Cones oblone-conical, tapering slightly to a blunt point, and drooping; from $2 \frac{3}{4}$ to $3 \mathrm{in}$. long, and $1 \frac{1}{4} \mathrm{in}$. broad, very hard, and of a glossy yellowish-brown colour, with short, thick foutstalks. and usually solitary. Scales elevated, priminilal, t-silert, teminating in an awl-shaped, strong, projecting prickle, pointing ontwands on slightly reflexed, $\frac{1}{2}$ in. broad, and nearly all of a size. Seeds very small, with a narrow wing, rather more than $\frac{1}{2}$ in. long. Seed-leares from 6 to 8 in number (Gordon, op. cit., p. 167).

Distribution. - The Scrub Pine is found rery abundantly throughout most of the Northern States of America from the Hudson liver down southwards into Carolina, and especially wher- 
ever the soil is of a poor and sandy description. In such situations it grows to a height of from 15 to $30 \mathrm{ft}$., or sometimes even $40 \mathrm{ft}$. In the harren trats of New Jersey, in particular, this species covers lange tractis of waste land, which are linown as the "Pine Barrens." It was introduced into Britain in 1739.

Description of Tree. - The Jersey or Scrub l'ine forms a tortuousbranched low tree, having a large portion of the more slender lranches peendulous, and the wood of the shoots of the current rear very glaucous, and tinged with violet-a characteristic which may be said to be almost peculiar to this species-while the stem and larger branches produce small tufts of leaves or abortive shoots. The branches grow from the stem, not in whorls, but irregularly, more in the manner of deciduous trees than is usual with the majority of the Abitincer. The bark in old trees is deeply furrowed, and through the fissures resin exudes in such abundance as to give the stem and branches the appearance of being candied over with sugar.

The appearance of this tree is strikingly peculiar, as the whole plant, when old; is almost covered with the exuding resin, which emits a very pleasant fragrance or balsamic odour, especially during sunny weather. From these peculiarities this species is easily recognisable from all other Pines.

It cannot be recommended as a timber-producing tree; but it well deserves a place along the sides of roads in woods and plantations, where its singularity of form and its delightful fragrance would give it an interest and make it worth cultivating from an iesthetic and ornamental point of view. And at the same time it is a very hardy species. In Britain the resinous matter does not exude nearly so plentifully as is the case in America, where the sum is warmer and altogether more powerful.

Soil and Situation.-Although in its indigenous home this tree is generally found only on dry sandy wastes, still it will grow and thrive on most lands that are of a dry, light character. It develops best in Britain when planted within the influence of the shelter of other trees, and on such situations as along the sides of roads in plantations.

Propagation and Culture.-The seed of the Jersey Pine is easily procurable from America. It should be sown on fine, light, dry, and well-prepared ground; and, as the seeds are small, they should only be covered very slightly with soil.

In various parts of England the Jersey Pine has attained heights of about $30 \mathrm{ft}$. Some of the best known specimens are at Kew and in the Derby Arboretum in England, and at Castle Kennedy in Scotland. 
(12.) BISHOP'S PINE, Pinus muricata Don.

Sxyoxyss-Pinus Edgariana Hartweg.

Specific Character.-Leaves in twos, not very thickly set on the lnanches; from $3 \frac{1}{2}$ to $t \mathrm{in}$. long; very stiff, rather broarl, luluntpointed; hollow on the inner side, round on the outer, and of a deep-rreen colour. The sheaths are rather short, smooth, and not more than $1:$ in. in length on the young leaves, and only slightly persistent on the older ones. Seed-leaves on the young plants in fives, and rather short. Branches not rery numerous, lut toleral,ly stout, and rather irregular. Buds below the middle size, inblricated, much pointed, and destitute of resinous matter. Cones in clusters of from 4 to 7 , and set in whorls round the stem. They are reddish brown when young, but change to a grey or ash colour when old; somewhat pendulous, and nearly straight, or very slightly incurver on the side next the branch; 3 in. in length, and $1 \frac{1}{2} \mathrm{in}$. broad near the base, and tapering to rather a blunt point. The base is slightly uneven, and the cone sessile, or nearly so. Scales largest on the outer side of the cone, particularly those near the base, where they are conical, nearly straight, or slightly bent backwards near the lase, much elongated, pointed, and $\frac{1}{2} \mathrm{in}$. in length; the scales on the immer side of the cone, and at the point, are much the smallest, quadrangular, and nearly flat, except those near the point, which are rather more elevated than the others, with a slight rilge rumning across their middle, terminated by a short, straight, broal prickle in the centre: each cone contains from 9 to 10 rows of scales, within each of which are two very small dark-brown seeds, with wings $\frac{1}{2}$ an in. long (Gordon, op. cit., p. 173).

Distribution.-This is a very distinct Pine, and was first discorered by Coulter at San Luis Obispo, in Tpper California, to the south of Monterey, at an elevation of $: 3000 \mathrm{ft}$, and within ten miles of the sea-shore. Hartweg also found it growing on the western declivity of the mountains near MIonterey, and within three niles of the sea-shore. Jeffrey found it on the Siskyon Mountains, in California, at an elevation of $7500 \mathrm{ft}$, growing in moist soil near the summit. It was introduced into Britain in 1848 .

Description of Tree._Bishop's Pine does not attain large dimensions, but only develops into rather a dwirfish, stunter linel of tree; it is seldom found above $40 \mathrm{ft}$. in height, and forms a stem of about $12 \mathrm{in}$. in diameter. It has very much the appearance of the Tiemarkable l'ine (Pines insignis) at first slance: but, when closely inspected, it will be foumel to be quite a distinct tree. It is a hirity species, and is well deserving of a place in parkis, and along the sides of ronds in plintations; for though of small size, it is an ornamental tree. 
Economic Uses of Timber.-Bishop's Pine has no sylvicultural value for Britain, as it does not attain the dimensions of a timber-tree. It is merely as an ornamental species that it can be recommentenl, and for purely arhoricultural purposes it deserves some little attention.

Soil and Situation.-This species grows well on any good light soil; but in our climate it requires a good and sheltered site, where at the same time it can have free exposure to light and air. It does not stand confinement among larger trees.

Propagation and Culture.-Bishop's l'ine is raised from seeds procurable through American seedsmen. Even in California, its native region, it is not found very plentifully; therefore the seeds are scarce, compared with those of some other kinds, and are still somerwhat high-priced. As the seeds are small, they should be sown on finely prepared soil, and but slightly covered with earth. After sowing, the bed should be shaded by a canvas cloth or sun-shade stretched over it, or covered with an awning of Spruce branches, in order to prevent the sun and weather from injuring the seeds before they germinate. As soon as the young seedlings begin to appear, however, the awning should be gradually removed. If possible, this should be commenced during dull weather; for if removed during dry, sunny weather, the sudden change from shade to sunlight would be certain to kill off a large proportion of the tender seedlings. None of the seeds of the newer Coniferæ should be sown till well on in the month of April, or even until the 1st of May; for if sown out earlier, the young seedlings are very apt to be injured by late frosts in our uncertain climate.

Specimens of Bishop's Pine are plentiful in all good collections of the newer Coniferæ, and many of them have attained heights of over $30 \mathrm{ft}$.

(13.) THE PERSIAN PINE, Pinus persica Strangways.

Specific Character.-Leaves or needles in twos, twisted, rather stiff, sharp-pointed, and not spreading; dense, and tufted towards the ends of the branches; of various lengths, from 2 to $5 \mathrm{in}$. long, deep green, channelled on the inner side, and convex on the outer one, with the edges rough and finely serrated; seldom remaining longer on the tree than the second year. Sheaths persistent, short, $\frac{1}{3}$ of an in. long, rather smooth, but shrivelled, not jagged at the ends, and guarded at the base with rather a broad, lanceolate, recurved scale, of a bright-brown colour, although green at first. Cones ovate, tapering to a very blunt point, and rounded at the base, $5 \mathrm{in}$. long and $3 \mathrm{in}$. across at the widest part; mostly in clusters round the stem or juincipal tn, branches, but frequently solitary, and printing down- 
wards; of a dull sreyish-l,rown colour, with a hard smorth surface, short foot-stallss, and destitute of resinous matter. Sicales slightly elevated, nearly $1 \mathrm{in}$. hroal, with apex depenserl, and hollowerl in the centre. Seeds large, with a broad wing $1 \frac{1}{2}$ in. long. Branches regular, short, and rather slender, but mostly pointing upwards; the larger and older branches rather naked on the lower parts, but tufted with leaves towards the points. Buds imbricated, very thready, and free from resin (Gordon, op. cit., p. 176).

Distribution.-This species is a native of the south of Persia, whence it was introduced into Britain by the Hon. W. F. Strangways.

Description of Tree.-The Persian Pine very much resembles the Aleppo Pine ( $P$. Tukepensis), but is readily distinguishable fron that by its longer and stiffer leaves, and by their being somewhat twisted, which is not the case with the leaves of the latter. The cones of this tree are also much larger than those of the Aleppo Pine; and whilst the latter is generally a tree of a low and spreading habit of growth, the Persian Pine is of a freer development, attains large dimensions, and is tolerably hardy.

Economic Uses of Timber.-In Britain there are no specimens of this tree that have attained sufficient size to enable a correct judgment to be formed as to the quality of its timber. So far as experience has gone, however, it is not at all probable that it can ever be of any real sylvicultural value to us, or become of much use on account of its timber. Although it is hardy enough to grow as an ornamental specimen on sheltered and warm-lying sites, it is by no means adapted for growing even on moderately elevated and exposed sites; and it can never compete with Conifers like the Douglas Fir and the Menzies Spruce, either in quantity or quality of the timber produced.

Soil and Situation. - The Persian Pine requires a deep, dry, light loam, and at the same time a warm and sheltered site, before it can thrive well.

Propagation and Culture.-The seed of the Persian P'ine is at: yet very scarce, and is only procurable throngh seed-merchants on the Continent. When obtained, it should be sown on a piece of fine, light, dry soil, in a warm situation, and shaded till the young seedlings appear, after which they should gradually be exposed fully to the light and air. In some nurseries the seeds are sown in a cold frame, and the seedlings transplanted into the open sround when one year old. The young transplants require to be protected muler a frame during the first winter.

This is a very doubtful species, imperfectly known; it is probably $P$. pyrencica or $P$. halepensis. Staph, who collected in South Persia, was nerer able to recognise it. 
(14.) THE STONE PINE or UMBRELLA PINE, I'imes pince L.

Specific Character.-Leaves or needles in twos, from 5 to 8 in. long, straight, very robust, and of a deep shining green colour. On romme plints they consist of a glaucous single bract-like leaf, thickly set on the shoots, and withont any sheaths, and from amongst which afterwards spring the true leaves. Sheaths when young $\frac{1}{2} \mathrm{in}$ long, but afterwards they become torn, and reduced to half their size. Cones from 5 to $6 \mathrm{in}$. in length, and nearly round or bluntly ovate, of a pale brownish glossy colour, very solid, and not coming to maturity till the third year. Scales large, from 2 to $2 \frac{1}{2} \mathrm{in}$. in length, and $1 \stackrel{2}{2}$ in. broad, with the thickened part pyramidal, and frequently 6 -sided, but mostly having but 4 ribs, from the 4 angles, which terminate in a blunt prickle. Seeds very large, $\frac{3}{4}$ in. long, with rather a broad but very short wing. Seed-leaves from 9 to $10 \mathrm{in}$ number (Gordon, op. cit., p. 179).

Distribution.-The Stone I'ine is a native of Italy, Spain, Greece, the coast of Barbary, and some parts of western Asia. It is also found wild in the south of France, but it is doubtful if it is indigenous there, as it never forms forests, and very rarely woods of any considerable extent. It was introduced into Britain in 1548 .

In addition to being partly indigenous, and partly artificially distributed, throughout the countries bordering the Mediterranean Sea, it is also to be found on the Canary Isles and in Madeira, although it is there probably not of true spontaneous growth.

Description of Tree.-In Britain this species attains only the size of a low tree, from 20 to $25 \mathrm{ft}$. in height, and having a roundedoff and bushy appearance. Its character among other trees is, however, very striking; its long leaves and round cones produce a fine effect when the trees begin to advance in age, if this species be made to grow among other Pines of a more upright habit, or among broadleaved trees. The branches are spreading, and when old are well clothed with deep-green foliage: the whole forms a round or bushy tree, with a reddish bark, which is generally cracked and furrowed. The Stone Pine is often mistaken for the Cluster Pine (P. Pinaster), as the leaves or needles of the two trees are very much alike. The nature of the two species is, however, quite distinct; for the Cluster Pine grows up quickly into a tree of open habit and form, attaining in a few years the dimensions of a timber-tree, while the Stone Pine in all cases retains its characteristic as a large-spreading, densely foliaged bush or dwarfish tree. In the case of trees of some age, the two species are at once distinguishable by means of the cones; for in the case of the Stone Pine these are round, while in the Cluster P'ine they are conical in shape. 
In the countries in which it is indigenous the Stone-Pine can attain a height of $100 \mathrm{ft}$. and a sirth of 1 f to $20 \mathrm{ft}$, although these dimensions are unusual. It can there also attain an age of over 500 years. It begins to froduce seed about the age of twenty years, and is most prolific between it: 40 th and 60th years.

Economic Uses of Timber.-The wood of the Stone Pine is whitish, moderately resinous, and very light. It is used in Italy and in the south of France for the general purposes of carpentry and joinery; but in Britain the timber is of little or no use, and the tree can only be cultivated for its asthetic effect. Like the two Mountain Pines, it answers well for growing for the purpose of hiding objects immediately behind it, as it forms a dense bush compactly clothed with its long leaves and beatifully rounded and shining cones.

Even where indigenous, the Stone-Pine is regarded rather as a fruit-tree than as a timber-tree. Its edible seed or "Pine-nuts" are largely sold throughout the towns of Upper Italy, where they are brought to market in large quantities. One forest alone, near Ravenna-now destroyed-yielded on the average 6000 bushels of Pine-nuts annually (Willkomm, op). cit., 1). 24.2). In this respect it resembles the Gerard Pine ( $P$. Gerardirna) of northern India.

Soil and Situation. - The soil for this tree should be deep, light, and dry, and the situation sheltered and warm. The plants should not be crowded, however, but should stand free of each other; for it is a light-demanding species of tree, and when planted thickly, or in close contact with other trees, it soon loses its matural characteristics, and appears rather unsightly.

Propagation and Culture. - The seeds of the stone l'ine are procurable from the continent of Europe in great abundince. They have a very thick shell. Cultivators generally sow them in boxes in the winter time, and shelter them under a frame till spring, keeping the earth rather moist in order to soften the shell. In summer most of the seeds will come up, although a portion of them will probably remain in the earth without germinating till the second year. Some prefer to break the shells of the seels hefore sowing them; lut this operation is apt to destroy the rerminative power of much of the seext. The plants are very tender during the first two years, and require to be protected from our winters by being liept unler glass frimes. The young plants, when yearling seedlings, should be transplanted out into the open nursery-beds, and merely covereel with a frame during winter. When they are three years old they will be quite hardy enough to stand our winters, and may at that age be plinted out into their permanent sites. Like the Cluster Pine, the Stone Pine has long tap-roots, and in consenuence of this many cultivators grow them in pots singly, thereby aroiding the frequent transplanting which is

VOL. I. 
necessary in order to stimulate them to the development of fibrous roots when raised in the open nursery-beds. When grown in the open ground they require to be transplanted every spring, in order to secure fibrous roots for safe final transplanting; by this method the healthiest plants are secured.

At Derby Arboretum, at Dropmore, and at Elvaston Castle, there are fair specimens of this Pine, ranging up to over $30 \mathrm{ft}$. in height.

The largest specimen reported to the Conifer Conference in 1891 had a height of $30 \mathrm{ft}$., and a girth of $4 \mathrm{ft}$. at $5 \mathrm{ft}$. above the ground.

\section{(15.) THE ALEPPO PINE, Pinus halepensis Mill.}

\section{Srxoxras -Pinus maritima Lamb.; P. Pithyusa Strangw.; $P$. arabica Sieb.; P. Abschasica Fisch.}

Specific Character.-Leaves in twos, but sometimes in threes, of a deep green, from $2 \frac{1}{2}$ to $3 \mathrm{in}$. long, thickly set on the younger branches, and very slender, not remaining longer on the branches than two years, in consequence of which the branches of old trees have a naked appearance, and the head an open, thin, and straggling aspect. Buds $\frac{1}{4}$ of an inch long, imbricated, roundish, and entirely destitute of resin. Cones pyramidal, rounded at the base, smooth, solitary, or in pairs, $2 \frac{1}{2}$ to $3 \mathrm{in}$. long, and $1 \frac{1}{2} \mathrm{in}$. broad, inversely turned downwards, with a footstalk $\frac{3}{4}$ of an inch long (Gordon, op. cit., p. 166).

Distribution.-The Aleppo Pine is a native of Syria, in the neighbourhood of Aleppo and Jerusalem. It is found in Barbary, on the mountains of Atlas, on the hills of Provence, and in the neighbourhood of Toulon in France; it is also common in Spain. It is always found on dry, sandy, warm soil, and thrives well even among rocks, where few other trees could prosper. It was introduced into Britain in 1683 .

As a matter of fact, this species of Pine is to be found from the western coast of Portugal eastwards into Arabia and Armenia, but chiefly in the tracts bordering the Mediterranean Sea. It is much more closely allied with the Pyrenean Pine ( $P$. pyrenaica) than any other species; but while that Pine forms woods in Western Europe, this species forms forests, often pure, on the Taurus Mountains in Asia Minor, as well as on the Balearic Isles. Its finest development, however, is said to be attained on the Lebanon range, where it assumes the proportions of a tree of the first magnitude.

Description of Tree.-The Alepro I'ine may he characterised as a low, spreading tree, seldom attaining a height above $40 \mathrm{ft}$., except under very favourable circumstances. It is somewhat sensitive and 
tender in the climate of Britain, and has therefore been very little planted, although it is now a long time since it was introduced into this country. In favourable situations, however, such as at Dropmore in Bucks and several places in northern England, it liats succeeded well, and has developed into trees of no nean magnitude; some of these are considerably over $50 \mathrm{ft}$. in height, and have stems of over $15 \mathrm{in.}$ in diameter. When the tree is young it soon forms a spreading head with slender branches, and those of the last two years' growth are clothed with very fine deep-green foliage, thus giving this species a beautifully soft and wavy expression. Then it becomes old, however, the tree has a naked and stragghling character, from the foliage never remaining persistent for longer than two years. This is not a tree to be planted for the sake of its timber, but merely as a specimen in a pinetum or in a park, where diversity and variety of effect in the way of fine foliage are the chief oljects in view.

Economic Uses of Timber.-The wood of the Aleplo I'ine is white, and has a very fine grain. On the Continent the tree attains large dimensions of timber, and there the wood is considered very superior, being used in joinery, as well as for building purposes. In Britain, however, it is not adapted to grow as a timber-tree, but merely as an ornamental species, in favourable situations.

As the wood is very resinous, it is used as torches by fishermen on the Istrian coast, whilst it is also employed for the manufacture of gas for illuminating purposes. The bark is rich in tannin, and is used for dyeing (Willkomm, op cit., p. 239).

Soil and Situation.-In Britain this tree requires a light, dry soil, and a sheltered and warm situation. It does not thrive on a rich soil, as under such circunstances its growth is stimulated too rapidly; the young shoots are rendered too succulent, they do not ripen well under our sun, and consequently die off during the following winter. To grow this species at all well, even in England, it must be planted in a poor, light, dry soil, in which mineral richness is not at all likely to stimulate abnormal growth during the first three or four years after planting. Under these circunstances the plants will make but little progress for some time; but this preserves them for later development. Their woody-fibrons tissues are mostly formed only during the warm summer months, and can therefore harden well before autumn, so as conseyuently to stant our winters; hence the trees remain healthy and uninjured by cold. When the roots have become well established in the ground, the plints wrow more vigorously; and when these still retain their healthy condition, they can develop into good specimens of the tree. 
Propagation and Culture.-The seed of the Aleppo Pine is readily procured from Continental seedsmen. It requires to be sown in a warm spot, and the plants should be covered with a frame during the first two or three winters, till they are of sufficient size and hardy enough to be planted out into their permanent sites.

Fair specimens of this Pine are common in the south of England.

\section{PINES HAVING THREE LEATES OR NEEDLES IN EACH SHEATH.}

(1.) GERARD'S PINE, Pinus Gerardiana Wallich.

Specific Character.-Leaves or needles in threes, stiff, threeedged, stout, and bluntly terminating in a short point, from 3 to 5 in. long, of a bluish-green colour, and glancous when young. Sheaths short at first, and composed of dry, reddish-brown scales, but soon rolling up and falling off. Branches ascending, but the lower ones spreading, and the branchlets short, somewhat slender, and irregularly disposed. Cones of a bluish colour, ovate, oblong, or somewhat cylindrical, widest at the base, from 6 to 8 in. long, and from 12 to $15 \mathrm{in}$. in circumference near the base. Seales thick, blunt, much recurved and spiny at the points. Seeds nearly $1 \mathrm{in}$. long, cylindrical, almost wingless, pointed at both ends, of a darkbrown colour, and agreeable to eat (Gordon, op. cit., p. 195).

Distribution.-Gerard's Pine is said to be found in great abundance beyond the influence of the periodical rains, on the northern side of the Snowy Range of mountains in Kunawur, where it grows on very dry rocky ground. It is found, also, to the north of Cashmere, and on the Astor Mountains in Little Tibet. Gerard states its highest limits on the inner Himalayas to be from 10,000 to 12,000 ft. above the sea-level. It was introduced into Britain in 1815 .

Description of Tree.-Gerard's Pine develops into a large tree of conical shape, not of a tall character but of large girth of stem. It is easily recognisable from all the other three-leaved Pines by the fact that the sheaths from which the leaves proceed are scaly, and fall off very soon. Another peculiar feature of this species is its smooth, silvery-grey bark, which falls off in silky-like flakes. It is a very slow-growing Pine, but is tolerably hardy, and is therefore worthy of a place in our arboreta and parks; for its general habit of growth is sturdy and massive-looking, and contrasts pleasingly with the taller and more slender development of most of the other Pines.

Economic Uses of Timber.- Where it is indigenous, no particular value is attached to the wood of this Pine. But even if it were good and durable, this species can have no other than a purely arboricultural interest for Britain. 
Soil and Situation.-Gerard's Pine rerguires a groorl, light, and dry soil, and a warm and sheltered situation, before it can thrive in our changeahle climate. If there be any considerable degree of smokiness in the air at places where it is planted, it will not grow at all, but will dwindle and die. Like all the other Pines, it likes a clear, pure air. In this respect, however, it is even more sensitive than most of the other species, and therefore liealthy plants of it are never obtainable from nurseries near towns.

Propagation and Culture. - The seeds of the Gerard Pine can be had in great abundance from India, as there they are solil as an article of food, just in the same manner as the "Pine-nuts" of the Stone Pine ( $P$. pinca) in Italy. They should be brought home in the cones, in order to preserve their vitality unimpaired. They germinate freely when sown in a light friable soil; but the young plants in most parts require protection during the first winter, whilst they are still yearling seedlings. After they have been transplanted, howerer, they become more hardy; and in all faroutrable situations they soon become stout, strong, and fit for planting out into their permanent sites, which should invariably be such as are sheltered from prevailing winds.

Well-grown specimens of this species are still rather scarce in Britain. It is, however, to be found in most of the larger arboreta in England, and particularly at Kew, where some of the specinems are now of fair size.

\section{(2.) THE LARGE-CONED PINE, Pinus Coulteri Don.}

Srxoxras-Pinus macrocarpa Lindl.; P. Sabiniana var. Coulteri Loud.

Specific Character.-Leaves or needles in threes, stout, and rather stiff, from 9 to $12 \mathrm{in}$. long, and of a glaucous-grey colour, ribbed on the inner side, rather flat, incurved, pointed and compressed. Sheaths ragged, thready, persistent, $1 \frac{1}{2}$ in. long on the young leaves, but shorter and torn on the old ones. Branches stout, rather distant, but regularly placed in whorls on the stem, nearly horizontal, slightly elevated towards the extrenities, and tinged with violet on the young shoots. Cones conical-oblong, tapering to the point, solitary, very large, 12 to $14 \mathrm{in}$. long and $6 \mathrm{in}$. broad, very hard, smooth, pale vellow, with a polished surface, and frequently weighing from 3 to $4 \mathrm{lb}$. each (Gordon, op. cit., p. 202 ).

Distribution.-This species is indigenous to California, and is found on the mountains of Santa Lucia, near the Mission of San Antonia, within sight of the sea; it thrives at an elevation of from $\$ 000$ to $\$ 000 \mathrm{ft}$. It was introduced into Britain in $18: 32$, and, as 
its botanical name implies, its cones form a very striking feature in the character of the tree.

Description of Tree.-The Large-coned Pine is a free-growing, handsome, and hardy tree, which in its native country attains a height of from 80 to $100 \mathrm{ft}$., with a stem of from 3 to $4 \mathrm{ft}$. in diameter. This Pine is easily known from all others by its very long and stout leaves or needles, and by the branches being nearly horizontal, distant from each other, and therefore giving the tree an open and airy aspect; it is further distinguishable by the violet tinge of the bark on the young shoots. This is a species that is very much admired, as it long waring leaves give it a peculiarly graceful aspect when seen in contrast with Pines of a more densely foliaged habit, or with broad-leaved trees; whilst the glaucous grey of its foliage is seen to great advantage when the tree stands among any other species of a darker colour. It should be planted in every park and aboretum where a suitable soil and situation can be had for it; for where variety of Pine foliage is an object, there are none of the genus more ornamental or deserving of a place than the Large-coned Pine.

Economic Uses of Timber.-This species can also put forward no claim to sylvicultural attention on account of the quantity or quality of the wood produced. It can only be recommended as an interesting tree on account of the beauty of its foliage, and the unusual and striking size of its cones.

Soil and Situation.-The Large-coned Pine, although it may be said to be hardy, and is found to grow freely in many parts of the country, is somewhat capricious with regard to soil and situation. It requires a very good, deep and porous, dry, light loam, and an open, dry subsoil; while the situation must be such as to prevent the direct rays of the sun acting on it till near mid-day. Trees of this species are often found to lose their tops from the action of the sun's rays on them in the early part of the day, after a night's frost in the beginning of summer; but where such exposure can be prevented, the trees do well, keep their leaders entire, and form good ornamental specimens.

Propagation and Culture.-The seed of the Large-coned Pine may be procured either direct from seedsmen in America, or through seed-merchants on the continent of Europe, who act as their agents. Like the stone l'ine, stenllings of this species also reruire the protection of a frame during the first winter after they have come up; but when once they have been transplanted into the nursery-ground, they will be found hardy enough to stand there in the more open parts of Britain, where the climate is mild in winter.

There are many good and promising specimens of this species in 
many parts in Britain, lut more particularly at Elvaston Castle, Kew, and Cinstle Kennedy. In these places there are healthy trees of the species, of heights ranging up to $40 \mathrm{ft}$., and even more.

The largest specimen reported to the Conifer Conference in 1891 was 44 $\mathrm{ft}$. in height, and $4 \frac{1}{2} \mathrm{ft}$. in girth at $5 \mathrm{ft}$. above the ground.

(3.) THE CHINESE LACE-BARK PINE, I'ines liminna Zune.

Srxorys-Pinus excorticata Gordon.

Specific Character.-Leaves or needles in threes, very stiff', convex on the back, and acutely keeled on the inner face, from 2 to 3 in. long, and thickly set on the branches, frequently in bundles towards the ends of the shoots, somewhat in whorls, and irresularly three-edged. Sheaths composed of numerous loose scales, which srom fall off and leave the base of the leaves naked. Buds non-resinous, and formed of several reddish-brown, smooth, fringed scales, larwest at the base, and rough at the edges. Male catkins from 5 to 6 lines long, cylindrical or conical ; when young, placed alternately at the base of the young shoots, but frequently afterwards very distant, owing to the rapicl elongation of the young shoot. Branches long, very slender, little divided, glaucous, and covered with a smooth grey bark, renderenl a little rongh on the stem and older branches by the transrerse sears forming rhomboidal-shaped figures, which in due time are sherl, and give the stem and branches a very peculiar appearance. Cones ovate or slightly conical, broadest near the base, $2 \frac{1}{2} \mathrm{in}$. long and $1 \frac{1}{2}$ in. diameter, and obtuse-ended (Gordon, op. cit., p. 190).

Distribution. - This Pine is a native of the north of China, and was introduced from that country by Fortune in 1846. It is cultivated by the Chinese as the "Lace-bark Pine."

Description of Tree.-Although from China, this species is quite hardy and free-growing, and attains a height of from $\ddot{30}$ to io ft. It is a very distinct and peculiar Pine, as in a young state its bark resembles the skin of a pea more than that of a Pine-tree. As the plant increases in age, howerer, the thin onter cuticle or epiclermis peels off in silky-like seales, leaving the brinches and stem with a greyish-white surface. Another reculiar characteristic of this Pine is that, in the ammal production of young shoots, its new leares are at first furnished with perfectly formed sheaths, which soun fall uff, leaving the leaves or needles sheathless, in the sime way as the onter bark falls off the stem and branches.

This is not a tree at all adapted to become of sylvicultural importance in this country; it is to be recommended only for the peculiarity of its appearance, for the rariety it forms among other Pines, and for its arboricultural interest as a strange species. 
Soil and Situation. - The Lace-bark Pine comes from the coldest and poorest districts of China, where, however, the summers are intensely hot. It is therefore found to be quite hardy in Britain, and by no means very particular as to soil and situation. The former should, however, be light and dry, and the latter favourable, and not exposed to prevailing winds, in order to ensure the thriving of the species in our changeable climate.

Propagation and Culture.-The seed of the Lace-bark Pine is very scarce, owing to the difficulty of oldtaining it from the north-west of China, whence alone it must be procured. It is got now and then, however, through the influence of merchants in that part of the comntry. The seeds germinate readily when sown in the usual way, and the plants soon make progress and become fit for planting out.

This species is scarce as yet, and fer good specimens are to be seen in this country. It is to be found, however, among the collections at Dropmore, at Kew, and in the York Nurseries.

\section{(4.) THE HEAVY-WOODED or YELLOW PINE, Pinus ponderosa Dougl.}

Sraroxrus-Pinus brachyptera Englm.; P. nootkaensis Ian.; P. Parryana Gord.; $P$. Beardslcyi Murr.; P. Craigiana Hort.

Specific Character.-Leaves or needles in threes, from $S$ to $10 \mathrm{in}$. long, twisted, rather broad and flexible, thickly set on the branches, sharp-pointed. Sheaths 1 in. long, smooth, but much shorter and shrivelled on the old leaves. Branches few, in regular whorls, robust, twisted, and somewhat drooping. Buds bluntly domed, with a prominent point, and full of resin. Cones straight, ovate, tapering to both ends, particularly towards the apex, $3 \frac{1}{2} \mathrm{in}$. long and $1 \frac{3}{4}$ in. broad; in clusters round the branches, on very short stout footstallss, and bent downwards (Gordon, op. cit., p. 205).

Distribution.--The Yellow Pine is found plentifully on the north-west coast of America, from California southwards into New Mexico, and particularly on the banks of Spoken River and the Kettle Falls of the Columbia, west of the Rocky Mountains, as well as in Rose River valley in California. It was introduced into Britain in 1826 .

Description of Tree.-The Yellow Pine, when advancing in age, is remarkable for the twisted character of its branches, which are disposed in regular verticillate whorls. The timber of matured urowth has a much higher suecific gravity than that of most Conifers (see table on p. 331), and is said to be so heavy as almost to sink in water. The tree grows to large dimensions, generally attaining a height of from 60 to $100 \mathrm{ft}$. with few branches, and a large girth of 
stem. It is a free-growing, hardy tree, and malies rapir progress when planted out on a suitable soil and situation. In eastern Nebraska this is called the "Bull Pine."

According to Engelmaine, it attains gigantic dimensions, resembling those of the Donglas Fir and the Menzies, fintuce in the Rocky Mountain forests.

Economic Uses of Timber. - Even judging from specinens grown in this country, the timber of the Yellow Pine is of fair quality, and is likely to be serviceable in Iritain for many technical purposes in which a fine polish is not requisite. It seems coarsegrained, but strong; and as the tree is hardy and free-growing, it may perhaps become one of our forest-trees, producing timler for various requirements.

In California, the home of many species of gigantic Conifers, the heavy wood of the Yellow Pine is said to be of excellent quality and very durable.

Soil and Situation.-The best specimens of this species in Britain are to be found growing on a poor gravelly soil, or on sandy loam-land. The soil for this species, as for most others of the Pine genus, should not be of a rich nature; for uncler such circumstances the plants generally grow too luxuriantly, and conseruently do not ripen the woody tissue of the points of their shoots sufficiently to enable them to resist the frosts of our winter. The situation for the Yellow Pine should be airy, but not much exposed.

Propagation and Culture.--The seed of this species is still scarce, although it is obtainable every now and then from the Far West, though only in small quantities. It may be sown, and the plants produced from it may he reared in the usual way, as they are quite hardy and easy of cultivation; it is well, howerer, not to expose the young plants to danger in localities where late frosts are common.

At Elvaston Castle, Dropmore, Kew, Linton Park, the Botanic Garden of Edinburgh, and at Hopetom House, there are specimens of this Pine of various heights, from 20 to upwards of $60 \mathrm{ft}$., all forming healthy and promising trees.

The largest specimen reported to the Conifer Conference in 1891 had a height of $63 \mathrm{ft}$., and a girth of $9 \mathrm{ft} .2 \mathrm{in}$. at $5 \mathrm{ft}$. from the ground.

Sylvicultural Qualities of the Yellow Pine.-Continental experience of the Yellow Pine as a forest-tree shows that it is decidedly accommodative with regard to the mineral nature of the soil, but that it thrives best on a deep loamy sand. Although at first of rapid growth, it afterwards derelops more slowly. It is not improbable that this species may le found of splvieultural importance to Britain. In any experiments having this object in riew, it would seem advisable to intersperse Yellow Pine, Bentham's Pine, and Larch along with Douglas Fir and Menzies Spruce, and to thin out and 
utilise the three former light-demanding species wherever the two latter begin to catch them up and to interfere with their normal development. It does not appear to be able to stand the winter cold of the Continent, and is there said to be liable to be attacked with the "leaf-shedding" disease.

(5.) BENTHAM'S PINE, Pinus Benthamiana Hartweg.

SrxoxrM-Pinus Sinclairii Hooker. It is now generally referred to $P$. ponderosa.

Specific Character.-Leaves or needles in threes in each sheath, thickly set on the branches, dark green, and resembling those of the Yellow Pine ( $P$. ponderosa), but much longer, usually 11 in. in length, very stout, rather flat, with a slightly elevated rib running along their inner side. Sheaths partly persistent, and nearly 1 in. long on the leaves of the young shoots, slightly shaggy, except at the extremity, where they are very ragged or torn. Branehes rather numerous, very stout, spreading, and somewhat irregular, with a rough bark. Buds large, dark brown, much imbricated, and generally free from resinous matter, although sometimes there is a little. Cones in clusters of from 3 to 5 together, slightly pendulous, and quite straight, 6 in. in length, and $2 \frac{1}{2}$ in. broad at the widest part, which is rather below the middle; the base is unequal-sided, owing to the numerous very small scales there curving to one side and forming a kind of hood round the base of the cone, which is quite sessile (Gordon, op. cit., p. 188).

Distribution.-This valuable Pine was first met with on the mountains of Santa Cruz in California, a coast-range running due north across the bay from Monterey; afterwards it was found in the Sacramento country, growing upon the ridge generally termed "The Californian Mountains." It was introduced into Britain in 1847.

Description of Tree.-This is truly a noble species of Pine, and is in all respects hardy, being entirely a tree of the mountains. It is said to attain a height of $200 \mathrm{ft}$. in its indigenous habitat, with a stem of from 9 to $10 \mathrm{ft}$. in diameter. Hartweg says of this Pine:-

"After crossing the Chuba River, you pass the prairie and enter the mountains near Lear Creek, where you hare to pass through an interminable wood of Sabine's Pine $(P$. Sabiniana); and in ascending the gradual acclivity of the mountain, you quit the region of the latter and enter that of Bentham's Pine (P. Benthamiana), which seems to be characteristic of the upper region."

This species very much resembles the Yellow Pine ( $P$. ponderosa) in its alpearance while young, but is readily distinguishable fiom it by the greater length of the leaves. On specimens of twigs taken from a tree of about $15 \mathrm{ft}$. in height, the leaves or needles are often nearly $10 \mathrm{in.} \mathrm{long} \mathrm{on} \mathrm{the} \mathrm{average;} \mathrm{whilst} \mathrm{those} \mathrm{on} \mathrm{similar} \mathrm{specimens}$ taken from the Yellow Pine are only from about 7 to 8 in. in length. 
This is undoubtedly one of the Pines which is likely to become a timber-tree in Britain; for it is both hardy and ornamental, and therefore is worthy of a place both in the parks and in the plantations of this country (see note to description of the Yellow Pine).

Economic Uses of Timber.-The timler of the Jentham Pine is said to be somewhat lighter and more elastic than that of the Yellow Pine, and also of even a more durable description.

Soil and Situation.-This species is by no means difficult to suit with respect to soil, provided that it is not of a heavy or clayey nature, and that it is deep and dry. It does well on most light loany soils, and makes annual shoots of about $2 \mathrm{ft}$. in length, even in moderately exposed situations. It appears to be a very valuable species, and should be cultivated as much as possible in our plantations, for it makes no great demands as to the mineral cuality of the soil, and is of a very accommodating nature as a tree crop.

Propagation and Culture.-A fair supply of the seed of this tree has been procured of late, and therefore it may now be obtained from most nurseries at lower prices than formerly. It should be sown in the same way as the seed of the Scots Pine, and similar treatment to that detailed for this common species may be accorled to the seerlings and transplants of the Bentham Pine.

At many places, both in England and Scotland, specimens of this Pine are now to be seen ranging from 40 to $50 \mathrm{ft}$. in height.

(6.) THE STIFF-LEAVED or PITCH PINE, l'inus righil, Mill.

Srnonyus-Pinus canadensis trifolia Duham.; P. Taede rigida Ait, P. Loddigesii Loud.

Specific Character.-Leaves or needles in threes in each sheath, from 3 to $4 \frac{1}{2}$ in. long, stiff, rather broad and sharp-pointed, light green, and spreading. Sheaths short, $\frac{3}{8}$ of an in. long, and white on the young leaves, but afterwards becoming nearly black and shrivelled. Branches very numerous on the upper part of the tree, and compact. Cones ovate-oblong, from $2 \frac{1}{2}$ to $3 \frac{1}{2} \mathrm{in}$. long, and $1 \frac{1}{3} \mathrm{in}$. broad, on short stout footstalks, in clusters of 4 or 5 round the top hranches, and remaining on the tree for years (Gordon, op. cit., p. 2007 ).

Distribution.-The Pitch P'ine occurs in most parts of the L'nited States, from New England southwarts to Tirginia, and is found growing both on dry and on wet soil. In America it is known by the name of the "Pitch Pine," owing to the abuntance of resin contained in it. It was introduced into Britain either in 1750 or 1759 .

Although found on sandy and marshy soil in many of the inland tracts of North America between latitude $38^{\circ}$ and $44^{\circ}$, its finest development as a tree of true forest growth occurs in the Alleghany. Mountains, where it often forms extensive woods. 
Description of Tree.-In America the Pitch Pine grows to a large size in some parts of the country. On light sandy lands in the State of Pennsylvania it may be seen upwards of $80 \mathrm{ft}$. in height, and with a stem of fully $2 \mathrm{ft}$. in diameter. Good trees of this species may also be found growing on the edges of swamps, where the ground is wet; but on poor high-lying parts it forms only a large-headed bush.

This tree has a thick, dark-looking, coarse bark, deeply furrowed on old trees, and it is generally of a very branching habit of growth, seldom having a clean stem, even when found growing in masses or among other trees; and in consequence of this its wood is very knotty.

It cannot be said to be a highly ornamental tree, nor is it valuable on account of its timber; but from its hardiness, and its very accommodating habits as to soil and situation, it is well adapted for planting on many sites where variety is an object, and where few other sorts of Pines would grow in such a way as to secure this end.

Economic Uses of Timber. - Wherever it can be had, the timber of this tree is used for many purposes in America; but the wood of this species is now comparatively scarce. In Britain it is of no economic value, the tree being grown in most places merely for variety among other Pines, and for its arboricultural interest.

The durability of the timber in America depends on the nature of the soil on which the trees are produced. When grown on the mountains, its wood is very resinous and durable; whereas the "Sap Pine" wood produced on low-lying marshy land is soft and of little value. Even where indigenous, it is a tree of the inland tracts, and not of the sea-board stretches having a damp climate.

Soil and Situation.-Few Pines are more accommodating than this one in respect to soil and situation. To grow it well, however, it requires a light, friable, deep soil, and a situation that is not too much exposed.

Propagation and Culture.-These are in all respects the same as the Scots Pine. The seeds can be easily procured from any seedmerchant in New York. Plants of it are now quite common in this country, and nurserymen quote them at very reasonable prices.

Sylvicultural Characteristics of the Pitch Pine.-Experiments conducted during the last half-century in the State forests of Prussia show that this species of Pine, when treated as a forest-tree, has a very marked resemblance to the Common Pine. It is somewhat slower in growth, as at 50 years of age the trees are not above $50 \mathrm{ft}$. in height; but it is equally hardy throughout Pomerania and Silesia, and has a stronger recuperative power in healing wounds inflicted by game and other enemies. It may therefore be 
possessed of some sylvicultural interest for the Highlands of Scotland, as it can thrive both on dry soil and on marshy land, although, of course, it grows best on tracts that are fresh or moist. Like the Scots Pine, it is a lightdemanding species of tree. On the poorer classes of sandy soil throughout Northern Germany it has been found to be perhaps preferable to the Sicnts Pine, although, of course, it is also, under such very unfavourable circumstances, exposed to danger from excessive drought.

Specimens of this Pine may be found at Dropmore, in Bucks, of heights ranging from 50 to $60 \mathrm{ft}$.

\section{(7.) THE RADIATED CONE PINE-Pinus radiata Don.}

SYNonyM-Pinus insignis var. macrocarpa Hartweg.

Specific Character.-Leaves or needles in threes in each sheath, very slender, twisted, deep sreen, thickly set on the branches, ancl from 3 to 5 in. long. Sheath short, smooth, $\frac{1}{4}$ of an in. long on the young leaves, but much shorter on the older needles, and only partially persistent. Seed-leaves on the young plants from 7 to 8 in number, rather long and slender. Branches compact, numerous, rather regular; and slender, particularly the lateral ones. Bark light brown, and rather smooth. Buds small, numerous, imbricated, and full of resinous matter. Cones mostly single, but sometimes in clusters of two on three together, rather conical, very hard, slightly incurred, pendulous, of a glossy light-brown colour, 6 in. long and $3 \frac{1}{2} \mathrm{in}$. broad near the base, which is uneven as well as the sides, the outer side being nuch the longest. Scales radiant, largest at the external base and down three parts of the outer side of the cone, deeply divided, much elevated, and prolonged into a blunt-pointed nipple, $\frac{1}{g}$ an in. in length ancl $\frac{3}{4}$ of an in. broad; those nearest the base are bent backwards, the others being more or less convex, widest at the base, bluntly conical, slightly angular, and terminated by a blunt point; the scales on the inner side of the cone, and for four or five rows round the point, are very much smaller, quadrangular, and slightly elevated, with their points quite flat or slightly depressed (Gordon, op. cit., p. 206).

Distribution. - This beautiful Pine was first discovered by Coulter in Upper California, in lat. $36^{\circ}$, near the level of the sea, and almost close to the beach, where it was growing singly to the height of $100 \mathrm{ft}$. Hartweg also met with it on the lescent tomaris the sea on the mountains of San Antonio, sixty leagues south of Monterey, where it formed a small wood extending along the beach, and where its deep grass-green foliage at that time of the year formed a marked contrast to the parched-up regetation round ahunt it. It was introduced into Britain in 1829.

Description of Tree. - This tree thrives best when growing singly, 
and within the influence of the sea: in such situations it attains lane dimensions, and is of an upright habit of growth. It is a beautiful Pine, and very much resembles the Remarkable Pine ( $P$. insignis) at first sight; but a closer inspection shows that its leaves or needles are much shorter and more slender than those of that species, while its cones are nearly three times as large, and have their scales much more elevated. The Radiated Cone Pine, in its natural habit of growth, forms a beantiful straight-stemmed tree, clothed with branches down to the ground: it is quite hardy in our climate, and accommodating with regard to soil.

Economic Uses of Timber. - The late Dr Coulter says that this species forms excellent timber, of a very tough description, and admirably adapted for boat-building, for which purpose it is much used at Monterey. It is as yet too early to express an opinion concerning the capacity of this tree for timber-production in this country; but judging from specimens of home-growth, there is every reason to believe that it will probably prove useful for its timber, as well as an ornamental tree in our parks and arboreta.

Soil and Situation.-This Pine thrives best on a poor gravelly soil on inland situations, considerably above the sea-level. It is said to be well adapted for planting near the sea; but only experiments can show whether in this country it will in this respect prove of anything like equal value to the Black Pines and the Pinaster for forming belts of shelter along the sea-coast (see p. 262). But at all events it is quite hardy, and seems to succeed well on most light soils, and on situations that are not too high-lying or too much exposed.

Propagation and Culture.-This Pine is easily cultivated from the seed, which is now neither so scarce nor so high-priced as it was a few years ago.

(8.) THE REIMARKABLE PINE, Pinus insignis Douglas.

Specific Character.-Leaves or needles three in a sheath, deep grass-green, rather slender, usually straight, but often twisted in all directions, very densely set on the branches, of different lengths, from 4 to 6 in. long, ribbed on the inner sides, and sharp-pointed (see Fig. 53). Sheaths very short, smooth, and rather more than $\frac{1}{4}$ of an in. long. Branches numerous, rather irregular, and thickly set with slender branchlets at the extremities. Cones ovate-conical, much pointed, most developed on the exposed side, particularly towards the base or outer part, $3 \frac{1}{2} \mathrm{in.}$ long and $2 \frac{1}{2} \mathrm{in}$. broad, mostly in clusters of from 3 to 5 round the stem or principal branches at the top of the tree, of a pale yellowish brown when ripe, and with a 
smooth glossy surface. They point downwards, and remain for several years on the tree. Seeds middle-sized, nearly black, and with an ample wing, more than 1 in. long. It takes two years to mature its cones and seeds (Gordon, op. cit., p. 197).

Distribution. - This very interesting Pine is a native of California, throughout which it is found growing in various parts. It was introduced into Britain by Douglas in 1833, and has become widely spread over the country on account of its very graceful habit.

Description of Tree. -In its native habitat this extremely handsome Pine attains a height of from 80 to $100 \mathrm{ft}$., and forms stems of from 2 to $4 \mathrm{ft}$. in diameter, whilst the branches are feathered with foliage down to the very ground. It is tolerably hardy, and makes very rapid growth; but it has a tendency to throw out autumnal shoots when planted in low-lying sites where there is a rich soil and a humid air, and under such circumstances it is of course very apt to get its soft leading-shoot frostbitten. When planted on soil of a very dry nature, or on a somewhat elevated situation having a free exposure to sun and air, this tendency is checked; it then ripens its wood

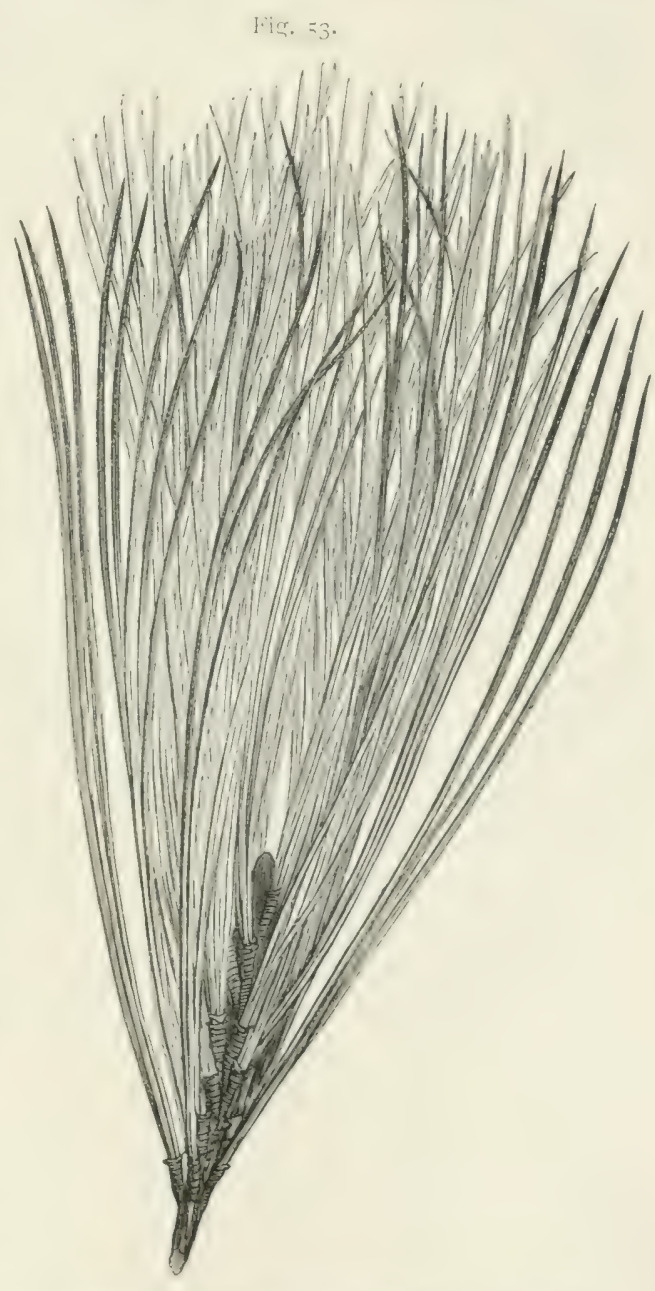

Spray of the Remarkable Pine (Pinus insignis). thoronghly early in antumn, and in consentence of this is not injured by our winters.

This is a very graceful tree, haring a free and irregular hranched habit of growth, whilst its beatiful grass-green foliage renters it an admirable object in a park or on a lawn among other Pines of a 
darker hue, or among deciduous trees: in the latter case it becomes a beautiful object, increasing the grandeur of the most highly finished landscape.

Economic Uses of Timber.- -Sufficient opportunities have not yet been given for forming any correct judgment as to the quality of the timber produced by this Pine in Britain. But its value must in any case remain of a purely æsthetic and arboricultural nature; for any attempt to treat it as a forest-tree, to confine its growing-space, and thus limit its ramification, must be fatal to its ornamental character, and to the beauty of its foliage.

Soil and Situation.-This species of Pine should be planted on a light, dry loam, preferably of a poor rather than a fertile description, and in a situation where it can have free access to sun and air without being exposed to strong winds. Like many other species of Pines of recent introduction, it continues growing too late into the autumn to harden its shoots properly, when planted on rich soils and low-sheltered sites; and from this cause it often loses its leader. But when planted out on poorer classes of land, it matures its shoots early, and gets through the winter uninjured. This tree thrives better near the sea than in inland districts, and is of better growth in the west of Scotland than on the east coast.

Propagation and Culture.-The Remarkable P'ine is raisert from seed in the usual way; but the young seedlings require the protection of a frame during the first winter, as, until they have formed perfect wood and leaves, they are always apt to be injured by frost.

Good specimens of this Pine are now plentiful in the country, many of them of heights ranging from 60 to about $90 \mathrm{ft}$., and having stems of proportionate girth at the base.

The largest specimens reported to the Conifer Conference of $1891 \mathrm{had}$, in one case, a height of $90 \mathrm{ft}$. and a girth of $11 \mathrm{ft}$. at $5 \mathrm{ft}$. above the ground; and in another, a height of $68 \mathrm{ft}$. and a girth of $13 \mathrm{ft}$.

\section{(9.) SABINE'S PINE, Pinus Sabiniana Douglas.}

Specific Character.-Leaves or needles in threes in each sheath, rather slender, from 10 to $12 \mathrm{in}$. long, glaucous grey in every stage, twisted, and when fully grown bent downwards, and drooping during winter, sharp-pointed, angular on the inner side, but rounded on the outer side. Sheaths $1 \frac{1}{2}$ in. long, nearly entire at the top, with numerous rings, and wrinkled when old. Branches numerous, not very robust, covered with a violet bloom when young, and devoid of foliage, except near the extremities. Cones ovate, most developed on the outer side, particularly towards the base, pointing downwards, pressing against the stem, and remaining on the tree for a number 
of years, from 8 to $10 \mathrm{in.} \mathrm{long} \mathrm{and} 6$ in. wide, on footstalks $2 \frac{1}{2}$ in. long, and full of resin, particularly towards the hase. Scales spatula-shaped, flat on the immer side, and romulerl or slightitly angular on the outer side, $2 \frac{1}{2} \mathrm{in}$. long, and $1 \frac{1}{2} \mathrm{in}$. broad on the larger bracts, but much less on the smaller scales towards the base, terminated by a strong, sharp, incurved hook, particularly on the exposed side and at the base, where some of the points are quite straight, and pointing upwards or towards the top of the tree. Seceds 1 in. long, oblong, tapering to the base, and flattened on the insirle, hard-shelled, short-winged, and edible, and nearly doul,le the size of those of the Large-coned Pine ( $P$. macrocerpa). Seed-leaves from 8 to 10 in number (Gordon, op. cit., p. 208).

The cones of the Lambert or Giant Pine ( $P$. Lambertiana) are, however, still larger than those of this species, being from 12 to $16 \mathrm{in.}$ long, and alson like the Stone Pines ( $P$. pinea and $P$. Cembra) containing edible seeds.

Distribution.-This species is also a native of C'alifornia, lueing found there on the western Cordilleras of New Albion at a great elevation, and in woods on the heights near Monterey at El Toro, a high mountain to the east of that place. It was introduced into Britain in 1832 .

Description of Tree.-The Sabine Pine is a handsome tree, attaining a height of from 100 to $150 \mathrm{ft}$, and with stems of from 2 to $5 \mathrm{ft}$. in cliameter: when growing in any isolated position, it is regularly furnished with branches down to the ground. It is said never to be found in masses or pure forests, but always intermixed with other kinds. The tree is of a tapering habit of growth, in which respect it somewhat resembles the Spruces and silver Firs, whilst its long foliage gives it a very graceful appearance.

Economic Uses of Timber.-The timber of this species is said to be white, but not of a durable character. It is therefore only as an ornamental tree on lawns and parks that it can be recommenderl for cultivation in Britain; but for this purpose it is admirably adapted. Its enormous cones are objects of very considerable interest.

Soil and Situation.-Although the Sabine l'ine is tolerally. hardy, it is rery particular with respect to soil and situation. It is found to thrive best in this country when planted in sheltered ravines and in hollows, where the soil is leep and somewhat rich in humus. It can also thrive fairly well, however, on any light land that is neither too much exposed nor at too high an elevation; lut on such parts its growth is slow as comprared with the rapid development attained in low-lying and sheltered hollows.

Propagation and Culture.-The information alrealy giren in detail with respect to the arboricultural propagation of the Temark-

VOL. I. 
alle l'ine ( $P$. insigitis) is equally applicable to the rearing of the Sabine Pine in the nursery. The seed of this species is still somewhat scarce, and therefore plants of it have not yet become low in price; the cones ripen in November.

In most of the extensive arboreta in this country specimens of the Sabine Pine are to be found, of heights ranging from 20 to $25 \mathrm{ft}$. and more.

The climate of Britain, and more especially of the colder northern half, is hardly suitable for this species to be introduced largely, for it demands a considerable degree of warmth before it can attain good development. The largest specimen of this tree reported to the Conifer Conference in 1891 had a height of $24 \mathrm{ft}$. and a girth of $2 \frac{1}{2} \mathrm{ft}$. at $5 \mathrm{ft}$. from the ground, and is growing at Pampisford in Cambridgeshire.

(10.) JEFFREY'S PINE, Pinus Jeffreyii Murr.

Srxoxrus-Pinus Jefficyana van Houtté; $P$. deflexa Torrey.

Specific Character.-Leaves or needles in threes, pendulous at the ends, deep green, keeled on the inner face, rounded on the back, rery acute pointed, and from 8 to $9 \mathrm{in}$. long; sheaths persistent, $1 \frac{1}{4}$ in. long when young, but very much shorter, lacerated at the ends, and of an ash-grey colour when old. Buds short, stout, imbricated, and resinous. Branches horizontal, a little declining, rather slender, and of a light yellowish-red colour. Cones large, ovate-conical, tapering most to the point, $8 \mathrm{in}$. long, and $3 \frac{1}{2} \mathrm{in}$. in diameter at the widest part, which is near the base, and for the most part produced in clusters round the branches (Gordon, op. cit., p. 198).

Distribution. - This species of Pine was found by Jeffrey in the Shasta valley in northern Califoruia, growing on poor sandy soil, and was introduced into Britain about 1852.

Description of Tree.-The Jeffrey Pine forms a handsome tree, and is a hardy species, besides being a free grower. In its native country it attains a height of from 100 to $150 \mathrm{ft}$., and forms a stem of from 2 to $4 \mathrm{ft}$. in diameter. In this country it makes fair progress, there being now many specimens which have attainesl a height of 40 to $50 \mathrm{ft}$., although none of them have yet been planted for forty years.

This species is by some considered to be merely a variety of the Yellow Pine (P. ponderosa).

Economic Uses of Timber.-In quality the timber of this species closely resembles that of the Yellow Pine.

Soil and Situation.-The Jeffrey Pine does not seem to be very particular with respect to soil and situation. It is to be met 
with in fairly healthy development on most soils, whether of a sandy or a stiff clayey-loamy description, and on situations sometimes sheltered, and at other times a good deal exposerl. It therefore seems to be a hardy and accommodating tree, and is perhaps destined to prove as useful as it is ornamental.

Propagation and Culture.-As the seel of the Jeffrey I'ine is still far from common or cheap, some care should le taken with it in the nursery. It should be sown in good soil in a sheltered corner, and the young seedlings should be protected during the first winter of their existence with a frame, in order to prevent their being injured by frost. After they are a year old, they should be transplanted into the nursery-lines; when they have once formed perfect wood and leaves they become quite hardy, and require no further protection. Were it not that the seed is still somewhat scarce and expensive, the young seedlings would really not require any protection at all during the first winter; but it is well to use every convenient precaution in order to avoid risk of clamage to the tender seedling plants.

Specimens of this Pine are now common, of heights ranging from 40 to $50 \mathrm{ft}$.

The largest specimens reported to the Conifer Conference of 1891 have respectively a height of $50 \mathrm{ft}$. and a girth of $3 \frac{1}{2} \mathrm{ft}$. at $5 \mathrm{ft}$. from the ground, and a height of $48 \mathrm{ft}$. with a girth of $6 \frac{2}{3} \mathrm{ft}$. They grow in Fife and Lincoln - i.e., both on the eastern side of Britain.

Sylvicultural Characteristies of the Jeffrey Pine. - Experiments have, during the last century, been made in the State forests of Prussia with this species as well as with the Yellow Pine. These prove the Jeffrey Pine to be accommodating, for whilst sandy soils are most farourable to its. development, yet it can do fairly well even on heavy, binding land. In its sylvicultural character it resembles the Scots Pine, and is, like it, a lightdemanding species of tree. It has not the same strong claims to sylvicultural attention that are possessed by several of the other Californian Conifers.

(11.) THE TUBERCULATED CONED PINE, I'inus tulurulute Goruhn.

Srnoxyrs-Pinus californica Hartweg; P. attcnuata Lemmon.

Specific Character.-Leaves wr needles in threes in each sheath, thickly disposed on the branches, lright green, rather stifl, loroal, and flat, with an elevated rib ruming along their mildle on the inner side, $4 \frac{1}{2}$ to 5 in. in length. Sheaths short, smooth, and not more than $\frac{1}{2}$ an in. long on the young leaves, but much shorter on the older ones, and only partially persistent. Branches not very stout, rather numerous and irregular, with a roughish bark. Buts below the middle size, imbricated, and not rery resinous or pointed. 
Cones mostly in clusters of four, but sometimes solitary or in pairs, and only produced on the main stems, of a long, conical shape, nearly $5 \mathrm{in}$. in length, and from $2 \mathrm{in}$. in breadth, the outer surface curved, the imer straight, widest near the base, and gradually tapering to the point, quite sessile, and uneven-sided at the base, very hard, of a light-brown colour, or silvery grey when old, very glossy, and full of resinous matter: they stand off at nearly right angles when old, although rather pendulous when young, and remain on the trees for years without even opening or shedding their seeds (Gordon, ol. cit., p. 211).

Distribution. - This tree was first discovered by Coulter to the south of Monterey, near the level of the sea, where it was intermixed with other I'ines, and especially with the Radiated Cone Pine (P. radiata), almost close to the beach. Hartweg also found it growing on the Santa Cruz Mountains, sixty miles to the north of Monterey by land. It was introduced into Britain about the year 1847.

Description of Tree.-This is a tree of slow growth, which seldom attains more than $40 \mathrm{ft}$. in height, and forms stems of only from 10 to $12 \mathrm{in}$. in diameter. While still young it is a handsome tree, and prettily clothed with green foliage; but when old it assumes a gnarled and rather deformed appearance. It begins to bear cones at a very early age, which at first are produced only on the main stem. The cones are persistent on the tree for a long time. Jeffrey found trees with as many as 20 whorls of cones on the trunk, which were the growth of as many years; and the branches were also covered with cones in the same way as the trunk. As the tree grows older, the branches, as well as the leadingshont, begin to bear cones; and as, even when the tree has a girth of $3 \mathrm{ft}$., they do not fall off, but remain persistent until they rot away on the stem and branches, the appearance of the mature tree, covered with cones, is very peculiar. It is quite hardy, and is in all respects suitable for arboricultural purposes in the climate of Britain.

Economic Uses of Timber.-The timber of this species is said to be red and hard; but further than that little seems known as to its technical quality and practical uses. It may be remarked here, however, that the species is not likely ever to become of any economic or sylvicultural value in Britain, as its rate of growth is too slow. Its place with us is therefore only as an interesting specimen among other Pines in a pinetum or park, or along the sides of roads in our plantations, where its cone-retaining characteristic will always give it an aspect peculiar to itself among trees of a different tendency or habit. 
Soil and Situation.-Arhoricultural experience in Britain shows that this tree thrives hest on a light, deep, dry loam, and on rather low-lying sheltered situations.

Propagation and Culture.-The details alrearly given with regard to the Jeffrey I'ine are also applicalle with respect to this species.

At various places throughout Britain the Tuherculated Coned Pine is to be found of heights ranging from 30 to $40 \mathrm{ft}$.

\section{PINES IHAVING FIVE LEAVES OR NEEDLES IN EACH SIIEATII.}

\section{(1.) CEMBRAN, SIBERIAN, or SWISS STONE PINE, Pinus C'embre L.}

Srxonyms-Pinus montana Lamk.; $P$. mandschurica Regel.

Specific Character.-Leaves or needles in fives, from 2 to $3 \mathrm{in.}$ long, sharp-pointed, :3-ribbed, one of the ribs green and shining, and the other two white (see Fig. 54). Sheaths deciduous. Buds lroad, globose, with a long narrow point, whitish, without resin, and mostly solitary at the end of the shoot. Cones about $3 \mathrm{in}$. long and $2 \frac{1}{2} \mathrm{in}$. broad, ovate, erect, and of a violet colour. Seeds very large, wingless, and edible (Gordon, op. cit., p. 219).

Distribution.-The Swiss Stone Pine is indigenous to Sileria, Tartary, Switzerland, Italy, and some parts of France. It is said to be sometimes found on the mountains of Switzerland at a greater height than any other species of Conifer. It is also found plentifully on the Alps of Hungary and Austria. It was introduced into Britain in 1746 .

This Pine is in reality far more of an Asiatic than a European species of tree, for its chief distribution lies throughout central Asia, and in comprarison with that, the tracts in the Alps and Carpathians, to which it is indigenous, are small, and mere outlying patches from the main area of distribution.

Description of Tree.-This is perhaps one of the hardiest of all the species of I'ine introduced into britain, and is very readily distinguished from any of the others by its erect habit of growth, by the shortness of its annual shoots, which, even under the most favourable circumstances, very seldom exceed $12 \mathrm{in}$, and by its branches being regularly disposed in whorls from the bottom to the top of the stem. It is of slow growth at all stages, and on most classes of soil, even when young, seldom grows more than $10 \mathrm{in}$. in any one year: from this it will be seen that it has no claim to be planted as a timber-tree. And it cannot even be said to be in itself a tree of any ornamental character; still, when properly placed among other trees in a park, its effect is rather striking in 
combination with Pines and other trees of a spreading habit of growth; and for this reason it deserves a place in any park scenery. The slowness of its development makes this tree unsuited to be

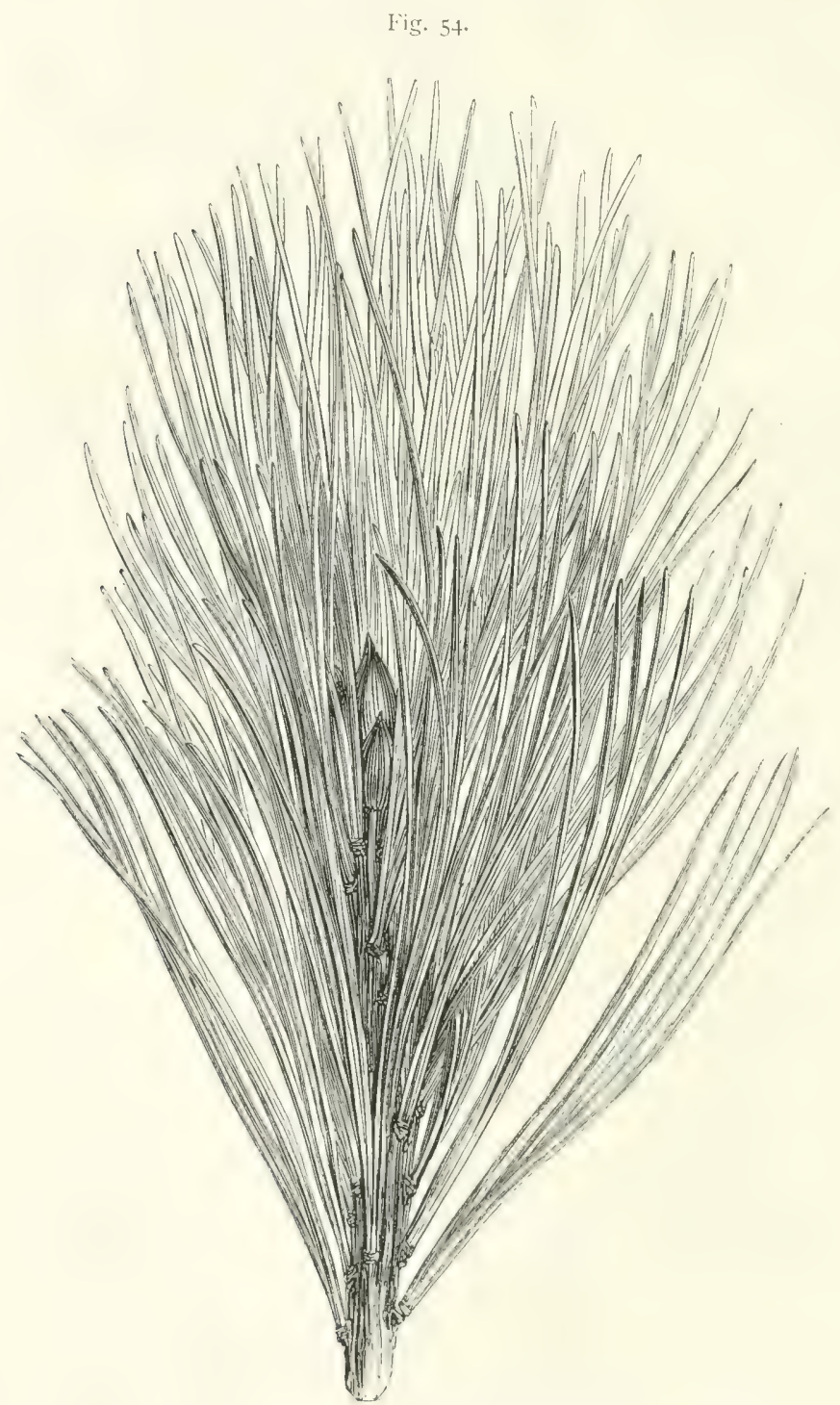

Spray of the Siberian, Cembran, or Swiss Stone Pine (Pinus Cembra).

planted among other Pines and Firs in a plantation; for in a very few years it gets completely suppressed when standing among trees of a more rapid growth. The best manner in which to utilise it for 
arboricultural purposes is therefore to plant it in pure patches, or merely as individual or single specimen trees on a lawn or in a park. Its formal character makes an effective contrast to other trees when it is found standing on the sides of roads in a plantation, and in such situations it lends itself well to landscape gardening.

When of spontaneous growth at the higher elevations in its Alpine home it takes nearly 70 years to attain a height of $6 \mathrm{ft}$. ; even when grown artificially in its quickest time of development, from the 10th to the 3joth year, it only increases less than $9 \mathrm{ft}$. in height there on the average. liegular whorls are only formed by it there from the fith to the 30th year, and its total height seldom exceeds $70 \mathrm{ft}$., whilst its stem varies from 3 to $5 \mathrm{ft}$. in diameter. Such trees are often from 500 to 700 years in age (Willkomm, op. cit., p. 172).

Economic Uses of Timber.-The timber, when matured, is said to be of fair quality, though rather soft. Of course in this country it will never be grown for the sake of its timber, but it is said to be much used on the Continent for wainscoting and joinery purposes. The wood is of a light-brown colour when matured, and is known throughout Russia as "Siberian Cedar." In the countries where this tree abounds, the inhabitants live much on the seeds as an article of diet; indeed many of the poorer classes in eastern Russia often have but little else than these "Cedar-nuts" for their winter's food.

Soil and Situation.-The Siberian or Swiss Stone Pine is by no means particular as to soil and situation, as it will grow in most places where the Scots Pine succeeds. Still, in order to attain a good size, and to get it to develop as quickly as possible, it must be planted on a good deep, rather light soil, which ought to be dry, whilst the situation should not be too elevated or exposed.

Its spontaneous srowth in the Alpine districts, in rery exposed localities near the perpetual snow and the glaciers, shows that the Cembran Pine is of a very hardy nature. Its natural requirements are a short but very warm summer, and a soil that is constantly fresh or moist, but not binding: given these conditions, its best development is attained on somewhat argillaceous, loamy, or limy soils.

Propagation and Culture.-The seeds of the Cembran I'ine should be sown at once after they are gathered, as if not, they are apt to lie dormant in the soil till the year following that in which they are sown. When they have become dry by keeping, the best way is to cover them with damp sand, and allow them to remain over summer. They ought to be sown during the following spring, howerer, and not later than the month of March. As the seeds are lingre, they should be sown thinly, and covered with about three-puarters of an inch of fine earth. 'The plants are very easy of culture, as the roots are 
always well fibred, and it is therefore easy to manage the seedlings in the way of transplanting. They should have two summers' growth in the seetl-bet before removal into the nursery-lines, as even then they will be but small as compared with other Pines. After standing for two years in the nursery-rows, they will, though four years of age, mot generally exceed $1 \mathrm{ft}$. in height, and at this stage they should be planted out into their permanent sites.

In the higher Alpine tracts the seed production does not commence till about 10 years of age; but in milder localities like Britain it often begins at the age of about 25 years, and even earlier.

In the Engadine, Cembran Pine seed is sown in strong boxes of larchwood corered with wire-netting, in order to protect it from voles and birds. These boxes, which are about $8 \mathrm{ft}$. long by 3 or $3 \frac{1}{2} \mathrm{ft}$. broad, and $2 \mathrm{ft}$. deep, are divided into two halves by a board running down the middle in order to give support to the wire-network above. They are let into the ground, and then filled up with good soil, on which the seed is sown. A box of this deseription costs about $£ 2,5$ s., and can contain from 10,000 to 12,000 seedlings when the seed is thickly sown (Burckhardt, op. cit., p. 467).

The Cembran Pine is now so well known and so common, that it is unnecessary to make reference to any particular place where specimens of it may-be seen. They are fairly plentiful in this country, and many of them have attained a height of from 40 to nearly $70 \mathrm{ft}$.

The two largest specimens reported to the Conifer Conference of 1891 were respectively $68 \frac{1}{2} \mathrm{ft}$. high by $5 \mathrm{ft}$. in girth at $5 \mathrm{ft}$. above the ground, and $45 \mathrm{ft}$. ligh by $9 \mathrm{ft}$. in girth, and were growing in Kent and Northumberland.

\section{(2.) THE WEYMOUTH PINE, Pinus Strobus L.}

Sraxrm-Pinus canadensis quinquefolia, Duham.

Specific Character.-Leaves or needles five in a sheath, very slender, 3 to $4 \mathrm{in}$. long, 3-sided, soft, and of a light-glacuous or bluish-green colour, marked when young with silvery channels on one side. Sheaths very short, almost wanting, and soon falling off (see Fig. 55). Branches short, in whorls, thinly clothed with folinge, and having a smooth shining bark. Cones long, narrow, lax, slightly curved, cylindrical, tapering to rather a sharp point, and pendulous, from 5 to $6 \mathrm{in}$. long and from 11 to $1 \frac{1}{3} \mathrm{in.}$ broad, with a foot-stalk $\frac{3}{4}$ in. long. Seeds small, ovate, of a dull-grey colour, and with the wing 1 in. long (Gordon, op. cit., p. 239).

Distribution.-The Weymouth Pine, or "White Pine" of the Anericans, is indigenous throughout Canada and all the Northeru stites of the Anerican Lnion. This tree is to tre found abundantly 
in most parts of Canada, and especially in the valleys of the rivers Ottawa, Madawaska, and Gateneau, where large quantities of it are felled every year and floated down the river St Lawrence, whence it is shipped for Europe. It was introduced into Lritain in 1705 , and was extensively planterl first of all on Lord Weymouth's estate in Wiltshire, from which fact it derives its common European name.

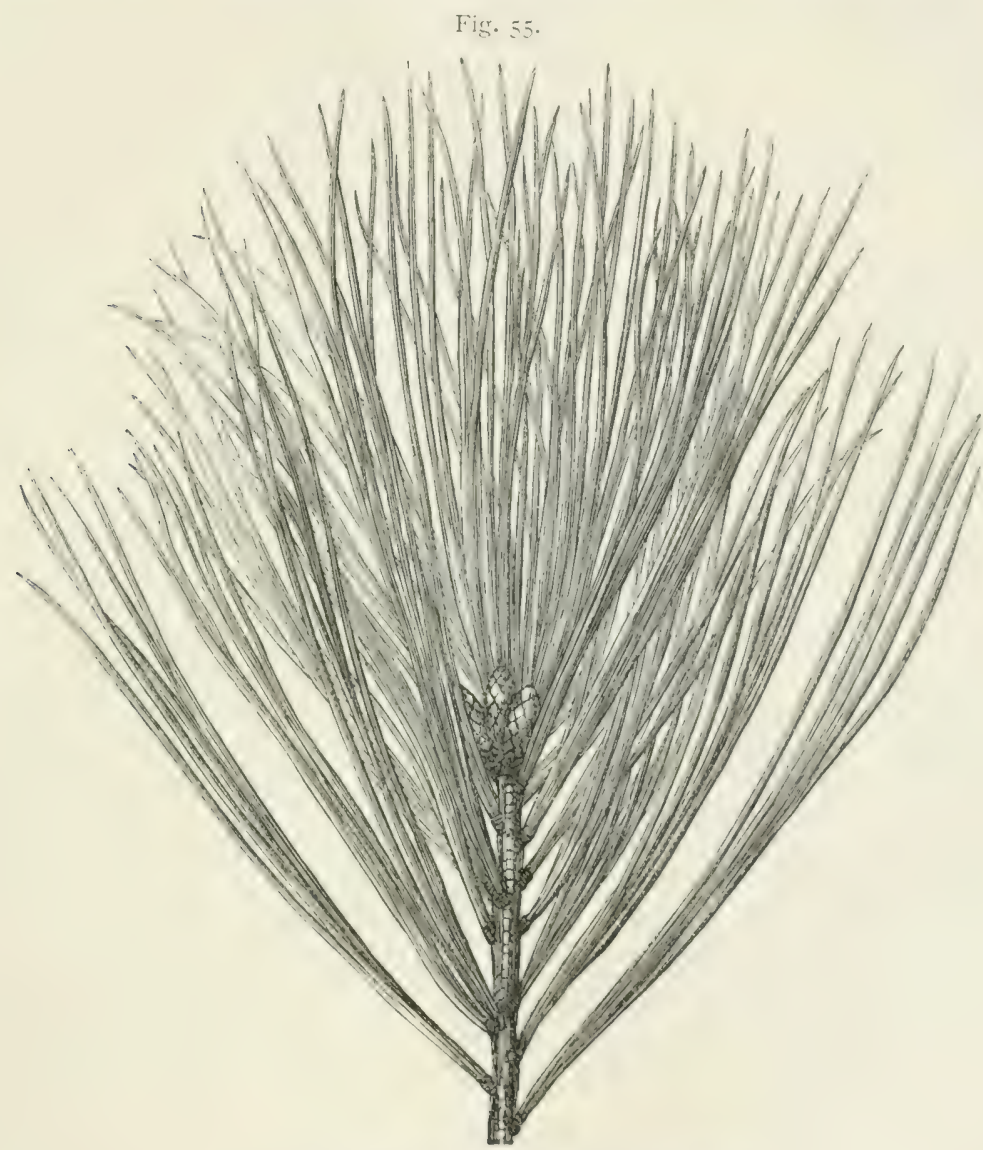

Spray of the Vieymonth Pine (Pinus Strobus).

It occurs most frequently between $43^{\circ}$ and $47^{\circ}$ north latitude, from the east of the Mississippi and the Alleghany Mountains northwards to the Giulf of St John and Lake Wimnipeg. It is a rery hardy species, and eren in Lirland and Kurland can endure the severe winters and the hot short summers of the far north of Europe, when planted out in parks as an ornamental tree.

Description of Tree.-In its native habitat this Pine grows to very large dimensions. Throughout Canadia and New Hampshire the stems are on the average about $150 \mathrm{ft}$. in height, and are about $2 \mathrm{ft}$. 
9 in. in diameter at $5 \mathrm{ft}$. up from the ground, although many of them measure upwards of $200 \mathrm{ft}$. in height, and have stems of from 5 to 7 $\mathrm{ft}$. in diameter at $4 \mathrm{ft}$. up from the ground. On counting the annual rings on the stumps from which such stems were cut, their ages were found to range between 350 and 425 years.

Pure natural forests of the Weymouth Pine are seldom to be met with on a sandy soil, but are generally to be found on gravelly ridges and knolls; whilst, on dry land of a more fertile description, it is usually to be seen forming mixed woods, in association with Beech, Lime, Maple, and other broad-leaved species of trees. And it is in these mixed woods that trees of the largest size are invariably to be seen.

The Weymouth Pine has a very strong tendency to straight upright growth; it has generally a stem free from ramification for at least two-thirds of its height, and the branches are never of large dimensions; nor do they extend far out from the stem. Even in the case of trees about $200 \mathrm{ft}$. high, the branches seldom extend more than $20 \mathrm{ft}$. out on either side, and are always arranged in regular whorls, with clear spaces letween, formed by the long leadingshoots. On young trees the bark is very smooth, and the leaves are longer than on old trees; in general appearance the needles have a very close resemblance to those of the Nepaul or Lofty Pine ( $P$. $c x$ $c c l s(t)$. As the tree advances in age, however, the bark becomes rough, or on matured specimens even rugged, and of an ash-grey colour; but it never scales off in flakes like the bark of many other Pines.

When grown singly, the Weymouth Pine forms a handsome tree; but, in order to develop satisfactorily in a comparatively isolated position, it requires shelter from other trees around it, as in this country it will not prosper in an exposed situation. It is a tree well worthy of a place in any park in Britain, as, on favourable soils and situations, it rapidly attains very fair dimensions, especially in the warmer tracts of central and southern England. Even in Scotland it reaches a height of 60 to $70 \mathrm{ft}$., and may contain upwards of $40 \mathrm{ft}$. of timber, when little over 40 years of age.

Economic Uses of Timber.-The timber of the species is more used in America than that of any other Pine; the "White Pine," indeed, forms the major portion of the P'ine-wood so largely imported into Britain from North America. Where it abounds, most of the houses on the country-sicle are built of it; and in the towns the woodwork of the houses is chiefly made from it. Indeed there are few purposes to which wood is applied in America for which "White Pine" is not used. Even in Britain the imported timber of this species enters largely into the construction of our houses, and of many other erections. It is not, however, so valuable as the "Red Pine" timber 
from the Baltic, which is harder, more clurable, and less liable to the attacks of insects and fungi (dry-rot).

The wood of the Weymouth Pine is light and soft, and its mean sp. gr. of 0.83 when green and 0.39 after seasoning stamps it as one of the lightest of Conifers (see table on 1. 3:31). But duralility camnot be said to be its strong point; for it ranks along with Aspen, Lime, Poplar, and Willow as the least durable of the forest-trees now cultivated in Europe. Like these sprecies of wood, however, it should be admirably adapted for the manufacture of packing-cases or of cellulose for paper.

It is soft in texture and even in grain, and can accordingly be worked and planed easily; and as it only shrinks from 2 to 3 per cent, it is well adapted for working up as flooring, or for the foundation of veneered furniture.

Soil and Situation.-In order that the Weymouth I'ine may thrive well in Britain, it requires to be planted on a good, deep, dry, and light loam, and in a somewhat sheltered situation. It often does well on dry sloping hanks among other trees, where it has sufficient room to spread out its branches a little, but has still some slight shelter to protect it against heavy storms. In America it is to be found growing on most descriptions of land, though seldom on sandy or on heavy argillaceons soils. The hest quality of timber is almost always produced on gravelly knolls and ridges.

This Pine requires a deep soil on account of its deep-reaching tap-root. Continental experience has shown that, though it grows well on sandy soils resting on a moist subsoil, yet it thrives best on loamy and clayey land ; eren when this is of a marshy description, it can often be rendered dry by the strong transpiration of water from the foliage of pure woods of this tree. A dry soil is unsuitable for it. It is rather a tree of the lowlands and of sheltered valleys than of exposed hilly or mountainous tracks.

Propagation and Culture.-Like all others of this genus, the Weymouth Pine is raised in the nursery from seeds, which generally ripen in this country about the end of October, and should be collected at once in order to prevent the seed from being scattered in November. The cones are easily opened, and the seeds extracted from them afterwards, by exposure to the sun. When the cones are gathered in early autumn and the seed has been taken from them during the winter, it should he sown about the beesimning of April, and the seedlings dealt with in every respect as recommented for the rearing of the common Scots Pine.

There are many fine specimens of the Weymonth l'ine throughout various parts of this country. At Dropmore it may be seen over 80 ft. in height, and with strong stems of proportionate cirth; at hew it has attained similar proportions; and in other prats of England there are even larger specimens, such as that at Longleat, where it is orer 
$100 \mathrm{ft}$. high, with a stem above $3 \mathrm{ft}$. in diameter. In Scotland, also, the tree attains fair dimensions, although the climate is not warm enough for its normal development as a lofty tree of first-class timberdimensions.

The two largest specimens reported to the Conifer Conference of 1891 are growing in Perthshire. The largest is one at Logie, near Scone, which was then $90 \mathrm{ft}$. in height and $7 \frac{1}{2} \mathrm{ft}$. in girth at $5 \mathrm{ft}$. above the ground.

Sylvicultural Qualities of the Weymouth Pine.-Thanks to the sylvicultural attention that this species of Pine has, for upwards of a century, received in the State forests of Germany, more is known of its characteristics, when of European growth, than of those of most of the American Conifers.

It is of more rapid development than Scots Pine during the early stages of growth, and forms woods containing a larger number of stems per acre, as, without being exactly a shade-bearing species of tree, it can thrive with less intensity of light than the Scots or even the Black Pines: after attaining the age of 20 to 30 years, however, it makes only a slightly increased demand for individual growing-space, and for a stronger ramification than is necessary for the normal thriving of Spruces and Silver Firs as woodland crops.

In rapidity of growth and in the quantity of timber produced, it excels all the other European Conifers; whilst, through its great transpiratory power and the rich fall of soft, easily decomposable needles, it has no mean capacity for the improvement of inferior soil of rather a moist description. It is admirably adlapted as a very hardy species, for filling up blanks in plantations on low-lying localities exposed to late frosts, where the side-shade cast by the rest of the crop might prove too great for the thriving of Larch and Scots Pine. With reference to its clensity of crop, and its productive capacity, Burckhardt (op. cit., p. 455) says as follows :-

"Along with the rapid development of the Weymouth Pine is combined a remarkable density of crop, maintained till its maturity, and differing entirely from the natural habit of growth of the Common Pine and the Larch, which thin themselves with advancing age, often to a very serious extent. In this respect the Weymouth Pine has much in common with Spruce and Silver Fir. Crops raised by planting are often so very crowded as to hinder the natural selection and development of the predominating stems, so that they need to be well thinned.

"Clearance of the crop at about 60 to 70 years of age yields a large quantity of timber. Even pole-forests and young tree-forests give a large return in timber. The mean annual increment in timber produced by 30- to 50-year-old crops, growing in close canopy on loamy, sandy, and marshy soils of only average quality, we have found to amount to 137 cubic ft. per acre, or including the returns of previous thinnings, 178 cubic $\mathrm{ft}$. per acre per annum. From other sources the quantity of timber in a 70-year-old crop is assessed at nearly 14,400 cubic ft. per acre. All crops will not yield such returns, especially when covering extensive areas; but the fact remains that this species is highly productive of timber. But so long as we cannot be sure of disposing of the wood, its rate of production cannot lead to extensive plantations being formed of it. More might certainly, however, be done than has hitherto been the case in order to provide stores of material for the supply of the coming future demands for timber."

Even if planted out in blanks in young Scots Pine woods, it catches the latter up within six or eight years, and then begins to suppress that more ralual, le species. For the formation of plantations of Weymouth Pine, yearling 
seedlings or two-year-old plants are put out naked. I'lantings should be closer than with the Common Pine, and is in Germany usually at $3 \mathrm{ft}$. by $3 \mathrm{ft}$. on inferior dry soil, or at $4 \mathrm{ft}$. by $4 \mathrm{ft}$. on land of better quality.

There must be a considerable demand for the seerl of the Weymouth Pine in some parts of Europe, for $7 \frac{1}{2}$ acres of prure Weymouth Pine near Frankfort were let annually for the 22 years, $1 \times 65$ to 1886 , at an average rental of $£ 27$ a-year, merely for the collection of the cones for seedsmen (Forst- und Jagdzeitung, 1886, p. 706).

The formation of extensive plantations of the best of the Californian Conifers, and especially of Douglas Fir and Menzies Spruce, seems to hold out financial and sylvicultural advantages to Britain, far greater than any that can be offered by the Weymouth Pine or by any other exotic species of Pine.

\section{(3.) THE NEPAUL or LOFTY PINE, Pinus eicelsi Wallich.}

\section{Srnonras-Pinus Strobus Hamilt.; $P$. Strobus excelsa Loud.; P. Nepalensis Pinet. Woburn. ; P. Dicksoniana Hort.; P. Peuce Griseb. ?}

Specific Character.-Leaves or needles in fives, very long, threeedged, very glaucous on the imner faces, bluish green, and rounderl on the outer one, from 6 to 8 in. long, very slender, and mostly drooping (see Fig. 56). Sheaths short at first, but soon rolling up, and finally falling off. Branches in regular whorls, and spreading; those near the bottom reflected, while the upper ones are more or less ascending; branchlets slender, long, and spreading; male flowers in dense clusters. Cones sulitary, or sometimes two or three together round the leading-shoots, of a cylindrical or somewhat conical shape, from 6 to 9 in. long, and about 2 in. broad near the base, tapering towards the point, and with a foot-stalk nearly 1 in. long; when young of a pea-green colour, and somewhat erect, but when fully grown completely pendulous, and of a pale-brown coloux, full of resinous matter in the shape of transparent drops (Gordon, op. cit., p. 222).

Distribution.-This species is from the Himalayas, where it is found plentifully along the central range, extending from Kafiristan eastwards to Bhutan and Nepaul, at elevations of from 5000 to $10,000 \mathrm{ft}$., and attaining a height of from 100 to $150 \mathrm{ft}$. It was introduced into Britain in 1823.

In the Kamaun district of north-western India it forms extensive forests in association with the Deodar Cedar. But it is also indigenons to Enropre, if it be identical with the $P$. Peuce which Grisebach found on Mount Peristeri in Macedonia, Pancic on the Kort in Montenegro, and r. Jankia on the Perimdagh in the Balkan range: recent evidence, however, goes to show that, though closely allied, it is not identical with that species. In these European habitats it is found at 5000 to $6000 \mathrm{ft}$. above the sea-level as a low tree, although near its upper limit it is merely a bushy shrub (Willkomm, op. cit., p. 189). 
Fig. 5 f.

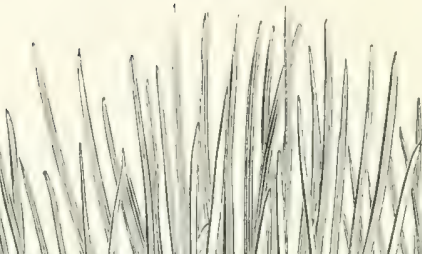

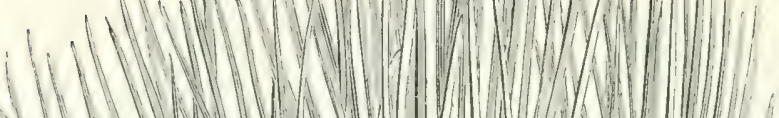

W

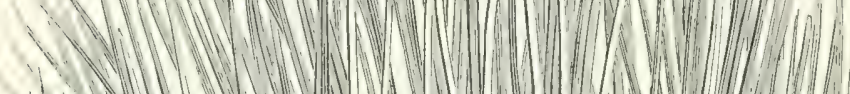

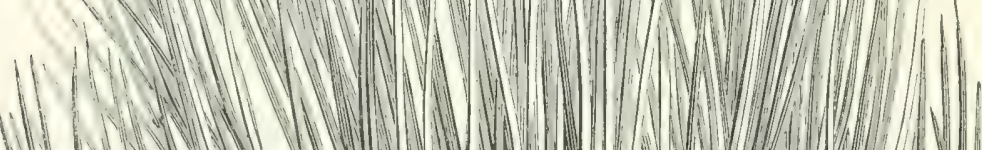
1 1 HANW WMLW H.W.1.1.WWW

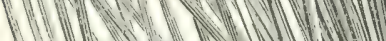

WWLW

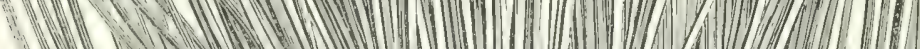
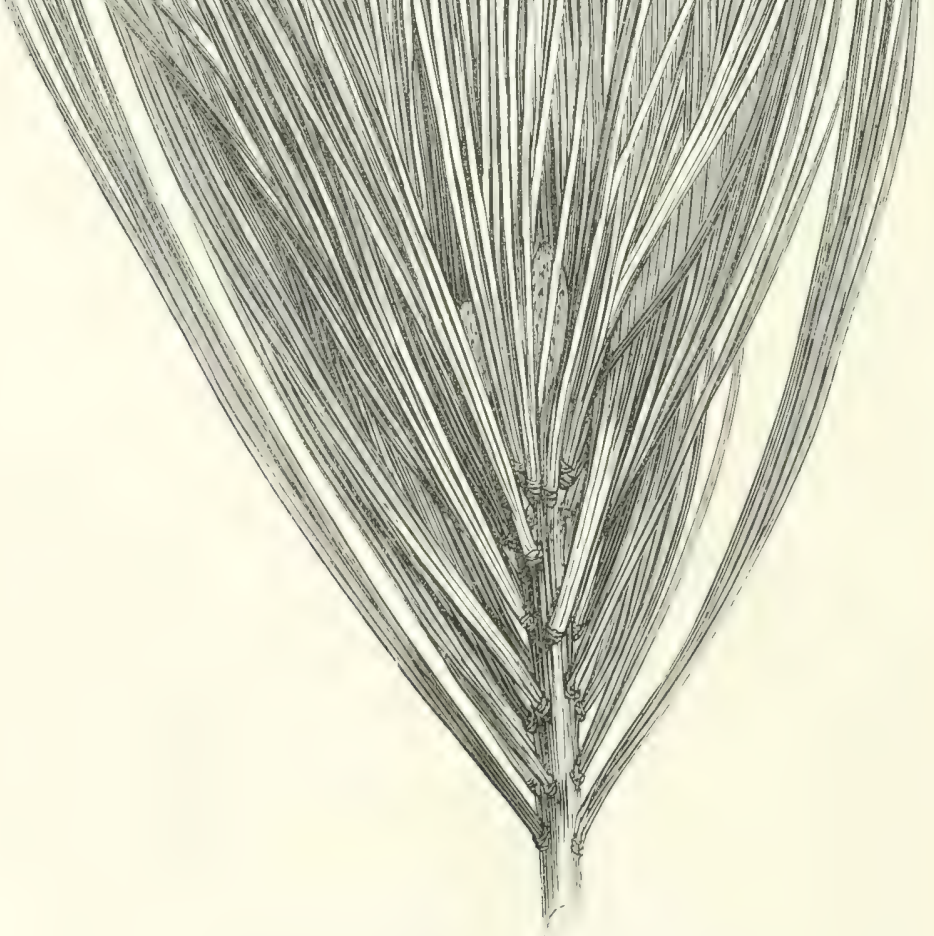

Spray of the Nepaul or Lofty Pine (Pinus excelsa). 
Description of Tree.-The Nepaul Pine has a very close resenblance to the Weymouth P'ine ( $I$. Strobus), lut is readily distinguishable from it by the needles, these being very much longer on the Nepaul than on the Weymouth P'ine; whilst the cones of the former are much thicker than those of the latter. The Nepaul Pine is a tree of open growth, with spreading luanches, and a somewhat conical outline; it is in all respects ornamental, and should be planted freely in Britain, as it is perfectly hardy. It is a very rapidgrowing P'ine, but does not thrive when exposed to high winds ant storms. In moderately sheltered parts of the country, however, it grows well, rapidly attains a good height, and is not aflected l,y the frosts of our climate. It grows best when planted in large patches, either by itself or else mixed with Larch, in plantations of that tree. Specimens of this species thrive well under such eirenmstances on situations nearly $1000 \mathrm{ft}$. above the level of the sea. When the tree stands alone as an isolated individual stem, it is apt to get broken by heavy winds; but when growing in a mass it is supported on all sides, and develops quickly.

Economic Uses of Timber.-The timber of the Lofty Pine remains somewhat soft, even when fully matured; it is white, but remarkably compact. This Pine is said to produce in abundance a highly fragrant and resinous turpentine. In this country it is not likely ever to be produced on any extensive scale for the sake of the quality of its timber. But it is a hardy species, and being of an ornamental habit of growth, it deserves attention from an arloricultural point of view; it is a large fine tree of a light-green glaucous colour and spreading habit, very hardy and ornamental.

Soil and Situation.-The Lofty Pine is not particular with regard to soil and situation, as good specimens of it may be seen growing on most kinds of soils, and in sheltered as well as exposecl situations. In order that it may thrive, however, it requires an open, light, dry, and deep soil, and a situation in some moderately sheltereil part of the country. It demands free exposure to air and light, and plenty of individual growing-space, for it does not stand being crowled among other trees; when grown in a plantation, therefore. the trees should be given ample room, as if they have not sufficient growing-space for ramification, they will hecome drawn up, slender, and unornamental in a very short time.

Propagation and Culture. - Seeds of the Nepanl l'ine are nuw comparatively plentiful. They should be sown on light well-prepared soil, and dealt with in the beds as recommented for the sowing of the Scots Pine. The plants are easy of cultivation, and when the yearling seedlings have been trinsplanted into the nursery-rows, they soon become large enough for planting out. 
The Lofty Pine is now plentifully distributed over most parts of Fngland, scotland, and Ireland, and specimens of it, ranging from 50 to $60 \mathrm{ft}$. in height, are far from uncommon. It is cheap enough to lee planted largely, for seedlings of $1 \mathrm{ft}$. in height now cost only from 9 d. to $1 \mathrm{~s}$. each.

The loftiest specimen reported to the Conifer Conference in 1891 had a height of $70 \mathrm{ft}$. and a girth of $6 \mathrm{ft}$. at $5 \mathrm{ft}$. above the ground; whilst the largest had $16 \mathrm{ft}$. of girth, with a height of $44 \mathrm{ft}$.

\section{(4.) LAMBERT'S GIANT-CONED PINE, P'inus Lamlertiana Donglat.}

Specific Character. - Leaves or needles in fives, $4 \frac{1}{2}$ in. long, rather stiff, of a dull but not shining green colour, rather rough at the edges, and slightly glaucous when young (see Fig. 57). Sheaths very short, or nearly wanting on the old leaves. Branches in whorls, numerous, rather pendulous towards the extremities, and densely clothed with foliage. Cones very large, from 12 to 16 in. long, and about $4 \mathrm{in}$. in dianeter, deep brown, cylindrical, tapering to the point, mostly straight, and destitute of resinous mitter, pendulous when full grown, although nearly erect when young. Seeds large, oval, $\frac{7}{8}$ of an inch long, and with the wing $1 \frac{3}{4}$ in. long, and dark brown. They require two years to ripen, are pleasant to the taste, and are used for food by the North American Indians (Gordon, op. cit., p. 228).

Distribution. - The Lambert or Giant-coned Pine, also called the "Sugar Pine," is indigenous to the northem parts of California and of north-west America, and is frequently found intermixed with other Pines and Firs, generally about a hundred miles inland from the sea. In its native habitat it is said to attain its greatest dimensions when growing upon a pure sandy soil. It was introduced into Britain by Douglas in 1827.

Although distributed between the $35^{\circ}$ and $45^{\circ}$ of latitude in North America, it nowhere forms pure forests.

Description of Tree.-The Lambert Pine attains large dimensions in its native parts, leing found growing from 100 to 200 , and even according to some accounts $300 \mathrm{ft}$. in height, and with stems from 7 to $15 \mathrm{ft}$. in diameter near the ground; it has an open and pyranidal crown of hranches spreading ont orer a clean bole of about $100 \mathrm{ft}$. From the appearance of specimens in this country, it seems to be an open-crowned, free-growing tree, with wide-spreading Iranches, but has nothing very characteristic or remarkable about it. It is, however, perfectly hardy in this climate, which is a great recommendation for it. Plants of this species appear never to be at all injured by the frosts and rapid changes of our climate. 
Like those of Sabine's Pine and of the Stone Pines ( $P$. pinea and $P$. cembra), the seeds of the huge 1:- to 16-in. cones (whence the name "Giantconed Pine") of this species are edible. The resin exuded from this tree is sweet, and forms the well-known "chewing-gum."

\section{Fig. 57.}

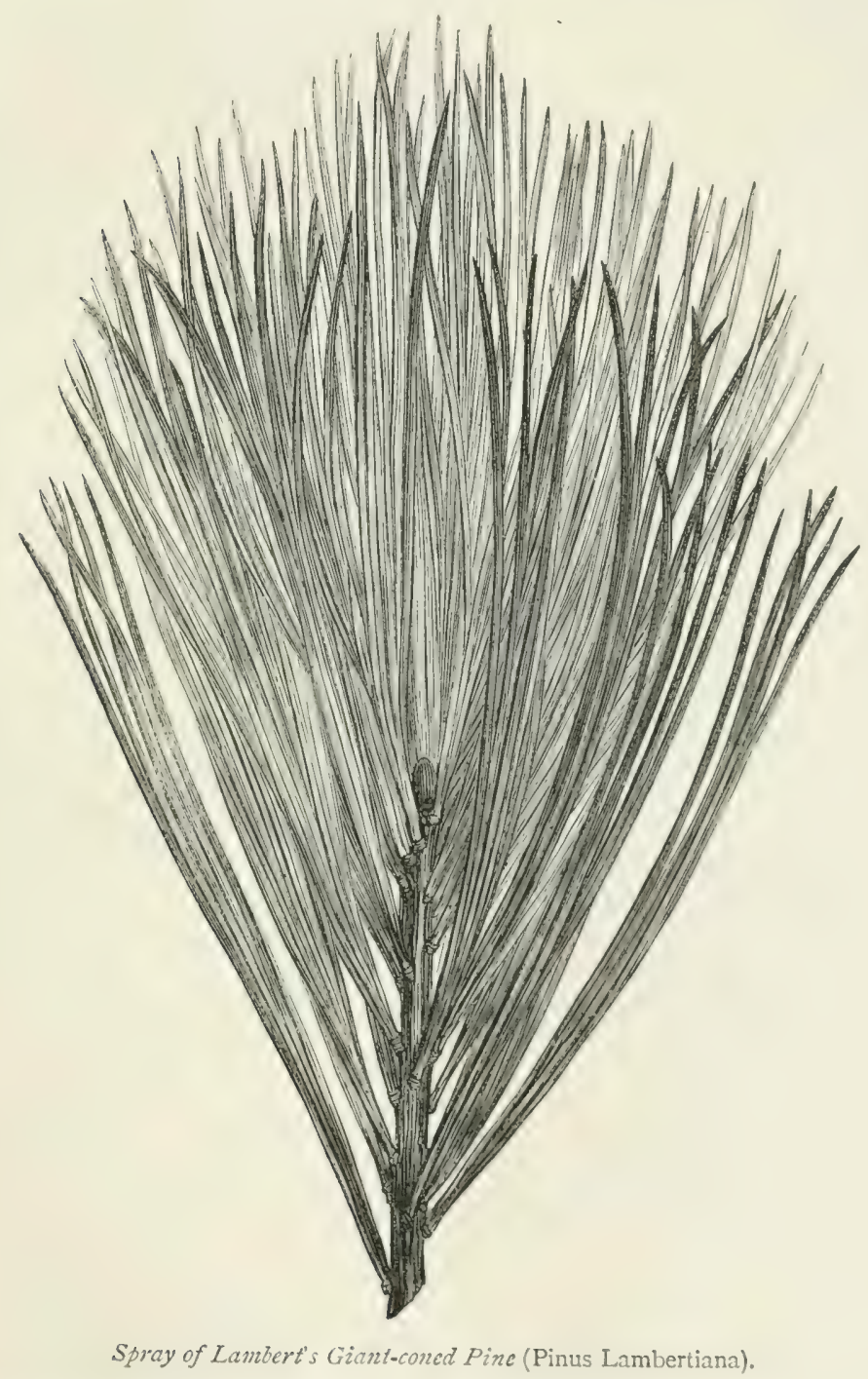

Economic Uses of Timber.-The timber of the Lambert I'ine is said to be white and soft. There will soon in this country be trees large and old enough to enable a correct judgment to be formed as to the quality of the timber produced by it in our climate: but

VOL. I. 
it is not likely that this Pine will be able to assert claims to sylvicultural attention.

Soil and Situation.-The Lambert or Giant Pine does not appear to be very particular with respect to soil, as good specimens of it may be seen growing on poor gravelly land, on a light peaty soil, on light as well as on heavy loam, or even on aroillaceous soil. If the land on which it is planted be dry, and the subsoil open and permeable, it will succeed on a great variety of soils, and find conditions for its normal thriving; but it seems, on the whole, to do best on a light loam, rather of a poor than a rich description, and on situations freely exposed to light and air-for, like most Pines, it is a light-demanding species of tree.

Propagation and Culture.--The seed of this I'ine may be sown on any well-prepared piece of ground in the usual way, as it vegetates freely, and the young plants, being hardy, recuire no protection whatever.

The Lambert or Giant Pine was about twenty years ago strongly recommended for sylvicultural introduction on an extensive seale into the State forests of northern Germany in admixture with Larch and. Spruce; but the proposal was severely criticised by many of the best sylviculturists, for many other species of Conifers seem far more deserving of attention from those financial and economic points of view which form the basis of the modern science of Sylviculture. In this respect Douglas Fir and Menzies Spruce, as also the Black Pines, have claims to attention which perhaps surpass those of nearly any other exotic Conifers of recent introduction.

At many places in England and Scotland there are fine healthy specimens of the Lambert or Giant-coned Pine that have attained a height of from 40 to $50 \mathrm{ft}$.

The largest specimens reported to the Conifer Conference of 1891 had respectively a height of $50 \mathrm{ft}$., with a girth of $6 \frac{2}{3} \mathrm{ft}$. at $5 \mathrm{ft}$. above the ground, and $45 \mathrm{ft}$., with a girth of $9 \mathrm{ft}$.

(5.) THE MONTEZUMA or MEXICAN PINE, Pinus Monti:ume, Lamb.

Srnonsus-Pinus occidentalis Humboldt; $P$. Russelliana Lindl.

Specific Character.-Leaves or needles in fives, from 3 to $4 \mathrm{in}$. in length on the wild specimens, but on young plants from 4 to 5 in. long, rather stout, rigid, 3-edged, and rough at the angles, thickly set on the young branches, and supported by long, sharppointed, brown scales at the hase of each sheath, of a dark green on the upper surface, and slightly glancous on the under side on the young leaves, but on old full-grown leaves dark green on both sides. Sheaths persistent, or not falling off, nearly $\frac{1}{2}$ an in. in 
length, and rather rough or jagged on the ends. Seed-leaves on the young plants from 6 to 8 in number. Branches few, very irregular, rather stout, and twisted. Jark very rough, particularly on the young wood, which is covered with numerous long, broad, sharp-pointed scales. Buds few, imbricater, non-resinous, and rather lengthened. Cones in clusters of three or four together, but frequently single, nearly horizontal, from 4 to 6 in. in lensth, ancl $1 \frac{3}{4} \mathrm{in}$. broad at the widest part, which is near the middle, then tapering to both ends, and slightly incurved, but especially towards the point, which is rather small (Gordon, op. cit., p. 232).

Distribution. - The Montezuma Pine is plentiful in the mountainous districts throughout many parts of Mexico. Hartwerg found it on the mountains of Mexico, near Ajusco, forming a tree $40 \mathrm{ft}$. high. It occurs also on the mountains of Orizaba, at an elevation of about 10,000 to $11,000 \mathrm{ft}$., where it grows to a height of 40 to $60 \mathrm{ft}$. It was introduced into Britain in 1826 .

Description of Tree.-This species of I'ine does not attain great height or dimensions of stem, and may be characterised as a broadly spreading, thinly branched, and rough-loarked Pine, only worthy of being cultivated as a variety in a pinetum.

Economic Uses of Timber.- - The timber of the Montezuma or Mexican Pine is sair to be very resinous and of excellent quality when grown in the subtropical forests of Mexico; but in Britain it is not wanted for its timber, as the indigenous and the many other exotic Pines are much superior to it for timber-production.

Soil and Situation.-Although, in a general way, this species may be said to be hardy in this country, still it has been found very fastidious with regard to soil and situation: for healthy and satisfactory development it seems to require a good light loany soil, and as sheltered and favourable a situation as can be allotterl to it.

Propagation and Culture.- Fomng plants of the Mexican Pine require to be protected by a frame during the first and also often during the second winter, until they have succeeded in forming good haxd woody tissue, and have become less sensitive to the effects of cold.

Specimens of this l'ine are by no menns uncommon throughout the arboreta of Britain.

The Montezuma Pine possesses hardly any claim to sylvicultural attention, for its general growth and development are inferior to those of the Heymouth Pine belonging to the same 5-leared class of Pines. But with its long needles, sometimes in young trees attaining a length of 8 to $12 \mathrm{in}$., it is undoultedly a very beautiful ornamental species for arboricultural purposes and landscape gardening. 
6.) THE FIVE-LEAVED MOUNTAIN PINE, Pinus monticola Donglas. Sxxoxyม-Pines Lambertiana brevifolic Hort.

Specific Character.-Leaves or needles five in a shenth, short, smooth, and blunt-pointed, from 3 to 4 in. long, rather 3 -sided, slender, glancons-green, and with a silvery appearance when young. Sheaths short and imbricated. Cones long, cylindrical, 7 in. long and $1 \frac{3}{4} \mathrm{in}$. wide, tapering to rather a blunt point, smooth, and full of resin, generally in whorls, and on short footstallss. Branches rather stout, short, and densely clothed with foliage (Gordon, op. cit., p. 233).

Distribution. - This Pine is indigenous to northern California, where it is found crowing abundantly on Trinity Mountain, at an elevation of about $7000 \mathrm{ft}$, , on a very poor soil formed from granite rock; it is also to be met with on the still higher mountains at the Grand Rapids of the Columbia, and on the rocky banks of the Spoken River. It was introduced into Britain in 1831.

Description of Tree. - This forms a very handsome tree, being well clothed with foliage, while the branches present a fine irregular outline. It is said to grow to a large size in its native parts, and even in this country has proved itself of rapid growth. It is very hardy, too, which is a great recommendation for it; it deserves a place in every park and pinetum, where its dense foliage is calculated to produce a good effect among trees of a more open habit of growth.

Economic Uses of Timber.-The timber of this Pine is said to be of a white colour, fine-grained, and tough.

Soil and Situation.- - It thrives well on most kinds of land, and appears to be of an accommodating nature. Good specimens of it may be seen in Britain doing well on a very light and gravelly soil, as well as on land of quite an opposite character. It seems a hardy tree, and possesses considerable power of accommodating itself to a great variety of soils, provided they are deep, porous, and dry. It stands well in an open airy situation, but can hardly be said to thrive if exposed to frequent storms.

Propagation and Culture.-The seed of this species of P'ine is still somewhat scarce, consequently the quotations of nurserymen for young plants are higher than those obtaining for most other kinds of Pine. The plants come up perfectly well when the seed is sorwn on the open ground in the usual way, but, from the scarcity of plants of the species in the country, cultivators usually protect the seedlings with a frame during the first winter after they have come up. This is done, however, more from a fear of losing any of them than from the young plants being sensitive or really requiring protection.

There are now many fine specimens of this Pine in various parts 
of the comntry, of heights varying from 50 to $70 \mathrm{ft}$. The specinens at Dropmore in England, and those at Keir in Scotland, are prolsalsly the best that are to be seen in Britain.

The largest specimen reported to the Conifer Conference of 1891 was a tree at Scone measuring $71 \frac{1}{2} \mathrm{ft}$. in height, and laving a girth of $\delta \mathrm{ft} .11 \mathrm{in}$. at $5 \mathrm{ft}$. above the ground.

(7.) HARTWEG'S PINE, Pinus Hartwegii Lindley.

Specific Character.-Leaves or needles generally in fives, though frequently only in fours, very dense, 6 in. long, rather slender, curved, and of a dark-green colour. Sheaths long on the young leaves, but with a shrivelled appearance on the old ones, and jaggeel at the ends. Branches few, very robust, and irregularly placed on the stem. Cones growing in clusters, pendulous, 4 to $5 \mathrm{in.}$ long, and nearly $2 \mathrm{in}$. broad, oblong, tapering to the point, which is rather blunt, incurved, and of a dark-brown colour (Gordon, op. cit., p. 226 ).

Distribution.-This species was found by Hartweg on the Canpanario Mountain in Mexico, at an elevation of $9000 \mathrm{ft}$., where its lower limit appears to commence when the upper limit of the Picen religiose is reached. It is also found growing to a lreight of about $100 \mathrm{ft}$. on the mountains of Orizaba, and near the Real del Monte, at an elevation of nearly $10,000 \mathrm{ft}$. It was introduced into Britain in 1839 .

Description of Tree.-This is a very handsome species of I'ine, which attains a height of fully $50 \mathrm{ft}$, and develops a dense, compact crown of beautiful dark-green foliage. It is a very robust tree, with stout branches, which form a striking feature in its general habit of growth; and it is readily distinguishable from most other Pines by the very strong appearance of its shoots, to which its long slencler leaves give a peculiar effect. It is hardy enough for favourable localities in Britain, and is deserving of a place in our arboreta : l,ut it possesses no claims to sylvicultural attention.

Economic Uses of Timber.-Hartweg's P'ine does not seem to be possessed of any value for timber-production in this country, althongh in its native climate its wool is said to be of excellent quality. There the timler is said to be very durable, and to be largely impregnated with resinous secretions. It is never, howerer, likely to become viluable on this accomnt in Britain. Its place here seems to entitle it only to the attention of the arhoriculturist for ormamental planting: but for this purpose its character is well suited.

Soil and Situation.-In order to attain its lest derelopment, this species of Pine requires to be planted on rather a poor and light 
loam, and to have the free exposure to light and air requisite for an essentially light-demanding species of tree. If planter on a rich soil, its young shoots are of a soft and immature description, and are therefore liable to be injured by frost.

Propagation and Culture.-Although this species of Pine is hardy enough for growing in the milder and more favourable parts of southern Britain, still the plants are somewhat sensitive and tender when young; they should therefore, like those of the Aleppo Pine ( $P$. halepensis) and some other species, receive the protection of a frame for the first two winters after corning up.

Hartweg's Pine has not been largely planted in this country; but at Kew and at Castle Kennedy there are specimens of from 30 to 40 feet in height.

The largest specimen reported to the Conifer Conference of 1891 is one on the Mountstuart estate, in Bute, which measured $33 \mathrm{ft}$. in height and $1 \mathrm{ft}$. $10 \mathrm{in}$. in girth at $5 \mathrm{ft}$. above the ground.

2. SPRUCE, Picea Link. (Linnean System, Monecia Moxadelphia).

Srronyus-Abies DC. ; Abies Loud.

Generic Character.-The leading characteristics of the Spruce Firs are: the projecting cushions at the base of the leaves, which give a rough, pegged appearance to the shoots; the four-sided leaves (flat in the section Omorica), uniform in structure; the usually pendulous woody cones, ripening in the first year, and the scales of which do not fall away one from the other, as in the Silver Firs. Bracts concealed, not projecting, free from the scales except at the base. Stamens in spike-like masses. Anthers 2-lobed, apiculate. Pollencells winged. Seeds small. Seed-wings obovate, separable, covering the upper side of the seed. Cotyledons 8-10, 3-sided, toothed, primary leaves flat, denticulate. Willkomm makes two sectionsI. Enupicea, with four-sided leaves; and II. Omorica, with flattish leaves with stomata, and with white bands on the upper surface (Masters, op. cit., p. 220).

The Spruces or Spruce Firs are all evergreen trees, indigenous to Europe, Asia, and America, and are remarkable for their tall, erect, pyramidal forms, and dense foliage. In Britain they flower in May and June, and ripen their cones in the spring of the following year. All the species bear seed at a very early age, and all of them may be readily propagated loy cuttings taken off in the spring or in autumn; throughnut Britain this is generally the practice hy cultivators of some of the rare species.

It is also a genus of trees possessing very great sylvicultural and 
arboricultural value. They are easily distinguished from the Pines by their tall pyramidal form, by their more rapid growth, and by their comparatively slender branches, which seldom attain the dimensions of timber, and which gradually die off under the shadow of the

Fig. 58a.

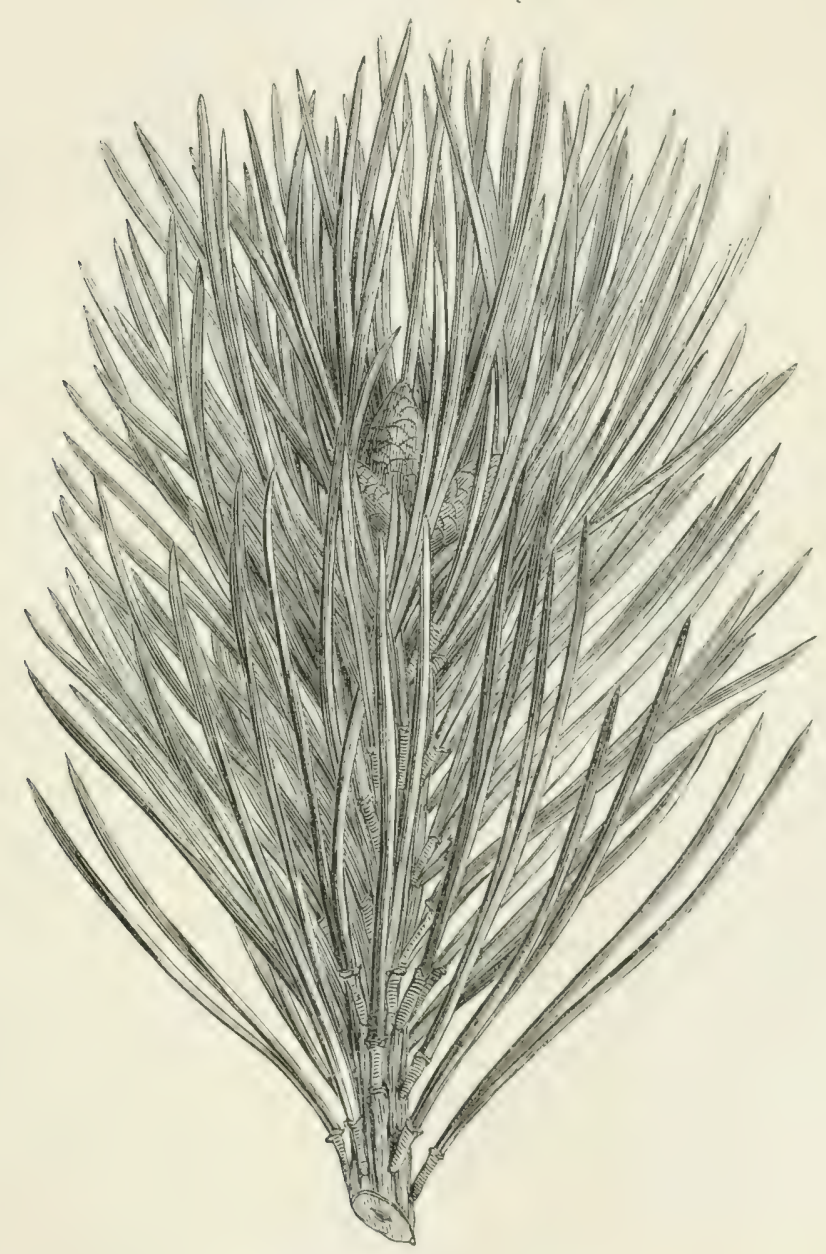

Spray of Scots Pine (Pinus sylvestris).

dense crown of foliage as the trees grow old. But besides this characteristic, the trees of the genus Picen are still more readily distinguishable from those of the genus Pinus by the clisposition of their leaves on the branches. In the l'ines the leaves of the short shoots are divided into two or more neelles in each sheath; whilst in the Spruce Firs the leaves or needles grow singly, and are scattered 
chiefly along the upper sides of the branches (see Fig. $58 a$ and Fig. 586).

The Spruces are trees that generally maintain density of eanopy much longer than the Pines. Hence crops formed by them make smaller demands for growing-space as they advance in age.

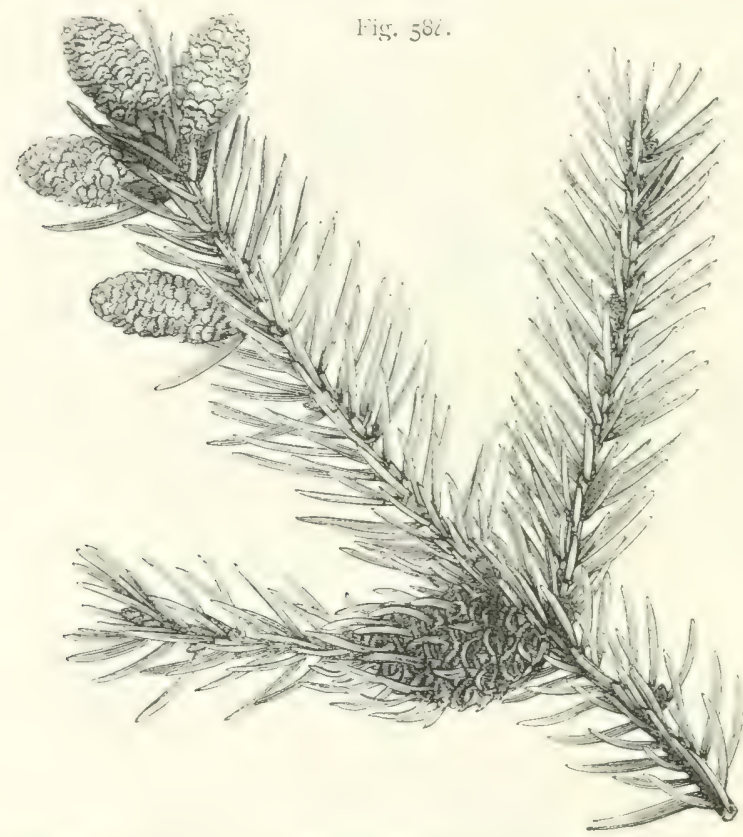

Spray of Spruce (Picea excelsa), showing the disposition of the needles on the twigs.

During the late summer, 3 to 5 buds are developed along with and immediately under the terminal bud, and these form a whorl during the following spring. These are not again budded in whorls; but 2 or 3 buds generally form near their ends, and these develop so as to give the extremities of the twigs a 3 -pronged, fork-like appearance. As the foliage is persistent for several years, the Spruces are a class of trees naturally capable of bearing a considerable degree of shade; hence they remain long in close canopy, and in their strong upward tendeney of growth form straight long stems that clear themselves thoroughly of branches. When growing in isolated positions, they retain a dense mantle of foliage down to the very gromnd, and assume a conical outline.

\section{(1.) THE SPRUCE, SPRUCE FIR, or NORWAY SPRUCE, Picecu excelsa Link.}

Sxxoxims-Pinus Abies L.; P. Picea Du Roi ; P. excelsa Lamk.; Abies Picca Mill.; Abics excelsa DC. and Loud.; Picea vulgaris Link.

Specific Character. - Leaves scattered, solitary, 4-sided, deep sombre green, curved, stiff, sharp-pointed, more crowded together 
laterally than on the upper and under sides, and nearly $1 \mathrm{in.} \mathrm{long.}$ Branches on young trees nearly horizontal, and clisposed in regular whorls from the base to the summit; but on old trees the bottom branches drop off, and the others become rather pendulous. Cones produced on the points of the upper branches, and when full grown becoming pendent; they are from 5 to $7 \mathrm{in.}$ long, and $1 \frac{1}{2}$ to $2 \mathrm{in}$. in breadth. Seeds very small, with a wing 3 in. long. Seed-leaves from 7 to 9 in number (Gordon, op. cit., p. 3).

Distribution.-The Common or Norway Spruce is indigenous to the hills and mountains of Europe and Asia, in places where the soil is moist, and the atmosphere cold and humid. It is, however, most common in Norway, Sweden, Lapland, Demmark, and the north of Germany. It is also found on some of the mountainous districts of France, on the Alps, the Pyrenees, and in Switzerland. It was introduced into Britain in 1548.

No other European Conifer has such a wide distribution throughout Europe as the Spruce; and, indeed, among forest-trees altogether, it is probably only surpassed in general distribution by the Scots Pine, the Rowan, and perhaps also the Birch. Its northern limit begins on the west coast of Norway at $67^{\circ}$, sinks to $65^{\circ}$ in Sweden, and then ascends to $691^{\circ}$ in Finland, where it reaches its polar limit, which thence trends in a south-easterly direction across Russia. Its eastern limit is not determinable, as it gradually merges into the Siberian variety (Picen olorata), having smaller and thinner foliage, and conical cones only about half as long as those of the Common Spruce. In general, however, longitude $55 \frac{1}{2}^{\circ}$ may be taken as about its eastern limit. In south-eastern Europe its southern limit is in Servia about $43^{\circ}$ latitude, whence it trends westwards in a curve across northern Italy and above Nice, thence following the southern boundary of the Cevennes, and stretching across the Pyrenees down to below the Maladetta Mountains, where its lowest equatorial limit is reached. From there it returns at an acute angle into the mountainous regions of France (Willkomm, op. cit., pp. 77-79).

The Spruce is essentially a tree of the mountains, and not of the plains or the lower hills; but the height to which it ascends the mountain-slopes varies, of course, enormously with the geographical position of any particular point. Thus in Norway at $67^{\circ}$, where the snow-line begins at $3600 \mathrm{ft}$, it does not ascend to higher altitudes than 2700 to $2900 \mathrm{ft}$., whilst in the Central Pyrenees it occurs at 4000 to $5000 \mathrm{ft}$., and is to be found in the Upper Engadine at an elevation of $6500 \mathrm{ft}$. above the sea-level.

Observations in various parts of Europe have shown that in order to commence active regetation in spring a mean cumulative warmth of $37.2 \mathrm{C}$. (or $670^{\circ}$ Fahr.) is requisite, and that the surue will only thrive in those localities in which the sun is above the horizon for at least 14 hours at the precise time at which this total of warmth is reached in sirning. Thus, near Vienna this degree of warmth is reached when the day is only 13 hours 54 minutes in duration, and there the Spruce will not thrive ; but at Kaltenleutgeben, at an elevation of over $1000 \mathrm{ft}$., that total amount of warmth is 
reached only two days later, when the day is actually of 14 hours' duration, and there the suruce finds the essential condition for its thriving fulfilled (Willkomm, op. cit., p. 92). This is a point that should receive careful consideration before the spruce is very extensively planted in the southern parts of Enylund, as it seems to he the natural law limiting the artificial distribution of this tree for sylvicultural operations.

Description of Tree.-The Spruce is one of the tallest of the European Coniferre. In the countries to which it is indigenous it fremuently attains a height of 150 to $160 \mathrm{ft}$, and forms full-wooded stems of from 4 to $5 \mathrm{ft}$. in diameter; and even in Britain it is not unusual to find specimens above $100 \mathrm{ft}$. in height, with stems of between 2 and $3 \mathrm{ft}$. in diameter. It assumes a distinctly pyramidal habit of growth. When growing in the open, the stem rises like a perpendicular stalk, clothed with a conical mantle of slender, feathered, horizontal branches from bottom to top. These, when the tree stands free and alone in an isolated position, gradually become smaller and shorter as they are found higher up the stem, thus giving the tree a rery regular conical outline. In the younger stages of growth the slender branches generally stretch out horizontally, but in old trees they droop a good deal, and this pendulous habit gives the tree a very graceful appearance. The Spruce is nearly as hardy in Britain as the Scots Pine. But it does not thrive well on high-lying sites if the soil be at all thin and dry: where the soil is favourable, however, it thrives in low-lying situations, as well as at considerable elevations, and is as hardy as any forest-tree that has become a denizen in Britain.

Economic Uses of Timber. - The timber of the Common Spruce is, next to that of the Scots Pine, perhaps the most useful for hoards, planks, and roofing scantlings which has hitherto been grown in this country. It is of excellent quality when of mature age, being very lingt and pliable. The quality of the wood of this tree is, however, like that of the Common Pine, very much influenced by the nature of the soil and the situation upon which it is produced. When grown on a thin dry soil, the wood is brittle and short-grained; but when grown upon a deep loam, resting on a cool subsoil, it is of a much superior character. In its younger stages of growth the spruce yields a far more durable timber than Scots Pine of the same age; but the reverse is the case when the trees are full grown, and when their timber has been allowed to attain its full technical and marketable maturity.

With the exception of the Silver Fir, the Spruce forms a more fullwooded bole than any other European Conifer. This point is of very great importance from a financial point of view; for the technical utility, and consequently the market value, of long logs depends to a great extent on the 
proportion which the diameter of the top-end bears to that of the butt-end. 'Thus, whilst the form-fertor of the Silver Fir ranges from 0.44 to 0.57 (the ideal true cylindrical bole being $=1.00$ ), that for siruce varies from 0.41 to 0.58 , and for Larch from 0.33 to 0.51 .

The wood of the Spruce is full of numerous microscopic resin-ducts, as well as often containing hollow spaces filled with resin. The best ruality of wood is of a reddish-white colour, but both cologur and texture, weight, toughness, elasticity, and general durability are to a consideral,le extent dependent on the nature of the soil and situation upon which the trees are grown. There is no marked change between alburnum or sapwood and duramen or heartwood, as in the case of the Larch and Scots Pine; and, indeed, both in coniferous and deciduous trees, any very distinct and immediately perceptible distinction in the nature of heartwood of a markedly different colour from the younger wood seems to have some very close connection with the formation of a pronounced tap-root, and with very unmistakable demands for light and for a large individual growing-space.

According to Gayer (Forstbenutzung, 1888, p. 28), the mean sp. gr. of the chief species of Conifers-which are all lighter than the hroad-leared trees, except the Aspen, White Alder, Silver Poplar, and Lime-is as shown in the following table:-

\begin{tabular}{|c|c|c|c|c|c|c|}
\hline \multicolumn{5}{|c|}{ Species of Tree. } & Green. & Seasoned. \\
\hline Larch & . & . & . & • & 0.81 & 0.59 \\
\hline Scots Pine . & . & . & . & . & 0.82 & 0.52 \\
\hline Black Pine . & . & . & . & . & 0.97 & 0.51 \\
\hline Silver Fir . & . & . & . & . & 0.97 & 0.47 \\
\hline Spruce . & . & . & . & . & 0.76 & 0.45 \\
\hline Cembran Pine & . & . & . & . & $\ldots$ & 0.44 \\
\hline Weymouth Pine & . & . & . & . & 0.83 & 0.39 \\
\hline Wellingtonia. & . & . & . & . & $\ldots$ & $0.3 \mathrm{~S}$ \\
\hline
\end{tabular}

Spruce is, therefore, a very light wood, capable of being easily floated immediately after being felled. But, for a Conifer, it is compratively hard: it ranks between Elm, Beech, and Sessile Oak on the one hand, and Silver Fir, Horse-Chestnut, Alder, and Birch on the other. Along with the Silver Fir it heads the list of woods that are easy to split; whilst it ranks only after the Yew and Larch with regard to elasticity. In general durability it slightly surpasses the Silver Fir, and when grown at high elevations, so that its annual zones are narrow and its stem full of resin, it is classifiable as a durable wood, although still ranking below Larch and Scots l'ine timber that is not of the first quality.

Soil and Situation.-This tree is naturally inclinel to grow on cool land having a moist subsoil, and in Britain it is found to succeed best in a low-lying and rather sheltered part. Indeed, upon a high site, if much exposed to strong or cutting winds, it is lialle to be blown down, and seldom attains anything like large climensions of timber in this country; and this is more especially the calse 
if the soil upon which it is planted be of a dry, thin, sandy, or gravelly nature, for then the tree generally becomes attacked by fungoid disease, and rots at the heart before it arrives at anything like a useful size. It is in sheltered hollows, with good deep soil anl coul sulwil, that the Spruce attains its best dimensions in this country; and in such situations it is frequently found of from 80 to $100 \mathrm{ft}$. in height, with stems of from 2 to $3 \mathrm{ft}$. in diameter. The Spruce grows well on moss-land, after it has been drained and the excess of stagnant moisture has been removed. The tree likes a cool and moist, but not a wet, subsoil.

With regard to this particular species of tree the experience of Continental, and more especially of German, sylviculturists is very much greater than our own. There it has been found to thrive best in a cool, damp, humid atmosphere; and the drier the climate of any particular locality, the greater are its demands for soil-moisture. Hence it is essentially a tree of the mountains, although, owing to its shallow root-system, it is little fitted for planting on localities where the crops are exposed to strong winds.

With regard to mineral nutrients, it makes moderate demands on the soil ; whilst in respect to the amount of water actually required for transpiration, it in reality makes only limited demands. Ebermayer's classification (op. cit., p. 231) of the Conifers, which make far more moderate demands than the broad-leaved trees, is as follows:-

\begin{tabular}{|c|c|c|}
\hline & $\begin{array}{l}\text { As to mineral food withdrawn } \\
\text { from the soil. }\end{array}$ & $\begin{array}{l}\text { As to soil-moisture withdrawn for } \\
\text { transpiration. }\end{array}$ \\
\hline $\begin{array}{l}\text { I. Naking great- } \\
\text { est demands. }\end{array}$ & $\begin{array}{l}\text { Silver Fir, Cembran Pine, } \\
\text { Larch. }\end{array}$ & $\begin{array}{l}\text { Cembran Pine, Austrian and Corsi- } \\
\text { can Pine, Larch, Weymouth Pine. }\end{array}$ \\
\hline $\begin{array}{l}\text { II. Making moder. } \\
\text { ate demands. }\end{array}$ & $\begin{array}{l}\text { Spruce, Weymouth Pine, Scots } \\
\text { Pine. }\end{array}$ & $\begin{array}{l}\text { Scots Pine, Spruce, Mountain } \\
\text { Pine. }\end{array}$ \\
\hline $\begin{array}{l}\text { III. Making least } \\
\text { demands. }\end{array}$ & $\begin{array}{l}\text { Austrian and Corsican Pine, } \\
\text { MIountain Pine. }\end{array}$ & Silver Fir. \\
\hline
\end{tabular}

As regards transpiration, this classification may seem inconsistent with practical experience; but it must be borne in mind that, thanks to their deepreaching tap-roots, Larch and Pines can draw constant supplies of moisture from the subsoil, whilst a sutficiency can only be obtained by the Siruce when the soil is already so moist that a fair proportion of the aqueous precipitations is retained near the surface-soil in the layers permeated by its shallow rootsystem. It will be noted that long-needled Pines transpire more than Spruces and Silver Firs.

Whilst making rather more demands on the general quality of the soil than the Scots, Austrian, and Corsican Pines, it can thrive on land that is too inferior for the production of satisfactory returns by means of broad-leaved crops of trees; and as it is a densely foliaged species, protective of the soil, it gradually (with proper treatment) improves the quality of the land by huslanding nutrients, and thus gradually enhancing its future productive capacity. 
Its finest development is attainable on sandy-loamy soil, but it can do well on moist sand, or even on somewhat tenacious land. Where a certain degree of soil-moisture is indicated by the spontaneous growth of weeds like foxglore, epilobium, ragwort, and succulent grasses, the syruce is almost sure to thrive.

It can hardly be disputed that in Britain the rlevelopment of the Sinuce is not so good as throughout central Ciermany. This fact is probably explainable by the circumstance that in its true northern home thromghout Germany, Torway, and Sweden, as well as in the Alps and over all its southern distribution, it has a very long period of complete winter rest from active vescetation, accompanied by a very low temperature for two or three months at a time; whereas in Britain, on the contrary, the autumn is often of long mild duration, and there is practically very seldom any lengthy period of continuous hard frosty weather, such as is the usual characteristic of the climates in which the Spruce is indigenous. That our damp, mild, insular winters, which form a very marked contrast with the dry, cold, continental winters of central and northern Europe, tend to predispose the tree to fungnid disease of the stem, can hardly excite surprise in any one who gives the matter careful consideration.

Propagation and Culture. - The Spruce is propargated by se+el in exactly the same manner as the Scots Pine; and as the details regarding the gathering of the cones, the liarvesting and sowing of the seed, are in every essential respect similar (except that the seed of the Spruce ripens and should be gathered in the early parts of spring), reference need here only be made to the detailed description of these operations already given under the scots Pine (see p. 257). The Spruce Fir, however, is much slower in growth than the Scots Pine while in its seedling state. The seedling plants remain two years in the seed-bed, but they generally require three years in the nursery-rows before they are fit to be put into their final situations in the forest, or even more if they are wanted of large sizes. As a nurse for hardwood trees, the Spruce does not answer well. Robinia, Larch, Birch, and Scots Pine are far superior for this purpose, as the side-shade they cast around them is not so deuse. Besides its being of too rapid growth and too deusely foliaged for the deciduous, broad-leaved hardwoods, Spruce has the additional disadrantage of forming very fibrous and matted roots. Now these, from their matted closeness, keep the air and moisture from penetrating into the soil for the benefit of the root-systems of the hariwoods, which send their roots deeper down, and consequently much injury is often done on this account. Spruce, like all the densely foliaged species of the coniferous tribe, may thrive well for timber-production when planted pure as a forest crop by itself; but, for various sylviculturial reasons, it is much preferable to intermix it along with other species of trees, broad-leaved kinds as well as Conifers, and to grow them all in mixed woods. It then not only forms a finer stem, but it is also less ex- 
posul to the danger of becoming windfall during violent storrns, or to suffer from the attacks of noxious insects or from infection with fungoid diseases.

Sylvicultural Characteristics and Importance of the Spruce.-From the very nature of its shallow root-system, the Spruce may be seen to be more naturally adapted for growth on mountain-sides than on alluvial deposits of light soil, where a tangled mass of shallow surface-roots could afford it little support against the violence of high winds, more especially of the southwestern storms that often come when the lofty crown of foliage is heavy with moisture, and the ground is sodden with rain.

Although rapid in early development, it is not at first of such quick growth as the Scots Pine; but it continues to grow in height for a considerably longer period, and it is not until about the 70th to 120th year (according as the soil is of inferior or better quality) that the crops begin to show signs of having reached their full mercantile naturity. It differs again essentially from the Scots Pine in its relation to light ; for whilst the Pine is a light-demendin! species, requiring a relatively large individual growing-space when it is beginning to attain the dimensions of a timber-tree, the spuruce is a shade-beriting species, content with a comparatively small growing-space. It therefore remains in close canopy till it reaches its full maturity, and is not only a good soil-protecting, but also, as has previously been explained, a soil-improving species. It is consequently well adapted by nature for the recuperation of soils that may have become temporarily deteriorated under lightly foliaged deciduous crops. But in many cases the same sylvicultural advantages may be attained by means of the Douglas Fir, which yields more remunerative returns in Britain than the Spruce.

The needles of the Spruce are persistent for from 5 to 7 years, and though they are short, they form a very thick and close canopy of foliage overhead.

Local markets for wood will, of course, in each case determine the age at which crops of Spruce should be utilised; but on the Continent a rotation of 60 to 90 or 100 years is considered most advantageous. In the formation of young woods, planting of sipruce is preferable to sowing; the plants should be put out between the ages of 2 and 5 years, at distances varying from $2 \mathrm{ft}$. by $2 \mathrm{ft}$. to $3 \mathrm{ft}$. by $3 \mathrm{ft}$.

Good specimens of the Spruce are plentiful in most parts of Britain, and therefore it is unnecessary to refer to them as being found more particularly in any special locality. Trees from 80 to $110 \mathrm{ft}$, in height, and with stems of from 2 to $3 \mathrm{ft}$. in diameter, are common in many parts.

\section{(2.) THE BLACK SPRUCE or BLACK AMERICAN SPRUCE, Picea nigra, Link.}

Srsoxrss-Abies denticulata Poir.; Pinus nigra Ait.; P. Mariana Du Roi; P. marylandica Hort.; Abies nigra Michs.

Specific Character.-Leaves or needles solitary, spreading regularly all round the branches, somewhat 4-sided, very short and stiff, 
of a sombre dark green, $\frac{1}{3} \mathrm{inl}$. long, thickly set, and erect. Branches horizontal, or in the case of old trees very slightly drooping at the ends. Cones pendulous, egro-shaped, $1 \frac{1}{2}$ in. to $13 \mathrm{in}$. long, and $\frac{3}{4}$ of an inch broad, deep purple in colour when young but of a reddishbrown when ripe. Seeds small, with a little stiff wing (Gordon, op. cit., p. 7).

Distribution.-This tree is indigenous to the Northern States of America, from Canada down to South Carolina and California ; but it occurs most abundantly between the $53^{\circ}$ and $54^{\circ}$ of north latitude. It is also very abundant on lands resting upon a cold sulysoil in the province of Lower Canada, where it forms large forests intermixed with the Hemlock $\left(T_{s u g a}\right)$. It is to be found plentifully on a great variety of soils in the valley of the Ottawa, intermixed with Weymouth Pine (Pinus Strobus) and various kinds of broad-leaved trees. It was introduced into Britain in 1700, and is now frequently to lue found in parks and arboreta.

Description of Treo.-On deep soil the Black Spruce frequently attains a height of from 80 to $100 \mathrm{ft}$; ; but even the tallest stems are seldom of more than $24 \mathrm{in}$. in diameter. Generally speaking, it forms a tall slender tree with a pyramidal crown, whose branches spread horizontally, and frequently droop at the ends in the case of old trees. The stem has usually a smooth, blackish bark, is very straight, and as it diminishes regularly from the bottom to the top, it has a low form-factor, indicative of a conical shape of the bole. The whole tree has an open and airy appearance, from light being admitted between the whorls of branches. These are never of a massy or heavy character, like those of the Common Spruce, but are light and pointed, each tier showing its outline distinctly. The tree is well worthy of a place in any park or lawn, for its light spiral form and dark-coloured foliage contrast agreeably, on well-chosen sites, with trees of a flat and denser habit, and especially with those having foliage of at light-green colour. It has always in good effect when planted along the sides of roads in a plantation of broal-leared deciduous treeg, or of Larch, as in such situations the contrast between it and the other trees is very striking, both in summer and in winter:

Economic Uses of Timber.-In America the timber of the Black Spruce is much valued for its strength, lightness, and elasticity. It is extensively used in house-building, and for fencing purposes, in all localities where it is abundint. The timber is considered durable, and is therefore applicable to many purposes; but it is seldom found of such large dimensions as to make it available for requirements where bulk of timber is an essential condition of its utility.

Soil and Situation.-The tree is well known to be perfectly lardy in Britain, and to grow on a great variety of soils. Good 
specimens of it may be found growing on almost all lands that are not too light and dry; but it appears to thrive best on a deep, somewhat mossy soil, with a cool, moist subsoil. It grows under much the same conditions as to soil and situation as does the Common spruce; it luxuriates on land having a cool subsoil, and occupying rather a low-lying and sheltered situation. It does not succeed on a very dry site, or in exposed positions.

Propagation and Culture.-The seed of this tree is abundant throughout North America, and may easily be procured from nurserymen. Like the seed of all the other North American Spruces and Firs, it should be sown on a light, dry, well-prepared, and rather rich piece of land, and on a warm site and a sheltered situation.

The seedlings should stand for two years before being planted out into the nursery-beds, within which they may remain for other two, three, or four years, according to the size of transplants desired for planting out in the open. When very large transplants are required, it is advisable to change them once a-year in the nursery-beds, in order to stimulate the production of rootlets; otherwise large transplants form long roots, and when these are removed during the single operation of transplanting, the plants fail to establish themselves readily in their permanent home.

Good trees of this species are common in the country, not only in Britain but in Ireland as well, many of them having attained heights of from 40 to $70 \mathrm{ft}$.

\section{(3.) THE WHITE SPRUCE, Picea alba Link.}

SrNoxims-Abies glauca et curvifolia Hort.; A. canadensis Mill.; Pinus alba Ait.; Abies alba Michx.

Specific Character.-Leaves solitary, incurved, sharp-pointerl, glaucous, 4-cornered, and scattered round the branches; about $\frac{3}{4} \mathrm{in}$. long, but frequently longer, and not very thickly set on the branches. Brauches compact, and rather dense. Cones oblong-cylindrical, 2 to $2 \frac{1}{2}$ in. long, and rather more than $\frac{1}{2}$ in. broad at the thickest part, slightly tapering to the point, pendulous, and not very firm (Gordon, op. cit., p. 2). When the cones are ripe, they are of a lightish-brown colour.

Distribution.-Like the Black Spruce, this species is also a native of the Northern States of America, from Canada to ('arolina, but is very much less common than the Black Spruce. In America it is grenerally to be found on dry light lands, and rery frequently groming along with or in the close neighbourhood of Weymouth Pine (P. Strobus). It was introduced into Britain in 1700 .

Description of Tree.-The White Spruce is easily distinguished from all the other species of the genus Picee by the lighter colour of 
its leaves, which are of a somewhat hoary grey colour,-lience its name. Even where indigenous this is not a tall tree, nor in any respect one of large dimensions; for it is hardly ever to lue met with over 45 or $50 \mathrm{ft}$. in height, or with a stem of more than 12 to 14 in. in diameter. It is a beautiful small tree, however, and forms a perfect pyramid when found standing alone and unencumbered. It deserves to be more planted in Britain thain it has been; not for the sake of its timber, however, but as an ornamental tree in parks and lawns, and along the sides of roals in plantations. In these situations its light colour and beautiful pyramidal habit of growtlı would produce varied and agreeable effects when seen contrasted against a lackground of other trees of darker shades and more rounderl outline. In the American forests opportunities frequently present themselves for admiring the gorgeous effect produced by this tree, when seen in the autumn in combination with the dark foliage of I'nes and the yellow and crimson leares of the Sugar-AIaple. The proprietor who may wish to produce a rich colouring of foliage in any particular part of his grounds has only to plant some dark-leaved clumps of Austrian or Corsican Pine in the background, the SugarMaple in front of that, and then again the White Spruce in front of the Maple; and when these trees have attained a fair size, he will find the autumn colourings admirable - the yellow, red, and crimson of the Maple, the very dark green of the l'ine, and the hoary grey of the White Spruce, blending so as to produce a brilliant eflect, almost beyond the art of the painter.

Economic Uses of Timber. - The wood of this tree does not appear to be applied to any technical purposes. In America its timber is not valued at all by the settlers, as in all cases they prefer the wood of the Black spruce or the Pine, which are usually found growing along with the White Spruce.

Soil and Situation.-This tree thrives best on dry sloping banki, where the soil is light and deep. It grows on heavy land also; but on the latter classes of soil it never attains the same limensions as it does on lands of a light and deep description. Like the Black Spruce, it prefers a sheltered situation; but it does not stand confinement among other trees. In the American woods, wherever confined in growing-space by the side-shade of other trees, it remains a mere unsightly pole; where, however, it stands alone, it bears a feathery mantle of foliage right down to the ground.

Propagation and Culture.-The methods of producing and of regenerating the White spruce are in all respects the same as lhas already been stated with regard to the Black Spruce.

At Castle Kennedy and at Hopetum Honse there are some good specimens of this Spruce.

VOL. I. 
(4.) THE MENZIES or SITKA SPRUCE, Picen Sitchensis Carriere.

Sravrus-Pinns Mensicsii Dougl.; P. sitchonsis Bongard; Abies Menzicsii Loud. A. sitchensis Lindl.; Picea Menzicsii Carr.

Specific Character.-Leares solitary, thickly scattered on the young shoots, narrow, linear, rigid, sharp-pointed, and incurved (see

Fig. 59.

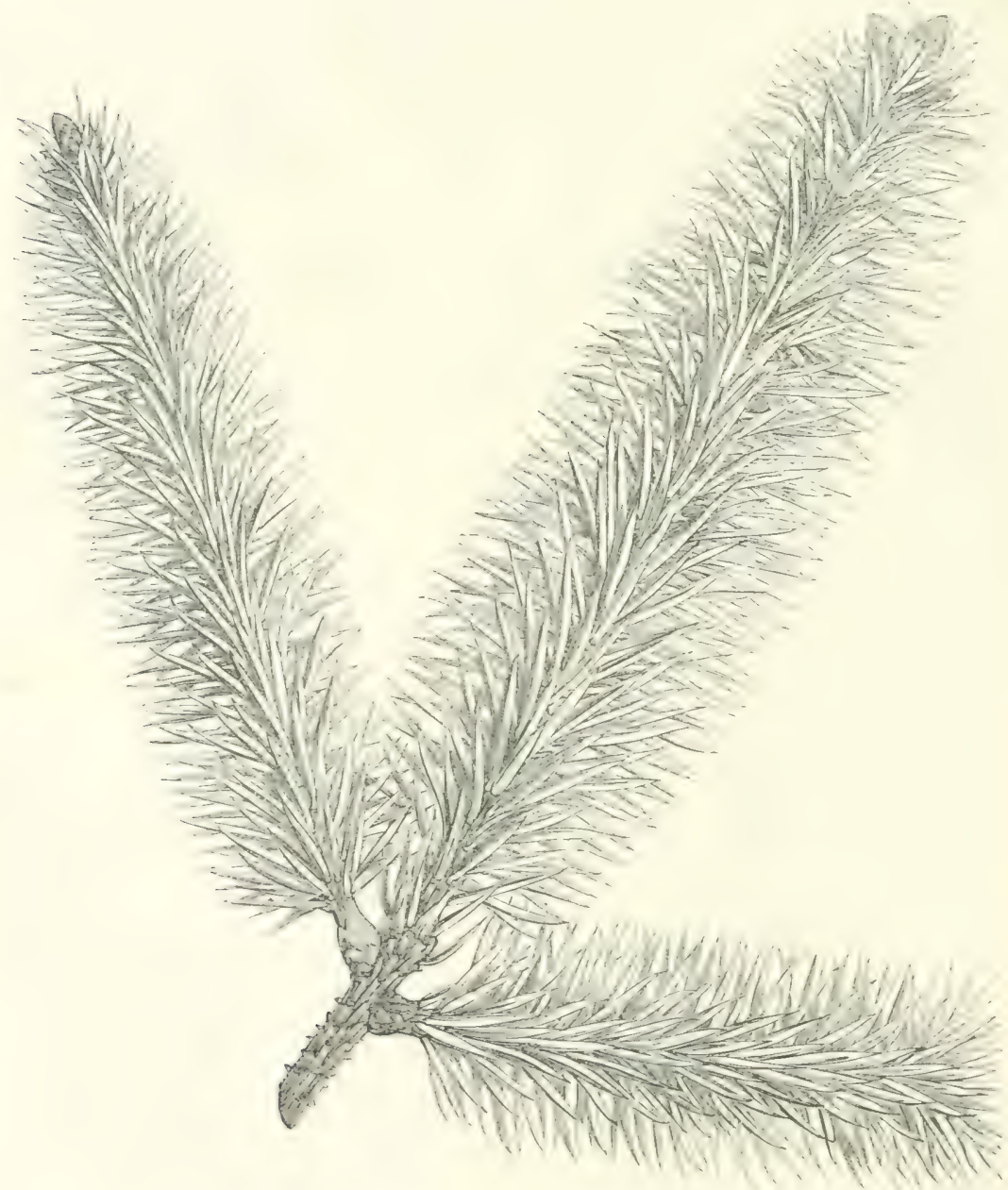

Young spray of the Menzies or Sitka Spruce (Picen Sitchensis).

Fig. 59), leaves or needles rich vivid green above and quite silvery below, from $\frac{3}{4}$ to $1 \mathrm{in}$. long, soon falling off after the first season, and leaving the old branches very naked, warted, and with a jointed appearance. Buds ovate-pointed, and covered with resin. Cones 
3 in. long, and 1 to $1_{4}^{1}$ in. broad, pendulous, cylindrical, bluntpointed, and with the scales lowse and not compact. Bracteas small, and hidden in the scales: seeds very snoll, and winged (Gordon, op. cit., p. 7).

Distribution.-This fine species of the suruce grenus was first intrreluced to notice by Douglas, who sent it home from Anerica in 18:3, and named it in honour of one of his predecessors as a pioneer in the American woorls, Menzies. It is found between $40^{\circ}$ and $57^{\circ}$ north latitude, and occurs in great alsundance in Northern California, on the island of Sitka or Sitcha, and also in the Shasta country. It ascends the Rocky Mountains to a height of $7000 \mathrm{ft}$.

Description of Tree.-This forms a highly ornamental tree, being of a pyramidal habit of growth, thickly hranched, and coverenl with dense foliage, having a beautiful silvery-green aspect. It is thoroughly hardy, and of very rapid growth. It ought to have a place in every arboretum, park, and ornamental plantation, as no doubt it will become ere long one of our forest-trees.

This handsome tree is of rapid growth, and is, along with the Douglas Fir, the most important of our introductions from America. It attains in California a height of nearly $200 \mathrm{ft}$., with a girth up to $30 \mathrm{ft}$. It is impatient of shade from above, but can thrive well in the side-shade cast by other species of equal height.

Economic Uses of Timber.-Douglits describes the matured timber of this species as being of excellent quality; and there can be no doult that this is the case, even julging only from the appearance of the wood of some of the larger specimens that have been grown in this country, and many of which are now from 60 to 80 ft. in height. The timber seems hard, firm, and of a durable description.

The quality of the timber produced on the Continent of Europe is said to entitle it to rank between the Douglas Fir and the Common Spruce.

Soil and Situation.-The Nenzies or sitka Spruce, like all the other Spruces, luxuriates in a cool, moist, loany description of land. It succeeds on most lands, however, that are not altoguther tno light and dry; but it makes the greatest and most healthy progress on rather loamy lands, which are porous, and at the same time somewhat moist and cool.

Although doing fairly well on dry soil, it appears to thrive best on fresh, mild, sandy or loamy soils. When plantations are formed by sowing, some light nurse, like Larch or Birch, is requisite to protect the seedlings against drought and late frosts. The growth of the seedlings is somewhat slow at first, but from the third year onwards it develops more rapidly than the Common Spruce. 
Propagation and Culture.-The seeds of the Menzies Spruce are now easily procurable, and plants are obtainable at very reasonable rates from nurseries. Plants, however, in the absence of seed, can be readily procured from cuttings; and to this mode of propagation cultivators are obliged to resort when seeds are not to be had.

It should usually for plantations be transplanted as a 4 - or 5-year-old schooled plant from the nursery-bed. At first it requires some protection against drought and late frosts, but soon outgrows this, and is then a very hardy species.

In nearly all good pineta in Britain there are specimens of this beantiful spruce, many of them ramging in height from $t 0$ to $60 \mathrm{ft}$. at 40 years of age.

\section{(5.) THE HIMALAYAN SPRUCE, Picea Morinda Link.}

\section{Sxwonras-Pinus Khutrow Royle; P. Smithiana Lamb.; Abies Smithiana and} A. Khutrow Loud.

Specific Character.-Leaves, singly at nearly equal distances round the shoots, mostly four-sided, somewhat curved, from $1 \frac{1}{2}$ to 2 in. long, and having very sharp points (see Fig. 60). Its branches spread out horizontally, but those nearest the bottom of the tree are somewhat bent downwards; the lateral branches are very numerous, slender, and drooping. The cones are pendulous when matured, from 5 to 6 in. long, and about $2 \frac{1}{2}$ in. broad, ovate-oblong, or nearly cylindrical; they have very even, brown, obovate, rounded scales, covered with a glaucous bloom when young. The young cones are at first upright, but owing to their own weight and the slenderness of the branches, they soon become pendulous (Gordon, op. cit., p. 12).

Distribution.-The Himalayan spruce is found on mountains in the interior of India, where it is more frequent on the cool northern slopes than on any other aspect. It forms extensive forests on the great Himalayan ranges of Northern India, at elevations of from 7000 to $12,000 \mathrm{ft}$. above the sea-level. Thence it extends eastwards into Japan. It was introduced into Britain in 1818.

Description of Tree.-The Himalayan Spruce is a magnificent tree, often attaining a height of from 140 to $160 \mathrm{ft}$., and with stems of from 4 to $6 \mathrm{ft}$. in diameter near the ground. It is a tree of a very graceful habit. On young stems the branches have an upward tendency, lut as the trees becone older the branches assume a horizontal position from their own weight, and finally in old specimens they gradually take a drooping form, more especially those of them that are situated at the lower part of the stem: and from these branches all the branchlets and small twigs droop downwarls in a very graceful manner. It is hardy in the climate of Britain; and though not 
at all likely to be of any real sylvicultural importance, yet it has a decided arboricultural interest. Hence it ought to be cultivated in every park and pinetum. It produces a fine effect when planted along the sicles of roads and drives running through plantations. Jint it can be recommended only for ornamental purposes, as its timber is soft, and is said to be, even in Britain, of a very perishable nature. In order that it may thrive well, the Himalayan Spruce requires to have a cool northern aspect, as in its own home.

Economic Uses of Timber.-As already just stated, the timber of this species is comparatively worthless, so that for timber-production it has no claim to our sylvicultural attention.

Soil and Situation.The Himalayan Spruce, like the majority of species of this genus, prefers a rather moist, deep soil, but without any tendency to stagnancy of the water in the subsoil. The soils upon which it thrives best are those of a light description, that are deep, cool, and moist, but not wet. These conditions of

Fig. 60 .

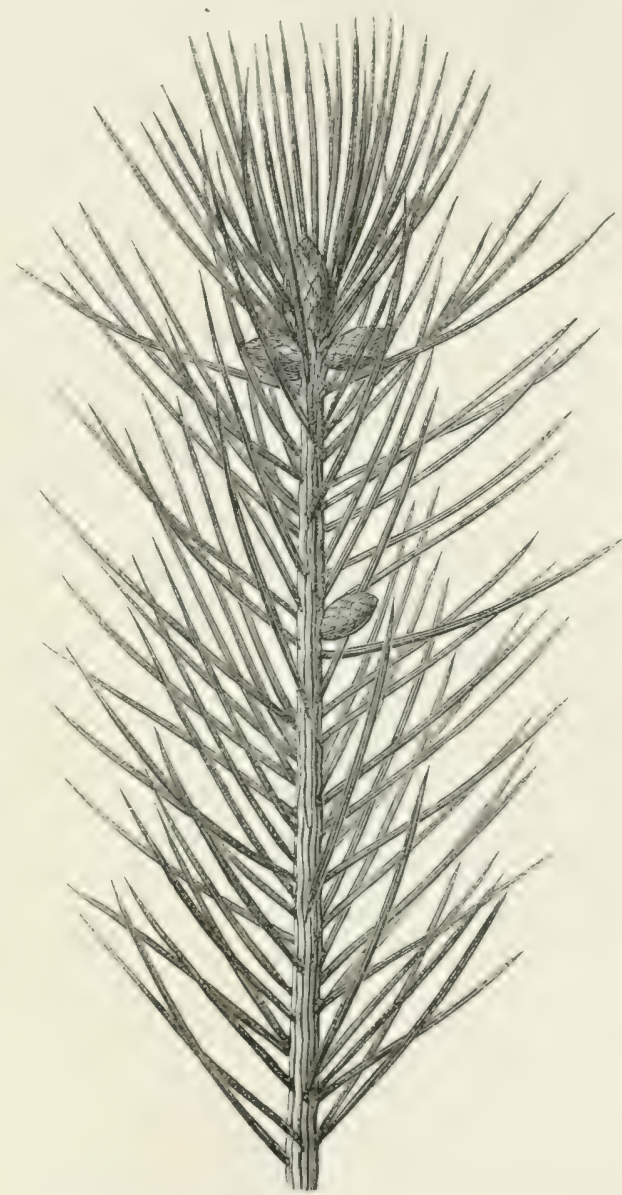

Truig of the Himalayan Spruce (Picea Smithiana).

soil can always be secured by planting on slomes where there is a good natural drainage, or by artificial draining where that is necessiry. A somewhat cool and shady situation is farourable to its development: for eren in our humid, temperiate climate it does not thrive so well as it is capable of doing, when it is planted out on warm, exposed, southern aspects. But with a judicious denree of shate and shelter combined, such as may easily be had when it is planted along the sides of roads in plantations, it thrives well, and soon 
becomes a lighly ornamental tree. It is chiefly the want of attention to points like these in the cultivation of the Himalayan Spruce that has been the cause of many of the specimens planted in the country not succeeding so well as their owners were led to expect. It will not stand confinement, however, among other trees; it must have perfect freedom all around.

That is to say, it appears to be less capable of bearing shade than the majority of the Spruce genus, and makes considerable demand for individual growing-space. As, however, this tree possesses no sylvicultural value for Britain, this demand for light is of no great consequence; for all trees cultivated with a view to the full development of their arboricultural qualities demand a larger growing-space than they could have as forest-crops.

Propagation and Culture.-The seed of the Himalayan Spruce is procured from India from time to time, but is still far from plentiful. It may be treated, in sowing it in nursery seed-beds, in the same manner as the seeds of the Common or Norway Spruce; and after the young seedlings have come up they may be transplanted out into nursery-rows in the same way as detailed for that tree (see p. 333). In the absence of seeds, plants may be procured by propagation from cuttings; but these do not grow so freely as seedlings.

Some of the finest specimens of this tree are said to be at Dropmore and Elvaston Castle in England, and in the grounds of Hopetoun House and Keir in Scotland.

At Shelsley Court, Worcester, there was in 1849 a tree of this species which had a height of $120 \mathrm{ft}$.

\section{(6.) THE ORIENTAL or SAPINDUS SPRUCE, Pica oricutulis Lk.}

Srmonxus-Pinus oricntalis Lamb; Abies orientalis Poir.

Specific Character.-Leaves solitary, very dense, partially 1 -sided, covering the branches on all sides, deep green on both sides, narrow, but not sharp-pointed, from $\frac{1}{4}$ to $\frac{1}{2}$ an inch long, and rather stout. The branches are straight, slender, and well covered with foliage. The cones are pendulous when full grown, cylindrieal, tapering rennlarly from near the base to the point, which is small, $2 \frac{1}{2}$ to $3 \mathrm{in}$. in length, and about $\frac{3}{4}$ of an inch broad at the widest part, which is near the base. Bracteas shorter than the scales, and enclosed (Gordon, op. cit., p. 9).

Distribution. - The Oriental Spruce is found on the coast of the Black seal, on the loftiest mountains of Ineretia, in Upper Ningrelia, and the neighlourhood of Teflis, forming pure forests in close canopy hetween Guriel and the Adshar Momtains, at an elevation of 4200 to $4800 \mathrm{ft}$. above the sea-level. It was introduced into Britain in 1838. 
Description of Tree.-.'The Oriental Spruce is saisl to attain the size of a large and lofty tree of the first magnitude. It is a very hardy tree, apparently as much so as the (mmmon or Norway. Since; for it seems to be compraratively insensitive to the frost of our severest winters. It appears, however, to be rather a slow-growing tree, at least in Britain, as in most places it seldom makes more than at enowth of 12 in. in height in one year, although ninder very farsuralle conditions it often grows more rapidly. In the countries to which it is indigenous it is said to attain a height of from 70 to $80 \mathrm{ft}$.; but in Britain it lags behind most of the other Spruces of recent introduction as regards its rate of growth in height.

Clear drops of resin, called "Sapindus tears," exude fron the tips of the young twigs.

Economic Uses of Timber.-The timler of the Orientul Spruce is full of resin, and is said to be of excellent quality, very tough, elastic, and durable. So far as one may yet estimate the quality of the timber produced by this tree in Britain, it promises to furnish wood of a useful kind; but with its slow rate of growth it can never offer sylvicultural attractions like those of the Douglas Fir and Menzies Spruce.

Soil and Situation.-With regard to soil and situation it appears to make demands very closely resembling those of the Meuzies or Sitka Spruce (see p. 339).

Propagation and Culture.-The seeds of the Oriental spruce are chiefly obtainahle from seed-merchants on the continent of Europe: they are almost black, and have short broad wings. The sowing of the seeds and the treatment of the young plants in the nursery are in all respects the same as has previously been described for the propagation of the Common Spruce (see p. 333).

In many arboreta throughout Britain there are specimens of the Oriental Spruce which range in height from 50 to $60 \mathrm{ft}$.

\section{(7.) ALCOCK'S SPRUCE, Picea Alcoquiana Masters.}

Syxoxyus-Abies ajancnsis Lindl.; A. Aleoquiana Hortor.; Picca jczocnsis Carr.; P. Omorice Pan.; P. ajencnsis Fisch.; P. bicolor Mayr.

Specific Character.-Leaves solitary, six lines long, and half a line broad, eurved, rigid, $t$-siled, sharp-pointed, and crowted on all sides of the shoots. They are deep green above, somewhat concave, and streaked with glancons bands below, and on twisted footstalks, placed on diamond-shaped cushions along the shoots. Cones solitary or subaggregate, oblong-cylindrical, olntuse at the ends, $2 \mathrm{in}$. long and 4 in. in circumference.

Distribution.-The Alcock Spruce is fount on the sacred moun- 
tain Fusi- Tama, in the province of Surunja, on the Island of Nippon in Japan, at an elevation of from 6000 to $7000 \mathrm{ft}$., where it forms a noble tree, with very small leaves, which are slancous on the under side.

Introduced by Messrs Veitch \& Sons in 1861, it was named after Sir Iiutherford Alcock, the British minister at the court of Feddo, in Japan.

This species is often mixed up in gardens with $P$. ajanensis. The latter is believed to be related to the Omorica Spruce (Picea Omorica Pan.), which was discovered in Servia in 1872 by Professor Pancic of Belgrade. The Ajan Spruce (Picec ajanensis Fisch.) is found in the drainage of the Amur and in Mongolia. Together with the Menzies or Sitka Spruce these Omorica species exhibit slight botanical differences both from Spruces and from Silver Firs; hence it is not improbable that they may soon be formed into a genus Omorica by themselves. Their bark is scaly like that of Pines, and not smooth as with Silver Firs and other Spruces. But P. Alcoquiana really belongs to a different set from the Menzies, Ajan, and Omorica species.

Description of Tree.-In its native lands this is a large tree, attaining a height of over $100 \mathrm{ft}$. As the Alcock Spruce is but of recent introduction into Britain, no large specimens are yet available from which to form a reliable estimate as to the true character of the tree; but it appears to be in all respects sufficiently hardy for our climate. It certainly forms a beautiful, silvery-foliaged tree, of a very graceful habit of growth; and it may confidently be recommended as a species in all respects worthy of occupying a place in our arboreta and parks.

Economic Uses of Timber. - The wool is said closely to resemble that of the Common Spruce, but to be somewhat harder and more durable. Its chief interest is of a purely arboricultural nature, as it does not hold out anything like the same financial and sylvicultural promise as some of the other Spruces of recent introduction.

Soil and Situation. - This species is by no means particular as to soil and situation, provided that the former is not wet, and that the latter is not exposed to strong winds. Fair specimens of it are to be met with throughout Britain on a great variety of soils, and apparently in healthy growth.

Propagation and Culture.-The seed of the Alcock Spruce is scarce; hence plants are frequently raised from slips, as is also the case with the Patton Spruce (see p. 351).

(8.) THE RED SPRUCE, Picen rubre Link.

Srnoxyas-Pinus mubra Lamb.; Abies nubra Poir.; A. nigra var. mbra Mlichx.; Picea rubre Carr.

Specific Character.-Leaves solitary, very slender, awl-shaped, rigid, sharp-pointed, thickly and regularly scattered all round the 
branches, somewhat 4 -sided, $\stackrel{2}{2}$ an inch long, and of a glaucous, pale green colour. The hranches are horizontal and slender. The cones are oblong, egg-shaped, tapering regularly to both ends, pendulous, about $1 \mathrm{in.} \mathrm{long}$ and $\frac{1}{2}$ an inch broad, and of a reddish-brown colour (Gordon, op. cit., p. 11).

Distribution.-The lied Spuce is found plentifully throughout Nova Scotia, Newfoundland, and the northern parts of North America. It occurs extensively around the Hudson Bay territory, and extends up into the Aretic zone, where, as a shrub, it is to be found at the limit of tree-growth (Willkomm, op. cit., p. 96). In Britain, into which it was introduced in 1755 , it is in all respects hardy enough for our comparatively mild climate; for it can thrive even in the north of Scotland.

Description of Tree.-It forms a tall and liandsome tree, varying in height according to the nature of the soil and situation. On good, deep, loamy land, in the northern parts of Canada, it is to be found attaining a height of over $80 \mathrm{ft}$. There it forms a fine, upright, pyramidal tree, clothed with a mass of branches and foliage from the ground to the top. It may be recommended as a beautiful and highly ornamental tree among others of a spreading habit, whetler in plantations, parks, or lawns; for in all cases its tall ancl regularly tapering form contrasts well with that of other trees of more lateral development, such as Pines and deciduous trees generally, when all are planted out merely in isolated stems.

Economic Uses of Timber.-The timber of this species is of a reddish colour and is hard and durable; it is much used in Nerrfoundland for many technical purposes. Like the Patton and the Alcock Spruce, any value it has for Britain is of a purely arboricultural and not of a sylvicultural nature.

Soil and Situation.-Although the Red Spruce is a native of the colder regions of North America, still it will not attain its hest development in Britain unless it be planted on a good, deep, and rather dry soil, and in a sheltered situation.

Propagation and Culture.-The Red Spruce is easily raised from seed sown in the nursery on open ground in the same way as the seeds of the Common Spruce. The seeds are very small, and should therefore not be covered with more than, at most, about $\frac{1}{2}$ an inch of very fine earth. As the seedlings are very small at the ent of the first year, they should be allowed to stand two years in the seed-heds before they are transplanted into the nursery-rows. 
3. HeMllock, Tsugc Endl. (Linnean System, Monecha Monadelphia).

The genus Tsuga comprises 6 species, of which 3 are indigenous to North America and the other 3 to Eastern Asia. So far as Britain is concerned, none of the species possesses any sylvicultural interest; but they are of arboricultural value as graceful exotics deserving of attention in arboreta and parks. Like the Spruces, the Hemlocks have their leaves persistent for several years.

Generic Character.-Evergreen trees, with flat or angular, stalked leaves proceeding from prominent cushions (as in Picce), generally spreading, distichous or apparently so, but erect and in many rows in T. Pattoniana. One resin-canal runs through each leaf beneath the mid-rib. Buds scaly. Male flowers lateral. Stamens on stalked heads. Anthers crested, opening lengthwise. Pollen two-lobed (discoidal in Pattoniana Engelmann). Seeds very small, wing obovate. Female cones terminal. Scales persistent, more or less woody (Masters, op. cit., p. 254).

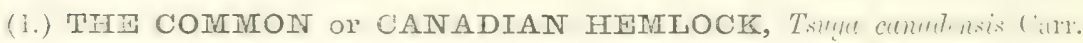

Srxonras-Pinus canadensis L.; Alies canadensis Michx.; Picea canadensis Lk.

Specific Character.-Leaves solitary, flat, and irregularly disposed in two rows, from $\frac{1}{2}$ to $\frac{3}{4}$ of an inch long, downy when young, rough at the margins, blunt-pointed, bright, vivid light-green on the upper surface, and with two silvery stripes underneath on each side of the mid-rib. Branches are numerous, slender, and downy when young, spreading, and rather flat. Cones are pendulous on the extremities of the branches, from $\frac{5}{8}$ to $\frac{7}{8}$ of an inch long, and from $\frac{3}{8}$ to $\frac{4}{8}$ of an inch broad, of an oval shape, green when young, but brown when ripe. Bark smooth, and of a light colour (Gordon, op. cit., p. 14).

Distribution.-The Common or Canadian Hemlock is found nearly all over Canada as far north as $49^{\circ}$, and in the greater part of the northern and eastern states of the North American Union. It is very plentiful in the Canadian woods, from Quebec as far westwards as Lake Huron. There is, indeed, no tree that is more plentiful in the forests of Canada. It is generally to be found occupying banks on the sides of rivers and along the edges of swamps; sometimes, however, it is also to be found on dry lands, but in such cases the trees are smaller than when growing on a cool, deep, moist soil. This species was introduced into Britain in 1736 .

Description of Tree.-The Canadian Hemlock is one of the 
handsomest trees found in the Anerican woods. In its earlier stages of development, up to about forty years of age, the tree is of a remarkathly graceful habit of growth, from the miform oli-josition of it: still somewhat slender branches all round the stem : these are invarially of a pendulons or drooping habit at the encls, and are thickly foliaged with light green leaves. As the trees become older, however, and hegin to approach maturity, the hianches become langer and stronger; and as these stand out horizontally, they wive this species very much the character of the Cedar of Lebanon. In the American woods, where the trees of this species are seen in perfection at all stages of growth, they present very varied outlines, aecording to their age. In the Canadian woods it is not uncommon to find Hemlock trees over $100 \mathrm{ft}$. in height, and with stems of from 4 to $5 \mathrm{ft}$. in diameter. The Common Hemlock has been much neglected by British arboriculturists. Landed proprietors may well be recommended to utilise it more than they have hitherto done for ornamenting their home parks; for few trees are more graceful in ontline and more ornamental than the Henlock, not only when it is young, hut also when it approaches its maturity. It has proved itself throughly hardy in Britain, although it requires a sheltered situation in orter to reach its finest development.

The height generally attained in North America by the Canadian Hemlock, when of true forest growth, is from 75 to $80 \mathrm{ft}$.; but Continental experience of experimental flantations shows that in Germany it develops only into a small tree of from 40 to $65 \mathrm{ft}$. in height. Hence it possesses no sylvicultural value whatever; lut that in no wise detracts from its imprortance from a purely arboricultural point of view.

Economic Uses of Timber.--The worl of the Canulian Hemlock is not at all valuable, even in the countries where it reaches its greatest dimensions. In America it is used only for rough planking, and never for any purpose requiring strength and durability. The tree, however, is very valuable for its bark, which is used all wer cimata for the tanning of leather.

Soil and Situation.-The Common Hemlock thrives best on a deep and somewhat moist soil, and in all cases requires a sheltered situation. In the Canadian woods the largest and handsomest specimeus are to he foumd growing on conl, moist, light, deepl, and rich land.

Propagation and Culture.-The Hemlnck is propraguterl from seed, which is imported from America. When received immediately after its ripening in the early spring, the seed should be sown in April, on sheltered seed-beds, and in a fine light soiland as the seed is small, it should only be covered slightly with 
earth. The seedlings should stand two years in the seed-beds lefire they are transplanted into the nursery-rows. They may stand in the nursery-beds for two, three, or four years, according as small or large plants may be wanted; but if they are desired to be of a large size before the final planting out, they should be frequently transplanted in the nursery in order to increase the number of short fibrous roots. Otherwise, when of a large size, they cannot be transplanted safely, owing to the damage done to the main roots.

Specimens of the Canadian Hemlock are now plentiful in most parts of Britain, many of which have attained heights of from 50 to 60 feet.

(2.) THE CALIFORNIAN HEMLOCK, Tsuy! Mestensime Cirriere.

Srsoxras-Pinus Mertensiana Bongard; Aties Mertensiana Lind. and Gordon ; A. Albertiana Murray; Tsuga Albertiana.

Specific Character.-Leaves green, glaucous beneath, irregular in size, from $\frac{1}{4}$ to $\frac{3}{4}$ of an inch in length, and about $\frac{1}{16}$ of an inch broad; they are solitary, grow spirally round the branch, though disposed in an alternate manner, are flat, slightly canaliculate on the upper side, with a mid-rib on the under one generally blunt-pointed, and having a very short footstalk, and are rather thickly placed on the branchlets (see Fig. 61). Branches very numerous, slender, and more or less bent downwards at the ends; branchlets very slender, flexible, long, drooping, and somewhat downy when young. Cones nearly 1 in. in length, pale brown, solitary, oblong-ovate, without any footstalk, and pendulous at the ends of the shoots.

Distribution.-The seed of this tree is said to have been first sent to Britain by Jeffrey in 1851, under the name of Abies taxifolia. On further supplies of seed arriving, the species was examined carefully and was supposed to he Bongard's Pinus. Ifertrnsiene, which is described in Gordon's P'introm under the name Abies .Mertensione, ly which it is still extensively known. It was believed, however, to be a new species, and was consequently named in memory of the late Prince Consort; hence it was for a time known by the specific name of Allurtiana. The Conifer Conference of 1891, however, adopted the name given above, Tsuga IFertensiana. It is to be found throughout Oregon, Torthern C'alifornia, British Columbia, and Vancouver Island.

Description of Tree.-As the Californian Hemlock is of comparatively recent introduction, no home-grown specimens of it are yet large enough for the purpose of enabling a correct judgment to be made with regard to its general character and habit. Where indigenons it is said to he a fine, graceful, round-headed tree, of 100 
to $150 \mathrm{ft}$. in height, and with a stem varying from 4 to $6 \mathrm{ft}$. in diameter. Judging from the appearance and habit of the young trees in this country, it is an elegant and graceful tree, which hears a dense mass of foliage on long, slender, and drooping hranches. This species very much resembles the Common Canadian Hemlock; l hut

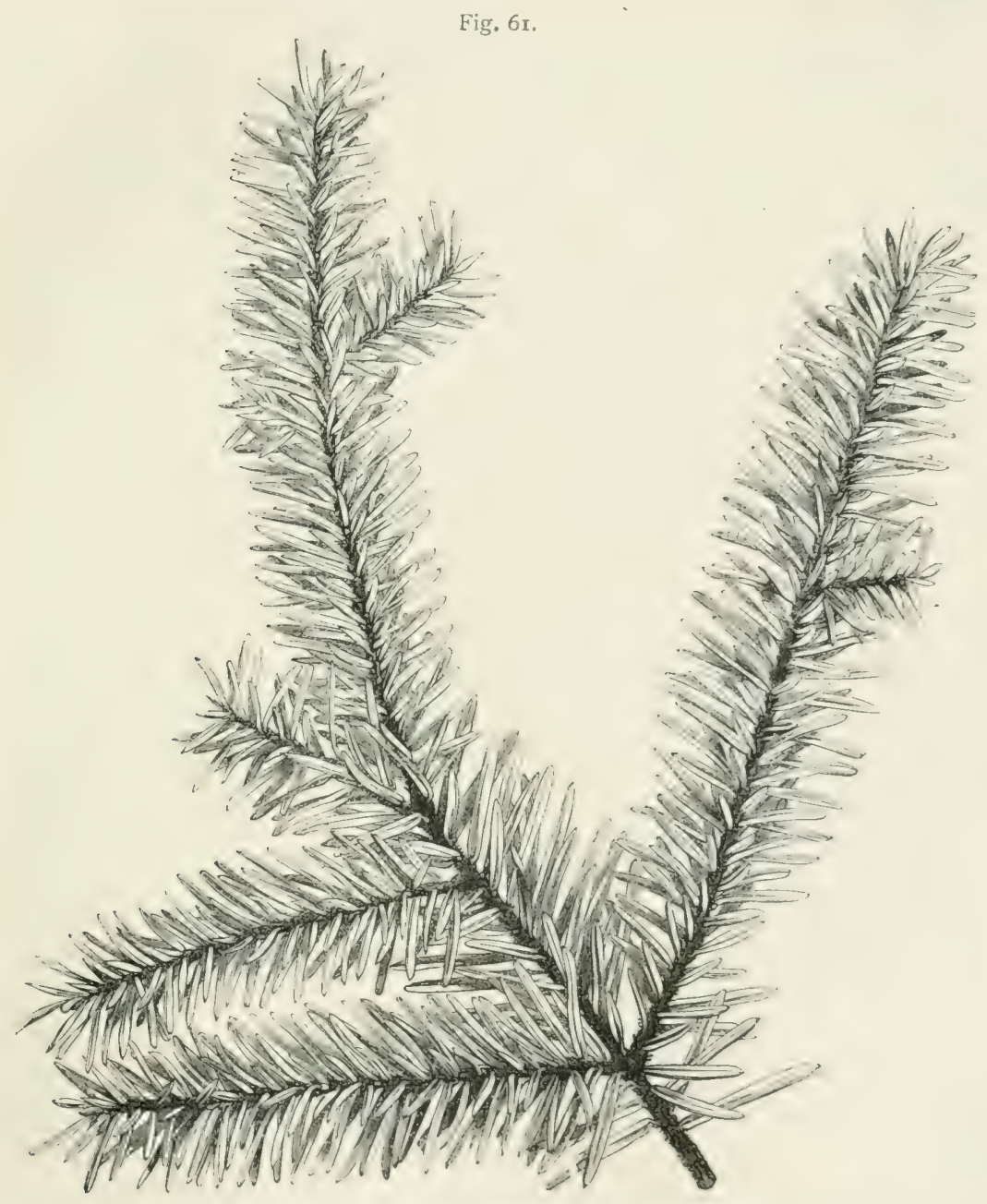

Spray of the Californian Hemlock (Tsuga Mertensiana).

it is more open in its ramification and development of branches, and is certainly a much freer grower, assuming a more upright and treelike form from its earliest years. It is found to be rapid-growing and hardy in the climate of Britain, and hats stoceeded well even in Scotland, where one of the oldest, and perhaps one of the best, 
specimens in the country is to be found growing at The Cairnies, in Perthshire. This specimen was raised from the first seed that was sent home. The tree is worthy of a place in every arboretum, and must in time become a general favourite with all ornamental planters in parks and throughout the residential portions of large estates.

- Economic Uses of Timber. - Very little can be said as to the timber produced by this species. Gordon says (op. cit., p. 19) with regard to this wood that it is "white, very soft, and yields but little turpentine"; whilst Brown remarks that "the timber is said to be firmer, finer, and straighter-grained than the Canadian Hemlock Spruce."

Soil and Situation.-The Californian Hemlock does not seem to make any very special demands with regard to soil, as in Britain it appears to thrive and to grow healthily and rapidly in most soils. So far as an opinion may be offered concerning this species at present, it appears, like the Common Hemlock and the majority of the short-leaved Abietinece, to thrive best on a deep, moist soil. On light, dry land it assumes rather a stunted habit of growth, which proves that a cool, moist, loamy soil is more suitable to its natural requirements.

Propagation and Culture.- Soon after the first importation of the seeds of this tree there was a great demand for it, which quickly exhausted the supply of available plants, and for a time no other specimens could be had. Seeds of it have been imported of late, howerer, and the Californian Hemlock is now compratively plentiful throughout Britain. In the absence of seeds, a good many of the existing plants have been reared from cuttings; for in this way it may, like most of the other species of Abietinca, be easily propagated.

Specimens of this tree are now common in most parts of the country, many of which have attained heights of from 40 to $50 \mathrm{ft}$.

\section{(3.) PATTON'S HEMLOCK Or THE CALIFORNIAN SPRUCE, T'sucya Pattoniana Engelmann.}

Syxoxys-Alies Williamsonii Newberry; Abics Pattoniana Jeffrey; Picca Pattoniana; Hesperopeuke Pattoniana Lemmon.

Specific Character.-Leaves solitary, ranged spirally round the manchlets, not close together, short, with the margin slightly toothed or serrated towards the point, from $\frac{1}{2}$ to $\frac{3}{4}$ of an inch long, boat-shaped in their section, dark green above, curved, not silvery below. The buds are small and conico-ovoid. The branchlets are pubescent. The cones are produced at the points of the branches, and are from 2 to $2.1 \mathrm{in}$. long, cylindrically oblong, tapering at both ends, but most so 
at the top, nearly $\frac{3}{4} \mathrm{in.}$ broad, and pendulous. The branches are pendulous. The bark is rough, and of a grey colour.

Distribution. - This species was found hy Jeffrey on the Bialien range of mountains, and on the Cascale Mountains, in California, at elevations of more than $5000 \mathrm{ft}$. above the level of the sea. Lobb afterwards found it in abundance on the highest pealks of the Sierra Nevarta, near the head-waters of the northi tributiry of the Feather. River, and more to the south, towards Lake Bingler. It was introduced into Britain in 1851.

Description of Tree.-The Patton Spruce is said to grow to an imnense size in the state of Oregon, where trees are not infrernently. to be met with towering to $25.0 \mathrm{ft}$. in height, and having stems above $10 \mathrm{ft}$. in diameter. Its branches spread out horizontally from the main stem, but become drooping towards the extremities; whilst the franchlets are thickly set round with solitary leaves of a grassgreen colour above, and a pale green below. It is said that in its habit of growth and general appearance it much resembles the Deodar; but it has thicker branches, is more densely clothed with foliage, and altogether forms even a more handsome tree. It is worthy of a place in every arboretum throughout Britain, as it is quite hardy enough for our climate.

Economic Uses of Timber.-From Jeffrey's account of the timber produced by the Patton Spruce, it seems not improbalule that this tree may, like the Douglas Fir and the Sitka Spruce, prove of sylvicultural value as an addition to our British timber-trees; but this can only be proved by time. It is said, however, that the timber is excellent; it splits freely, is very straight in the grain, and is therefore of considerable utility for various technical purposes.

Soil and Situation.-.'The remarks previously made with reference to the Menzies or Sitka Suruce are generally applicable to thi. species (see p. 339).

Propagation and Culture. - The seeds of the Patton Spruce ate? still comparatively scarce, and in consequence of this a lare proportion of the plants that are to be had of it are merely such as have been propagated from cuttings. They can therefore not be exprected to be so hardy as plants of seedling growth.

Specimens of the Patton Spruce are plentiful in most of our arboreta; but it is still too early to estimate the height to which they are likely to attain ultimately in our climate. 


\section{THE FALSE HEMLOCK, Pseudotsuga Carrière.} (Linnean System, Monecta Monadelphia).

The seneric characteristics of Parulotsugu have already been given in the table on p. 250, from which it will be noted that it presents very much closer resemblances to the Silver Firs than to the Spruces and Hemlocks.

Generic Character.-Concerning this genus of the tribe Alictinen, Masters (op. cit., p. 245) makes the following remarks:-

"A genus constructed for the reception of the Douglas Fir. The habit and foliage are those of the Silver Firs, the male flowers like those of Picea; cones pendent, ripening in the first year; scales persistent; bracts markedly 3-lobed; wing of seed narrow, pointed; cotyledons 5-7, 3 -sided, entire as are the primary leaves. It differs from the Spruce in the foliage. The structure of the wood is quite distinct."

Only one species has been found and introduced into Britain. But it possesses very great importance from a purely sylvicultural point of view; for it is of very rapid growth, thrives in our moist climate, and promises to yield an exceptionally large out-turn in timber of very good quality.

\section{THE DOUGLAS or RED FIR, or OREGON PINE, Pseudotsuga Douglasii Carrière.}

\section{Synonyas-Pinus Douglasii Endl. and Lambert; Abies Douglasii Lindley; Picce} Douglasii Link.; Tsuga Douglasii Carrière; Pseudotsuga taxifolia Britton.

Specific Character.-Leaves solitary, flat, entire, narrow, linear, spreading and irregularly two-rowed on the older branchlets, but on the younger trees growing plentifully along their upper side and more sparingly on the under, from $\frac{3}{4}$ to $1 \frac{1}{4}$ in. long, bluntly pointed, bright green above and slightly glaucous, and much paler below (see Fig. 62). Branches numerous, irregularly placed along the stem, spreading horizontally, sometimes a little ascending, sending ofl numerous twigs, and nearly flat. Branchlets long, slender, mostly in two rows, and more or less declining. Cones ovate or oblong, terminal at the points of the upper hranchlets, solitary, pendulous, yellowishbrown, with many linear, extended, sharp-pointed bracteas, loosely imbricated, from 3 to $4 \mathrm{in}$. long, and from 1 to $1 \frac{1}{2} \mathrm{in}$. in diameter. Scales rounded, smooth, leathery, concave, quite entire, thin, and persistent. Bracteas linear, three-pointed, the middle one longest and pointed, the two outer ones being comparatively short. Seeds small, with a wing fully $\frac{5}{8}$ of an inch long.

Distribution. - The Douglas Fir is very plentiful on Vancouver Island. It is found in large forests in the north-western parts of 
North America and at different elevations on the Rocky Mountains, forming a small bush on the higher mountain-tracts. But it heconnes sradually larger as it is found lower down, till, on the lower slopes and on the plains, it attains a height of fron 150 to 2.50 ft., and frequently a diameter of $10 \mathrm{ft}$. at the hase. Thees of such dimensions are said to be found plentifully on the banks of the Columbia River. It was introduced in 1826 .

The Douglas Fir is said to be distributed throughout an area of about 50,000 square miles between $43^{\circ}$ and $52^{\circ}$ of north latitude in America, where it was discovered first of all by Menzies towards the end of the eighteenth century, although it was not introduced into Britain until 1826 by Douglas. Its finest growth is in Oregon, where it is said to attain the gigantic dimensions of up to $300 \mathrm{ft}$. in height and $27 \mathrm{ft}$. in girth. In the Sierra Nevada it ascends to $8000 \mathrm{ft}$. It is known locally as the Red Pine in some parts of America.

\section{Description of Tree.} -This is one of the noblest of forest-trees, and is, without doubt, Young spray of the Douglas Fir (Pseudotsuga Douglasii). destined to become highly useful as a timber-producing crop throughout Britain, as well as an ornamental tree in our arboreta, parks, and lawns. Its rapidity of growth, and the excellent quality of its timber, are very strong arguments in favour of its sylvicultural utility. It is not yet serenty years since the Douglas Fir was first introduced into this comtry, but alveady many specimens, ranging often from 100 to $130 \mathrm{ft}$. in height, and with fine boles of a proportionate diameter, still remain healthy and in good increment. They are rapidly beenming the giants of omr woods, besides yielding timber of better quality than the spruce or the Silver Fir. With this actual practical experience before us, and 
the knowledge that in its own home it attains an age of 500 to 600 years, with a height of $300 \mathrm{ft}$. and a girth of 12 to $15 \mathrm{ft}$., it may mbesitatingly be aftirmed that the I)ouglas Fir is probably the most valualle species of tree, from a purely financial and sylvicultural point of view, that has ever been introduced into Britain. This is more especially the case with regard to the green rariety indigenous to the Pacific coast, where the climate more closely resembles our humid insular atmosphere than does that of the central American tracts where the blue variety (glauca) is predominant in the forests.

Its habit of growth is much in its favour as an ornamental tree for parks and lawns; for when it stands in an isolated position it is clothed to the ground with densely foliaged hranches, thiclily covered with bright green and somewhat silvery-looking leaves or needles, which give the whole tree a grand and imposing effect. Every arboriculturist and every sylviculturist should plant this tree as extensively as his circumstances will admit, in any parts of the country at all suited to its growth. It should be planted not only as single specimens for ornament, but in masses at moderate elevations for the sake of timber.

As young plants of Douglas Fir are still comparatively highpriced, in making plantations of the tree they should be put out about 30 feet apart as the permanent crop, the blanks between each being filled up with Spruce, Silver Fir, or Austrian Pine, and Larch and Acacia (Robinia) perhaps planted here and there as a nurse: the whole of the plants throughout the plantation should then not stand more than 4 feet apart.

As the Douglas Fir is of more rapid development than any of these other trees, it will soon shoot ahead of them. Hence the more lightdemanding species, Larch and Robinia, will have to be cut out first of all, and the Austrian Pine next; whilst a certain proportion of the Spruce and the majority of the more shade-bearing Silver Fir will probably remain to form a portion of the mature crop along with the Douglas Fir. Dealt with in this way, the Larch and Robinia could be thinned out as they become interfered with in their development by the Douglas Fir and other trees, so that in the course of about twenty years a mixed plantation of shade-bearing, close-canopied Conifers would remain. The Douglas Fir is quite hardy on all lowlying and moderately elevated parts of the country, even in the north of Scotland; but this is rather on account of its being tardy in sending out shoots in spring than from natural insensitiveness against cold.

The Douglas Fir may easily be recognised from the Silver Fir by the larger pockets of aromatic resin which collect in pustular sacks below the outer skin of the bark. 
Economic Uses of Timber.-Specinens of the timber of this tree grown in Lritin seem strong and elastic, free from knots, and likely to prove at least equal to Spruce and silver Fir in quality, though perhaps ranking helow the better kinds of mature Scots l'ine and Larch. But its far greater productive capacity must at the same time be considered in correctly estimating its undoubterlly great sylvicultural importance for Britain.

As with other species of timber, the quality and durability of the wood is dependent on whether the soil and situation are favourable to the tree or not. The best wood comes from moderate elevations on the western slopes of the llocky MLountains, and is of high technical quality and great duralyility. It is used for ship-lutilding, house-building, carpentry, funiture-making, and various: general technical purposes.

Whilst the alburnum or sapwood is white, the duramen or heartwood is of a reddish colour, and of excellent quality, somewhat resembling the wood of the Yew in texture; hence the frequent local name of Red Pine.

Soil and Situation.-The Douglas Fir has in Britain proved itself very accommodating with respect to soil, as many fine specineus in the country are to be found on soils of different descriptions, rarying from those of a light and dry character to such as are of a heary, stiff, cold, and moist nature. It seems, however, to thrive best on deep, free, open, moist soil, and on situations that are not tor elerated nor too much exposed to violent storms.

Large sylvicultural experiments have been made with the Douglas Fir throughout Yorthern Germany, and the experience thus won shows that it is well worthy of cultivation on account of the rapidity of its growth and the good quality of its timber. This Continental experience seems to point to fresh, loamy sands, or sandy loams, as heing the soils best suited to its healthy development. It is said to do fairly well on dry soils; whilst wet or marshy land and all situations exposed to constant late frosts in syring are unfarourable to its thriving. Depth and freshness seem of much more importance for it than any great degree of mineral strength in the soil.

It is not exactly a shade-demanding species; for, although capable of bearing a considerable degree of side-shate, it suffers under any heary direct overshadowing. It is consequently not adapited for underplanting except perhaps under the shade of very light crops's of ()ak, I'ine, and Larch as they approach maturity.

When forming mixed woods along with other species of trees, it soon outstrips them in growth in height. It then throws a considerable shade across them, which can only be borne hy the more distinctly shade-hearing class of trees.

On account of its rapidity in growth, it is particularly well suited for the filling up of blanks in all plantations formed in localities not unduly exposed to late frosts in spring. 
Propagation and Culture.-The Douglas Fir begins to bear seed of fair quality as early as about the 25 th year. As large quantities are now produced in this country, a good supply of plants may be olitained at a reasonible rate little in excess of that fetched by young Spruce transplants. No tree is easier of cultivation than the Douglas Fir. The seeds may be sown on the open ground of the forest or in the seed-beds of nurseries, in the same manner as the seeds of the Scots Pine and the Spruce; and in the latter case the young plants may be transplanted into nursery-lines, and treated in the same way as the seedlings of the latter are usually treated.

Continental experience has shown that for the formation of plantations the use of four-year-old transplants is to be recommended. The treatment of the seedlings and the conduct of planting operations are the same as in the case of the Spruce.

As has been previously remarked, when any choice is open as to the seed, it is advisable to select that from the humid tracts of Western Canada, in place of what has been collected in the inland forests, where the parent trees have by heredity become specially adapted to a dry continental climate. British-yrown seed will, for sylvicultural purposes in Britain, probal,ly be preferable to the latter.

The Douglas Fir are now so plentiful throughout Britain that it is unnecessary to refer to any specimens in particular. Perhaps those at Dropmore in England, and at Rossie Priory in Scotland, are, however, among the best known in this country. The largest at the former place was $120 \mathrm{ft}$. high in 1887 .

The largest Douglas Fir at Dropmore in Bucks, and probably in Europe, was planted in 1830, and is now $120 \mathrm{ft}$. in height and $11 \mathrm{ft}$. in girth at $5 \mathrm{ft}$. from the ground. It is estimated to contain 270 cubic $\mathrm{ft}$. of clean timber. The next largest reported to the Conifer Conference of 1891 had a height of $91 \frac{3}{4} \mathrm{ft}$, and a girth of $12 \mathrm{ft}$. at a similar height. It was growing on the Lynedoch estate in Perthshire. Another Douglas Fir, grown from seed produced by the Dropmore specimen, and planted in 1843 , is now is $\mathrm{ft}$. hight, and has a girth of over $8 \mathrm{ft}$.

For the information of the student it may be remarked that an article on

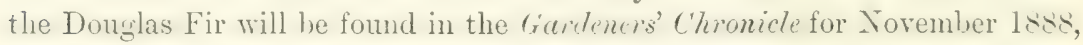
p. 598; and other papers referring to it will be found in the T'rans. Scot. Arbor. Socy., vol. xi., part. ii., 1886, pp. 165-172, and vol. xii., part ii., 1889, pp. 226-241.

Besides the two natural bluish and greenish varieties throughout the forests of North America, several gardeners' varieties of this tree are occasionally to be met with-viz., $P . D$. fastigiata, with a conical crown of foliage; $P . D$. Standishiana, with foliage of a silvery-white colour on the lower side; $P . D$. mecruentu, bearing large, long cones; and $I^{\prime}$. IJ. pentuln, with long hanging branches of 9 or $10 \mathrm{ft}$. in length.

The following details of a pure plantation of Douglas Fir were given by 
the late Mr MI'Corquodale, the Earl of Mansfield's head-forester, before the Parliamentary Forestry Committee in $1887:-$

"It is 8 acres in extent and is 27 years of age. It was thinned in the spring, and 620 trees were taken out of it; and they are the largest of their age I ever saw. They measured about $60 \mathrm{ft}$. in length, and many of them are $5 \mathrm{ft} .9 \mathrm{in}$. in circumference at $3 \mathrm{ft}$. abore the ground : I never knew that in any coniferous trees before.

"There are two trees of the Douglasii Fir growing on the estate of Lyndoch; and when they were 50 years of age, they were $73 \mathrm{ft}$. in length. These trees measured $150 \mathrm{ft}$. of timber each.

"The Larch is a very fast-growing tree; but very rarely indeed hare I found a Larch 50 years of age to measure 50 cubic $\mathrm{ft}$. of timber. But in Douglasii they have added 3 cubic $\mathrm{ft}$. for every year they stood."

\section{THE SILVER FIR, Abies DC. (Linsean System, Moxecta Moxadelphia). \\ Srxonrus-Abies Link. ; Picca Loudon.}

Generic Character.-Trees with whorled branches: adult leave: 2-ranked, sessile, narrow, flat, leaving a circular scar on the liranch when they fall. Male catkins scattered, axillary; anthers crested, opening crosswise; pollen-cells winged. Cones erect, maturing the first year. Bracts more or less conspicuous, free from the scales except at their base, seed-scales becoming detached from a central column when ripe, and each falling separately. Seed with a large inseparable wing. Testa with resin-canals. Cotyledons 4-8, flat, leafy, entire. Primary leaves of the same order, but much smaller (Masters, op. cit., p. 188).

The silver Firs are remarkable for the regularity and symmetry of their pyramidal heads, and are readily distinguished from the genus Picea or Spruces by their leares being more decidedly in two rows; by their cones being upright in their position on the branches; by these having the scales deciduous, or falling off' when ripe; and by the seeds being irregular and somewhat triangular in form. They are natives of Europe, Asia, and America, but are generally found in regions more temperate than those in which the sipruces abound. All of them require a good deep soil and a more or less sheltered situation in order to attain their finest development: lunt in most ordinary soils they will do tolerably well if not too much exposed, nor at too high an elevation. The great majority of them are sufficiently harily for the average climate of Britain, and grow freely after they have once established themselves in the soil. Some of them have only recently been introduced into Britain, however, and are therefore still comparatively rare; hence our experience of such species is as ret but limited. For ornamental planting of erery sort they are particularly well adapted. All of the kinds about to be described may be considered hardy and suitable for ordinary arboricultural purposes. 
They are evergreen, shade-bearing species of trees capable of maintaining close canopy either in pure woods or when forming mixed crops along with other conifers or broad-leaved kinds of trees. As the leaves or needles are ranged closely on the twigs, and are persistent for many years, they cast a strong, deep shadow over the ground, and maintain it cool and fresh. They form long, straight stems and full-wooded boles, having a form-factor of 0.44 to 0.57 , which indicates a higher average degree of good top-girth than any other European conifer. The seed of the Silver Firs ripens within a year of the flowering.

There are 33 known species, 5 of which occur in Europe, 14 in Asia, 15 in North America, and 1 in Africa; the latter and 1 of the Asian species are included in the 5 occurring also in Europe (Willkomm, op. cit., p. 107).

\section{(1.) THE COMMON SILVER FIR, Abies pectinata DC.}

Srronyus-Pinus Picee L.; P. Abies Du Roi ; P. pectinata Lamk.; Picea pectinata Loud.; Abies pectinata Link; A. alla Miller; A. vulgaris Poir.; A. taxifolia Desfontaines.

Specific Character.-Leaves solitary, flat, obtuse, two-rowed, and with their points turned up; from $\frac{5}{8}$ to $1 \frac{1}{2}$ in. long, stiff, and of a shining dark-green above, with two lines of a silvery white on each side of the mid-rib beneath (see Fig. 63). Cones from 6 to $S$ in. long, and from $1 \frac{1}{2}$ to 2 in. broad, cylindrical, erect, and axillary, green when young, afterwards reddish, and when ripe of a brown colour (slightly altered from Gordon, op. cit:, p. 151).

Distribution.-The Silver Fir is indigenous to the mountains of central Europe, and is found also in the west and north of Asia. It occurs largely in France, on the Pyrenees, throughout the Alps, in Austria, Italy, Spain, Greece, and in the south of Germany and Russia. On the Carpathian Mountains it is said to be found growing at an elevation of more than $3000 \mathrm{ft}$. above the sea-level, and on the Alps to the lieight of nearly $4000 \mathrm{ft}$. It was introduced into Britain in 1603 .

Although of spontaneous growth throughout the greater portion of central and southern Europe, the Silver Fir has nothing like the same distribution as the Spruce. Its northern limit of indigenous growth commences in the western Pyrenees at $43^{\circ}$ in Navarre, thence trends eastwards along the northern slopes of that mountain-chain, and bends to the north on reaching the hills of Auvergne. From there it passes in a north-east direction across Burgundy and Lorraine to the eastern slopes of the Tosges and across the southern part of Westphalia, thence skirting the southern edge of the Harz Mountains into Saxony and Silesia, eastwards of which it reaches its most northerly point at $51^{\circ} 40^{\prime}$ near Soraw. Its indigenous area forms an irregular ellipse, extending over about $32^{\circ}$ of longitude and about $14^{\circ}$ of latitude; but within this area there are large tracts where it is not of spontaneous growth, as it does not naturally occur on the warmer plains and lower hill-ranges of the southern portion of its habitat. The most extensive forests of pure Silver 
Fir are to be found on the northern slopes of the Pyrenees, in the Vosges, the Jura, the Black Forest, Franconia, and Thuringia, at elevations ranging from 1200 to $4000 \mathrm{ft}$. (Willkomm, op. cit., pp. 118-120).

From this it is therefore evident that it attains its finest development in the humid momintainons tracts of central Furne, where, howerer, the clinate is of an essentially dry, continental character, as compared with our much more damp, insular atmosphere. It would therefore hardly be reasonable to expect from our plantations as large an outturn in timber as is obtainable from the Silver Fir in central and southern Europe, where it produces, along with the Spruce, larger supplies of timber per acre than any other indigenous species of forest-tree.

Description of Tree. -This is a noble-looking and very useful tree, which is by far too little cultivated in our home plantations. It attains large dimensions in favourable situations in Britain, being often found rising to heights considerably above $100 \mathrm{ft}$., and with stems from 3 to $5 \mathrm{ft}$. in diameter. When young, this species is one of the most tender of our timber-trees; for it is apt to be injured by late frosts in spring, which retard its growth considerably. After the roots of young transplants have

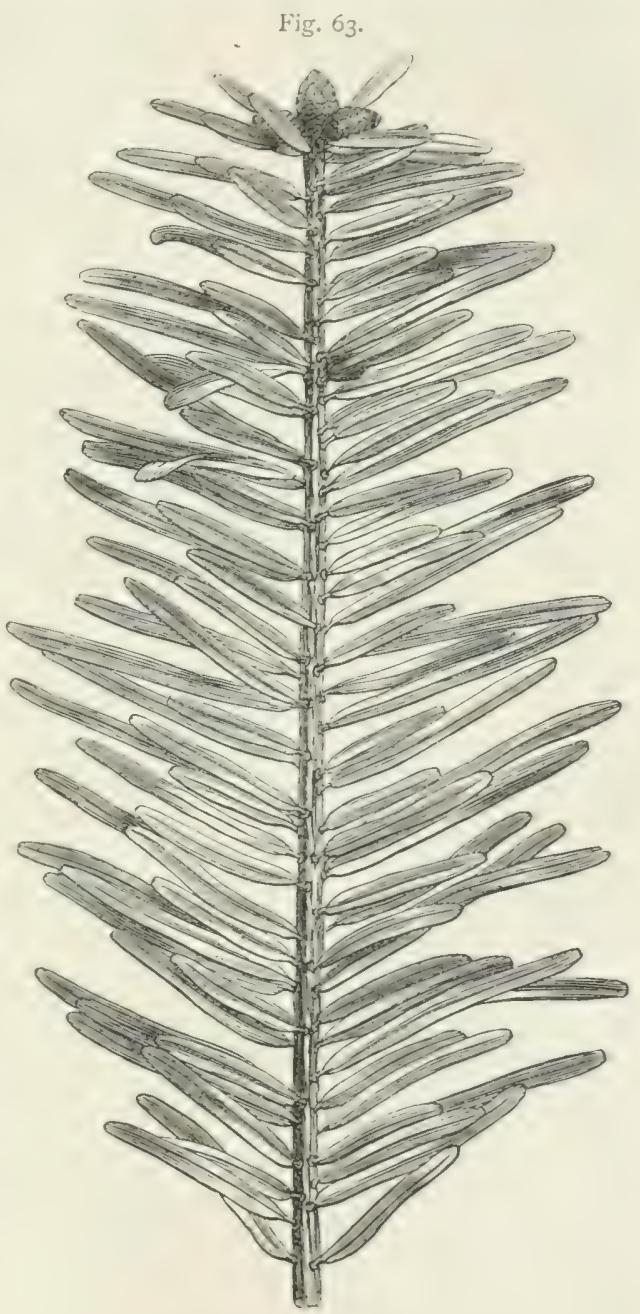

Spray of the Cummon Silver Fir (Abies pectinata), showing disposition of the line'cs or needles. become properly established in their new lione's, however, aml when the plants have attained a height of about 5 or $6 \mathrm{ft}$, and have thus got out of the coldest damp layers of air near the ground, the frost has no effect on the young trees. They then begin to grow rapidly, so as soon to make up for their slow growth when young. By the 
time they hive attained from 15 to 20 years of age, they generally succeel in catching up even the Spruce, after which they maintain the ascendancy thus won. Although the tree is somewhat tender while in its young stages, it is, notrithstanding, quite hardy enough for cur clinite, as the many fine specinens now growing in all parts of the country give proof. When treated on rational sylvicultural principles as a forest-tree, it may easily be protected at first by standaril trees, or in young plantations hy having Larch, scots P'ine, or Birch as a nurse; whilst for arboricultural purposes the use of stout transplants, whose leading-shoots are above the "frost-level" is sufficient to obviate danger in general.

Throughout western France and central and southern Germany the Silver Fir is a forest-tree of the first magnitude, often worked with a rotation of 180 to 200 years, attaining a height of over $200 \mathrm{ft}$. and having a girth of 10 to $12 \mathrm{ft}$. in the woods. At first its crown is pyramidal and very regular; but with adrancing age it becomes more irregular and bushy. Its root-system is deep-reaching and spreading, but neither so deep as Larch and Pine nor so spreading and shallow as the Spruce. During the earlier stages of growth the branches, occurring in regular whorls, have a somewhat upward tendency, as in the Spruce; but in older trees they are throughout almost at right angles, and are of unequal length.

The foliage is very dense, as the leaves or needles are persistent for 8 to 10 years. Small pustules filled with resin develop early under the leathery cuticle of the bark; but these are not so long as those formed by the Douglas Fir. On older stems these resin-sacks burst simultaneously, and the resin forms white streaks down the bark.

Economic Uses of Timber. - When the timber of this tree has arrived at maturity it is of good quality. In Britain it is generally reckoned equal to that of the Norway Spruce, and is used for the same purposes. The quality of the timber of course varies greatly, according as the trees have been grown singly in a park, or in closecanopied masses in woods and plantations. When the tree is grown singly, with free growing-space for the development of branches, the timber is open, soft, and inferior, as compared with that of trees grown in the cluse anopy of properly managed woods in which the stems have been cultivated so as to form but few branches. In the latter case the timber is of much closer grain, and in every way of much finer technical quality; and, as a matter of course, it sells at a higher price than can he commanded by the inferior quality of wood produced by arboricultural methods as contrasted with the operations of rational sylviculture.

Although of a somewhat greater sp. gr. than Spruce (see table on p. 331), the wood of the Silver Fir is softer than that of Spruce. It is also less resinous, whence its name of "White Pine," owing to a paucity of resin-ducts 
within the medullary rays; but in many parts of the Continent its timber is preferred to that of the Spruce, although neither of them are so durable and good as the better classes of Larch and Scots Pine timber.

Soil and Situation.-The Silver Fir thrives lest upon a good deep loam, neither too light nor too dry. It is, however, by no means particular as regards the quality of the soil, provided this be deep and the sitnation sheltered; it may therefore be found thriving on rather stiff clays, as well as on light land. It does not succeed well on an exposed situation; nearly all of the best trees in this country are to be found in sheltered localities, while those on exposed situations usually remain small, and do not attain any considerable height. This species is well adapted for planting on lanrl upon which a mixed crop of timber is being formed; for even if it fail to maintain its equality with the other species in the upward struggle for light, air, and warmth, it is better endowed as a distinctly shacte-bearing species for remaining in healthy growth under the shade of the kinds of more forward growth, unless they too are densely foliaged species like Douglas Fir and Menzies or Sitka Spruce.

Owing to its deeper root-system the Silver Fir requires a deeper soil than the Siruce; and at the same time it also makes the highest demands among the European Conifers with regard to the amount of mineral food amully withdrawn from the soil. It therefore demands at least freshness in the soil ; for it is only when the nutrient salts are held in solution that they can be imbibed by the suction-rootlets, although in respect to transpiration it really requires less water than the other ('onifer's. (See Ebermayer's classifications, previously given on p. 332.)

Continental sylvicultural experience has shown that it thrives best on deep sandy loams; that on light sandy or heary argillaceous soils its growth is less energetic; and that on wet land with stagnating moisture, or having a limy impervious subsoil, its growth is least satisfactory.

Propagation and Culture.-The Silver Fir is propagated from seed in much the same general mamner as has been already recommended for the Spruce. The cones are generally ripe about the 1st of November, and the seeds are very easily separated from these by the heat of the sun on dry, airy days. The seed should be sown about the first week of April upon the seed-berts in the nursery. It should be sown rather thinly, as, when germination takes place and the secdlings come up, they are somewhat sprealing in their habit. The seedlings should remain for two years in the seed-heds, when they may be transplanted into the nursery-rows. Here also they should stand rather thinly; for when young they are of a somewhat bushy nature, and require a fair amount of growing-space. They are of 
slow growth in their young state, and will require three years in the rows before leing liuge enough for transplanting out into the open. It has already been stated that the plants are tender during their early years. This is so much the case, that it will generally be found necessary to protect them in the seed-beds when they first appear above ground in the months of May and June; otherwise a very slight late-frost injures the seedlings in their still soft and tender state.

Sylvicultural Characteristics and Utility of Silver Fir.-The Silver Fir makes greater demands than Spruce both with regard to soil and climate. It is therefore better fitted for cultivation as a forest-tree in the milder parts of central and southern England than in the rawer climate of northern Scotland. For its normal development a mean temperature during August of at least $66^{\circ}$ Fahr. is requisite; whilst a mean temperature during January below $21^{\circ}$ Fahr, or over $77^{\circ}$ in August, is incompatible with the essential climatic conditions for its growth (Willkomm, op. cit., pp. 131, 132). As our average temperatures in July and August are respectively below $63^{\circ}$ and $62^{\circ}$, it therefore follows that the Silver Fir should only be planted out in warm tracts. And, at the same time, its sylvicultural importance as a shade-bearing species will be, to a greater or less extent, prejudiced on all localities that have not a mild warm climate. The moister the atmosphere in which its crown of foliage is developed, the less are the demands made by the Silver Fir for soil-moisture; hence it should thrive in Britain on drier kinds of soil than suit it throughout central Europe.

When growing in the dense canopy of pure woods it begins to produce seed about the 60th to 70 th year, although it is not such a rich seed-producer as either the Spruce or the Scots Pine. When such woods are reproduced naturally from seed shed by parent standards, the growth of the seedlings is very slow at first, a 10-year-old Silver Fir being no larger than a 4-year-old Spruce seedling; but from about the 8 th or 10 th year it begins to grow more rapidly in height, and to form more regular whorls than is up till then the case. Its growth in height continues very energetic until about the 100 th year, when it begins to fall off, and the thickening of the stems proceeds at a quicker proportionate rate than the continuous growth upwards. When worked with long periods of rotation, exceeding 150 years (as is often the case in the mountain-forests of central Europe), there is a tendency to the crowns becoming "stag-headed." The stems of the Silver Fir are, however, much less liable to red-rot than those of the Spruce; and on the whole it suffers less than Spruce or Scots Pine from parasitic diseases, although it has one fungoid enemy, Ecidium elatinum, which particularly affects both the stems and the top branches of old trees of this species.

For the formation of Silver Fir woods either sowing or planting may be adopted; but in general planting should be preferred in Britain. Continental experience has shown that the best class of plants for putting out into the woods, whether pure or mixed plantations, are 4- or 5-year-old transplants that have been transferred from the seed-beds to the nursery-lines at 2 years of age. Up to that age they may easily be transplanted without balls of 
earth attached to the roots; lut when planting is being earrierl out in rather dry weather, it is well to clip the ronts from time to time in a mixture of loam and water, so as to keep them cool and moist. In southern Germany the seedlings are put out in the nursery-beds about $3 \mathrm{in}$. apart in lines, with 5 in. between the rows, when it is intended to transplant them as 4-year-olds, or at $4 \mathrm{in}$. by $8 \mathrm{in}$. if required as 5 -year-old transplants, or at $5 \mathrm{in}$. by 7 or $8 \mathrm{in}$. if wanted at $(;$ years of age. No advantage is gatinerl by transplanting yearling seedlings into the nursery-beds, for they simply have to stand a year longer there, and therefore for one year occupy a larger growing-space than there is any necessity for. As in the case of all seedlings or young transplants, any inclividuals attacked with parasitic (fungoid) disease should he at once remover from the seed-beds or nursery-rows, in order to prevent the sprear of the disease to neighbouring plants.

Large specimens of the Silver Fir are common in most parts of the country, many of them of heights from 90 to $110 \mathrm{ft}$, with diameters of stem from 3 to $4 \frac{1}{2} \mathrm{ft}$.

There is a famous group of Silver Fir in the Duke of Argyll's grounds at Rosneatl. At Drummond C'astle there also exists a noble and pratriarchal avenue of Silver Firs, but the great north-east storm of 17 th November 1893 laid low six of them, which were probably the finest trees in Perthshire.

The two largest specimens reported to the Conifer Conference of 1891 were respectively $111 \mathrm{ft}$. high and $15 \frac{1}{2} \mathrm{ft}$. in girth at $5 \mathrm{ft}$. above the ground, and $110 \mathrm{ft}$. high with a girth of $17 \frac{3}{4} \mathrm{ft}$. The former was growing at Carton, in Kildare, and the latter at Rossdhn, in Dumbartonshire.

A monograph on the Silver Fir will be found in the Trans. High. and Agric. Socy. of Scot. for 1885, pp. 229-243.

\section{(2.) THE BALSAM or BALM OF GILEAD SILVER FIR, Abies balsamea Miller.}

Srxoxys-Pinus balsamea L.; Picea balsamea Loud.; Abies balsamifera Michx.

Specific Character.-Leaves solitary, entire, or emarginated at the end, irregularly two-rowerl, and mostly on the upper part of the branches, or scattered round the leading-shoots, spreading, Hat, silvery beneath and bright green above, in. long, and thickly set on the branches. Cones cylindrical, tapering towards the point, erect on the upper part of the branches, or nearly so, 3 to $4 \mathrm{in}$. long, and about $1 \frac{1}{4}$ in. broad, of a dull violet colour, and sessile. The bark of the tree is thickly interspersed with small vesicles containing a clear limpid resin. Points of the cones generally tipped with resin, and also the buds. Seeds very small, angular, soft, and only half the size of those of the common Silver Fir, with a broad, ample wing (Gordon, op. cit., p. 143).

Distribution. - This tree is indigenous to the northern states of America, to Canada, and Tora scotia. In these comntries it is to be 
found growing on cold moist lands, and frequently along the erlges of swamps. In all cases it forms a low tree only of the second magnitude, seldom exceeding 50 to 60 , and often of not more than about $40 \mathrm{ft}$. in height. It was introduced into Britain in 1696.

Description of Tree.-The Balsam Fir is a well-formed pyramillal tree, resembling the common European Silver Fir in its general appearance; but even where indigenous, it is very seldom to be found much above $40 \mathrm{ft}$. in height, and has usually a stem of from 12 to $14 \mathrm{in}$. in diameter near the ground. It grows rapidly in its younger stages; but in Britain it does not live to a great age. It is seldom found here of more than about thirty years old; for in our climate it seems to attain its maturity at a very early age, and, if not then utilised, soon dies off. It is a useful small tree, however, as it grows up at first much more rapidly than the Common Silver Fir, and in a comparatively short time produces shelter for other more valuable trees. From the premature character of the species, it has become rather scarce in this country, although it is hardy and perfectly adapted to our climate. Arboriculturists seem to have lost taste for it from the fact that it generally becomes matured and dies off at a very early age, when other kinds of trees are just in their most vigorous state of growth. It camnot, therefore, be recommended as having the slightest claim to any sylvicultural consideration whatever. It is merely of purely arboricultural interest as an elegant and hardy specimen of the Silver Fir genus (Alics), suitable for affording a variety in any pinetum for a few years, and to give temporary shelter to less hardy species of Conifers until they attain a sufficient height to raise them out of the cold damp layers of air near the ground, which cause the greatest damage during late frosts on cold nights in spring.

The bark of the stem is of an ashy-grey colour, whilst that of the younger branches is of a yellowish brown, and has a slight bloom. It is a very resinous species of conifer, and yields the "Canada Balsam" used for microscopic work. It is alike insensitive as regards late frosts and hard winter cold.

Economic Uses of Timber.-In consequence of the smallness of this tree, its timber is not applicable to many purposes, even in America. It is not plentiful in Britain; still there are some fair specimens here and there.

Soil and Situation.-The Balsam Fir will not prosper except on a deep, rich, moist soil ; and on light and dry soils it soon dies off. On such classes of land it matures and dies off when only about twenty years of age, although to all outward appearance it may have developed very favourably for the first ten or twelve years of that period. In order to have this species thrive for the greatest length of time 
that it is naturally capable of existing, it should lee planterl in a soil such as the Willow grows best in.

Propagation and Culture.-The Balsan Fir jroduces cones, and sometimes ripens its seeds in this country; and it may be readily propagated from either home-srown or importerl seed by the mode of treatment that has been already recommended for the cultiration of the Common Silver Fir. But, as the young seedlings of this species grow much more rapidly than those of the Silver Fir, they do not require to stand for two years in the seed-beds; nor do they need to be so long in the nursery-rows before they are fit to be put out on their permanent sites on lawns and similar situations.

On many of the estates throughout Britain specimens of the Balsam Fir are to be found ranging from 25 to $35 \mathrm{ft}$. in height.

The largest tree reported to the Conifer Conference in 1891 had a height of $68 \mathrm{ft}$., and a growth of $9 \mathrm{ft}$. at $5 \mathrm{ft}$. from the ground. It was growing on the estate of Saltoun in East Lothian.

\section{(3.) THE LOVELY SILVER FIR, Abies amabilis Forbes,}

Synonyus-Pinus amabilis Douglas; P. grandis Lambert; Picca amabilis Loudon.

Specific Character.-Leaves solitary, linear, flat, entire, hluntpointed, $1 \mathrm{in}$. long, irregularly and densely two-rowed, incurver on the upper side of the branches, bright green ahove and glancous lelow (see Fig. 64). Branches irregular on the main stem: lateral branches numerous, tolerably flat, and densely covered with leaves. Cones erect, solitary, large, ovate-cylindrical, 6 in. long and $2 \frac{1}{2} \mathrm{in}$. broad, slightly tapering to both ends, and woolly when young. Seeds angular and soft, with a membranaceous wing (Gordon, op. cit., p. 154).

Distribution.-This species is indigenous to Northern Califormia, where it is found growing to a height of $200 \mathrm{ft}$. in its native forests. Jeffrey recognised it there on the slopes of the mountains at an elevation of about $4000 \mathrm{ft}$, and forming a stem of $250 \mathrm{ft}$. in height amel $5 \mathrm{ft}$. in diameter on a gravelly soil. But the leaves were then very small, dark green above and silvery heneath: and the branches were horizontal, short, and bushy. It was introduced into Britain in 1831.

Description of Tree. - This is a very handsome and hardy species of Silver Fir, which forms a densely foliaged tree, and assumes a beautiful, pyramidal habit of growth as it attilins age and size.

Economic Uses of Timber.-No reliable data appear to he available as to the quality of the wood of this species; but it 
mobally is not rery dumble, nor endowed with any special technical yualities, otherwise its timlier would he more in lemand throughout America than seems to be the case, unless (as is not improbably the fact, in view of the difficulty of obtaining seed) it is only a tree of comparatively rare occurrence even in the Californian forests.

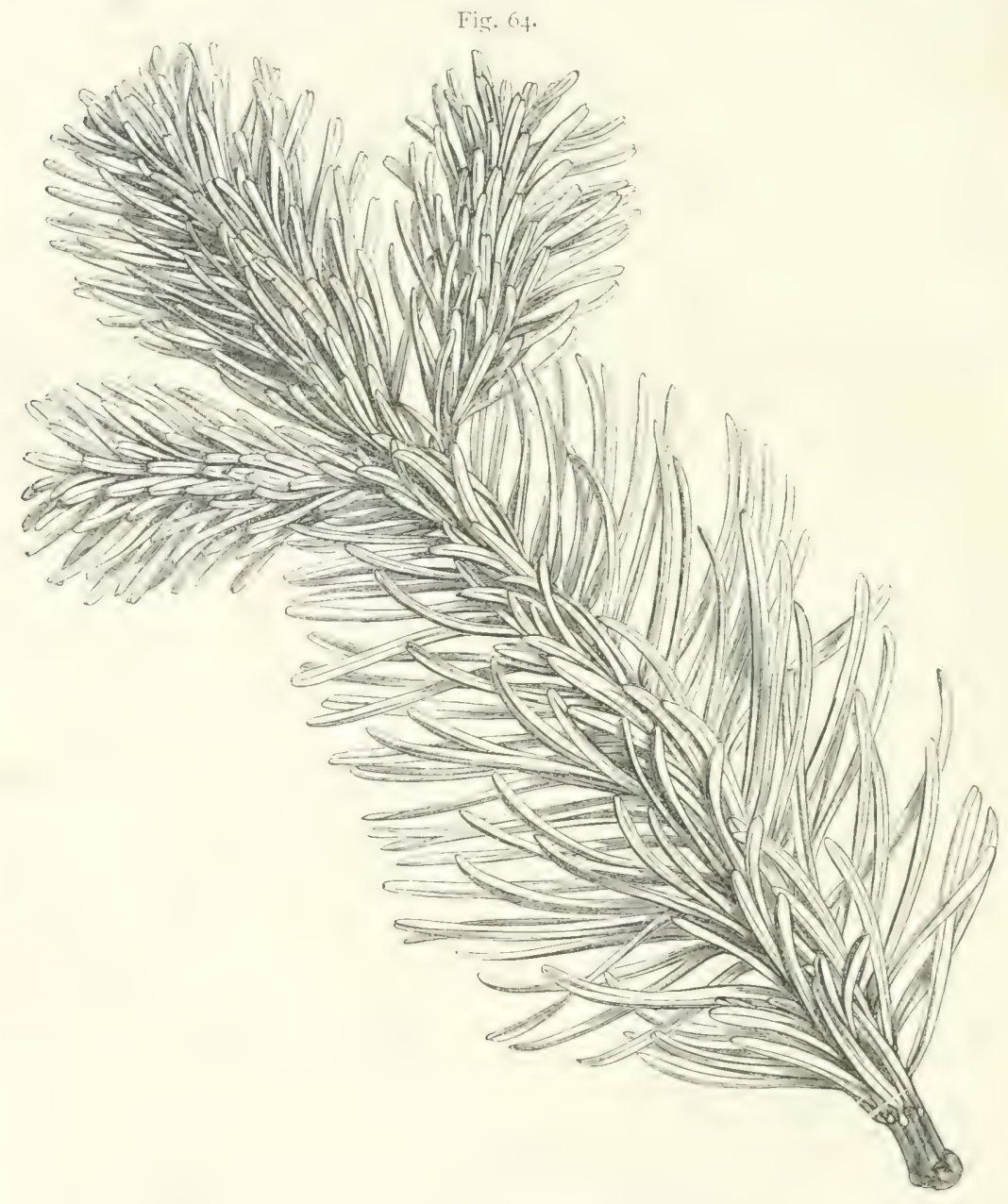

Spray of the Lovely Silver Fir (Abies amabilis), showing the disposition of the lcaves or needles.

Soil and Situation.-So far as local experience in Britain in the cultivation of this species may be followed, it seems to grow well in any common loam that is deep and open in the subsoil; but it appears to do better on a somewhat heavy rather than on a light soil, and its place is certainly in a low-lying and rather sheltered situation. It thrives well, however, even on moderately exposed 
parts, although on such it does not grow so rapintly as on low-lying and sheltered localities.

Propagation and Culture.-The seeds of this species are still rather scarce, and therefore most of the plants cultirated in this country have been raised from cuttings and grafts. Young plants are still comparatively high-pricerl in consernence of the want of seed; :3-ft. transplants usnally cost ahout is. Gil., althongh plants of the same size raised from side-grafts are obtainable for 1 s. each. Owing to the difficulty in obtaining supplies of sced from the Californian forests, where it is evidently anything lut a common tree, nurserymen are still compelled to raise the greater portion of the stock of their young plants of this species by grafting cuttings on stocks of more plentiful kinds.

In most good collections of the newer Coniferæe fair specimens of this tree are to be found, varying from 10 to $15 \mathrm{ft}$. in height.

The largest specimen of this species reported to the Conifer Conference of 1891 had a height of $32 \mathrm{ft}$. and a girth of $3 \mathrm{ft}$. at $5 \mathrm{ft}$. from the ground. It was growing on the Duke of Buccleuch 's Dumfriesshire estate, Drumlanrig.

The true A. amalilis is relatively scarce in cultivation. Its "leaders" are very apt to die off.

\section{(t.) THE LEAFY-BRACTED SILVFR FIR, Alis: limet.atu Nuttall.}

Syxoxpars-Pinus venusta Douglas; Picea brecteata Loudon.

Specific Character.-Leaves solitary, 2-rowed, linear, tapering to both ends, alternate, flat on the upper side, entire, and sharppointed, from 2 to $2 \frac{1}{2} \mathrm{in}$. long, and rather more than $\frac{1}{10}$ of an inch wide, bright green above, ribbed with two silvery white lines below, crowded and scattered at the insertion on the branches, lut 2-rowed and extended above. Branches in whorls, spreading, slender: luwer hranches drooping, lesser tranches bent downwards. Buls composed of large, loose, elliptic, pale yellow scales, destitute of resin, axillary, and scattered along the branches, but mostly towards the points. Cones ovate, erect, on very short footstalks, $4 \mathrm{in}$. long and $2 \mathrm{in}$. wide, in great clusters on the upper sile of the top adult branches. Scales reniform or kidney-shaped, concave, rounded on the upper mingin, and stipulate at the back. Bracteas werlge-shaped, :-lohed, the millile one $2 \mathrm{in}$. long, recurved, particularly those towark the base, which are the longest, while those towarls the summit are nearly straight, much shorter, and but little chimged in appearance or colour from the ordinary leaves. The lateral lobes are very short, and extend very little beyond the end of the scales. Secels wedge-shaped, suft, and angular, with rather a short, lut hroad, memhranaceous wing (Gordon, op. cit., p. 145). 
Distribution.-This species was first discovered by Coulter on the sea-range of Santa Lucia in Upper California, at an elevation of from 2500 to $3000 \mathrm{ft}$. above the sea-level. Douglas afterwards met with it at an elevation of $6000 \mathrm{ft}$. on the Californian mountains, in lat. $36^{\circ} \mathrm{N}$. It was introduced into Britain in 1857 .

Description of Tree. - This species is said to attain a height of from 120 to $150 \mathrm{ft}$., and to form stems straight as an arrow, but rather slender, seldom exceeding from 2 to $3 \mathrm{ft}$. in diameter. In this country there are as yet no large specimens of the tree to enable a correct estimate to be formed of its arboricultural character; but judging from the development of such plants as there are, it seems likely to form a handsome tree, and is well worthy of a place in our parks and arboreta. It can only be characterised as fairly hardy, for it begins active vegetation comparatively early in the season; and in consequence of this, it is liable to get injured by the late frosts in spring. On this account it should always be planted on a cold northern aspect, and never on eastern or southern exposures, where the vegetation becomes stimulated earlier in the season.

Economic Uses of Timber.-As yet no particular accounts are available as to the qualities of the timber of this species. It is reported to be very resinous, and this may be taken as a good general index of its durability.

Soil and Situation.-It is said that the natural soil for this Silver Fir is that yielded by a limestone formation. If so, the tree may perhaps be naturally well suited for the chalk and limestone districts of southern Britain. It seems to grow well, however, on the common loams of the country; but apparently it does not thrive either on very light or on very heavy soils. From its tendency to bewin active vegetation with a comparatively low temperature early in spring, it would seem most advantageous to plant it on cold northern or north-western aspects; for it will then not start so early into growth as it does on warmer southern and south-eastern exposures, and will on that account be less likely to be injured by late frosts in spring.

Propagation and Culture. - The seeds of the Leafy-bracted Silver Fir are still very scarce, and rather difficult to be obtained. It requires to be sown in a cold frame in Britain; and the young seedlings need protection for the first two winters after they have come up. As they attain size and firmness in the texture of their wood, however, they become quite hardy; and after they have begun to develop fairly, the only thing to guard against is the lialility of the young plants to be injured by frosts in the late part of spring when they commence their active vegetation for the season. In this respect the species mider notice resembles our Common Silver Fir: for both are liable to be injured hy late frosts in spring when young, 
but gradually outgrow this sensitiveness and beenme hardy as they attain a size which carries them above the level of the coldest strata of air near the surface of the ground.

Specimens of this very pretty Silver Fir are now plentiful throughout Britain, and in most good arloreta they are found of heights of from 15 to $20 \mathrm{ft}$.

Like some of the other rarer Silver Firs, it possesses no sylvicultural value for Britain, but is merely of arboricultural interest and ornamental heanty.

The largest specimen reported to the Conifer Conference of 1891 had a height of $49 \frac{1}{2} \mathrm{ft}$, and a girth of $4 \frac{7}{2} \mathrm{ft}$. at $5 \mathrm{ft}$. from the ground. It was growing at Boconnoc in Cornwall.

\section{(5.) THE GREAT CALIFORNIAN SILVER FIR, or VANCOUVER ISLAND PINE, Abies grandis Lindley.}

Sxnonrus-Pinus grandis Douglas; Picea grandis Loudon.

Specific Character. - Leaves linear, flat, channeled above, emarginate, or with a small notch at the point, and all irregularly arranged horizontally in double rows on each side of the branchlets, in a more or less pectinate or comb-like manner, on short twisted footstalks; those forming the upper tiers on each side of the shoots are much the shortest, and little more than $\frac{3}{4}$ of an inch in length, while the majority of those comprising the uncler series are of varions lengths, and mearly double that of the upper ones, but not broader, and all of a deep glossy green above, and with two silvery-white bands below, hetween the mid-rib and thickened margins, both of which are of a bright-green colour. Branches mostly in horizontal whorls, flat and spreading; branchlets glossy, smooth, rather short, compact, and placed laterally in two horizontal rows, and, when young, with quite a varnished appearance. Cones erect, cylindrical, and from $3 \frac{1}{2}$ to $t_{2}^{\frac{1}{2}}$ in. long and $1 \frac{1}{2} \mathrm{in}$. broad. Scales broad transversely, crescent-shaped, rounded on the exposed part, incurved at the edges, closely placed, tolerably equal in size, downy externally, deciduons when fully matured, and with the small fringed dorsal bracteas entirely hidden by the overlapping scales: sedels small, angular, soft, and with persistent wings, $\frac{3}{4}$ in. long (Gordun, op. cit., Supplement, p. 52).

Distribution.-This truly grand species of Silver Fir was first discovered by Douglas in Northern California; but more recently Bridges and others found it also in British Columlia and Tancouver Island. Douglas first sent its seeds to Britain in 1831.

Description of Tree.-The Vancouver Island Pine is really worthy of its botanical name, for it is a tree of magnificent growth. In the countries in which it is indigenous, the cireat silver Fir is a 
tree of the first magnitude, which attains a height of from 150 to $200 \mathrm{ft}$, and assumes a habit very much resembling that of the Common Silver Fir when the trees are full grown; but it differs in the young shouts having a somewhat polished and glossy appearance. The rery deep shining green of the foliage of this species lends it a cheerful aspect. The denseness of its thick foliage also gives the tree a richly mantled appearance, which makes it in all respects as handsome and as ornamental a species of Silver Fir as has yet been introduced into Britain. This Fir is hardy enough for our climate, although, like the Common Silver Fir, it is liable to have its young shoots injured by late frosts in spring during the younger stages of its growth. It has a tendency to begin active vegetation early in spring, especially if it he planted on an early or southern exposure: hence cool northern aspects are hetter suited for it than warm southern exposures.

Economic Uses of Timber.-No reliable information can be given on this point; but even in America it does not appear to be a species of common occurrence, as its timber is not used extensively for any purpose.

Soil and Situation.-The Vancouver Island l'ine seems to grow best on cool and somewhat moist soils, such as are generally to be found in flat parts of the country that have been formed alluvially. It does well, however, on dry lands at considerable elevations, where the atmosphere is more humid, and transpiration will therefore be lessened: this is proved from the success of many fine specimens now growing luxuriantly in many high parts of the country. It is as hardy as the Common silver Fir, and is deservedly a general favourite with all arboriculturists. This species may be recommended for extensive planting in the parks of landed proprietors; for there are few trees of a more ornamental character. It has a very fair chance of succeeding well on most lawns or parks when planted in proper situations among existing old trees, which would aftord it sufticient shelter against strong winds mili it estahlished itself well enough in the ground to resist them, by means of its own well-developed rootsystem.

Propagation and Culture.-The seed of this species is not yet available in any great l,ulk, and can only be had in small quantities from time to time. It is therefore still so valuable that most arboriculturists sow it in a cold frame, in order to prevent damage to the young plants from frost. The seedlings are generally protected for the first year or two, and are after that gradually exposed as they become stronger. As already stated, the tree is as hardy as the Common silver Fir; and were the seeds of the former anything like $\therefore$ plentiful as those of the latter, no sowing in cold frames would be 
necessary for the Vancouver Island Pine. It is the scarcity of the seed of this tree that makes nurserymen so careful of the seedlings raiserl from it. Many plants are, lowever, still reared loy grafting and layering.

Specimens of this Silver Fir are now plentiful in the country, and vary in height from 40 to $50 \mathrm{ft}$.

The two largest specimens of this tree reported to the Conifer Conference of 1891 had respectively a height of $83 \frac{1}{\mathrm{ft}}$., with a girth of $3 \mathrm{ft}$. $8 \frac{1}{2} \mathrm{in}$., and a height of $64 \mathrm{ft}$, with a girth of $7 \frac{3}{4} \mathrm{ft}$. at $5 \mathrm{ft}$. from the ground. The former was growing on the Riccarton estate, in Mid-Lothian, the latter at Poltalloch, in Argyllshire.

Owing to the scarcity of the seed, this species is not yet possessed of anything more than a purely arboricultural interest for Britain; nor is it likely to be at any time worthy of serious sylvicultural attention, such as has been recommended with regard to the Douglas Fir and the Menzies Spruce.

\section{(ii.) THE MOUNT ENOS or GRECIAN SILVER FIR,} Abies cephalonica Loudon.

Srnonxus-Pinus cephalonica Endl. ; Picea cephalonica Loudon; Abies cephalonica Loud,, Lawson, Carr.; A. Apollinis Link.

Specific Character.-Leaves solitary, that, dagrger-shaped, and standing at nearly right angles on every side of the branches, but chiefly on the upper side, of a dark shining green above, and with two silvery lines beneath, tapering from the base to the point, which terminates in a sharp point; footstallss very short, dilated at the base, and twisted. Buds prominent, stifi, pointed, and covered with a glossy resin. Branches very numerous, in regular tiers on the main stem, but branching in all directions in the lateral ones. Cones erect, straight, cylindrical, axillary, tapering at hoth ends, 5 or $6 \mathrm{in}$. long and $1 \frac{1}{2} \mathrm{in}$. broad. Scales rounded on the upper part, broad and entire, werlge-shaped below. Bracteas projecting heyond the scales, linear-oblong, with the lower end much attentrated, and tapering gradually into a stiff, unequally toothed, and reflexed sharp point at the top (Gordon, op. cit., p. 146).

This species is considered by some authorities to be merely a climatic variety of the Common Silver Fir, in the same way as the Siberian Spruce (A. obovata) has been regarded as but a climatic variety of the Common spruce, and as the Corsican Pine (P'inus Lucricio) is certainly merely a climatic variety of the Black or Austrian Pine ( $P$. Austriaca).

Distribution.-The Greeinn Silver Fir is found on Mount Enos or the Black Momntain, the highest mount:in in the Ionian island of Cephalonia, at an elevation of abunt 3000 to $5000 \mathrm{ft}$. It was in- 
troduced into Britain in 1824 by General Napier when he was Governor of Cephalonia; but it has since been found on the various diflerent mountains throughont Greece, particularly on the Sacred Apollo and Mount Parnassus, and also on the lofty and rugged Mount Eta.

Description of Tree.-It is said that this Grecian species of Silver Fir in its native mountains produces a large quantity of timber, but does not attain any very great length of stem. It seems to grow with a spreading head to the height of about $60 \mathrm{ft}$., and the stems are often to be found over $30 \mathrm{ft}$. in circumference. It forms a very beautiful object when standing alone in a park, as its numerous and regular tiers of branches stand very close together, and give it that peculiar aspect characteristic of the genus Araucaria. In its younger stages the tree is of rery lranching growth, so that it generally looks more like a large bush than a young tree; but after it once gets fairly established in the soil, it derelops more rapidly in height, and soon assumes a fine pyramidal habit of growth. It is quite hardy on dry situations at a moderate elevation, but does not prosper well on high or exposed localities. It seems to thrive best on situations not far removed from the sea, and least so on high-lying inland tracts, where its foliage is liable to be stimulated to excessive transpiration. In the latter situations it is also more liable to get injured by frost, as its general vigour is less than under conditions more suited to its normal development.

Economic Uses of Timber.-The timber of the Grecian Silver Fir is said to be hard and durable. So far as it may be judged of by a mere examination of the nature of the young wood produced by it in Britain, the timber seems close-grained, and likely to be of good technical quality when mature.

Soil and Situation.-The Grecian or Cephalonian Silver Fir appears to prefer a good, dry, light loam to any other description of soil. On heary, moist, and cold lands, where many of the other Silver Firs grow luxuriantly, this species does not seem to thrive, but generally remains of stunted bushy growth: on light and dry loams, however, that are not much elevated above the sea-level, it is always found of better development, and generally makes shoots of from 12 to 14 in. a-year, or sometimes even more, in the leading-shoots. Although not a species of any true sylvicultural value to Britain, it is a tree which deserves a place in every park and pinetum, as its dagger-shaped foliage, standing out nearly at right angles to the branches, gives it a peculiar effect among trees of various other kinds.

Propagation and Culture.-Although a few packages of the seed of this tree come to hand every now and then, yet it is still 
very scarce and difficult to olitain; and as it very often happens that the seeds imported are bad, only a few plants can generally be raised from them. When seed has been received, it is hest to sow it as has been recommended in the case of the immediately preceding species, the Vancouver Island Pine. It may, however, be mentionerl here that this Grecian species is very readily propagated l,y means of cuttings; indeed the great majority of the plants at present olltainatle from nurseries are produced in this way. They may he also prophagated by layering; and when cut back to the stool this species often throws out stool-shoots.

There are few arboreta in this country that have not fair specimens of the Grecian Silver Fir, some of them of heights ranging from 40 to about $50 \mathrm{ft}$.

There are two climatic varieties of the Grecian Silver Fir. One of these, A. c. var. parnassica Henk. (the A. Aprollinis of Link and Carr.), forme on the mountains of Greece, and forming pure roods or mixed forests along with Beech and Corsican and Cluster Pines, has shorter, broad, and less hedgehoglike leaves, and long-stalked brown cones about $7 \mathrm{in}$. in length; whilst the other, A. c. var. arcadica Henk. (the A. Regince Amalice of Heldr.), found in the Peloponnesus, and especially on the Areadian mountains at elevations of 3300 to $4200 \mathrm{ft}$., has shorter and softer leaves and smaller cones than the specific Grecian Silver Fir.

The largest specimen reported to the Conifer Conference of 1891 was 77 $\mathrm{ft}$. in height, and $11 \frac{1}{6} \mathrm{ft}$. in girth at $3 \mathrm{ft}$. above the ground. It ras growing at Powderham in Devonshire.

(7.) LOW'S CALIFORNIAN SILVER FIR, Hics Lomicence MIurmy.

Srmontar-Pica Lowiana Gordon; $P$. lasiocarpa and $P . P a r s o n s i i$ of gardens and arboreta.

Specific Character.-Leares long, linear, flat, and quite straighth, chamneled above, more or less twisted at the hase, rather distant, and strictly arranged in two horizontal rows along the shoots, and from $1 \frac{1}{2}$ to $2 \frac{1}{2} \mathrm{in}$. long, and $\frac{1}{10}$ of an inch broad, blunt-pointed, or with a slight notch in the centre, particularly those on the adult trees, and all of a dull glaucous green above, but much paler, and with two faint glancous bands lelow, between the elevated mid-rib and thickened margins. Branches in distant whorls, horizontally plinesl, and rather slender; branchlets more or less oplusite, quite smonth, slender, laterally placed in two horizontal rows, and of a pale yellowiwh colour. Cones from $3 \frac{1}{2}$ to $5 \mathrm{in}$. long, and $1 \frac{1}{2} \mathrm{in}$. broad, erect, cylindrical, obtuse at the point, rounded at the base, of a pale brown colour, and emitting numerous trinsparent rusinoms tear-drops externally, lut very similar in shape and general appentrance to those of 
the Tancurer Island I'ine, but somewhat larger. Scales broad, more ar less cresent-shaped, rounded on the outer side, incurved round the margins, woolly on the exposed parts, tolerably equal in size, and deciduous when fully matured. Bracteas very minute, dorsally placed at the base of the scales, broader than long, somewhat rommiten, wetge-shaped on the upper part, toothed or fringed round the edges, and with a prolonged sharp point in the centre; seeds angular, sult, and with a lroad hatchet-shaped persistent wing (Gordon, op. cit., Supplement, p. 54).

Distribution.-This species is found in British Columbia and Northern ('alifornia, where it frequently attains upwarts of $250 \mathrm{ft}$. in height, and forms stems of from 4 to $6 \mathrm{ft}$. in diameter. It is there to be met with for the most part in valleys and on the alluvial banks of rivers. It was introduced into Britain in 1860 .

Description of Tree.-This Silver Fir is rery frequently found in gardens and arboreta under the name of Abies lasiocarpa, a point that may perhals be noted here to avoid any misunderstanding which may arise from the difference in the nomenclature. Some consider this $A$. lasiocarpa as a distinct species from A. Loviana; but the difference seems too unimportant to be specific.

The true lasiocarpa, also called subalpina, differs widely, however, in many respects.

Low's Californian Silver Fir forms a grand and beautiful tree, and is well deserving of a place in every collection of Coniferæ, as well as in every park where the aim is to have a variety of form and of foliage in the most perfect manner that can be attained. There is no stiffness in the habit of this species, as the branches are developed in distinct whorls, and are horizontally placed; and their rather slender forms give the whole plant a natural and graceful outline. This is much enhanced by the long leaves, which are of a comparatively light-green colour for any species of Silver Fir. It is also a very hardy species, which is a great recommendation. It does not begin active vegetation early in the spring like some others of the Silver Fir tribe: its young shoots are therefore hardly ever injured by late frosts, hut are preserved healthy and uninjured all throvinh the spring and autumn seasons. Like many species of this genus which have been introduced into Britain, however, it can prefer no claims whatever to sylvicultural value, as the tree is simply one that should be of interest to arboriculturists. Int its hardihood in our climate seems mulouhiten and already estallished, although its introduction is not yet of many years' standing.

Economic Uses of Timber.-No reliable data seem available as to the quality of the timber of this species; lut, as it will never be 
grown in Britain with a view to timber-production on a financial basis, the guality of the wood is of compraratively little consequence. Soil and Situation.-Low's Californian Silver Fir seems to thrive best on the soils and situations that are most favourable to) the Vancouver Island Pine (see p. 370).

Propagation and Culture.-The seerls of this Silver Fir are as scarce as those of the Vancouver Island-Pine, and are comparatively seldom to be had. When seed is olstainalse, it should be sown in a cold frame to ensure its success, and in order to prevent, if possible, the failure of even one plant. Plants are, however, generally propagated from grafts and layers.

Of this species specimens are plentiful in many parts of the country, and may now be seen of heights ranging from about 30 to $40 \mathrm{ft}$.

(8.) THE NOBLE SILVER FIR, Abies nobilis Lindley.

Srnonras-Pinus nobilis Douglas; Picea nobilis Loudon; Abies nobilis Henk. and Hochst.

Specific Character.-Leaves solitary, rigid, crowded, irregularly 2 -rowed, mostly on the upper side of the branches, from $\frac{3}{4}$ of an inch to 2 in. long, linear, falcate, compressed, and turned upwards, flat, rich bluish green above, and silvery below; when viewed from a short distance the foliage appears a beautiful mass of rich silvery green, with shades and tints of violet (see Fig. 65). Cones solitary on the upper part of the top branches, cyliuclrical, thick, and rather obtuse, from 5 to 8 in. long, and from 2 to 3 in. broad; at first yellowish green; but changing to yellowish purple as they arrive at maturity. Scales triangular, with the edges incurved, entire on the margin, and without the bract, $1 \frac{1}{4}$ in. long, and about the same broad. Bracteas projecting, imbricated backwards, and longer than the scales, jagged round the edges on the exposed part, $\frac{5}{8}$ of an inch long, and with a long and rather broad point or tail in the middle; seeds small, angular, soft, with the wing $1 \frac{1}{4}$ in. in length, and $\frac{5}{8}$ in. broad in the widest part (Gordon, op. cit., p. 149).

Distribution. - The Noble Silver Fir forms vast forests upom the mountains of Northern Califurnia. It is also met with growing m the north-west coast of North America, along the banks of the Culumbia River. It was found by Jefliey on the Shasta Momntains at elevations of from 6000 to $8000 \mathrm{ft}$. above the sea-level, and was introduced into Britain by Douglas in 1831.

Description of Tree.-This is perhaps one of the most ornamental of the Silver Fir tribe. It is a misnificent tree, with regular, horizontal, spreading branches, and foliage that is light wreen above 
and silvery below. It grows to heights varying from 150 to 200 $\mathrm{ft}$, and runs to a bole of from 3 to $4 \frac{1}{2} \mathrm{ft}$. in diameter. It thus forms truly grand stems, both in respect to the quality of timber produced and to the ornamental appearance presented by the mature tree. The branches grow out nearly at right angles to the stem, forming as it were horizontal tiers, and are densely foliaged with beautiful, short, curved leaves, which, on the younger branches, are of a delicate silvery green, and on the older ones of a much darker hue. The

Fig. 65 .

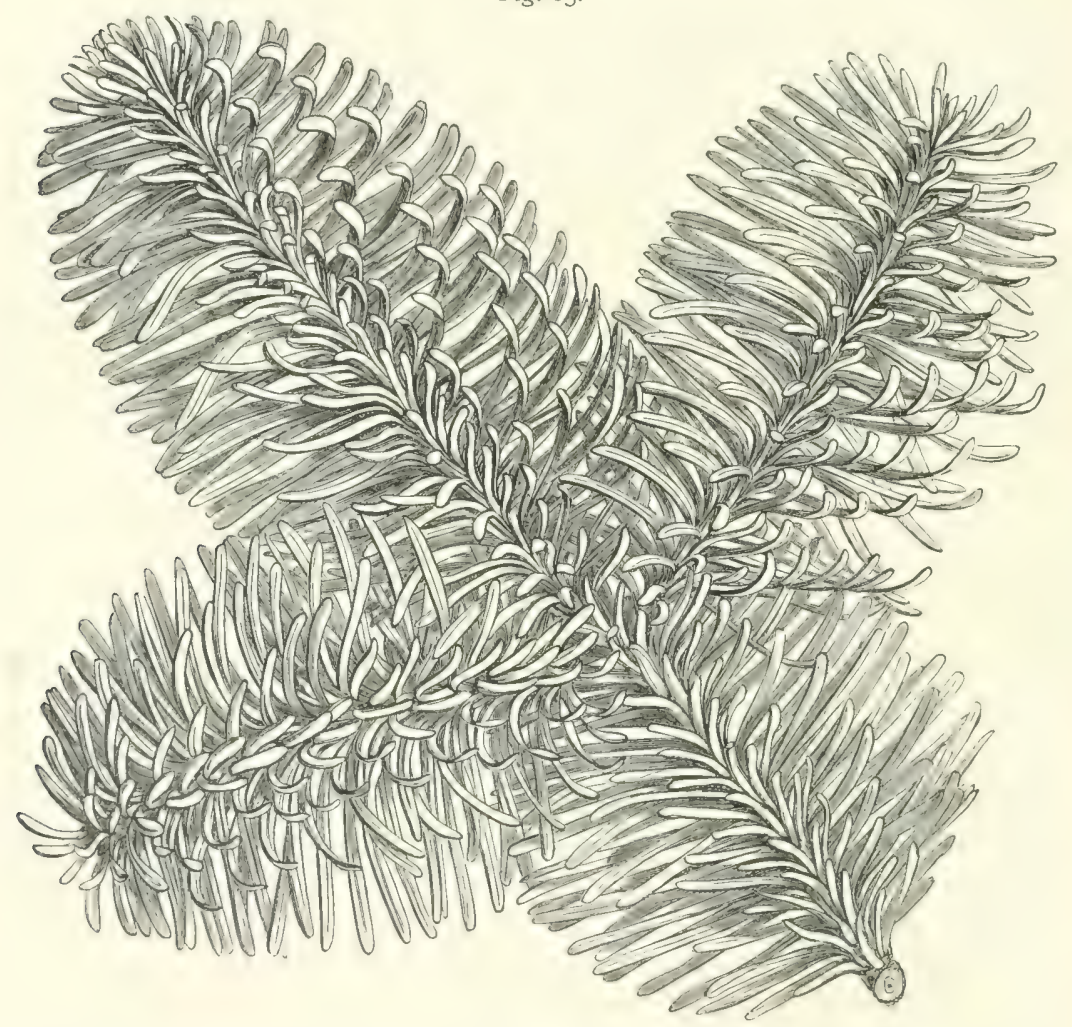

Spray of the Noble Silver Fir (Abies nobilis), showing the disposition of the leaves or needles.

bark of the stem of the tree is of a cinnamon colour; but on the younger branchlets it is of a yellowish green, while on the older branches it is of a purple hue. This is a thoroughly hardy tree, of tolerably rapid growth in this country, and seems to suit our climate well. It has, so to speak, a good sound constitution, and never appears to be at all injuriously affected by our coldest winters, which are, of course, much less severe than those of the lofty mountainous localities to which it is indigenous. 
Economic Uses of Timber.-The timler of the Noble Silver Fir is of a soft description, and white in colour, so that as a timbertree it must rank only in the second class, like nearly all of the Abietinee that have been introduced into Britain from Anerica, except those two fine species of unruestionable sylvicultural value, the Douglas Fir and the Menzies Spruce.

Soil and Situation.-This tree scems by no means particular as to soil and situation; for good and healthy sprecinens of it may be found in many parts of Britain growing well in most linds of soils, and on a great variety of situations. Hitherto it has, of course, like all other of our rarer trees, only been planted in selected spots, so that there has as yet been no wide range of experience as to how far it may be suited to grow on very dry and exposed hillsides, or in cold moist hollows, such as suits the Common Silver Fir. Still, judging from the apparently robust constitution of this species, it seems perhaps better adapted for growing on cool moist soil than for land of a dry nature.

Propagation and Culture.-The Noble Silver Fir is hardy, and may easily be raised from seed sown in the usual way without any special protection or precautions whatever. Seeds of this tree ripen in Britain, and plants have been raised from them. But, in all cases where seeds can be had gathered from trees grown in its native forests in California, such are to be preferred; for plants raised from seed taken from trees grown in Britain are generally found to be only of a comparatively weak constitution, and frequently hecome diseased at an early stage of their growth. It is now an acknowledged fact, supported by practical experience, that plants-not only of this species in particular, but also of all kinds of exotic conifers in general-which have been raised from our home-grown seeds are not so strong and healthy as plants grown from seeds brought from their native country; and it has been observed that a very large proportion of the seedlings reared from seed prodnced in Britain become liable to fungoid diseases at an early stage, the leaves first decaying at the points, and gradually becoming wholly dead. As this is a subject of vast importance both to Sylviculture and to Arhoriculture. a special section will be devoted to its consideration, which the reader will find in its own proper place in this work (see chap. xii., concerning the Pathology of Forest-trees).

Plants differ from animals with regard to heredity of disease. None of the infectious diseases occasioned by parasitic fungi, or by other natural causes, can be perpetuated by the seed of the tree. Any outbreak of disease in the younger generation of plants must be the outcome of direct infection of the individual seedling, pole, or tree. But the seed formed by trees may be, and very often is, of less than normal vitality from the very moment of its 
production; and of course plants raised therefrom have more of a predisposition to diseases of various kinds than plants raised from healthier and more vigorous seed.

Large specimens of the Noble Silver Fir are now plentiful in the older artweta of Britain; and many of them are already of heights varying from 60 to nearly $80 \mathrm{ft}$.

The two largest specimens reported to the Conifer Conference of 1891 had respectively a height of $83 \mathrm{ft}$., with a girth of $6 \mathrm{ft}$., and a height of $77 \frac{1}{2} \mathrm{ft}$., with a girth of $7 \mathrm{ft} .10 \mathrm{in}$. at $5 \mathrm{ft}$. above the ground. The former was growing at Birr Castle, in King's County, Ireland; and the latter at Coul, in Ross-shire.

\section{(9.) NORDMANN'S OF THE CRIMEAN SILVER FIR, Abies Nordmanniana Spach.}

Srvoryas-Pinus Nordmannia Endl.; Picea Nordmannia Loud.; Abies Nordmanniana Lk. and Carr.

Specific Character.-Leaves solitary, somewhat 2-rowed, curved upwards, linear, from $\frac{3}{4} \mathrm{in}$. to $1 \mathrm{in}$. long, with the point emarginate, prale yellowish green alove, channeled below, with a silver glaucous line on each side of the mid-rib, equal in breadth to the keel, and thickened margins, more or less twisted at the base, and flat. Branches dense, and regularly disposed, the lower ones horizontal, the upper ones rising at a more acute angle; young shoots quite smooth and glossy. Cones on very short footstalks, erect on the upper side of the branches, from $4 \frac{1}{2}$ to $6 \mathrm{in}$. long, $2 \frac{1}{2} \mathrm{in}$. diameter, and egr-shaped, a little blunted at the ends. Scales closely adpressed, cup-shaped, very obtuse. Bracteas adhering to the narrow base of the scales, lont afterwards free and extending beyond the scales, getting wider by degrees from the base outwards, rarely ovate, often cordate, reflexed at the apex, and incumbent on the lower scale, with the point a line and a half long. Seeds triangular, soft, and two under each scale. Wing obliquely expanded, membranous, with the imner margin straight, and ripe in September (Gordon, op. cit., 1) 150).

Distribution.-The Nordmann Fir is found very ahundantly on the monntains of the Crimea, and throughout the Alpine regions to the east of the Black Sea. Professor Nordmann of Odessa discovered it first on the summit of the Adshar Mountains, towards the sources of the Kur, at an elevation of $6000 \mathrm{ft}$. It was introduced into Britain in 1845 .

Description of Tree.-This is decidedly the hardiest species of the Silver Fir tribe that has yet been introduced into this country. It is more hardy than the Common Silver Fir, since its young shoots are not in any way injured by late frosts in spring, while those of the (common silver Fir are generally rather liable to be injured until it 
outgrows the coldest layer of damp air near the ground. This, of course, to a very considerable extent arises from the fact that the Common Silver Fir starts into growth early in the season; while the Crimean species does not begin to grow till the season is well advanced, and the chief danger from late frosts has passed away. Nordmamm's Fir forms a fit companion to the Vanconver Island I'ne: for its branches are also regularly disposed, and are thickly foliaged with dark glossy green leaves. It attains a height of 80 to $100 \mathrm{ft}$. in the Crimea. It is perhaps worthy of general cultivation in all plantations, not only for ormament merely, but also for the sake of its timber, as this is known to be of a quality fully equal to the wood of the Common Silver Fir. Its halit of growth while young is broad, bushy, and slow. As it becomes well established in the ground, however, it pushes rapidly upwards, and soon develops into a well-balanced and majestic tree, densely clothed with beautiful light-green foliage, such as altogether forms a highly ornamental olsject on any lawn or park.

Economic Uses of Timber.-The timber of the Nordmann Fir is said to be of very good quality, and harder than that of the celebrated Oriental Spruce. This species does not, however, produce such a large out-turn of timber as the Common Silver Fir; for its height generally remains under $100 \mathrm{ft}$., and it is seldom fomd alsove that even in forest crops.

Soil and Situation.-In Britain, the Crimean Silver Fir appears to thrive fairly well on almost all descriptious of land that are neither absolutely wet nor excessively light and dry. The tree, so to speak, seems to possess an iron constitution, and to be capable of growing healthily and profitably in all soils and situations where Pines, Spruces, and Firs generally are able to grow.

Continental experience shows that it makes moderate demands as to quality of soil, being less exacting than the Common Silver Fir, but more so than the Scots Pine. In this respect it resembles the Spruce. Wet soils are unsuitable to it; but it can be grown on dry land, althongh it thrives best on land that is fresh or moist, whether it be binding or light.

Propagation and Culture.-This sprecies requires no prarticular mode of treatment in its propagation. The seeds can now be hat plentifully as compared with those of many other kinds of silver Firs, and are easily procuralle from seed-merchants on the continent of Europe. When received they may be sown on any moderately good piece of land, in the sime way as recommented for the Common Silver Fir; and the young plants maly be dealt with in the manner jreviously recommended for the seedlings of that species (see p. 362).

Specimens of this species of Silver Fir are plentiful in many parts of the country, of heights from 25 to $40 \mathrm{ft}$. 
The two largest specimens reported to the Conifer Conference of 1891 were respectively $70 \mathrm{ft}$. high, with a girth of $6 \mathrm{ft}$., and $50 \mathrm{ft}$. high, with a girth of $101 \mathrm{ft}$. at $5 \mathrm{ft}$. above the ground. The former was growing at Poltalloch, in Argyllshire, the latter at Killarney, in County Kerry.

On the whole the Nordmann Fir does not possess very much value for Tritain, looking at it from a purely sylvicultural and financial point of view. Is a distinctly shade-bedring species, its chief use will probably he found for the formation of underwood below standard trees that are unable to protect the soil against deterioration, or also for forming the matrix in which lightdemanding trees like Larch and Scots Pine may be more economically and profitably grown than in pure crops.

For the benefit of the student, it may here be remarked that a short paper on The Culture and Management of this species of Silver Fir will be found in the Trans. Scot. Arbor. Socy., vol. ix., 1879, pp. 94-99.

\section{(11.) THE UPRIGHT INDIAN SILVER FIR, Alics Pimlme Spach.}

\section{Srxoxrys-Pinus Pindrow Royle; Taxus Lambertiana Wallich; Abies Webbiana var. Pindrow Brandis.}

Specific Character.-Leaves solitary, flat, and at first all round the shoots, but finally disposed into two rows on the branchlets horizontally, with the upper surface of the deepest green, almost black when fully matured, and the under one having two faint, white, silvery lines, from $1 \frac{1}{2}$ to $2 \frac{1}{2} \mathrm{in}$. long, and rather more than one line broarl, with acutely two-toothed ends. Branches in whorls, horizontal, and spreading; branchlets opposite in two rows. Cones erect, solitary, $4 \frac{1}{2}$ to $6 \mathrm{in}$. long, and from 3 to $4 \mathrm{in.}$ broad, cylindrical or elongaterl, flat at the ends, rleep purple, smooth on the surface, and growing on the upper side of the top branches; seeds soft, angular, full of turpentine, and ripe in Octoher; wing long and aniple (Gordon, "y). cit., p. 157 ).

Distribution. - This species of Silver Fir was introduced from India, as its name indicates, where it is found abundantly in Bhutan on mountains at elevations ranging from 10,000 to $12,000 \mathrm{ft}$. above the sea-level. In Kamaun it is found at from 7000 to $9000 \mathrm{ft}$. elevation, where it clothes the sources of the "Kosilla" in a forest of unusual gloom and density. It grows also on the most easterly range of the Himalayas, and also on the Chur and Kedarkanta Mountains, at elevations of from 8500 to $12,000 \mathrm{ft}$., and on all other ranges of similar heights. The stems attain a great height and a large girth. Some of the trees on the Chur Mountains measure over $6 \mathrm{ft}$. in diameter at $5 \mathrm{ft}$. from the ground, and are upwards of $150 \mathrm{ft}$. high; whilst the stem is densely clothed with short branches, bearing but little proportion in length to the great height of the tree. It was introduced into Britain in 1837. 
Description of Tree. - This Indian Silver Fir is, generally spealing, quite hardy in Britain. But, like our Common Silver Fir, it is disposed to awaken to active vergetation early in the spring ; and consequently it is very lial,le to have its young shoots injured by late frosts in the latter part of the spring. It forms a handsome upright-growing tree, and is well worthy of a place in every pinetum where it can have a northern aspect with a suitable soil. It can only be recommended as an ornamental specimen, however, as from its general characteristics it does not seem to be adapted ever to become a useful timber-tree in Britain.

Economic Uses of Timber.-The timber of this species is soft and spongy, and is evidently not of a durable description. It is said to rot very quickly when exposed to the action of rain and sun.

Soil and Situation.-The Pindrow Fir grows rapidly on any deep and porous soil of a light loamy character, that is neither toc sandy, too dry, nor too clayey, moist, and cold. It thrives better on a moderately elevated and dry situation than on a low-lying and humid locality; and its growth is better with a western or northern aspect than on an eastern or southern exposure. To preserve this species in health, it requires to be shaded from the morning and forenoon sun; for when exposed to the direct rays of the sun before mid-day, it is stimulated to active regetation too early in spring, and consequently gets its shoots injured by late frosts.

Propagation and Culture.-The seed of the Pindrow or Indian Fir is, like that of all the other Silver Firs of comparatively recent introduction into Britain, very scarce, and can only be had in small quantities from time to time. It may he sown and the young plants treated in all respects as has been recommended for the Leafy-bracted Silver Fir (see p. 368). This species also may be very readily propagated by grafts and layers.

Specimens of the Pindrow Fir are now plentiful in this country, ranging in heights from 40 to $50 \mathrm{ft}$.

The largest specimen reported to the Conifer Conference in 1891 had a height of $43 \mathrm{ft}$., and a girth of $4 \mathrm{ft}$. at $5 \mathrm{ft}$. above the ground. It was groming on Viscount Powerscourt's estate in County Wicklow.

\section{(11.) THE SPANISH SILVER FIR, Abics Pinsapo Boissier.}

SrNonxas-Pinus Pinsapo Endl.; Picca Pinsapo Loud.

Specific Character.-Leaves solitary, resularly and thickly disposed around the branches, short, 늘 an inch long, and plicesl at right angles to the branchlets, very stiff, sharp-pointed, hlat on the upper surface, and with a central rib slightly marked on eatch side by two 
furrows, which forms the only and very superficial indication of the two silvery lines so strikingly conspicuous on the under side of the leaves in the Silver Fir tribe. Branches regularly in whorls on the main stem, very densely clothed with laterals even to their lase, and scarcely extending any wider than those branches nearer, giving the tree a cylindrical rather than a pyramidal shape; the young shoots also have a cylindrical shape on account of the leaves being so thickly placed at right angles all round the stem. Bark darker in colour and more scaly than that of the Common Silver Fir. Cones (rect, in sreat numbers on the upper part of the top brinches towards their extremities, and without any footstalks, oval, cylindrical in form, terminating abruptly at the top, often with a small elevated point, from 4 to $6 \mathrm{in}$. long, and from 2 to $2 \frac{1}{2}$ in. broad. Bracteas small, concealed by the scales, and not extending beyond them. Seeds angular, soft, and with a membranaceous wing (Gordon, op. cit., p. 159).

Distribution. - The Spanish Fir is now found only in Spain on the momntains between Ronda and Malaga in Granada, and also forming forests on the Sierra de Tunquera and the higher parts of the Sierra de la Nieve, at an elevation of from about 3200 to $4000 \mathrm{ft}$; but it was formerly much more widely distriluted thronghout the lower elevations. It abounds in all the higher mountains, particularly on the northern exposures, reaching up even near to the summits, where the snow lies during at least four or five months of the year. It was introduced into Britain in 1838.

Description of Tree.-The Spanish Fir attains a height of from 70 to $80 \mathrm{ft}$., with a girth of over $3 \mathrm{ft}$. It has a dense foliage and branching crown, and is a most beautiful tree at all stages of its growth. In its younger stages it very much resembles Grecian Fir. It may be easily distinguished from that species, however, by the different form of its leaves, which are broader, not so sharp, and are not twisted at the base as in the case of the former. It is a thoroughly hardy species, of a moderate rate of growth, and is by no means particular as to soil and situation. For the first few years of its growth the leading-shoot makes but little progress, while the lateral branches srow vigorously, thus giving the tree a rather flatheaded and bushy appearance; but after the root-system has once s-r fatrly established in the soil, the top-shoot rises rapirlly, and the plant soon develops into a tall tree of a cylindrical shape. It deserves a place in every park and pinetum, for it is of rapid growth, hardy, and very ornamental. It is said to be of particular beauty when the male-flowering trees throw out their catkins. It is a handsome tree for lawns, as it has the close-branched conical habit uf growth of the Crimean Fir, but with very distinct foliage; hence it contrasts well with that species. 
It cannot be said to possess any distinct claims to anything more than it purely arboricultural interest. For British woorllands, to he manased on scientific, financial, and sylvicultural principles, it possesses no such importance as other exotics like the Douglas Fir, Menzies Syruce, Common Spruce, and Common Silver Fir.

Economic Uses of Timber.-The timluer of this species is said to be of aljout the same quality as that of the Common Silver Fir, and to be full of resin, which is a fairly good inclication of considerable durability.

Soil and Situation.-The Spanish Fir seems to thrive well on most soils that are found suitable to the Common Silver Fir; but it requires a sheltered situation that is neither too elevated nor ton exposed to high winds.

Continental experience shows that a considerable amount of warmth is requisite for the Pinsalı Fir before it can produce seed of germinative calacity. Thus in southern Germany it cannot be relied on to ripen its cones, for which reproductive effort a very considerable amount of summer warmth is required, as for example in the Adriatic basin; and even the mildest parts of England do not offer such a climate.

Propagation and Culture.-Seeds of this species are imported from Spain every now and then through seed-merchants on the continent of Europe; the supply is, however, not plentiful. Nurserymen in this country generally sow the seed in a cold frame for fear of any risk to the young plants, and in order to protect them for the first and second winter; but the seerllings are freely exposed during the summer months. The young plants seem perfectly harly, however, as they do not appear to be in any way specially liable to be injured by the frosts of our winters.

Specimens of this beautiful Silver Fir are to be found in many parts of the country, ranging from 35 to $50 \mathrm{ft}$. in height.

The largest Spanish Fir reported to the Conifer Conference of 1891 had a height of $43 \mathrm{ft}$, and a girth of $4 \mathrm{ft}$. at $5 \mathrm{ft}$. above the ground. It was growing at Pampisford in Cambridgeshire.

A variety of this species (P. P.var. baborensis), found growing in the mountainous tracts of Algeria at 4.500 to nearly $6000 \mathrm{ft}$, and often to be met with in the Kabyl country forming forests along with the Mount It lits Cedar (Cedrus atlantica), seems very suitalle for introuluetion into British arhoreta. It is now generally considered to form a distinct sprecies known as . 1. numiliou De Lamroy.

(12.) WEBB'S INDIAN SILVER FIR, Alics Wi himue Limlley. Srxomsas-Pinus Webtiana Wallich; Picce Webbiance Loudon.

Specific Character.-Leaves solitary, at first scattered all round the shoots, but finally more or less arramed in two rows laterally. 
from 1 to $2 \mathrm{in.}$. long, linear, flat, leathery, bidented on the end, of a dark and glossy green above, and furnished with two broad white bands below (see Fig. 66). Branches in regular whorls, horizontal and spreading; branchlets opposite, 2-rowed, and stout. Buds oval,

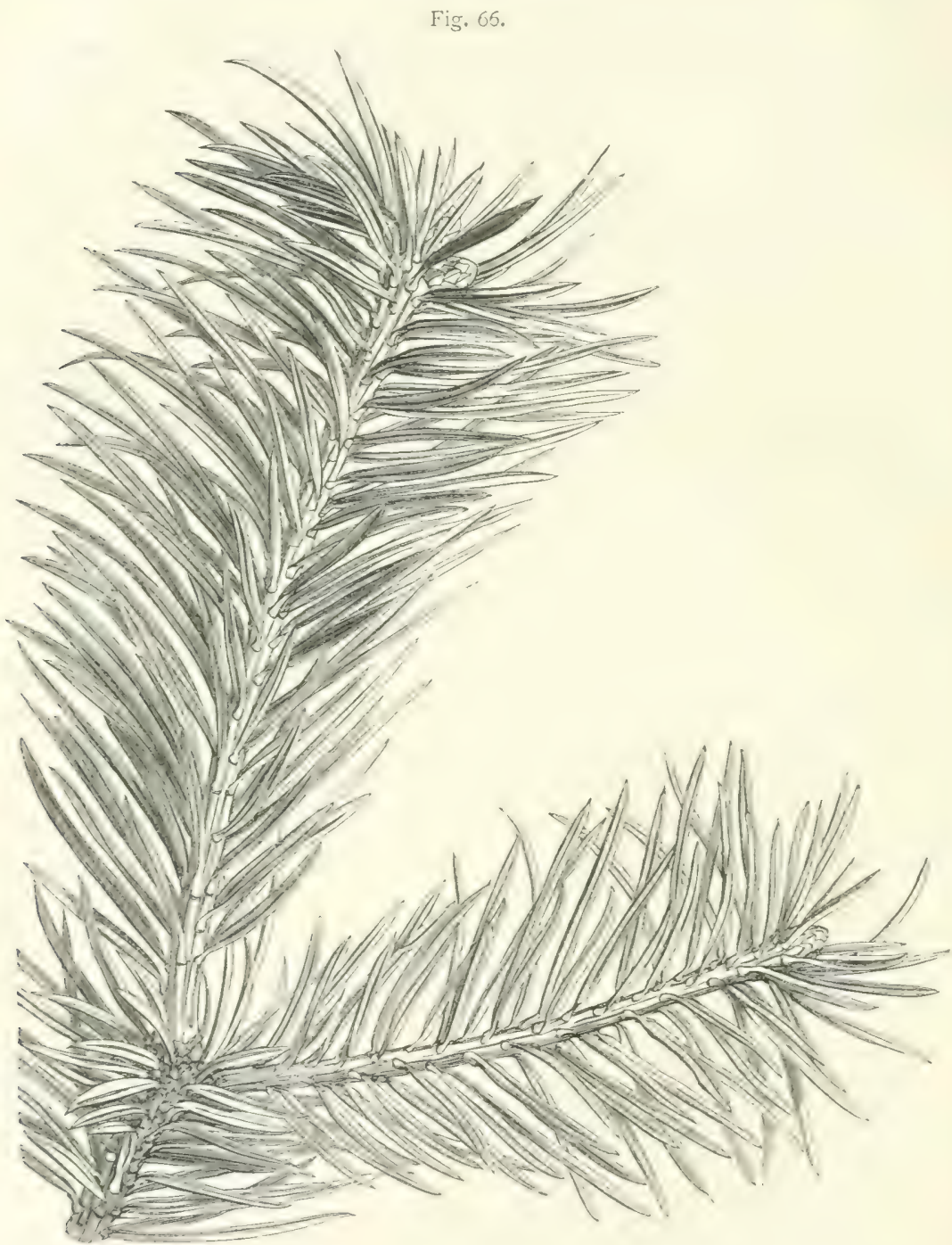

Spray of Webb's Silver Fir (Abies Webbiana), showing the disposition of the leaves or needles.

covered with brown scales, and resinous. Cones solitary, erect, and of a rich purple colour, from 6 to $7 \mathrm{in}$. long, and about $2 \frac{1}{2} \mathrm{in}$. broad, "rlinhlicat, l,lunt-enderl, full of resinous matter, and growing on short stout footstalks on the upper surface of the top branches. Seeds 
soft, oblong, or angular. Wing thin, broad, and somewhat obovate (Gordon, op. cit., p. 160).

Distribution.-Weblj's Fir also forms a nolle tree, growing from 70 to $80 \mathrm{ft}$. high at different elevations on the Himalayan MIountains. Its lowest limit on the southern slope of these mountains is about $10,000 \mathrm{ft}$. Griffith states that this species is rare lelow $9500 \mathrm{ft}$. in Bhutan, but is of true forest growth, anct forms vast woods at from 12,000 to $13,000 \mathrm{ft}$. of elevation. Hooker found it in Sikkim measuring $30 \mathrm{ft}$. in girth. It also forms extensive forests on the northern side of the Shatul Pass; but on the south face it does not appear to flourish. It was introduced into Britain in 1822 .

Description of Tree.-The Webb Fir is, without doulst, one of the prettiest of the Silver Firs. It has more of the silvery tinge on the lower side of the leaves than any other species of Silver Fir, and this gives it a very distinctly marked character. It may, indeed, readily be distinguished from all the other species by the very decided whiteness on the under side of the leaves. The tree forms a beautiful object when standing out on a well-shaded lawn; the dark and glossy green of the upper sides of the leaves, blending with the silvery white of the under surfaces, gives the foliage a cheerful and rich effect, that contrasts very pleasingly with the darker foliage of most other Conifers. It is quite hardy after once it gets up to a fair age and size, and has ontgrown the coldest, heavy, damp layer of air near the surface of the ground. But upon all southern and eastem aspects the young shoots are apt to suffer from frosts in late spring and early antumn, owing to its being easily stimulated into active regetation when the diurnal temperature begins to rise in early spring.

Economic Uses of Timber. - The timber of the Webl Fir is of rather soft and inferior quality; hence this species, like not a few of the Silver Firs, is hardly to be recommended as possessing any sylvicultural or timber-producing value for Britain.

Soil and Situation.-The details already given with regard to the Pindrow Fir are also applicable to this species (see 1. 381).

Propagation and Culture.-The seels of the Webb Fir are generally sown in a cold frame, so as to protect the young seedlings during the first two winters. Plants of it may, however, be readily propagated by grafting and layering.

Specimens of this Indian Silver Fir, ranging from $: 35$ to $40 \mathrm{ft}$. in height, are now common in most of the arboreta thronghout Britain.

The two largest specimens reported to the C'onifer Conference in 1891 were respectively $52 \mathrm{ft}$. high, with a girth of $6 \frac{1}{1} \mathrm{ft}$., and $51 \mathrm{ft}$. high, with a girth of $8 \mathrm{ft}$. at $5 \mathrm{ft}$. above the ground. The former was growing at Courtown, in Wexford, and the latter at Howick Hall, in. Northumberland.

VOL. I. 


\section{THE LARCH, Larix Miller \\ (Limiaax Systemi, Monacia Monadelphia).}

Generic Character.-Trees with long shoots and scattered foliage, or with short spurs and leaves in tufts; the leaves in both cases linear, deciduous, soft. Male flowers in short spikes, anthers apiculitte, „--lohed, dehiscing transtersely. Pollen grains very large, globose. Cone-scales woody, persistent. Seed without resin-canals. TVing of seed oblong, acute. Cotyledons 6-8, 3-cornered or flat, entire. Primary leaves entire (Masters, op. cit., p. 216).

There are, up to the present, 9 species of Larch known. All of these are deciduous trees; and some of them attain large dimensions. They are indigenous to the whole of the northern portions of the North American continent, Asia, and Europe, as well as to the mountainous regions of central Furope and Asia, extending eastwinds to Japan. As, however, there is only one species, the Common Larch (Larix europece), worthy of sylvicultural attention as a timbertree in this country, the following details will be confined to it.

\section{THE COMMON LARCH, Larix europece DC.}

\section{Srxoxyas-Pinus Larix L.; Larix excelsa Link; L. decidua Miller; Abies Larix} Poiret; Larix pyramidalis Salisbury.

Specific Character.-Leaves in wisps, tufts, or bundles, many together round a central bud (short shoot), but singly on young plants and the leading-shoots (long shoots), deedluous, linear, soft, blunt or rounded at the points, spreating, slightly recurved, and of a heantiful bright and light green (see Fig. 67). Cones of a longish oval shape, erect, of a brown colour, about 1 in. in length, and remaining for a long time on the trees. Scales persistent or not falling off', roundish, streaked, and slightly waved on the margins. Bracteas generally longer than the scales, particularly towards the base of the cones. Seeds small, of an irregular oval form, with a broad wing. Seedleaves from 5 to 7 . Cones ripen late in the autumn (Gordon, op. cit., p. 124).

Distribution. - The Common Tarch is indigenous only to Europer, where it is fomml acemying the hilly resions throughom the central portion of the Continent, and forming large forests on the Alps of France and Switzerland. Its proper region seems to be at an eleratim of from :0000 to $6000 \mathrm{ft}$, although it is sometimes fomm as high as $7000 \mathrm{ft}$; but at the latter height the tree is much dwarfed. It is

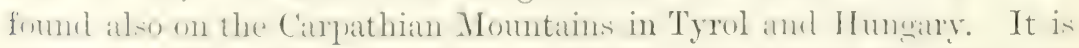
not truly indigenous to the (ierman platins; lut is there frepuently to be fomin forming forests of antificial production. It was introduced 
into England in 1629 , into the Lorlands of Scotiand in 1725 , and into the Perthshire Highlands in $17: 27$.

The natural limits of the Larch are now hard to determine, as so much has been done for its artificial distribution without any record haring been maintained. Its polar or northern limit seems to be reached on the northern outliers of the Carpathians at about 5()$^{*}$ of latitude: whilst its equatorial or southern, and at the same time its mesterm, limit is situated on the Dauphing Alps at about 11 tiv. As regards locality, its northern sphere of indigenous gromth is probably ciremescribed br an irregular line across the tura range and the Central and Bararian Alps tomards the morthern Carpathians. whence it trends somth-east to Firomstadt in Transtrauia, where its eastern limit is probally tixable. The southern limit of gromth runs irregularly aloug the sonthern slopes of the Alps skirting Crontia and southern Hungary (11illkomm, op. cit. p. 14t).

As a knowledge of the climatic conditions mader which the Larch can thrire, and may contime in healthy normal development, is of immense importance for the practical purposes of sylvieulture in Britain, the following summary of Willkomms investigntions on this point may be quoted (on. cit. 1. 153 ) :-

"The essential climatic conditions for the norand derelopuent of the Larwh appear $\tau_{1}$ consist of a mean ammal temperature vot below $I^{*}$ nor below $s$

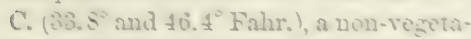
tire period of winter rest extending over at least four months, a short spring. with rapid ransition from

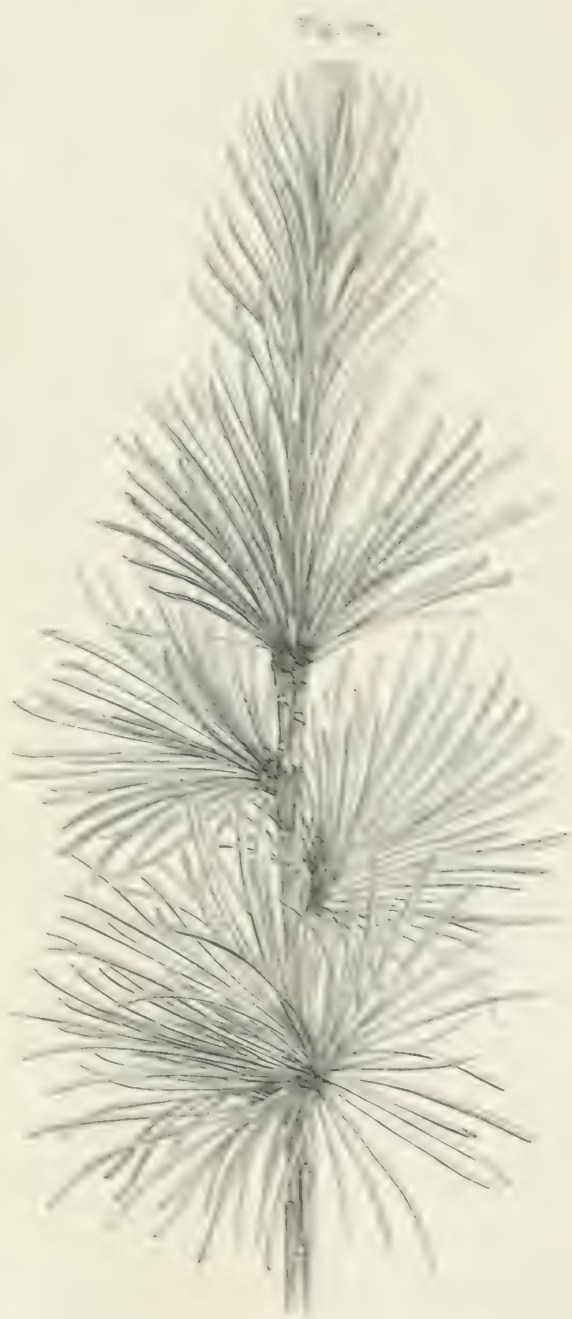

Sorut a the Lario (Luix europea). spring to summer (i.c, a ropid rise in temperature at the time of the development of the foliage and Aorrers), a damp spring and early summer, a constant and equable marm summer for three months, a situatiou proterted agniast cold and diry wiuds, undisputed exposure to light amd air, aud cousequent? a large groming-space, and, fimalle, a modentely moist, hight, deep, lims or argillaceous soil." 
Description of Tree.-The Larch is an open, airy, and gracefullooking tree, of a conical form, which, in favourable situations, attains large dimensions, having frequently stems of from 80 to $100 \mathrm{ft}$. in height and of from 3 to $4 \mathrm{ft}$. in diameter. It generally forms a very stratght bole, and where it has sufficient growing-space for the natural development of its numerous branches, these clothe the stem from bottom to top in a graceful and pendant manner. There is one feature in this tree which distinguishes it from all others of the coniferous tribe-viz., its deciduousness; that is to say, it sheds its leaves in the autumn of the same year in which they are produced. It is decidedly one of the most valuable of the coniferous trees ret introduced into this country, both with respect to the rapidity of its srowth and to the real value of its highly durable timber. In point of sylvicultural importance for Britain, it will prohably only ultimately be equalled by the Douglas Fir and the Menzies Spruce, although neither of these species can yet compete with the Larch as to the present extent of their production as true forest-trees throughout Britain. Being a native of the mountainous districts of central Europe, it is found to endure the climate of the hilly districts of the north of England, and of the mountainous tracts in Scotland, as well as our only indigenous genus of the Abictince, the Scots Pine: lut it is nuch more particular and decidedly less accommodative than that tree with regard to the circumstances of soil and situation which favour its healthy growth and normal development. In the Larch plantations of this country several varieties of the tree may le noted. Some of these have white flowers, or female spikes or catkins, and some have red; some produce timber of a whitish colour, and others of a reddish; and in certain localities trees may very generally be found with their flowers and timber of all shades between white and red. These differences in the colour of the flowers aud the heartword are no doubt occasioned by some definite cause; they are probably due to accidental circumstances of climate, soil, and situation.

Economic Uses of Timber. - It is allowed by all who are acquainted with the tree, and who have had occasion to use the timber, that in point of durability the wood of the Larch is decidedly the toughest and most lasting of all the coniferous fanily excepting the Yew. It also has the valuable and characteristic feature of being durable and tough when of only a few years' growth; of this peculiar property ample proof may easily be had by erecting fences with the wood of young Larches. Larch is extensively used for all purposes in our rural economy. Its durability makes it much sought after for mining purposes. In the pits very large quantities of it are ammually used, and in some mining districts the demand for it, of small sizes, often far exceeds the supply. For use as railway sleepers there is 
also very considerable demand, as for this purpose Larch is always preferable to creosoter I'ine, when it can be had at anything like the same cost; for it is found to last longer than any other lind of homegrown or European wood when lair on the earth and exposed to the wear and tear of traffic, and the disintegrating and decomposing influences of damp, warmth, and saprophytic fungoid organisms.

On the Continent it is used for all purposes for which the wood of the S'cots Pine is suitable; but, as it has been found liy practical experience to be of better and more durable quality, it possesses a higher market value than that species. It is the heaviest of our European Conifers grown for timberproduction (see table on p. 331); though, as its average sp. gr. is only 0.81 when green and 0.59 when seasoned, it is floatable immediately on the fall of the crop taking place. When grown at high elevations, and with well-dereloped and resinous heartwood, it ranks along with, and often above, the I'edunculate Oak as the most durable of European woods; and in respect to general durability is only approached by the Scots and Black Pines (Austrian and Corsican), the Acacia (lialinir), and the Sweet Chestnut. Yet at the same time, the wood is soft and very elastic.

Soil and Situation.-For healthy, thriving growth the Larch must have a deep and light soil, within which its deep root-system can easily be developed. It should also contain a considerable amount of freshness or moisture, which, however, must be water in motion and not stagnant soil-moisture. Where there is any tendency towards dryness in the soil, this may often be remedied at a comparatively slight cost by means of well-made drains conducting the water from higher levels. This method is often carried out in the Scottish Highlands when Lareh plantations are to be formed on mountain-slopes, where there is a continual descent of water from the higher to the lower grounds in burns or rivulets, which may easily be tapped by drains running more or less horizontally, so as to allow the water to percolate to the lower levels and moisten the soil. The Larch does not succeed on thin lands, nor on those having a cold, retentive subsoil. In planting this tree, therefore, if the land be at all of an argillaceous or otherwise of a retentive character in the subsoil, it should be well opened up and made porous by a proper system of deep drainage, according to the rules laid down for soilpreparation in a special part of this work (see chap. vi.) Although the Larch canker, which causes such enormous losses in Larch-woods, both in England and in Scotland, is due to a fungus (Peisce Williommii, see chap. xii.), yet there can be no doubt that much of the predisposition and weakened natural resistance of our Lareh plantations towards infection with fungoid disease, and towards general constitutional debility, has in many cases arisen from imperfect preparation of the land on which the tree has been 
planted, or from putting it out on soils or situations not naturally suited for its normal development. Hence the great financial and practical sylvicultural value of scientific investigations and decluctions like those of I'rofessor Moritz Willkomm, already referred to. No tree we have - if we may except the Scots Pine-is so hardy as the Larch; therefore, as to situation, it may be planted at any altitude at which the Scots Pine will prosper. Still it must be observed that, on very high-lying sites with poor soils, the Scots Pine is certainly the better tree to plant, both with a view to profit and to producing shelter.

Continental experience proves that limy soils are those most suitable for the Larch, whilst loamy or argillaceous sands rank next as favourable classes of soil, and dry, wet, or very binding land is under all circumstances decidedly unfavourable for its healthy and normal development. Throughout the Hanoverian forests, the Larch has on the whole been found to thrive best on light, stony, moderately fresh soil (Burckhardt, op. cit., p. 433). Neither tenacious and binding clays or limes, nor poor soils, nor land that is between moist and wet, are favourable to its development up to the attainment of its normal maturity; and in suppressing rank growth of heath and heather, the Spruce and the.Scots Pine have there been found to yield better service than the Larch. Where, however, grazing considerations are simultaneously being taken into account, the Larch has better claims to attention than either of these European species, or than those valuable North American introductions, the Douglas Fir and Menzies Spruce.

Propagation and Culture.- - The Larch is propagated from seed in the same manner as other coniferous trees. The speediest way to extract the seeds from the cones is to subject them to heat on a timber-kiln in the same way as recommended for extracting the seeds from the cones of the Scots Pine (see p. 257); with this exception, however, that in drying the cones of the Larch the heat should not on any account be raised above $105^{\circ}$ Fahr. Even when the cones are subjected to heat on a kiln as stated, the seeds of the Larch will not fall out so readily as those of the Scots Pine, but will have to be threshed out with a flail. On the kiln the cones will be merely dried and made lrittle, and thus prepared for extracting the seeds from them. After the cones of the Larch have been dried on the kiln, they should be removed in the warm state and laid some 8 or $10 \mathrm{in}$. thick on a stone or pavement flowr, on which they should be threshed to pieces with flails, care being taken to sift out the seeds by means of a sieve from time to time, until the whole of them have been extracted. The later treatment of the Larch seedlings and trans1 lants is indicated in the chapter on the management of the nursery (see chap. ix.) As to whether foreign or home-grown seed should be used in our cultivation of the Larch, is a question that will also be argued subsequently. 
Sylvicultural Characteristics and Value of the Larch.-In Scotland, the Larch has to srow under climatic conditions which vary from those obtaining in the Alpine tracts to which it is incligenous. On the northem slopes of the Alps, where it occurs most extensively, there is jractically no long spring or autumn, and anything like the commencement of active vergetation so early as the begiming of March (as usually takes place throughout the southern tracts of Britain) is inimical to its healthy and normal develop)ment. On the northern slopes of the Alps everything remains frost-lonnd till the middle of April. But by the middle of May it is practically summerlike in temperature; all the forest-trees (Beech, Suruce, Larch, Pine) are in leaf, and heath and forget-me-not in full flower. The transit from summer to winter is equally rapid, and there is no long-continuer, almormal period of autumnal vegetation. The long periods of spring and autumn vergetation necessitated by our milder insular climate are unnatural to the growth of the Larch; and, judging from the practical results throughout Britain, they are decidedly prejudicial to its value as a sylvicultural crop. They weaken the inherent power of the Larch in resisting the attacks of insect enemies (like the aphis or "bug," Chermes Laricis, and the mining moth, Coleryllerme liricellu), and of the canker fungus (Pe:iza Hillkommii) which has followed the tree from the $A l p s$, and in this milder climate is able to fructify more abundantly, whilst it also finds the Larch less able to resist the infecting power of the germs, so much more numerously developed here than in the true home of the tree.

Its root-system is deep-reaching like that of the Scots Pine and the Oak. Hence depth of soil is essential for its thriving. But its leading characteristic as a forest-tree is its intolerance of anything like oversharlowing or even sileshate; for it is the most essentially liylut-demanding species of our forest-treer, not even excepting the Birch. It is therefore not naturally adapted for forming pure forests, as has so generally been the mistake made throughout Britain. Whenever it begins to make rery umistakable demands for large individual growing-space between the 20th to 30th year of age, it is unalile to protect in a satisfactory manner the productive capacity of the soil. Plantations of 30 to 40 years of age have only about half the density of those formed with Scots Pine.

It should, therefore, either be raised in pure plantations, and then thimed and underplanted with some shade-bearing species of tree like Spruce, Douglas Fir, Menzies Spruce, Silver and Nordmann's Firs, or Beech and Hornheam; or else it should be interspersed among other trees when plantations are being made with mixed crops. In the latter case it will be of forward growth; but its light side-shadow will not usually interfere much with the normal development of other forest-trees. In wooks of spruce the Larch is generally caunht up in growth about the 30th year, and in woods of Silver Fir about the soth year. Whenever this is likely to take place, it can be freed from the sidepressure by means of thinning out the other species; or if this cannot conveniently be done, then the Lareh ean be cut out and utilised, as at that age it will often be of fair marketable size.

As a standard over coppice it does very well, and can hold out a rotation of 100 to 120 years for the production of timber of specially valuable dimensions. In such situations a little money expended in trimming away the lower branches at each time of clearing the colpice will prove a very profitable 
ontlay in keeping the bole free from large knots, and thereby enhancing its technical value; lut these branches should be removed before they get above $2.1 \mathrm{in}$. in diameter, otherwise danger is incurred of allowing fungoid spores to infect the wound-surfaces. The operation should be carried out in late autumm, and the surfaces treated antiseptically with a coating of tar.

Owing to the strong demands for light, Larch-woods cannot be conveniently regenerated naturally. And in the formation or artificial reproduction of woods, planting is preferable to sowing. It is recommended not to plant the young Larch closer than $6 \mathrm{ft}$. by $6 \mathrm{ft}$, and to put in some shade-bearing species of tree at the same distances between the latter. If the Larch be planted thicker, some of them will usually require to be removed about the 10 th year.

They can easily and cheaply be put out into the open as two-year-old transplants, after having been schooled for one year in the nursery-beds at about 6 in. by 4 in. They establish themselves readily, grow rapidly, and are hardy; owing to their insensitiveness to late frosts, indeed, they are frepuently; like the Birch, utilised as nurses for less hardy species of trees in localities exposed to danger from late frosts in spring.

On most of the great landed estates throughout Britain, and especially in Scotland, good specimens of the Larch are so plentiful that it would be superfluous to refer here to those in any particular place. It is to be found in many places forming crops varying in height from 80 to over $100 \mathrm{ft}$, and with stems from 3 to $4 \mathrm{ft}$. in diameter when the trees occupy isolated positions.

The two largest specimens reported to the Conifer Conference in 1891 were respectively $100 \mathrm{ft}$. high, with $10 \mathrm{ft}$. in girth, and $80 \mathrm{ft}$. high, with 11 $\mathrm{ft}$. in girth at $5 \mathrm{ft}$. from the ground. The former was growing at Rossdhu, in Dumbarton, and the latter at Howell, in Worcester.

It may here be noted, however, that the two oldest Larches north of the Forth (1727) are to be seen in the grounds of the dower-house of the Athole family at Dunkeld. Treated first as tender exotics, they were grown in the greenhouse; becoming sickly, they were thrown out on a litter-heap, where they took root and began to recover in the cooler air. On this being noted, they were planted out in their present places, where they form very interesting arboricultural objects.

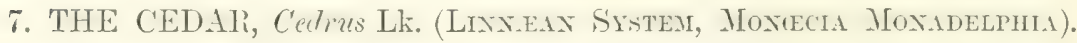

Character of the Genus.-Trees with long shoots and scittered leaves, or with short "spurs" and tufted leaves, the latter in all cases linear and persistent. Stamens in catkins; anther-lobes 2, crested; jollen-cells winged. Cone-scales overlapping, ultimately falling, but leaving no central axis. Scales much larger than the bracts. Wing of seed truncate, very large. Seed with resin-canals. Cotyledons leafy, 8-9, entire, 3-sided (Masters, op. cit., p. 200). 
The Cedars are trees of a majestic character, evergreen, and highly ornamental in whatever place they are found. They are natives of Mount Lebanon, the north of India, and the Barbary and Atlas Mountains in northern Africa. They are perfectly hardy in Britain.

Up to the present only 3 species are known of this genus-viz., the Cedar of Lebanon (Crrlrus Libuni), the Atlas Cedar (C'. retlentica) common to Asia Ninor and northern Africa, and the Deodar ( $C$. Defuterim) of the Himalayas. Both of these latter species are, however, regarcled by Hooker and Griscluach as probably only climatic varieties of the Ceclar of Lebanon (Willkomm, " $\%$. cit., p. 158).

(1.) THE CEDAR OF LEBANON, Cedrus Libani Loudon.

Srronysis-Pinus Cedrus L.; Larix Cedrus Miller; Abics Cedrus Poir. and Lindley; C. patula Koch.

Specific Character. - Leaves simple, very dense, in alternate tufts, of about thirty in number, evergreen, rigid, partially 4 -sided or cylindrical, tapering to the point, straight, $1 \mathrm{in}$. long, sharp-pointed, and of a dark grass-green colour (see Fig. 68). Branches horizontal, and with the branchlets disposed in a flat, fan-like manner on then, very numerous, and thickly set with leaves. Cones erect, ovate, flattened at the ends, and depressed, 4 to 5 in. long and $2 \frac{1}{2}$ in. wide, with rather a long footstalk, of a greyish-brown colour, and persistent, remaining firmly attached for years to the branches. The cones require two years to ripen, and exude a large quantity of resinous matter while growing (Gordon, op. cit., p. 43).

Distribution.-This well-known species is a native of Mount Lebanon in Syria, and was introduced into Britain about the year 1683 .

Besides the ancient Cedar forests of Lebanon, frequently mentioned in the Old Testament, which are now limited to a few trees, this tree occurs of spontaneous growth throughout the Taurus range in Asia Minor, where it still forms extensive woods, and also on the Atlas Mountains in northern Africa at elevations ranging from 4000 to $6400 \mathrm{ft}$. above the sea-level (Willkomm, op. cit., p. 159).

Description of Tree.-Although more frequently a tree of the second rather than of the first magnitude, the Cedar of Lebanon is perhaps one of the most majestic-looking trees introduced into Britain. There is hardly any other tree that has stamped upon it so deciledly an expression of majesty and grandeur. The Oak is certainly a noble and admirable tree in its general outline and bearing, and the I'ine, the Larch, the Spruce, and the Silver Fir are tall and stately- 
specimens of the regetable kingdom; but when these are compared with the lroad, massive, wide-spreading branches and grand, majestic untline of a full and well-grown Cedar of Lebanon, they seem tame, and are somewhat apt to lose the

Fig. 68 . effect they had before comparison. In short, as an ornamental tree

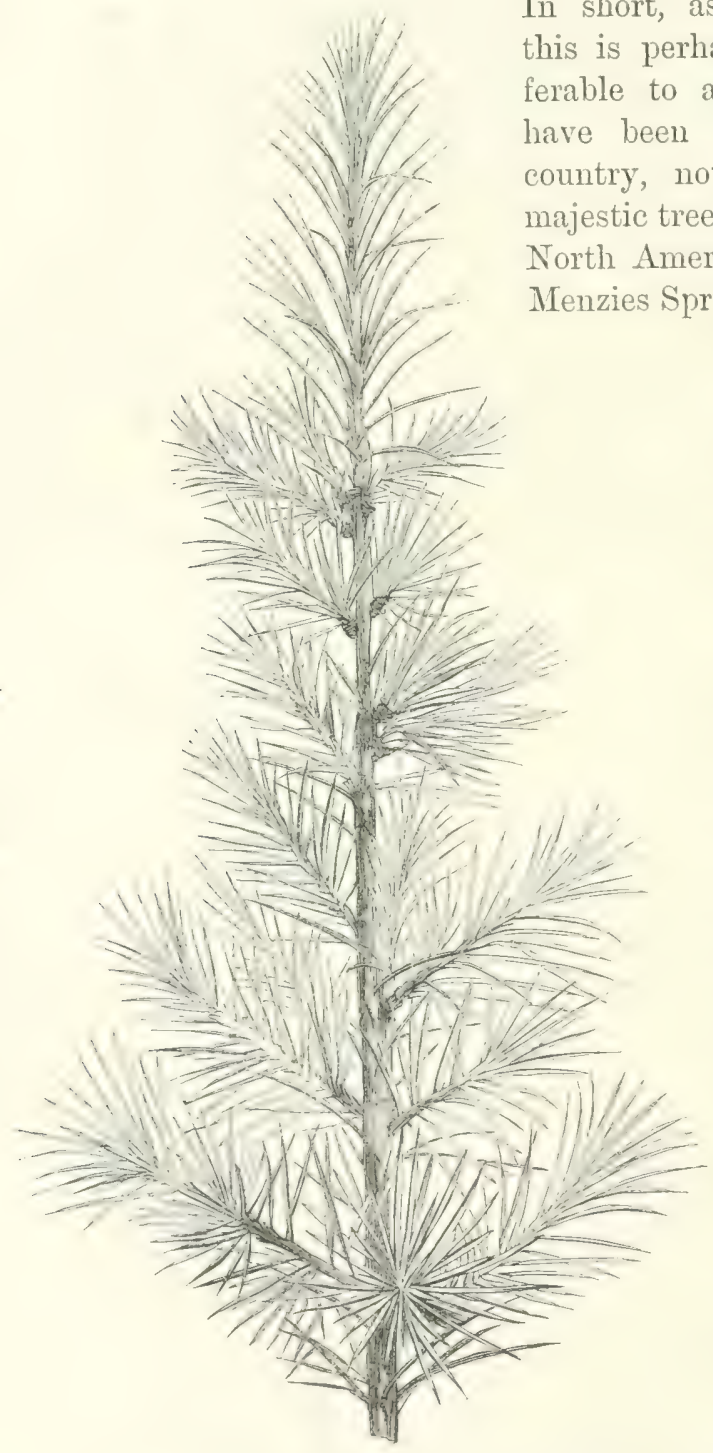

Spray of the Cedar of Lebanon (Cedrus Libani). out lateral branches of great size in proportion to the height; and, even after it has attained its full growth upwards, the branches continue to extend until the fullgrown tree presents a rounded-off head, with a broad and almost flat surface. This is the character of the tree when it is found standing alone with a free growing-space all round; but if it be at all confined among other trees, it rises with an upright stem like any other coniferous tree. It has absolutely no sylvicultural value at all; it possesses, however, very great airboricultural interest. Its place is as an ornamental tree in parks; and for this purpose no other species is better calculated to produce a grand and striking effect. 
In its indigenous forests the Cerlar of Lebanon is said to attain a height of $120 \mathrm{ft}$; but in general throughnut Britain it does not exceed 80 to $100 \mathrm{ft}$. when full grown. In 1860 Hooker found the remains of the ancient Cedar forests of Lebanon to consist of nine sroups of C'erlars, amountines to about $400 \mathrm{in}$ all, whose ages he estimated as varying from 100 to 2500 years.

Economic Uses of Timber.-The timher of this C'erlar, although said to be of great durability when growi on its native momntains, is but soft and of inferior quality when grown in Britain, and is not nearly so valuable as that of many of our Pines and Firs. I'ut eren were its timber of first-class quality, this tree is of much tor slow a rate of growth for it to be recommended as a timber-crop. Its only utility is simply and solely for ornamental purposes; but this rolject it fulfils most satisfactorily, and in a mamer surpassed by no other coniferous species of tree.

Soil and Situation. - This Cedar is exceedingly hardy, and never suffers from any degree of cold in our climate. It is in no way particular with regard to soil, provided always that this be dry, deep, and of an open, light, and porous mature, with a yermeable subsoil. In short, it will grow well in most soils suitable for ordinary foresttrees.

Propagation and Culture.-The C'edar of Lebanon does not begin to hear seed till it has attained a considerable age and size, and seldom flowers before it is from 50 to 60 years old. It flowers in the autumn in September or October, and the seed takes two years to ripen. When the cones are ripe, they do not fall off the tree at an early stage like those of many other cone-bearing trees, but remain attached to the branches for several years, with all their seeds in them. When seed is to be harvested from home-grown trees, the cones should be gathered in spring, and the seeds extracted immediately after; or if the cones be procured from the Lerant, they may be laid past in a dry airy loft till the time of sowing has arrived. British nurserymen usually have supplies of both homegrown and foreign seed.

The seeds should be sown in April, in auy piece of light and wellprepared ground, and placed on the bed about an inch apart; whilst the covering of earth should not be more than five-eighths of an inch. The plants will spring up about five or six weeks after sowing, according to the state of the weather. Afterwards they may be dealt with in all respects as recommencled for the Scots l'ine see p. $25 S$ ); that is to say, the seedlings should be transplinted into nursery-rows when one year old, and should remain there till they are of sizes fit to tramsplant out into their permanent sites. IIany arboriculturists, howerer, plant a large portion of them into small pots when one year old, and shift them into larger pots as they make 
progress and require more root-room. By growing a part of the plants in this way, their removal can be effected at any time of the year, just as is convenient whenever they may be wanted.

Some of the finest specimens of the Cedar of Lebanon in Britain are to be found at Syon House, near Brentford, Middlesex. One of the trees there is over $80 \mathrm{ft}$. high, and has a stem of $8 \mathrm{ft}$. in diameter; at Claremont, near London, there is also a specimen about $100 \mathrm{ft}$. high, and with a stem considerably above $5 \mathrm{ft}$. in diameter; at Hopetoun House, the seat of the Earl of Hopetoun, near Edinl,urgh, there are several fine Cedars of Lebanon, one of which is alyout $80 \mathrm{ft}$. in height and nearly $7 \mathrm{ft}$. in diameter. Even in the north of Scotland there are some fine trees of this species. At Beaufort Castle, the seat of Lord Lovat, in Inverness-shire, there is one, the stem of which measures about $6 \mathrm{ft}$. in diameter, with a height of fully $60 \mathrm{ft}$.

The two largest specimens reported to the Conifer Conference in 1891 were respectively $90 \mathrm{ft}$. high, with $9 \mathrm{ft}$. $10 \mathrm{in}$. in girth, and $82 \mathrm{ft}$. high, with $16 \mathrm{ft} .2 \mathrm{in}$. in girth at $5 \mathrm{ft}$. from the ground. The former was growing at Methven, in Perth, and the latter at Bretby, in Derbyshire.

On the Dropmore estate in Bucks there is an avenue of 170 Cedars of Lebanon, planted 80 years ago, that have now attained an average height of about $75 \mathrm{ft}$., and a girth of about $8 \mathrm{ft}$.; and though the roadway between the lines is about $50 \mathrm{ft}$. across, the heads of the trees (which are $25 \mathrm{ft}$. apart) on each side have closed up so as to shut out the sun's rays, and give the road a sombre and shady appearance. An older Cedar there, planted in 1792, or just over a century ago, now girths $13 \frac{1}{2} \mathrm{ft}$.

A monograph On the Cedar of Lebanon (Cedrus Libani), syn. C. atlantica and C. Deodara, will be found in Trans. Royal Scot. Arbor. Socy., vol, xiii., part ii., 1892, pp. 200-219.

(2.) THE DEODAR or INDIAN CEDAR, Cedrus Deodare London.

Srxosmas-Pinus Deodara Roxburgh; Abies Dcodara Lindley.

Specific Character.-Leares evergreen, somewhat 4-siled, needleshaped, acute-pointed, pungent, very glaucous, and from 1 to $2 \mathrm{in.}$ long; those on the principal and lateral branches are collected in tufts or close bundles of from thirty to sixty in number, on very short and numerous branchlets, while those on the young shoots are solitary, alternate, ani scattered along the twigs; when young very glancous, lut getting much greener as they get older (see Fig. 69). Branches very stout, irregularly flaced along the stem, much divided, horizontal, and quite flat, the lower ones being more or less deflected and hanging close to the ground. The general aspect of the tree when young is drooping and very graceful; but as it grows older and larger the loranches assume a stiff, flat, and solemn appearance, like 
that of the Cedar of Lebanon. It flowers in September, and the seeds are ripe in October or November of the following year, or in about thirteen months. The male catkins, though solitary, are very numerous, erect, 2 to $3 \mathrm{in}$. long, and are at first oval, but gradually become cylindrical; the majority of these and the female flowers are produced on separate trees. But a considerable number of these trees also produce both male and female flowers on the same individual. In about a month after the Deodar has flowered, the young cones, covered with a bluish bloom, appear. They are cylindrical in form, without any footstalks, and solitary on the top of the little tufts of leaves. Cones erect, solitary on the upper side of the stout top branches, ovate, obtuse, or nearly cylindrical, from 3 to 5 in. long, and $2 \frac{1}{2}$ in. wide, flat, slightly depressed at both ends, and very much resembling, in general appearance, those of the Cedar of Lebanon; but they are of a rustybrown colour, and when the seeds are ripe they break up and fall to pieces, shedding both scales and seeds on the ground (Gordon, op. cit., p. 40).
Fig. 69.

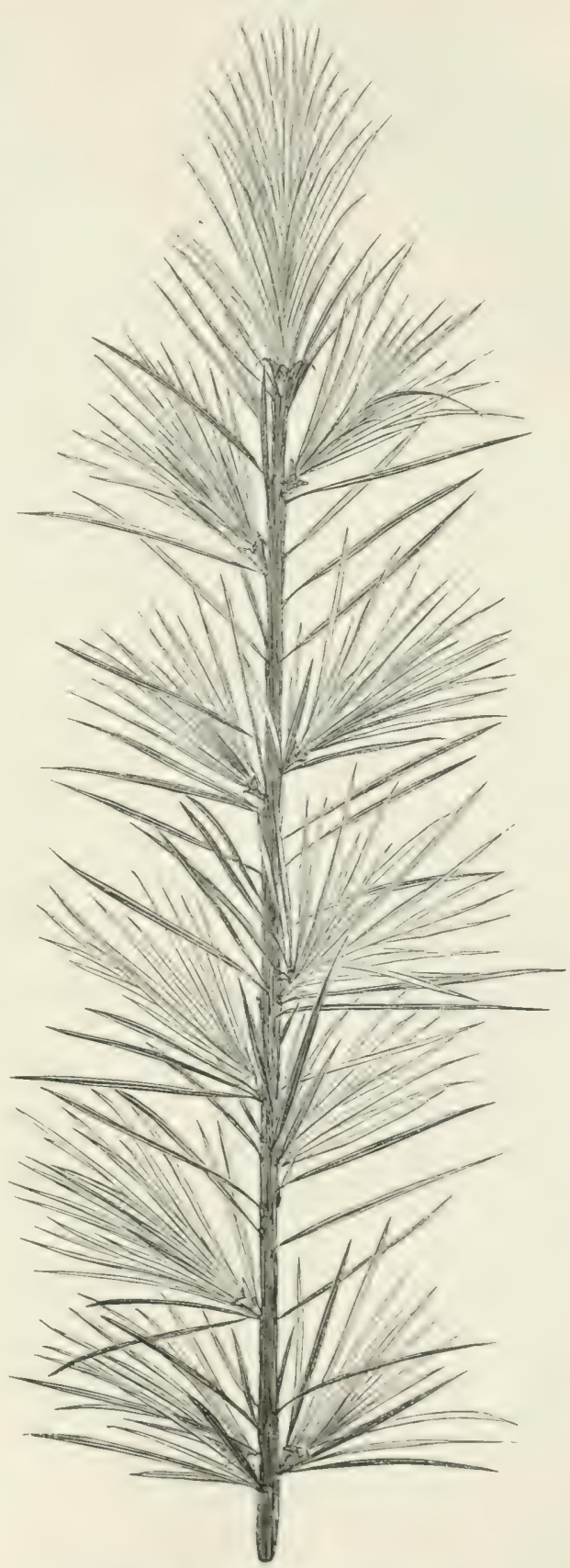

Spray of the Deodar or Indian Cidar (Cedrus Deodara). 
Distribution.-The Deodar is extensively distributed both in pure forests and throughout the mixed forests on the Himalayas, and is found growing at an elevation of from 4000 to $12,000 \mathrm{ft}$. Up to ahout $6500 \mathrm{ft}$. its chief associate is the Long-leaved Indian Pine (T'inus longifulia); while from about 8000 or $9000 \mathrm{ft}$. npwards its principal associates are the Himalayan Sprnce (Picen Smithicene) and the Lpright Silver Fir (Abics Pindrow). It is found on all the higher mountains from Nepal up to Cashmere; and Griffith describes it as occurring in vast forests and of great size towards Kafiristan, where it flourishes at an elevation of from 6000 to $10,000 \mathrm{ft}$. above the level of the sea. In the lower Kamaun, Madden measured one tree in 1830 which was fully $36 \mathrm{ft}$. in circumference near the base; and he saw several on the northern declivity of the Burum and Rupin Passes not less than $30 \mathrm{ft}$. in girth, and from 150 to $200 \mathrm{ft}$. high. It was introduced into Britain in 1822 .

Description of Tree.-The Deodar is easily distinguishable from the Cedar of Lebanon by its drooping habit of branches, especially during the younger stages of growth, and by its lighter appearance generally. The Cedar of Lebanon has a dark-green aspect, and is strong, firm, and horizontal in the spread of its branches, even while young; whereas the Indian Cedar assumes quite the opposite appearance of this, and has also at all stages of its development a freer growth. As it becomes older, however, it gradually assumes very much of the character and outline of the Cedar of Lebanon, for its branches become stiff and flat like those of that species. Judging from the best specimens to be seen in this country, it is perhaps quite as ornamental as the Cedar of Lebanon in its haljit of growth and in the display of its branches; lut it lacks somewhat of the imposing majesty and grandeur of the latter. The drooping or weeping habit of its branches gives the tree, in its younger stages, a rather more graceful appearance than the other; but at the same time this somewhat detracts from it in point of grandeur and of majestic effect. Still, all travellers who have seen the tree in full maturity on its native mountains agree that it is a tree of majestic and imposing effect, and that it unites those qualities with beauty and gracefulness. All these statements may cuite easily be accepted; for even in the case of the old trees to be seen in this country, which are now between 60 and 70 years of age, the Deodar is, like its close relative the Cedar of Lebanon, a tree not surpassed by any other conifer or broad-leaved tree when regarded from an ornamental point of view.

Economic Uses of Timber.- The timber of the Deodar is said to be highly valued by the inhabitants of Northern India. The specinens of nature timber which reach this country from India 
prove that its texture is indicative of excellent quality in the wood, and show that it appears deserving of the character it las got in its native country. It takes a very beautiful polish. But whether, even when it may have arrived at maturity, it will in this comntry produce timber nearly erqual in quality to that of Himalayan growth, remains to be seen; and many years will have to elapse before a proper judgment can be formed on this point.

The experiments conducted with the Deodar in central Germany show that it is of rapid growth, and produces wood of excellent technical quality. But it has not there proved itself a sufficiently hardy species for cultivation on any extensive scale.

Soil and Situation. - The Deodar is by no means of a delicate constitution in respect to mineral food, for it is to be found growings in Britain on soils of every description, from those of a light sandy character to others of a strong argillaceous nature. In all cases, however, the soil should be of a dry and permeable description; it should neither be retentive in the subsoil nor in any way cold or sour. Indeed on cold, moist lands, or on those that are thin and lying on a retentive sulbsoil, the tree sickens and dies off at an early stage. In order, therefore, that this tree may thrive, the land must be made deep, light, and dry by drainage, if it be not naturally of this description. The tree likes a free and open exposure, and is well suited for growing on sites of moderate elevation, if the soil on which it is planted be dry, and deep enough for its roots to spread in.

Propagation and Culture. - Ioung Deodar plants are rearecl from seeds in the same way as has already been stated with respect to the propagation of the Cedar of Lebanon. Some of the oldest trees in the country have alrealy borne cones, particularly those at Dropmore, at Sunning Hill, Knaphill, Chiswick, and several othex places in the south of England. Considerable supplies of seeds are obtained from the native forests in India from time to time. But still it is far too scarce to admit of the plants being reared so abundantly as to make them cheap; and until a greater supply of seed can be had from India than is now obtained, this tree will nut be planted extensively in our woods.

Good specimens of the Deodir are now plentiful in this country; miny of them having attained heights of from 60 to 70 .ft., with stems of proportionate girth.

The two largest specimens reported to the Conifer Conference of 1891 were respectively $70 \mathrm{ft}$. high, with a girth of $7 \frac{1}{2} \mathrm{ft}$., and $46 \mathrm{ft}$. high, with a girth of $10 \frac{1}{\mathrm{ft}}$. at $5 \mathrm{ft}$. above the ground. The former was growing at Studley Royal, in Yorkshire, and the latter at Coollatin, in County Wicklow. 


\section{(3.) THE IMOUNT ATLAS CEDAR, Cedrus atlantica Manetti.}

SrNoxyMs-Pinus atlantica Endl.; Abies atlantica Lindl.; Cedrus argentea Hort.

Specific Character.-Leaves in tufts, or singly, on the young sluots, stifl, needle-shaped, cylindrical, or flattened on the upper side, sharp-pointed, and straight; evergreen, with a silvery appearance, and shorter and denser than those of the Cedar of Lebanon; very irregular in length in the fascicles, varying from $\frac{1}{2}$ to $\frac{3}{4} \mathrm{in}$., longer on the leading-shoots, and with a furrow ruming along the whole length of the leaf. Branches rather slender, less rigid, and covered with seattered bundles of leaves, mostly olyosite, but sometimes rery irregularly placed. Cones ovate, flattened, or rather depressed at the ends, from $2 \frac{1}{2}$ to 3 in. long, erect on the upper side of the external branches, of a shining light-brown colour, and full of resinous matter (Gordon, op. cit., p. 40).

Distribution. - This tree is found in great abundance on the highest momntains in Barbary, particularly on the famous Atlis range in northern Africa, at an elevation of from 7000 to $9000 \mathrm{ft}$. It is quite harly and more rapid in growth than the Common Cedar. It was introduced into Britain in 1843.

Description of Tree.-The Atlas Cedar is readily distinguishable from the Cedar of Lebanon by its more upright and its freer habit of growth; it varies also from the Indian Cedar or Deodar by its never assuming the peculiar pendulous habit obtaining with that tree. In the young state, however, it very much resembles the Cedar of Lebanon, and may easily be mistaken for it; but the more erect, open, and free-growing habit should at once enable it to be distinguished. It is of much more rapid growth than the Cedar of Lebanon; for the average height of young plants of that species may not exceed 18 in. at about five years of age, while those of the Atlas Cedar will be at least $30 \mathrm{in}$. This tree seems as hardy as the Indian Cedar, and equally deserving of being extensively cultivated in our parks and pineta. Although in a general way hardy as far as winter cold is concerned, still, like the Deodar, it does not stand well against high winds. In a situation where it is much exposed to strong winds, its progress is slow, and it assumes a stunted appearance. In planting it, therefore, it should not be put out on sites where it is likely to be exposed to stormy winds. In all other respects, however, it is perfectly hardy and free-growing.

Economic Uses of Timber.--At the present stage of the growth of the tree in Britain, not much can be said with respect to the jolnalse quality of its timber that may be matured in this climate. From the present appearance of the wood of young trees, it does not alpear likely that its timber will be of so durable a description as 
that of the Deodar. Still it may tum out useful for many purposes in which timber of light texture suffices.

Soil and Situation. - The demands of the Atlas Cedar, with regard to soil and situation, correspond very closely with those made by the Deodar.

Propagation and Culture. - This species is propragated from seed in the same way as has been stated-for the propagation of the Cedar of Lebanon. Fresh supplies of seeds are obtainable every now and then, and are comparatively plentiful.

There are now many fair specimens of the Atlas Cedar in this country, which range in height from about 40 to $60 \mathrm{ft}$., with sterus of proportionate girth.

The two largest specimens reported to the Conifer Conference of 1891 were respectively $66 \mathrm{ft}$. high, with a girth of $5 \mathrm{ft}$. $10 \mathrm{in}$, and $4 \mathrm{st}$. high, with a girth of $9 \mathrm{ft}$. at $5 \mathrm{ft}$. above the ground. The former was growing at $\mathrm{M}$ Iulgrave, in York, and the latter at Brahan, in Ross-shire.

\section{CUPRESSINEAE RITH.}

The family of the Cupressineæ is divided into four groups or tribes, of which only three, the True Cypress, the Arborvitæ (Thujopsidece), and the Junipers, contain genera that are either indigenous to, or suitable for growth in Europe. The foliage consists of needles or scale-like sessile leaves, usually ranged in whorls or opposite, and less frequently alternating; when like scales in appearance, they are imbricate, or ranged one above another like tiles overlapping each other on a roof. The cones usually have thin woody scales; but, in the case of the Junipers, these sometimes enclose the seeds in a sarcous fleshy mass.

Under another system of classification the Cypress tribe may be divided into three sub-tribes, of which only two, the Thuine and the Juniperine, contain genera.

\section{THE TRUE CYPRESS, Cupressus (Linnala System, Monecia Monadelphia).}

Generic Character.-True Cypresses are known hy their sealelike, adpressed adult leaves, never in two ranks, moncecions flower's, male flowers spiked, anthers four or niore, crested, pollen globose: cones globular or oblong, wookly, ripening in the secont year, with peltate scales, and numerous seeds to each scale. Cotyledons 2, leafy, longer than the primary leaves, which are opposite, or in whorls of 4 (Masters, op. cit., p. 203).

The Cypress tribe consists altogether of linge trees or bushes indigenous to the south of Europe, North America, California, Mexico,

VOL. I. 
Guatemala, China, and the East Indies. In this tribe the leaves along the lranchlets are mere scales, closely overlapping each other, and generally in four rows, with the branches always scattered along the stem, and the buds not scaly. The cones are always more or less of a round shape, small, and composed of from 6 to 10 woody scales, each having a projecting point in the centre; and when the seeds are ripe, the scales become dry, and separate. All the species exude resin, but yield no turpentine.

\section{(1.) THE COMMON UPRIGHT OI ITALIAN CYPRESS, Cupressus sempervirens $\mathrm{L}$.}

Srvorms-Cupressus fastigiata DC.; $C$. sempervirens stricta Ait. and Loud.

Specific Character.--Leaves imhricated, in four rows, small, deep, glossy green, closely pressed to the stem, convex, blunt, or pointed on young plants, and persistent. Cones large, globular, 1 in. or more in clianeter, with numerous large angular scales, slightly convex, and mucronate, or tipped with a hard point, in the centre, which become woody, and separating when ripe. Seeds numerous under each scale, yellowish brown, irregularly angular, and covered with a thin membranaceous skin (Gordon, op. cit., p. 67).

Distribution.-The Upright or Common Cypress is a native of Greece, Asia Minor, ant Persia ; it is now acclimatised all throughout the south of Europe. It is cultivated in all the countries on the Mediterranean, in Italy, Sicily, and Turkey. It was introduced into Britain in 1548 .

This tree, probably only a denizen from Eastern lands, and not really indigenous to Europe, has been very extensively cultivated throughout sonthem Europe, and in southem France and Italy forms quite a characteristic feature of many parts of the country. Being a tree of sombre aspect like our Yew, it has been largely planted in churchyards and cemeteries as a symbol of mourning.

At Sabioncello, in Dalmatia, there is a small Cypress forest, formed probably from seed shed by trees originally planted, which now reproduces itself naturally (Willkomm, op. cit., p. 246).

Description of Tree. - In its native countries the Common Cypress attains a height of from 70 to $90 \mathrm{ft}$., with a proportionate stem; but in Britain it is seldom found above $40 \mathrm{ft}$. high. It is a heautiful, throm sombre and sal-looking, evergreen tree, growing with all its liranches in an upright direction, and fastigiate or closely pressed to the stem, like those of the Lombardy Poplar (Populus fastigiata). The erect habit of this species gives it a striking character when found standing among trees of a more spreading habit; and on this account it is very often found occupying a position in parks and on lawns. 
When young, the plants are somewhat tender and sensitive to frost; but as they grow older, and consequently attain greater firmness and maturity of filore, they become perfectly hardy, and stand our climate well both on dry and on airy situations. On low-lying and humid localities, however, this tree does not always ripen its wood well, and is therefore in such cases sometimes more or less injured by frosts. Still the Cypress is sufficiently hardy to grow well on all favourable situations that are dry and not much exposed to wind or frost.

Economic Uses of Timber.-Like the Yew, which it resembles so closely in habit of growth, and to which it is so very closely allied, its fragrant wood is of excellent quality and very great duralility. Perhaps there is no forest-tree that produces better timber than the Common Cypress. In very old buildings in Italy it is known to have stood from 600 to 1000 years, and is still sound. In this country no practical experience has been availahle as to its durability; but it is of common use in Candia and Malta, where it is considered the most durable of all timber.

Soil and Situation. - The soil on which this tree thrives best is a deep dry sandy loam, with a free exposure to light, and air, lut not exposed to prevailing winds or storms. It grows on any soil that is moderately light and dry, although it may even be somerhat exposed; but, as already stated, low-lying and humid tracts are not situations favourable to its normal and healthy development.

Propagation and Culture.-The seed of the Common Cypress ripens in Britain, and the cones may be gathered early in spring. The latter are generally opened by subjecting them to a heat of about $100^{\circ}$ Fahr., when the seeds readily fall out. The seed should be sown about the middle of April, on rather warm-lying beds, and on a light well-prepared piece of ground. The young seedlings will come up in about six weeks after the seed is sown. They should be protected during the first winter, as, while they are young and soft, they recuire protection and are liable to be injured by frost. The plants should be planted out into nursery-rows as yearling seedlings, and they should be transplanted two years afterwards, in order to stimulate them to the development of numerous short fibrous roots before removing them to their permanent sites.

specimens of the Fastigiate (ypress are common in this country, and may often be seen ranging to nearly $40 \mathrm{ft}$., or occasionally more, in height.

The largest specimen reported to the Conifer Conference in 1891 was $40 \mathrm{ft}$. in height, and had a girth of $1 \mathrm{ft} .9 \mathrm{in}$. at $5 \mathrm{ft}$. from the ground. It was growing on the estate of Keir in Perthshire.

The oldest and largest ('ypress in Europe is probably that near Somma in 
Lombardy, which was noted for its size and beauty even as early as Ciesar's time. A still older tree of the same species was that at Sparta, which was in 401 I.c. mentioned hy Pausanias, and which was destroyed with fire by Gipsies in 1881 : it was $173 \mathrm{ft}$. in height, $33 \frac{1}{3} \mathrm{ft}$. in girth of bole, $83 \mathrm{ft}$. in diameter of the crown of foliage, and was supposed to be about 3000 years old (Willkomm, op. cit.)

There are also several other species and many varieties of this genus that are either raised from seed or else propagated carefully by cuttings as ornamental trees. These other species include, among many others, C. horizontalis Miller, with pointed needles and marbled brown cones, and C. glandulosa Hooker, a small shrub-like tree with blunt oval needles, having an oil-gland pitted into the back of each needle. They all closely resemble the Common Cypress as regards treatment in the seed-bed and nursery, so that there is no necessity for repeating the details above given.

(‥) THE IARGE-CONED CYPRESS, Cumesss murecupu Hartwe-

Srxoxiss-Cupressus Lambertiana ; C. Hartwegi Carrière.

Specific Character.-Leaves or needles ovate, imbricated, in four rows, bright grass-green, and closely set upon the old plants; they are exprandecl, awl-shaped, sharp-pointed, and thickly set upon the young plants (see Fig. 70). Branches irregularly spiral, but sometimes alteruate or opposite; younger ones and laterals opposite, dense, and quite green; older branches dark brown, and nearly horizontal from the main stem. Cones in clusters of three or four together, oblong, from 1 to $1 \frac{1}{2}$ in. long, and nearly 1 in. broad, with ten scales, the larger dark brown, and more or less angular. Seedleaves in fours, but sometimes only in threes. Seeds angular (Gordon, op. cit., p. 65).

Distribution. - This species is a native of the wooded heights near Monterey, in Upper California. Hartweg found it there as a tree attaining a height of $60 \mathrm{ft}$., with a stem $9 \mathrm{ft}$. in circumference, and with a far-spreading, branching, flat top, like a full-yrown Cedar of Lebanon, which he says it very much resembles when old. It was introduced into Britain in 1838.

It is said to attain a height of over $150 \mathrm{ft}$. in North California.

Description of Tree.-This stately and graceful Cylress is sometimes found in nurseries and arhoreta under the name of the Lambert Cypress (C. Lembertiune): indeed Gordon, in his Pinctem, 1. 65, sily's in the following passage that the two are the same plant:-

"That there is some difference in the shape of the plants may be, but then it arises from nearly all of those plants known under the name of C. Lambertiana being raised from cuttings, whereas all those called $C$. mucrocarpa are seedling, and have a more pyramidalshaped head, while the cutting plants (C. Lambertiana) hase a horizontal and rather flatheaded appearance."

But even in its wild state the tree assumes a flat top. 
This is noted here in order to put the young arboriculturist on his guard, and to avoid confusion regarding the two names given to this species. It forms a fine tree, remarkal,le for the bright grassgreen colour of its foliage. It is a rapid-growing species when young; but its rate of growth diminishes as the tree advances in age. It does not assume its spreading horizontal hat,it of growth till of considerable age, and then it begins to exhibit a Cedar-like characteristic. It is quite hardy, even in Scotland, when planted on the dry and airy situations that are alone suitable for it; but on low-lying and humid localities it is very liable to be injured by severe frosts. It may not be considered so hardy as the Lawson Cypress; still practical arboricultural experience has shown that it does well on all dry and airy sites, and has suffered only on low-lying and damp situations, where, from a too-luxuriant growth, its young wood does not become properly matured before the early frosts occur in autumn.

Economic Uses of Timber.No particular information seems to be available as to the character of the wood of specimens of this tree that have been grown in Britain. Its interest is, however, in any case only arboricultural and not sylvicultural.

Soil and Situation. - The Largeconed Cypress thrives best on the same descriptions of soil and situa-

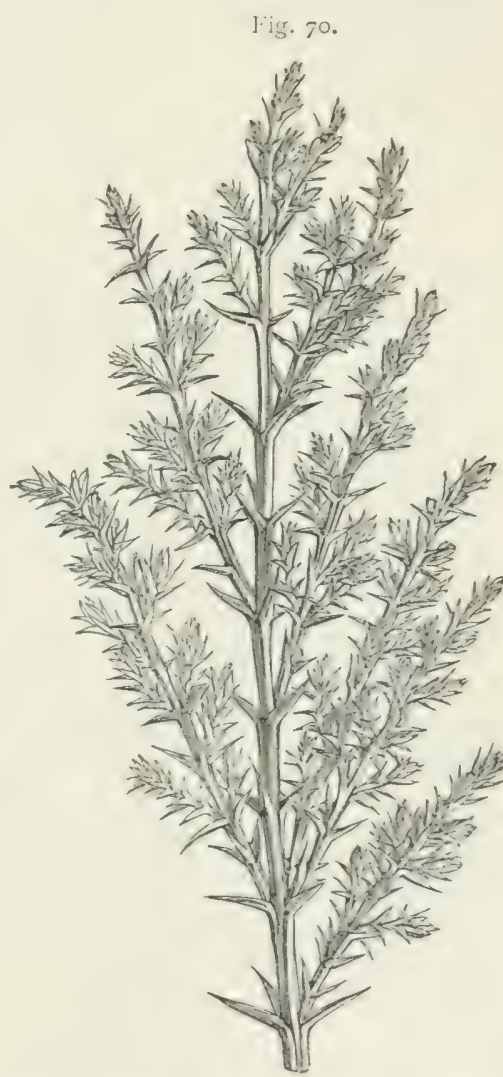

Spiny of the Laryi-comet Cy, hess (Cupressus macrocarpa).

tion as are well adapted to the Common Cypress. That is to say, it thrives best on dry grouml, and on moderately airy situations, but should not be planted on low-lying humid localities; for in such positions it is liable to be injured by frost, in consequence of its leading-shoots only heing imperfectly ripened hefore the cold nights set in. With regard to this species, it may also be added that it thrives better in a mild part of the country bordering on the sea than on situations far inland. On the whole, indeerl, the sea-breeze and a humil atmosphere seem farouralile to the gronth of this 
species; whilst on high-lying inland sites, having a drier local climate, it does not appear to thrive so well.

Propagation and Culture.-This Cypress may be propagated from seed in the same way as described for the reproduction of the Common Cypress. It may also be propagated by slips or cuttings, as is very often done in the absence of seed, or in order to perpetuate varieties and sports; but plants reared from seed are always preferable to those reared from cuttings, as they possess much more vitality and are better calculated to attain great longevity.

Fine specimens of the Large-coned Cypress are now plentiful in this country, ranging in height up to over $40 \mathrm{ft}$.

The two largest specimens reported to the Conifer Conference of 1891 were respectively $82 \mathrm{ft}$. high, with a girth of $10 \mathrm{ft}$. $7 \mathrm{in}$., and $64 \mathrm{ft}$. high, with a girth of $9 \frac{1}{4} \mathrm{ft}$. at $5 \mathrm{ft}$. from the ground. The former was growing at Carclew, in Cornwall, and the latter at Coollatin, in County Wicklow.

\section{DWARF CYPRESS oR FALSE ARBORVITE, Chamcecyparis (Linnean System, Monecia Monadelphia).}

Generic Character.-Male flowers terminal, forming cylindrical or ovoid catkins, and consisting of oval or shield-like anthers ranged crosswise oppositely, and each with 2 or 3 round anthers on the lower side. Female flowers terminal, round, consisting of scales, also ranged crosswise oppositely in groups of seldom more than 6 or 8 , bearing 2 or 3 upright ovules. The leaves or needles are like those of the true Cypress; but those on the upper and under sides of the twigs are flat, whilst the marginal leaves at the edges are folded together, so as to give the twigs a flattened appearance like those of the true Arborvitæ (Thuja). Cones small, round, angular scales, having a knob in the middle, which opens wide in order to scatter the seed when the cones ripen. Seeds compressed, and surrounded by a membranaceous wing. Monœcious trees, whose seed ripens in one year (Willkomm, op. cit., p. 247).

The plants belonging to the subgenus Chamcecyparis (= genus Chamacypireris of Spach), Parlatore and others, together with the genus Retinosporre of Siebold and Zuccarini, differ from the true Cypresses in having generally tworanked branchlets and flattened branch-systems; smaller cones ripening in the first year; the scales less woody, and usually with a smaller number of seeds. They are referred to Thuy by Bentham, Lor. cit., iii. 427, but in their globular cones, peltate scales, and general habit seem more fitly to belong to the Cypresses (Masters, op. cit., p. 203). 
(1.) LAWSON'S CYPRESS, Chamecyparis Lanesoniuna Parlatore.

Sxnonyas-Cupressus Lawosoniana MLurray; Channecyparis Boursieri Carrière.

Specific Character.-Leaves or needles on the adult plants ovate, in alternate opposite pairs, closely presserl, in four imbricated rows, and of a glaucous-green colour (see Fig. 71); while those on the young plants are lanceolate, sharp-pointed, spreading at the ends, whitish at the margins, and frequently furnished with a small gland on the back. Branches crowded, flexuose, and more or less ascending. Branchlets very slender, flattened on the upper and lower surfaces, much divided, bending alternately inwards and outwards, and thickly covered with decurrent leaves in alternate opposite pairs, closely pressed together on the adult plants, but spreading on the younger ones. Cones solitary, terminal, manysided, of a light-brown colour, covered with a glaucous bloom when young, and about the size of a large pea, on rather a short footstalk. Scales mostly 6 in number, but sometimes more, flat, with a rough external surface, of a corky texture, light brown, and irregularly 4 - or 5-sided, with an elevated straight point in the centre. Seeds

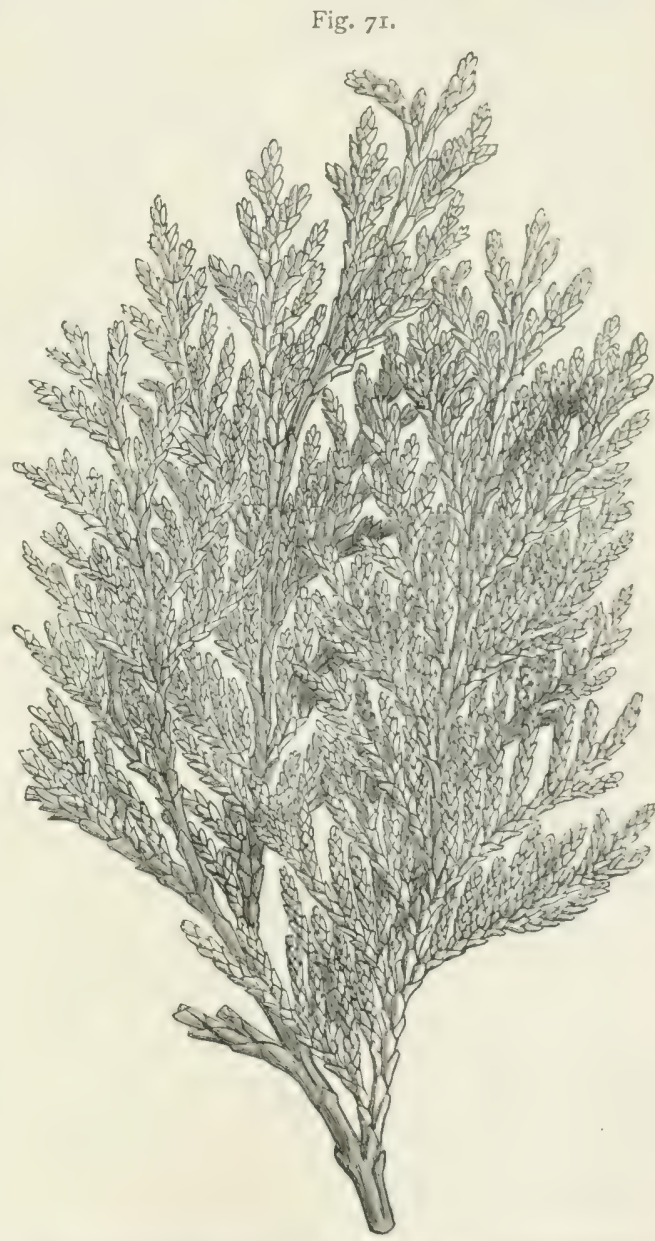

Spray of Lawson's Cypress (Chamæecyparis Lawsoniana). somewhat ear-shaped, rather large, and mostly 3 under each scale (Gordon, op. cit., p. 62).

Distribution.-This fine species of Cypress is found in the Shasta and Scots valleys, and also, according to Murray, along the banks of streams in a valley in the momntains of northern Califomia, 
in lat. $40^{\circ}$ to $42^{\circ}$, where it forms the handsomest of the forest-trees. It was introduced into Britain in 1854.

Description of Tree.-The beauty of the foliage of this tree, together with the gracefulness of its habit of growth, and its hardiness, have established this species as one of the most suitable of the genus for ornamental purposes in Britain. It forms a fine tree, rising to about $100 \mathrm{ft}$. in height, and with a stem of $2 \mathrm{ft}$. in diameter. The branches first curve upwards like those of the Spruce, and then hang down at the ends like ostrich feathers.

It is not only very suitable for ornamental plantations, but is also worthy of sylvicultural attention on account of the rapidity of its growth, its hardiness, and the good quality of the wood. Experiments are being made with it in Bararia in small patches of pure forest in order to study its characteristics and peculiarities as a forest-tree.

Economic Uses of Timber.-In California its timber is held in high estimation, and is much used for building. The tree has not been growing long enough in this country to enable a jurgment to be formed as to the quality of the timber produced by it in our climate; but, judging from the mere appearance of the wood, it seems of a compact and close-grained description, and somewhat resinous.

Soil and Situation.-The Lawson Cypress is perfectly hardy, and seems to develop fairly on most soils and situations. It is to be seen growing healthily, and making leading-shoots of fully 12 in. a-year, on soils varying from a light sandy to a heavy argillaceous loam, and on situations which might perhaps be called exposed, for they are more than $800 \mathrm{ft}$. above the sea-level, and are by no means sheltered. This proves that the tree is hardy and accommodating, and that it is at any rate adapted to most soils and situations which are neither wet nor too much exposed. In order to have the tree thrive well, however, it should be planted on a good dry loam, and in rather a sheltered situation than otherwise.

The experience of the German sylvicultural experiments goes to show that this tree thrives best on a dry or merely fresh, but not moist, sandy soil ; and that during the youngest stages of growth it is only sensitive to winter frost when it is suddenly exposed to the full insolation or sunshine after having had some shelter from standard trees. Young plants require some shelter, however, as they are somewhat sensitive to late frosts. It is treated like the Spruce as regards planting and tending.

Propagation and Culture.-Seeds of the Lawson Cypress are imported from time to time, and many of the older trees in this country produce cones with fertile seeds, so that now the species is by no means scarce. It is also very readily propagated by cuttings. Some nurserymen prefer to raise a large proportion of their plants in 
this way, as in rearing it from seed there is generally considerable diversity to be found among the seedlings, and only a portion of them come quite true to the normal character of the species.

There are now many fine specinens of this Cypress in both England and Scotland, ranging in height from $30 \mathrm{ft}$. to upwards of $40 \mathrm{ft}$.

The two largest specimens reported to the Conifer Conference of 1891 had respectively a height of $5.5 \mathrm{ft}$., with a girth of $4.3 \mathrm{ft}$, and a height of 34 $\mathrm{ft}$., with a girth of $8 \frac{1}{2} \mathrm{ft}$. at $5 \mathrm{ft}$. above the ground. The former was growing at Dupplin, in Perthshire, and the latter at Torloisk, in Argyllshire.

This very handsome evergreen genus consists of a great many species and innumerable varieties, many of which are quite distinct from an arlonicultural point of view, and all of which are worthy of introduction into arboreta, as they are of free growth, ornamental, and hardy, although thriving lesst in sheltered situations.

These different species and arboricultural variations all more or less resemble in general manner of treatment the Ch. Lonusmianu. They include, among many others, the following typical species: ('/. nuthansis (see below), Ch. spheroiden Sp. (C'upressus thyoides L., C'h. glauce, Ch. thujpides), one kind of the "White Cedar" of the Americans, and C'h. ericoides Carr. (Retinosyorch ericoides Zuce.) The two latter are handsome Juniper-like trees from North America (Virginia), which are hardy and form beautiful lawn plants. The Ch. Fraserii also belongs to this genus. It is a very distinct and beautiful species, with an erect, compract habit of growth, and a strikingly rich glancons hue.

\section{(2.) THE NOOTKA SOUND OY ALASKA CYPRESS,} Chamocyparis nutkaensis Spach.

Stronrys-Cupressus nutkaensis Lambert; Throjopsis borealis Hortor.

Specific Character. - Leaves or needles in four rows, in opposite pairs, broadly ovate at the hase, sharp-pointed, and $\frac{1}{8}$ of an inch long, very thick, smooth, of a glossy green, when young sometimes a little glaucous on the upper side, and pale dull green lelow, convex on the back, decurrent, and closely alhering at the base; alult needles much shorter, awl-shaped at the points, keeled on the lnack, without any gland, but furrowed and closely imbricated; those on the young plants glancous, somewhat lanceolate, quite straight, extending at the points, loosely imbricated, and bristle-pointed. Branches rutund, spreading, or curved upwards towards the ends, but sometimes those near the bottom of the trees are more or less deflected, scaly from the withered leaves, and of a brownish colour; lateral branches in two xows, regularly placed alternately on each side, flat and dlexible: hranchlets in two rows, 4 -sided, rather distant, extemeled, and thickly covered with short, straight, regularly imbricated leaves. Cones solitary, globular, almost sessile, or on the ends of very short, scily branchlets, about the size of a linge pea, and corered with a glincons 
bloom. Sicales small, rough, and from six to eight in number, embossed, shich-shaned, with four or five angular or orbicular sides, elevated in the centre, in alternate opposite pairs, furnished in the middle with a strilight, thick, conical, olstuse point, the lower pair much the thinnest, and rery closely inserted at the base. Seeds mostly three uncler each scale, freely inserted on the interior of the upper surface of the scales, flat, and ear-shaped, with a bony shell along each side, and a membranaceous wing, frequently much broader than the seeds, and cut more or less sloping to the bottom (Gordon, op. cit., p. 66).

Distribution.-This species is found along the north-west coast of North America, and particularly at Nootka Sound, in Olservatory Inlet, and on the island of Sitka. It was introduced into Britain in 1850.

Description of Tree.-This heautiful species of Cypress in many respects resemhles the Lawson ('ypress. But it is easily distinguishable from that by having the male catkins of a yellow instead of a crimson coluur, and by having a much more rolust appearance, although it is not so graceful in its habit of growth as that species. It is further distinguishable from that Cypress by the scales of its cones being from six to eight in number, while those of the cones of the latter seldom number more than six. The foliage of the Sitka Cypress is also harder, and of a paler green, than that of Lawson's Cypress, and the plants are, generally speaking, not quite so well clothed with foliage. It is perfectly hardy, being perhaps the hardiest species of Cypress that has been introduced into Britain. In Upper California it is said to grow to a large-sized tree; and, being of a very graceful laabit wif growth, it is certainly well deserving of a place in every park and arboretum.

Economic Uses of Timber.-Little is yet practically known regarding the quality of the timber produced by this tree in our climate; but in any case its interest is arboricultural rather than sylvicultural, and it is not likely to compete in favour with some of the other great Californian Conifers, in respect either to rate of production or quality of the timber produced.

Soil and Situation.-This species seems to grow well on most soils which are not wet, and on most situations that are not too high and exposed. It seems to be a very accommodating kind of tree, and will probalyly do well if planted wherever our common hroadleaved trees are found to succeed.

Propagation and Culture. - The Sitka Cypress may be regenerated either from seeds or from cuttings. The methou of treatment exhilits no special peculiarities varying from the details already given for the propagation of the other species.

In most arboreta throughout the country, specimens of this Cypress are to be found ranging from 30 to $35 \mathrm{ft}$. in height. 


\section{(3.) THE OBTUSE-IEAVED Or JAPAN CYPRESS,}

Chamcecyparis obtusa Endlicher.

Srnonysrs-Cupressus obtusa Koch ; Retinospora obtusa.

Specific Character. ${ }^{1}$ - Leaves or neerlles mostly in whorls of four, ovate-rhomboid, blunt, seldom pointed, decussate, all scale-like, closely pressed along the branchlets, and adhering almost as far as the points, the lower part only being visible; the needles along the upper and under rows are ovate-rhomboid, obtuse, and seldom acute, while the side or lateral leaves are keeled, and lapping over at the edges, somerwhat pointed, and almost sickle-shaped; those on the younger plants are more open, longer, and remain persistent for several years (see Fig. 72). Branches spreading; lateral branches in two rows, very dense, spreading out like a fan, and of a light shining green colour. Cones solitary, on the ends of the branchlets, globular, about the size of a small grape, with eight or ten scales in alternate opposite pairs (Gordon, op. cit., p. 295).

Distribution.-This tree forms a large portion of the forests in the mountains on the island of Nippon, in Japan, and is hardy in Britain.

Description of Tree.-It is a tall evergreen tree, growing from 70 to $100 \mathrm{ft}$. high, and forming a stem of from 3 to $5 \mathrm{ft}$. in diameter. It has very much the habit of growth of an Arborvitæ (Thuija), from which, however, it is easily distinguishable at a glance by the more spreading habit

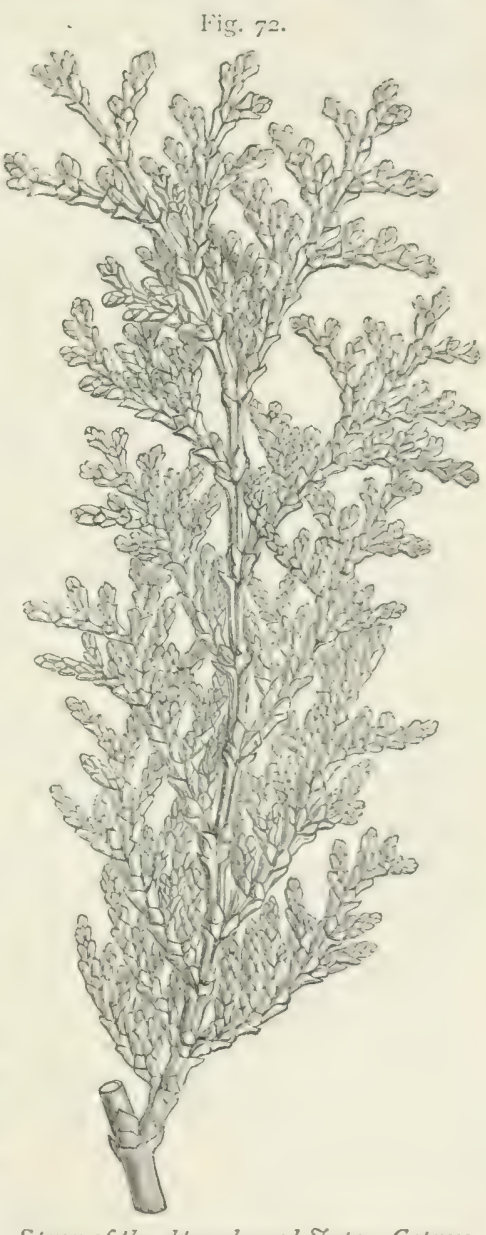

Spray of the obtuse-leaved 7 apan Cypress (Retinospora obtusa). of the branches, and by these having a peculiar fan-like appearance. It forms a fine specimen in a pinetum.

1 Hasters makes the following remarks (op. cit., p. 245): "Rctinospora, Siebold and Zuccarini (see Cupressus, section Chamecoyparis, Junipcrus, Biota, and Thuya), sometimes written Retinispora. The so-called species are really forms or stages of gromth of a few species of one or other of the above-named genera, so that two or three forms may sometimes be seen on one bush. These forms may be perpetuated by cuttings or grafts, which retain their characteristics for an uncertain period." 
Economic Uses of Timber.-The timber of this tree is said to be white and fine-grained, of a compact texture, and durable.

This and Ch. (Retinospora) pisifere are among the most valuable timber trees of Japan.

Soil and Situation.-Good specimens of this handsome tree may be found growing healthily on most kinds of soil; but in order to attain its best development in this country, it requires a mild and sheltered situation.

Propagation and Culture.-This species of Japau Cypress may best be reared by sowing the seed in a cold frame, and in the following spring transplanting the yearling seedlings into the nursery-lines, where they may be schooled for two or three years before being finally planted out.

Fair specimens of this tree are now plentiful in the majority of the arboreta of this country.

The largest sprecimen reported to the Conifer Conference of 1891 had a height of $23 \mathrm{ft}$., and a girth of $2 \mathrm{ft}$. $7 \mathrm{in}$. at $3 \mathrm{ft}$. above the ground. It was growing at Carclew in Cornwall.

There are several varieties of this species, whose names,_alba, aurea, erecta, compacta, nana, dc.,-,as given in the lists circulated by nurserymen, sufticiently indicate their special peculiarities.

\section{THE TRUE ARBORVITE, Thuja (Thuya). (Linnaan System, Monecta Monadelphia).}

Generic Character.-Evergreen shrubs or trees with flattened branch-systems, minute adpressed leaves, globular or oblong cones, the scales of which are thickened upwards (not peltately expanderl as in Cupressus). The two uppermost pairs of scales are fertile (not one only, as in Litocctiris). Seeds usually winged equally on both sides. $\S$ Biota has wingless seeds (Masters, op. cit., p. 250). See Fig. 73.

The Thuja or Arborvitæ tribe consists altogether of large evergreen trees or shrubs, found in north-east America, California, and Japan.

They are of a very slow rate of growth. Their scale-like leaves assume a dirty reddish-brown colour during winters in which the cold is severe; but they resume their natural dark-green colour with the return of active vegetation in the following spring.

\section{(1.) THE COMMON OO AMERICAN ARBORVITA, Thrija occidentalis $\mathrm{L}$.}

Specific Character. - Leaves very small, in opposite pairs, ovate-rhomboid, blunt-pointed, closely imbricated and flattened, thickly pressed along the branchlets, in four rows, and with an 
elevated gland on the back of the upper and under leaves, which are the broadest, while those at the margin lap over on both sides; the leaves on the older branches are more distant, acute, extended at the points, decurrent, of a dull yellowish green, and strongly scented when bruised. Dranches distant, horizontal, and irregularly seattered along the stem; smaller branches drooping, and twisted in varions directions. Pranchlets spreading out laterally, numerous, two-edged, alternate, short, flattened, ramified, and crovered with numerous small leaves of a bright, shining green colour. Crones obovate, $\frac{1}{3}$ of an inch long, solitary, on short footstalks, and crevered with small scale-like leaves. Scales, each containing two seeds, and mostly six in number, oblong, spreading at the points, the centre scale truncate and divided to the base. Seeds very small, surmounted by a short wing (Gordon, op. cit., p. 323).

Distribution.-This species, one of the several kinds of trees that produce the so-called "White Cedar" of the Americans, is found in most parts of North America, from Canada southwards to the states of Virginia and Carolina; but its occurrence is most plentiful in Canada, where, along with the American Larch, it occupies the wet and swanpy tracts throughout the great forestdistricts. It often likewise occurs in these localities, forming pure woods of large extent. It was introduced into Britain as early as 1566 or 1596.

Description of Tree.-This common species of Arborvitæ is well known in Britain, having been cultivated in this country for nearly three hundred years past. The size that this tree attains in its native country is generally understated by most writers, being set down at heights of from 40 to $50 \mathrm{ft}$.; while in reality it attains, generally speaking, heights of from 70 to $90 \mathrm{ft}$., with proportionate stems. It is not infrequently to be found of such proportions in the American woods, and with holes ranging from 2 to $t \mathrm{ft}$. in diameter, forming fine trees with a conical crown of foliage, and having its trunk clothed with loose, open, spreading branches down to the ground. It is a very hardy tree, and is useful for many purposes where shelter and ornament are required on exposed parts of the country. As an ornamental tree, however, it is certainly somewhat inferior to the Giant Arlorvite (T'. giganted); for it is seldom foumd so well clothed with branchlets and slender twigs, nor is it so graceful in its general habit of growth.

Economic Uses of Timber. - The timber of this species of Arhorvitie is of a very light texture, and is foum to he decidedly of a durable nature. In America this variety of "White Cedar" is used wherever it can be had for fencing purposes. l'alings male of it may often be seen which have stood for thirty years, and which, 
on examination of the wood, are found to be still perfectly sound and without the least appearance of decay. It is also much used for house-huilding in America, as its lightness makes it well adapted for roofing purposes: when utilised thus, under cover from the decompusing influence of alternating damp and dryness, it outlasts most species of pine-wood.

Soil and Situation.-Although this tree will grow well on most soils and situations on which our common broad-leaved trees can usually thrive, still, in order to have it grow to a good useful size, it rerpuires to be planted on a low-lying and sheltered situation, and on deep, open, and fresh land. In its native habitat it is always found growing along the sides of flat-rumning streams, or on swamps, where there is ample moisture for its roots; but the best specimens of individual trees are generally to he met with on sheltered situations near the sides of rivers, where its root-system can have plenty of moisture of a flowing and not of a stagnant description.

Propagation and Culture.-The Common Arborvitie, like the Giant species (T. Lobbii), is easily propagated either by seed or by cuttings. So far as possible, the seeds used should always be ol,tained from America, as the best plants are raised from seeds that have been ripened in the countries to which this tree is indigenous.

This common species of Arborvitxe is now so plentiful and so well known throughout Britain that it would he superfluous to give any particular instances of its growth in any special localities. There is hardly any arboretum, and there are but few ornamental grounds of any note, in which specimens ranging from 35 to $50 \mathrm{ft}$. in height are not to be found.

(2.) THE GIANT ARBORVITÆ, Thuja gigantea Nuttall.

Srxoxrus-Thuja Lobbii Hortor; T'. Menziesii Douglas; T. Craigiana of gardens.

Specific Character.-Leaves in alternate opposite jairs, closely imbricated, and without any gland on the back; those on the branches are more distant, enlarged at the base, decurrent, and tapering to an acute point, while the needles on the branchlets are very flat, closely placed, regularly imbricated, in four rows, much shorter, more rounded, and furnished with a short spiny point, the marginal leaves being more or less lanceolate, bristle-pointed, and lapping over on each side, but extended at the points (see Fig. 73). Inimches spreading, llat, horizontal, irregularly scattered along the stem, slender, and of a deep brown colour. Branchlets flattened, short, slender, flexible, and alternately two-rowed. Cones small, crat, tapering to hoth ends, nodding, and solitary at the extremities of the short branchlets (Gordon, op. cit., p. 323). 
Distribution.-This species of Arhorvite is found more or less plentifully along the north-west coast of America, and also on the mountains in California. In the latter country it is usually found at an elevation of alsut $5000 \mathrm{ft}$. It was introduced into Iritain in 1854 .

Description of Tree.--In the mountainous districts of California this tree is said to attain a height of from 50 to upwards of $100 \mathrm{ft}$.,

Fig. 73 .

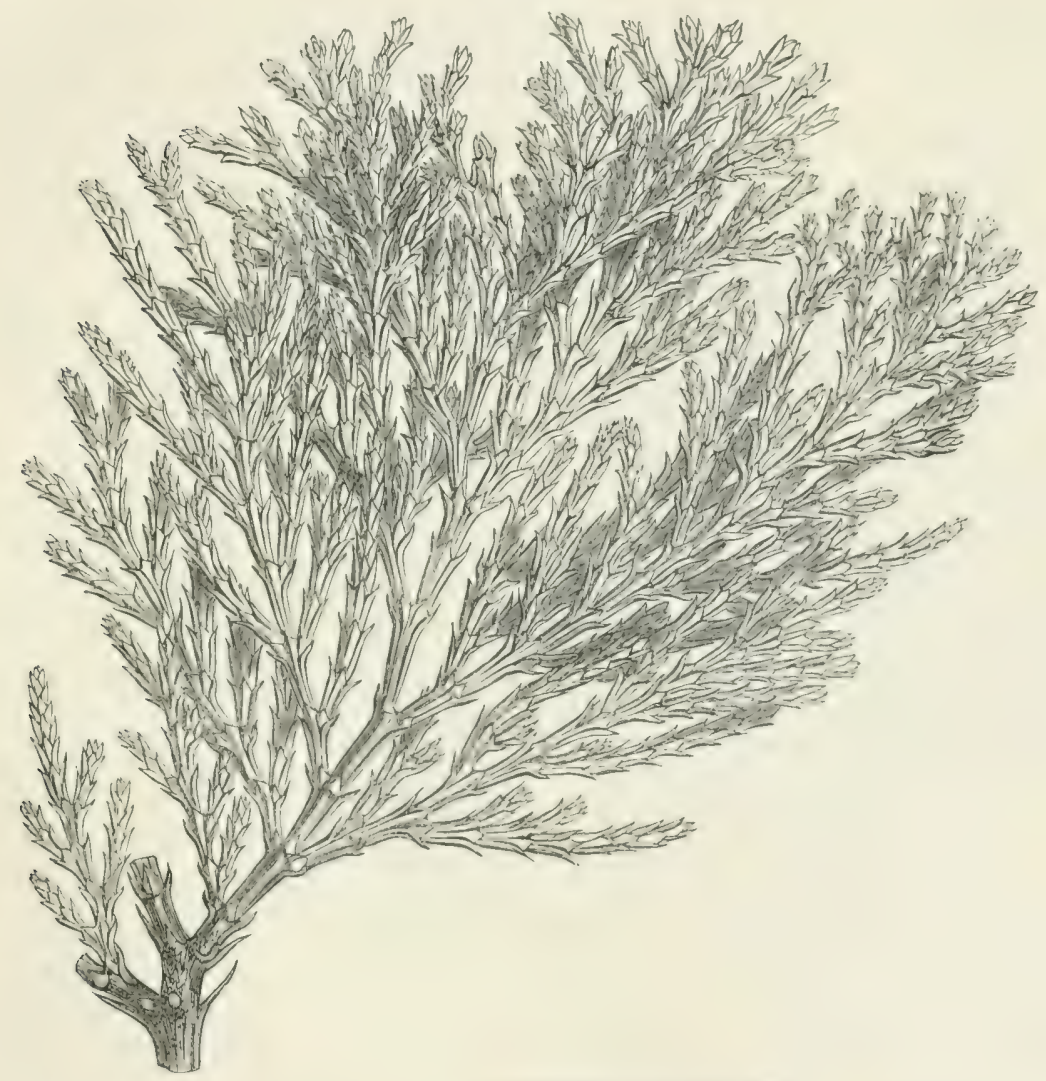

Spray of the Giant Arborvita (Thuja gigantea).

with stems from 2 to $5 \mathrm{ft}$. in diameter, which are well elothed with long flexible branches, thickly set with branchlets and inconsplicmons foliage. It is a thoroughly hardy species, and may be plinted with every reasonable hope of thriving on most soils and situations on which our common broad-leared species of trees succeed. It is, for an Arborvite, a comparatively rapid-urowing tree, and soon malies a beautiful, well-clothed, and middle-sized tree. It deserves a place in every park and arboretum where variety and beauty of foliage is 
considered an object worthy of being striven after. Its hardiness is one of its great recommendations, as it is almost sure to establish itself even on rather exposed localities where many of the other Coniferæ of recent introduction could not succeed.

Economic Uses of Timber. - It is said that the timber of this species is very valuable, fine grained, and of a bright yellow colour; but of course its interest for Britain is solely of an arboricultural character.

Soil and Situation.-As already remarked, this Thuja is of an accommodating nature, and is able to thrive on any soil and situation on which our common broad-leaved trees succeed; but it will, of course, attain its largest dimensions on a deep, fresh soil and in a sheltered situation.

Propagation and Culture.-This species is usually regenerated from seed, though it may also be propagated readily from cuttings.

It is easy to cultivate, and is of more rapid development than most trees of this class. At 3 years of age it not infrequently attains a height of $2 \mathrm{ft}$., and after that it soon shoots ahead if not disturbed in growth by subsequent transplanting.

Specimens of the Giant Arborvitæ are plentiful in the country, from 20 to $30 \mathrm{ft}$. in height.

The largest specimen reported to the Conifer Conference of 1891 had a height of $65 \mathrm{ft}$. and a girth of $6 \mathrm{ft}$. at $5 \mathrm{ft}$. from the ground. It was growing at Linton Park in Kent.

A monograph on The Giant Arborvitce (Thuja gigantea) will be found in Trans. Scot. Arbor. Socy., vol. xii., Part II., 1889, pp. 341-350.

\section{CHINESE ARBORVIT E, Biota \\ (Linnear System, Moxecla Monadelphia).}

Generic Character.--This genus differs from that of Thujo only in its thickened cone-luracts being bent into a hook-like shape at the apex, by their having two unwinged seeds at their base, and by having a longitudinal furrow channeled along the back of the leares in place of being provided with an oil-gland.

\section{THE CHINESE ARBORVIT开, Biota orientalis Don.}

\section{STNONTM-Thuja orientalis $\mathrm{L}$.}

Specific Character.-Leares or needles on the adult plant rery mall, in four rows, wate-rhomboid, acute-pointed, scale-like, imbricated, adpressed, decurrent, and furrowed along the base, the outer or marginal needles lapping over on both sides, the upper and lower needles flat, with the points thickenerl, glancous green' and shining 
when young, but afterwards dull green when old and glandless (see Fig. 74). Branches somewhat vertical and horizontal at first, lut soon afterwards tuming up at the ends, and finally becoming fastigiate with the stem. Branchlets disposed in two rows, densely croweded along the extremities of the branches, and placerl sirleways. Cones ovate-elliptic, 6 -valved, solitary at the ends of the small branchlets, $\stackrel{1}{2}$ an inch long, green when young, but light-brown when ripe, and composed of six scales, two being central, and four around the sides.

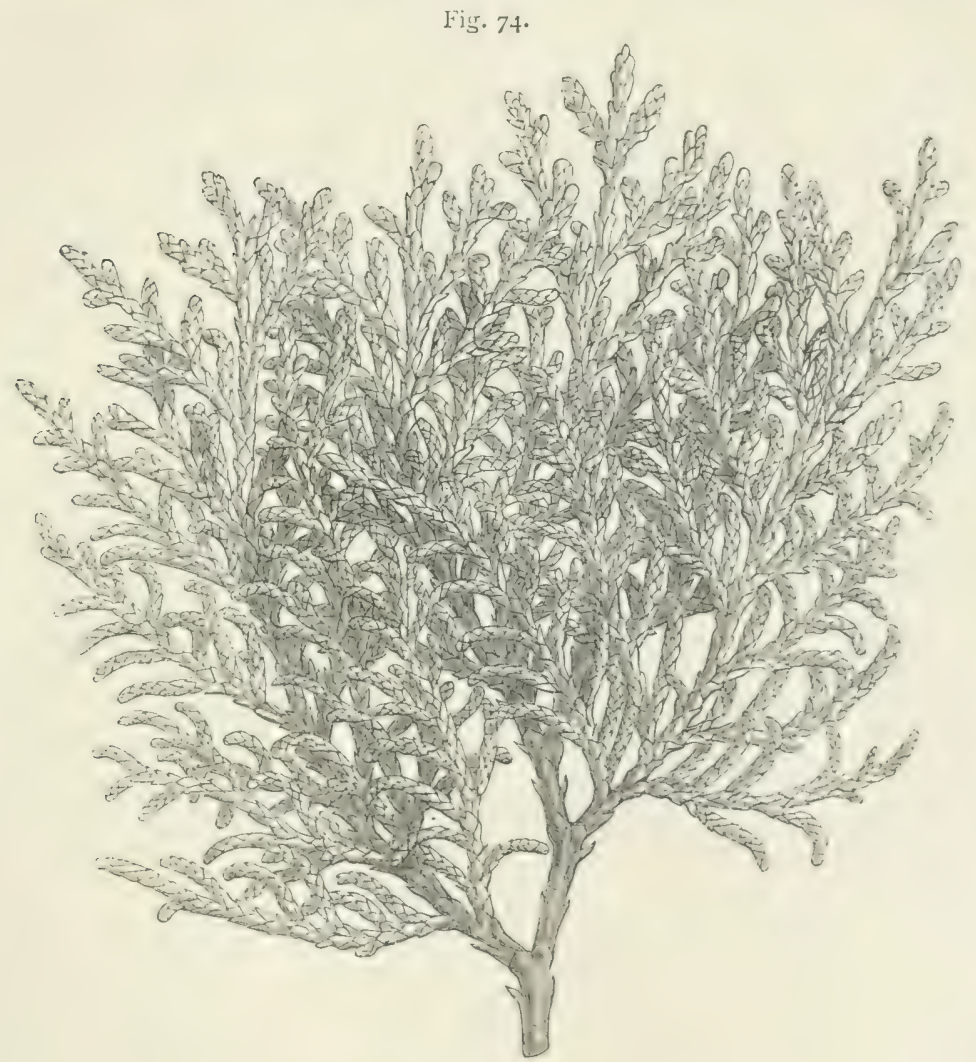

Spray of the Chinese Arborvite (Biota orientalis).

Scales blunt, the central scales being truncate, with a short stout projecting point below the alpex, and each seale corering two maked, egg-shaped, somewhat angular, wingless seeds ((

Distribution. - This evergreen tree is found growing indigenunsly in rocky situations throughout Chima and Japan.

Description of Tree.-The Chinese Arhorvitiv forms a heantiful and well-foliaged tree all the year round. The densely folinged branchlets give the whole plant a very compact look, such as is not

VOL. I. 
exhiliter by any other Conifer. It does not attain a large size, being seldom found much over $25 \mathrm{ft}$. in height. But its compactness and its rich, deep-green colour give it a character which contrasts pleasingly with other foliage when this species is found standing on the sides of roads in plantations: it is for such situations that it is most to be recommended. It has no sylvicultural claims to urge, but is merely of arboricultural interest.

Economic Uses of Timber.-This tree forms very little timber. It assumes more the character of a large bush than a timber tree.

Soil and Situation.-The Chinese Arborvitæe will grow well on almost any soil and situation, provided these are dry and not too much exposed.

Propagation and Culture.-This small tree is readily propagater from seed, which should as a rule be sown in a cold frame. When the seedlings have attained full yearling growth, they should be transplanted into the nursery-rows, and should stand there for two or three years until required for planting out.

Specimens of this quaint and beautiful little tree are now plentiful in this country, and may often be seen ranging from 20 to $25 \mathrm{ft}$. in height.

5. THE INCENSE CEDAR, Libocedrus Endlicher (Linnean System, Monecia Monadelphia).

Generic Character. - Trees with flattened branch-systems: leaves small, flattened, decussate; male flowers in spikes, antherlobes 4 ; cones oblong, woody, with 2-6 valvate scales, of which the middle pair is alone fertile. Seeds with 2 unequal wings. Cotyledons 2 (Masters, op. cit., p. 218).

\section{THE DECURRENT-LEAVED ARBORVIT无,}

Libocedrus decurrens Torrey.

Synonyas-Thuja Craigiana Hurray. It is often misnamed Thuja gigantea in gardens.

Specific Character.-Leaves on the young plants awl-shaped, somewhat lanceolate, decurrent at the base, extending at the apex, and sharp-pointed, loosely imbricated in four rows, thickly set on the branchlets in olposite pairs, the outer or marginal pair being longest, and folded partially over the inner pair on both sides, giving the young shoots a jointed, trident-like appearance (see Fig. 75). Leaves on the adult plants very small, scale-like, $\frac{1}{12}$ of an inch long, and $\frac{1}{24}$ of an inch wide, ovate, blunt-pointed, thick in texture, in close opposite pairs, rather distant along the branchlets, pale green, and shining, the maryinal leaves overlapping the sides, and having the 
appearance of being in three rows on each side. Branches rather erect, long, slender, and spreading laterally, with numerous smaller branches. Pranchlets short, flattened, channeled along the sides, distantly jointed, many, short, and alternate. Cones erect, solitary on the ends of the upper branchlets, oblong, tapering to the points, 1 in. or more in length, and $\frac{1}{2}$ an inch wide near the base, and composed of two opposite pairs of scales, with a flat scale down the middle, and of a pale olive-brown colour (Gordon, op. cit., p. 321).

Distribution.-This tree is found occurring plentifully along the north-west coast of America, near the banks of the Columbia River, and on the mountains of northern California. It is also found growing on the Sierra Nevada, and along the Sacramento River.

Description of Tree.-This forms a grand evergreen tree, growing from 50 to $140 \mathrm{ft}$. in height, and attaining a diameter of from 3 to $5 \mathrm{ft}$. It

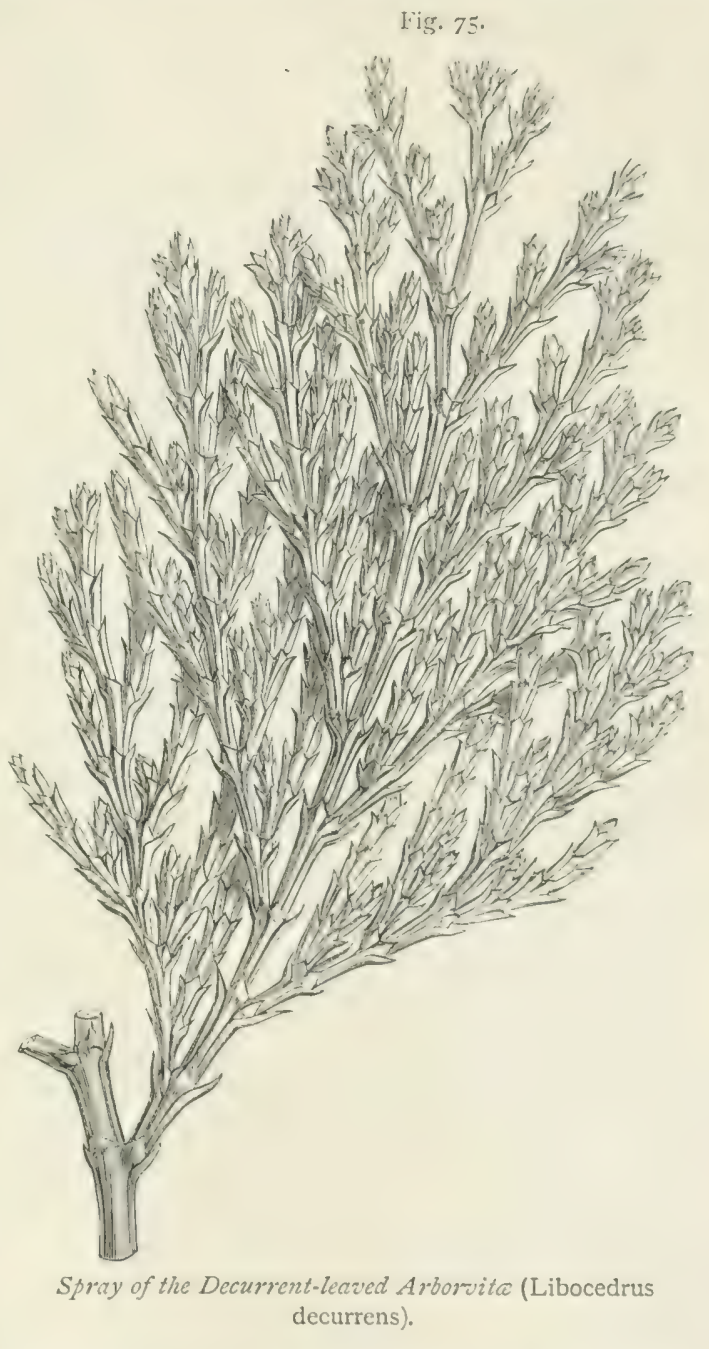
is quite hardy, is a free grower, and is well worthy of a place in every pinetum.

Economic Uses of Timber.-This is anther of the trees whose wood is called "White Cedar" by the Americans. The timber is much used throughout California for many country purposes, and it is sail to be of a durable character.

Soil and Situation.-For the attaimment of its best growth this 
species has very much the same recuirements as have already been detailed with respect to the Giant Arborvitæ (T. Lobbii).

Propagation and Culture.--This Arborvite is propagated from seeds chiefly ; of late rears these have been somewhat abundant, and the plants are now comparatively cheap in consequence.

Fair specimens of it are now plentiful in most of the arboreta throughout the country.

The tallest specimen reported to the Conifer Conference in 1891 had a height of $50 \mathrm{ft}$; whilst another stem having a height of $37 \mathrm{ft}$. had a girth of $6 \frac{1}{\mathrm{ft}}$. at .5 $\mathrm{ft}$. abore the ground. The former was growing at Orton, in Huntingdonshire, and the latter at Torloisk, in Argyllshire.

\section{THE JUNIPER, Juniperus L. (Linjean System, Diecla Moxadelphia).}

Generic Character.-Male fluwers axillary or terminal catkins; female flowers, small axillary bud-like bodies, bracteated at the base. Fruit, a globular kind of berry, composed of a fleshy or fibrous juicy substance, covered with a glossy skin, more or less furnished externally with minute scales, and somewhat angular and naked at the apex. Seeds from one to five, but mostly three, in each fruit, obscurely three-cornered, and covered with a hard bony covering, having gland-hearing pits towards the base. Leaves simple, opposite or ternate, lanceolate or scale-formed, and either in extended whorls or closely imbricated in four rows (see Fig. 76). Seed-leaves in twos (Gordon, op. cit., p. 91).

Easily recognised by the peculiar odour and by the globular cones of 3-6 fleshy, valvate seales in which the erect seeds are imbedded. Yrale flowers in spikes, anthers crested, 3-4 lobed, pollen globose. Embryo with 2 blunt leafy cotyledons. Primary leaves pointed (Masters, op. cit., p. 211).

The Juniper tribe consists altugether of $3 \pm$ species of evergreen small trees or shrubs, found in the temperate and frigid regions of Europe, Asia, Africa, or America.

As the Common Juniper is only a shrub, and very often a weed in place of being a useful plant, only one species of this genus need be referred to in detail, the Red Cedar (J. virginiana), as it is well known to be a hardy, useful, and ornamental tree in our climate, and may be said to be about the tallest and hardiest of the genus.

A large number of other species have now been introduced, and are much favoured on account of their beauty as shrubs, and in some instances small trees. These include $J$. canadensis, $J$. chinensis, $J$. hibernica, $J$. japonica, $J$. macrocarpa, and $J$. oxycedrus among the shrubs; and $J$. phenicea and $J$. 
S'abina among the smaller trees. They all have very much in common with the Red Cedar, so far as arboricultural treatment is concerned.

For the formation of quaint live-hedges in old-fashioned gardens our Common Juniper, $\%$ communis, is worthy of the attention of horticulturists.

\section{THE VIRGINIAN JUNIPER OP RED CEDAR, Juniperus virginiance L.}

SrNonyars-Juniperus arborescens MLonch.; J. Caroliniana Du Roi.

Specific Character.-Leaves or needles in twos, opposite, and 4 rowed, but frequently in whorls of three on the young shorts: those on the adult plants closely imbricated, very small, and sharp-pointed, but afterwards as they get older become spread out at the joints, glossy and light-green in the common form of the tree, but frequently becoming of a tawny-brown colour in winter. Branches horizontal, numerous, close together, and feathered to the ground. Branchlets 4 -sided, slender, straight, spreading, and very numerous on the onter parts of the branches. Berries dark purple, small, ovate, smooth, or slightly warted on the surface, and covered with a white glaucous powder when ripe. Male and female flowers sometimes on the same plant, and sometimes on separate ones (Gordon, op. cit., p. 113).

Distribution.-This species of Juniper is found in the United States of America and in Canada on dry rocky hillsiles, but is not now plentiful in any particular clistrict of these countries. It is also to be met with on the sides of low hills in the valley of the Gatenean River growing along with the lied Pine (Pinus resinos(c). It almost always occurs on ridges and knolls having a poor soil, and never on low-lying parts of the country or on soils of a rich description. It was introduced into Britain in 166t, and is now fully acclimatised.

It is more particularly to be found throughout the eastern States of America, from Cape Florida and the northern shores of the Gulf of Mexico ul' to the State of Mlaine and the Cectar Isles in Lake Champlain. It therefore extends through about $48^{\circ}$ of latitude, from $20^{\circ}$ to $68^{\circ}$.

Description of Tree.-The Real Cedar forms a rery handsome tree, being always, when freely exposed, well clothed with branches and leaves from bottom to top. It does not, even in its native woods, ever attain the size of a large tree, as even there it seldom reaches a height much above 45 or $50 \mathrm{ft}$., with a stem of from 12 to $18 \mathrm{in}$. diameter, and it is generally fomm of smaller dimensions. Incleed in this country the tree has lecome a true denizen, and thrives as well as it does in its native woods. The leaves take very varied forms, some being needle-shriped, some lanceolate, some oval or ovoid, and some round; while at the same time both biunt and sharp-pointed 
leaves or needles are common on the same branch. Sometimes the leares wreetles are found in pairs and sometimes in whorls: some-

Fig. 76 .

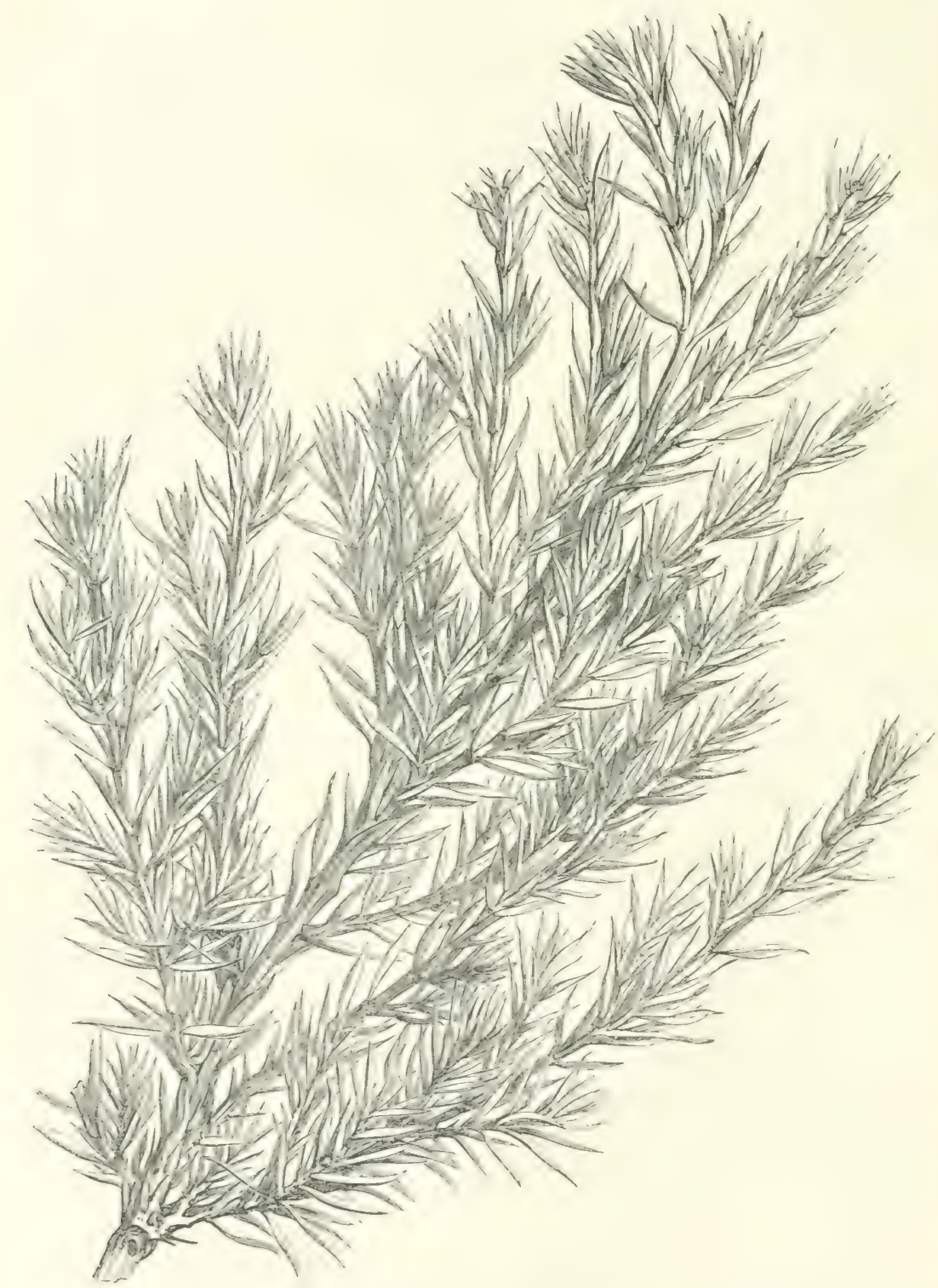

Spray of the Virginian Funiper or Red Cedar (Juniperus virginiana).

tines shont and sometines long; and they are often of varions colours or shades of green, from a silvery glaucous to a purplish green. The 
tree generally assumes a heautiful upright hal,it of growth, of rather a conical shape, and its dense clothing of leaves affords excellent shelter to every other plant near it. It is in all respects perfectly hardy; conserguently it is a general favourite on the residential portions of large estates.

Like the Common Juniper, this American species can well be utilised for the formation of ornamental live-hedges in the residential portions of estate:.

Economic Uses of Timber.-The Virginian Juniper prorluces excellent timber, which is much sought after in America for caljinetmaking purposes, turnery, and other general technical wool-worlk. It is chiefly with the "Red Cedar" wood of this tree that blacklead pencils are covered; and in America the tree itself is best known by the name of Red Cedar. The smallness of the stem of this tree, however, renders it unsuitable for sylvicultural purposes on a financial basis in this country, and it is only as a hardy ornamental tree that it can really be recommended.

Soil and Situation.-In Britain the Red Cedar grows best on a rather rich, jorous, deep, and light loam, and lives longest on land resting on a dry subsoil. It is found to thrive best, and to attain the largest size, on a rather sheltered but airy situation.

Propagation and Culture.-This tree is propragated from seed, which it begins to produce from about the 12 th to 20 th year onwarls. The seed often lies dormant for one year before germinating: but after the young plants come up they grow rapidly, and may be treated in very much the same way as the seedlings of the Scots Pine. They should be transplanted into nursery-rows as yearling seedlings. As they are rather apt to run to long root-strants without a due amount of fibrous rootlets if left long unclisturbed, they should be transplanted once in every two years till they are finally put out; how often this trausplanting in the nursery-lines should take lliace will, of course, depend upon the size they are wanted to attain lefure they are planted out finally. The seedlings of this tree syon't a gomel deal-i.c., are apt to deviate individually more or less from the cornmon specific type-so that from the same seetl-berl several varietics are usually obtaned, differing in leaves or in the habit and arrangement of the branches.

Many of the varieties thus formed of this species are named as constant varieties by arboriculturists, so as to indicate their sprecial preculiarities. Thus there are $J . v i r g . v a r . a l b a$, argentea, aurea, pendula, plumosa, cinereascens, dic.

Good specimens of the Red Cedar are plentiful in all parts of this country, and may be seen in almost every arboretum, as well as in most public gardens. 
The largest specimen reported to the Conifer Conference of 1891 had a height of $70 \mathrm{ft}$. and a girth of $6 \mathrm{ft}$. at $5 \mathrm{ft}$. above the ground. It was growing at Studley Royal in Yorkshire.

The Red Cedar has received some sylvicultural attention throughout Germany, where it attains a height of from 40 to $60 \mathrm{ft}$. It has proved itself thoroughly hardy and accommodating as to soil; but thrives best on fresh, humose sand, and exhibits a preference for limy soils. Though it can do fairly wull on dry land, either of a light or a slightly binding character, it is most productive on fresh, humose loams. In the colder northern parts of the country new strains of seed should be obtained from time to time, as, owing to imperfect pollination, much of the seed produced fails to germinate when trees bearing only female flowers stand together.

\section{TAXODIXE.}

The various genera forming this group of the Coniferce are nonindigenous to Europe. They are chiefly to be found indigenously throughout tropical and sulstupical Asia, and the southern portion of North America (California and Mexico). They are often of great importance as timber-trees in the countries to which they are indigenous; but this climate is, even in its mildest parts, probably unsuited for the cultivation of any of these subtropical species in extensive woodlands managed on purely financial principles. Others of the Coniferce, from the northern and colder regions of California and British Columbia, prefer stronger claims to attention.

Concerning the above, Masters (op. cit., p. 187) writes as follows:"The Taxodium tribe (Taxodiece). - Trees with narrow linear leaves, spirally arranged, sometimes apparently two-ranked, not whorled.' Buds not scaly. Flowers moncecious. Cones globular or oblong; scales spirally arranged, more or less woody. Bracts partially consolidated with the scales. Seeds 2-6 to each scale, erect or inverted, winged."

\section{JAPAN CEDARS, Cryptomeria \\ (Linxeat System, Moxecta Monadelphia).}

Generic Character.-Evergreen trees with linear leaves, often heteromorphic; flowers monœcious. Males in axillary spilies; anthers crested, 4 or more lobed, pollen-cells globose. Cones globular; cone-scales palmately divided at the edge, so that the ripe cone is somewhat prickly. Seeds erect, $4-5$ to each scale, slightly winged. Cotyledons 2-4, flat, leafy. Primary leaves in whorls of 3 (Masters, op. cit., p. 202).

There are two species in this genus, both of which are large evergreen trees, and are found in the north of China and Japan. Reference will here be made to each of these. 
The Japan Cedars are sometimes apt to he confused with the dmoventirn.

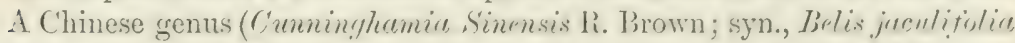
Salish).), a somewhat tender small tree inrligenous to the north of China, is cultivated in arboreta throughout many parts of the continent of Europe, but does not apleear to have found any favour in Britain, as its name is not usually to be seen in nurserymen's lists--menless it be the plant intended to be specified under the name of Cunninghamia lanceolata.

All of the Cryptomeria or Japan Cedars are noteworthy for their elecrant habit of growth, for the facility with which they may be cultivaterl in alnost every situation if moderately sheltered, and for their very marked and distinetive appearance if associated on lawns with other kinds of trees.

(1.) THE JAPAN CEDAR, Cryptomeria Japonica Don.

Srnovrus-Cupressus japonica L.; Taxodium japonicum Brongn.; Cryptomeria Fortunei Koch.

Specific Character.-Leaves five-rowed, without any footstallss, short-pointed, very close together, incurved or sickle-shaped, compressed on the sides, of a 4 -sided, rhomboidal shape, rumning downwarls on the under side, and with a sharp projecting mid-rib, from ${ }_{4}^{1}$ to $\underset{4}{3}$ of an in. in length, bright green, and quite smooth (see Fig. $7 \%$ ). Branches erect or horizontal, and spreading; lateral branches dividing alternately into numerous branchlets, thickly clothed with leaves. Cones about the size of a large cherry, mostly standing singly, but sometines in clusters on the extremities of the branchlets, and without any footstalks, mostly erect, of a globular shape, and a dirty brownish-red colour, but not very compact or solid. Scales numerous, rather loose, of a dull brownish-red colour, and with rough fringed edges. Male flowers on the same tree, intermixed with the young cones, at the extremities of the branchlets, and of a small oval or oblong shape, in large loose clusters. Seeds ripen in Sepitember and October during the year of thowering (Gordon, op. cit., p. 52).

Distribution. - The Japan Cedar is found plentifully about Shanghai and other northern parts of China in the form of groves and avenues; but it is said to have been introduced there from Japan. Professor Thunberg states that it is found both of spontaneous and of artificial growth on the hills of Nagasaki ant elsewhere throughout the mountainums clistricts of sonthern Japan, at an elevation of between 500 and $1200 \mathrm{ft}$., where it is generally met with growing on damp soils. It was first introduced into Britain by Fortune in 1844.

Description of Tree.-The Japan Cedar is a most distinctive conifer in appearance. It forms a handsome, light, and gracefullooking tree, with a pyramidal crown, which has a highly ormamental effect among broad-leaved kinds of trees on a lawn or in a park. Throughout all the southern parts of Irritain it seems per- 
fectly hardy, and grows luxuriantly; but in Scotland it requires the warmest situations and the best soils in order to enable it to ripen its wood sufficiently to stand our harder winters. It thrives, however, even in the north of Scotland, where the climate is often (as in the neighbourhood of Inverness and Nairn) milder than in the ele-

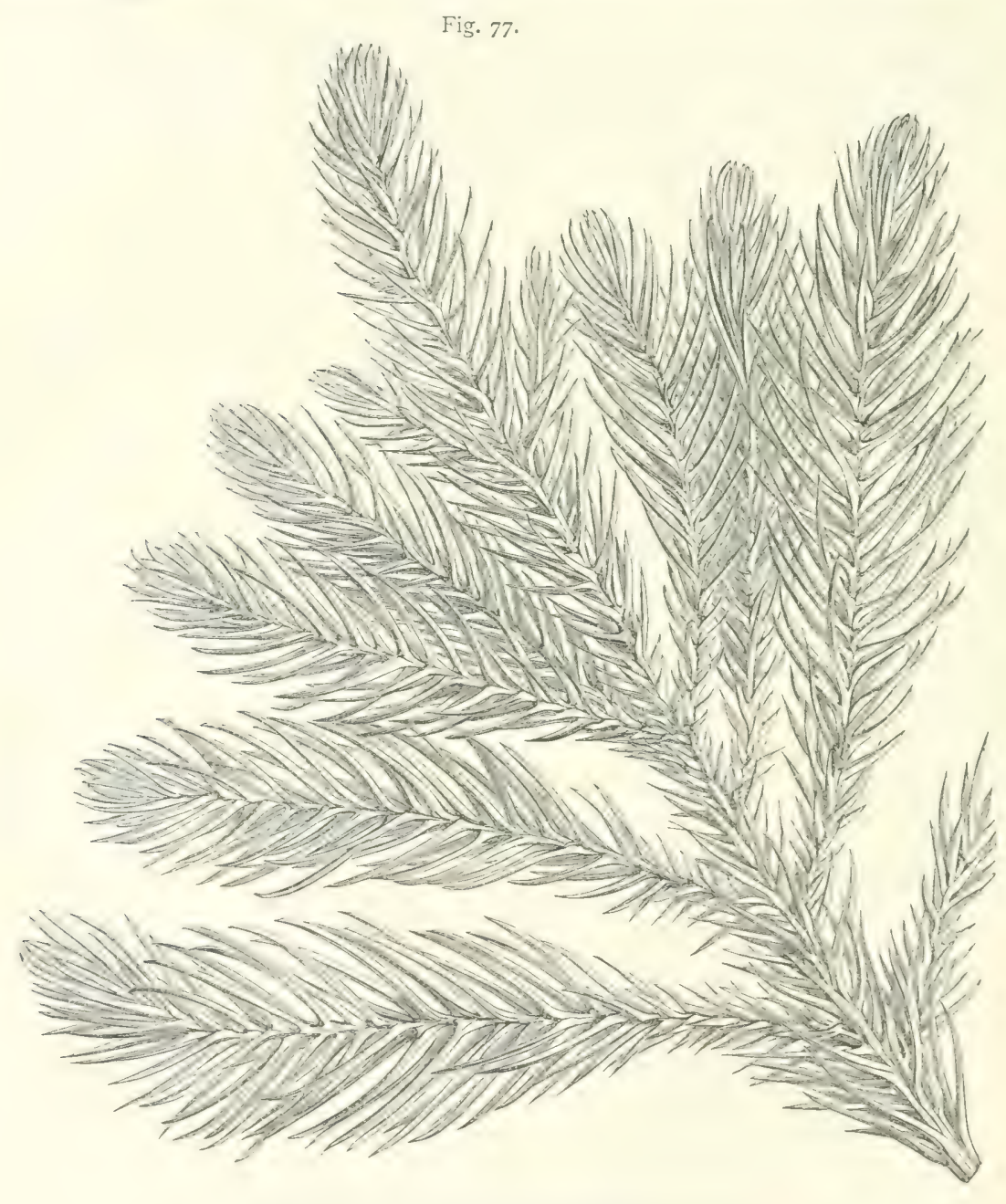

Spray of the Fapan Cedar (Cryptomeria japonica).

vated tracts forming the central Scottish Highlands, and the borderlinds between Scotland and England. Speaking generally, it is quite hardy enough for this climate; and such being the case, it deserves a place in every park and arboretum where a suitable soil and situation can be given it. It is said to attain a height of from 60 to 100 
$\mathrm{ft}$., with stems of from 3 to $5 \mathrm{ft}$. in diameter. Judging from the progress that many specimens have already made in this country, it seems not improbable that it will attain equally large dimensions in those localities of Britain that are most favouralie to its development.

Economic Uses of Timber. - The wood of the Japan Cerlar seems soft, white, and brittle; hence it is not likely ever to luecome nseful as a timber-bearing tree in Britain. Its place is rather as an ornamental specimen in a park or lawn; and for this prurpose it is well adapted.

Soil and Situation. - This Conifer seems to grow best on a deep, light, permeable soil, and in an elevated but sheltered situation. It may, however, be found growing on various linds of land; though the most vigorous growth usually seems to be attained on a deep, fresh, fertile, and humose sandy loam, with rather a cool moist sulbsoil, such as is often to be found near the edge of a watercourse. It does not stand exposure to winds, especially in spring; and when planted out in Scotland on an exposed situation, its leaves are apt to get browned and discoloured. In all cases, therefore, it is well to let this tree have a sheltered though not a confined situation; for if at all limited in growing-space, or hindered in its normal tendency towards ramification and lateral expansion, it loses much of its natural gracefulness and its general beauty.

Propagation and Culture.-The Japan C'edar is reared from seeds, which ripen in the September and October of the year of flowering. It is also readily propagated from cuttings.

Specimens of the Japan Cedar are plentiful in the country, and many of the trees are now of heights ranging from 40 to upwards of $50 \mathrm{ft}$.

The two largest specimens reported to the Conifer Conference of 1891 were respectively $67 \mathrm{ft}$. in height, with a girth of $5 \mathrm{ft}$., and $42 \frac{1}{2} \mathrm{ft}$. in height, with a girth of $9 \frac{2}{3} \mathrm{ft}$. at $5 \mathrm{ft}$. from the ground. The former was growing at Coollatin, in Wicklow, and the latter at Keir, in Perth.

There are several purely arboricultural varieties of this species, including, for example, Crypt. japon. var. elegans, gracilis, viridis, nana, Lobbii, and araucarioides. The foliage of $C . j$. elegans changes in winter to a dull red colour, which is very effective when contrasting with dark-green foliage.

(2.) THE ELEGANT JAPAN CEDAR, Cryptomeria elegans.

Specific Character.-Leaves linear, narrow, sickle-shaped, rigid, acute-pointed, decurrent at the hase, somewhat distinctly pliceel spirally all round the branchlets, and when fully grown bent backwards: they are slightly channeled on hoth sides, quite smouth, and of a cinereous or ash-greyish green colour in summer, lut change to 
a rich bronze hue in the autumn and winter; they are from $\frac{1}{2}$ to $\frac{3}{4}$ of an inch long, and only of about $\frac{1}{2}$ of an inch wide near the base. Branches munerous, horizontal, spreading, somewhat flat, and irregulurly placed along the stem: lateral branches and branchlets alternate, curved downwards at the points, and in winter of a reddish-brown colour. Cones very similar to those of Japan Cedar (Cryptomeria japonica).

Distribution. - This species is foum on the island of Xippon, in Japan, where it forms groves around sacred edifices.

Description of Tree.-This is a tree of a robust habit of growth, which very much resembles the Araucaria Cunninghamii, and in its native country attains a height varying from 60 to $100 \mathrm{ft}$. It is quite a hardy species in Britain. Like the other species just referrecl to in the foregoing section, it thrives best in a sheltered situation; indeed it does not grow at all freely in any position much exposed to stoms, but develops best when well sheltered under the lee of taller trees. Healthy specimens of this tree are usually of a robust and branching habit of growth, and form beautiful oljects among trees having foliage of a dark-green colour, as the rich bronze hue grenerally assumed ly the leaves contrasts pleasingly with the various shades of green presented by the foliage of other trees around them.

C. elegans is, in reality, only a state of $C$. japonica, like the Retinospora forms of Cupressus.

Economic Uses of Timber.-The wood of this species of Japan Cedar does not appear to possess any better technical quality than that of the Common Cryptomeria when produced in Britain.

Soil and Situation. - As already stated, this tree cannot be expected to thrive except on a low-lying and sheltered situation. With regard to soil it is not particular, provided that it be not too wet; for though a considerable amount of soil-moisture is favourable to its developnent, any excess of moisture, such as would be indicated by wetness, is injurious to it.

Propagation and Culture.-Like the Japan Cedar, this slecies may also be reproduced from slips or cuttings. But regeneration from seed is preferable, as the trees attain greater longevity, and have more inherent vitality than plants raised from cuttings. The seed also ripens in the early autumn of the year in which the flowering takes place.

Fair specimens of this beautiful Cryptomeria are now plentiful in most of the arboreta throughout the country. They attain about the same height as trees of the other species.

The largest specimen reported to the Conifer Conference of 1891 had a height of $24 \mathrm{ft}$., and a girth of $1 \mathrm{ft}$. at $5 \mathrm{ft}$. abore the ground. It was growing on the estate of Poltalloch in Argyllshire. 


\section{THE MAMMOTH TREES AND REDWOOUS OF CALIFOMNIA, Sequoia (Linnden System, Monecia Monadelphia).}

\section{(1.) THE MAMMOTH TREE, Sequoia gigantea Torrey."}

Srxoryus-IVellingtonia gigantea Lindl. ; Washingtonia gigantea Hort. Amer.; Sequoia Wellingtonia Seemann.

The nomenclature of this tree is of interest. It was termed Wellingtonia by Lindley; but this name will probably only be retained as a garden term. An endeavour was made to change the name into Iraskingtrmiu. There was, however, already a recornised species of plant named Irashingfrinin; henre another name had to be cast about for, and this was found in the more comprehensive term Sequnia. This generic name, which is now commonly arcepter among botanists, has the great additional advantage of long antedating ITellingtoniu. Hence the nomenclature may be finally accepted as serqusiu gigunten Torrey.

Generic Character.--Under Sequoia, Masters (op. cit., p. 247) gives the following generic details: "Evergreen trees with small leaves, scatteresl, or apparently in two ranks. Flowers monocious; male flowers in terminal stalked oblong or globose heads; anther-lobes 2-5; pollen globose. Conescales and hracts united into a woody, wedge-shaped, or peltate mass. S.eeds $4-9$, winged, without resin-canals."

Specific Character.-The leaves are all somewhat needle-shaped, spirally altermate, spreading, persistent, and of a light-green colour on the young plants; those on the adult trees scale-like, closely inlaid, rounded on the back, and concave un the inner face; those on the branchlets inuch shorter, rery close, and regularly imbricaterl; those on the larger branches longer, looser, decurrent at the base, and tapering to an acute point, but sometimes rather acute. Branches spread out horizontally, much divided, and furnished with mumerous laterals. Branchlets cylindrical, frequently pendulous, and thickly covered with light-green glaucous foliage; cone-bearing branchlets slightly thickened, and entirely covered with scale-like leaves, closely imbricated, the upper leaves oval, and broadest at the lose. Comes solitary on the ends of the branchlets, about 2 in. long, and fully 1 in. in diameter, orate, llunt-ended, and slightly tapering tuwaris both extremities. Scales in series, placed nearly at right angles upon the axis of the cone, stipitate, or supported by a stall, thickened, and enlarged from the point of insertion as far as the summit, which is depressed and wrinkled on the external face, and fumished with a small prickle in the centre of the little hollow. Sexts from five to six under each scale, but mostly in fives. Seed-leaves from three to six in number, but mostly in fours (Gorclon, op. it., 1. 330).

Distribution.-Lilie many of the trees of north-west America, the great Mammoth Trees of California (Willingtoniu giguntea) seem 
to be confined merely to isolated patches here and there. The first place where they were found was at the spot now generally known as the Mammoth Tree Grove, near the head-waters of the Stanislaus and San Antonio rivers, in lat. $38^{\circ} \mathrm{N}$., long. $120^{\circ} 10^{\prime} \mathrm{W}$., and at an elevation of about $4590 \mathrm{ft}$. above sea-level. The number of trees still standing there is about 200 , of which 92 are of large size. The next lucality in which they were discorered was the Mariposa Grove, about fifty miles south-east of the Mammoth Tree Grove. It is about $5000 \mathrm{ft}$. above the level of the sea, and on the western slope of a high ridge of the Sierra Nevada. The trees here are spread along a lateral valley, on the flank of a main ridge, in two groves, about half a mile apart, known as the upper and lower grove. The number of trees of considerable size in these groves is about 600 in all. A third grove, containing about 500 trees, has been found in Fresno County, eight miles south-east of the Mariposa Grove. Another grove is reported by Blake as having been discovered further south and east, upon the Kaweeab, or about fifty miles from Visalia. These interesting groves have obtained protection by heing included within the Tellowstone, Tosemite, and Serpoia Reservations, which have recently heen formed as great National Parks, and which include the most charming scenery of the Californian forest districts, with the celebrated "Big Trees," the Bridal Veil Falls, and many other objects of sylvan and natural beauty. The Mammoth Tree is said to have been introduced into Britain in 1853.

Description of Tree.-The Mammoth Tree of California is certainly one of the largest known trees on the earth, if not absolutely the very largest. The average dimensions of the tree, when full grown, are about $300 \mathrm{ft}$. in height, and up to $30 \mathrm{ft}$. in diameter near the ground; but it has been found about $400 \mathrm{ft}$. high, and nearly $40 \mathrm{ft}$. in diameter. This tree seems quite hardy in our climate, even in the north of Scotland, although the foliage sometimes becomes browned in a severe winter. Yet, on the whole, it has proved itself fairly entitled to be classed as a hardy tree; and it is probably destined to take a prominent place in our ornamental woods and plantations, although our climate is not warm enough for it to be of any sylvicultural importance. They are supposed to attain, like the Yews and Cypresses, an enormous longevity.

Economic Uses of Timber.-The wood of this tree seems light, soft, and brittle; hence, even if the climate were mild enough to encourage its heing grown as a sylvicultural crop, it would have less chiam to attention than the Spruces and Firs of the colder regions of writhern California, such as the Donglas Fir, the Menzies spruce, and others. It is, however, an interesting and ornamental tree, deserving of arboricultural attention chiefly on account of its very rapid 
growth, and of the large dimensions which it attains in comparison with other trees.

This is one of the very lightest of woods, for when seasoned it has a mean sp. gr. of 0.38 , which is even lower than that of the Weymouth l'ine, and considerably less than that of most other conifers (see table on p. 331).

Soil and Situation.-The MIammoth Tree appears to thrive best in rather a moist than a dry climate. In so far our climate seems naturally well suited to it; and this has aiready been well testerl from the vigorous growth of the specimens that are now to he found throughout all parts of the kingdom. It thrives luest, however, as practical arboricultural experience of the tree goes to prove, on a dry and deep soil, and on rather an open, but not an exposed, situation. One of the best specimens in this country stands on a dry sloping bank of very light suil, at Longleat, in Wiltshire, and must now he over $50 \mathrm{ft}$. in height, and with a fine proportionate stem and crown. The tree grows rapidly on most soils, however, if they are deep, open, porous, and permeable. Its growth is less satisfactory on land that is cold, retentive, or wet in the subsoil; nor does it thrive if its crown is confined among other trees, or if it be exposed to high winds in unprotected localities.

Propagation and Culture.- Seeds of the Mammoth Tree are now easily obtainable in considerable quantities from time to time, and are therefore gradually becoming lower in price than they were. MLost nurserymen sow them in cold frames or in boxes in glass houses, and afterwards only gradually expose them. But they succeed perfectly well even when merely sown on a warm protected piece of ground in the open air; and seedlings raised thus ultimately make much better and hardier plants than those that are reared and nursed tenderly under glass during their first stages. In general, the seeds and young seedling plants of this tree succeed perfectly when treated in much the same way as is adopted with the Scots P'ine. Those who do not wish to risk their seed in this manner, may certainly be recommended to sow it in a cold frame; but, as soon as germination has been effected, the young seedling plints should be gratually accustomed to full exposure to sun and air during the summer, though covered up throughout serere weather in winter. Trhen the seedling plants are one year old they should be planted out intn mursery-lines, plenty of growing-space being allotted to them, as they are of rapid development. They are essentially light-demanding species of plants. They require to be tramsplantel every two years in order to make them fibrous, so as to develop numerous rootlets and roots, and to prepare them for safe removal to their permanent 
sites. C'uttings of this tree root freely, and make very good plants, although seedlings will probably attain greater longevity.

sinecimens of the Alammoth Tree, of heights varying from \pm 0 to $50 \mathrm{ft}$., are now common in many parts of the country.

The two largest specimens reported to the Conifer Conference of 1891 hatd respectively a height of $80 \mathrm{ft}$, with a girth of $8.1 \mathrm{ft}$., and a height of 52 $\mathrm{ft}$., with a girth of $13 \frac{3}{\mathrm{ft}} \mathrm{f}$. at $4 \mathrm{ft}$. above the ground. The former was growing on the Shanballey estate in Tipperary, and the latter at Castle Menzies, in Perthshire.

This tree is found to do well sylviculturally in the southern regions of Austria, where it has been largely planted throughout the Banat in the forests owned by the State Railway Company. For Britain it has, as previously remarked, no claims to attention except from an arboricultural point of view, as our climate is not warm enough for its finest development.

(2.) THE CALIFORNIAN REDWOOD, Śquoia smprirens Endlicher.

Srnonras-Sequoia taxifolia Koch ; Taxodium sempervirens Lambert.

Generic and Specific Character. - Leaves on the lateral branches and branchlets linear, blunt-pointed, two-rowed, spread out, flat, alternate, straight, rarely falcate or bent like a sickle, leathery, persistent, shining, dark green, and smooth above, more or less glaucous, and channeled below; from $\frac{1}{2}$ to 1 in. long, but much shorter and smaller near the extremities of the shoots; those on the principal hranches and terminal points of the flower-bearing branchlets are very short, narrow, sharp-pointed, or scale-like, somewhat imbricated or closely spiral, decurrent at the base, ribbed, and glaucous below, whilst those on the leading shoots are distant and very acute (see Fig. 78). Branches spreading, horizontal, rather distant, irregularly scattered alternately along the stem, and furnished with numerous lateral branches in two rows, those nearest the base being frequently bent downwards, while those towards the extremity are more elevated; branchlets very numerous, in two rows, and frequently drooping. Male flowers glolular, solitary at the extrenities of the branchlets, on slender footstalks, thickly covered with very small scale-like leaves. Cones solitary, terminal, somewhat globular or egg-shaped, rather blunt at the ends, and ahout $1 \mathrm{in.}$ long. Scales numerous, wedge-shaped, from 16 to 20 in number, smallest near the base, transversely keeled, very much sunken in the middle, irregularly shaped, wrinkled on the summit, and furnished in the michlle of the hollow centre with a stout, horn-shaped, blunt point, directed outwards. Seeds from 3 to 5 under each scale, variously shaped, and winged. Seed-leaves mostly in twos, but sometimes in threes, orate-lanceolate, obtuse at the ends, slightly convex, and pale 
green on the under side, but of a much darker colonr and somewhat glossy above (Gordon, op. cit., 303).

Distribution.--The Califomian Iierlwood was first discovered by Menzies in 1796, and afterwards by Douglas in 1836 ; later on it was again found hy the Riuswians, who first introluced live plants of

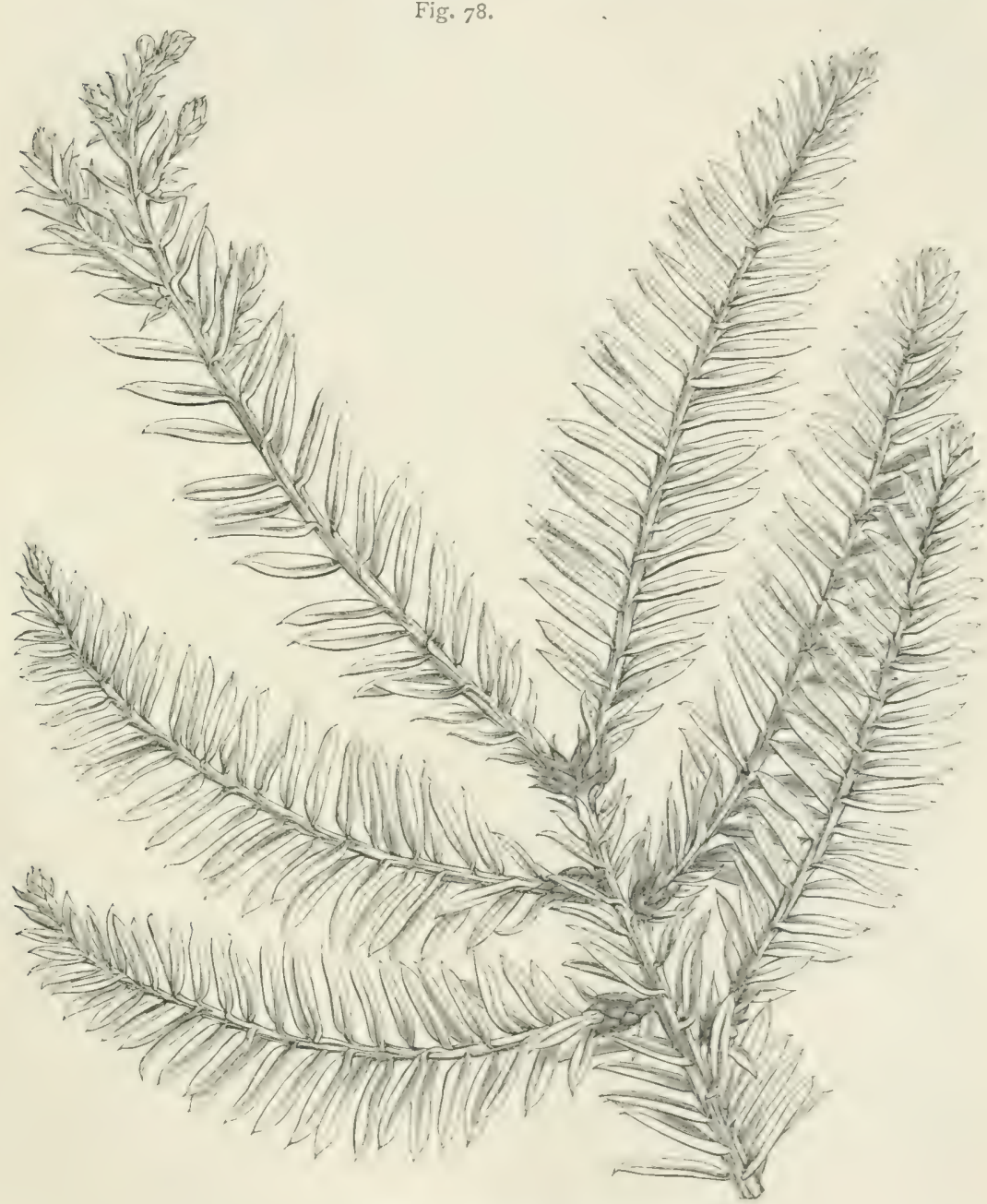

Spray of the Californian Redtrood (Sequoia sempervirens).

it into Europe in $18+3$. Since that time, however, it has been found growing abundantly on the mountains of Santa Cruz, about sixty miles from Monterey, in California, where Inartwey fomm that it averaged $200 \mathrm{ft}$. in height, with trunks of from 18 to $24 \mathrm{ft}$. in circumference, which rise up like pillars, quite straight and clear of

VOL. I. 
branches to a height of $60 \mathrm{ft}$. One tree, which was called by the American settlers "the Giant of the Forest," measured $270 \mathrm{ft}$. in height, and had a trunk $55 \mathrm{ft}$. in circumference at $6 \mathrm{ft}$. from the ground.

Description of Tree.-The Californian Redwood seems quite a hardy tree in the midland and southern counties, and also in favourable situations even in the northern counties of England; but it has been found unable to stand the longer and severer winter in most parts of Scotland. It is a rapid-growing species on favourable soils and situations, where it soon attains large dimensions, develops into an upright-growing tree of noble proportions, and has a very graceful and rather imposing appearance. It assumes an entirely different appearance from its close relative the Mammoth Tree (Wellingtonia gigantea); it is much more graceful in its general habit of growth, whilst its fine Yew- or Spruce-like foliage gives it a light and feathery aspect. It is well worthy of a place in every park and arboretum in all parts of the country suited to it; but its comparative want of hardiness will prevent its ever becoming such a favourite in Britain as the Mammoth Tree has proved.

Economic Uses of Timber.-The timber of this species is not of a very durable description, for, although close-grained, it is shortfibred and brittle. But in California there are many enormous lumber firms doing a gigantic business in the extraction and conversion of Redwood, which forms one of the great staples of the trade of San Francisco.

Soil and Situation.-This species requires a deep, light, dry, and permeable soil, and a sheltered situation, in order to thrive well in even the milder parts of England. It is very irregular in starting into growth, as it often makes its shoots late in the season in spring, and then continues growing late into the autumn. It consequently requires favourable soils and situations in order to enable it to mature its young wood so as to secure it against being injured in early winter. This tree should not have a rich soil; that would be apt to stimulate it to carry on growth too late into the autumn season, and when the first frosts cause active vegetation to cease, the shoots might still be of too soft and succulent a character to resist the action of our winter cold. It is chiefly, indeed, to this cause-viz., to its having generally been planted on soils of too rich a description-that this tree has been found wanting in hardiness in the northern part of our island. Were it planted on rather poor but deep and porous land, it might thrive well on many places where at best it can only be said to have partially succeeded. In all cases, however, the Californian Redwood tree requires a sheltered though airy situation.

Propagation and Culture.-The Redwood is raised from seed in 
frames, and after the young plants are $" 1$, they are gradually accustomed to exposure to the open air. They require protection for the first winter, and should in Scotland have it for the second winter also.

Specimens are now common in this country, and range in height from 40 to nearly $60 \mathrm{ft}$.

The largest specimen reported to the Conifer Conference of 1891 had a height of $75 \mathrm{ft}$., and a girth of $13 \mathrm{ft}$. at $5 \mathrm{ft}$. above the ground. It was growing on the estate of Boconnoc in Cornwall.

3. THE DECIDUOUS CYPRESS, T'cxodium (Linnean System, Monecra Monadelphis).

\section{THE SWAMP CYPRESS OP DECIDUOUS CYPRESS, Taxodium distichum Richard.}

Synonras-Cupressus disticha L.; C. virginiana Plukenett; Schubertia disticha Mirbel.

Masters (op. cit., p. 247) gives the following generic details: "Trees with deciduous foliage. Male flowers in branched catkins. Anther-lobes 5-8. Cone-scales thick, peltate; seeds erect, angular, with projecting points, but without wings. Cotyledons 6-9, 3-angular.

Generic and Specific Character.-Leaves small, $\frac{1}{4}$ to $\frac{3}{5}$ of an inch long, linear, tender, and ranged pectinately in two rows. Branches in whorls. Cones situated at the base of the shoots, either singly or in clusters of two or three, upright, of a spherico-ovoid shape, a spongy wooden consistency, and a dark-brown colour; they are from $1 \frac{1}{5}$ to $1 \frac{3}{5}$ in. in diameter, and take two years to ripen. Seeds in twos under each scale, upright, and unwinged.

Distribution. - The Deciduous Cypress is indigenous to the swampy hollows of Virginia, Louisiana, and Florida, or the subtropical portion of the castern sile of North America (see fig. TSe).

It was introduced into Britain.

Description of Tree.- - In its native tracts it develops into a fine tree upwards of $1: 0$ ft. in height, and capable of attinining a girth of over $40 \mathrm{ft}$. It also develops in Britain into a singularly graceful deciduous tree of rapid growth.

Economic Uses of Timber.-The rood of the Swamp (ypress is of a resinous description, and is, when freshly ent, of a pale whitish colour, which afterwards deepens into a redelish tome when exposed long to the action of the air. It is hard and durable, and is used extensively for various technical pupposes throughout the southeastern States of America. In Europe, even at 50 years of age, it has been found to produce excellent timber for art furniture. 
Soil and Situation.-A considerable supply of soil-moisture is essential for the thriving of the Swamp Cypress; hence it will find its most favourable situation on the margin of lakes or ponds, or near the edges of streams, or in any similar moist localities.

Propagation and Culture.-The Swamp C ypress is a fairly hardy species of tree, which can easily be raised from seed in the open. As it is of rapid development, it can be transplanted at an early age into the position it is intended to occupy permanently. Young plants are now obtainable from nurserymen at a very moderate rate.

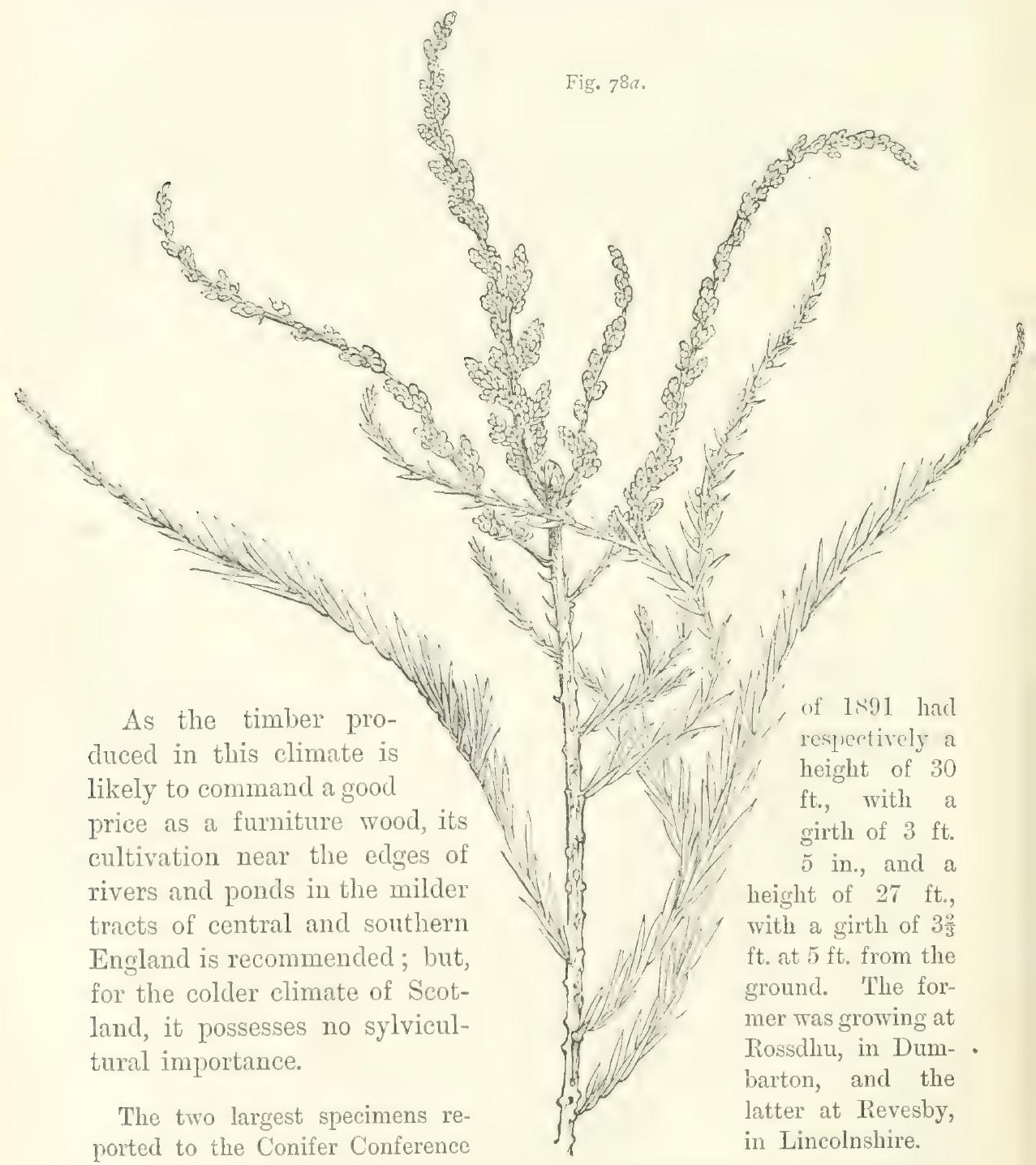

Spray of the Swamp Cypress (Taxodium distichum). 


\section{B-PSEUDODRUPACEA WILLKOMM.}

\section{TAYACE.E' LINULE:}

The Taxacece, the chief family of the natural order of the Pseudodrupacece, differ from the Coniferce or true cone-bearers (1) by having only one-seeded fruits in the form of a Heshy pseudodrupe or false berry; (2) hy the seed, which ripens in the autumn of the year of flowering, being surrounded and encrusted by a lony scale; and (:3) by the bark, wood, and leaves containing no resin-ducts. The natural order is represented by five families; but only one of these is indigenous to Europe, and the other four are regarderl by most hotanists as mere tribal or generic forms of the Taxacec. 'The Yews form dicecious evergreen trees, whose branches are irregular and not arranged in whorls: there are four genera and sixteen species, most of which are indigenous to China and Japan, like the Cryptomerier.

\section{THE YEW, Taxus L. (Linnean System, Diecla Monadelphia.)}

Character of the Genus.-Evergreen trees, with 2-1anked leaves, flowers diocious; stamens in stalked heads; anther-scales peltate; pollen globose; seed solitary, erect, and borne in a scarlet, fleshy cup or aril. Cotyledons 2, leafy, flat, green on both sides, without resincanals. Primary leaves similar in form, but smaller (Masters, op. cit., p. 249).

The Yews are low evergreen trees or bushes, found scattered throughout the temperate parts of Europe, Asia, and America. Reference need here be mate only to one species, the Common Yer, which is in Britain a well-known tree, and sometimes attains considerable dimensions. As a timber tree, however, it is now of much less national importance than it was in the days of early warfare, when tough bows of Yew formed the chief part of the equipment of the English archers.

\section{THE COMMON YEW, Taxus baccata $\mathrm{L}$.}

Specific Character.-Leaves in two rows, crowded, linear, slightly curved or falcate, pointed, flat, entire, and slightly revolute on the margins; from $\frac{3}{4}$ to $1 \frac{x}{4} \mathrm{in}$. long, and $\frac{1}{8}$ of an inch broad, of a dark shining green above, much paler below, with a prominent mid-rib, terminating in a small point at the apex. Jirinches spreading, much divided, and dense. liranchlets long, slender, and drooping. Male flowers axillary. F'nit a filse berry, rouncen, shtinous, drooping, open at the top, and enclosing a brown, oval, partially naked nut, uncomnected with the flesliy disc, which is of a scarlet colour, and sweet. Seed-leaves in twos (Gordon, op. cit., p. 311). 
The development of the male flowers begins in the autumn, whilst the female flowers do not appear till spring. The leaf-buds do not open till about a week later than the flowering buds.

Distribution. - The Common Yew is found in most parts of Europe, at elevations ranging from 1000 to $4000 \mathrm{ft}$. It is frequently met with on the Apennines and the Alps, in Greece, Spain, the Pyrenees, and the Caucasus, as well as in Britain.

Throughout the southern portion of Europe the Yew is distinctly a characteristic plant of the mountains, whereas in northern Europe it is to be found at the sea-level. Its northern limit of spontaneous growth reaches to about $58^{\circ}$ in Scotland and $61^{\circ}$ in Norway; whilst its southern limit trends along the northern lands bordering the Mediterranean Sea from about $36^{\circ}$ in southern Spain to $37^{\circ}$ in Greece, whence it stretches farther eastwards into the Caucasian mountains at upwards of $2000 \mathrm{ft}$. above the sea-level.

Description of Tree.-The Common Yew-tree rises from the ground with a short but straight stem, which, at the height of 3 or $4 \mathrm{ft}$., sends out very numerous and spreading branches, forming a dense head. When full grown it usually has a height of from 30 to $40 \mathrm{ft}$., and is always characterised, except in the case of trees that have attained a very great age, by the tuftings and the sky outline being pointed or peaked. After the tree has approached the limits of senile decay, however, these angular points gradually become either rounded off or else stag-headed. The stem and branches are channelled longitudinally, and are generally rough from the protruding remains of shoots which have decayed and fallen off. The Yew is of very slow growth; but in favourable situations it will attain the height of from 6 to $10 \mathrm{ft}$. in 12 years, when grown from the seed. The Yew-tree attains a great age. Some of those in this country, as well as in other parts of Europe, are well known to be considerably over 1000 years in age; and many of them are supposed to be from 2000 to 3000 years old.

Not infrequently some of the lower branches assume a strong upward tendency, and develop like secondary stems. Examples of this are to be found in the 5-stemmed Yew in Withycombe in Devonshire, and the 12-stemmed Yew celebrated throughout Cardiganshire.

Economic Uses of Timber. - The wood of the Yew is very hard, close, fine-grainerl, flexille, and elastic; it splits readily, talies a high polish, and is of great durability. It is allowed to be wood of the very best description for cabinetmaking purposes. It is also very durable for country fencing purposes; so much so, that in some parts of England where it is plentiful, there is a common saying that a paling-post of Yew will outlast a post of iron.

Soil and Situation.-The Yew will grow on most soils that are 
not too sandy and dry. It seems to thrive best on strong loams, and succeeds well even on strong argillaceous lands; whilst, as regards situation, it prefers rather a sheltered locality. Being a decidedly shade-bearing species, it thrives well within, on even under the sharke of, other trees.

For its best development the Yew requires a fresh calcareous or limy soil, and a damp climate. Its power of thriving under shade excels that of even the Silver Fir. During the first few years of its existence, it is less liable to suffer from overshadowing than from drought and excess of sunlight.

Propagation and Culture.-The Yew can be propragaterl from cuttings up to between 3 and 4 in. in diameter, but it is much better to raise it from seed. Its varieties, however, require to be propagated from cuttings. The seeds ripen in October, and should then be gathered and cleared from the pulp by washing them. The seeds lie dormant for one year. Hence, after the pulp has been removed by washing, the seeds should be mixed up with about twice their bulk of sand, and laid in a pit for fourteen or fifteen months, when they may be sown in beds on any good loamy or limy soil, and covered with earth to about $\frac{5}{8}$ of an inch in depth. When the seedlings have stood two years in the seed-beds they should be transplanted into nursery-rows. Very much the same treatment may be accorded to it as has previously been detailed with regard to the Ash (see p. 128).

There are many remarkable Yew-trees throughout the country, both in England and Scotland. At Syon House there are some fine old specimens; and in the two great natural woodlands, the Forest of Dean and the New Forest, there are many remarkable specimens, which are traceable back to the days of William the Conqueror. At Temple Farm, Corsley, Wilts (Marquis of Bath), there is a fine old specimen considerably upwards of 1000 years old. It is $50 \mathrm{ft}$. high, with a diameter of stem about $10 \mathrm{ft}$., and has a spreading expansive crown of foliage upwards of $50 \mathrm{ft}$. across. MLost great estates throughout England and Scotlind have their specinens of old and interesting Yews, many of which have a connection with the history of the respective places; and in many parts of Ireland there are equally interesting specimens of the spontaneous variety, the Irish Yew (T. baceata hibernica Hort., 'T'. hibernica Hook.)

The largest specimen of the Common Yew reported to the Conifer Conference of 1891 had a height of $40 \mathrm{ft}$., and a girth of $13 \mathrm{ft}$. at $5 \mathrm{ft}$. above the ground. It was growing on the estate of Rossdhu in Dumbartonshire.

But in the old deer-park near Kentchurch, in Hereford, there is a Yew which measures $30 \mathrm{ft}$. in eircumference at $4 \frac{1}{2} \mathrm{ft}$. from the ground. In that same park there is also an Oak which tyirths $32 \mathrm{ft} .5$ in. at $5 \mathrm{ft}$. from the ground, and a Scots Pine that girths $11 \mathrm{ft} .7 \mathrm{in}$. at the same height. 


\section{CHAPTER IV.}

CONCERNANG T'TELT AIBORICTLTETAA OPERATIONA, OR THE CULTIVATION OF TREES CHIEFLY FOR ORNAIENTAL AND ESTHETIC PURPOSES.

LANDED estates belong, generally speaking, either to one or other of the four following classes:-

1. Those situated on the low-lying and level plains of the country;

2. Those on the plateaux of considerable elevation above the sea ;

3. Those consisting partly of table-lands and partly of undulating hills; and,

4. Those situated entirely in hilly and mountainous districts.

Estates situated on the low-lying and level plains of the country usually have the best soils and the warmest climate; hence the Oak, Ash, Elm, Sycamore, and Maple, with Horse-Chestnut and SweetChestnut, Beech, Lime, Poplar, Willow, Walnut, Tulip-tree, and other broad-leaved species requiring good soils and situations, should be planted on them. Larch, Pine, Silver Fir, Spruce, and other coniferce, as well as all of the trees described in the two preceding chapters, will thrive normally on them, if the land be properly prepared, and if the sites are well chosen with reference to the special requirements of each individual species of tree.

On estates situated on plateaux at a considerable elevation above the sea, the different kinds of broad-leaved trees should be more sparingly planted than on estates situated on lower-lying districts; whilst all the conifers that have proved themselves hardy in our climate may be cultivated more abundantly. On estates of this class, much more skill is necessary on the part of the forester, in order to enable him to suit the trees to the different situations and localities on the estate, than is required in cases.where he has to deal with the growing of trees on lower-lying estates, where the soil is more equal and 
the climate is usually very much more genial and favourable. On estates of the class now under consideration, there is generally a greater variety of soils and situations than oltains on estates situated on level plains or on merely undulating land; and in all cases of planting trees upon them, the place of the hroart-leaverl species shoulil be on the heavier and less exposerl portions of the lands, while the deep-rooting Pines may be put out upon the lighter soil and the more exposed situations. In dealing with any concrete case of this nature with regard to planting, the common-sense rule is, that the lardiest kinds, both of broad-leaved trees and of conifers, sloruld be selected and placed on the more exposed localities, whilst the less hardy species are confined to the less exposed situations.

With regard to estates consisting partly of table-lands and partly of undulating hills, the broad-leaved species of trees should be placed on suitable soils and situations throughout the lower-lying parts of the property, while deep-rooting coniferous linds alone should be used on the hilly portions of it. The hardiest kinds of conifers should, of course, be put out on the poorest, highest-lying, and most exposed localities; whilst the somewhat more sensitive species should be confined to the less exposed situations, and be planted out chiefly along the lower slopes of the high grounds, or partly interspersed in admixture with the broad-leared trees.

On estates situated wholly within the hilly and mountainous districts of the comntry, practical experience has shown that-except in cases such as coombes or hollows and ravines here and there, where a portion of the hardier kinds of broad-leaved trees may be placed-coniferous trees alone should be planterl; for on properties of this kind both soil and climate are naturally better aldipted to the growth of conifers than of hroad-leaved species, and l'ines, suruces, and Firs therefore ultimately form the most profitable clissies of trees that can be grown on the woodland areas.

In all cases the broad-leaved species of trees should, as a rule, be placed upon the more sheltered parts of any estate, and the hardier Pines, Firs, and Spruces, \&c., allocated to the higher and more exposed districts. This is only imitating the teachings of nature in the same operation. It may be noted that in the natural disposition of trees over the surface of the globe, the Pines, Spruces, Firs, and other cone-bearing trees mostly inhahit cold, high-lying ilstricts where the soil is variable in character, and often companatively poor: while the Oaks, Ash, Elm, \&c., occupy the more temperate regions nearer the level of the sea, where the land is usually deeper, more porous, moister, and richer in quality. In order that the broadleaved species of trees may thrive well, they require a fresher and a considerably richer soil than the conifere do; hence, in dealing 
with the profitable planting of trees, the hard-wooded kinds should be placed in the heaviest and richest parts of the land on any estate.

With reference to the newer kinds of coniferæ described in the preceding chapter, it may here be remarked that the great majority of them are of purely arboricultural interest merely; they are best suited for the adornment of parks and woods in the residential portions of large estates. There can be no doubt, however, that some of them, such as the Red or Douglas Fir, and the Sitka or Menzies spruce, possess undoulited sylvicultural value for Britain. They must ere long be cultivated to a much greater extent among us than they are now, and will by the middle of next century be commonly reckoned as profitable timber-producing trees in the British sylva. But, in the meantime, the seeds of most of them are still too scarce and too high in price to admit of their extensive growth as woodland trees; and therefore their cultivation is at present only carried on to a comparatively limited extent on any property.

On estates lying along the sea-shore, no trees thrive so well as the Cluster Pine (Pinus Pinaster), the Black Pines (P. Larieio and $P$. austriaca), the Maritime Pine (P. maritima), the Common or Norway Maple, the Holm Oak or Evergreen Oak (Quercus Ilex), the Common Yew, and the Common Beech. Upon estates having the sea as one of their boundaries, it is often difficult to get trees of any description to thrive to any considerable extent, or even to do well enough to make a moderate shelter; and it is in such situations that these trees are found to be of special utility. Planted in such unfavourable situations, they do not, of course, rise up so as to form valuable timber; but as they grow very bushy, they form an excellent shelter for trees inland. By the shelter obtained from the outer belt of trees, the more valuable plantations lying in their lee find more favourable conditions for normal development; and this is, of course, the end in view in planting the outer fringe of shelter-wood (see chap. vii.)

Pineta and Arboreta.-A Pinetum means, strictly speaking, a tract of land set apart on any estate for the experimental cultivation of exotic coniferous trees of recent introduction into this country.

Within the last fifty years many such pineta have been made; and there are now very few landed properties of any considerable extent on which there is not a pinetum of greater or less extent, according to the taste of the proprietor and the possibilities of the soil and situation.

These pineta are, for the most part, found occupying sheltered situations in the home parks of their proprietors, or in the immediate neighbourhoods of their mansions, so that they combine ornamental 
effect with more practical experimental cultivation. In this way the sylva of every country, to which our commerce has reached, has furnished exotic trees that are now to be found sprearl over our islinmt from south to north and from east to west; for there are but few estates in Britain which cannot show fair specimens of recently introduced trees interspersed with the denizens that lave been long in cultivation in our plantations, and forming new and very varierl and distinct features in the rural landscape of our country. From these very praiseworthy exertions of landerl proprietor's in all parts of the country, arboriculturists are now in possession of an amount of knowledge and experience, with respect to the indivirlual retuirements and the general hardihood of the newer coniferæ, which is very valuable and highly important both to the interests of Arboriculture and of Sylviculture. An Arboretum, on the other hand, is a tract of land set apart for the experimental cultivation of all linds of trees, broad-leaved and coniferous; it is therefore of greater general interest, and is on the whole more instructive, than a pinetum from an educational point of view.

As it may be interesting to arboriculturists to know where some of the best collections of the newer coniferæ may be seen in the country, the following list of the principal Pineta and Arboreta is given. The names are ranged in alphabetical order without any attempt at reference to their comparative completeness or importance.

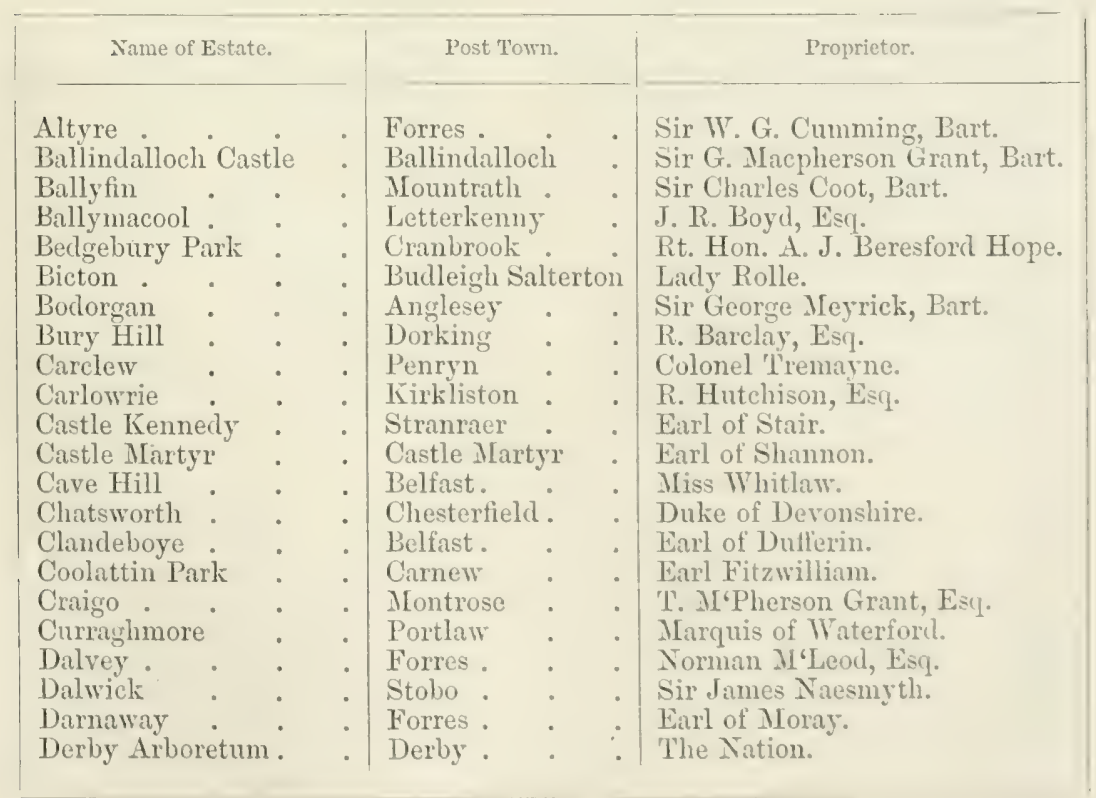




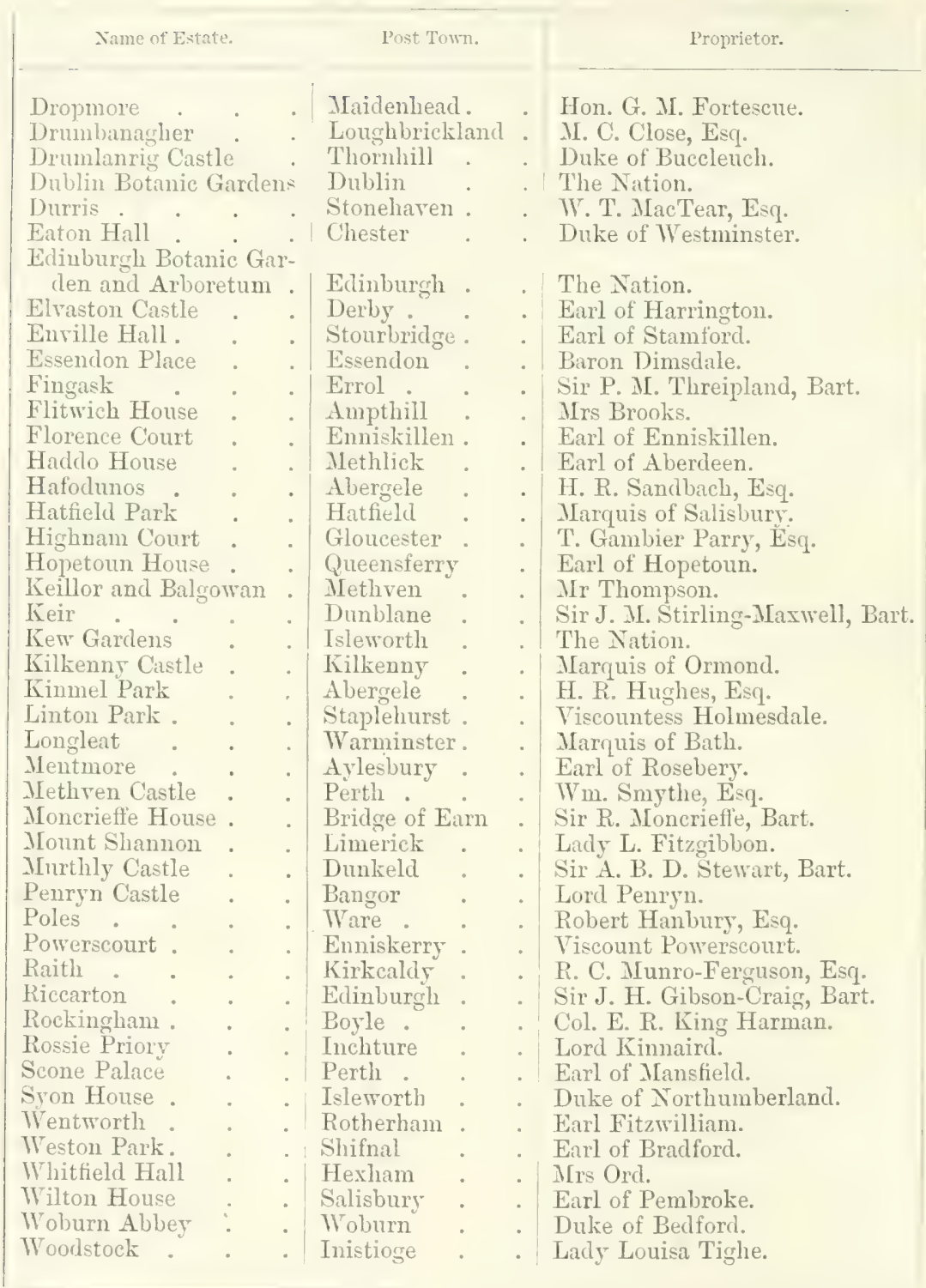

From what has just been said, it may be inferred that great advantages have been gained to Forestry in Britain by the arboreta existing throughout different parts of the country; and this is undoubtedly the case, although the lessons they teach must only be taken as exhibiting the development of trees under more than ordinarily favourable circumstances as to soil and situation. But, so far as they go, the lessons taught by the existing arboreta have been of 
great advantage to all concerned, for they have proved much that we han no linowledge of hefore ther were estallished on extensively over different parts of the country. Still, in order to ascertain the true chancteristies and the sylviculumal eapalilities of the coniferat: of recent introduction, so as to be in a position to judge of their fitness for becoming profitable as crops of timber, they nunt he treaterl in the same way as the more common species of forest-trees, and should be planted out experimentally on the sinne soils and situitions along with these. Until experimental operations of this practical kind are carried out on estates throughout all parts of the country, and at the different elevations on which planting is usually undertaken on them, our experience of the exotic conifere must be limiterl to their growth in the more sheltered situations and on the better classes of soils to be found in arboreta.

Any proprietor wishing to grow the newer coniferæe with a distinct view mot only of ascertaining the general hardihood of the various individual species and their probable suitability for growing as timber-crops in close cinopy, as well as their adaptability for purely ornamental purposes, but also of proving how far the different species are affecterl by differences in elevation and in aspect, should flant them on all the various soils, exposures, and elevations he has available on his estate. But, at the same time, care must, of course, be taken to endeavour to suit, so far as possible, the different species with their natural requirements in regard to soil and situation.

In carrying out this mode of procedure with regard to the cultivation of conifere of comparatively recent introluction into Britain, the trees should partly be plinted in patehes or small yroups, each kind by itself, while part of them should also be planted in admixture with each other. A large portion of them should likewise be plinntecl intermixed with Larch, or, on some particularly exposed localities, with some deep-rooting and hardy species of Pine as nurses.

When these nurses have attained considerable size, and it may be found desirable or necessary to thin them out, this can be done in many experimental sorts of ways. On some portions of the crops the thimning may be severe, in order to permit of the species developing their lranches more rapilly, so as to show more marketly their natural tendency towards ramification. On other parts again, the nurses might only be removed to a more moderate extent, in order to ascertain their essential characteristics in relation to light and shaule. and to prove the effects of al considerable denree of sille-shate and of confinement on their normal development and rate of growth. And, finally, on other portions the nurses might he left somewhit croweler. in order to prove whether the exotics can shoot up so as to form tall and straght boles for timber. All these different clengees of thiming 
might be applied to the various different species, for the lessons they would teach are of great practical importance from a sylvicultural or financial point of view. Of course, in carrying out experiments of this kind, it would not be necessary to plant the whole of an enclosure with the newer conifere in the way proposed, but only portions of it here and there, embracing the different altitudes, soils, and situations.

Among the trees that have been introduced purely for arboricultural purposes at first, the following appear to be worthy of sylvicultural attention throughout those different localities of Britain which seem best to satisfy the normal requirements of the various species as to soil, situation, and general climate :-

Pines. - Black Pines (Pinus Laricio and P. austriact), Red Pine ( $P$. resinosa), the Heavy-wooded or Yellow Pine ( $P$. ponderosa), Bentham's Pine (P. Benthamiana), Miountain Pine (P.monticola).

Spruces.-Sitka or Menzies Spruce (Picea MLenziesii), Oriental Spruce (P. orientalis), Red or Douglas Fir (Pseudotsuga Douglasii).

Silver Firs.-The Mount Enos Fir (Abies cepplalonica), the Noble Fir (A. nobilis), Nordmann's Fir (A. Nordmanniana), and the Spanish Fir (A. Pinsapo).

Cedars.-The Deodar (Cedrus Deodara), the Atlas Cedar (C. atlantica).

Cypresses.-Lawson's Cypress (Chamecyparis Lawsoniana), and the Sitka Cypress (C. nutkatensis).

Arborvitæ.-The Giant Arborvitæ (Thuja gigantea).

These species are well known to be hardy in our climate, and to produce timber of good quality; hence experiments should be made on a large scale in order to prove their sylvicultural capabilities. The Red or Douglas Fir and the Menzies or Sitka Spruce seem, in particular, to offer good promise for the future.

Of late years a great number of different new coniferæ have been introduced into this country, chiefly from the mountainous regions of Asia and America, and especially from the Himalayas, Japan, California, Mexico, and the north-west of North America. Some of these have been proved hardy enough to stand our climate; while others are evidently too tender to bear the winter, even in the most sheltered parts of our open grounds, without a certain amount of protection.

Besides the species of conifers above recommended, there are others which at present may be said to be hardy enough to grow on favourable sites in various parts of the southern portion of the comntry ; but, before any opinion can be expressed as to their ultimate value, it is necessary to test such species still further than has been already done in the southern part of Britain, in order to see how they develop when planted on more elevated situations, and in a colder northern clime.

Such species include the Californian Redroods (ITellingtonia gigantea 


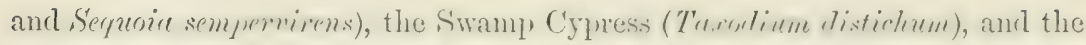
different kinds of Australian Gum-trees (Eucalyptus), which are either not

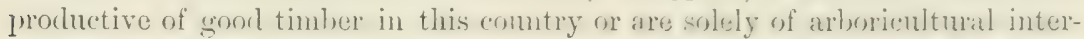
est, and are chiefly confined to the midclle and more genial trarts of trouthern England. 'The climate of S'cotlanul is jerhays far ton severe for theses species, which can probably only attain good development in the milder tracts of Southern England, as in Devonshire. And even there they can hardly be expected to command any sylvicultural attention.

In the meantime, however, it may be stated, in a general way, that there are probably many more kinds among those described in chapter iii., which will be found hardy enough to thrive, and even to become valuable, both as timber and as ornamental trees,--provided always that they be properly dealt with in resard to sril, situation, and mode of culture.

No branch of Arboriculture has received so much attention as, or seems to be more popular than, the cultivation of the newer conifere: and this is probably to be attributed chicfly to their asthetic value as ornamental species of trees. But among them there are, as has been already stated, several species which are likely to become of great sylvicultural value to Great Britain. For profitalle planting in the various soils, altitudes, and different degrees of climate in onr comntry, no species of trees are better adinted than some of those helonging to the great coniferous family. Many of them are thoroughly hardy, produce excellent timber, srow rapidly, and attain large dimensions: and at the same time they are, as a rule, very accommodating with regard to soil and situation, besides being by no means, if properly planted and tended, subject to premature or early decay. Many of them hold out, in fact, such very fair promises to far-seeing landowners, as to entitle them to be recommended to the attention of all landed proprietors who may have convinced themselves that the past steady appreciation in the exchange value of timber is likely to be maintained, and will very probably become greatly enhanced in the future, in consequence of the gradual increase in the civilised world's demands for timber and other forest produce, and of the simultaneous shrinkage in the areas under forest.

Arboriculture in Cities and Large Towns.- It is now a recosnised fact that trees to a certain extent purify the air, and therefore aid in maintaining it in a normal conlition, and in renclering it better fitter for the support of animal health and life at populons centres. This being the case, it is evident that a systematic distribution of trees, in places where large bodies of men are congregated together, must tend very much to promote the health of the community, by absorbing the surplus carbonic acid with which the atmospbere is necessarily surcharged. 
Concerning the Impurities of Town Air the following data were given by Dr G. H. Bailey at the Meeting of the British Association in 1892 (Section B-Chemical Science) :--

"During the past twelve months the Air Analysis Committee of Manchester, in conjunction with the Royal Horticultural Society, had been engaged on the analysis of the air of large towns. A large amount of information having been already collected by previous observers as to the carbonic acid in the air, it was thought desirable to devote more special attention to such impurities as sulphurous acid and organic matter. Furthermore, since the object in view was not merely to collect data, but to lay the foundations of what may be termed chemical meteorology, the atmospheric conditions prevailing at the time of the observation have been noted. From the results of several hundreds of analyses carefully conducted in London, Manchester, and Liverpool, the following conclusions are drawn : 1. That in clear breezy weather the amount of sulphurous acid is less than 1 milligramme per 100 cubic ft. of air. 2. That in anticyclonic periods it rises very considerably, and in times of fog, maxima of 34 and 50 milligrammes have been recorded for the morst districts of Manchester and London respectively. 3. That wherever an open space or a less densely populated area occurs, there is a very marked diminution in the amount of impurities in the air. 4. That an increase in the amount of sulphurous acid is accompanied by at least as large an increase in the amount of organic impurities in the air. 5. That smoke, promoting as it does the formation of fog, and preventing free diffusion into the upper stratum of the air, must be regarded as the principal cause of the impure state of the atmosphere in large towns."

And in Section D (Botany) he also gave the summary of the results of his investigations into The Conditions affecting Plant-Life in a Town Atmosphere :-

"A]though it is well known that plants in towns exist under very unfavourable conditions, there is rery little precise information as to the nature of these conditions. A series of observations extending over more than a year, and carried out by the Town Gardening Committee of the Manchester Field Naturalists, in conjunction with the Royal Horticultural Society, has supplied many important details, a summary of which may thus be given: 1. A comparative measure of the amount of light received each day at stations in different parts of Manchester and district, and in other localities, shows that, whilst the record for the suburbs of a large town falls below that of a country district, there is a still greater falling-off to the extent of 50 per cent, or even more, within the town area. For the same period of the year the measure for bright sunshine is ten to twenty times that for dull weather, and as much as three hundred times that during dense fog. As to the effect of the season, an hour's sunshine at mid-day in June gives five times the record of that for December. Moreorer, comparative measures for sunshine taken simultaneously in Switzerland, Torquay, and the suburbs of Manchester were in the proportion of $20: 11: 3.2$. The amount of sulphurous acid in town air in heavy weather is ten to twenty times that in bright, clear weather, and in fog the proportion is still greater. 3. Freshly fallen rain collected in Manchester showed as much as 70 parts per million of sulphuric acid. Snow is usually more free from sulphuric acid than rain; whilst rime, which has formed on the leaves during frost, is by far the most impure form of moisture which comes in contact with plants, and samples have been collected containing nearly 400 parts per million of sulphuric acid. Estimations have also been made of the amount of organic matter and soot deposited on the leaves of plants, and the nature of the deposit has been examined."

But, besides being directly conducive to health in the way stated, trees are also highly beneficial to life, inasmuch as, when properly distributed and arranged, they secure an amount of ornament, shelter, and shade which must reasonably be supposed to be favourable to 
health in towns and cities, by giving pleasure to the eye, shelter from the cold and cutting winds of winter, and protection from the rays of the hot sun of summer.

In most of the large towns in Britain the inhabitants live in a state which may be said to be in all respects artificial. In their shops they see nothing but the works of their own hands, and when they go out to the crowded streets they see only the dull walls of stone or brick, with but few trees to enliven the monotony of the long lines of houses. It is therefore of very great rsthetic and social importance to place the inhabitants of large towns nore in contact with nature in their everyday life. It is well for them if they can see the foliage of trees as soon as they step out of their workshops, and can hear the rustling of the wind, and the pattering of the rain as it falls on the leaves, while they walk along under their shade and shelter. It may possibly lead their minds to reflect on nature, and on nature's laws; but even if this be not so, the outlay incurred by municipalities for the healthy adormment of towns is money that can hardly be grudged by any right-thinking person.

The making of parks, squares, and gardens in a town or city is no doubt highly commentable, and these form noble features in the architecture of our hives of industry. But it is evident that they only partially supply the necessities of most of our large towns, for the greater part of the inhabitants cannot always be in or near these parks and gardens. Many of the poorer working classes, indeed, have little enjoyment from them at all except at rare times; for as a rule the parks are laid out far from the busiest thoroughfares and the most thickly populated centres, and nearly all of the garlens in squares are private, and are only open to the richer individuals in the neighbourhood, who pay for their maintenance and up-keep. What is very much required is that trees should be planted along the streets of our populous towns, so that all persons, whether rich or poor, old or young, may equally and at all times enjoy their shade and shelter, and may breathe under them the fresh and invigorating air of heaven. They might serve to suggest to the inhabitants something of nature's purity, even in the sullied atmosphere of smoke and dirt, and in the very closest proximity to the haunts of vice.

Trees in Towns. ${ }^{1}$ - As plants give out oxygen and assimilate carbon in deromposing the carbonic acid of the atmosphere muler the action of sunlight, trees must have a certain hygienic as well as an atsthetic effect in large towns whose atmosphere is surcharged with impurities.

It is true that during the hours of darkness an opposite action takes place,

${ }^{1}$ Compare also the section on Poisoning of Street Trees in chapter xii.

VOL. I. 
when oxygen is absorbed from the air; but as, throughout nearly all the annual period when the deciduous trees are in foliage, the hours of light vastly outnumber those of darkness, more especially during June, July, August, and September, when assimilation is most actively proceeded with, the actual effect of trees in crowded towns and cities must be in the direction of purifying the vitiated atmosphere.

All species of trees, however, are not endowed with a like capacity in this respect; nor are they all alike capable of thriving in the impure atmosphere of large populous centres. In comparison with trees having broad, flat leaves, coniferous species bearing needles, - or "spines," as they were formerly called, before the botanist usurped the term for a different and special portion of certain plants, - whether short as in the case of Spruce and other true Firs, or long as in Pines, are much less suited by nature for resisting the choking effect of the soot-laden atmosphere and the chemical action of the sulphurous acid with which the air is tainted.

It not only requires to be taken into account that the leaves of conifers are per se more liable to damage from the poisonous effects of sulphurous acid than those of broad-leaved species like the Oak, Plane, Elm, \&c., but also that the foliage of the former is persistent for several years, varying from three to four years in healthy Scots Pine up to six to nine in healthy Silver Fir, and even more in Iew. And, during the winter months, the foliage of evergreen conifers is exposed to the most suffocating and poisonous fogs, from which deciduous trees escape. Whilst about 4 volumes in 10,000 are the normal amount of carbonic acid in large towns, it sometimes rises to as many as 14 volumes in a London fog. And what is far more important as regards plantlife, along with this abnormal excess of carbonic acid a simultaneous increase also takes place in the percentage of the sulphurous acid evolved in the combustion of coals; for of all the impurities in the air of large cities, by far the 'most injurious to the normal and healthy development of trees is sulphurous acid acting upon the foliage. And owing to the more extensive use of mineral coal with us, the atmosphere of our large towns contains more sulphurous acid than that of Continental cities. When this is washed down into the soil by rainfall, it is rapidly transformed into sulphuric acid, and, coming in contact with various alkalies, soon enters into combinations which make it innocuous to the root-systems of the trees. But the sulphurous acid is absorbed both by the upper and the under surfaces of their foliage (the under surface being the more easily affected owing to the large number of air-holes scattered over it), and is conducted from there to the tissue of the young shoots and twigs. The first action of the acid is to interfere with the normal rate of transpiration of moisture through the foliage, thus disturbing the due balance hetween absorytion through the rootlets, diffusion throughout the stem and branches, and transpiration through the leaves or needles.

The power of doing damage is, however, greatly intensified when rain falls or dew is precipitated on the foliage, as the moisture, by acting on the sulphurous acid, converts it into sulphuric acid $\left(\mathrm{SO}_{2}+\mathrm{H}_{2} \mathrm{O}=\mathrm{H}_{2} \mathrm{SO}_{4}\right)$, which is very markedly injurious in its action. According to Dr Bailey's paper read before the British Association in 1892, freshly fallen rain in Manchester was found to contain as much as 70 parts per million of sulphuric acid, whilst rime formed on the leaves during frost proved by far the most impure form of moisture, 
some samples collected showing nearly 400 harts jer million of smlphuric aciel. He also found that the increase in the amount of sulphurous acid in foggy weather was accompanied by at least as large an increase in the amount of organic impurities in the air, whereby the pores of the leaves were apt to get clogged with soot, drc. Hence, in comparison with deciduous trees, conifers are in great cities exponserl to more serions and much more prolonged deteriorating influences predisposing them to a discased condition; whilst at the same time they are by nature less vigorous in throwing off the effects of impaired vitality, owing to the smaller reserves of starchy and nitrogenous nutrients which they are able to store up as compared with broad-leaved species of trees. It has recently been asserted that the chemical action of the sulphurous and sulphuric acids is of much less real importance than this physical rlowring of the pores in the leaves with fine particles of carbon; and the argument has been adduced that rough-leaved trees like Horse-Chestnut and Elm must he less suitable for towns than smooth-leaved species such as Lime, Ash, Plane, and Poplars, whose foliage gets washed cleaner during rainfall. If it mainly depended on this clogging of the pores with organic matter, however, then conifers would suffer less than other trees, as their needles are smooth and easily cleansed by heavy rain. Against this we have the fact, that conifers do not thrive well in large, densely populated cities. The specific action of the sulphuric acid is to produce a yellowing of the needles near their tips, which gradually turns into a dark brown, and ultimately occasions the premature shedding of the older foliage one, or two, or more years before it otherwise would have become defoliated if the trees were growing in an atmosphere of normal purity. In broad-leaved trees similar effects may be seen in yellow, brown, or red patches on the leaves, and more particularly round the edges, though the specific action of the poison varies according to each kind of tree.

Even should the spring flush of leaves get clogged up in the latter genera, and become defoliated during the second half of summer, the midsummer flush, appearing in the hottest time of the year, when vegetation is most energetic, carries on the work till all the leaves are shed, perhaps somewhat immaturely, in autumn. But in conifers the foliage remains persistent, except on the deciduous Larch; and the late days of autumn, the wintry months, and the bleak days of early spring, are more laden with poison to the foliage than is the case at any time of the year when the broad-leaved deciduous species are decked with green.

Coming to the practical side of the question, experience and actual experiments have shown that, among conifers, the Silver Fir suffers most from atmospheric impurities, then the Spruce, the Scots Pine, and last of all the deciduous Larch; or, in other wordis, the longer persistent and the denser their foliage, the more are they naturally liable to injury, and the less likely are they to thrive, or to maintain themselves in a tolerably healthy condition.

Among broad-leaved species, however, seemg that they thow off their leafy mantle partially in early autumn, and totally long before the windy weather of late autumn has given place to the short wintry days, other factors practically determine their suitability or non-suitability for the adornment of densely populaterl centres like London, Biminghan, or Manchester. The two factors which are of greatest importance are unlouldedly the susceptilility of the leaves of each individual species, and the inherent reproductive and 
recuperative power possessed by it; for those kinds of trees will be most likely to maintain a successful struggle against predisposition to disease which are endowed with a strong recuperative power combined with a small degree of sensitiveness in the foliage. Whilst it is impossible to make any hard-and-fast classification of trees as regards their suitability or non-suitability for cultivation in towns, it may at least be stated that Beech suffers most from gaseous atmospheric impurities, and Oak and Oriental Plane least; between these extremes, Birch, Lime, Alder, Ash, Maple, Sycamore, Aspen, Poplar, HorseChestnut, and Elm occupy intermediate positions, to which may also be added the Acacia or Locust-tree of North America (Robinia) and the Tree of the Gods (Ailanthus) among exotics of comparatively recent introduction into Britain. Of these, only the Plane, Maple, Sycamore, Lime, Horse-Chestnut, and Elm are really suitable as boulevard trees; whilst all the others find their proper places in gardens, open spaces, and parks, rather than in formal rows along streets or in the formation of avenues lining embankments and the adormment of broad thoroughfares.

So far as actual hardiness against the injurious effects of atmospheric impurities is alone concerned, no trees are capable of resisting their effects more strenuously than our own Oak and the Eastern Plane; and, other things being equal, these would appear to deserve special attention when planting operations are carried out in towns or in their immediate vicinity. But, as the Oak is comparatively slow in growth, this will of course, to a very great extent, militate against its use on any large scale when speedy results are desired.

Other asthetic considerations beyond the healthiness of the trees themselves also, however, play an important part as regards the adornment of streets by the planting out of trees; and in many cases there are what one might almost call national differences of taste exhibited in the matter.

Throughout the whole of central Europe-in France, central and southern Germany, westem Austria, and northern Italy - the Horse-Chestnut and its prettier half-sisters, the red and the yellow-flowering Pavia, are, along with the Oriental Plane, undoubtedly the trees in general demand by municipal authorities for the adornment of towns. And this, too, despite the fact that in very dry seasons like 1892 on the Continent, and 1893 in central and southern England, the Horse-Chestnut sheds its leaves long before they can be nipped by early frosts in autumn. Last year, after the exceptionally hot weather in July and in the early part of August, nearly all the Horse-Chestnuts in the well-laid-out vicinity of the railway station at Salzburg were almost completely defoliated by the middle of August, in consequence of the effects of the excessive drought. But this early defoliation does not necessarily, as some recent writers in contemporary papers seem to suppose, indicate any diseased condition of the trees. Nor is there any reason to deduce from such premature shedding of the leaves that the wealth of foliage or of flowers in the following spring will be provided by nature with a more sparing and a less generous hand than has been wont to be the case.

In the larger cities of northern Europe, again, Lime, Elm, Maple, Sycamore, and Plane appear to be the most frequent trees, although Horse-Chestnut is still favoured on account of the undeniable beauty of its flowers and foliage in the early spring-time. In Rotterdam, for example, a town that is largely planted up, most of the trees in the streets are Elms of the small-leaved species; 
whilst Sycamore and Horse-Chestnut, the trees next in favour, form but a comparatively small number of the large total. And there can be no doubt that, taken all in all, Elm is certainly one of the species best adapted, along with P'ane, Horse-Chestnut, Maple, and sycamore, for the beantification of populous centres. Where spring beauty is particularly desired, as in Paris, with its gay season at Easter, the Horse-Chestunt will most likely find greatest favour; and where more weight is laid on securing pleasant autumn tints in the foliage, the Maples will deserve special attention. Thut, for the purposes of general adornment throughout all the leafy season from April till October, Plane and Elm will certainly hold their own against all other rivals.

The plan, so conspicuous in Paris, of having large open gratings-larger than those on the Thames Embankment in London- $6 \mathrm{ft}$. in cliameter, and capable of being lifted easily from time to time, is one that should be arlonted everywhere. Even though it may not be necessary for the purpose of providing adequate supplies of soil-moisture, yet it tends to aerate the soil, and to quicken that circulation of oxygen which is undoubtedly an essential to healthy growth. This benefit would, of course, be enhanced if the gratings were to be opened periodically, and the surface-soil loosened by means of a pick.

At no time has Arboriculture received more attention in Britain than is being given to it now. And more particularly may this be said of London, where a special branch of the County Council has taken this department under its protecting wing. But the numerous very contradictory short letters that have recently appeared in several of the leading daily newsiapers with regard to "London Trees" distinctly show how indefinite and unsatisfactory is the knowledge which seems to exist, or to have been collected, on the subject up to date (September and October 1893).

Considering the importance of the matter from the resthetic rather than the less unequivocal hygienic point of view, it might be well if official steps were taken towards gaining sound scientific assistance in the matter of making and recording observations as to the manner in which the various kinds of trees thrive in the largest cities of England. Mfuch valuable experience might thus be gained at a very nominal cost; and mistakes in planting might be prevented which may otherwise ultimately canse considerable disalpointment, and may entail a loss of time, and of money, that might easily be aroided.;

Trees in Towns. - This is a subject whose importance is almost daily becoming more and more recomised in this country. But, up to the present time, it is one which has been very much neglected in the development of our towns and cities. For example, that such a city as London, ${ }^{1}$ in particular, where nearly five millions of people are congregated together in densely proked masses, shumli still be without trees along all of its streets that are broad enough to admit of planting, must be humiliating to erey susilue Englishman in the present age of enlightenment, when he considers how sanitary measures of every other inaginalle description are leing discussed

1 On this point see an article entitled "A Model City, or Reformed London," in the Now Review for August 1891. 
from north to south. This is the more surprising when we compare with the dark, dirty, and naked-looking streets of our own populous centres, some of the cities on the continent of Europe and in America, which have well-arranged streets and promenades flanked by avenues of beatififul trees.

There are few cities in which Arboriculture might so fitly be carried out largely as in the broad and stately streets of Edinburgh - that city which may wrell be considered the seat of greatest activity with regard to all that appertains to the Forestry movement in Britain. Owing to the cold, grey, dull, and rather monotonous colour of the stones with which the long rows of streets in "mine own romantic town" are built, there are few cities that would gain so much by arboricultural adornment, wherever the lines of houses do not already face gardens.

Paris was, at the commencement of the Second Empire in 1852, a very close and dirty city; and now, within a very few years, it has been converted into one of a pleasant and comparatively healthy character. This change has been brought about partly by the formation of the "Great Boulevards " running from central points in all directions through the city. These boulevards are wide, open streets, bordered with fine trees, and flanked by broad and well-made footpaths. They extend to a great length in one direction through the metropolis, while others are made running round the city, so as to form in their entirety a kind of open network. They are generally about $100 \mathrm{ft}$. wide from house to house, though occasionally they are about $140 \mathrm{ft}$. in width, and even more in the case of some of the outer boulevards. The side footpaths of the more frequented thoroughfares are generally upwards of $20 \mathrm{ft}$. wide.

The trees, when first planted out along the streets of Paris, are nearly all young, and have previously been pruned and trained so as to form a clean-stemmed plant with a straight leader; and when first brought into the position they are to occupy in the streets, they are protected by a cast-iron or wood-work basket or tree-guard. They require to be supported with stakes when young, and these supports are kept in good order till the trees are strong enough to do without them. In order to ensure the earth about the roots of the trees being kept in a permeable and porous state in the more frequented parts of the city, each tree is provided with a cast-iron grating, about 6 feet wide. The trees are planted at a distance of about $18 \mathrm{ft}$. apart in the lines, and from 3 to $4 \mathrm{ft}$. from the edge of the pathway. This close planting is in order to provide immediate effect. In preparing the ground for the planting of the trees, a pit or hole of about $6 \mathrm{ft}$. in width, and from 4 to $5 \mathrm{ft}$. deep, is dug for each tree; and beture inserting it into the pit, drain-pipes, made with lapped 
joints so as to prevent the roots from entering them, are laid along the sides of the trench. The saplings are then planted, each being a stout transplant with perfect roots, and in all respects a healthy, well-developed, young tree. If the weather be dry at the time of planting, the trees are copionsly supplied with water. The species of trees that have been most generally planted out in Paris are the Oriental Plane, Horse-Chestnut, Elm, Sycamore, and Maple.

In Paris, nurseries are entirely devoted to the rearing of trees for planting on the boulevards, and in the public squares and gardens. There is one at Petit Bry, near Nugent-sur-Marne, which covers about 45 acres of ground. As in this locality the ground is apt to be at times flooded by the river Marne, and as the young plants are therefore exposed to danger from inumdations, ridges of earth are formed about $6 \mathrm{ft}$. in width, and on the top of these the plants intended for the avenues in the city are inserted in lines, at about $3 \mathrm{ft}$. apart. This necessary precaution of raising the plants above the common level of the ground, so as to be out of the reach of the river-water, has an additional advantage; for the saplings, being planted in the loose earth of the ridge, are placed above the general level of the ground, and are consequently much easier removed for transplanting, besides having a better supply of filorous roots thau they could have if otherwise dealt with on ordinary nursery-beds.

When the young trees are sent out of the nursery for planting along the boulevards in Paris, they are well-trained, straight-stemmed plants of a nearly uniform height. They must have a clean stem of about $10 \mathrm{ft}$. in height, with a thickness of about $3 \mathrm{in}$. in diameter, and must possess a good, well-balanced crown.

The Americans, as well as the French, are alive to the advantages of having trees planted along the silles of the streets in their towns and cities. Throughout America this lnanch of tree-culture is very carefully attended to, so that most of the large towns in Americasuch as New York and I'hiladelphia in the Lnited states, and Montreal and Toronto in Canada-have a clean, cool, cheerful, and airy aspect. In all these towns very fine specimens of most of the deciduous kinds of trees indigenous to America are to be found growing along the sides of the principal streets, and forming beantiful avenues of verdant growth. Their crowns spreat from the exlges of the causeway so closely up to the house-windows on each side, that persons occupying the second and third stories could put out their hands from their windows and gather the leaves and flowers. In the summer season, when the sun pours down its intensely hot rays upon these towns, the shade of the trees planted along the sides of the streets is most agreealile and refreshing: the leaty croms of foliage catuse a cool and invigorating draught of air to circulate 
along the streets, for which the passer-by cannot be too grateful. Such well-planted towns offer a marked contrast to our British cities, where seldom anything but the lamp-posts stand out to break the monotony of the streets, and where every one is exposed to the full glare of the sunshine and the scorching heat of the sun in summer. The species of trees planted along the streets in the American towns are all deciduous, such as Plane-tree, Elm, Chestnut, Hickory, Poplar, Maple, Butternut, False Acacia, and others; and they are all planted in a tasteful manner, so as to produce as much variety in the foliage as possible. Nothing can be more beautiful and agreeable than the foliage of these trees both in summer and autumn. It gives an effect to the streets quite enchanting to the visitor from this country, as it forms such a pleasant contrast to the monotonous state of things which he is accustomed to see in most of the larger towns throughout Britain.

In the American towns the trees are planted in holes, which are prepared for their reception in the same way as has been described with regard to the planting of street-trees in Paris; but the distances are usually from 25 to $30 \mathrm{ft}$. apart in the lines, and in most cases from 12 to $15 \mathrm{ft}$. from the houses on each side. The young trees are generally protected for a time by a guard or gabion of strong wood-work. The trees grow up very rapidly; for in a very few years they become so large and thick in the crown, that liberal pruning has to be applied on all sides in order to keep them within bounds, and to prevent them shutting out the light from the windows of the houses and interfering with the traffic of the streets. In all the large towns, therefore, a staff of men, called "Town-foresters," is maintained for the purpose of attending to the trees.

But, like all other workmen, these "Town-foresters" require skilled supervision. This is amply proved by the following extract from $\mathrm{Mr}$ C. V. Riley's Report to the Government concerning the Shade-T'rees and their Insect Defoliators in the city of Washington (Bulletin No. 10 of 1888, U.S.A. Department of Agriculture):-

"Before closing this article it may be well to call attention to another danger from which our shade-trees are threatened in the future. We refer to the reckless and almost cruel pruning which has in the past been indulged in, and which, if we are rightly informed by Mr. Saunders, the Park Commission find it very difficult to prevent. No one looking to the future of our shade-trees can have witnessed without indignation the gangs of careless men who periodically go through our streets cutting, hacking, and lopping indiscriminately and without intelligence the limbs of the trees, until they have become on many of the older streets deformed and unsightly objects. The result of senseless pruning is easily seen on some of these older streets as compared with the trees in our parks which have been more often left alone and more intelligently pruned. Street shadetrees should be pruned from below, and not lopped off from the top, so that in the future there will result a tall straight trunk, not intercepting the view of the buildings from the street, and yet furnishing the desired sharle and beauty." 
In the neighbourhood of all the principal American towns there are extensive nurseries, in which young trees are reared solely for the purpose of planting out along the streets. In these nurseries the trees are carefully trained to the necessary height and strength hefore they are removed. Transplantation generally takes place when they are from 12 to $15 \mathrm{ft}$. high, and have a stem of from 3 to $4 \mathrm{in}$. diameter at $4 \mathrm{ft}$. from the ground.

These statements concerning the manner in which the French and the Americans cultivate trees in their towns and cities, with a view to ornament, shelter, and shade, should perhaps be suficient to convince us that we are very far behind our neighlowurs in this lranch of Arboriculture, however tastefully laid out the parks and gardens in the vicinity of many of our towns may be. These latter merely form a part of what is requisite. The great mass of the people can only take advantage of them on Sundays or on holidays; but they hardly suffice to promote to the fullest possible extent the health, morals, and happiness of the working classes in their everyday life.

Planting in Order to Hide Objectionable Objects.-In order to secure a rapid growth of trees on any particular part, for the purpose of screening some object which it is wished to keep out of view, the first point to attend to is the trenching and manuring of the land to be planted, if the soil be not already of a deep, light, and fertile character. When this point has been secured, the next thing is to use such plants as are known to develop rapidly under ordinary circumstances. Sprecies of trees, for example, like I)ouglas Fir, Lofty Spruce, the Plane, Sycamore or Scottish Ilane, the Tree of the Gods (Ailanthus glandulosu), Chestnut, Lawson's Cypress, the Lofty l'ine, the Black P'ines, the Californian Mammoth Tree (Wellingtoniu giganten), the False Acacia (Robinia I'scudacaciu), the White Willow, the White Poplar, and the Big Cottonwood or Carolina Ioplar (I. menilifere Ait.), all offer special advantages under different circumstances.

Although these trees are all of rapid growth under ordinarily favourable circumstances as to soil and situation, still it must be recollected that, if planted on unfavourable soil, or in an exposed situation, they camnot possibly develop nearly so rapidly as under less adverse circumstances. For example, the Poplars named, when planted on the deep alluvial soil of a sheltered valley, will make annual growths of from $3 \frac{1}{2}$ to $4 \frac{1}{2} \mathrm{ft}$.: but, when they are planted on a light gravelly soil having an exposed situation, they will probably not make shoots of over $2 \mathrm{ft}$. annually. And the same thing holds good with respect to all the other kinds named. In order to secure the rapid growth of any of the particular species named, it must be plinted not only in a fertile soil, which will easily be alile to supply all its natural requirements as to fool-supplies for constructive pur- 
poses and water for transpiration, but also in a situation suitable for its normal and healthy development.

On a good, deep, dry soil, and in a situation not exposed, the Douglas Fir (Pseudotsuga Douglasii), the Remarkable Pine (Pinus insignis), and the Mammoth Tree (Wellingtonia gigantea) will make annual growths of $30 \mathrm{in}$; ; while on shallow soils, or with an exposed aspect, they will not make leading-shoots exceeding 12 in. during the course of a season. The Sycamore or Scots Plane, the Tree of the Gods (-tilunthus glamtulosr), the Sweet-C'hestnut, the P'lane-tree, and the False Acacia (Rotinie I'stucterencie) will, on good strong loams and in sheltered situations, often make shoots of from 3 to $4 \mathrm{ft}$. and upwards in one year; but on soils and situations of an opposite description they make very slight growth indeed-even much less than the Scots Pine would do under the same circumstances. Unless, therefore, the trees be in all respects suited to the soil and situation, rapidity of growth cannot be expected. The species named are all fairly well adapted for growing rapidly on most soils of average quality and on situations that are not too much exposed; and, of course, their natural rapidity of development is much encouraged in the first stages of growth when the land has been manured, trenched, and well prepared for their reception. It is not to be deduced from this that the application of manure to trees is in general advisable. On the contrary, where the object is to raise a healthy permanent crop of trees for timber-production, manuring is prejudicial to their normal development and to their natural vigour. It can only be recommended, in the case under consideration, in order to secure the desired end in the shortest possible space of time, and for the express purpose of screening a disagreeable object from view as quickly as practicable.

Where it is desirable to raise trees in the least possible space of time on a high and exposed part, with the view of hiding some disagreeable object, it will often be advisable to use the common and other hardy Pines; and they had best be planted very thickly, so as to stimulate them and to ensure their drawing each other up quickly. If manure be put to the land, it will, of course, encourage a more rapid growth and development of the young plants.

In general, nurseries should be formed on good land that is not of too rich and fertile a description. If the soil be plainly somewhat below the average in quality, the transplants do not attain their full, normal vigour; but if, on the other hand, the soil be so rich as to yield food-supplies to the rootlets much in excess of the physiological requirements of the individual species of plant, then the transplants soon become predisposed to disease, and are also apt to wilt or droop when finally planted out on soil which cannot yield to them the same ample food-supplies that they have been accustomed to in the nursery. 
Where manuring seems called for, either on the musery-lueds or in the pits into which the transplants are finally put, it should be given in the shape of compost-earth, leaf-mould, or wood-ashes, and not in the form of rich stable or stall manure.

Arboriculture in Residential Parks. - Every arboriculturist who aims at anything like taking a high standing in landscapegardening should be able to produce plans for, and to carry out, ornamental planting on the parks forming the resiciential portions of estates. And knowledge of the same sort does not come amiss to the practical forester, for it does not interfere in any way with the good management of the sylvicultural crops throughout the woollands on the property. Unless endowed with true natural taste, however, there are few foresters who can undertake and execute this branch of Arboriculture. It involves the arrangement of trees from a pictorial point of view, and as forming concrete parts of the general natural scenery of a neighbourhood, viewed in connection with hills, ravines, plains, undulations, \&c., on the one hand, and with whatever natural woods, lakes, or streams on the other as may be comprised within the landscape.

Before any forester can, with any chance of his doing credit to himself, or of giving his employer satisfaction, undertake ornanental planting in a park surrounding the mansion of any proprietor, he must have studied the subject of trees with special reference to the form and magnitude that each kind of tree is likely to take on the given soil and situation upon which he is to operate; he must know the outline that each species will naturally assume when observed against the backiground, whether this may consist of other trees or happens to be a grass-covered slope or any open expanse of the sliy; he vaust know how to make the prevailing colour of the bark and of the leares of each kind harmonise; he must study the effects obtainable by grouping each lind separately, and by intermixing them, hoth on low lands and on hillsides or hill-tops ; and he must forecast the combination of all these points before he can plan out what will probably form a pleasing whole picture ont of the matural features of the tield, together with the trees as arranged and planted on it. For the information of foresters who may not have deroted much attention to this branch of arboricultural study, it may be useful to devote a few paragraphs to the enmeration of the principal points to be kept in view in landscape-gardening or the laying ont of plantations in parks surrounding the seats of landed proprietors; and afterwards some practical directions will be given as to the hest monle of raising trees for planting out in parks, so as to produce an appreciable effect within as short a time as is consistent with the successful attainment of the object in view. 
The first point to be taken into consideration is the situation of the mansion-house. This should, of course, be a considerable way back from a public road, and, if possible, equally as far from a town or village. The house should be situated on a gentle slope, facing the south, with rising ground behind, on which to form a background of woods. The park should extend from the house southwards, eastwards, and westwards, and should consist of a field of not less than 150 acres, bounded by roads, or by the farm-fields of the estate. It should not have a formal outline, such as a square or a circle, but should be irregular and natural-looking in this respect; and, if possible, it should be of much greater length than breadth, so as to give from the windows of the house the command of an extensive view southwards towards the front. As to its surface, the park should, where practicable, be of a varied and somewhat undulating character; for a dead-level and flat surface always produces a dull and monotonous effect. The boundaries should, as it were, run into the country beyond, without showing any distinctly defined terminations; and where there is a running stream, or a natural lake, it should be utilised as a very distinctive pictorial feature.

The rising ground behind the site on which the house is now sulposed to tre built should be planted with trees of linds to suit the soil and the particular part of the country. A considerable portion of them should be coniferous species, as their dark canopy forms a better luackground for a mansion than the lighter green of the foliage of the broad-leaved trees. This is a point not generally attended to : hence the outlines of a mansion-house are often so much blended with the colour of the trees behind it as not to be distinctly recognisable until it is seen near at hand; whereas, when the background is, in great part, made up by trees of a dark-green colour, the outlines of the luilding are brought prominently out, and therefore the house is seen to much greater advantage from a distance. The plantations to the north, on the rising ground behind the house, should be made to extend so far back as to secure the appearance of a continuous wooded district in that direction, when seen either from the park in front, or from the roads in the country beyond it to the south. This gives an extensive aspect to the domain, and withal adds to its appearance a degree of comfort and security which it could not otherwise present. The plantations on the north side, or at the back of the house, should be laid off so as to extend beyond the eastern and western sides of it, flanking the house on these sides, and coming down from the higher ground with a bold sweep on each side. It will thus afford shelter to the mansion from three points, north, east, and west; whilst it will still leave the view open from the house to 
all points from the east on the one hand, over all the south, and round to the west, on the other side.

All along the boundary of the park, plantations should be laid off in such a way as to exclude any objects which it may be considered desirable to hide from the view of the house and park, and to bring more prominently into notice any features that it may be considered desirable to have always under the eye of the proprietor. In laying off these plantations along the boundary of the park, they should be made to approach it with bold curves at well-chosen pwints, and according to the natural undulations and other peculiarities of the district; but, at the same time, particular care should be taken to make corresponding sinuosities, and to form glades or vistas here and there, showing the better features of the country beyond. Tothing like a continuous belt of woodland should be formed on the boundary, but merely well-defined plantations: the position of these can only be determined by a careful and tasteful consideration of the field, and of the different objects surrounding it or forming any connection with it.

The park itself should be broken up by groups of trees of different kinds, in various proportions of intermixture, and by small patches or individual specimens of rare species. All of these details should be arranged as the circumstances of each case may require, in order to bring out a perfect and natural picture of the whole scene in all the diversity of its bearings, and in all its comnections, both with respect to its own particular features and to the framework of more or less distant landscape surrounding it. In the immediate neighbourhood of the house the field should be left fairly open, so as to form an irregular lawn, with only a few of the very best specimens of trees on it, and such as may be considered in all respects ornamental, or at least likely in time to become so; and gradually, at greater distances from the house, the park should be dotted with groups of trees, and with single specimens, the groupings and massings being male more extensive as the distance from the louse becomes greater. But in no case should the massings and groupings be made so large, or be allowed to come so close together, as to show any continuity like the close canopy of a wood; on the contrary, the whole should form such an agreenble harmonising of trees, field, water, and other objects in the neighbourhood, as may give pleasure to the eye, without offering any crutity that can oflent, either with reference to the blending of the colours or the arrangement of the objects. Any sheet of water, or any running stream that may be embraced within the landscape, should not he shown ats of one piece from any part of the park, but should be, as it were, broken up into several portions, by planting trees and bushes at ablvantageous points along its edges, so as to cause the one liklie or stream to repre- 
sent several: hence it may thus be made to produce the appearance of a greater extent of water than really exists.

The whole field beyond the lawn should, when finished, represent natural forest scenery, with open glades occasionally bringing into view the listant prospect of any picturesque olject in the surromnding country, and with thickets to hide objects of an opposite character. In striving after such results, every advantage should be taken of the natural inequalities of the land, so as to cause the whole to have the appearance of merely representing natural scenery.

The principal approach to the residence should enter the park at a point of its boundary where there are some old and picturesque trees, and where an open glade has been left for a distant view of the country beyond. Here it should enter and be continued through the field by one regular bold sweep for a considerable distance, carrying: it along so as to obtain the most commanding views of the park itself, and of the scenery beyond it, and, if possible, so as to keep the mansion-house out of view for the first half of its length. This object being attained, the road should next be led in such a way as to give the best possible view of the water, whether this be in the form of a stream or a lake, and of its wooded surroundings; afterwards it should by a contrary bend be first carried gracefully towards one of the ends of the mansion, where a glimpse of the flower-garden may be had in passing, and thence round to the main entrance, from which point the park should be seen as a whole. Of course, the principal approach should be introduced into the park at a point near the railway station of the district; while such other paths may be made to different points from the back parts of the mansion as may suit the objects in view, whether these be for the convenience of the kitchen, the garden, the stables, or merely for getting at the country lying to the north of the house.

The kinds of trees should consist of all that may be considered suitable for the climate and the soil of the district; but, if the locality be in a favourable part of the country, the greater portion should consist of Oak, Sycamore, Elm, a few Spanish Chestnuts and HorseChestnuts, with Maple, Linden, and Beech. A suitable proportion of Larch and of other coniferous species should of course be introduced in properly chosen parts, so as to produce a variety of effect in contrast with the other kinds. But, besides these commoner kinds of trees, there are also many other species which deserve to be introduced, and sometimes to a considerable extent, such as the Red or I) nulas Fir, the I eorlar or Indian Cedar, Swann, Cypress, and various hardy kinds of Silver Fir, Redwood (Sequoia), Pine, Arborvitæ, Cypress, \&c., many of which are well calculated to produce useful timber as well as ornamental effect. 
It may not be out of place here to give a few practical directions as to the best mode of raising trees for plinting ont in parks, so as to produce an appreciable effect within the shortest possible time.

When it is arranged to builel a mansion on a certain site, the park in connection therewith should be laid off, and its surmmoling plantations mare without delay, in order that they may have attained fair growth by the time the house is crmpleted. These surromding plantations may properly be planterl with young trees in the usual way of forming other plantations on the estate: lut, in clothing the park itself with its group of foliage and its single trees, the plants for these should be reared in a nursery formed temporarily for the purpose in a corner of the park, and should be planted ont only after they have attained such a size as may enable them to produce inmediate effect.

The site for this temporary nursery should be chosen in rather a sheltered part of the field, where the land is of a fresh, porous, loamy character. The extent required will of course depend upon the number of trees that may be necessary to adorn the field; and this again will depend on the extent of lind comprised within it. The forester, having ascertained the number of trees recquired for the arboricultural ornamentation of the park, with all its groupings, de., must next calculate how many of them can be raised on an acre of nursery-ground when planted in lines at $t \mathrm{ft}$. apart and $6 \mathrm{ft}$. between the lines. At these listances between the young transplants he will be able to raise, in round numbers, about 1800 plants on the acre: hence he will at once know how much land to enclose for the nursery; in order to rear the full number of plants required.

When once a sufficient extent of ground has been enclosed as a temporary nursery for the cultivation of the roung trees, the forester must next lay the whole off in the form of nursery-beds $4 \mathrm{ft}$. broad, and having an alley or path $2+$ in. in brealth between each two of these, thus making the beds $6 \mathrm{ft}$. broal from centre to centre. Haring done this, he should take a full spit and shovel of earth out of each alley, and throw it on its corresponding bed, thus deepening all the alleys to about $9 \mathrm{in}$. and raising the beds correspondingly. On this soil now laid on the beds, well-rotted manure (good leaf-monld or woodashes for preference) should be laid to the depth of about 2 in., which should be slightly dug in immetiately afterwards. This will complete the preparation of the beds for the reception of the young trees to be planted on them.

The young saplings or transplants should now be selected from a public nursery, care heing taken to have all the deciduons sprecies selected of about 4 to $5 \mathrm{ft}$. in height, and all the evergreens or con- 
iferous kinds of from 1 to $2 \mathrm{ft}$. high, according to the nature of their respective root-systems. In choosing plants for the purposes of landscape-gardening, none should be taken except those of the most healthy, well-rooted, well-branched, and clean-stemmed characters; for if these points be not attended to at the very outset, there will be difficulty experienced in afterwards training the plants to become really good and well-developed young trees for the purpose. When once the selection of all the different plants required has been made, they should be carefully brought to the nursery, with the motherearth well protected around the roots, and sheughed or temporarily bedded there, preparatory to their being planted out in the lines on the beds.

In planting the young saplings in the beds, the roots of each individual plant should be placed on the surface of the manured ground, and the plant held in an upright position till enough of the earth around it is put about its roots to support it for a time, but no more. This should be done to each plant, care being taken to put only one row along the middle of each bed, to keep the plants $4 \mathrm{ft}$. apart from each other in the line, and to arrange each kind on the same bed or beds continuously till it is all planted. Simultaneously with the operation of setting the plants in their places along the beds, as above described, other men follow taking more earth out of the alleys, and laying it on the adjoining beds, so as to ensure that the roots of the trees now standing on them may be properly covered with and planted in it. As the earth is thus taken out of the alleys, it should be carefully broken and levelled about the roots of the young trees, so as to ensure their being planted at a proper depth, and in a satisfactory manner in all respects. Whilst the work of removing the earth from the alleys and adding it to the beds goes on, attention should be paid to giving the sides of the latter such uniform slope as the nature of the soil may require, in order to prevent the earth falling down into the bottoms of the alleys again after the work is finished.

The alleys will now act as drains to the beds. But, as water might lodge in them after rains, provision should be made to olsiate this by cutting an open ditch along one of the ends of the beds, into which all the alleys should run; and this should be carried out away from the nursery, so as to enable it to empty the water collecting in it into some other ditch or conduit.

When once the young trees have been planted in the way described, they should be carefully attended to and kept clear of weeds at all times by the frequent use of the hoe in summer. And, in order to promote their growth as much as possible, they should have a slight manuring of old and well-rotted, but not rich, manure, 
or of well-decayed vergetable mould, or woorl-ashes, or charred turf, every autumn or spring, which should be dug into the earth very shallowly, in order not to disturb the young roots of the plants. Pesirles this, they should he earefully temiled with respect to the shortening of any branches that seem to grow unduly strong, amr to the maintenance of only one top-shoot or leader on each plant, in order to check any premature tendency to forked growth.

If the trees are dealt with in this way, they will grow up rapidly, and will very soon attain a height of stem and a breadth of crown which will warrant their being planted out so as to produce an immediate effect. The object of schooling them in this way is to gain a few years in growth, as compared with the-time they would require to attain the same height if they were planted out in the field at once in the places they are intended to occupy. By means of the above procedure, the trees will be about $12 \mathrm{ft}$. high in half the time they would have taken to attain this height had they been placed out in the open immediately, in place of being schooled.

Great advantages are gained by planting the young trees on ridges in the nursery, instead of on level ground in the usual way. In the beds, the roots of the plants are all kept within the lorearth of about $3 \mathrm{ft}$, and are therefore not allowed to spreaci out so far that they camnot afterwards be lifted for safe transplanting, as is the case with plants inserted in the surface in the usual way; hence, by this mode of culture, security is given that all the roots of every plant may be carried with them when they come to be removed, as this is of great importance for perfect success in transplanting large plants. And in addition, from the roots of the plants being confined within a griven breadth, they rise more to the surface than is the case with the roots of plants placed in the ground in the usual way. In consequence they get all the advantages of food, air, and sun in a greater degree; and this results in a much more rapid growth. And when the time for transplanting arrives, the plants are in all respects fully and perfectly prepared for the operation being successfully performed; for, whatever method be adopted, the plants can be remored with perfect balls of earth around the roots, by simply placing the transplanting machine at the end of one line of plants and raising up or slackening the roots of each individual plant from the sides of the bed, when the whole mass in connection with the root-system can lie removed entire without any excavating whatever, and can be conveyed to and placed in the pit previously prepared for it. Plants treated in this way have the very best chance of establishing themselves soon and of developing well; hence this mole of culture can be recommented for all the purposes for which plints of laree size are wanted, even for hedgerow trees. 
In transplanting young trees of this description into their permanent sites, the first point to be attended to is to make sure that the field is in all respects of a merely fresh character of soil ; for if it be not so, disappointment may be the result. Of course, if the land be not naturally dry, it should be made so by means of a system of thorough drainage previous to the planting being undertaken on it. When once the soil has been freed from any injurious superfluity of moisture, the holes for the trees should be made about $4 \mathrm{in}$. deeper than the thickness of the balls of earth containing the roots, and about $2 \mathrm{ft}$. wider in diameter, in order to admit of a sufficient quantity of prepared earth being put into each, so as to assist the roots in establishing themselves quickly. As each hole is made for a tree, about three wheelbarrow-loads of previously prepared compost-earth, or of good, light, turf loam, containing about a quarter of its bulk of well-rotterl vegetable mould, or of common manure or wood-ashes. of the same character, should be laid down on the outside of it, keeping this clear of the soil that is taken out. The hole for a tree being made ready for it in this way, a quantity of the prepared earth should next be thrown into the bottom, say to the depth of $3 \mathrm{in}$. all over; and on this the ball of earth containing the roots of the tree should be placed, care being taken to see that it is inserted neither too deep nor too high, but with its former top-level, that at the bottom of the stem, about 2 in. under the surface of the land around. When these points have been attended to, and the tree has been set in a true upright position, what remains of the prepared earth should now be put carefully all round the ball. It should be put under the ball where any hollowness appears, and should be made to cover it in such a way that every part of it and of its roots may have a covering of 3 in. of the fine earth; and when this has been done, the hole may be filled with the soil previously taken out of it, care being taken to break it finely, and to apply it regularly as it is put in, in order not to displace any of the finer earth now lying on the ball.

As each tree is planted it should have a copious watering about its roots, so as to settle the earth around them; but no tramping down of the earth should take place till two or three days after planting, when the soil can be made firm and level in the usual way, and when supports may be put to such of the young trees as appear to require them.

Physiological Effects of Transplanting.-For miny years past, the transplanting of large trees from the forest, or from temporary nurseries, to the park has been practised with more or less success, with the view of producing an immediate effect where trees were wanting upon the home grounds of proprietors. Some disturbance must then of course take place, owing to the interference with the 
normal processes of inbibition, transpiration, and assimilation; but this raries in proportion as the oneration of renoving the trees has been done in the manner least tending to disturb the regularity and extent of the vegetative processes.

It appears very evident that any tree, however large it may be, if only in a healthy and growing state, may, under certain circunstances, be as safely removed from one position to another as the nerest sapling from the nursery-bed. If, in everyday practice, the cortainty of a small Oak-tree growing, when it has been renoved from the nurseryrow and planted out in the open forest, nary he calculater on, then it does not seem unreasonable to expect that a large Oak-tree may continue to thrive well, when merely transplanted from one part of a landed property to another,- - provided always, of course, that the operation, in the case of the large tree, be performed with such an amount of care and skill as is necessary to preserve all its functional organs, and to maintain vital processes, in healthy action.

It is true that many persons entertain opinions differing from those above expressed, relative to the transplanting of large trees; and those who difler therefrom as to the propriety and practicability of safely transplanting large forest-trees, say that the constitution of a young tree is more vigorous, or is not so easily injured, as that of a large one, and consequently that it is not so easily affected by sudden change or removal. This is no doubt true; but if, in the removal of a large tree, the operation can be as proportionately and adequately adjusted to the natural wants and requirements of the larger plant as to those of the smaller one, is it not probable that, according to the ordinary laws of nature regulating all plant-life, the linger tree will continue in health as well as the smaller? It therefore seems hardly open to doubt that with regard to the transplanting of all trees, whether young or old, large or small, all that is required in the operator is, to adjust the operation to the naturul. rants and requirements of the plant, when the success will be as complete in any one case as in another.

The above seems one of the principles of the late author: the editor, therefore, does not feel justified in altering it, althongh it is at variance with his own practical experience. The natural wants and requivements of trees beyond a certain age are to remain where they are, and with the least possible disturbance of the root-system. Any disturbance therewith is really a direct interference with the normal procesists of the withlrawal of fool-supplies from the soil, and with the transpiratory, assimilative, and construetive processes within the plant. In order to re-establish itself in its new home, the tree has to utilise its reserve supplies of starch aml dextrine; and these camnot be so easily replaced in older trees as in younger plants in more vigorous growth and in greater activity of development. Exactly as in the case of human beings, the power of accommodating themselves to different circumstances 
with regard to food-supplies and to environment is weaker in old trees than in vigorous young saplings and poles.

Those who maintain that success in the transplanting of large trees camnot be olntained in anything like equal proportion as in the case of young ones, point to the many failures that have undoubtedly taken place in this branch of Arboriculture on very many landed properties in Britain; and they also say, at the same time, that a creat deal of money has been uselessly expended upou that operation by propuietors, who have reaped nothing but disappointment as their return in the end. And this must be admitted. But were those trees, which failed to grow accorling to the expectations of the proprietors who so laudably endeavoured to ormament their estates, and which cost them so much labour to little purpose, transplanted in such a manner as to fulfil the conditions above specified? Probably not. Wherever the rational method has not been attended to in times past, disappointment has been the result; and wherever it may not be attended to in future, disappointment will also follow as the natural consequence.

It is not to be wondered at that many of the past cases of transplanting large trees have failed of that degree of success which was anticipated, seeing that few of them have been conducted upon principles consistent with the ordinary laws which are known to regulate the normal processes of vegetable life. Every tree of any considerable size has its principal feeding-roots situated, for the most part, at a considerable distance from its stem; consequently, in the case of removing a lare tree from its original site, these must necessarily be cut off, and camnot afterwards imbibe supplies of food for the parent stem. Keeping this in view, then, is it to be wondered at that a tree should die off after it has been separated from its means of deriving food-supplies from the soil? Such a result is quite in accorlance with the laws of nature regulating vegetable life. And this has been exactly the state of things relative to those large trees which, after having been transplanted, either died suddenly or lived a few years in a languid and sickly state, and that just in proportion as they might have had less or more healthy fibrous roots left upon them at the time of removal.

In the case of the trees dying suddenly, the power of even utilising the reserve supplies of nutrients, which in young broad-leaved trees sometimes even amount to about 7 per cent of the whole organism, appears to have been denied; whilst, in the case of those that first of all wilted and then died off, even the utilisation of the reserve nutrients may have failed to enable the individual plants to accommodate themselves to their new environment.

Not unfrequently, trees of a considerable size have been lifted 
from their original site and transplanted into another, where they were expected to thrive well; and yet they have heen, as it were, simply torn from the soil, all their roots being left in it, and but little or no precaution having been used to retain them. In such cases, the soil was removed from a considerable distance rumbl the stem, leaving only those roots attached which were large and bare, and which had no supply of small fibrous strands and rootlets, owing to the latter having been separated in the act of removing the earth; and, with as much soil attached to the part where the roots issue from the stem as the nature of the means of conveyance would admit of, the trees were again put into the earth. Of course, in nine out of ten such instances the trees so dealt with never again recover sufficient vigour to assume a tolerably healthy or satisfactory appearance.

This is, indeed, the most primitive method of transplanting large trees. As an improvement upon it, a system of previously preparing the roots for removal has been adopted, which, considering all the circumstances, has certainly been a decided advance upon the old style; but it has not yet been attended with that full amount of success which is desirable, and which it seems quite possible to attain. The following is the somewhat more advanced system of preparing trees for transplanting which has been successfully and consistently practised for a number of years past.

Any large tree, the transplantation of which was anticipated, had a trench dug round it, at such a distance from the stem of the tree as was considered expedient for the purpose of removal, according to the size of the tree to be handled. This trench was dug so deep into the earth as to cut all the side roots as far down as those were found. It was then again filled up; but, if the soil was naturally bad, a quantity of better earth was substituted, with a view to encouraging the cut roots attached to the tree to push out fresh rootlets the more readily, in order to act as feeders when the tree was removed to its new site. In this state it was again generally left for a period of two years, when all the cut parts of the roots had thrown out rootlets into the new soil. The tree being now considered fit for removal, transplanting was performed in the following manner :-

In taking away the earth from its roots, the workmen began first by opening a new trench all round, exactly upon the outside of the one which had been formerly made, and making the level of its base a few inches under that of the latter, with a view to getting the more readily under the level of the supply of young roots, now supposed to be made within the compass of the first trench, This being done, the workmen, with small picks made for the purpose, loosened very carefully the body of the soil as contained in the previously made trench; a besinning was mate upon the ontside of the circle, and then sralually workins 
in among the young roots made, so as to separate them from the soil. As this work progressed, other men were employed in throwing out the soil thus loosenedcare being taken to disturb as little as possible, and not to injure, any of the small tender roots now hanging loose. In this manner the men followed each other regularly till they had reduced the size of the ball of earth contained within the compass of the first trench, but of course retaining all the young fibrous rootlets and other roots as well as the nature of the work would admit of. When all these had been separated from the soil on the outer part of the ball, the remaining part, immediately round the base of the stem, was preserved entire, and taken along with the tree. As soon as this part had once been undermined, or freed of any perpendicular hold it had in the earth, a pole, which was fixed upon an axle with a pair of wheels, was applied to the stem of the tree, and tied firmly to it. By means of this it was pulled down, with the ball and all its appendant roots resting upon the axle and hanging between the wheels. In this state the tree was drawn by horses to the place where it was to be replanted. In the act of replanting, the bottom of the pit, which had been previonsly made for the reception of the roots, had a quantity of good soil put over it. The tree was then put in, and the roots spread out, and replanted in as careful a manner as possible, new soil being used when that was considered necessary for the health of the plant. In all cases where the situation was an exposed one, and the ball of earth was comparatively light in proportion to the weight of the crown of the tree, large sticks or ropes had to be used in order to keep the newly planted tree firm in its position until the roots had become properly established in the new soil.

Having thus given a brief outline of the manner in which the transplanting of large trees has been conducted by many hitherto, it now remains to consider how far the above systems fulfil the conditions required, and how far they are commendable or not.

First of all, no tree can attain a really healthy development of leaves and branches muless it be supplied with a corresponding healthy development of the root-system, by means of which to draw foodsupplies in the form of soluble salts from the surrounding soil; and yet no healthy tree, although deprived of a portion of its roots, will sustain any permauent injury, provided it be allowed to remain undisturbed in the soil till it has again replaced those roots, if, after new roots have been made, they be preserved from further injury.

In other words, the supply of reserve nutrients stored within the organism in the form of starch $\left(\mathrm{C}_{6} \mathrm{H}_{10} \mathrm{O}_{5}\right)$ can be transformed again into dextrine or grape sugar $\left(\mathrm{C}_{6} \mathrm{H}_{12} \mathrm{O}_{6}\right)$, and utilised for the purpose of forming new roots and rootlets, and for generally assisting in the vital processes until the plant is firmly established in its new home.

Secondly, the mere woody-fibrous portions of the roots of a tree are not in themselves capable of drawing food-supplies to any considerable extent from the soil, unless they be well furnished with small suction-rootlets, capable of imbilsing the mutrient salts lueld in solution by the moisture present in the soil.

Thirdly, those small rootlets, which are so essential to the continuation of healthy vegetation in any tree or plant, are very suscep- 
tible of injury, either by being unduly exposesl to the action of the atmosphere, or by their fine outer coating or cuticle conning roughly in contact with any body harder than themselves.

Applying those facts, known to affect regretalje life, to the operation of transplanting large trees, as already describen, it is obrious that the plan of digging a trench rouml the trees to be transplanterl can have no permanent bad effects upoi the constitution of a tree unless the trench be dug too close to the stem. It no doubt gives a temporary check to the system as regards the ascent of the sap; but, as soon as the roots have again renewert thenselves, the strength of the circulation will gradually resume its former level. So far, therefore, as regards this part of the operation, no inportant evil can arise. But with regard to the second and third considerations, the system of transplanting formerly adopted was much at fault; for in (listurt)ing and removing the soil from the rery soft and tender suction-rootlets, which are produced for the natural imbilition of the food-supplies of the tree, the functions of these are so much interfered with, in consequence of coming in contact not only with the dry atmosphere but with the hands and implements of the workmen, that they are almost all rendered unfit for any further healthy action. It is in this respect alone that the operation is not adjusted to the natural wants and requirements of the tree handled; for, so far, it is diametrically opposed to sound natural principles. On examining trees transplanted on this system, they may sometimes indeed have a fair outside appearance, like the hectic flush of a delicate person; lut, on close examination by an experienced eye, external indications are at once tiscernible that the constitution of the tree is damaged, and consequently, that the duration of its life will be comparatively short. Besides this, the machine which has been in general use for the purpose of removing large trees by the above method is so very imperfect, that no tree of considerable dimensions can, with any degree of safety, be conveyed by it.

Best Method of Transplanting Large Trees.-In the transplanting of large trees, much of the ultimate suceess of the operation depends upon the character of the species and individual sclected. In selecting the trees, therefore, the following points should be kept in view :-

1. A tree of any given species is better supplied with small fibrous roots when growing in a light porous suil than on land of an opposite character.

The plant has then more difliculty in ohtaining the reyuisite supplies of food than when it is rooted in binding soils of greater retentiveness as regards moisture; hence, in order to obtain the necessary amount of food (salts held in solution by water), a greater mumber of suction-roots is developect in the 
natural effort of accommodation to the given soil and situation, or, in other words, to its environment.

2. The roots of trees growing in a heavy or clay soil extend themselves to a greater distance from the main stem than they do when growing in a light and open soil.

As there is much less probability of the nutrient salts throughout the soil being washed down into the subsoil by heavy rainfall, argillaceous soils contain, volume for volume, more mineral food in a soluble form available for imbibition than porous, siliceous soils ; and as, in consequence, there is not the same natural necessity for large development of suction-roots throughout the former, the energy of the constructive process tends towards the prolongation of the main roots and the side roots, in place of increasing, beyond the necessity of physiological requirements, the number of the small filbrous roots and of the suction-rootlets.

3. The small fibrous roots of trees are most plentifully formed near the surface of the ground; and the deeper in the eartl the large roots are found, the fewer fibrous roots are upon them.

When the trees are growing in the close canopy of woodlands this is not the case, except as regards very shallow-rooting species of trees like Spruce; but when trees are growing in isolated positions, the greater warmth of the surface soil will naturally stimulate the formation and ramification of the smaller roots, and consequently of rootlets also.

4. The more confined any tree is among others in a wood, the fewer and the weaker are its roots; and the more exposed it is to the free influence of the surrounding air, the more abundant and healthy these are.

In all woodlands forming close canopy there is a constant struggle for individual supremacy in the case of the more vigorous boles or trees, and for existence itself in the case of those of less advanced development. The actual growing-space of each individual plant is therefore not only limited in extent, but that allotted on the average to each is also subject to further limitations in the case of individuals of backward growth, owing to encroachments on the part of those that are more vigorous and forward in growth.

When growing in the open, however, trees have no competitors for foodsupplies, light, and air; hence they will develop to the fullest extent that the vital power of the plant is capable of attaining under the given conditions of soil, situation, and climate.

5. The more that a tree becomes clothed with branches, the better is it supplied with small fibrous roots.

There is a certain natural balance maintained between the rate of imbibition through the rootlets and the power of transpiration and assimilation possessed by the foliage.

It is precisely this balance which is disturbed in transplanting, and which 
necessitates the removal (trimming or juming) of a certain portion of the transpiratory and assimilative organs (foliage) when the inblibitory organs (suction-roots) are disturbed.

6. In soils naturally of a cold and moist character, the roots of trees are few, weakly, and mhealthy; and in those of a naturally dry character, the opposite is the case.

For whatever tends to check the aeration-i.e., the circulation of oxygen -throughout the soil, likewise tends to prejudice the development of the plant. And the same may be said as to the biological activity of fungoid organisms and animalculæe.

7. The great majority of the fibrous roots are generally found to coincide with the extension of the branches forming the crown; and they are also generally found to be most numerous upon that side of a tree which has been freely exposed to the influence of light and warmth.

For the suction-rootlets are of the latest growth, and are most numerous near the ends of the ramifications of the roots. In trees growing in the open, the suction-roots will be found to be more numerous, and the root-system altogether stronger and larger, on the warmer southern side of the tree than on the cooler northern side.

In selecting large trees for transplanting, they should, if possible, be taken from land of a light, fresh, loamy character. In such classes of land, trees are usually much better supplied with fibrous roots than on soils that are either of a very light or of a stiff and clayey nature. In selecting a large tree of about $30 \mathrm{ft}$. in height for transplanting, one of a fine spreading habit should be chosen, whose branches fully correspond to its height and to the size of its trunk. When once the selection is made, a cord should be fastened loosely around the base of the trunk of the tree; and then, keeping this cord in the hand, a circle shonld be described all round the stem, with a radius of $3 \frac{1}{2} \mathrm{ft}$., so as to mark off the circumference of a ball of earth whose diameter is $7 \mathrm{ft}$. This being done, have a 24 -inch trench dug all round on the outside of the circle thus marked out, and reaching deep enough to go completely under all the sile-roots. Thilst the digging of the trench progresses, all the roots should be carefully and smoothly cut, so soon as they appear upon the imner sile of the trench; otherwise the rough surfaces of the wounded parts atford resting-places for the lodgment of water about them. Beyond a depth of $2 \mathrm{ft}$. from the surface it will be found that the roots are scarce, and with few or no fibres; therefore, at this stage of the operations, these should be rather closely ent in, so as to canse them to produce a more plentiful supply of small roots for the better and more speedy establishment of the tree when removed. The ball 
of earth situated between the trench and the stem of the tree should therefore be undermined all round, leaving it only about $20 \mathrm{in}$. deep upm the outsicle, and gradually sloping it downwards as an approach is made towards the centre of the ball under the tree, where it may be fully $30 \mathrm{in}$. deep. This undermining, however, should not be carried to such an extent as to come in contact with any of the taproots situated immediately under the stem of the tree; for if this were done, it would create too severe a disturbance in the tree. The maintenance of the tap-roots is essentially necessary for the support of the stem-at least until the roots, which are now supposed to be shortened, may have thrown out fresh suction-rootlets for imbibing adequate supplies of food. The ball of earth packed about the roots should merely be undermined to the extent of about $2 \mathrm{ft}$. inwards from the perpendicular of the edge all round. All loose pieces of soil should next be removed from the sides of the ball by means of a small pick. In doing this, wherever a deficiency of roots is found, the pick should be applied for the removal of the soil till roots are come in contact with; but wherever these are found, no further disturbance should be permitted. At this stage of the operations, the ball about the roots of the tree will present rather a rough appearance. On some parts the cut points of rather large roots will protrude, and on others the earth will be hollowed out, showing that many fibrous roots are contained within the knots of protuberant earth; but the object of all this will be better understood after the succeeding operations have been explained.

Whilst the above work of preparing the ball of earth enclosing the roots is in progress, a quantity of half-rotted vegetable mould should be collected, to which an equal quantity of light peat-mould may be added, mixing the two well together; and this compost-earth should be coated all round the ball to a thickness of about 9 in. A commencement ought to be made at the base or the lowest point of the excavated ground, the soil which was thrown out being gradually replaced with the compost; and in order to make it adhere better, slight pressure should be applied with the foot so as to compress it a little. Part of the soil which had been removed is then put in again behind the compost; and to this a firmer tramping should be given, making it pretty solid, and keeping all the worst of the soil thrown out next the compost. Wherever there is a hollow part in the ball of earth, showing where there had been but few roots developed, the spraces should be completely filled up with compost, and smonthed oft to the level of the ordinary thickness of the coating round the outside of the ball. Thus, in places where any of those hollows occur, the compost may even be sometimes fully $2 \mathrm{ft}$. in thickness; for this crating of rich soil is put on with the express intention of stimulating 
the growth of an extra supply of fibrous roots and suction-rootlets at such parts. The work is thus proceeded with till the whole outer surface of the ball is equally coated; and when the surface-level of the ground is reached, about $6 \mathrm{in}$. of the compost should be spread over the top of the ball. At this stage the prelininary work may lue considered to have been completed. In preparing large trees for transplanting, it is well to shorten the principal of the large lranches to the extent of about one-third of their length. In doing this, however, no approach should be made to anything like a regular pruning of the tree by taking off any branches close to the stem; but it will suffice to shorten any large overgrown limbs which may appear to utilise an undue proportion of the sap of the tree for their transpiratory and assimilative processes.

In preparing a tree for transplantation, which is growing in a tenacious soil, a trench should be opened around its roots in the same manner and to the same extent as above described for trees growing in a lighter loam. When the trench is dug, and the ball of earth surrounding the tree has been undermined as in the former case, rather a large quantity of the stiff clay soil forming the ball should be removed with the pick, and especially in places where there appear to be no roots. In this case it will in all probability be found necessary to reduce the ball very much, in some parts even right through to the bottom of the trench; but wherever roots appear, whether large or small, work with the pick should be left oft. The ball of earth being in this way reduced till the roots are visible, all the openings in it should be completely filled up with compost-earth as in the previous case; and this should be packed rather tightly between the roots by pressure applied with the hands. When the openings which were made with the pick are all completely filled up over the surface of the ball, the compost should be coated all round the outside, keeping it about $12 \mathrm{in}$. in thickness between the clay soil put in behind and the nearest of any one of the points of the roots projecting from the ball. This should be done in exactly the same manner as in the former case, always packing the clay very solidly behind the compost put in, and the compost itself more slightly; and when the whole forms a level surface, the top of the ball should be covered with compost to the thickness of about $9 \mathrm{in.}$ When this work has been completed, an open drain should be male from the level of the base of the trench; becanse, from the stiff nature of the soil, it may be anticipated that water will lodge in the trench and destroy the health of the young roots whose formation may be expected. Wherever the soil is heavy this precantion is ahsolutely necessary to the successful issue of the work. By this very simple process of carrying away an open drain from the bottom of the 
trench, the lodgment of water is lindered, and the tree, therefore, has the advantage of a drier and a more healthy condition of soil than if the earth around the ball should become sodden with rain-water.

With regard to the third point-viz, that the small fibrous roots of trees are most plentifully formed near the surface of the ground, and that the deeper in the earth the large roots are found, the fewer fibrous roots are upon them-this is a fact which every one engaged in transplanting operations will find verified. In most cases, indeed, it will be found that there are comparatively few fibrous roots formed under about 20 in. from the surface; and it is in order to stimulate and to encourage the growth of those under that depth that the ball of earth is undermined, and a coating of compost is given to it.

Trees which have been drawn up in the close canopy of a plantation are not suitable for transplanting. When, therefore, trees must be selected from plintations for the purpose of transplanting, they should always be taken from the edge of the wood, where they have had, at least in one direction, a free growing-space for the development of their branches and the extension of their root-system. Trees which are to be transplanted, after having attained any considerable size, should be possessed of a good, sound, thick, and fleshy bark. If a tree has a thick cortaceous rind, it is not so apt to be affected by sudden change or exposure as one with a smooth or thin bark; for the latter classes of stems are much more exposed than the former to sun-burn, and consequent disease of the stem. In choosing large trees for transplanting out into the open from any part of a plantation or other wood forming close canopy, care should be taken to see that the bark of the individual stems to be removed is in a good healthy state; and as the coronal development and the expansion of the root-system are mainly dependent on the same chief factor, the amount of individual growing-space, it therefore follows that the planter, in looking out for specimens which he would have with good roots, has only to observe the development of the crown. If the latter be of a spreading and well-branched description, he may rely upon plenty of good roots; but if the tree be tall, and with only a slight crown formed of comparatively few branches, then the probability is that the development of the root-system is also indifferent. Hence trees of this latter class are, of course, the most difficult to transplant with successful results.

On all cold, wet soils the growth of trees is invariably slower than upon warm, dry land; for in the former case the development of the root-system is not so good as in the latter. In removing trees from a naturally cold, wet, and inactive soil, therefore, the ground must first be well drained about the roots of the individuals to be removed; and either at the time of draining, or after the trees have 
begun to exhibit signs of more vigorous vergetation in conserpuence thereof, the trees may be prepared alout the roots, and afterwards removed with safety.

Although the majority of the filmous roots of trees are usually to be found developed just alout the edge of the area corered by the spreari of its branches, yet the bulk of them may sometimes be fouml to extend very much beyond this. But in such exceptional cases there will generally be some special cause assignalile, such as the proximity of a watercourse, or a stratum of soil of a more fertile nature than that in which the tree may be standing, or heaps of manure, \&c. Then stimulated by any such extraordinary ails to growth, the development of the smaller fibrous roots becomes almormally great, and may eren extend for a considerable distance beyond the extension of the branches. This may often be observed in the case of hedgerow timber, or of trees growing along the side of a wood contignous to a well-cultivated piece of land. Under these circumstances great tufts of roots may be found in profusion throughout the soil, at a great distance from the trees themselves; and very much the same sort of thing may be observed in the case of roots getting into drains. All these cases, however, are exceptional, and are not in accordance with the normal development of trees under the ordinary circumstances of growth.

In connection herewith the following practical questions arise: Should not, in the removal of a large tree, a ball of earth be carried along with it equal to the ordinary spread of its roots in the earth ? If not, then what should be the rule for guidance in the operation?

Some maintain that, in the act of transplanting a large tree, all its roots should be bared, traced out to their full extent as necrly as possible, and removed entire along with the tree, without any respect being paid to a ball of earth; while others hold that no previous preparation is necessary for the removal of any tree, but that lifting a ball of earth, varying from 8 to $12 \mathrm{ft}$. in diameter, according to the size of the tree, is quite sufficient for its safety, without any attention to the natural spread of the roots in the earth.

Neither of the above opinions seems quite sound; although the former is the more obriously opposed to the primary teachings of regetathle physiology.

As no tree can attain a healthy and normal development of foliage and branches unless it be supplied with a corresponting healthy and normal development of ronts for the imbilition of food-supplies in the shape of the soluble silts contained within the soil, and as, by virtue of the reserve supplies of mutrients stured up in the form of starch $\left(\mathrm{C}_{6} \mathrm{H}_{10} \mathrm{O}_{5}\right)$, and convertible into grape-sugar $\left(\mathrm{C}_{0} \mathrm{H}_{12} \mathrm{O}_{6}\right)$ for constructive processes for active regetation, or if neces- 
sary every tree possesses more or less power of recuperation when its organism is subjected to disturbing influences, - it therefore follows that no healthy tree, although deprived of a portion of its roots, will sustain any permanent injury, provided always that it is allowed to remain undisturbed in the soil till it has replaced those roots, or until, if transplanted, it has established itself in its new home, and has accommodated itself to the soil by the formation of such a quantity of new roots as will maintain a healthy and normal balance between the imbibition effected by means of the root-system on the one hand, and the transpiration and assimilation effected by means of the crown of foliage on the other hand.

It will therefore at once be seen that to deprive a tree of its roots, and to remove it to another soil at the same time, interferes very directly, and in a double manner, with its normal development. And, on the other hand, it will be clear that, although any tree may lose a portion of its roots, no permanent injury will necessarily follow if it have a sufficient supply of reserve nutrients, and if it be allowed a due amount of time to replace the lost roots without being further disturbed in the meantime. In young and vigorous plants both the accommodative power and the recuperative capacity are greater than in large trees, just in the same way as youth has the advantage over old age with regard to disturbances in the human organism. Hence, in the transplanting of large trees, the root-system must previously be prepared. Practical experience has shown that the best means of effecting this is by digging a trench all round at a distance from the tree equal to two-thirds of the diameter of the spread of the branches; that is to say, if the diameter of the average spread of the branches be $12 \mathrm{ft}$. (not including the extreme points of large limbs), the diameter of the ball of earth inside the trench should be $8 \mathrm{ft}$., and so on in proportion.

The practical results attained by the cutting in of the roots, previous to the removal, may perhaps best be illustrated by the following experiment. If two rows of Oaks, or of any other kind of broad-leaved species of trees, of about 5 or $6 \mathrm{ft}$. in height, are standing in the nursery, and if all the side-roots of one row be cut in with the spade upon each side,-say to within about $6 \mathrm{in}$. from the trees in the line, but not so deep as to cut any of the tap-roots, which can supply the tree with food till new roots are developed at the sides,whilst the other row is left uncut and in its natural state, then, when they are lifted twelve months later, the plants in the row which has been cut in will be found to have developed side-roots and fibrous rootlets plentifully, and to be in a much better condition for being transplanted than those in the row which was left uncut. The sideroots of the latter will be sparse in number, and will have the fibrous 
rontlets mostly reaching far from the stem: these will therefore le left in the ground when the lifting takes place. And when the plants taken out from these two rows are transilanterl ont into the open, under enual conditions as to soil, sitnation, and tenline, it will very soon be apparent that those which had their side-roots cut in twelve months previous tu their heing removerl are fur more healthy, and make much more rapid progress, than those whose roots were not cut till the time of their removal.

It is exactly on this very same principle that the side-roots of all large trees should be cut in previous to their being lifted. The operation is simple, and its effects are unquestimathy heneticial; for there can be no doubt as to the improvement that takes place in trees so treated in comparison with others which may be simply lifted and planted out at once. By cutting in the side-roots of a tree previous to transplanting it, the development of a large supply of young filmous rootlets is stimulated, and these cmable it to continue imbibing food-supplies when its organism is disturbed ly removal into its new site; and this continuity of imbibition can never be so thoroughly maintained in the case of a tree being removed without any previous preparation.

The whole operation, in fact, consists of converting one violent major disturbance into two minor disturbances. Though not of the nature of antiseptic or antiprretic treatment, yet it is somewhat anaiogous to Pasteur's method of preparing the human frame against the disturbing influence of prevalent zymotic derangements of our organism. And it stands to reason that the operations will be the more effectual the younger am more riforons the trees operated mon are; whilst it seems equally justifiable to exprect that beyond a certain age, varying both according to the species of tree and the vigour of the individual plant, the accommodative and recuperative power becomes so weakened that transillanting must be attended with greater risks.

The distance of two-thirds of the diameter of the natural spread of the branches is laid down in preference to any other, lecause at that distance from the stem of a tree all the larger and matured portion of the root-system is enclosed within the circunference of the ball; while on the circumference of the ball itself, at that distance from the stem, the roots are found ramifying regularly, and of the character most likely to send out numerous healthy fibrous ronts for the future maintenance of the food-supply of the tree.

The fullowing rules for practical guliance in transplanting oprerations are based upon the above considerations:-

1. In choosing a tree of a large size for removal to another place, the development of the crown should be carefully examined; for if the branches be few and the foliage scanty, the roots and rootlets will be correspondingly weak. 
2. If one or more of the branches forming the crown appear to bear an undue proportion to the main stem, they should be shortened by at least onethird of their whole length, but never in such a way, or to such an extent, as to give the tree a formal or artificial outline. By this operation the demands made by the crown of foliage upon the root-system, after it has been cut in, are proportionately diminished to as great a degree as is consistent with the health of the tree.

3. Taking the perpendicular drip from the points of the branches as the circumference of a circle approximately round the stem of the tree, after the strong limbs have been shortened in, two-thirds of the given diameter is taken as the diameter of the ball of earth to be left inside the trench to be formed.

4. A circle being inscribed round the stem of the tree, a trench should next be dug round the outside of that circle. The trench should be from 18 to $36 \mathrm{in}$. broad, according to the size of the tree, and the earth should be thrown out to the outside; and all the roots, as they appear upon the inside of the trench, should be smoothly and carefully cut to a depth of from 2 to $3 \mathrm{ft}$. under the surface, as that is the layer of soil within which they are chiefly developed in most species of broad-leaved trees.

5. The trench being made, all loose soil should be pared off with the spade from the surface of the ball of earth now containing the roots of the tree; and at the same time all earthy parts of the ball in which no roots exist should be hollowed out with a pick, with the intention of putting in compostearth to stimulate the development of rootlets. In order to encourage the growth of rootlets in the lower part of the ball, it should also be undermined to the extent of 2 to $3 \mathrm{ft}$. within the perpendicular, the earth which is thrown out being replaced with better soil.

6. These preliminary operations being completed, a quantity of previously prepared compost-earth, or of light vegetable mould, should be put about the roots of the tree to the extent and in the manner already detailed.

7. If the trees be originally growing in soil of a light, loamy nature, and naturally favourable to the production of a good root-system, they may be safely removed in two years after the roots have been cut in. But if growing upon soil of a heavy argillaceous character, and not so favourable to the development of the smaller roots, the trees will be all the better for remaining three years in their preparatory state; for as the original quantity of roots is comparatively small, all the more time will be required to stimulate the production of rootlets within the good soil put in for that purpose.

This system of preparing large trees for transplanting may be considered more expensive than is necessary; but it is really the cheapest and most satisfactory method in the end. Trees may no doubt be removed at a cheaper rate from one place to another without any such preparation; yet extensive practical experience in all parts of the country has shown that the operations are not then attended with anything like an equal chance of ultimate success. Even those who may have no practical experience of the matter to guide them, may easily understand how trees, on being removed from their original sites, must have a much better chance of establishing themselves in their new home if they are well supplied with rootlets, than those that are remored without any previous treatment having for its olject the development of an increased number of the suction- 
roots so essential to the imbibition of the forml-supplies. No proprietor of judgment and taste would lesitate as to the outlay of a dew extra pounds upon such a work as the transplanting of liaree trees, when he is made aware that ly the system of preparing their roots he is likely to have the greatest amount of ultimate satisfaction. The extra cost is practically merely of the nature of an insurance of the other ontlay incurred in the operations of park adornment (see also p. 489).

Machines for Transplanting Large Trees.-In orler to secure complete success in the removal of large trees, it is necessary that a machine of great power should he constructed, ly means of which the whole tree, together with the ball of earth containing the ronts, should be lifted up out of the soil, conveyed in an upright and natural position, and laid down in its new bed as entire as when taken up.

There are many different kinds of machines in nse at the present time for the removal of large trees; but as those now ahout to be described appear to be perhaps the most suitable for the jurpose, they may be recommended for practical operations.

The first machine to which reference will be made is that which was so extensively used for lifting large trees at Kingston Hall, near Derby, some years ago. There, by means of this machine (see Firs. 79 to 82 ), a bare knoll was transformed into a well-wooded park within the short space of about four or five years.

Two machines of this kind were used in the transplanting of the large trees at Kingston Hall, both of which were of similar construction, though different in power. That used for transplanting trees of $25 \mathrm{ft}$. in height and under is capalle of safely remoring a weight of about 5 tons; whilst the other, used for transplanting trees of from 30 to $40 \mathrm{ft}$. in height, is thoroughly capable of safely removing a total dead-weight of from 10 to 15 tons.

The Kingston Hall Machine consists of two pairs of wheels, each pair working upon a strong axle of superior cyuality. In the larger machine, each pair of wheels is about $9 \mathrm{in}$. lroad in the riugs. The front pair (Fig. 79, 6) are about $5 \frac{1}{2} \mathrm{ft}$. in diameter, and the back pair (Fig. $79, a$ ) about $7 \mathrm{ft}$. in diameter, whilst the length of the machine from axle to axle is about $15 \mathrm{ft}$. On each of the axles is placed a strong frame, in order to raise the horizontal bearers to a convenient height, and at the same time with the view of making the whole machine easier to work (Figs. $80, k$, and $81, l$ ). The front frame is also made to turn npon a horizontal wheel, in the same manner as in the case of a carriage, for the easy moving about of the machine in any required direction (Fig. \&.2, m). Two strong beams of wood, about $10 \mathrm{in}$. deep by 6 broad, and parallel to each other at a distance of about $2 \mathrm{ft}$. apart, rest upon the frames, as is shown in

VOL. I. 
the front and back sections (Fig. 79, $c$, and Fig. 82,n). The beams are fastened to the frames placed above the fore and aft axles, by means of strong iron holts, which ean be unscrewed as occasion may require; whilst, placed across and above these horizontal beams again, there are two other short beams (Fig. S2, o), into which the jack-screws

Fig. 79.

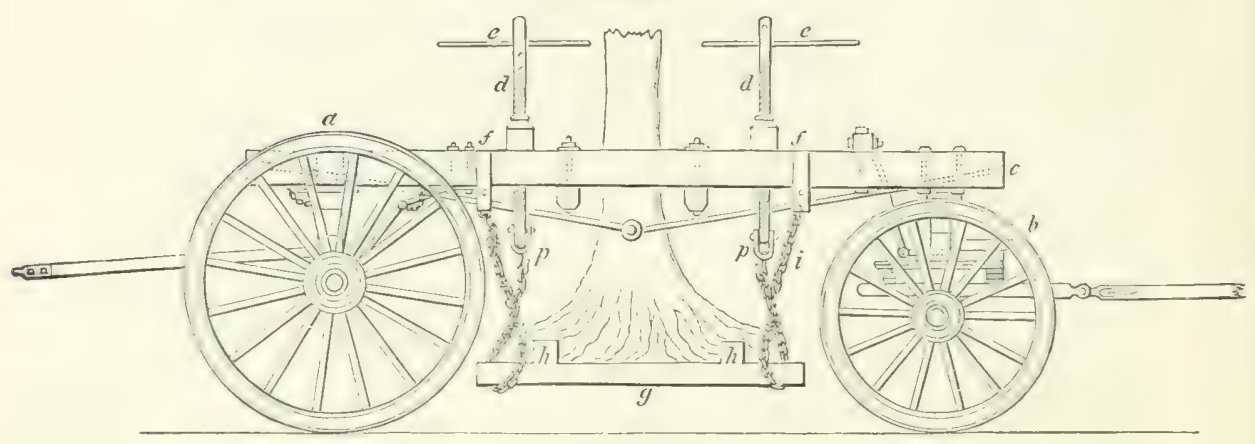

Side elevation.

Fis. 80.

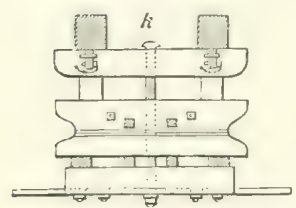

End section.
Fig. 81.

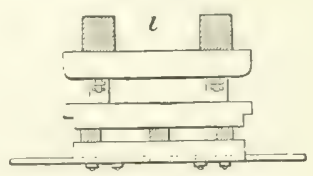

End section.

Franework resting on the axles.

Fig. 82.

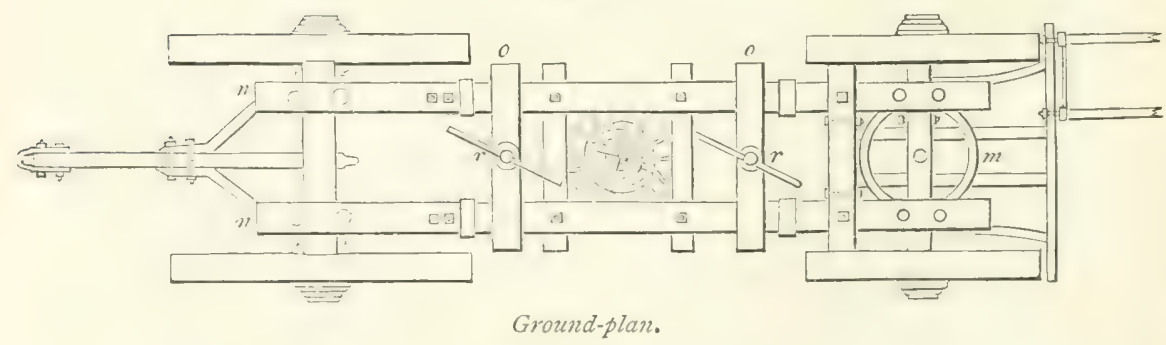

are placed. The mammer of working these serews is at once intelligilule from the illustration given of the side elevation (Fig. $79, d)$, which also shows the cross-handles used for turning (Fig. 79, e). To the moder part of these jack-screws, as passed through tise cross-beams, the strong chains are attached by means of which the tree is principally taken out of its place (Fig. $79, p)$; and, as an assistance to them, 
there are side chains fastenerl to strong iron rings fixed upon the beams (Fig. 79, $f$ ). These side chinins are marle to act along with the others attached to the screws, and are also found necessary to sustain the weight of the tree and of the ball of earth during the reversing of the screws for a new hold. The horizontal planks unon which the ball of earth rests, supported by the chains, are shown in the illustration of the side elevation (Fig. $79, y$ ); the two cross pieces, which are placed upon the horizontal pliunks for the letter support of the ball, are also shown (Fig. 79, h). All these planks require to be made of the best Oak woorl, and should not lue less than 4 in. in thickness.

The following quotation describes the actual operation of transplanting a large tree by means of this machine:-

"The work of transplanting a tree with the machine above referred to is perfectly simple and easily understood. Some of the trees that were transplanted in the park at Kingston Hall were brought from consilerable distances by means of this machine. Many of them were about $40 \mathrm{ft}$. in height, and weighed each, including the ball of earth and the machine, upwards of 10 tons; these had to be drawn by 9 horses. We shall now, therefore, give the following details as to how this was accomplished. The trees to which we now allude were growing on the outskirt of a wood. The ground around the tree was cleared, and at $4 \frac{1}{2} \mathrm{ft}$. from the stem of the tree a circular cutting was made to the depth of about $3 \frac{1}{2}$ or $4 \mathrm{ft}$., and about $2 \frac{1}{2} \mathrm{ft}$. in width. This done, then on the most open side of the tree a sloped cutting was made, from the surface of the ground to the bottom of what may now be called the ball of earth, and a similar sloped opening was made on the opposite side of the tree. The first of these sloped cuttings was made for the purpose of drawing out the tree up this slight incline to the surface of the surrounding ground. The circular opening in the earth around the tree, and the two sloping roads on each side, being now prepared, the workmen commenced to undermine the ball of earth : this being done all around, four stout oak planks, long enough, were placed under this ball of earth in front and behind-that is, crossways to the direction of the machine; and under these two others were placed lengthways, with their ends in the direction to back and front of the machine. It will now be understood that these four oak planks under the ball of earth cross each other at their four extremities; and around their extremities, at each of the four corners, four sets of strong iron chains are fastened. A reference to the diagrams given will assist in explaining this. The first set of chains brought into play were those attached to the bottom of the jack-screws. Being made as tight as possible over the ball of earth, they were then hooked on the end of the jack. The two jacks were then turned by two or four men each, as the case might require, until the tree and the bali of earth were raised from the ground abont 6 or 10 in. The jacks were then permitted to rest, and what is called the side-chains were then put in requisition. These, as we have already stated, are fastened to the planks under the ball of earth at the same point as the others, the opposite ends being made fast to the side beams, as shown in the engraving. This being done at the four corners, the jacks are then reversed, and the first set of chains slackened; the weight of the earth and tree is then sustained by the side chains. The first set of chains are again adjusted, and made as tight over the ball of earth as manual power can effect. The jack is then run down, and again attached to the chain at the lowest point it will reach. The jacks are once more applied, and run up till the end of the screw 
has been completely worked up to the under side of the cross beam on which it rests. By this second lift the jacks have probably gained upon the 6 or 10 in. which they made at the first lifting, and the bottom of the ball is now 15 or $20 \mathrm{in}$. from the ground. The side chains, which are now quite slackened by the second lift of the jacks, are again made as tight as possible : this accomplished, and all securely and equally fastened to the side beams again, the jacks are gently rerersed, till the weight is equally divided betwixt the side chains and the jack chains. The tree is now in a condition to be drawn out, unless it should be necessary to give it a third lift with the jacks, so as to raise it still higher from the ground ; and if so, the side chains must always be attended to, as already described. They may be properly called the guard-chains, as they prevent accidents in the erent of breakage of any of the jack-chains, when the former would take the weight of the tree, and prevent its falling. About 10 or $15 \mathrm{ft}$, up the stem of the tree four ropes extend from this point to the two front and two back corners of the machine; and this is all that experience has found necessary to preserve the tree in its perpendicular position during its transport on the machine to its future place of growth. The perpendicular position of the tree is, however, very greatly secured by the four side or guard chains. We have now to deseribe the mode of introducing the stem of the tree within the machine. This is effected in the following manner: The machine is drawn as near to the tree as circumstances will allow; it is then taken to pieces by unscrewing the different bolts-that is, the main horizontal beams are unfastened, and thrown over the wheels on either side. The larger hind-wheels are then placed in their proper position on the sloped cutting behind the tree, and the smaller fore-wheels on the sloped cutting before the tree; the large beams are then lifted on to their places, one on either side of the tree, and made secure with the iron bolts and the requisite fastenings. The tree then stands with its stem betwixt the sicle beams, and with a pair of wheels behiud and another before. The chains and jacks are then applied as already described, and thus the process is complete. The next and only point deserving further allusion is that of planting or placing the tree where it is ultimately to grow; and this is effected in the following way: The hole, sufficiently large to receive the ball of earth, is dug to the necessary depth; then, on the opposite sides of the hole, a sloped cutting, wide enough to admit the machine to be drawn down and through it, is also provided. Into this cutting, therefore, the machine and tree are drawn, and through it the team of horses must first pass. When the tree has reached the proper point, the machine is permitted to rest; props of brick or stones are then raised at the four corners immediately under the ends of the cross planks. These props may be three or five bricks in height; and when all is prepared in this way, the jacks are reversed, and the ball of earth is gradually lowered down till the ends of the cross planks rest upon the corner props, and the tree has taken its proper perpendicular position; and this is effected by the raising or lowering of these corner props. All being adjusted, any opening that may remain, between the bottom of the ball of earth and the bottom of the hole provided for the tree, is filled up with earth - the whole being made firm around and under the roots of the tree. The brick or stone props are then struck out, and the planks removed-a process easily effected, as the tree now rests upon the earth which has been placed under and about it. These planks are, however, well ironed at each end, so that, in case of any difficulty in their removal, a horse or horses may be readily yoked, and the planks withdrawn."

This machine may be strongly recommended for use with regard to the operation of transplanting large trees. By proportionately increasing the strength and power of the machine in all its various 
parts, it might practically be made to remove a tree of any given weight and dimensions. The machine just referrerl to is superior to any other thing of the kind that has ever been introduced to the notice of landed proprictors for the speerly ormanenting of their home grounds. Wherever proprietors will take the troulle to prepare the root-systems of the trees in the manner previously recommended, and to allow them to remain in the preparatory stage for two or three years, till the ball of earth has become permeated by filbrous roots, the whole may be then lifted, ly means of this machine, in one entire piece, almost without creating any disturlance of the root-system; and any tree removed under such favoural,le conditions will certainly be much less likely to exhibit such grave symptons of derangement as are certain to be manifested to a very serious extent in the case of large trees transplanted with less regard to the elementary teachings of vegetable physiology.

The French Transplanting Machine. - The French employ quite a different kind of machine for transplanting large trees to their

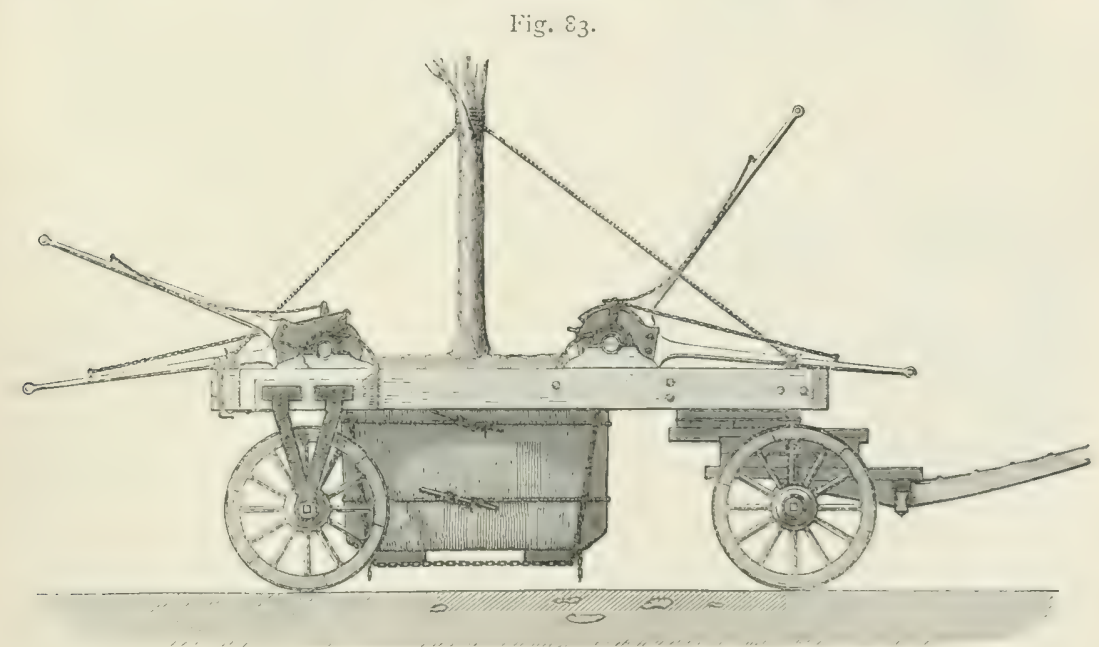

public partss. That chietly used by them, although perhaps not of so powerful a construction as the one just referred to, is nerertheless well adapted for lifting comparatively young trees of any ordinary size. The detailed description of this machine given helow, and the illustrations of it (Figs. S:), 84), are taken from livbinson's I'triks, Promonades, and Gardens of Paris:-

"Wè take, for example, a specimen tree, 30 years old, $30 \mathrm{ft}$. high, the trunk of which has a circumference of $3 \mathrm{ft}$. at a height of $3 \mathrm{ft}$. from the ground; its total weight, with the earth-ball, being nearly 2 toris. The operation is commenced by staking out, round the stem, the circumference of the earth-ball, which will be, on 
an average about $4 \mathrm{ft}$. in diameter for most species, and larger according to the size of the trees to be removed. A second concentric circle is then made about $2 \mathrm{ft}$. outside the first, the space between which will be the place for the trench to be dug for preparing the tree. The soil is then removed from this trench to the depth of $3 \mathrm{ft}$, and the small and delicate roots are drawn out of the earth, left hanging, and carefully preserved. The earth-ball is then undermined, to prevent the roots from adhering to the subsoil ; two thick planks, a foot wide, and a little longer than the ball, are placed underneath parallel with the width of the cart, so that they sustain the weight of the earth when the tree is lifted. Privet stems are now placed vertically, close together, all round the earth-ball, tied at the top and bottom with

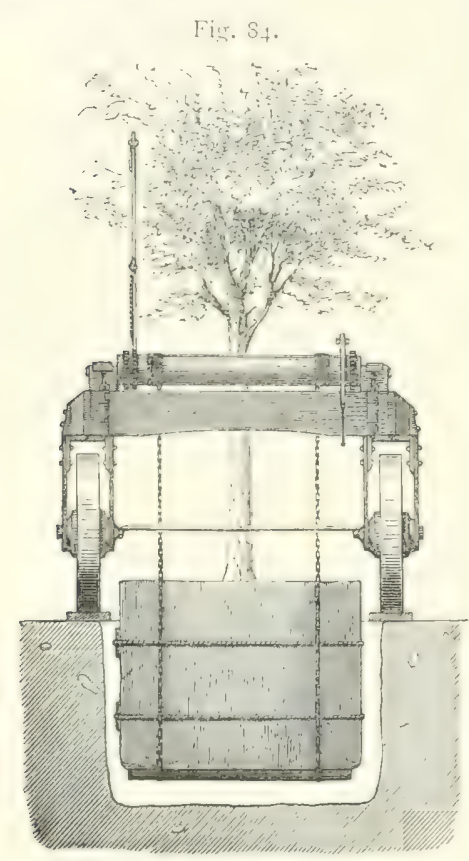
ropes, so as to prevent the earth from crumbling away, and also to protect the small roots from the inclemencies of the weather. The removal of the tree is then commenced in the following manner: Two stout thick planks, strong enough to support the cart with the tree slung in it, and a little longer than the entire excavation, and having iron plates about 2 in. higher than the surface, bolted on each side so as to prevent the wheels from slipping off, are placed, parallel to each other, across the excavation, with the exact width existing between the wheels. The movable bars at the back of the cart are then removed, and the cart is backed into the ways until the trunk of the tree is exactly in the centre of the frame. The movable bars are then put in their place again, so as to strengthen the back of the wheels, which do not run on an axletree, but are fitted in wrought-iron frames hanging from the upler part of the eart, as shown in Fis. 83 and 84. The chains attached to the rollers on each side of the cart (as shown in Fig. 84) are now lowered, and passed under the planks before described, which are placed under the earth-ball. When all is fast, four workmen begin simultaneously to turn the handles attached to the cast-iron cogwheels, by which great power is obtained on the rollers. The tree is raised slowly and steadily until it just swings clear of the ground, and then nothing is left to be done but to steady the tree before it is hoisted up to its proper height. For this purpose there is at each corner of the cart a strong wROUGHT-IRON hook, to which is attached a block, through which runs a strong rope fixed at the other end to a leather collar. These four ropes are then raised up together, and the collar firmly fastened on the stem of the tree about 7 or $8 \mathrm{ft}$. from the top of the earth-ball. The tree can now be easily removed without fear of its falling over.

"The horses are then attached to the cart, which is drawn slowly off the ways, and the tree can be removed with safety to its future resting-place. If the tree be vigorous and healthy, a hole a little wider than the one from which it has been removed should be dug beforehand: the earth, being placed carefully on one side of it, should be of a kind to suit the tree about to be planted; and if not, it should be replaced by suitable soil." The hole being in readiness, and suitable soil being prepared for the tree, "the planks or ways are placed in position, as before described, 
and the cart is very carefully drawn on them until the earth-lall is exactly in the centre of the hole. The tree is then slowly lowered, and when it touches the ground, the guy-ropes from the corners of the cart are pulled tight, so as to have the tree perfectly upright and steady; the chains are unfastened and hoisted up romm rollers; the two planks beneath this earth-ball are umbrmines and removert, and the privet shoots taken off. They then proceed to fill up the hole, particular attention being paid to the small roots, which are each separately covered in. When this is finished, and the tree is comsidered sufficiently steatly, the ropes are removed, the bars are taken out of the back of the cart, which is drawn away, and the bars having been refixed, all is ready for another removal."

The lifting power of this machine is obtained by means of racks, pinions, and levers, as may easily be understoor from the engravings given in illustration of the letterpress.

The Raising of Fallen Trees.-As windfall trees are usually thrown down by heavy storms only when the soil is soft and sodden with rainfall, the root-system generally tears up along with it a large mass of earth, within which the rootlets are numerous. There is, therefore, in the operation of raising blowm timber less disturbance than when the displacement is artificial, as when it is followed by removal to another situation. The modus operandi under such circumstances is well described in the following letter, which appeared in the Scotsman of 25 th November 1893. The only additional remark which it seems desirable to make is that judicious lopping or pruning of the crown will be necessary in order to enable the balance between imbilition hy means of the rootsystem and transpiration through the foliage to be more spreedily established when the flush of new leaves takes place in spring, or, in many cases of very large trees, in order to make any rehabilitation possible :-

"The report in Thursday's Scotsman of the upsetting by the gale of the finest specimen in Scotland of the Tasmanian "blue gum-tree" (Eucalyptus globulus) at Corswall House, Kirkcolm, Wigtownshire, is a sad record to all interested in the cultivation in this country of these rare and interesting exotics; and wherever they are not damaged beyond all possibility of recovery, prompt action should be taken to raise them again in their places. Where they have been blown over with a mass of soil attached to their roots, as is generally the case with conifers, they are easily replaced in an upright position, and will grow and thrive as well as ever if the work is properly done and precautions taken to prerent the wind swaying them too much. This applies to nearly all the coniferous tribe ; and it is also applicable to many kinds of deciduous trees, especially the more ornamental species, and many of the beautiful specimens that have been upset by the present gale may be restored again to vigorous health, if proper skill and judgment are employed in the operation. The success of this can be pointed to in many parts of Scotland. There is scarcely a well-managed domain in the country where some fine tree does not exist which has been upset by a storm and restored again by the skill and ingenuity of those employed to carry out the work. As a notable instance of this, the restoration of the fine old Lime-tree avenue at Duns Castle, Berwickshire, after many trees were upset in it by the Tay Bridge gale in the end of 1879 , is a splendid monument to the skill and energy of the late Mrr Alexander Shearer, long the well-known gardener at Jester, Haddingtonshire, under whose superintendence the giant Limes were raised from the prone position in which the storm left them, and set as perpendicular as if they had never been disturbed. The largest tree raised was $12 \mathrm{ft} .6$ in. in girth at six feet from the ground, and was computed to contain 300 cubic $\mathrm{ft}$. of timber; and the trees varied in height between 70 and $\mathrm{S} 0 \mathrm{ft}$. That occurred in 1880 , soon after the trees were upset, and the arenue at the present day shows rers little sign of the fearful damage it suffered from that memorable gale. All trees of a 
similar kind may be as successfully restored if due care is taken with them by those skilled in the operation. Ornamental trees, especially in prominent positions, are well worth restoration."

Machines for Transplanting Smaller Trees and Shrubs.-For the transplanting of small trees and large shruls, however, or which, together with the halls of earth, may weigh only from 1 to about 2 tons, the use of such large and powerful machines is not necessary. For these minor requirements a more simple machine, in the form of a flat sledge mate of thick, strong sheet-iron, and supported with hars of the same material, will amply suffice. Such a machine as descrihed below will be found very suitable for the removal of trees and shrubs not exceeding the total weight that can be dragged by two horses. The author may here give the specification of the one he had made, and which he is in the habit of using.

The under frame of the sledge (see Fig. 85) is formed of three

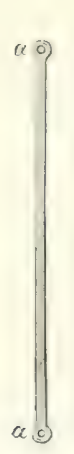

Fig. 85 .
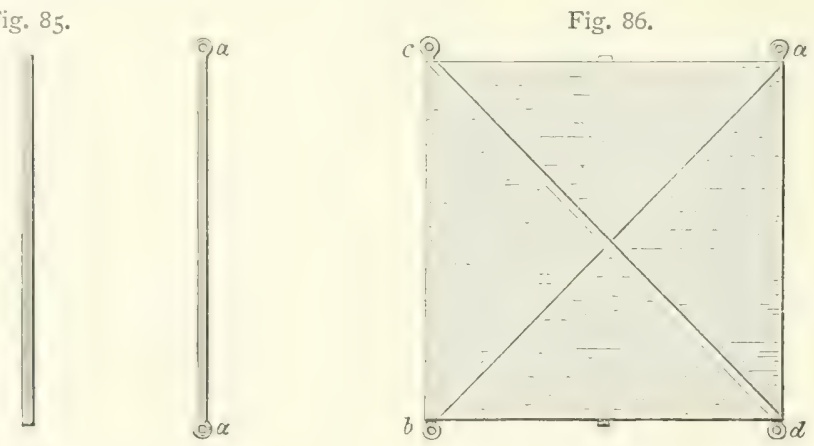

bars of iron, $1 \frac{1}{2} \mathrm{in}$. broad and $\frac{5}{8}$ of an inch thick. The two outer of these bars are made with holes at each end (Fig. 85, a), for attaching the hooks of the chains by which the horses drag the sledge along. This frame is covered with the strongest description of sheet-iron, and has a basal area of $5 \mathrm{ft}$. square. The sheet-iron is of course strongly nailed to the three parallel bars; and in order to prevent the twisting of the sledge when being dragred with a heavy plant on it, two cross-bars of iron, of the same dimensions as the others, are fixed diagonally on the upper side, and above the covering of sheetiron (see Fig. 86, $a b$ and $c d$; this figure represents the sledge, as it lies on the ground and ready for use). With this very simple mode of converance, trees having a weight of nearly 4 tons may cuite easily and satisfactorily be removed.

At first sight it might seem that there would be some difficulty in getting such a sledge put under the ball of a tree preparatory to removing it; but in practice this is not the case, as the sledge is of itself so thin, and yet so strong, that it is a comparatively easy matter to 
get it under the ball as the earth is being removen from it. This is managed loy previously undermining the hall rather reeply, first of all on that side of the hole from which the plant is to be remoserl, and then upwards under the ball, so as to grive the bottom of the hrole a slight ascending slope from the point of commencenent to the centre of the ball: the slerlge being then put muter the hall, anr the other sirles being loosened, this can easily be slir down the incline now formed by the sledge, till it is fairly upon it. At this stage of the operation the tree is fixed to the sledge by ropes attached to the sten, alout $\mathrm{S}$ or $10 \mathrm{ft}$. up from its base, and reaching from that point to the four holes provided in the ends of the bars of iron, in which also the tackle for the horses is fixed for hauling. Previous to pulling the tree out of its hole upon the sledge, the earth on the outer circle should be dug away at the point where it is intended to remove it, and which will of course be where the sledge was entered, so as to make an easy incline for the horses hauling it out. On arrival at the hole in which the tree is to be planted, it should be pulled in by an incline on the one side; and when the ropes are untied from the sledge, and the ball has been eased to one side by means of the ropes still attached to the tree, the sledge should be pulled out by an incline on the opposite side.

Transplanting (continued from p. 481). - In lifting large trees which have been first of all prepared in the manner previously recommended, care should be taken to open up the earth only upon the outside of the good compost-earth which was put in about the roots, so that no part of that rich soil should be disturbed in the act of removing the tree. This better soil should be retained as part of the ball; and as the young roots will have pervaded it thoroughly, it will easily adhere, and can therefore be safely removed along with the tree. In all cases of transplanting large trees into moist soil, the ground should be freed from any injurious superfluity of moisture by drainage; and where the land into which the tree is to be planted is of a heavy argillaceous nature, the hole should be made limpe in proportion to the size of the ball, say from \pm to $5 \mathrm{ft}$. willer than the ball of earth, and this space should be filled up under, around, and ahore the ball, with earth of a medium, loany character, mixed with deciryed vegetable mould, or with well-rotterl turf-mould, to the extent of nearly one-half of the whole bulk; for such a mixture is always found more farourable to the growth and development of roots and rootlets than either a very light or a heary soil. At the saine time, it is of importance to observe that, in the case of planting trees upon a stiff' claty soil, the roots should be liept proportionally shallower in the hole than if they were planted in light earih. There is often an error committed by planting trees too deep; nure than $t$ in. of soil 
should never be put over the top-roots even of large trees. When very large balls of earth are conveyed, as in these cases, the mere weight of the ball is sufficient, without the use of props of any kind, to keep the tree in an upright position, notwithstanding the effects of high winds on the top branches. In putting the soil about the roots of a large tree that has been transplanted, it is of immense importance to the future health of the tree not to put the earth in too compactly, as is rery frequently done; for this is quite inconsistent with the natural laws of tree-growth. When about 6 or 8 in. of the soil have first been put in about the roots in the bottom of the pit, a good watering all over should be given, so as to convert the whole into a thick mortar as it were. When this has been done, other layers of similar thickness may be added and watered alternately, until the whole is filled to the surface, when the soil should be beaten with a heavy mallet. The water causes the particles of soil to become more intimately associated with the roots, and this is far more effectual and advantageous than any tramping. When the whole is finished, the surface of the opening should at once be turfed all over and well watered; the turf will soon begin to grow, and will then tend, better than any other plan which can be adopted, to diminish the risk from drought. A point of very great importance, for securing the speedy establishment of large trees that have been transplanted, is to give repeated waterings over the surface of the ground above and about their roots, during the first four months after removal; after that waterings only require to be given occasionally, and more especially during very dry weather.

With reference to the kinds of trees best adapted for safe transplanting, those that develop compact heart-shaped root-systems are of course easiest to deal with. But, if the root-system be previously prepared in the way recommended, all kinds of trees may be with equal success removed. The Turkey Oak, the Evergreen Oak, and the Holly when of large size, have been considered uncertain as to safe removal; but by judicious preparation they may be transplanted with as much hope of success as the Lime-tree or the Elm.

It sometimes happens, in the case of large trees that have been removed from shady places and transplanted so as to obtain full exposure to warmth and light, that a flush of stoles or suckers may be thrown up from the crown of the roots, or that adventitious shoots may exhibit themselves along the stem of the tree, which often result in stag-headedness or atrophy of the top, branches of the crown. In order to check any tendency to disease of the crown, all such young shoots should be at once removed, in order to force the sap upwards; for, if they are allowed to grow on undisturbed, they will :l'propriate a large proportion of the sap to their own use 
as it ascends, and must conseruently deprive the top luanches of their due supplies of mineral food and water.

Best Season for Transplanting.-- Iarge trees of the decirlurus species may best be transplanterl during any of the nuonthis from the midule of Octoher to the michlle of April ; lut the meatest success is usually attained when the operation is carried out either in the month of October or else in March. In trees transplanterl during the month of October, the root-systems are still active, and the roots very soon begin to lay hold on the new and fertile soil laid in about them; hence disturbance is reduced to a minimum, and they may estal,ish themselves in their new home even hefore the winter sets in. A win, in the case of those transplanted during the month of March, the root-system is just on the point of becoming once more active, after having been gradually imbibing moisture previous to the flow of the sap commencing; and here also the roots quickly lay hold of the new soil in which they are imbedded, and have likewise a minimm of disturbance to overcome.

Trees removed during the winter months, while their roots may be said to lie inactive, do not imbibe water so reaclily in preparation for the spring flow of sap; hence they are placed in somewhat unfavourable circumstances for overeoming the disturbances conseruent on transplanting. Very often the action of their tender rootlets thereby receives a considerable check, which restrains their healthy action, and often retards the full normal flow of sap in the tree till late in the season, or sometimes even for a period of two years.

These remarks have reference only to deciduous trees. In transplanting large trees of the evergreen conifurons species, the operation should in all cases be performed just when the buds are beginning to open. This is generally some time during the month of April; but it may be either in the beginning or the middle or the end of the month, according as the particular species to be lealt with may be early or late in coming into growth, and according as the seasun itself may be early or late. Occasion may sometimes arise for the transplanting of large conifers at all times from Octoler till the middle of May; but the hest suceess almost infamialy attenuls work of this sort when it is carried out just before the lunds are berinning to open in early spring, for at that time there is most sip in the tree, and also the maximum of nutrient reserves.

Practical experience has shown that in Fritin the transplanting of large specimens of conifers should never be attempted during autumn. When they are transplanted at this season, the winds of the following winter act so powerfully upon their heavily chothed branches as to shake the trees from top to bottom; hence the rootsystem is also much disturherl, and hats not a fair chance of establish- 
ing itself in its new abode. Large conifers that are transplanted in autumn generally wilt or remain in an unhealthy state of growth for a year or two after, and make little or no progress till their roots have laid hold of the soil; and their establishment is but slow, in consequence of the check they receive during the winter following upon their removal.

Stimulating the Vigour of Old Trees. -1 s it is sometimes a matter of rery great importance to those who have the management of the home-grounds of landed proprietors to know what can best be done for the preservation and improvement of favourite ornamental old trees, it may be useful to some, into whose hands this book may fall, to be made acquainted with the best method of stimulating the vigour of aged trees.

Wherever it is desirable to stimulate the vitality of a tree that may be in a declining state of health, the first step is to have all dead branches cut clean away; and this must be done in such a manner as to remove entirely all decidedly dead and decaying portions, till the healthy wood appears at the cut parts.

It may not be out of place to note here that, when branches are being removed, either close to the stem or at any distance whatever from it, by means of the pruning-saw, the latter should be applied first of all at the lower side of the branch; and only when the bark and the outer sapwood there have been well cut through should the saw be applied above in order to sever the branch. Otherwise, in falling, the weight of the portion cut off tears away the bark from the lower part of the branch below the cut ; and this not only retards the cicatrisation of the wound-surface, but also offers a larger surface for the entrance of disease-producing fungoid spores.

The stem of the tree, as well as all the larger branches, should next he scriterl and cleared of all moss that may be growing upon the surface; and all the parts scraped should be well washed down, beginning at the highest part, with a brush and cold water, so as to free the bark from dirt and to keep the lenticels open. When this has been done, a trench should in the next place be opened all round, cutting the roots in the same manner, and at the same proportionate distance ( $\frac{2}{3}$ of the average diameter of the tree-crown) from the stem, as hats alrearly been described in treating of preparing trees for transplantation. Supposing, for example, that the roots have been cut in, at 6,8 , or $10 \mathrm{ft}$. from the stem all round, making the diameter of the ball of earth containing the root-system of the tree respectively 12,16 , or $20 \mathrm{ft}$, as may be necessary according to the size of the tree, then the trench immediately upon the outer circle of the ball should be made from 3 to $6 \mathrm{ft}$. broad, and deep enough to cut every root attached to the tree down even under the subsoil, and as far as 
they may be found to exist, without having any respect to rule on this point. In throwing the soil out of the trench, the workmen should be instructerl to lay all the goorl pertion (which will probalily be that forming the upper stratum) innnediately upon the outer entge of the trench opened; for in this position it will be ready at hand for mixing along with any better soil or comprost-carth that is afterwards to be put in. Beyond the good-soil thrown out, all earth of inferior cuality should be immediately carterl off, betore a comnencement is made to fill in the trench alout the ronts again. The trench having been made, and all inferior soil removed, as above clirerterl, the next thing is to fill up the former with a mixture of compostearth to whatever extent is necesary for the special work in hamc. The compost may consist of two parts well-rotted cow-dung, four parts half-decomposed leaf-mould, and one part powdered line. When a sufficient quantity of the above compost has been prepared and brought to the trench, it should be mixed up with an equal quantity of the fairly good soil which was thrown out of the trench; and then the latter should be entirely filled up with this mixture. Here again, as well as in the case of transplanting linrge trees (see p. 490), plenty of watering should take place as the filling in of the new soil proceeds, and at the same time a molerate tramping in with the feet may also be given. When the trench has been filled to the level of the surface of the surrounding ground, the turf growing upon the upper face of the ball between the trench and the stens ought to be pared off to the depth of about 4 or 5 in., and may be thrown back on the top of the new soil; and above all this again about 8 in. of the compost-earth may be spreal orer the whole extent from the stem of the tree to the outer circumference of the trench, making the ground upon that part $S$ in. higher than the level of the surrounding surface. A good watering and tramping down of the earth completes the whole operation.

In order to encourage as healthy a state of growth in the trees as possible, it is of great adrantage to syringe the foliage repeateilly, and to keep the lenticels of the bark clean, by means of a brush and cold water, in the summer season. One may even, in the event of a continuous run of dry weather, give repeated waterings at the roots, more especially orer the new soil put into the trench, where of course the young roots will be making rapid progress. By such a system of treatment old trees, which were eridently rapilly decaying, sometimes assume cuite a revived appenrance. MImy fine specimens of old trees, which have been operated on in this manner, after apmearing to be decaying, have been rastly improved by the operation : and, from what he has seen in the way of trees being treated after this fashion, the author feels confictent that the health of many old trees might be 
re-extallisher by attention to this method of stimulating their failing vigour.

In all cases of resuscitating old trees in the above manmer, it is of the greatest moment to have a drain made all round the bottom of the trench before putting in the compost. For it sometimes haphens, more especially if the original soil be of a heavy character, that water will lodge at the base of the trench; and by simply making a drain, so as to lead it away by a proper outlet, any danger of this kind may be obviated. If water were allowed to lodge, the tree woukl, instead of improving, decay more rapidly than if it had never been meddled with.

In the course of his visits to landed proprietors' seats, the author has seen many old and ornamental trees which could be much improved by dealing with them in the manner above detailed; and it is on this account that he has given these few hints for their improvement. Still, in order that proprietors may not be too sanguine on the point under consideration, he may state that there is a stage of unlealthiness and of old age at which trees may arrive, which will render them quite unfit for being stimulated, whatever means may be used for that purpose. An examination of the indivictual trees on the spot is therefore necessary before the operations are begun.

In regard to the method indicated above, the editor finds himself at direct variance with the author, although he would not feel himself justified in excising it, or in altering very materially or essentially the full expression of the author's views.

From a physiological point of view, the benefit of the above elaborate, and not altogether inexpensive, method of treatment is, to say the least, exceedingly questionable. For, in the first place, any such deliberate disturbance of, and direct interference with, the normal balance existing naturally between the imbibition of the root-system and the transpiration through the foliage should be most particularly and carefully avoided when the trees are approaching the limits of their physical vigour owing to senile decay.

It would seem altogether more rational to assist nature simply by pruning the branches, with the express purpose of reducing the foliage-i.e., of reducing the number of mouths that have to be provided with food. When such reduction has taken place, the undisturbed root-system can ordinarily, notwithstanding its decreased activity, quite well satisfy the demands made for nutrients for assimilation and water for transpiration.

Removing the turf, and giving the soil a top-dressing of compost-earth before replacing the sods, so as to allow the nutrient salts to be washed by rainfall down to the rootlets, would probably be the most efficacious method, combined of course with diminution of the total extent of foliage.

Prevention of Further Decay in Wounds and Holes.Holes which have originally been caused by wounds are often to 
be found on the stems of old trees standing in parks and on lawns. When a piece of bark has been removerl from the stem of a tree so as to lay bare the soft sap-wood, the part thus exposed loses its vitality, dies, and then becomes liable to infection with the spores of saprophytic and parasitic fungi. The living or uninjurer cells surrounding the exposed spot will, however, begin to form callous growth, and, if the injury be not extensive, will in due time cicatrise or close over the wound-surface; but, if damage be done to any considerable extent, the wound-surface naturally remains longer exposed to the danger of infection, and, before the surrounding healthy parts have had time to form callous growth to close over it, a rotten cavity is formed.

Such wound-rot may set in without the presence of fungi. But, as a rule, either saprophytic or parasitic fungi assist in the more rapid decomposition of the dead woody tissue.

The rotten cavities thus occasioned in the stems of trees vary greatly in size according to the extent of the original wound. Such holes not only cause decay in the stems of the trees affected, lut are likewise injurious by harbouring noxious insects whose larva feed upon decaying wood; and this of course hastens the destructive process.

When an old tree has been injured in the above way, no time should be lost in having the wounded part protected from the action of the air and of the weather. The simplest and most effectual way of doing this is to apply a coat of coal-tar to the exposed part by means of a brush. This antiseptic coating will prevent the injured part from rotting; whilst, if the wound-surface be not too large, and if the tree be in good health, the wound may soon become cicatrised, so as more or less completely to resume its normal appearance. If the wound be large, however, its cicatrisation and the formation of new wood are not to be expected. But at all events the coating of tar will hinder the entrance of fungoid spores into the wound-surface, and will, in consequence, prevent the formation of any carity, thus contributing very materially towards the preservation of the tree in a sound and healthy state.

Where decayed holes are found on the stems of old trees, they should, in the first place, he thoroughly cleares of all rotten wool and other matter, to such an extent as to show the healthy wood all round the walls of the hole. The hole shomld then he completely filled with pitch or coal-tar, which not only acts antiseptically as a preservative of wood, but also prevents noxious insects from lodging in it afterwards. In order that these black spots of tar may not be seen on the stems of the trees, a piece of bark, as nearly as possible 
of the same colour as that of the tree operated on, should be nailed over each hole, in a neat and well-finished, workmanlike way.

Where, however, no great weight is attached to outward appearances, the holes may be filled up tightly and compactly with Portland cement, which acts in exactly the same way as the pitch. That is to say, neither of them possesses the slightest curative properties; but, by occlusion, or the shutting out of the entrance of light, air, moisture, warmth, and organisms of any description (fungoid spores, insects, dc), they prevent all further progress in the decomposition of the woody fibrous tissue, and hinder the enlargement or spreading of the infection with parasitic or saprophytic fungi. 


\section{CHAP'TER V.}

\section{THE DISTRIBUTION OF TIMBER CROPS ON LARGE ESTATES.}

Extent of Afforestation.-There are few districts of really considerable extent in any country that might not be greatly inproved in their productive capacity by the presence of well-laid-out plantations, especially on high-lying parts having naturally a poor soil. On lowlying plains, with generally a more fertile soil-except in the case of dunes or shifting sand and poor sandy tracts, like the great NorthGerman Plain or the Lantes, near Bordeaux-it is not usually necessary to plant to any considerable extent. In such districts the climate is, as a rule, comparatively mild, and the soil is well adapted to agriculture; hence it is more profitable, both from a private and a nationaleconomic point of view, to cultivate the cereal and other crops for food than to produce timber. Even in such districts, however, it may often be found desirable to plant to a moderate extent, in orler to protect the agricultural crops against the prevailing wints during the spring and the early part of summer. Without the shelter of woodlands, or of trees in the form of broad and well-defined belts, great damage may be done by wind to crops: whilst even the heilgerows often afford a welcome shelter to young live-stock. Hence, for the purely financial reasons which onght to govern all the agrieultural and sylvicultural operations of private persons, only moderate portions of the fertile and low-lying plains of a country should therefore he put under woodlands; and the extent of the plintations male should in all cases be regulated by the character of the district.

The nature of the prevailing winds is one of the chief points to be obserred in the formation of shelter-wools. The winls most detrimental to agriculture are the drying and exhansting east winkls, which draw out the moisture from the surface-soil, and thus tend to interfere with the normal formation of the soluhle salts which form the food of agricultural erepis. Lud when this process is interrupted, there always remains the danger that after heary rainfall a portion of the nitrates, ite, may be washed down into the lower layers, where

VOL. I. 
they cannot be so easily imbibed by the roots of the crops. But, in districts where the average aunual rainfall already exceeds $40 \mathrm{in}$, the formation of extensive woodlands is apt to increase the rainfall to an extent which may possibly be prejudicial to the agricultural interest (see chap. i., pp. 23 and 36).

On undulating and somewhat hilly parts of a country, as well as on elevated table-lands, a greater extent of plantations is necessary or permissible than in low-lying tracts. In order to modify so far as possible the general rawness of the climate in lofty localities, a greater amount of shelter must be artificially given to the higher grounds. The advantages of shelter-woods may often be seen in those hilly parts of the country which border on low-lying and flat tracts. On the former classes of land the farm crops often come up as early as, and better than, on the latter; and this simply arises from the lowlying districts being less protected against the cold and drying east winds than the artificially protected tracts at higher elevations.

In order, therefore, to provide shelter for crops and herds, all mululating and somewhat hilly districts shouhl he well wooled along the ridges of the heights, in whatever direction they run, and even to some extent down the slopes on both sides, where the soil is generally rather poor in quality; for by such means the lower grounds will be well protected against winds from all directions. But planting should be undertaken to a moderate extent only in the hollows between the hills, as heavy masses of trees always present an unpleasant object to the eye in a highly cultivated part of the country.

A much more cogent reason is that the soil is usually of good quality in the coombes; and both for purely private and for national-economic reasons it is desirable that all good soil should be utilised to the greatest material advantage of its productive capacity.

Although on the hilly parts of a country, such large dimensions of timber cannot be produced as on the lower, still the quality of the wood is often superior to that produced on the more fertile land. And, besides this purely technical difference in the quality of the timber, the higher hills and the mountain-tracts are the only proper districts for the cultivation of timber on a large scale. More especially, indeed, is this the case in a comparatively small country like Britain, in which the better classes of land should be set apart for the intensive cultivation necessary to enable farmers to compete with imported grain. This is a fact which no one can attempt to gainsay. It must be laid down as a rule that in any comparatively small country the object should be, in growing timber, to plant it stangly, and only where ahsolutely repuisite on all gool agricultural tracts. But, on the other hand, Sylviculture should be practised, also intensively, on all the hilly ground and the poorer lands, on which 
higher returns may be expected from woodlands than from agricultural or pastural occupation.

Hence, speaking generally, on all such high-lying districts of a country as will not admit of profitalle farming, trees should be planted as the principal crop. This should be done to such an extent as to be limited only, on the one hand, by the better portions of the lower grounds being made arable, and on the other by the extreme elevation and poorness of the land not being capaljle of sustaining tree-growth.

As has previously been indicated (chap. i., p. 25 et scq.), the preservation of the forests of any country is a duty devolving on its legislators, not only in order that a sufficient supply of timlser may be kept up perpetnally for the wants and necessities of its people in their pursuit of various industries, but also with the view of ameliorating and improving the climate for their healthy existence and consequent greater usefulness as subjects.

But, besides preserving existing forests, it becomes the duty of every Government also to plant trees extensively on all parts of the country not at present suitable for agricultural operations, and also to encourage the landholders of the country to clo the same on their respective properties,- - both to such an extent as may be considered judicions with respect to the most advantageous utilisation of the productivity of the land everywhere, and to the greatest welfare of the majority of the population subject to its laws. Where this has not been attended to, and the woods have been cleared indiscriminately, as throughout various parts of Britain, agriculture has ultimately failed to be profitable; hence large tracts of country have often become barren, and are now left almost totally unproductive, as in many parts of the Scottish Highlands. Many examples could be given of a similar state of affairs in other countries where, at the present day, this unprofitable state of things also exists; but this would be neexlless, as most people of intelligence are arware of the fact (see chap. i., 1). 2-4).

The necessity for reserving and lieeping in good rondition all the forests of the country, and for planting all waste lankts, unfit for present agricultural occupation, with profitable sylvicultural crops, shouli therefore be pressed upon the notice of Corexnment. Agriculture might then become more profitalue thim at present: and the agrieultural interests might he supported at the sime time, as utherwise ministering to the wants of the people, who have a right to see a better state of things bronght abont than now exists. This matter lies with the people themselves, and all should lend their assistance to haring matters put on a better footing without further delay.

Laying Out of Plantations. - I Forest, in the lewal sense of the word, means a tract of lind, not necessarily woodland, formerly 
laid under the royal ban for the benefit of the chase. In the common acceptation of the word nowalays, however, it practically means either a natural tree-growth or an artificial plantation of very large extent, or a large district of country partly under trees and partly waste. As examules in illustration of these definitions, reference may be made to the national forests of Delanere in Cheshire, 1)ean in Gloucestershire, and the New Forest in Hampshire, in all of which Oak has been planted, and is being reared for the purposes of the State; to the private forests of the Duke of Atholl in Perthshire, in which Larch is grown to a larger extent than on any other property in the island; and to those of the Earl of Seafield in Strathspey, in which the Scots Pine is grown more extensively than on any other individual property in Britain. All these forests are made up of a number of separate enclosures or plantations, of various extents, and of different ages as regards the growing crops.

There are comparatively few landed properties in this country so large as to admit of planting to an extent sufficient to warrant the appellation of Forest being applied to their woodlands. Any area that is much under 10,000 acres is hardly worthy of being called by this name, but forms simply a woodland. This, however, is merely a matter of opinion. It is practically of no importance whetherr the woodlands upon a property be called a forest in the aggregate, or be designated by the names of the plantations respectively: this is a point to be decided entirely by the choice of proprietors.

Every piece of land enclosed as woodland, whether it may be of large or small extent, is called a plantation, if its crop be planted and not of natural growth; but when the crop on a piece of woodland is of natural growth, it is called a wood. Foresters therefore speak of woods and plantations upon a property, meaning that the timbercrop on the former has been formed by natural regeneration, whilst that on the latter has been produced artificially, either by means of sowing or of planting.

It is admitted by every person of refined taste that no object is so ornamental upon a landed estate as an extensive healthy plantation, situated upon a well-chosen spot, and having a well-defined, tastefully bending outline; and from a purely arboricultural point of view this consideration is of the first importance, and ought to receive due attention in laying out plantations.

In Sylviculture, however, gracefully bending and curved lines are not always consistent with the fundamental principles of scientific Forestry. Esthetic considerations, which sublie the principles of Arboriculture, must in the case of Sylviculture give precedence to coldly calculating actuarial and financial considerations. But utility possesses a beauty of its own. And it 
is wonderful how woodlands seem to fit into a landssaje; for cven the straight lines of the outer edge of plantations become softencel in course of time, and, from the wealth of foliage clothing the outer line of trecs, ultimately offer a pleasant effect to the eye.

As the future welfare of a plantation is considerably, and indeerl most essentially, affected by the manner in which it is laid out, it must be determined beforehand whether arboricultural or sylvicultural principles are to be mainly followed. It must lue determined whether the plantation is to be made from the lamrlscape-gardener's point of view or on sound financial principles, with the express view of obtaining the largest and most valuable supplies of timber in the shortest space of time, or, in other words, of utilising the productive capacity of the soil to its most remunerative extent. In the former case, it is necessary that the person who would lay out a new plantation should be possessed of a knowledge of the nature of the growth of each sort of tree when planted upon any given soil or situation. This knowledge will enable him to judge rightly as to the effects that certain trees will have when planted in any given spot; and he will also be enabled from such knowledge to judge correctly as to whether or not these different species of trees will grow well in the situation chosen for a new plantation. And it is further necessary that, in the laying out of a new plantation, the arboriculturist or landscape-gardener should be acquainted with, or at least have in view, any local peculiarities of the climate, relative to cold and destructive winds from certain points. Without this knowleclge he will not be able to lay out the proposed plantation in such a manner as to have the greatest possible effect in giving shelter to the surromuling country, which is often the principal end a proprietor aims at in having woods upon his estate.

In the latter case, however, the resthetic effect of the plantation is a matter of indifference; and the shelter given to agricultural lands is not the first concern of the sylviculturist. From a knowlectge of the local clinate, prevailing winds, nature of seil and situation, and habits of trees under similar physical conditions, his duty is to select such species of trees, and to admix them in such proportions and manner, as will ultimately yield the most remunerative returns.

For petty operations, the larger the area planted in, the sooner will the trees therein come to useful size, and attain the llesired end: whilst the smaller it is, the more likely are the hopres of the planter to be disappointed. And the reason of this is obvinus. The youmg trees growing in an extensive plantation hegin to shelter one ancther as soon as they rise a little above the surface of the natural herbage: whereas, if the plantation be narrow, the young trees can haruly be said ever to get the length of sheltering one another, as erery breeze 
of wind blowing through the whole breadth, acts upon each tree almost as powerfully as if it stood singly and alone. Therefore it is most profitable for proprietors always to plant in large masses.

Even in extensive sylvicultural operations, practical experience on the Continent has shown that dense masses of homogeneous woods are more productive per unit of area than small scattered crops; for in the former case the productive capacity of the soil is not interfered with so much by the action of winds, and the circulation of the soil-moisture is rendered more equable.

Trees planted in a mass of 100 acres in extent will be more healthy, and will sooner attain profitable size, both with respect to timber-production and to shelter, than if the same total area were planted in smaller tracts. From this it follows that, if a proprietor wishes to plant 100 acres upon his estate, he will raise more healthy timber by planting in one mass, than he would do by planting the same extent in four masses of 25 acres each, or in other broken allotments.

So far as can be conveniently arranged, no young plantation formed upon an exposed situation for the purpose of providing shelter should be less than 100 yards broad at any given point; and where the soil is of a light, shallow nature, upon which lofty trees are not likely to be raised, a breadth of 100 yards may even be too little. If there be much mossy ground upon the site intended for a new plantation, or if there be much of it consisting of poor, thin, gravelly heights, as is often the case in unimproved districts, a narrow or small plantation will not thrive well and profitably. A small plantation may succeed upon a good loamy soil in a sheltered situation; lut upon a thin shallow soil, and in an exposed situation, it would sometimes be better not to plant at all, unless the plantations can be formed in large blocks of from 200 to 1000 acres or more in extent.

Almost every landed estate has some peculiarity of its own. The wind that might prove injurious to agriculture on one estate may not affect that of another marching with it; hence the particular local climate, and especially the winds, which prove most unfivourable to an estate, should always be taken into consideration in the laying out of plantations upon it.

Such local differences with regard to the effects of situation on the prorluctive capacity and the anenity of landed property is illustrated on the opposite page (see Fig. 87).

The estate of Whitelands, being situated upon the west side of the hill ", which runs nearly north and south, would be greatly sheltered from all storms of wind from the east and south-east. Consequently, in laying out plantations upon the estate of Whitelands, the greater 
length of the same, in order to protect the land from the north and south winds, would reruire to be marle from east to west; and if the situation were exposed to destructive west winds, plantations meant to protect the lands from it would rerpuire to lue made from unstle to south. The Newbury estate, howerer, being situated upon the east side of the hill ", would be shelteren from the west and south-west winds, but would be much exposed to the north and east winds; conserquently this estate would require to be sheltered by plantations extending for their greater length from east to west, in order to protect the lands from the north winds, or else running from north to south, in order to protect them from the east winds.

As there is a considerable opening between the south end of the hill $a$ and the north end of the hill b, - the north part of the lands of Ashwell, which occupy the west side of this opening, and those of Bucklands, which occupy the east,great care is necessary in laying down plantations on either of these estates; for either the east or the Fig. 87.

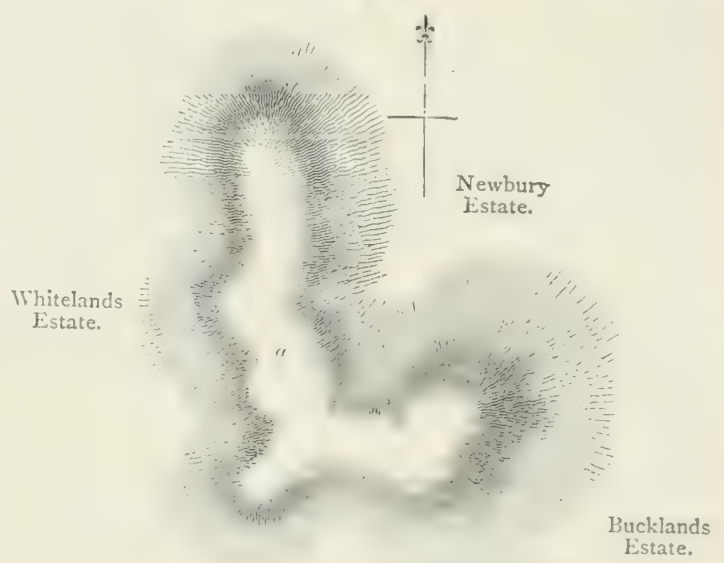
west wind, in passing through such an opening, gathers force from being confined in its passage between the two hills. Therefore, in order to protect each estate from the effects of wink pasing through uncherked to either side, a mass of plantation would require to be situated right in the opening, having a conver side turned to the east, and another to the west, which would naturally tum the wind to either side, and cause it to spread along the hills.

Again, in order to protect the lands upon the west of Ashwell from the north, plantations would require to be laid off from east to 
west; and in order to protect them from the west, they should be laid off from north to south.

Upon the estate of Bucklands, however, the land requires to be shelterel more particularly from the north and east winds; therefore plantations laid out upon it with the view of protecting the estate from these winds would require to be made from east to west in the one case, and from north to south in the other.

From what has been said, it will be readily intelligible how one estate may be injured by the wind from a certain point, while another marching with it may not be injured by the same at all. Thus the estate of Whitelands, from being situated upon the west side of the hill $a$, is completely sheltered from the east wind; while, on the contrary, the lands of Newbury are naturally exposed to the east. The northern parts of both the estates of Ashwell and Buckland are, from their natural situation mear the opening between the two hills, exposed nearly alike to the east and west winds; while the southern parts of these estates are differently sheltered by the hill $b$. Therefore, in the laving out of plantations upon any landed property, such matters as those that have here been indicated must in all cases be kept in view by the intelligent forester.

Of the action of storm-winds on woodlands, an unfortunate and very striking proof was given by the great north-east storm of the night of 17th November 1893. This, following after continuous and heavy rainfall, threw no less than about 1,500,000 trees in Perthshire and Forfarshire alone, valued at nearly $£ 300,000$. $^{1}$

The worst storms come as a rule from the west, south-west, and northwest; and as they are often accompranied hy rain, these are on the whole the most dangerous to timber-crops. In the case of ornamental trees the root-system naturally accommodates itself to its special requirements by forming stronger roots on the southern and south-western sides, so as to be the better able to resist the pressure of the wind. This natural endeavour to throw out a much greater proportion of roots in that direction is also assisted by the fact that, in consequence of the greater amount of warmth given to the soil on the warmer southern and south-western side, the root-system is more active, and naturally better developed, than on the colder northern side overshadowed by the foliage of the crown.

With soil sodden by rainfall, and with the powerful leverage given by the foliaged crowns of trees, the damage done by westerly winds is often great, more especially in the case of evergreen coniferous crops. In the throwing of timber, the north and south sides of valleys running east and west suffer more than woods facing west, whose outer roots are generally well developed.

The north wind can occasionally be not less injurious; but it is not usually so riolent as west winds, and more frequently blows at a time when

${ }^{1}$ A detailed list of the amount of damage done on the individual estates will be found in the Dundee Advertiser of 1st December 1893. 
the soil is not sordenerl by heavy and continuons rainfall. Its action is more generally confined to the batse of the valleys; and to the lower sides of lilll: than to the higher tracts.

'The south wind, on the contrary, is generally more violent at hill-tops, and is not apt to do much damage to woods skirting the valleys.

Although most exhausting and injurious from an agricultural point of view, the east wind is, on the whole, the least injurious to timber-crops so far as the throwing of timber is concerned; for it is usually of a drying nature, and blows at a time when there is little chance of the soil being soft from recent heavy rainfall. But as regards youmg ylantations it is of a drying and exhausting nature, tending to rol, the soil of its moisture, and to interfere with the normal process of the humification of dead foliage.

All winds have a tendency to be more violent when the local configuration of the soil enables them to take a downward direction, than when they are forced to ascend; hence, when storms rush down valleys, they are apt to be more destructive than when blowing up the valley. And when valleys grow gradually more confined, the fury of the storm becomes increased, oring to the growing pressure from behind.

It has already been mentioned that the welfare of a young plantation depends in a great measure upon the manner in which it is laid out, and that every plantation laid out according to scientific rules will necessarily succeed much better than one in which the plants are distributed merely in a careless, unscientific mamner. The following rules may, therefore, be laid down for general suidance in the laying out of new plantations in which arboricultural considerations may be allowed to have precedence over the purely financial and actuarial principles of Sylviculture:-

1. In laying out the boundary-line, avoid all straight lines upon the exposed sides. If possible, make no straight lines upon any side. They are objectionable to the eye, and are without meaning when applied to natural objects. In nature there are, for a very good reason, no straight lines; for they are without strength to resist outward pressure.

2. The greatest length of a new plantation should extend in the direction contrary to that of the prevailing wind of the district. And, at the same time, the greatest extent should be kept along the highest part of the ground to be planted.

3. The best possible form of boundary-line which can be thrown out against the wind, upon the most exposed side of a plantation, is the convex. Such a form of boundary-line weakens the strength of the wind when it strikes upon it ; for the strength of the storm is, as it were, divided by the projecting bend of a well-defined convex.

4. Upon the most sheltered sides of a plantation the boundary-line may be made to bend one way or another, as æesthetic considerations may direct. But in all cases a concave bend should only be made where there is a good breadth of plantation immediately behind it.

5. The highest parts in a neighbourhood, if they are not too lofty and exposed to admit of trees being grown profitably upon then, ought to be chosen for the site of a plantation. By choosing such a situation, the greatest 
possible shelter is likely to be attained for the fields of the surrounding tracts; and, at the same time, a plantation situated upon a height always forms a prominent and a pleasing object to the proprietor. A bare height, at only a moderate elevation, always carries along with it the idea of barrenness; but when planted with trees, it often forms one of the most pleasing objects in the landscape of an estate.

6. In the laying out of a new plantation intended principally for the protection of live-stock on a high, exposed country-side, there ought to be several rather deep sinuosities upon the most sheltered sides. These sinuosities ought to be upon a bold wild scale, so as not to cause any weak point to project from the body of the plantation; for if this be the case, the plants will not thrive at such weak points, and will consequently always have a mean appearance.

7. If, in the general arrangement of the boundary-line, it should be found necessary to make a bend having its concavity facing the side from which the storm comes, then care should be taken to construct such a bend in a hollow part of the ground, or at least as low as possible; and it should be backed by a good breadth of planting behind (see Fig. 88 at 1 ).

In the accompanying figure (Fig. SS) a sketch is given of the outline of a plantation having its exposed sides $(a$ and $b$ ) facing the north and east respectively, and offering two convex lines to the storms acting upon it from those points.

From an attentive consideration of this, it will at once be evident that trees growing behind a bend of this description, and the outer

Fig. 88.

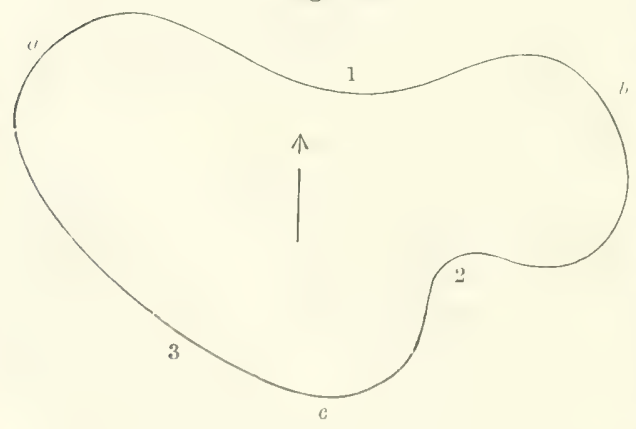

trees actually forming the bend, are, from the position in which they are arranged, more capable of resisting the effects of storms than those forming a straight line, or a concave bend. For, when the wind impinges upon the convex bends (at $a$ and $b$ ), its force must become weakened, because the line of fence recedes from the wind, as it were, at any given point; and, in proof of this, reference may be made to the similar action of the sea upon the differently shaped bodies which may be made to pass through the water. For example, the forepart of a sailing-ship is nearly of the convex form, and when the water strikes upon it, it spends itself along each side of the vessel. Again, were a ship to have its forepart made flat, it could not be urged through the water at all; and further, were it made concave, instead of the vessel being made to go forward, it would be driven back. This is exactly the principle of the action of the wind npon the different forms of plantation-lines; and from this it will be 
seen that the concave hend is the worst for the purpose of protecting the interior wools from the storm. Conserquently, in making such a bend in the line of a plantation-fence, great discrimination is reruisite to know when it is permissible.

By glancing at the concave hend marled 2 (in Firg. S8), it will he observed that it is backed by a great brealth of planting from the north (ab), and is also well protected by the convex bends, T, upon the north-east and $c$ on the south-west: besides, its situation is upon the most sheltered side of the plantation, the sonth-east. IIence such concavities may be made to a greater or less number upon the same principle, according to the extent of the ground planterl, and also as the individual taste of the proprietor may suggest. In general, the fewer of such concave bends there are, the better for the welfare of the plantation: where farm live-stock is to be sheltered, however, it is often necessary to make them. For example, if there were no concavity at 2 , and a storm blows from the east, cattle could have no real shelter along the edge of the wood at that point; but in such a bend in the outline of a wood as shown at 2, stock would not be exposed to any wind except from the south, which is, generally speaking, not a very cold or stormy wind in this country.

The bends in the outline of a plantation should always be made to follow the natural rising and falling of the ground. Thus, where any lateral heights may project from the main body of the land haid out for a plantation, the fence-line should take a bold convex turn in the same direction, though just so far as may be considered necessary : and where a hollow of the ground occurs, the fence-line should be made to take a bold concave turn there, coming up again in the form of the convex where the ground begins to rise.

This will be more easily understood by reference to Figs. 89 and 90. Fig. 89 represents the side of a hill as laid off for an ornamental or shelter-wood plantation, the dotted line representing the fence. The concave bend $a$ is made in a hollow, sheltered part; and the convex bend $b$ rises over the high ground adjoining, but is not extended to the extreme tail or bottom of the hill-ground. For it may be, and often is, found extremely advantageous to retain a part of such high gromel in the field, in orter that sheep and other stock may have the benefit of the same for lying upon at certain seasons of the year when the lower grounds may be in a damp state; and besides this, it has already been stated that the bends need only be extended so far as may be considered practicable for general purposes. In all cases, however, the retention of the natural form of the ground should be kept in view. The concave bend $c$, it will be observed, is made to extend far back into the hollow ground; for such a coomb, when sheltered by plintations nearly all round, is one 
of the greatest benefits possible for farm live-stock at all seasons, both as regards protection against storm in winter and affording shade from the sun in summer, and more particularly if the soil in it be of a dry description.

The convex bend $d$, again, is extended beyond the tail or bottom of the hill-ground, in order the more effectually to yield good shelter to the adjoining hollow part $c$; and the same remarks apply to the

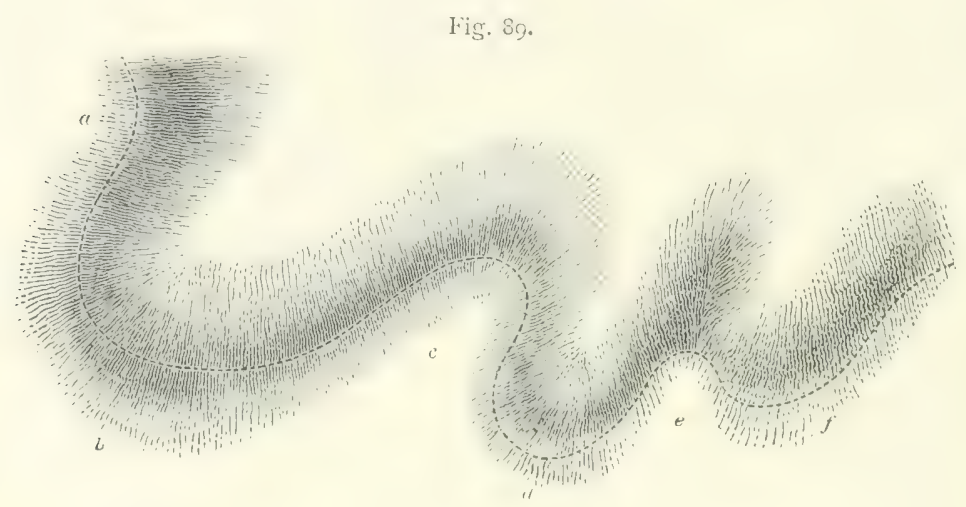

Fig. go.

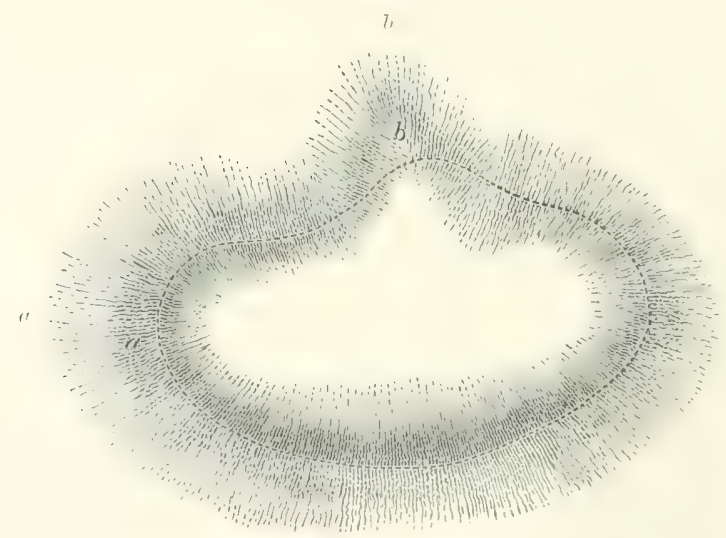

concavity $e$, which is also much sheltered by the bends $d$ and $f$. These points are most necessary to be attended to in the laying out of woodlands for shelter in hilly districts, where, indeed, the welfare of farm live-stock is often more to be taken into consideration than the giving of mere shelter to field-cropping.

Fig. 90 is the representation of a hill which it is wished to form into a plantation in an exposed district. At a the hill-ground runs out to something like a mere point; and in this case the line of fence 
is kept a little ligher, in order to give the convex bend a bolder anrl wider turn. For, as has already been stated, all weak projecting points ought to be avoider in the proper laying ont of a plantation boundary. Had the fence-line at a just been brought ont in the exact natural form of the tail of the hill, a mere point would have been made, which should, in all cases of this nature, be avoided. And somewhat similar reminks apply to the projecting point of the hill at 7 , where the fence is also kept back in order to strengthen the interior; but by the line of enclosure being lept a little back in this manner, the appearance is improved. Yet in all these cases the true natural form of the hill has been retained.

In the laying out of a new plantation, if it is at all visible from the windows of the proprietor's mansion, or from any part of his pleasure-grounds, great care should be taken to ensure its haring a pleasing effect when viewed from such points. If it should he hadly laid out, from an æsthetic point of view, it will prove a continual eyesore ; whereas, if it be bounded by a graceful outline, it will form a constant source of pleasure.

Besides the converting of hill-ground into plantations, the planting up of ravines and of other local hollows has also to be considered. Not infrequently such land, unless in the form of broad coombes, is of very little value to the proprietor for any agricultural purpose; but if judiciously planted, and carefully tended according to the precepts of Sylviculture, they may often be made the most profitable of all situations for the growing of timber. Relative to this point the remark may here he made that, even upon inferior classes of soil, trees will often thrive far better upon slopes and in hollows than upon richer and more fertile land situated upon a level tract of country; hill-slopes, therefore, appear to be most natural situations for the growth and welfire of sylvicultural crops. This seems a wise provision of nature, seeing that such land can very often not be cultivated profitally with agricultural erops, and may sometines even be unsuited for permanent pasture-land.

With reference to the above, it may be noted that on sloping hillsides the actual area of the soil is of course greater than if it were reduced to the level of a plain in the proportion of the hypotenuse to the base of a rightangled triangle-ie., exual to the hase multipled by the cosine of the amule of inclination. In consequence of this, the growing-space occupied by the rootsystem, and the amount of light, air, and warmth enjoyed by the canopy of foliage, are also greater. Again, the percolation of moisture leads down nutrients from above past the root-systems below; whereas in soil on the plain the nutrients are carried off towards the subsoil and out of reach of the roots of the trees altogether. but when the hillsilles are stecp, these alvantages are lost, and the rate of production is less than on level ground. 
In the laying-out of such hollows or ravines for the formation of llantations, it may here be remarked that the fence or boundary-line ought, for the greater part, to be made to follow the undulations of the brow of the ravine. That is to say, the boundary-line of the ground to be planted in the hollow should be made to correspond, so far as local circumstances will allow, with the natural line of the tail of the background above and the head of the slope. This is certainly the method which gives the most satisfactory results, so far as a pleasing effect is concerned. But this must not be understood as intended to advocate that nothing ought to be done in order to improve the natural appearance of such irregularities as are often to be found existing along the edges of hollows or ravines. On the contrary, there is no branch of Arboriculture in which there can be more taste displayed than in this, not only with the view of giving effect, but with the more important object of giving the benefit of increased shelter from storm to the cultivated grounds lying under the lee of the woods.

It is well known to all country people, that in glens or hollows of any extent there is generally a draught of cold wind wafting along when the same is not sensibly felt upon the higher grounds above, at least at any considerable distance back from the brow of the hollow; and such cold winds are often very injurious to crops in the adjoining fields, particularly in the case of late frosts or cold damp nights in the spring months. Now, in order to prevent the evil effects of such draughts of damp and frosty winds in the spring, it is very advisable to have convex bends rising, at well-chosen points, out of the ravine or hollow, and extending a considerable way upon the level ground above. Hence endeavours should always be made to bring up such a bend at a part most likely to intercept the current of cold air from the ravine to the higher grounds; and such bends should not be made upon a small contracted scale, but should extend to a considerable distance. By this means the ground above may be greatly protected from the effects of sudden gusts of wind, which are very apt to arise in such places, and which are almost always more or less injurious to the agricultural interest.

Many maintain that the planting of hollows with trees adds very little to the shelter of the neighbouring country. But those who are of this opinion seem to overlook the fact that belts of trees in hollows break the violence of the winds passing through them, and at the same time tend to modify the temperature if it be either very hot or very cold. This is more particularly the case when projecting points are made to jut out at proper and judiciously chosen parts upon the level country. And not only do such projecting angles of woodland prove beneficial as regards shelter, but they at the same time add greatly to the general picturesque effect of the landscape. 
The method of laying out plantations in the form of strips, so often to be met with in many parts of the comitry, grives a for and mean appearance to an estate. The form in which they have generally been made is in straight lines, from 20 to 40 yards lroad. In such narrow belts of woor the trees are very seldon foum in good health; and, upon consideration of the matter, this is hardly to be wondered at. From the narrowness of such strips, the proprietors must always be afraid to thin them, as their power of giving shelter of course depends very materially on the (lensity of crop); and the natural consequence is that, from the trees leeing left ton thick, the one tree soon affects the normal vigour and development of the other. And even where such strips have been well managed, it cannot be expected that they could produce either good or healthy timber, or make a good shelter; for, being so narrow, the trees are never able to shelter one another to anything like the same degree as is the case in extensive woods. But it is a happy circumstance in the history of Arboriculture that few such strips are at present planterl. Most landed proprietors are now heginning to see the disadvantages of such a method of raising plantations; hence, on almost all estates that are well managed, the old-fashioned narrow strip has given place to the well-defined extensive plantation, which is, indeed, the only remunerative way of cultivating trees for useful and profitable purposes.

And in conclusion, upon this head, the author begs to state that, in all cases of good management, he has found hedgerow trees infinitely superior in every respect to narrow strips of plantation, even where such were under what might be considered fair management. Trees in narrow strips, even when tolerably managed, seldom live to any great age, owing to the want of growing-space; whereas hedgerow trees, when properly reared, from having ample growingspace, attain their full natural vigour and dimensions, and live to double the age of trees found in a strip. And, when allowed to grow rather closely together, they make a much better shelter than an unhealthy strip. Therefore, in all cases where lamel is considered of great value for farm-cropping, and where strips cannot be made of sufficient breadth, he would recommend the planting of hedgerow trees in preference to the usual methor of planting narrow strips.

On this subject the views of the editor are diametrically opposed to those of the author; but he considers it only fair to the latter to let his recommendation stand.

Hedgerow trees, and more especially those which, like the Ash, throw out long, spreading, superficial roots, not only rob the land of nutrients that might be available for the agrienltural erops, hut also, by orershatowing the crops, withdraw, from all such as lie to the north of the stem, the full extent 
of sunshine under which alone the productive capacity of the soil can be completely utilised. This is a matter of very real agricultural importance to the landowners and farmers of Britain. In former days the landowners in Oxfordshire, for example, used to stipulate for at least a certain number of trees being maintained; but now tenants stipulate that at most only a smaller number shall be retained.

The rural beauty of England would be ruined if the hedgerow trees were all cut down. But the country would gain immensely if all such trees were felled, and the soil utilised to its fullest capacity; whilst woodlands should be formed, on rational sylvicultural principles, only on the hillsides and wherever the land is not more remunerative under arable or pastural occupation.

The purely agricultural view of the matter is contained in the following extract from Macdonald's edition of Stephens's Book of the Farm, 1893, Div. V., p. 219 :-

“Trees and Hedges. - If cattle are to be grazed on the fields, Beeches or forest-trees should never be planted in the line of thorns, for it is impossible, eren with the greatest care, to rear thorn plants, to become a good and beautiful fence, under their drip. Thorns are impatient of being orershadowed by taller trees; and trees planted on the top of a mound, betwixt double hedges, not only rob both of moisture at the roots, but pour their drip directly upon the branches of the thorns.

" 'To plant trees in the line of a hedge,' says Lord Kames in his Gcntleman Farmer, p. 283 , 'or within a few feet of it, ought to be absolutely prohibited as a pernicious practice. It is amazing that people should fall into this error when they ought to know that there nerer was a good thorm hedge with trees in it. And how should it be otherwise? When suffered to grow in the midst of a thorn hedge, the tree spreads its roots everywhere, and robs the thorns of their nourishment. Nor is this all; the tree, overshadowing the thorns, keeps the sun and air from them. At the same time, no tree takes worse with being orershadowed than a thorn.'

"Hedgerow-trees are strongly recommended by the old writers on agriculture as being the best means of growing timber for the nary, and giving sheiter to fields; and a writer on timber (Matthew On Naral Timber, p. 359) seems to farour the plan of planting the Oak in hedgerows, as if that tree could not be sufficiently gnarled for naval pur. poses, and rendered thick in the bark for tan, in other exposed situations than in thorn hertact."

On the Selection of Trees for Planting.--The first law of Sylviculture is that, in order to ensure continuity in the returns, only those species of trees should be grown as timber-crops which are able to protect the productive capacity of the soil. It is only when this primary principle has been satisfied that a choice may be made between the several species of trees to be grown, either in pure woods or, as is in general preferable, in mixed roods. For, if plantations be made of species of essentially light-demanding trees, like Larch, Scots Pine, and Oak, when once they begin to exhibit natural demands for increased individual growing-space as young trees of 25 to 30 or 50 to 60 years respectively, then the productive capacity of the soil can only be duly safeguarded by underplanting. Otherwise the landowner is squandering his capital, in place of merely harvesting the interest from it.

When once the importance of this fundamental principle has been fully realised, however, then, in raising timber as a profitable 
crop upon any landed property, two things resuire to be kept in view - namely, 1st, to plant those sorts of trees which will come to be of the greatest value in the marliet; and 2ud, to plant those sorts which are most likely to grow to useful size upon the sisil to be planterl. In illustration of this, the case may be supposed of a proprietor resirous of planting larrwoods like ()ak, Ash, Elm, and sycanore. If his gromel were not naturally adipted for the liealthy swowtl of these trees, he would ultimately be a loser by planting them, even arluitting that he could get a ready market for the timber, and that he intended to underplant, when this operation becane necessary, for the sake of protecting the productive capacity of the soil. On the other hand, were the same proprietor to plant P'ines am Firs rpon his land instead of broad-leaved species of trees, then, eren although he could not get a ready market for such woor in his neishlourhood, he might, if the land were only suitable for the growth of Pines and Firs, ultimately, from the healthy state of his trees and the greater bulk of timber produced, be a great gainer by such culture. Hence, in order to receive the lighlest possible monetary returns from timber on any given land, it is of the first importance to grow only those species of trees for which the soil and situation are adapted.

In all the districts near any shipbuilding port, or close to the principal stations of our railways, no wool can pay better than Oak and Larch, both of which are used in the construction of coasting craft, and of merchant vessels of much larger size. Oak timber brought from a distance sometimes draws a higher price per foot than Oak grown near the market, in consequence of any known superiority in the quality of the wood. Hence proprietors whose plantations are within a few miles of thriving seaports, will occasionally find that their plantations of l'ine and Larch pay them much better than their Oak woods when the land is not so well adapted for the raising of Oak as for Pine and Larch. 'The net value of timber as a crop upon any piece of land, no matter in what locality it is situated, does not so much depend upon the linds of trees planted, as on whether the soil and situation are adapted to their natural requirements with regard to food-supplies and climate. The only sound adrice that can theretore he given to proprieters of land is to plant only those trees for which the given soil and situation are best suited. In the neighbourhood of all large towns there is a continual demand for seots l'ine, Larch. and sinue Fir for railway purposes and for deals: and, wherever the soil is atlunted for the growth of these kinds of trees, they in general pay as well as, if not better than, any other surt of timber-erop, sering that their crowth is quick. Ash is a wood much in demand about all considerable towns for agricultural implements, hamble-wood, coateh-building, de. and pars

VOL. I. 
any proprietor well when his land is adapted to its healthy growth and nomal derelopment, as, for instance, in dells, coombes, and other local hollows having a good strong loamy soil, and a sufficiency of soil-moisture. The Scots Elm is also much used in large towns, frecuently for the same purposes as the Ash; lut, unless it be grown in a loamy soil, it will not prosper well, nor will it ultimately turn out a profitable tree to the planter.

In the neighbourhood of all large towns a great quantity of fuel is generally consumed; and for this purpose many sorts of wood are used. Where coals are plentiful, wood is never grown for the purpose of being consumed as firewood, as is so extensively the case throughout continental Europe. Only the tops and larger hranches of full-grown trees are usually sold for this purpose, when the mature timber is cut down for utilisation. In England, however, and particularly in counties like Suffolk, where coal is scarce and highpriced, the raising of wood as a substitute for other fuel is necessarily resorted to, and constitutes a branch of economic Forestry. For this purpose there are large tracts of mixed coppice grown in the usual way for producing firewood; that is to say, this sort of coppice is planted in the usual form of a plantation, and enclosed with a proper fence. The trees which are intended to form the future coppice are generally planted at $4 \mathrm{ft}$. apart, using none but such species of broadleaved trees as are known to produce a great quantity of stoles or root-suckers and stool-shoots from the base or collar of the stem when cut over - as, for example, the Oak, Ash, Sycamore, Hazel, Willow, Poplar, Birch, Hornbeam, Sweet-Chestnut, \&c. These trees, when first planted, are treated in the same manner as in the formation of plantations of the broad-leaved species of timber-trees; but instead of thinning any out when they come to such a size as to stand close together, which will be when the plants are from about 15 to $20 \mathrm{ft}$. in height, and from 3 to $5 \mathrm{in}$. in diameter in the stem, they are cut over to the surface, and allowed to push up another supply of stool-shoots and stoles for another crop. In this manner these stools may be cut over for a supply of firewood for an indefinite number of years, and at such regular intervals of from about 12 to 20 years as may be found necessary in order to supply the demand, and yield the most remunerative returns. In cutting down these coppice plantations, the whole is not used for firewood. All the straight rods are sold for utilisation as hop-poles, bobbinwood for thread-manufacturers, hoops, crate and basket willows, poles for various purposes, besom-spray, implement-handles, \&c.; and when the best of the wood has been picked out for these purposes, all the spray, and what may properly be termed refuse, is bundled up and sold in the form of "pimps" or faggots. In poor 
tracts, where the land is not suited for the production of large timber, as also in low swampy grounts, this sort of crop answers well, and is indeed often fairly remunerative. But wherever land is of a fair quality, the more profitalule system is to form plintations with the express intention of allowing them to orow ul, as high-forest into mature timber of full size, and to allow the thimnings to be used for minor purposes or for firewood às they are cut out. By this mode of going to work a greater quantity of woorl will be taken from an acre of land at the end of a specified time than if the soil were kept entirely under coppice; and consequently a greater return of profit would be received.

Continental experience of Sylviculture, conducter on true scientific principles and in a sound economic manner, has shown that on the whole Highforest is the most profitable class of timber-crop, then Copse or Coppice under Standards, and that Coppice is the least jrofitable, as it is less conservative of the productive capacity of the soil.

But these broad generalisations are, of course, subject to a great many exceptions. Thus Osier-holts, or Oak-coppice for tanning-bark, wherever the young bark yielded by a rotation of 16 years is well paid, or Coppice of Common Alder where there is a demand for wood for charcoal or cigar-boxes, may all prove, under given conditions of soil and situation, and of the timbermarket, much more profitable than many kinds of Copse, or of High-forest. Again certain classes of Copse pay better than certain classes of High-forest.

And the reason is obvious. For, when once the Coppice or the Underwood in Copse has been formed, each rotation of 12 to 20 years in the former case, and 20 to 25 years in the latter, involves comparatively slight regenerative costs, practically amounting only to the outlay for filling up blanks: whereas the cost of the production of high-timber crops keeps continually growing at compound interest, and as time rolls on this increases very rapidly, except there be a good per contra in the shape of returns from thinning.

On entailed estates the laws relating to timber (High-forest) and Sylva caedua (Coppice) has previously been noted (see chap. i., p. 72); and these are points often of equal importance to landowners with the actuarial promises held out by timber-crops that will probably only become mature during the life-time of their children or grandchildren.

In the districts in England where hops are grown, the cultivation of small Larches often palys very well. These may he planted rather closely together, say at from 18 to $24 \mathrm{in}$. apart, or 10,890 to 19,360 per acre, so as to be drawn up quickly for hop-poles. And ats the given land will produce several crops of the sime sort, when plinted in succession, very profitable returns are mate at compramively little expense. This form of crop has at the same time the additional advantage that little or no professional skill is necessary in the person who grows it.

In districts where coal-mines abound, great quantities of woul of 
various kinds are in request. There the demand for wood of all sorts in weder to supply different purposes is very great, more particularly for pitwood or propwood, which generally consists of minor thinnings of various sorts of wood, not less than 3 in. in diameter at the small end. In the neighbourhood of coal-mines, the most profitable wood to plant is Larch, which, when taken out in a young state as thinnings of from about 3 to $5 \mathrm{in}$. in diameter, is in great demand as propwood. When of the larger size of about $8 \mathrm{in}$. in diameter, it is much sought after for small sleepers to lay under the rails upon molerwround ritilways in mines; and when of full-grown and mature size, the Larch is used extensively as common railway sleepers, and as boards for various purposes. The second rank in remunerativeness and general utility is held by Scots Pine. This is also used for propwood when of small size; and, when of full size, for sleepers and boards. Poplar and Willow may perhaps be said to take the third place; for they are much sought after about mines, particularly when of dinensions yielding gooul large scantling, and are used in the form of planks for clothing the waggons. Ash and Elm are also much used in mining and similar establishments, the former for handles to picks, and the latter for shafts to the underground waggons. Finally, Oak is also in considerable demand in mining operations. It is used both for framing for the large waggons and for various other purposes connected with such establishments. The above are the principal sorts of wood used for mines. But in mining districts any small thinnings of wood of almost every kind are most easily disposed of, provided they be a size averaging from 3 to $5 \mathrm{in}$. in diameter. For this class of forest-produce there seems to be a good and increasing demand.

In the neighbourhood of flax-manufactories there is always a great demand for bobbins about $6 \mathrm{in}$. in diameter made of Sycamore, as well as for others of a smaller size, which are generally made of Birch.

Thus, for example, a Bobbin-mill exists near the Falls of Tummel in Perthshire, in which only Birch timber, grown largely in the immediate neighbourhood, is utilised for bobbins and pirns. This is perhaps the finest district in Britain for the growth of Birch. But the woods are not managed on sylvicultural principles; hence the productive capacity of the soil is not utilised to anything like its fullest and most economic extent.

For railway requirements vast quantities of wood are now used in the form of sleepers. Larch and Pine are generally preferred, and for these there is a constant and almost an unlimited demand. Again, in the erection of posts and rails for the purpose of fencing 
the fields along the railway lines, Larch and l'ine are still largely used, althongh wire-fencing is really more econmuical in the end. And in the form of railway waggons of varions kincls, Ash, Elm, Uak, Pine, and Fir are used. In the making of a line of railway, the contractors require a great guantity of wool from the different proprietors through whose gromuls they pass in the act of worling: and in cases of this nature a good price is generally wiren for it. Isut the sales of this description are only of a temporary nature, in so far as the contractor's work is to be calculated upon. When, however, a line of railway is opened up through any property, although it should be a considerable way off, the proprietor is, in respect of a market for his wood, or indeed of any other produce upon his estate, nearly on a level with his neighbours who may be within a comparatively short distance of the same market. In such circumstances, the proprietor may plant any crop that will best succeei upon his land, and calculate upon having it lorought to market in a cheap, sure, and expeditious manner. In such a case, if the proprietor find his land adapted for growing the more valuable linds of timber-trees, he need not hesitate as to planting and rearing them, although he may not have a market near for their sale. When his wood is ready for cutting down, he can avoid the expensive process of horse-cartage, and put his trees at once upon the railway trucks; and at a very trifling expense he may have them conveyed for 50 miles to market, and sold and delivered much quicker than his neighbour, who may have to cart his wood only 5 miles to the same place, although the trees may have been all cut at the same time.

The above remarks should be qualified by pointing out the iniquitous system uncler which the railway companies grant preferential rates for the conveyance of imported foreign timber as compared with the transport of home-grown wood. Abundant evidence of this grave economic injustice was given before the Parliamentary Committee on Forestry in 1887 (see chap. i., p. 46).

In conclusion, it may be stated that every propureter of land who intends to plant a portion of it with forest-trees, shoulit not reason with himself merely as to what linels of trees will sell best in his neighbourhood when grown. He should, on the contriry, also study the mature of his soil and situation, and plant those sont of trees upon it which will thrive best and are most likely to be grown to the greatest state of perfection for technical purposes, let the sprecies be what they may. If he do this, he will have the greatest possible bulk of timber from a giren number of acres in a giren number of 
rearrs, and will most probably realise the greatest sum of money as their value. But if he act in an opposite way, and plant trees not naturally adapted to the soil and situation at his command, then he will without doubt invest his money in an uneconomical manner; and the after-results will most probably be vexation and disappointment.

It is impossible to forecast the prices that will be obtainable for different species and dimensions of timber in about 50 or 60 years hence. But, judging from the past history of timber prices on the continent of Europe, whence our chief supplies are imported, and from the prospects of something very like a timber-famine within half a century, it is hardly open to reasonable doubt that timber-crops of mixed woods of trees like Larch, Pines, Spruces, and Silver Firs of various species, - and more particularly including the very promising Californian roods, like Douglas or Red Fir and Menzies or Sitka Spruce, species which, with sound sylvicultural treatment, can be made to attain good marketable dimensions within from 50 to 70 years, - offer pecuniary advantages of no mean order.

And if the railway companies are not prepared to listen to reason, then the owners of woodlands could easily, in very many instances, facilitate the transport of their forest-produce by the formation of Timber-slides and the use of floating channels for the conveyance of their timber to convenient marts (see chap. xi.)

Should Pure Plantations be formed, or Mixed Woods?-In the author's opinion, it is found, generally speaking, most advantageous in respect to the ultimate value of a crop of trees, as well as a saving in the expense of training, to plant the crop of a plantation as much as possible-taking all cireumstances in connection with it into due consideration-of one sort of tree only. If of more than one sort, it should be planted in masses of each separately, to suit soils and situations. As these statements are made chiefly with respect to the growing of coniferous trees, he thinks it necessary to devote a few paragraphs to the fuller consideration of the subject brought forward, as stated in the heading of this section.

As the editor's views are at variance with the author's on this most important point, it seems desirable to collate the two opinions, for the purpose of allowing the student of Forestry to think over the matter for himself.

In extensive natural woods whose past history is traceable, it is almost invarial,ly fom that in their original condition they were distinctly classifiable as Mixed Woods, although this is more prarticularly the ease with lroal-leaved trees than with the coniferous species. And the tendency to assert their possession of the soil is of course far more decided in shade-bearing trees, like Beech, Spruce, and Silver Fir, than in light-demanding species like Oak, Ash, Larch, and Scots Pine. That the ancient forests, with which the Scottish Highlands were at one time clothed, consisted of vast stretches of pure Scots Pinewood, is easily explainable by the well-known fact that that tree is the only species of the Abietinece which is indigenous to Britain. 
The editor's convictions on this matter are summarised in the following extract : ${ }^{1}$

"Mixed forests have the great advantages of dense growth, larger and finer production of timber both as regards quantity and technical quality, lessened danger from storms, snow, ice, insects, fire, and fungoid clisease. Against all of these inestimable solid advantages the only drawback that can be named is that the tending of such woods is much more difficult, and that their formation and mauagement require a considerably greater knowledge of Sylviculture than is requisite for the treatment of pure forests. . . .

"In France, where Forestry is well understood and practised, although not quite so scientifically as in Germany, mixed forests form the bulk of the woodlands, according to Mathieu's statistics for 1876 occupying over 70 per cent of the total wooded area, which was comprised as follows: ${ }^{2} 50.3$ per cent mixed forests of broad-leaved, deciduous species, 17.6 per cent mixed crops of broad-leaved trees and Conifers, 2.5 per cent mixed crops of Conifers, and 26.7 per cent pure forests of various species. In Germany, according to the imperial statistics for 1884 , the total area under forest consisted of 65.5 per cent of Conifers and 34.5 per cent of broad-leared species; but the area of mixed forests is not given. ...

"Wherever ancient forests still exist, or wherever woodlands remain whose prerious history can be traced back for any length of time, it will almost invariably be found that in their original natural condition they were undoubtedly classifiable as mixed woods, and that, if they now cover the soil as pure crops, this has been due to artificial means brought into operation for financial reasons. Owing to the ease with which they can be made to establish themselves, their rapid growth during jouth, and the promise they gire of yielding comparatively high returns for the capital represented by soil and growing stock, pure forests of coniferous species, Scots Pine and Spruce in particular, have both at home and abroad been chosen to replace the former erops of mixed species.

"In weighing the adrantages and disadvantages of mixed forests, the following points may be considered : ${ }^{3}$

\section{"Advantages :-}

1. A greater density of crop is attainable.

2. The soil is retained in better condition and productive capacity than under many pure crops.

3. A larger percentage of timber is arailable for the higher technical purposes, at any rate in mixed forests of deciduous, broad-leared species.

4. Demands of varying nature for timber can more easily be supplied.

5. It is easier to modify or transform the crop at any time so as to meet the present or the probable future requirements of the market.

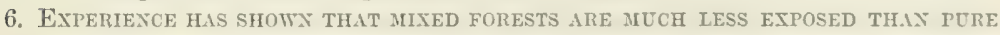
FORESTS TO DANGER FROM EXTERXAL CAUSES, WHETHER OF ORGANIC OR INORGANIC ORIGIN.

7. Natural reproduction or regeneration of mixed woods is on the whole easier than in the case of pure crops.

8. By concentration of rarious species in one series of crops the operations of tending, harresting, \&c., can be conducted most economically.

"Disadvantages are summed up by Gayer in the following words : "

" 'It is easy to understand that mixed crops make higher demands on the capacity of the forester, as it is much more troublesome and difficult to give proper care and attention to each of several species in a mixed crop than to look after one species only. But, when weighed against the many important advantages offered by mixed crops, this drawback can surely seldom be seriously taken into account."

1 Nisbet, Studies in Forestry, 1894, p. $115 \mathrm{ct}$ seq. In that work a chapter is cleroted to the special consideration of the point in question.

2 Gayer, Der Gemischte Wald, 18s6, p. 9.

3 Nisbet, op. cit., p. 118.

* Dor Haldbau, 1Ss9, p. 215. 
If nature be taken for our guide in the cultivation of the trees, it will be found that in natural forests the Pines for the most part grow in masses of each kind separately, and that the Larch and Firs do the same, although not so decidedly; for each species of tree tends to rewenerate itvelf naturally in patches or groups on certain spots or tracts, according to the suitability of the soil of these to the natural wants and to the shade-bearing capacity of the given species.

Thus Larch, for example, an essentially light-demanding species, will only occur in patches when it reproduces itself from seed sown so far in advance of any regenerative effort of other trees that the seedlings can shoot ahead so as to ensure the crown of foliage being kept fully exposed to light and sunshine. But if, under the light shade of old Larch, seedlings of shade-bearing species like Spruce, Silver Fir, Douglas Fir, or Nordmann's Fir, or even Austrian Pine, begin to germinate, then the Larch does not find the physical conditions as to light and warmth that are necessary for its normal development as a seedling; the seeds whel either do not germinate or else soon die offi, under the dense shade of the Spruce or Firs; and, as a perfectly natural result, the various shadebearing species oust the light-demanding kind from tenure of the soil. ${ }^{1}$

In the natural forests of North America the author found that Pines, Firs, and Larch are for the most part to be met with forming separate family groups or masses, and seldom intermixed individually along with any other species. On dry ridges and knolls the Weymouth Pine (Pinus Strobus) forms extensive and dense masses by itself, intermixed here and there with small groups of the Red Pine (Pinus resinosa); while on the wet flats the Larch is found luxuriating, and also in family groups or chmps by itself, with here and there groups of Arborvite adjoining. The Silver Firs and Spruces are to be found occupying every variety of soil and situation, from dry hill-slopes and banks of rivers to rich and somewhat wet soils on level parts of the country; and these kinds are seldom found in large masses separately, but generally either in small groups or clumps, or intermixed with broad-leaved trees of various species.

The tendency to regeneration in patches or family groups is, of course, most pronounced in species of trees having heavy seeds like Oak, Beech, Chestnut, silver Firs, and certain l'ines. But all light and wingerl seeds, like

I Evelyn, eren a couple of hundred years ago, noticed this supplanting of a lightdemanding species by a shade-bearing kind, and the reoccupation of the soil later on by a quick-growing though essentially light-demanding species, whose seed was lying dormant in the ground, and could only find its physiological requirements as to light satisfied when once the heavy overshadowing of the soil was removed by the clearance of the crop. In a letter published in Aubrey's Surrey, he says: "That which I would observe to you from the wood of Wootton is, that where goodly Oaks grew, and were cut down by my grandfather almost a hundred jears since, is now altogether Beech; and where my brother has extirpated the Beech, there rises Birch." 
Ehm, Ash, Birch, Willow, Scots Pine, Spruce, anrl Larch, are more likely to spring up sporadically at consirlerable distances from the prarent trees; and the same applies to the regeneration of trees whose fruits form part of the fordsupplies of birds and animals.

The broad-leaved kinds of trees the author seems never to have founc, at least to any important extent, growing in masses of each lind separately. Indeed he states that throughout the natural forests of North America, he never found even the extent of a few acres occupied by one single broad-leaved species. The different genera of Oak, Ash, Elm, Mrple, Beech, Lime, Birch, \&c., associate together in all proportions of intermixture, according as the condition of the soil is most suitable for each respectively. On light sandy soils the Beech and the Sugar AIaple are found to prevail; on soils of a strong loamy nature the Oak, Fim, Plane-tree, and Lime are the chief trees: on land of a cold wet nature the Ash is generally found in greatest numbers; while the Birch occurs on all these different kinds of soil. From these observations he therefore inferred that uncler natural conclitions of forest growth, which are productive always of the best timber of whatever kind, the Pine tribe of America is principally found growing in large masses of each species separately, and upon the higher-lying and poorer portions of the land; that the American Larch, a tree of a very different habit from the European species, is also found growing in masses by itself, and separate from other linds, the only difference between the European and the American species being that the one luxuriates in a dry soil and the other in a wet one; that the Silver Firs and Spruces naturally occupy a very much wider range of soils and sites than the Pines and Lareh do, and that they are found to associate extensively with the broad-leaved species; and finally, that the broad-leaved species do not generally grow in masses of each sort separately, but are found chiefly growing intermixed with one another in various proportions, accorling to the suitability of the soil to the respective species.

Basing his arguments for Britain on the results of these persomal observations in America, the author recommends that all the different species of Pine and Larch should be grown in masses of each selarately, excepting in so far as trees of another species maty he requirerl to be planted with them as temporary nurses for at time. Thus, for example, if it be found judicious to plant (orsican l'ine (P'ines.s Luricio) as a permanent crop on a certain district, then this species should be put out at $10 \mathrm{ft}$. apart as a permanent crop, and mixed with Larch as nurses at similar distances, so that all the plants should stand at it ft. by $5 \mathrm{ft}$., or 1742 per acre. Here the Larch is only meant to occupy a portion of the land temporarily, and to be removed in the way of thimnings, so as not to interfere with the healthy development of the 
permanent crop; but an admixture of Larch must add to the ultimate value of the crop by its open and light habit of growth, and by admitting more air to the Pines in their young state than they could possibly obtain had the whole crop been planted of Pines alone.

In the formation of mixed woods there need be no intention of allowing all the species to grow up together till the crop is finally harvested. If plantations were made at $3 \mathrm{ft}$. by $3 \mathrm{ft}$., or 4840 plants per acre, it would be a physical impossibility for anything but a small proportion of these, say from 100 to 200, to reach maturity. And Birch or Maples, for example, could not hold out the same period of rotation as Pines, Spruce, Firs, Oak, and Beech ; for they attain maturity at a much earlier date. The express intention is always to utilise certain species when they are marketable, and when their removal will benefit the species to remain on the ground; hence it usually happens that in mixed crops only one individual species remains to be finally harvested as the mature crop.

And in the above instance of Corsican Pine and Larch, the latter can certainly not be regarded as a nurse only; for the Corsican Pine is a hardy tree (see clap. iii., p. 264), and requires no nurse. Financial considerations alone evidently suggest the admixture; and it is impossible, from any point of view whatever, to consider a plantation, formed half of Pine and half of Larch, anything but a mixed crop, no matter how soon either species, or both of them for that matter, may be cut down and utilised.

The genera of Silver Fir and Spruce may be planted either in such masses of each sort separately, or intermixed with each other, or with broad-leaved trees, as the nature of the land or as taste may suggest.

This contains the gist of the whole matter under consideration. Soils on true forest-land are seldom homogeneous, or of exactly the same composition, depth, moisture, and other physical properties throughout large areas. Here there is a patch of good soil ; there, close by, it is not as good; in some spots it is moist, in others dry; and the sylviculturist notes these varying conditions, and endeavours to utilise the productive capacity of the soil on each patch to its fullest extent. But this can only be done by judicious admixture of the different species, here in small groups or patches, there in individual plants only. Such a sylvicultural principle is founded on the law of nature; but the utilisation of the productive capacity of the soil is subjected to artificial methods.

The broad-leaved species of trees may all be planted intermixed, or each kind may be planted in a separate mass by itself, according as the soil and situation may be found suitable for each species respectively, and according as the taste and judgment of the planter may suggest.

If the planter bases his judgment on actuarial calculations, then he must usually, but not necessarily always, come to the conclusion that mixed forests are more remunerative than pure crops. 
The three immediately preceding paragraphs contain the anthor's answer to the question put as the heading of this section. This answer is based on the usual laws of nature in respect to the known habits and peculiarities of trees: but he has still to refer to it from an economic and an ornamental point of view.

From the economic point of view the following may be said. Each species of tree has its own peculiar habit of growth; hence when individuals of each species are planter in masses separately, from the habits of all the trees in each mass being alike, ther one drees not injure the other nearly so readily as when composed of different kinds. But in consequence of this a great advantage is gained by planting trees in masses of one sort, both with regard to the general health of the crop itself, and in respect to the less amount of attention and expense necessary to be bestowed in training. And, besides, it will in all cases be found that where trees are planted with each kind in a separate mass by itself, and at the same time in the soil and situation most conclucive to its healthy development, a greater bulk of available timber is produced from each acre occupied, and consequently a greater revenue from it, than could be taken from a crop of a mixed description. The author very frequently observed this, both in natural and artificial forests; and he considers that all foresters should take this point into careful consideration before commencing to plant on any piece of land.

The editor's views on this matter are again at variance with the author's conclusion. They are summarised in the following extract: ${ }^{1}$

"A larger percentage of Timber is available for the higher technical purposes, at any rate in mixed Forests of deciduous broad-leaved Species. - As alrendy alwre indicated, many of our more valuable timber-trees are, when once they have passed through the initial stage of pole-forest, by nature so light-demanding, and so dependent on increase of growing-space if they are to continue in vigorous growth and normal development, that they are unable of themselves to maintain such degree of density of canopy as is necessary to retain and duly conserve the productive capacity of the soil, and to prevent it ultimately becoming to a greater or less extent deteriorated.

"And even if, on the better elasses of soil, pure forests of such species, or mixed crops of the more valuable light-demanding trees only (Oak, Ash, Maples, Larch, Pine, \&c.), be grown without admixture of any shade-bearing species, their demands for light, and naturally rapid process of thinning themselres out, farour branch development to an extent quite inconsistent with purely financial and sound sylricultural trentment of our woodlands. This, too, is a drawback not even affeeted by underplanting for soil-protection. Thus an admixture of one or other of the chief shade-bearing species (Beech, Douglas Fir, Spruce, Menzies Spruce, Silver Fir) not only protects and stimulates the productive capacity of the soil, but also acts directly and mechanically in preventing the formation of short boles and of strong branches interfering with the technical utility and market ralue of the individual trees forming the crop. The admixed shade-bearing species performs in this respect identically the same rêle as underwood when it grows up into the cromns of the standards.

1 Nisbet, op. cit., pp. 12t, 137 . 
"It is a matter of practical experience that Pine and Larch form more raluable boles and a larger percentage of duramen or heartwood when gromu in company with Spruce or Silver Fir than in pure forests; and that all the better species of deciduous trees gain in shape, increment, and age up to which they can continue to thrive in a technically as well as financially healthy and desirable condition, when the Beech forms part of the crop. And these beneficial effects are still more plainly visible when, on suitable soils, the mixed crops are formed of Conifers and broad-leaved trees, even when all are shade-bearing, as in the case of Spruce and Silver Fir grown along with Beech.

"Thus, as shown under paragraphs (1) and (2), the total quantity of timber produced is not only greater in mixed than in pure crops, but the predominating trees form longer, more cylindrical, and cleaner stems, whose freedom from branches and knots gives the timber its highest possible ralue for technical purposes, owing to the superiority of its various technical properties from every point of riew. That such higher classes of timber will of course be readily disposable at better than ordinary rates is self-erident.

"Taking everything into consideration, a mixture of species in woodlands, far from being any hindrance to profitable management, has many inestimable advantages over pure plantations, not the least being the greater security with which the crops may be expected to attain thein normal maturity. But in Sylviculture there are no hard-and-fast rules applicable to all soils and situations, and circumstances can often occur not only to justify, but even to recommend, the formation of pure crops. As has been mell remarked by Heyer : ${ }^{1}$ -

"Notwithstanding the manifold and decided advantages which mixed forests offer in general, the formation of pure crops, to be permanently worked as such, is by no means precluded; for they in many cases offer such peculiar advantages as render it advisable or even necessary to retain or form them. Where, for instance, the local market or the nature of the soil and situation-e.g., when the soil is either very wet or very dry-is favourable to one particular species of tree only, that individual kind should be cultivated. But, at the same time, such cases are rather exceptional, and as a rule the formation of mixed crops is certainly to be recommended."

Again, when considered from the æsthetic or ornamental point of view, the planting of trees in masses of each kind separately has a lad effect on the landscape, especially when carried out so as to affect it to any considerable extent; therefore the formation of pure woods should never be undertaken with regard to planting on parks or lawns, where judicious groupings and blendings of species are desirable, so as to produce a variety of foliage from every point of aspect.

One other point in connection with this subject requires yet to be brought under notice; and this is that, where trees are planted in masses of each kind separately, great judgment is required in the planter to give each species that soil which is best adapted to its healthy development. Where this is not attended to, and unsuitable jlinits are put into the soil, creat disappointment must ensue, and the crop may ultimately be of comparatively little value. When a crop is mixed up of several kinds of trees, it generally follows that at least one or more of the kinds are found to prosper on the land, and from this state of things a crop can generally be secured although some of the kinds fail; but where the trees are of one kind only, and thint linml has leeen planted on an unsuital,le suil and situation, there

1 Wraldbar, 1891, p. 39. 
is no alternative but to clear, and afterwards replant with species whose requirements are better adapted for the given locality.

This is not consistent with the experience of sylviculturists on the Continent; for, as alrearly stated (sce 1, 51!1), the only drawhel of mixel workls, as compared with pure woods, is that the former require more careful tending, and greater knowledge on the part of the forester, than are requisite for the cultivation of the latter. 


\section{CHAPTER VI.}

SOIL-PREPARATIOA FOR THE FORMATION OF TIMBER-CTOLS.

Object of Soil-Preparation.-It is a matter of very considerable sylvicultural importance that the soil should, before being planted up with a crop of forest-trees, be subjected, to a greater or less extent, to some special course of preparation, in order to promote a more rapid growth, and consequently a much earlier development than has hitherto usually been obtained in our woodlands. This is a very natural and proper subject for the consideration of every forester, seeing that with reference to all classes of agricultural crops so much attention is now paid to the preparation of the soil; whereas in the rearing of sylvicultural crops comparatively little attention is generally given to the preparation of the land on which they are to be planted. It is not necessary that such soil-preparation should extend over the whole area enclosed within plantations. Although this would be beneficial, yet it would involve an outlay incommensurate with the benefits from a purely actuarial point of view. But at any rate soil-preparation in strips or patches, or merely in the places immediately surrounding the roots of the transplants, can be froverl by long practical experience in the skilfully managed forests of continental Europe to be a very profitable investment of the outlay incurred.

In the first place, those conditions of soil must be ascertained which are found to fromote the most rapid growth and a nurmal healthy development of tree-crops, and consequently to produce the quickest and lighest returns from them. For it is the closer consideration of, and the more careful attention to, these conditions of land, which hare brought agriculture in this country to the advanced state it has reached in the best-cultivated districts. They are the conditions of land on which the largest and most valuable crops of timber are finmel in the natural forests of America and other prarts of the world; and they are the conditions we must secure to our ground in this 
country, wherever we wish to grow the most valuable crops of trees within the shortest possible time,-or, in other words, at the least cost of production.

These conditions depend to a very much less degree on the chemical or mineral composition of the soil than on its physical properties-viz. :

1. Cohesiveness or Tenacity, with regard to permeability, dc.

2. Relation to Moisture, with regard to the absorption, retention, and diffusion of aqueous precipitations.

3. Relation to Warmth, with regard to the conductivity and retention of the solar heat; and

4. Depth or distance below the surface to which decomposition of the soil has proceeded.

All these physical properties act and react on each other to a very considerable extent in determining the productive capacity of any given soil. A full consideration of this subject cannot be given here. But the following quotations will suffice to inclicate the nature of the case from the loint of view of sylvicultural chemistry. ${ }^{1}$

"When it is considered that one and the same rock has not always the same composition, that the products of the decomposition of any particular kind of rock often differ in their composition from that of the parent rock and may be endowed with different physical properties, and also that these latter are not dependent on the parent rock, then the conclusion must be arrived at that no hard-and-fast deductions can safely be drawn concern. ing soils from consideration of their geological origin only. Depth, nature of subsoil, relation to moisture, and admixture of humus, are often of equal and even much greater importance as regards the growth of timber-crops.

"Humus not only adds depth to the soil, but from its strongly hygroscopic quality condenses atmospheric moisture ; whilst as a bad conductor of warmth it acts as a regulator and protects the soil from parting too rapidly with its soil-moisture and becoming parched and dried up. By developing carbonic acid it also assists in the decomposition of the mineral constituents in the soil. It modifies all extremes of physical properties, and though not an absolute necessity for forest growth, yet exerts a powerful influence on it, and is of inestimable value in stimulating the productive capacity of the soil, no matter of what origin the latter be. Soils that are rich in humus take their main character from their mineral composition. But the beneficial influence exerted by humus on tree-growth is permanent so long as the natural re-formation of the leaf-mould is not interfered with by interruption of the canopy, \&c.; for high-forest annually gires larger supplies of dead foliage for the formation of humus than it consumes."

This is a matter that is of even more importance with regard to the germination of seeds and the thriving of young seedlings, when woods are being regenerated naturally or produced artificially by sowing, than with regard to the formation of plantations with trimsplinuts that have alleatly pasied through the dangers incidental to their earliest period of development.

A light soil that is porous and permeable is more favourable to the establishment of young seedlings than a heavy and binding soil; for in the former case the circulation of air is more favourable, and the atmospheric precipitations (dew, rain, melting snow) can be absorbed more freely by it, whilst in

1 Nisbet, Studies in Forestry, 1891, p. 101. 
the latter they are apt to flow off from the hillsides without percolating into the soil, or to collect as stagnating moisture on level tracts. And the shallower the soil, the more danger is there of these latter inconveniences manifesting themselves, more especially if the subsoil be of a nature unfarourable to treegrowth.

In woodlands forming a good, normal close canopy, the tendency to "caking" or condensation of the upper layers of the surface-soil, such as must take place if the latter be exposed to the deteriorating influences of sun and wind, is naturally obviated by the annual fall of foliage. This decomposes into humus, and is then capable of ameliorating the physical properties and enhancing the general productive capacity of the soil, except under the abnormal circumstances of wet soils.

And on soils that have already been under sylvicultural crops, the rootsystems left in the ground as not being worth extracting and utilising gradually undergo decomposition, and form a network of humose soil, tending to better aeration, and to the more favourable absorption and retention of aqueous precipitations.

But on bare hillsides, that have perhaps been cleared of their original woodland covering, or that may perhaps have remained naked so far back as our historical knomledge extends, the case is different. There is either almost no humose admixture to ameliorate the physical conditions and stimulate the productivity of the soil, or it may even be a dry, dusty humus of heathermould and lichens, which is more likely to be injurious than advantageous from a sylvicultural point of view. Both of these conditions are unfavourable to the best development of woodland crops; for they fail to render assistance as regards the most advantageous dengee of alssorption, retention, and diffusion of soil-moisture. Hence a certain amount of soil-preparation is desirable, by making at least the upper layer of soil more porous and permeable in the case of stiff or binding land; whilst for sieve-like sandy soil, the only practicable method is to encourage woodland growth of any kind that seems able to grow, and then the land will naturally and gradually improve, owing to the humus formed from the annual defoliation.

When soils of a strong loamy or argillaceous nature cake or set on the surface, and are exposed to direct insolation and to the drying action of east winds, they part with their moisture, owing to capillary attraction, to a far greater extent than soils that have a loose upper layer ; for in the latter instance the aqueous precipitations not only percolate more easily into the soil, but the action of capillarity is also checked by the greater size of the interstices between the individual grains of earth.

The first step towards the work of soil-preparation should consist in the clearance and burning of the surface-growth of weeds, such as heath, heather, furze, dc. It is usually most adrantageous to undertake the operation just before the sowing or planting operations are to be carried out in spring, except, of course, in cases like the preparation of moorpan, where the action of frost is essential to the thorough disintegration of the impermeable stratum of sand and heather-mould, caked by means of a very slight proportion (2 to 5 per cent) of ferric oxide. And, as a matter of course, the depth to which the preparation must extend depends on the density, tenacity, and wetness of the soil. 
The investigations of sylvicultural chemists in Germany on this point have led to the following information of practical value with resgard to the effects of soil-preparation on various distinct classes of land : ${ }^{1}$

1. Stony Soils.-Any soil-preparation on lands of this class has mostly an injurious effect. The finer earthy particles are apt to be washed away, and the soil becomes so loose that the roots of the young plants find difficulty in establishing themselres. In sylvicultural operations under these circumstances, soil-preparation should therefore either be avoided, or else confined to the collection of pockets of good earth for the reception of the plants; and when the planting is being carried out, the soil should be partially protected by laying small stones over the earth.

2. Sandy Soils.-Soil-preparation is generally advantageous on sandy soils; and the deeper it is carried out the better. The retention of soil-moisture is usually thereby favourably influenced; and the admixture of deeper soil which comes partially to the top benefits its productivity, as the top-layers are generally less rich in mineral nutrients than the lower strata, owing to the washing-out effects of heavy rainfall.

3. Loamy Soils.-The soil-preparation should hardly extend below the upper lajer which contains the earthy ingredients, or in which, at any rate, the soluble nutrients are least plentiful. If it extends to the more argillaceous layers, the earthy nature of the top layer may be quite destroyed; and then much more harm than good may ultimately result.

4. Clayey Soils.-The soil-preparation should be confined only to superficial work with the pick. Any deeper-going operations are injurious.

5. Limy Soils.-Shallow limy soils are mostly stony and poor in eartliy ingredients; hence soil-preparation is, as a rule, of little practical advantage. Deep limy soils correspond very much with clays, so that the same rule may be applied to them.

6. Humose Soils.-Light soils are made still more porous by being opened up. Hence any soil-preparation on humose sands in damp localities can only be disadvantageous, and may materially increase the danger of the soil being lifted by frost. But when the preparation of land of this description extends to bringing up the layers of pure sand to the surface and imbedding the humose surface-soil, then it is decidedly advantageous.

7. Soils composed of different Layers.-Soil-preparation is essentially necessary in all cases in which an impervious or impermeable layer divides the surface-soil from the subsoil (as in moorpan and limonite). Any insufficient preparation is really more injurious than no attempt at all to improve the productivity of the soil. In carrying out the operations, no general rule can be laid down, as the concrete conditions of each case must be taken into consideration.

8. Soils with Wet Subsoil.-Unless at the same time accompanied by drainage, any soil-preparation in such cases remains without farourable results. In the ricinity of the water-level capillary attraction is strongest; hence by loosening the soil, the level of the injurious superfluity of moisture is often practically raised. This drawback is, however, only felt when the water-level in the soil is comparatively high ; for the lower the waterline, the more beneficial soil-preparation will prove, especially on sandy soils.

Advantages of Drainage.-Dramage is the chief means of securing the most favourable conditions of land for the wrowth of tree-crops on wet soils; for it is only by drainage that their productive capacity can be fully utilised.

The advantages of drainage consist not only in the removal of an injurious superfluity of soil-moisture, but also in effecting areration, or a beneficial circulation of oxygen throughout the earth. Water is not of itself a disadvantage in land. On the contrary, plints could not live without it, and its absence would be attenderl with the most fatal

${ }^{1}$ Ramann, Forstliche Bodenkunde und Standortslchre, 1893, p. 425.

VOL. I. 
results to them. But it is the excess. of water throughout the soil occupied ly their root-systems that injures plants; whilst very large supplies of soluble salts held in the water imbibed by the suction-roots have a similar effect upon many species of trees. Drainage is likewise a means of raising the temperature of the soil, as, owing to the latent power of water, wet lands remain cold and inactive, so that the process of imbibition by the suction-roots is not stimulated.

Professor Schiibler long ago came to the conclusion that the loss of heat caused by evaporation in undrained land amounted to from $11 \frac{1}{4}^{\circ}$ to $13 \frac{1}{2}^{\circ}$ Fahr. Mr Parkes has shown, in his Essay on the Philosophy of Drainage, that in draining the Red MIoss, near Boltonle-Moors, the thermometer in the drained land rose, in June 1837, to $66^{\circ}$ at $7 \mathrm{in}$. below the surface; while in the neighbouring waterlogged land it would never rise above $47^{\circ}$.

The effect of judicious drainage, then, is to increase the summer temperature of the land from $10^{\circ}$ to $20^{\circ}$ as compared with wet and undrained land; and the cause of this increase in heat is the increased capacity of the land for absorbing the sun's rays as they fall on it after the removal of the superfluous water which was contained within it before the operation.

The scientific statement of the case is as follows: ${ }^{1}-$

"The Temperature of Soils is dependent on various factors; but the quantity of the soil-moisture is of most influence. Not only the high capacity of water for absorbing heat, but also the heat dissipated in the work of evaporation, reduce the temperature. The action of humus is in the same direction; for it influences the soil in respect to the absorption, retention, and diffusion of moisture. Moist and humose soils are therefore slow to become raised in temperature when warmer weather begins to set in during spring; but on the other hand, they are warmer during summer, and more particularly during autumn, than soils which contain less moisture. A practical difference is therefore made between mild and cold soils. In the latter class are reckoned humose soils (like peat-hags), argillaceous soils, and in part also those of a loamy character ; whilst the former comprise all lands of a sandy nature."

Another important effect of the drainage of land is that of adding to its available depth, so as to permit of the roots of trees securing a large increase in their supply of food. The deeper that drainage can he made thoroughly operative on land, the deeper will the conditions of its permeability be secured; hence its capacity for absorbing heat will be greater, and it will tend to become a larger and richer storeliouse for sulplying the roots of trees with their normal requirements in the way of mineral food and water.

Soils which are merely fresh are most conducive to the thriving of timber-crops in general,- - apart from the cases of species like Alder, and some Poplars, that make great demands for water for

I Ramann, op. cit., p. 94. 
transpiration. They respond only gradually to the increase of temperature in spring, and are therefore not likely to cause vegetation to become awakened so early as to be liable to late frosts occurring merely after a few days' warm weather; they are not apt to become overheated during either the summer or the antumn months; and their stores of accumulated heat are only gradually given off towards the close of the normal period of vegetation. Hence, before the approach of early frosts in late autumn, the maturing of the woody tissue in the shoots of young plants, or of the crown of the tree, is attained normally.

In order, therefore, to promote a more rapid growtlı and a much quicker return from sylvicultural crops than has hitherto usually been obtained from them, the land on which they are to be planted should be prepared to a greater or less extent, either by drainage or by ploughing strips, or by turning orer the soil in patches with the spade or with the pick.

The author believes, as the result of more than forty years' experience in the raising of plantations upon all descriptions of land, - varying from only a few feet above the level of the sea to about $2000 \mathrm{ft}$. in elevation, - that whatever be the nature and character of land, - whether it may be clay, heavy loam, light loam, sand, or gravel; whether it may be situated on a high and exposed part of the country, or on a low-lying and sheltered district-an efficiently conducted system of drainage is alone required to prepare it for the growth of trees; for thereby its absorbing capacity for heat is increased to the greatest available depth. If the land is not at an altitude too high for the healthy development of any of our common trees, a properly executed system of drainage will result in hearier and more profitable tree-crops being yielded than have hitherto been obtained. Whatever may have been the former conclition of the laul, he thinks that by a proper and efficient application of drainage, by a right selection of the plants in accordance with the soil and situation, ly opening holes for the plants in order to improve the soil previons to their being planted in it, and by a judicious system of planting, the physical factors are secured for the growth of a crop of heilthy trees on any description of soil.

In the above paragraph it will be apparent that the anthor inclutes under the word Drainage all operations which are comprehended ly the elitor in the term Soil-preparation. Strictly speaking, the worl drainage mens only the drawing oft" of a surplus of water from the soil ; and the aeration and changes with regard to conductivity of heat, and to other yhysical properties, are consequences of the opreration not included in the idea of clramage at all. But in the case of the word "soil-preparation" these main oljeets of the operation are distinctly comprised within the term. To speak of chaining a dry soil woukl be a 
misuse of the mord; but land of such a class can of course be subjected to a course of soil-preparation. This latter operation also includes the formation of mounds between parallel trenches, so as to increase the depth of soil available for the root-system. It is evident that this operation is included by the author under what he means by the term drainage.

Although the draining of lands that are absolutely wet is easily understood to be necessary before planting trees on them, it may not seem so requisite that all lands having a retentive subsoil should also be subjected to preparatory treatment to a greater or less extent. It is, however, an incontrovertible fact that trees in all cases thrive very much better on lands that have been improved by a course of soil-preparation than they do on the same description of land in an unimproved state. The theories of the sylvicultural chemist in this respect may easily be tested by any one who cares to take the necessary trouble in examining the results of practical operations.

The idea is by no means a new one; for in the time of James I., among the orders giren for the conduct of operations in the New Forest, "the ploughing of the land for raising of new woods" was specially mentioned (see also p. ว6อ̃).

Let any forester who thinks it unnecessary to prepare, previous to plantiug, any land that appears dry on the surface, take the trouble to examine it in the subsoil. In the case of binding land he will not only find the upper layer of soil caked and set so as to hinder the penetration of atmospheric air, but below this depth he will also find the subsoil unfavourable to aeration or the circulation of oxygen, and so compact that he has considerable difficulty in digging into it even to the depth of other 8 or 10 in.; and farther down he will find that he must even use a pick in order to make an opening of little more than $2 \mathrm{ft}$. in total depth. Is it possible that the roots of young trees ean easily penetrate and ramify within this poor, stubborn land in search of food, when it requires an iron pick to break it up? In consequence of such a condition of subsoil, the roots of the trees become arrested in their descent, and are spread out on the surface only, where they struggle for an existence in the upper 10 or $12 \mathrm{in.} \mathrm{of} \mathrm{the} \mathrm{soil.} \mathrm{But,} \mathrm{on} \mathrm{the} \mathrm{other} \mathrm{hand,} \mathrm{where}$ the same class of land has been,.in whole or in part, subjected to a course of soil-preparation, the physical properties of the land become improverl, and the plants find very much better opportunities of developing their root-systems normally, as well as of obtaining food-supplies for the satisfaction of their natural requirements.

One has only to compare the miserable crop of timber that is generully taken from land having a subsoil of moorpan, for instance, with what can be grown on land of a permeable character, to be 
convinced of the great utility of preparing the soil for the growth of trees. Take the crop of matured l'ine, for example, standing on land of a retentive nature in the subsoil, but still apparently dry enough on the surface. Taking the crop on a few acres, the trees will sometimes be found to average not more than 15 culfic ft. each ; while on deep land having a fuvourable subsoil Scrots l'ine of the same age will probably measure on the average about $40 \mathrm{ft}$. per tree. This at once exhilits the great difference there is letween the value of a crop of trees grown on land having a subsoil of an unfavourable nature, and that of a crop grown on deep open land after it has been improved either by breaking throngh and decomposing the subsoil, or by artificially raising the level of the land through forming mounds by trenching and piling up the output between the ditches. Generally speaking, the crop of any lind of tree grown on land of a deep, porous, dry character is of very considerably greater technical aud marketable value than that produced on land having an impervious sulosoil, although seemingly dry on the surface; and these differences are mainly due not to any deficiency in the total amount of mineral nutrients available within the soil, but rather to the physical factors being unfavourable to their utilisation until a certain amount of soil-preparation has been carried out. There is no species of tree which is more responsive than the Scots T'ine to the beneficial effects of soil-preparation; for even in light sandy soil its root-system develops much more vigorously than under other circumstances. And on sandy soils of rather a poor description, there is a very decided advantage obtainable by bringing the somewhat better mineral soil up to the surface. Throughout large stretches of the great North German l'lain thousands of acres are amnually prepared for cultivation with crops of l'ine for the most part, as the land is often too poor for other species to be admixed with it; and during the last twenty years the use of the steamplough has been more and more extensive in this work. This is very especially the case in the wide stretches of land where a thin impervious layer of moorpan has formed at distances of about 1 to 3 ft. under the surface. Where this lies deep, it has been found advisable to trench down to below the moorpan, which ustully forms quite a thin layer, and to spreal the output on the beds between the trenches; but when it does not lie deeper than a couple of feet or so, then the land is broken up either in whole or in lint by powerful steam-ploughs. This method has been foumd so alvantigeons to the growth of the Scots Pine, that it is now finding further application year by year.

Besides draining those parts of their woodlands which are eridently wet, foresters should do what they can to increase aeration of 
the soil, thus rendering it a richer storehouse of food for trees, increasing its temperature by several degrees, and making a practical change in the land perhaps almost equal to removing it from a site $1000 \mathrm{ft}$. in elevation down nearly to a level with the sea. Such are the immense advantages gained by judicions soil-preparation that trees which in Britain will usually thrive only in low-lying situations may, by well-directed operations, be made to prosper equally well on land at an elevation of fully $1000 \mathrm{ft}$.

Every agriculturist who is not behind the times knows well that unless he incurs some judicious outlay on the preparing of his land for the growth of the plants he cultivates, he certainly will not succeed in raising them of first-class quality, and in abundant crops; and the landed proprietor who wishes to secure first-class crops of trees on his woodlands must go to work on the same principle.

It is more particularly in the very earliest stages of growth that the greatest benefits can be derived from soil-preparation; for unless the young seedlings or transplants can develop, their root-systems rapidly and establish themselves securely within the soil, then the whole of their later develogment becomes prejudiced, and they never attain at any subsequent stage of growth the same vigour that is acquired when they are placed in favourable circumstances at the commencement of their life-period. And, of course, the greater the tendency of the species of tree towards the development of a strong tap-root, as in the case of light-demanding genera like Oak, Pine, and Larch, the more beneficial does the soil-preparation prove.

Sylvicultural experience acquired on the Continent with respect to the Scots Pine may have a great and profitable interest for the Highlands of Scotland. The following extract from Burckhardt on this matter therefore deserves the attention of landowners and foresters : ${ }^{1}$

"Low-lying tracts of flat land and other situations favourable to wetness often make cultivation difficult and expensive, not only because the soil is heavier to work, but also because the superfluity of moisture must be got rid of. To this class belong soils of a wet, sour, and marshy description, sometimes already bearing a thin covering of moorland growth, damp, cold, binding sands of a loamy nature, hollows from which the water can only partially escape by means of evaporation, and land that is constantly kept moist by stagnating subsoil moisture, especially on old, wet, heather-covered stretches with a binding subsoil, which are often marked by the growth of heath or bell-heather (Evica tetralix) either by itself or in admixture with common heather.

"Such tracts must be made dry by means of ditches; but the output from the trenches may be utilised for preparing the soil. Hence both of the operatious are combined by forming parallel trenches in connection with the ditches requisite for drainage. In some cases narrow beds or mounds of from 15 to $20 \mathrm{ft}$. in breadth are formed between trenches of 3 to $4 \mathrm{ft}$. in width; whilst in other cases the beds are formed up to $30 \mathrm{ft}$. wide, with trenches of $3 \mathrm{ft}$. in breadth between, from which the soil is spread over the mounds for immediate sowing and harrowing.

1 Säen und Pflanzen, 1893, p. 297. 
furrows 24 in. broad and up to 27 in. deep. These ploughs can be provided with subsoil tines, so as to break up the ground from 4 to 5 in. deeper.

Fig. 92 exhibits a form of Subsoil Plough constructed and worked

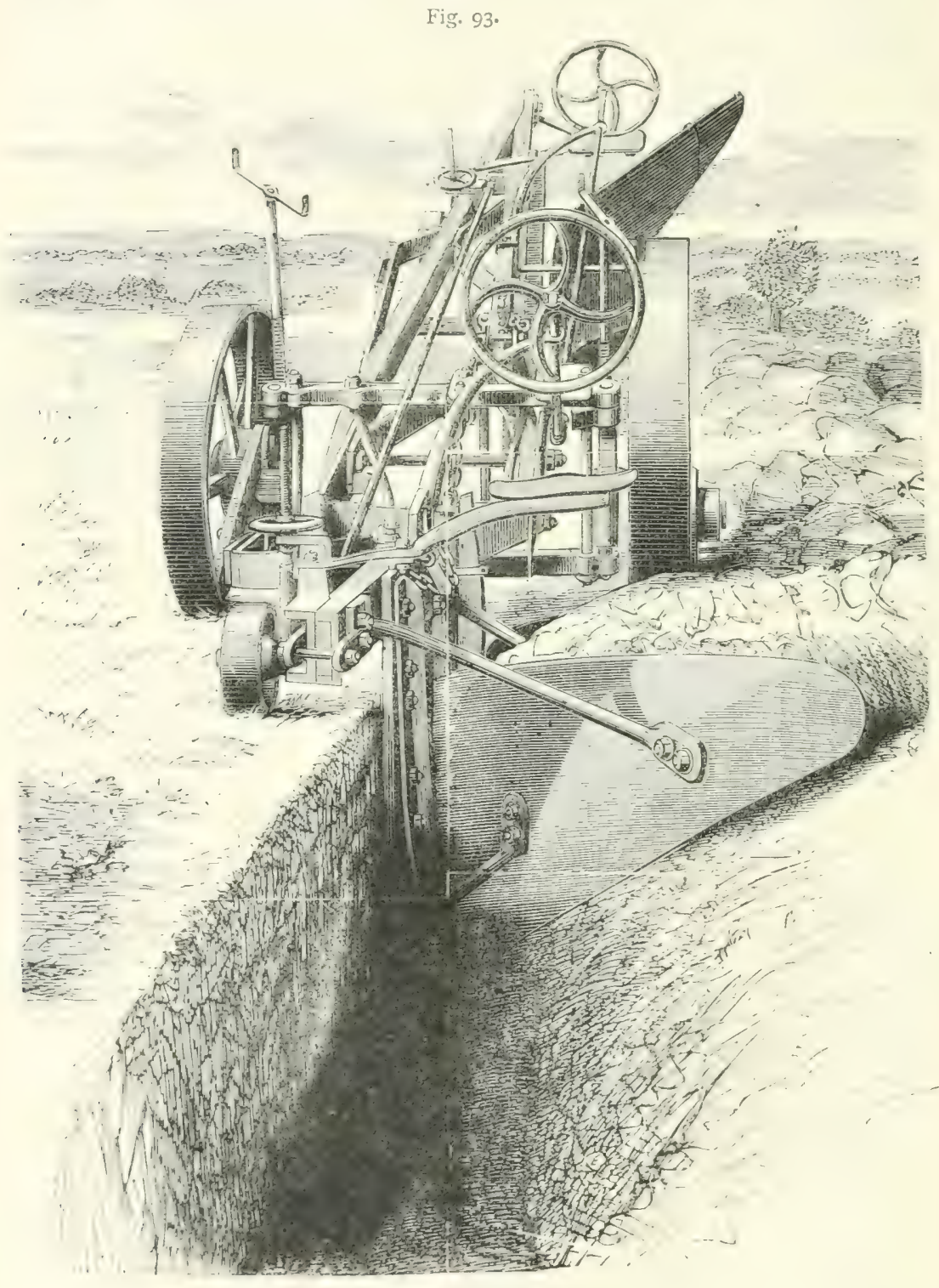

Funler's Olizer Plough.

on the principle of a balance-plough. In addition to the ordinary ploughs attached to it, it is fitted with a time following each plough, so as to break up the sulsoril to the depth renuired without throwing this on the top of the land. 
Fig. 93 shows an Oliver Plough at specially deep work. These ploughs are constructed very strongly for rough work. They cut only one furrow of $24 \mathrm{in}$. wide and $30 \mathrm{in}$. in depth. With a view to divide the work, the Oliver is usually preceded by another plongh of smatler size, which forms at preliminary furrow.

According to Gayer, ${ }^{1}$ the cost of ploughing the whole land then comes to from $24 \mathrm{~s}$. to $40 \mathrm{~s}$. an acre, according to the difficulty of transport and of procuring water ( 4000 gallons per diem being requisite). Below that dep,th the formation of mound and trenches is the best soil-preparation that can be given (Fig. 94). When the usually thin layer of moorpan lies between 1 and $2 \mathrm{ft}$ : below the surface, it can be broken through by horse-ploughs.

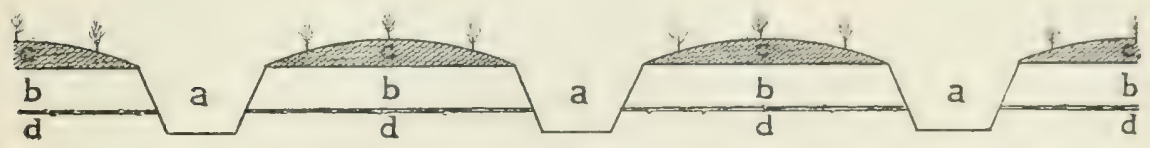

a, trenches. b, mounds. c, output from the trenches. d, impervious layer of moorpan.

For the sowing of acorns, or Beech-nuts, \&c., or the planting up of areas with small plants, the use of the Spiral-spade, a twisted spacle about \& to 9 in. long and 5 or $6 \mathrm{in}$. broad, $S$-shaped at the top and rumning to a point below, yields excellent results. In order to give greater purchase, it is provided with a long wooden crook, which passes through an iron staple at the top of the iron landle; hence, by moving this round, the soil is broken ul' a good deal, and can easily be removed for crumbling up and replacing in the hole. According to $\mathrm{Ney},{ }^{2}$ a man can make from about 40 to 80 holes in an hour, according to the nature of the soil.

Drainage of Woodlands.-Although the application of drainage and of soil-preparation generally, as a means of improving and stimulating the soil for agricultural purposes, is now well understood and appreciated in this country, still this camnot be said to he the case with regard to its application for sylvicultural purposes, as a comparison of the state of the land moler farming with that under plantations would abundantly prove. Notwithstanding this, the benefit. resulting from thorough drainage and soil-preparation are as certain in the one case as in the other, although a sreater lengtl of time is often necessary to prove its beneficial effects on a crop of trees than on one of corn; and partly on this account, perhaps, proprietors of woodlands have been slow to expend nuch noney upon the improvement of the soil. With respect to this matter, in fact, the woodlands of this country are at the present day just about as backward as agricultural lands were some forty or fifty years ago.

1 Waldbau, 1859, p. 306.

"Lehro rom Waldbau, 1S55, p. I11. 
Drainage, as applicable to Sylviculture, is necessarily a very different operation from what is usually carried out for farming purposes, inasmuch as the plants grown in the former case are of much greater dimensions, and send their roots deeper and deeper down into the earth every year successively, till their maturity is attained; while the plants raised in the latter case are mere ammuals, with soft, perishable roots, and, with the exception of the grasses, generally dying within a few months after they are sown.

Drains made on agricultural fields are properly covered up and hidden, both in order to preserve the material of which they are fornied from accident, and to secure all the breadth of land possible for farm cropping; while those made on woollands are with equal propriety left open, as they would, generally speaking, he gradually rendered inoperative by the descent of the roots of trees into them in consequence of the natural expansion of the root-system.

Where they have been properly applied to agricultural land, drainage and soil-preparation have been the means of improving its productive capacity to an extent which formerly could perhaps hardly have been credited; and if they have thus increased the revenue of both the proprietor and the farmer, it is only reasonable to suppose that if they were extended judiciously to Sylviculture, they could not fail to be the means of increasing the value of forest-produce in an equal degree. In proof of this, large districts of wet land could be pointed to whose mature crops of 70 -year-old timber was of a very poor description; whilst, after drainage, the new crops of trees are now in a fair and promising condition.

In agricultural improvements drainage and soil-preparation are being lrought into operation on nearly all descriptions of lands, as experience has taught farmers that they can rear much more valuable crops from land which has had its subsoil opened up and cleansed by thorough drainage, and its top-layers ameliorated by thorough aeration, than they could ever obtain from the same land while it lay in an undrained and unimproved state. And the same results will naturally follow in respect to crops of trees on drained and prepared lind as compared with those on undrained, whether it may have been wet or seemingly dry before the operation.

When once any land intended for a new plantation has been well fenced, the next important step to be taken, in order to fit it for the operations of sowing or planting, is to drain all the portions of the encloserl land which have a wet and retentive subsoil, no matter whether they may look wet or dry on the surface; and this work of drainage must be done in such a manner as to free the whole of the land from all superfluons moisture, so as to keep it in a clean, open, well-aerated, and healthy state to a depth of from $\ddot{3}$ to $4 \mathrm{ft}$. It may here be remarked 
that all drains made in plantations among trees, whether these may be old or young, ought to be left open. To cover drains where the roots of trees have access to them is the most effectual way of ultimately rendering them useless. They might, indeed, answer the purpose for a few years; but as soon as the roots of the trees begin to ramify throughout the soil, they will collect alıout the drains more than in any other part, and the consequence must be that in a very short time covered drains will be entirely choked up with the roots, and rendered useless and ineffective.

Burckhardt's experience, which is certainly entitled to very ligh respect, is very nearly in accordance with the above. What he says is as follows: ${ }^{1}$ -

"For leading off water, ditches are dug; these are the drains of the forester. Open ditches are the rule, although covered drains are also of great advantage, as they incur no loss of useful area, do not interfere with traffic, and are less active in their operation, especially when filled up with brushwood. Wide drains are used here and there at culverts ; but any extensive and regular system of thorough drainage, such as is applied with so excellent results to agriculture, can hardly be undertaken by the forester except on a small scale (as in nurseries, \&c.) His field, the forest, is too vast; the sowing and harvesting of his crops lie too far apart. The yield could not repay such far-reaching ameliorations; and, even if it could, drain-pipes are not the proper things to use, as the roots would get into them and stop them up. A suitable system of open ditches is the only practicable method applicable in forestry."

It may here be noted, however, that the drainage of woodlands already bearing crops of timber is a very hazardous operation. It is very seldom within the power of the forester to lower the water-level artificially without creating a more or less serious disturbance in the root-system and the general health of the existing crop. Wherever possible, drainage operations should therefore be carried out and completed before the land is actually sown orer and planted.

The distance apart at which drains should be put on the ground depends entirely upon the nature of the soil to be operated on. If the land be a stiff clay, or any other soil of a very retentive character, the drains may require to be made as close as only $35 \mathrm{ft}$. apart; but if, on the contrary, the soil be an open sand or gravel, through which the water can percolate freely, then $60 \mathrm{ft}$. apart may not be too great a distance. In all cases of drainage for the planting of forest-trees, of whaterer nature the soil may be, the drains are hardly ever in Scotland made closer than $35 \mathrm{ft}$, or further apart than $60 \mathrm{ft}$; for beyond that distance between the trenches land can seldom be said to be drained efficiently.

Sylvicultural experience on the Continent recommends other less costly methods. Thus Burckhardt says that ${ }^{2}$

"The distance between the side-drains depends upon circumstances; but, as a rule,

$$
{ }^{1} \text { op. cit., p. } 547 \text {. } \quad \text { lbid. }
$$


this does not exceed $33 \mathrm{ft}$. [10 mètres]. A less distance is demanded in the case of very binding wet soils, in which the sideward percolation of the water is slow. In some cases not enough of side-drains and feeders are made, or they are formed too large and too far apart to be thoroughly effective. Where the soil is not too light, small trenches, with perpendicular sides and an upper width of 12 to $16 \mathrm{in}$., often suffice; but then it is well to sink them fairly deep in order to collect the water. In such narrow trenches, which require to be cleared out occasionally, the water runs off better than when smaller quantities of water are distributed over a greater breadth of sole in the drain. They also have the additional advantages of being cheap and of interfering less with traffic than broader. trenches."

The depth and general size of the drains must in a great measure be regulated by the nature of the soil. In a heavy clay soil open drains, such as are generally used in woodlands, should be at least $4 \mathrm{ft}$. deep, whilst upon light friable land, a depth of $3 \mathrm{ft}$. may be quite enough; and according as the soil may be inclined to be light or heavy, any intermediate depth between 3 and $4 \mathrm{ft}$. may be fixed upon. The more the land is of an argillaceous or a mossy nature, the deeper the drains should be made. Drains formed to a depth of 2 to $3 \mathrm{ft}$. only, as at one time recommended, are not always deep enough to dry and open up the subsoil of land sufficiently for the healthy growth of trees. Three ft. is the least depth that the author would recommend for draining under any circurnstances in this country, and $4 \mathrm{ft}$. the greatest. In all cases of draining on mossy land, a sufficient allowance should be made for subsidence, as such soils generally shrink from a fourth to a third of their bulk after drainage, according to the quantity of the organic matter in them.

The breadth of all such drains at the surface of the ground must of course vary according to the depth required, and the natural texture of the land itself. A good practical rule is to make all open forest-drains, on land of a light texture, one-third wider at top than the depth intended,- - that is to say, if the depth of a drain be fixed upon as $3 \mathrm{ft}$., the breadth of the opening at top will require to be 4 $\mathrm{ft}$, this breadth at the top being necessary to admit of the sides of the drains on light lind having sufficient slope to support themselves without crumbling down. On the other hand, in making open forestdrains on land of a stiff and retentive nature, whose sides are not apt to crumble down, and therefore do not require so much slope as drains on light land, it will suffice to make the surface-opening only three-fourths of the depth; thus, for example, if the depth of a drain be fixed at $4 \mathrm{ft}$., the breadth of the opening at top will require to be $3 \mathrm{ft}$. only. The above proportions have been found to answer very well in practice. But, in applying them, considerable judgment is necessary to distinguish as to the retentive or non-retentive nature of the land; for if it be of an open and somewhat free character, and the sides of the drains are marle with too little slope, much mischief 
may follow by their crumbling down and partly obstructing the action of the drains. 'The hreadth of the hase of all forest-drains ought to be about 8 in., or sufficient to allow a spade of this breadth to pass along for the purpose of cleaning them out from time to time, if necessary.

According to $\mathrm{Ney},{ }^{1}$ the costs of forming trenches and mounds comes to from 25 to 30 per cent less than the making of drains; for in the latter more attention must be paid to the cutting of the slopes at a certain angle, according to the nature of the soil.

In Macdonald's edition of Stephens's Book of the Farm, 1893, Div. V., p. 274 , the following data are given regarding the cost of drainage in Britain :-

"The cost of cutting drains varies greatly in different localities, fluctuating most in the vicinity of large mining and manufacturing centres, and remainings more stationary in purely agricultural districts.

"The chief factors which determine the price are the nature of the soil and the depth of the drain. The deeper the drain, the greater is not only the actual cost, but also the cost per cubic yard of soil removed, which may vary from $3 \mathrm{~d}$. to $6 \mathrm{~d}$. per cubic yard.

"Quantity of Earth Removed.-The accompanying table gives the quantities of soil, or 'spoil,' according to the depth and average width of the trench :--

Table showing Number of Cubic Yards of Earth iN each Rod, $5 \frac{1}{2}$ Yards ix Length, in Drains or Ditches of various Dimensions.

\begin{tabular}{|c|c|c|c|c|c|c|c|c|c|c|c|c|}
\hline \multirow{2}{*}{$\begin{array}{l}\text { DEPTH. } \\
\text { Inches. }\end{array}$} & \multicolumn{12}{|c|}{ MEAN WidTH. } \\
\hline & 7 in. & S in. & 9 in. & $10 \mathrm{in.}$ & $11 \mathrm{in.}$ & $12 \mathrm{in.}$ & 13 in. & 14 in. & 15 in. & $16 \mathrm{in.}$ & 17 in. & $18 \mathrm{in.}$ \\
\hline 30 & 0.89 & 1.02 & 1.1 & 1.27 & 1.40 & 1.5 & 1.65 & 1. & 1. & & & 2.29 \\
\hline 33 & $\begin{array}{l}0.99 \\
0.98\end{array}$ & $\begin{array}{l}1.02 \\
1.12\end{array}$ & $\begin{array}{l}1.140 \\
1.26\end{array}$ & 1.40 & $\begin{array}{l}1.40 \\
1.54\end{array}$ & $\begin{array}{l}1.50 \\
1.68\end{array}$ & $\begin{array}{l}1.000 \\
1.82\end{array}$ & 1.96 & $\begin{array}{l}1.91 \\
2.10\end{array}$ & $2.0 \pm$ & $\begin{array}{l}2.10 \pm \\
2.38\end{array}$ & 2.52 \\
\hline 36 & 1.07 & 1.22 & 1.375 & 1.53 & 1.68 & 1.83 & 1.986 & 2.14 & 2.29 & 2.244 & 2.60 & 2.75 \\
\hline 39 & 1.16 & 1.324 & 1.49 & 1.655 & 1.82 & 1.986 & 2.15 & 2.32 & 2.48 & 2.65 & 2.81 & 2.08 \\
\hline 42 & 1.25 & 1.426 & 1.604 & 1.78 & 1.96 & 2.14 & 2.32 & 2.495 & 2.674 & 2.85 & 3.03 & 3.21 \\
\hline 45 & 1.34 & 1.53 & 1.72 & 1.91 & 2.10 & 2.29 & 2.48 & 2.67 & 2.865 & 3.055 & 3.216 & $3.43 S$ \\
\hline 48 & 1.426 & 1.63 & 1.833 & 2.04 & 2.24 & 2.444 & 2.65 & 2.85 & 3.056 & 3.26 & 3.46 & 3.667 \\
\hline 51 & 1.515 & 1.73 & 1.95 & 2.161 & 2.38 & 2.60 & 2.81 & 3.03 & 3.25 & 3.46 & 3.68 & 3.896 \\
\hline 54 & 1.604 & 1.83 & 2.06 & 2.29 & 2.52 & 2.75 & 2.99 & 3.20 & 3.44 & 3.666 & 3.895 & 4.125 \\
\hline 57 & 1.69 & 1.935 & 2.18 & 2.42 & $2.66^{\circ}$ & 2.90 & 3.14 & $3.3 \mathrm{~S}$ & 3.63 & 3.87 & 4.11 & 4.354 \\
\hline 60 & 1.78 & 2.036 & 2.29 & 2.546 & 2.80 & 3.056 & 3.31 & 3.564 & 3.82 & 4.074 & 4.33 & $4.554^{\prime \prime}$ \\
\hline
\end{tabular}

Laying out of Drains. - $\perp$ particular point to attend to in the draining of moor or waste land for sylvieultural purposes is the manner of laying out the drains unon the ground. They must be projected in that position which is found to be the best aldapted for intercepting or drawing ofl' the superfluous water in its natural descent; as, unless the drains have been properly laid down upon the ground, it is impossible to derive the full advantages from the operation. A bad system of drainage, indeed, often aggravates in the lower parts of

$$
{ }^{1} \text { Op. cit., p. } 116 .
$$


the land the evil it is intended to obviate altogether. To those who may be unacquainted with the art of making open drains upon moor or waste lind, the following hints may be useful. It is a very simple process to drain any piece of land having a moderate natural descent to one side. (Fig. 95); for in such a case nothing is necessary but to make the drains in that direction which is indicated by the fall of the ground.

The angle at which the feeders should debouch into the side-drains, and the latter into the main drains, depends on the nature of the soil and the angle of descent. The stiffer the soil and the lower the angle of inclination, the

Fig. 95.

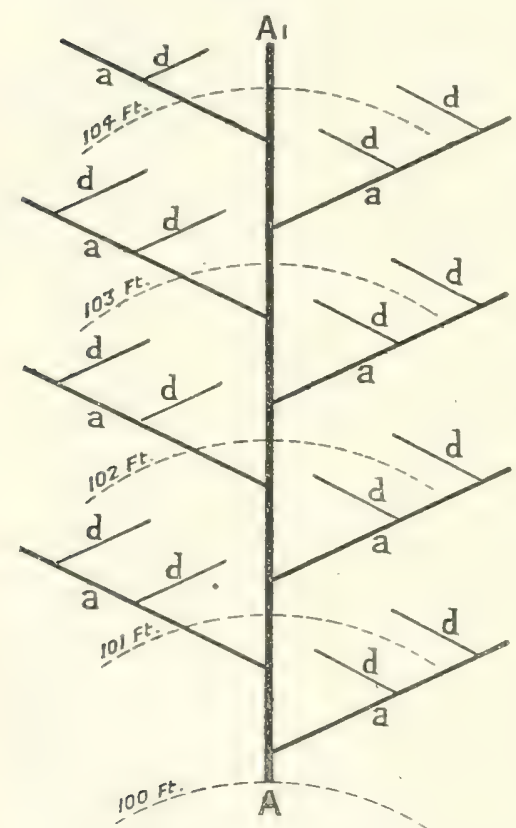

A, A1, Main drains. a, Side-drains. d, Feeders. The dotted lines represent the rise of the ground from $\mathbf{A}$ to $\mathbf{A}$. nearer these may approach the angle of $45^{\circ}$, at which the maximum of drainage effect is obtainable; whilst the lighter the soil and the steeper the slope, the more obtuse should be the upper angle formed between the drains. So far as the individual side-drains are concerned, however, the more nearly horizontal the side-drains are the greater the effect they have in draining the land between every two parallel ditches. But the greatest total effect is obtainable when the whole system is arranged as nearly as practicable at an angle of about $45^{\circ}$.

But where the ground may appear to be a dead level, having no distinctly perceptible fall to either side, the case is altogether different; and it then requires the use of levelling instruments to lay out the lines of drainage on such a piece of ground properly. Again, where the surface to be drained is a steep slope with many inequalities, much caution and consideration are necessary in order to lay out the crains upon the ground in that position which is most likely to be effective in intercepting the water as it falls from the various high parts into the hollows; and in order to prevent erosion, it is often advisable to terrace the drains in place of making them at one constant angle in their downward course.

In making open drains upon moorland, the operator must be provided with the common tools generally used for that purpose-viz., the line upon a reel, with an iron pin attached to the other end, for 
marking off the drains; a turf-spade (Firg. 96), for the purpose of cutting up the surface or turf; a common pick (Fig. 97), for loosening the subsoil and taking out stones where they occur; and the

Iig. g6.

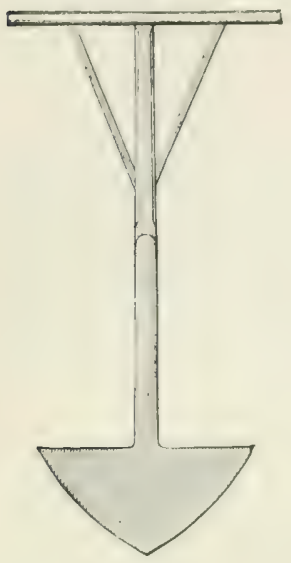

Fis. 97 .

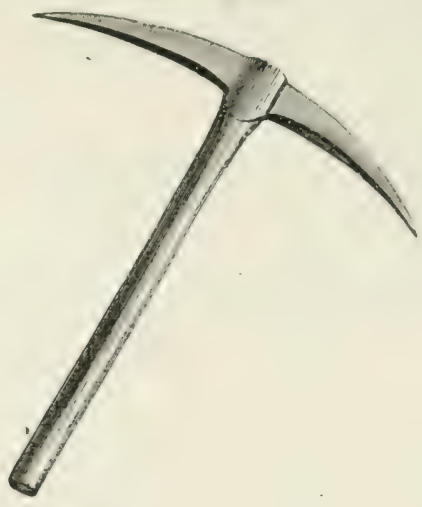

common spade, for throwing out the earth and clearing up the bottom of the drains. In operating among the roots of old trees, it is also found necessary to have the mattock, or pick-axe, in use; this is merely a sort of pick having its two ends made in the shape of an axe-the one end with its axe made at right angles with the handle, and the other in a line with it (Fig. 98). With this implement, having its axes made to cut different ways, the operator can with convenience sever roots lying in any position within the ground. But the most necessary implement for the superintendent of draining operations is the spirit-level, without which no proper system of drainage can be projected on land that is nearly level. There are various descriptions of levelling instruments sold for the purpose, at prices varying from $15 \mathrm{~s}$. to $45 \mathrm{~s}$; ; but a simple instrument like that shown in the illustration (Fig. 99), and costing about $15 \mathrm{~s}$, is all that is really requisite. In addition to being of a simple construction, it has the allvantage of heing easy to carry ahmut in the pocket. The whole instrument, with appendiges, can easily be fixed into a hole bored by a gimlet in the top of a walking-stati, as shown in the figure. When in use, the spirit-level is placed in a frame of brass, a part of which operates by pressure against the luttom of the instrument as a spring to aljust it to the level pusition e?, hy turning the large-headed brass screw $c$. 
A perpendicular stud is fixed to the under part of the framing and pliacterl firmly into the gimlet-hole in the top of the staff $e$, which is pusher into the ground at the spot from whence the level is clesired to be taken. There are two eyesights, $a$ and $b ; a$ is merely a small hole for the eye to be placed against, and $b$ is a square opening, with a hair-wire crossing it in the middle.

Being furnished with the level and the above implements, the drainer would proceed as follows in laying out a system of drains upon a flat bog for the purpose of preparing it for sylvicultural purposes. If he could not at once ascertain by

Fig. 99.

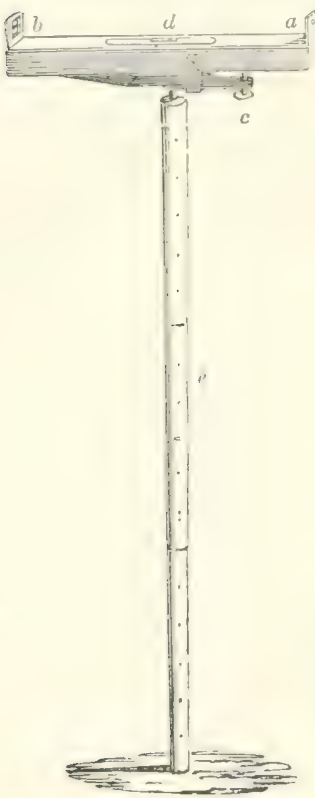
the eye which was the lowest part of the ground to be drained, he would set up the spirit-level about the centre of the flat gromel, and take sights from it all round in order to fix this lowest point. As regards the use of this instrument, it may be necessary to note that the height of the eye-sight $a$ from the ground must be deducted from the point observed. For example, if the object-pole used be marked in feet and inches, and the hairwire, in taking a sight, hit the same at $6 \frac{1}{2} \mathrm{ft}$., then, if the eyesight be $3 \mathrm{ft}$. from the ground, the difference of level between the two stations will be exactly $3 \frac{\pi}{2} \mathrm{ft}$. - that is to say, there would be $3 \frac{1}{2} \mathrm{ft}$. of descent from the spirit-level station to that of the station where the object was placed. On the other hand, if, in looking through the eyesight, the hair-wire hit the object-pole at $1 \mathrm{ft}$. from the ground, this $1 \mathrm{ft}$. must be deducted from the height of the eyesight; and supposing that to be $3 \mathrm{ft}$., then the ground at the station-pole must be $2 \mathrm{ft}$. higher than that at the spirit-level. Having ascertained, by the use of the spirit-level, the lowest part of the ground to be drained, and being aware how deep a main drain must be made there in order to carry off the water from it, cut a main drain along the lowest part of the ground all through, and make it empty itself at the lowest point possible. This main drain must be made of a size proportionate to the quantity of water it is likely to be required to contain; and this will of course depend to a certain extent upon the area of the ground to be drained. On nearly level land the main drain must be deeper than there is any necessity for it to be on land having a good slope, in order to provide a fall to the smaller side-drains debouching into it. 
It must therefore sometimes be rather wide and deep, more especially towards the lower end. But it should be borne in mind that numerous sidedrains of $1 \frac{1}{2}$ to $2 \mathrm{ft}$. in breadth and depth cost far less to make than one main drain of large dimensions, say about $6 \mathrm{ft}$. by $5 \frac{1}{2} \mathrm{ft}$.

Having made the main drain with sloping sides as shown in Figs. 100 , the side-drains should next be formed at proper distances, say

Fig. roo.

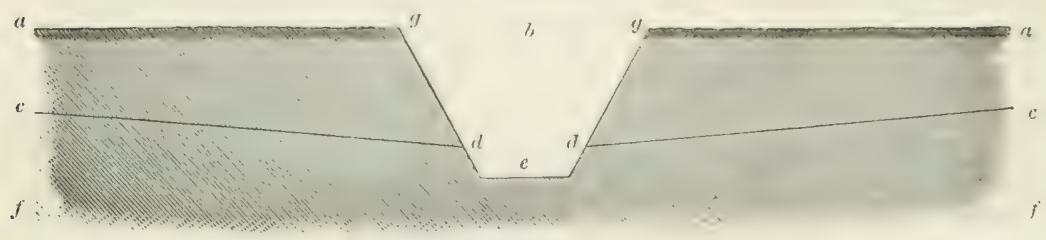

from 25 to 30 ft. apart, and at nearly right angles to the main drain; and in making these, it is necessary that they should become gradually deeper as they approach the main drain. Thus, supposing the original depth of the side-chrains to be ac, it should, before debouching into the main drain, be gradually deepened to the difference in level between $c$ and $d$, so as to prevent water lodging in it. Supposing the land to be almost level, a difference of from 6 in. to $1 \mathrm{ft}$. or even $1 \frac{1}{2} \mathrm{ft}$. of descent may thus be effected between the two ends of the drains, which is quite enough for any drain of ortinary length in a plantation; for as they are left open, they can of course be scoured out from time to time in order to keep a clear run. The run of these side-drains is represented by the two lines $c d$ on each side of the main drain $b$ in the figure. In the instance above given by the author, from the surface at $a$ to the bottom of the upper end of the drains at $c$ is supposed to be 42 in.; and from the surface upon the side of the main drain at $g$ to the bottom of the lower end of the small drains at $d$ is 69 in., giving 18 in. of a fall upon the small drains from $c$ to $d$. It will be observed that the lower ends of the small drains at $d$ are kept a few inches above the bottom of the main drain at $e$ : this precaution should in all cases he used where there is not much descent for the water. Were the smaller drains made to terminate exactly at the base of the main trench, the acemulation of mud from the different side-drains wonld soon he so wreat as to chech the progress of water at the ends, and to canse the drain to become choked. But, by keeping the bottom-level of the minim drain a few inches under the bottoms of the side trenches, although mud should acemulate in the former to a considerable extent, the others are not affected by it; and if the main drain be cleaned out once a-year, all is kept right in regard to the side-drains.

VOL. I. 
The editor would again call attention to the advantage of numerous sidedrains, rather than to the formation of such broad, deep, and consequently expensive trenches; for they necessitate still broader, deeper, and much more expensive main drains.

It is a point of practical wisdom in draining not to have too many small trains rumning into one single main trench, unless, indeed, it be of rery areat dimensions: it is letter to form sereral main drains. But if it should be found necessary to continue all small drains into one main for a great length, which will depend upon the nature of the ground, the latter should be made larger as it increases in length, with the view of containing the increase of water from the small drains upon its sides. When water increases to a great quantity in a main drain made upon soft soil, it is very apt to be injured, and to have its sides broken down by gradual erosion. In order to avoid this, it is a better plan not to allow the small drains to run above 150 yards withont filling into a large trench, which, if possible, should be made to have an outlet for itself, without the bounds of the plantation, or into a stream, if the ground contain one. A natural stream or buru makes at all times the best outlet for water from main drains: and, if possible, this should always be arranged in laying out a drainage network.

In laying out open drains upon land having a steep declivity, they should be run nearly at right angles with the descent of the ground. But, at the same time, care must be taken to make every drain with a slight fall downwards; for if the trenches have not at least one foot in a hundred of descent, they will be apt to become choked up with mud and vegetable matter, which is sure to accumulate if not carried away by a brisk run of the water in the drains.

Sylvicultural experience of a very extensive nature in northern Germany has shown that (Burckhardt, op. cit., p. 562)-

"From the usual situation of moors [on the North German Plain] one has generally to be content with a very slight gradient. A fall of 1 in 2000 is very favourable, and is even somewhat large if much water is to be run off; for too high a gradient causes cracks in the soil. Frequently one must be content to work with a fall of 1 in 6000 or $8000 . "$

Under such circumstances the following plan is adopted in order to lead to the speedy setting of the soil (Fig. 101). Several, usually three, side-clitches, $a b, 3 \mathrm{ft}$. broad and $2 \mathrm{ft}$. deep, are formed parallel to the main drain $A$, at distances of from about 75 to $150 \mathrm{ft}$. apart, and are connected together with horizontal ditches, c, of $2 \mathrm{ft}$. in breadth and $2 \mathrm{ft}$. in depth, formed at distances of $75 \mathrm{ft}$. apart. By clearing out the ditches from time to time, by deepening them when necessary, and by increasing their number, the work of drainage may be very effectually completed, even with a very slight fall to work upon. In ileepening the secondary drains, the operation must of course be begun at the lower end near where it debouches into the main drain $A$. 
Where the ground has a natural fall of alsout 2 or $\ddot{3}$ per cent, the drains may be made to run in the direction of the same; but beyond this the fall would be too much, and would certainly prove injurious to drains. Caution, therefore, is necessary; for if the trenches were to be made with a natural fall of 4 to 6 per cent, the effect during a flood would be to ruin the drains. Again, if the soil were of a sandy or gravelly nature, the undermining of the sides of the ditches could not but take place, and the whole work would be ruined. Where the soil is of a light, sandy, or gravelly nature, therefore, it is best to give no more descent to the drains than will carry the water along so as to prevent stagnation; but where the soil is stiff, a quicker descent may be given without being so apt to do damage as in light soil.

In order to exhibit clearly the method of draining upon steep slopes, an illustration may again be made use of (Fig. 102), representing the network of drains upon a hillside.

Fig. Ior.

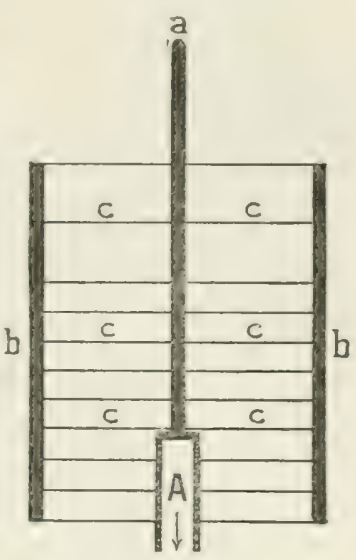

A, Main drain.

$a, b$, Side-drains.

c, IIorizontal trenches o: feeders. This last illustration has been taken from Stephens's Manual of Practical Draining. In speaking of making open sheep-rlrains upon

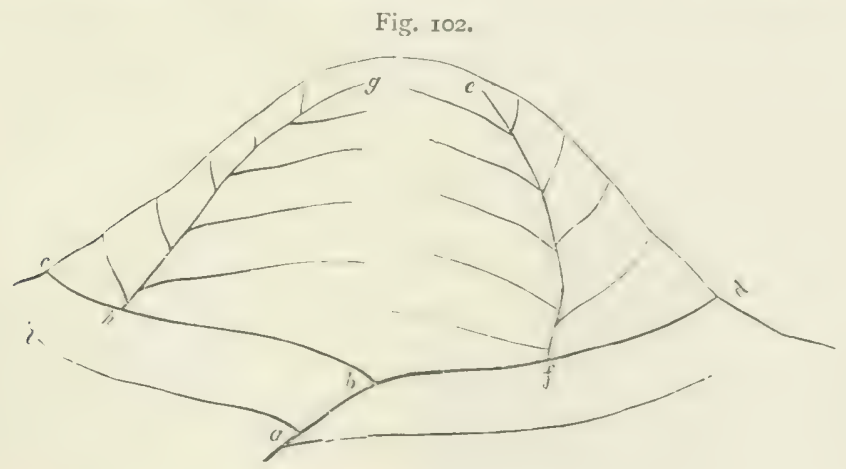

hill-pasture land, a method which is equally applicalle to plantationground in like circumstances, he says:-

"Open surface-drains in permanent pasture (or plantation-ground) exhibit the form represented in Fig. 102, where the leaders (or sub-main drains) $e f$ and $g h$ are cut with the greater slope down the hill the steeper the face of the acclirity is, and the feeders (or small drains) are cut across the face, nearly in parallel lines, into their respective leaders. In this way the water is entirely intercepted in its passage down the hill. Where one drain enters another, the line of junction should 
never be at right angles, but always at an acute angle with the line of the flow of water, as at $b$. And where small drains enter a large, they should not only enter with such an inclination, but where they come from opposite sides, as in the case above, they should enter at alternate points, as shown by the three drains above $f$, and not as represented by the three pairs of drains above these towards $e . "$

The large drain $c b d$ may either form a part of the lower fence of the plantation, or rum along the bottom of the hill-ground; and the main drain, from $b$ to $a$, may be made to run out in the direction of the outlet; whilst other small drains, as at $\alpha$ and $i$, may be made to run into it upon the level ground, if required.

All the drains should be made with a regular and equal slope from top to bottom on both sides; and the bottom of each should be left with a smooth and regular run from the higher end to the lower, where it enters the main drain, and into which it should be turned so as to throw its water on the line with that running in the main.

As each drain is opened and completed, the earth and turf taken out of it should be broken and spread in a regular way over the ground between it and the next drain, in order to improve and deepen the land all over. On no account should the output be left in ridges along the margins of the drains, as is too frequently done; for before long it is almost sure to tumble down into the cuts, where it obstructs the free passage of the water in them, and therefore interferes with their efficiency.

All secondary trenches or side-drains should be made in a position between the main drains and the smaller trenches or feeders; and as the former are intended to collect the water from the latter and to convey it to the main drains, they should be of a convenient size between the two. All open drains in a wood ought to be examined and cleared out at least once in two years; for, if they are not attended to in this respect, they are apt to become choked by resetalile matter lodging in them if the ground be level, or by gravel if it be steep and the land be of a light character.

Drainage-ploughs. - Where extensive drainage operations are heing undertaken, the use of drainage-plonghs, like the following (see Firgs 103 and 105), manufactured ly Messrs Hornsly of sons of Grantham, is advisable as being economical both as to outlay and time.

For the formation of shallow feeders or surface drains the Gripping-plough (Fig. 105) is in use; whilst the Drainage-plough (Fig. 103) may either serve the same purpose or be used in the first turn of work for the side-drains.

The Drainage-plough is used for taking out the top spit for the drainers. It leaves a grip from 9 to 12 in. wide at the top, 6 to 8 in. wide at the bottom, and 7 to $9 \mathrm{in}$. deep, as may be required. 
Its average weight is 3 cwt. 1 qr., and three to four horses will draw it easily. It will be found to work even where tussock, rushes, and rough grascover the land; and having taken out the spit, it will place it from 6 to $9 \mathrm{in}$. clear of the grip.

Fig. 103.

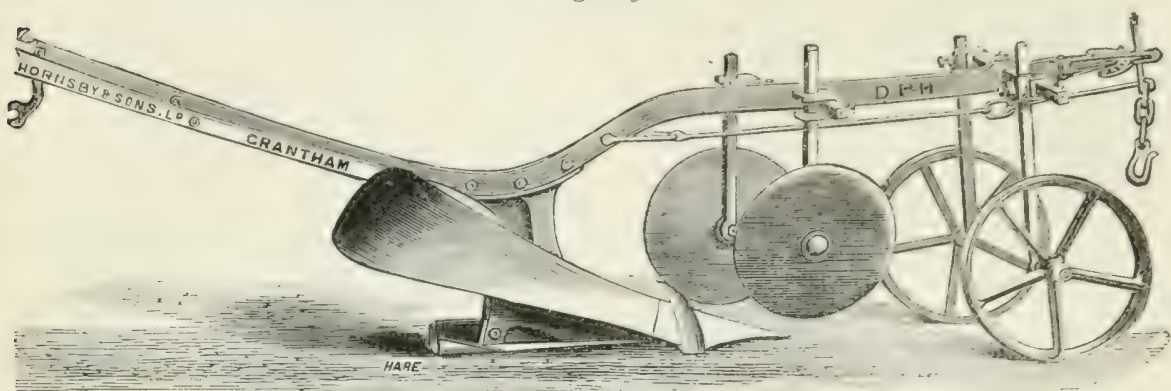

The following are the particulars of two days' work with this plough on the Syston Park estate, near Grantham, viz.:-

716 chains were drained $2 \mathrm{ft} .6$ in. deep with 2 -in. pipes-the top spit, 9 in. deep, being removed by the plough, and the remainder taken out and the tiles put in by the men; the price paid being 10d. per chain . . . . . . . $\$ 29168$

8 horses for two days, at 5 s. per horse per day . . $\begin{array}{lll}4 & 0 & 0\end{array}$ $£ 33 \quad 16 \quad 8$

The same work all done by manual labour cost $£ 65,12 \mathrm{~s}$. $8 \mathrm{~d}$. (1s. 10d. per chain being the price given to the men for doing the whole). The use of the former therefore showed a saving of $£ 31,16 \mathrm{~s}$. on the 716 chains, or about $10 \frac{1}{2} \mathrm{~d}$. per chain in favour of the plough.

Fig. 104.
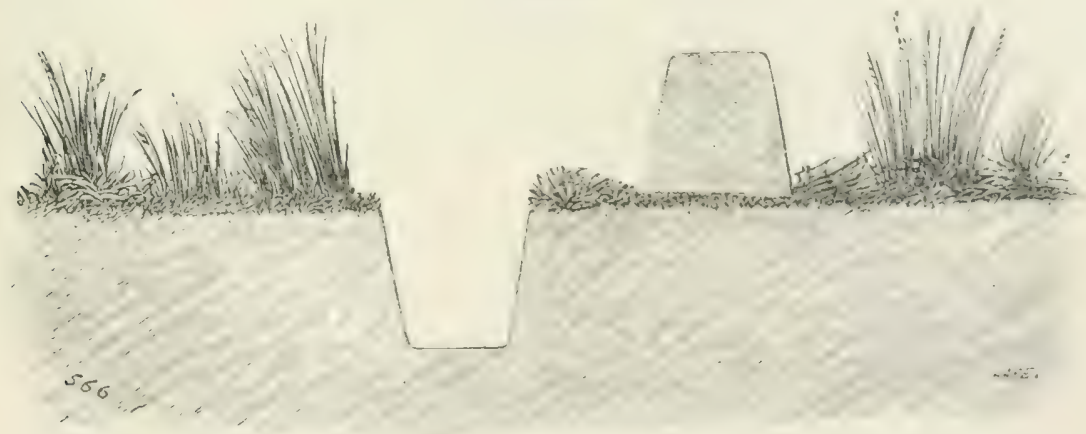

The Gripping-plough is an implement for making surface-rains more cheaply and quickly than they could be formed by hand.

It is constructed with two knives rising from the sides of the share, cutting the grip either $V$-shaped or with that bottom, the sloping sides in either 
case keeping the ground from falling in. In advance of these knives, and in the centre of the grip, is fixed a skeith or wheel-coulter, dividing the slice into two parts, which are thrown out by the breasts, one on each side of the grip. It can be adjusted to cut a grip from 4 to $9 \mathrm{in}$. deep, from 9 to 11 in. wide across the top, and $1 \frac{1}{2}$ to $2 \mathrm{in}$. wide at the bottom, or V-shaped, as desired. The soil taken from the grip is placed on each side, about 6 in. from the grip,

Fig. 105.

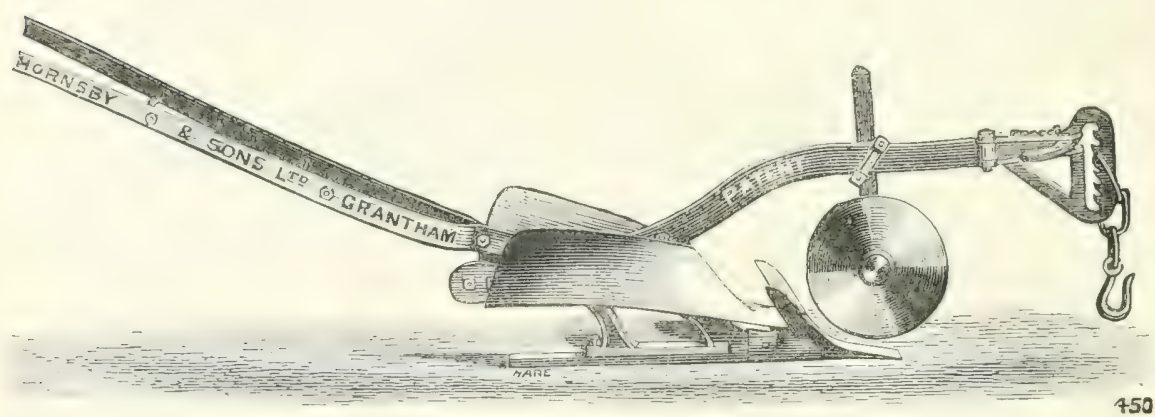

convenient for being either carted away, thrown on the land, or left to be returned in the spring. It is light in draught, being within the power of two horses, and can be recommended as a labour-saving implement; it may be easily converted into a ridging-plough, if desired, or may have an ordinary plough body attached for producing any kind of ploughing.

The following illustration shows the two shapes of grips produced (Fig. 106) :-

Fig. 106.

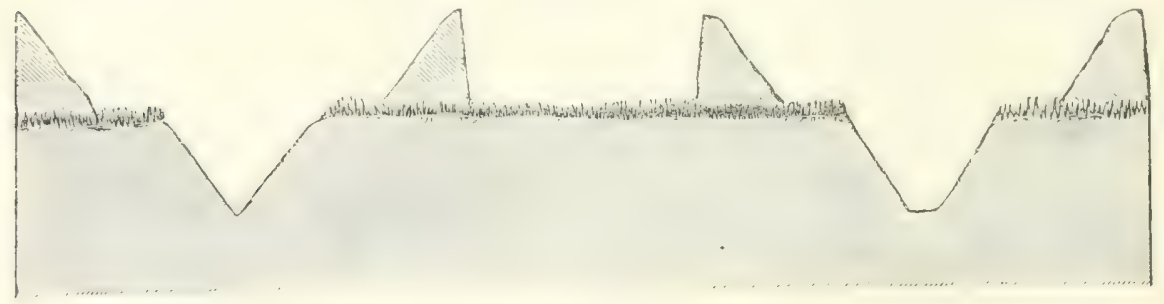

When the land is uneven or covered with rushes, the best work will be done by using the plough as a swing-plough; but when the land is level, for convenience and ease of management it may be used as a one-wheel plough.

The average weight of the plough is $1 \mathrm{crvt} .3 \mathrm{qr}$.

Closed or Covered Drains. - It often happens that open trenches are an eyesore near the home-grounds of landed proprietors' seats, although drains of some sort may be actually necessary for the welfare of the trees which may be growing upon the ground in such situations; and in cases of this nature closed or covered drains must be formed. 
It is a well-known fact that the roots of all trees incline more to spread about the sides of drains-whether those may be closed drains or open trenches - than towards any other part of the soil they may grow in; and of this ample proof may be har in the case of fields along the margin of woods. No reasonable depth of drain will sufice to keep the ronts of trees from getting to them, for they may even be choked at a depth of more than $7 \mathrm{ft}$. And seeing that the roots of broar-leaved species of trees in particular incline towards drains, whether these may be open or covered, it is therefore necessary to adopt some plan which will hinder the roots of trees from interfering altogether with their efficacy.

The following plan may accordingly be recommended to those who may have occasion to form closed drains near omamental trees; for it secures the safety of the drain, and, at the same time, allows the roots to ramify freely, and even to have access to the water in it to a certain extent (Fig. 107). The depth of this drain, from $a$ to $b$, may be $48 \mathrm{in}$., width at the base $9 \mathrm{in}$., and 12 at top. In filling it, about 10 in. of broken stones or large gravel should be put in at the bottom, as from $b$ to $c$, and above this a sole of slates should be laid down, as at $c$, for the draintiles, $d$, to rest upon. Between each sole there should be a vacancy of about an inch, in order to allow the water to rise up into the tiles from the gravel. The tiles being laid, they should be surrounded with a puddle of good clay to a thickness of $3 \mathrm{in}$. on each side, and the same on the top, $e$, and afterwards the drain should be filled up again with soil in the usual way.

This plan of making covered drains in ground occupied by ornamental trees, with the view of securing the drainage-pipes against being easily injured by their roots, will be found to continue efficicious for a long time.

The principle of this method of drainage is that the roots of all trees in the vicinity of drains, when they come in contact with them, travel along the sides of the drains, following the descent of the water to the bottom. Now, when there is a quantity of broken stones put into the bottom of a drain, the water will gather there from each side of the drain and filter along through it, consequently the routs of the trees will lodge there also; and as the space nceupied by the stones would not in all cases be able to contain the quantity of water that might lodge in the drain, a provision is likewise mate for any extraordinary flow, hy having the tile placed abore upon soles set a little apart, in order to allow the water the more readily to ascend into the tile, and to find egress thus whenere'r it may attain this height. In 
general, hwwever, the water would lodge at the bottom of the stones, and seldom rise to the top; consequently the roots of the trees will not tend to turn upwards into the tiles, seeing there would not be there any moisture to attract them. By placing a band of clay over the tiles, the roots of trees are prevented from going downwards into them; hence, before they can enter the drain, the roots must run to the hottom, where they are retained along with the moisture. Supposing that the part filled with stone's were to become so full of the roots of the trees that the water could not flow past them, it could still have a passage in the tiles which have been provided for this purpose; and as the water would continue to lie to a considerable extent among the stones, the roots would be detained there, and would not push themselves upwards until after a considerable time. 


\section{CHAPTER VII.}

\section{THE FORMATION OF TIMBER CROPS,-NATURAL REGENERATION, SOWING AND PLANTING.}

NExT to thorough drainage and aeration of the soil, nothing is of more importance, in order to ensure the future welfare of any young plantation, than the proper adaptation of the different kinds of trees to the various soils and situations therein. This is a point in Sylviculture which has been much too little attended to liy planter's in general; and it is in a great measure owing to want of attention to this most essential point that so very many of our existing plantations are to be seen in an unsatisfactory state at the present day. It is sad to see coniferous trees standing in an unhealthy and dying state on soil that is too rich for their natural requirements, but which would have yielded good crops of broad-leaved species of trees; whilst on the other hand it is just as bad to see stunted-looking, broad-leaved trees, striving for existence on land of indifferent quality, where a crop of Firs or l'ines would have lreen quite alile to thrive normally and to produce large supplies of good timber. It requires no great amount of intelligence to understand that Sylviculture can only be successful when the forester is fairly well acquainted with the natural halits, requirements, and peculiarities of the different species of trees that he attempts to cultivate; for without such knowledge the ultimate result of his work must in a great measure be left to chance. Gardeners have been assisted by the advice of many able and scientific men, who have written much for their instruction; but the forester has hitherto had compratively little written for his information. A gardener may cultivate several hundreds of distinct speecies of plants: yet he is generally ahle to adapt each species to that sort of soil which is found to be best suited to its nature. The gardener, in cultivating a rare kind of heather, for instance, gives it a light, mossy soil, and a cool, dry situation: and he does so because he knows that the heather, in its 
native conntry, thrives naturally on a light dry soil, and in a hilly or mountainous situation. And so on with every other plant he cultivates. The most successful gardener is he who can furnish his plants very nearly with the soil and situation which are found to be most suitable to their natural requirements. And this is just the point that the forester ought to attend to also.

Unless the natural requirements of any given species of tree, with regard to climate, exposure, soil and situation, food-supplies, transpiration, power of accommodation to cireumstances not exactly fulfilling all the natural requirements, \&c., be known to the forester, it is impossible that he can select the kinds of trees best suited for any given soil and situation, so that they shall hold out fair promise of yielding higher returns from the land than any other species of trees can reasonably be expected to give.

In chapters ii. and iii. an endeavour has been made to give in brief detail the habits and peculiarities of the various species of the trees cultivated in Britain. But it will often be found of importance to take cognisance of the geographical distrihution of exotic trees introduced for sylricultural puposes. It may not infrequently happen that muler the climatic conditions of Britain a tree exhibits different sylvicultural characteristics from what it prossesses in a drier climate.

All our forest-trees of well-known worth are natives of the temperate zone, for it is only the different species of Pine, Spruce, Birch, and Alder that extend morthwards into the arctic circle. The trees natural to each of these zones are not, however, always bounded by a certain degree of latitude; for the temperature of any siven place does not always depend upon its distance from the equator. Various causes have a tendency to modify the heat both of the earth and the air, such as large extent of continent, proximity to the sea, and locality as regards the east or west sides of continents or islands. The height of any given place above the nearest sea-coast also greatly affects its temperature. Elevated situations are in all cases colder than others under the same latitude near the level of the sea; and the higher the altitude upon any mountain or hill, the lower the temperature becomes, till at last the line of perpetual snow would be reached. This may occur upon any part of the surface of the glohe, provided the mountain rises high enowgh; and from this it will he seen that a change of clinnate does not alwars depend upon the degree of latitude, much depending upon the elevation of the ground. Under varying circumstances, therefore, a change of vegetation takes place. About the base of the Pyrenees, for example, the Vine and the Oak grow luxuriantly; on going a little way up those mountains, these disappear altrother, but the I'ine, the Birch, and the Alder are found. On proceeding still farther up, the Pines dis- 
appear also, and but little is found in the shape of veretation except dwarfish Willows, lieath, and mosses. And the same thing is olsservable in our own country, although not to the same extent. In all the lowland counties of Scotland, the Oak, Ash, Ehn, and Sycamore thrive well; while upon the high mountainous districts of the northem counties these will not attain their nomal derelopment. At this height the Fir and the I'ine tribes (Abictiner) are found in excellent growth; but there is an altitude beyond which even the Fir and Pine will not grow to useful size, and in their place dwarfish Birch, heath, and moss are to be seen. There is one print relative to the altitude of a place which is perhaps worthy of being noticer here. Given two situations, each at an altitude of $1000 \mathrm{ft}$. alove the level of the sea : if the one situation be at the top of a hill, and the other on a flat table-land of some extent, the former will often be much colder than the latter, although both are of the same height; and supposing the soil to be of equal quality upon both, trees will thrive much better on the flat table-land than they would do upon the top of the hill, although the one is as high as the other.

The explanation of the above fact is that on table-lands the warmth is radiated more gradually and slowly than from peaked mountains; whilst the soil is more homogeneous and generally of better quality, because it is not so apt to be washed away.

The healthy growth of trees is also much affected ly the peculiar locality of the part of the country in which they grow. In Norway, for instance, on the coast of the Atlantic Ocean, the Oak is found growing in lat. $63^{\circ}$; while in the eastern parts of Europe, on the confines of Asia, it will not grow in lat. $57^{\circ}$. This shows that the west of the continent of Europe is much milder than the inland tracts, and also that the sea-coast is much more temperate than an interior country upon the same latitude. Again, in Asiatic Russia, upon the river Argoun, in the same latitude as London, the Oak can scarcely be said to exist, owing to the extreme cold of winter. This shows the comparative mildness and equability of a maritime comtry such as Britain, and proves its better adaptation for growing trees, as compared with the extensive regions in the north of the Asiatic continent. At the same time, it also proves that the climate of the west of Europe is much milder than that of the east, or of the continent of Asia under the same.latitude.

If any corroboration of the opinion above expressed be desirable, it may

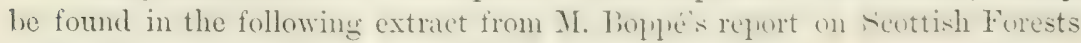
to the Committee on Forestry in 1885 (Appendix, p. 48) :-

"In wishing Scotland, then, a hearty farewell, we venture to predict for her forests a great and prosperous future. It does not need that oue should be a very great prophet 
to predict this for a country where the Oak and Beech, the Scots Fir and Larch, flourish with equal rigour, and where the Abies Donglasii, Abies nobilis, and Abies Menziesii, the Sequoia, and the Cedar, form mighty trees, in company with Araucaria and rarious exotic shrubs, which only languish miserably under the climate of Paris."

It is generally remarked that the west side of an island or continent is milder than its east side; but this does not always hold good in regard to our own island, for it is well known that the east coast of Britain is warmer than the west. The west coast may indeed be reckoned more equable in temperature thronghout the year; but the principal com-growing counties are situated upon the east side of the island, from the Lothiaus in Sicotland to Kient in England. The east side of Ireland is much warmer than the west of Scotland which is opposite to it; and this is occasioned by the storms from the Atlantic beating upon the west side of Scotland, while the east of Ireland is sheltered from them. Upon the east of Ireland, about Donaghadee, the most tender of our forest-trees grow with great lnxuriance: while upon the west coast of Scotland, about Portpatrick, which is only 18 miles distant from the latter place in Ireland, not a forest-tree of any consequence can be made to grow for a considerable distance back from the sea-shore. This proves that in planting out trees, even in places of the same altitude, the kinds to be chosen must depend not only upon the general aspect, but also on the amount of exposure to prevailing winds.

In Norway and Lapland the Scots Pine is said to attain a height of $60 \mathrm{ft}$. in lat. $70^{\circ}$; and $\mathrm{v}$. Buch says that in Tornea, at the head of the Gulf of Bothnia, the Birches are magnificent. Let these results be compared with those attained in the northern parts of Britain. In the Orkney Islands, about lat. $60^{\circ}$, scarcely anything having the form of a tree is to be met with but the Hazel, which bears the winds of the Atlantic better than either the Scots Pine or the Spruce. This is occasioned by the extraordinary rush of storm frassing along the Atlantic among the northern islands, which prevents trees from growing to any useful size. On the other hand, it is very remarkalile that the spruce Fir in Sweden is found eight degrees farther north than the Hazel, and this occurs on the coast of the Baltic.

In Scotland we have extensive natural forests of the Scots Pine, but none of the Spruce. It was therefore formerly said that the Spruce is not nearly so harly in Britain as the Scots Pine: but this entirely overlooked the fact that of all the gymnospermous trees only Scots Pine, Common Juniper, and Yew are indigenous to Britain. Again, at the same time it is a fact that, in order to grow it to advantage, it must be planted in a much more sheltered situation than the Scots Pine requires. Now this is the more remarkable 
when we take into notice that there are forests of the Siruce Fin in Norway as far north as lat $67^{\circ}$, which is much colcler than the climate of Scotland; but this paradox can be accounted for by the extreme humidity of the climate.

The finest development of the Siruce is attained in the mountainous tracts of Central Europe, where the climate is dry; and where there is a lons period of continuous cold from about the end of October till well into April usually. The long continuation of the autumn vegetation in Britain seems to the editor the most probable reason of its not thriving so well here as on the Continent.

This opinion seems borne out by Prof. Willkomm (Fistlicke Flora, 1S87, p. 319) in the following passage :-

"Most of our central European forest-trees demand not only a certain amount of warmth during their period of vegetation, but also a period of rest of a certain duration. Thus Spruce, for example, can no longer thrive in countries where the winter is so short, and the average temperature of January is so high, that the regetative process of this tree cannot attain rest; for comparative observations have shown that Spruce demands both a period free from frost and a winter rest of at least three months for its normal development."

Again, in Norway and Sweden it is said that the Larch is not found of indigenous growth, just as the Spruce is not found in Britain; yet the Larch and the Spruce occur indigenous ly in Siberia, much farther north than either the Scots Pine or the Birch. This shows that the Larch is more hardy than even the Scots Pine in inland districts.

In Asiatic Russia the tree found farthest north upon the Arctic Ocean is the Larch (Luri: sitirier); next to it, in progrexsing sunthwards, comes the Spruce (I'icel woreate), then the sicuts I'ine, and, still farther to the south, in succession, Lime, Ash, Oal, Beech, Elm, and Poplar.

Now, if deductions be made from the above observations as to the natural distribution of our common forest-trees over the continents of Europe and Asia, it will at once be seen that the same natural laws to a serat extent sule their development in artificial woods on our island; but with modifications, of cmuse. aceording to the aspect of the different parts of the comntry upon which they are planted. In some high-lying inland parts of Britain, Larch is known to be more hardy than the Scots Pine; while, again, in the more humid northern parts, bortering upon the sea, sonts l'ne is found to thrive better than the Lareh. The Sintues, assain, in Initain is less vigorous in growth than either the scots l'ine or the Lareh; but in this it is not so much affected by the dengee of enll ats ly the situation it may be planted in. For it will stand, and will indeed thrive best, with a much greater degree of cold than is usual in Britain; provided always that the winters are clear and dry as in 
continental Europe. The Pedunculate Oak is also found to thrive much better in a moderately level part of the country than when exposed to sudden and frequent storms of wind; and it is, like the Spruce, not so much retarded in growth by any degree of cold as by exposure to high winds. In making calculations relative to the climatic requirements of any given species of tree, it must be kept in view that the air upon a mountain side $1000 \mathrm{ft}$. above the level of the sea will, in the neighbourhood of the sea, be much more temperate than at a height of $1000 \mathrm{ft}$. upon a mountain far inland and away from the influence of the sea; but for shallow-rooting trees, like the Spruce, exposure to south-west winds must be avoided, as likely to cause windfall among the crops.

In planting any part of an estate, whatever is likely to affect the thriving of the crops must be taken into consideration at the same time along with all the individual requirements and peculiarities of the different kinds of trees being studied; and only those species of trees should be planted which are likely to answer at the given altitude and aspect. As a general rule, deep-rooting species of trees like Pines, Larch, and Silver Firs should be planted on the more exposed parts; whilst on lower localities the broad-leaved trees should have all the better forest-land, and only the inferior tracts should be planted up with Conifers like Spruce, Pines, \&c. And at the same time an excellent opportunity may often be given for forming mixed crops; for only the more exposed parts need be planted with Pines, and all the lower parts having a good soil may be stocked with the more valuable broad-leaved species. This not only gives the best possible effect to the plantation from an ornamental point of view; but it also adds considerably to the healthy growth of the whole as a timber crop. For, when heights are planted with conifers, the broadleaved species under them are thereby sheltered; whilst from being sheltered they grow quicker, and attain marketable dimensions earlier.

The analyses made by sylvicultural chemists prove that, with regard to the actual quantities of mineral food abstracted from the soil, coniferous crops make far smaller demands than broad-leared species: and that at the same time, notwithinanding their heing evergreen (except the Larch), they also make far smaller demands for soil-moisture for the purposes of transpiration. ${ }^{1}$

Regeneration of Woods.- When existing woodlands hecome mature, and are fit for utilising, the choice of the method of regeneration lies between natural reproduction or artificial reproduction, and in the latter case between sowing and planting.

Natural Regeneration has hitherto in Britain not been so much

1 Compare pp. 331, 332 ; also the editor's Studics in Forcstry, 1894, pp. 79, 85, 86. 
practiser in high-timber forest as is the case on the Continent, and it is chiefly in Copse and Coppice that it has mostly leeen made use of. This is certainly not due to the climate; for in this country most species of trees, eren those distinctly classifial,le as lightdemanding species, can bear rather more sharle than they could on similar soils situated in the dry inland tracts of the continent of Europe. In proof of this, the following extract from M. Boppé's report on Scottish Forests ${ }^{1}$ may be quoted :-

"As foresters of the Continental school, accustomed to live among forests regularly managed, and having for their sole object the froduction of timlser, we had no little difficulty in understanding the widely different motives which actuate forest cultivation in this country.

"We were also struck by the monotonous regularity in the height and age of the trees, unmistakalle sign of their artificial origin and want of methodical management. The forest, here left to its own derices, continues growing just as the hand of man has planted it.

"When under such circumstances the time arrives for the trees to be cut down, or should they be uprooted by a hurricane, the forest disappears in its entirety, owing to the total want of young growth which is necessary as a link between the old forest and the new one which ought to be created. Such at least appears to us to be the case in all the forests that we risited in the ralley of the 'lay and its tributaries, and farther north near the foot of Cairngorm.

"It is easy in Scotland to perpetuate a forest by natural means, "and of this a practical proof was given us in two forests which we visited-the one near Grantown, in Strathspey, the other at Beauly. In these the results obtained, under the skilful and intelligent direction of the gentlemen who manage these forests for their employers, form a striking example of what may be done in the way of reproducing forests by natural means. In fact, nothing had been neglected which even the most critical forester conld desire; the gradation of age was here complete, and the reservation of specially rigorous trees of known pedigree duly carried out. The modus operanti here pursued consists simply in the exclusion of the sheep and deer, in the judicints thinning ont of the growing crop, and in the removal of the mature seed-bearing trees by successive fellings as the young forest grows up and acquires more vigour."

\section{The advantages of natural regeneration are-}

1. That the reproduction of the crop can be effected with only a comparatively small outlay for soil-preparation.

2. That there is generally a greater density of crop, and that therefore it forms close canopy sooner, so as more fully to utilise and to protect the productivity of the soil.

3. That there is little danger of the crop not being suited to the soil.

1 Report of Committce on Forcstry, 1857, Appendir. 
4. That it affords better protection against drought, frost, insects, and fungroid diseases.

5. That it protects the productivity of the soil better than any other method.

The disadvantages of this system of reproduction are-

1. That the time of regeneration depends on good seed-years, which cannot always be relied on, and that therefore the allocation of the annual falls and the provision of the working plan are apt to be interfered with to a greater or less extent.

2. That this method requires a greater amount of supervision and higher knowledge on the part of the forester.

3. That it is apt to produce somewhat irregular crops.

t. That it is only really cheaper than sowing or planting when the operation is successful, but not when there are many blanks to fill up.

As a matter of fact, in all extensive woods the natural regeneration of existing crops has many practical advantages. On the whole, the costs of formation are less than when either sowing or planting is adopted: and the importance of this will be seen when ground-rent and formative costs are calculated for 70 to 100 years at compound interest, for actuarial comparison as to the more profitable method. It may be argued, and with truth, that during the early years of growth loss of increment is sustained which can be avoided by raising plants in nurseries and transplanting them at 1, 2, 3, or more years of age; but it is apt to be overlooked that, in consequence of the heavy thinnings or partial clearances which take place in the mature crops for the purpose of stimulating to large production of seed, and of preparing the soil for the reception of the seed, a larger increment msually takes place on the parent stems than if the whole crop were left standing until cleared for the planting up. This is a fact founded on sylvicultural experience throughout Germany. At the same time, excellent opportunities are also afforded for the introduction of other species here and there, so as to form mixed woods.

In natural regeneration three distinct classes of fellings may be distinguished, viz.:-

1. Preparatory fellings, in order to stimulate the more rapid decomposition of any layer of dead leaves littering the ground, as is often the case when woods are maintained in close canopy.

2. Seed-fellings, carried out so as to stimulate to a richer production of seed in consequence of the enhanced exposure of the crown of foliage to light and warmth.

3. Gradual clearances, for the purpose of permitting the young seedling crop to have, according to its actual requirements, such increased supplies of light as may be to its advantage.

Wherever circumstances permit of it, the method of natural reproduction 
in groups or patches has strong recommendations. It is very extensively and successfully practised throughout the Plack Forest and in Bavaria (nefe Fig. 108).

Fig. 108.

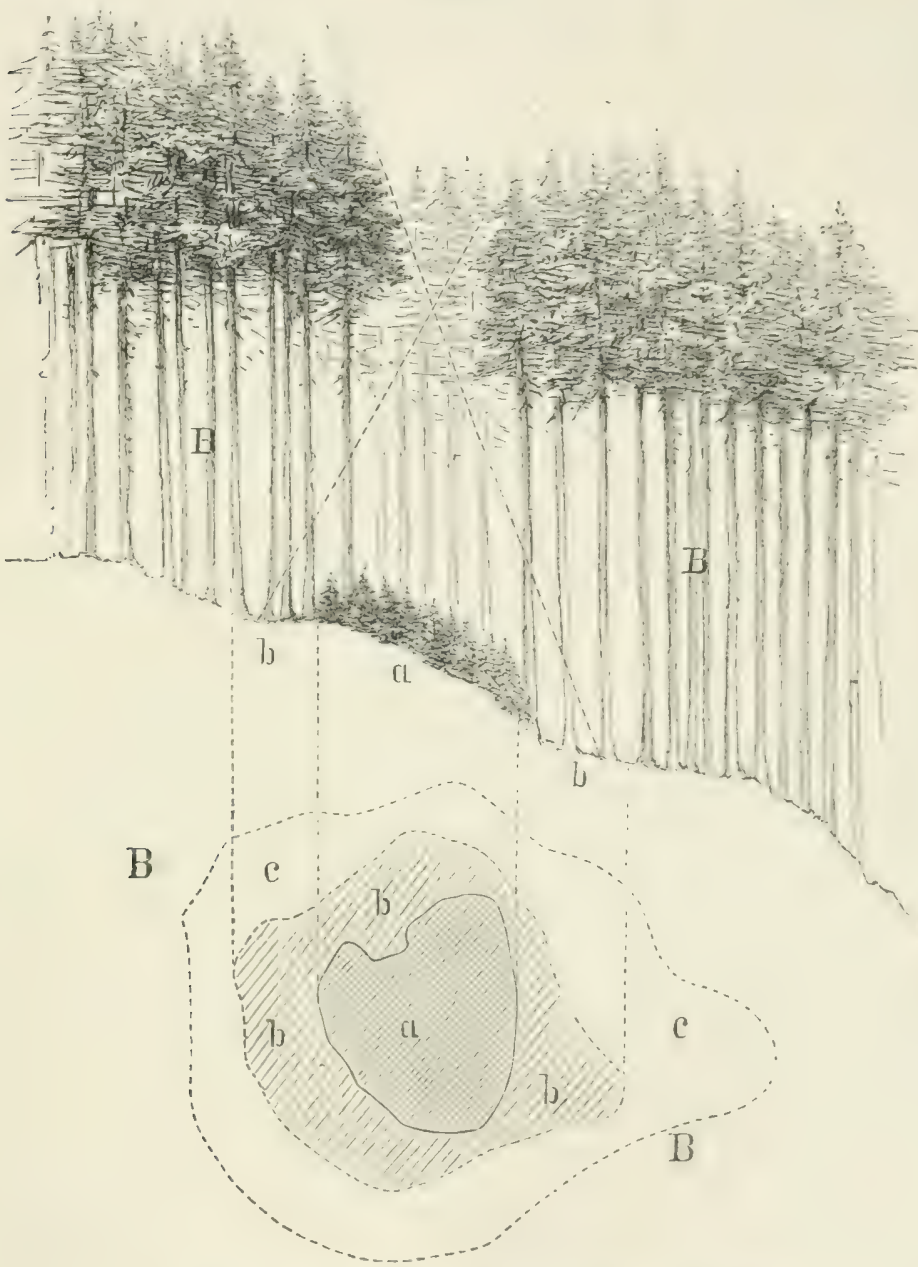

Natural reproduction of Spruce or Silver Fir in patches.

a Young seedling growth, above which the parent standards have been cleared away in order to provide a sufficiency of light, air, dew, \&ic., for its further normal development.

$\delta$ More extensive patch, now being regrenerated by the seed shed.

$c$ Exhibiting the method of extending the patches of seedling growth.

$\mathrm{BB}$ The extent to which the reproduction is being carried out.

It of course stands to reason that these different classes of fellings are not carried out with anything of stencil-like regularity for different kinds of forest-trees, or even for one and the same individual species within the arear operated upon. Thus, in the case of

VOL. I. 
()ak or Scots Pine, preparatory fellings may not be requisite; there may perhaps be no layer of dead leaves or needles to be stimulated into more rapich decomposition by allowing them to be more freely exposed to light, warmth, and moisture. They are, however, usually necessary in all crops of shade-bearing trees, like Beech, Spruce, and Silver Fir, which maintain even till their maturity a considerable density of canopy overhead.

And in the same manner, with reference to the gradual clearances of the prirent trees, when once a satisfactory crop of seedling growth has been obtained, the standards must be cleared away with due regard to the specific and concrete demands of the seedlings for light. The seedlings of light-demanding species, like Oak and Pine, become sooner intolerant of oversharlowing than those of shade-bearing trees; and on somewhat dry sandy soil any species of seedling will need to be freed from shade at an earlier stage of its development than on fresh or moist loamy soil. In the former case the seedlings drons unless they can obtain the benefit of the night-dews; whilst in the latter case not only can they thrive with smaller supplies of light, but they even require to be protected somewhat against late and early frosts.

So favourable is our humid climate to the growth of young seedlings, that there can be no doubt natural regeneration might profitably be carried out to a very considerable extent in the case of our existing woodlands. And if actuarial calculations be made on purely financial principles, then the benefits of the system must become very apparent-more especially when comparisons are male with the cost of expensive plantations, the plants for which are bought from nurserymen at an outlay, for material alone, often far exceeding the expenditure necessary for the natural regeneration of woods by seed.

It has been previously pointed out (see p. 518) that mixed woods have great advantages over pure woods; and in this method of regeneration excellent opportunities are given for the advantageous introduction of all such species of trees, broad-leaved or coniferous, as are desired to be introduced either in groups or patches, or merely as individuals here and there on pieces of land specially suitable for their cultivation.

In the above method the forester must take an active part in stimulating the mature crop to seed-production. But it not infreguently happens that even the simple enclosure of woods, or the mere l'rohilition of grazing, will result in successful natural regeneration, on the mature trees being removed. This system is open, however, to grave oljections; it is much too haphazard for properly conducted sylvicultural operations, and gives no guarantee that the crop, which springs up in place of that harvested, is such as may be desired or 
expected. Light-winged seeds, like those of 13irch, which lie dormant for years, then often spring up as weerls, and interfere with the utilisation of the soil in the most economic manner.

Natural Regeneration by Enclosure merely.-In countries which have lately been to a large extent cleared of their natural growth of forest, as is the ease in the United States and Canada at the present time, much of the land so cleared entrl be readily again occupied by trees, were it properly enclused, so as to prevent cattle destroying the young plants as these rise on it.

It is quite certain that large tracts of the land now lying in the unprofitable condition referred to would produce, within a few yeais, a young and promising crop of nearly all the kinds of trees that formerly grew ufon them, were they only protected from the inroads of cattle by fences erected around them. In the majority of cases where clearings of the forests have been made in North America, young seedlings immediately spring up all over the ground, whicis would soon grow up to form a thick and healthy crop, were it not that cattle eat them as they apyear above the surface; hence they are prevented from rising so as to form crops of any value. In many parts of Canada it may often be observed that, where the forest has been cleared, and where cattle are not kept in any considerable number, the cleared land becomes covered again with a dense crop of trees within a very short time; these grow rapidly, and might easily be made valuable if attention were paid to thimning the trees and to weeding out the less remunerative species.

This natural law of reproduction in respect to trees is taken advantage of to a large extent in many parts of the continent of Europe. Where work is conducted in a highly scientific manner, this often forms the chief method of reproducing the forests. With more or less of artificial aid in the filling up of llamks, this methoul secures full crops over all the ground, which have a greater density than would be attainable by planting, except at a high cost.

The same method is now being practised on a large scale, though rather on extensive than on intensive principles, in India, Australia, and New Zealand. 'There, where large portions of the natural forests have been cut down, the Govermments are enclosing the land and protecting the young trees which spring up niturally on it : and in this waly healthy erops are heing estathlished, where formexly only too often a mere scrub jungle followed upon the clearings.

It is well to bring this fact under notice; for were it properly acted upon in all countries having lands in a similar condition of unprofitalleness, new erops would ere long he estallished, and only a small outlay would afterwards be required to plant up the spots where young seedling growth had failed to germinate. 
Planting:-Planting having hitherto been one of the most important operations of the forester in Britain, every point bearing upon it, and having a tendency to secure its success, should be carefully and maturely considered before engaging in it; otherwise failure is as likely to attend the operation as success.

Every judicious and intelligent forester, before he commences to plant any enclosure of considerable extent, should calculate how he is to get on with it under all or any circumstances that are likely to occur, so that he may never be taken mawares whaterer may happen. During the planting season this can always be managed by having other works besides planting ready to go on with if the weather should prove unfavourable. Thus draining, road operations, and thinnings may be kept on hand, so that at any time the men can be turned to these if the weather proves unfit for planting; and the whole arrangement of work may be so ordered that at an hour or two's notice all the hands can be put to planting when the weather takes a favourable turn.

The planting season ought to be to the forester what the harvest season is to the farmer,-a time of anxiety and looking out on the weather; for the results of inattention in this respect are often very great. Large areas may sometimes have to be replanted from no other real cause than that of doing the work hurriedly, and in an apparently cheap manner. But let it be kept in mind that work done hurriedly is generally only half done.

Artificial Regeneration or Formation must, of cuurse, consist either of sowing or planting. As a matter of fact, the choice between sowing and planting has practically been settled in this country by the adoption of planting as a rule. This does not, however, prove anything; for there is probably less known about scientific Forestry, or Sylviculture, in Britain than in any other country in Europe, not even excepting Greece and Turkey.

In comparison with natural regeneration, the advantages of the artificial proluction of forest crops consist mainly in leing alsolutely independent of seed-years,-for nowadays supplies of seed can casily be olstained from other localities and even other comntries, whenever requisite,- - and in the freer hand that is undoubtedly left to the sylviculturist with regard to the general nature of the crop and the introduction of other species of trees in forming mixed woods. And when the methods of sowing and planting are simple and comparatively incexpensive, artificial regeneration of woorlands does not always or necessarily come more expensive than natural regenerations in which large blanks require to be filled up artificially. As operations can also be confined to small annual areas, the work of supervision and tending is also simpler than when several annual 
falls are grouped together for the various classes of fellings in natural reproduction necessarily extending over several years in the case of even the most light-demanding species of trees.

There appears good reason for believing that formerly in the oak-woods of England, sowing was carried ont to a greater extent than is now the case. Thus, among the orders of James I. for the conduct of operations in the New Forest, it was specially commanded that, after the requisite work of soil-preparation harl been completerl by "plomghing of the land for raising of new woods," acorns were to be gathered and planted "by men's hands"-i.e., sown, most probably in the manner now termed dibbling. ${ }^{1}$

Choice between Sowing and Planting.-The proper method of apuroaching this subject is the actuarial one, although, of erurse, there are given circumstances of soil and situation for which suwing is not naturally adapted. But, aprart from such cases, it is a well-linown fact that the remunerativeness of wools and the quality of the timber produced depend to a far greater extent on the tending of the crops at all stages of their develonment, than on the method of forming the crop from seed. And this being the case, the question of initial costs of furmation hecomes of great importance when calculated at compound interest till the harvesting of the mature crop, 70 , or 100 , or 150 years hence.

The following extract ${ }^{2}$ will exhibit the chief points to be taken into consideration in otherwise estimating the comprative advintages and disadvantages of sowing and planting operations under given circumstances :-

"Where woodland crops are to be formed for the first time, a choice only exists hetween sowing and plinting, in comnection with which-leatring out of sight the special requirements of the varions individual species of forest-treescertain general considerations require to be weighed.

"With regard to soil, experience has shown that on places unfavourable to the early development of young crops planting is preferable to sowing, owing to the greater sensitiveness and need of protection of young seedlings during the first stages of their existence. And better results are usually obtainable from planting than from sowing, both on very damp, wet, cold, or stiff soils with a tendency to being lifted by frost, and on very loose soils apt to clry up easily, or on such as may have become deteriorated superficially through insolation and exposure to exhausting winds, or are apt to be inundated, dc. Where, owing to rank growth of grass and weeds, joung growth has to struggle for its existence, sowing is the exception amel plinting the rule, more especially when the species of trees forming the young wop are of slow youthful development. I'nfavourable sitnation with regarl to rlimate, by retarding the growth during the first few years, also weights the latance in favour of planting, especially in raw loealities exposed to frost. But on scils

1 Lascelles, pamphiet on Arboriculture of the New Forcst, 1593, p. 7.

- Nisbet, Studics in Forestry, 1894, p. 172 . 
merely fresh and of a light mild consistency, the happy mean between loose and stiff, neither apt to become too heated or too rapidly cooled, and having no immoderate tendency to rank growth of weeds, sowing is principally adopted, as also on rocky, stony outcrops where there is hardly sufficient soil for the proper carrying out of planting operations.

"On the Continent sowing was formerly most generally practised, and it was not till the introduction on an extensive scale of the method of total clearance with artificial reproduction that the present preference for planting became general abroad. In Scotland the total destruction of the woodlands, originally clothing vast extents of still bare mountain-sides, naturally led to the artificial formation of forests wherever the proprietors desired to grow timber, and in the vast majority of cases the condition of soil and situationraw northern climate, rank growth of heather, heath, and other weeds, and deterioration of the surface soil by long exposure to the effects of sun and wind-naturally pointed to planting as the best, often the only, means of attaining the object in view; as good nursery seedlings, and especially sturdy transplants, had les. difficulty in extablishing themselves than tender seedling: germinating on the area had in overconing the disadrantages with which they had to struggle during the first two or three years of their existence.

"Where sowing can take place under the shelter of standards or in the lee of crops nearly mature, it is much more likely to be satisfactory than in the open; but under nearly all circumstances there is usually a good deal of work and outlay required for the filling up of blanks, so that the final cost of such young crops is not always less than if planting had been carried out orer the whole area at the outset."

The sowing of tree seeds at once. on the forest-land has been largely put into practice in the United States of America. But experience has sometimes shown that in that part of the world the rearing of woods from seeds sown at once on the forest-land is attended with much greater trouble and expense than the raising of plantations. The crops are apt to be of a patchy and irregular character. On some parts the young trees may be about $10 \mathrm{ft}$. high; whilst on other parts they are not over half of that height, and may not even exceed $2 \mathrm{ft}$. in height. Very many of the seeds fail to germinate, or blanks are caused by seeds having been sown too deep or too shallow; late frosts kill off many of the young plants after they have risen above the ground; birds and mice destroy a large portion of the nuts; weeds choke many of the plants; and the frost of the first winter after sowing destroys many seedlings. All these failures have to be marle grond during the second year, partly ly resowing and partly by transplanting from places where the plants stand thickly. Such resowing and planting does not always succeed, however; and generally these operations have to be performed in the third and even in the fourth year after the first sowing, before the crops can be made of proper density. Hence the crops look irregular and patchy. 
In Australia, New Zealand, and South Africa, a considerable extent of woods has heen raised from seeds sown on the land; but in nearly all of these cases the crops are also found patchy and irregular, and not equal, as a whole, to crops reared fom young trees plinted out from nurseries. Foresters in Britain should, however, make experiments in this lranch of tree-culture, in order to satisfy themselves as to its advantages and disadvantages. The author recommends planting as a rule, and sowing only where planting cannot, owing to some particular circumstances of soil, be. well put in operation.

It is not advisable to lay down hard and fast rules as to the general advantages of sowing and planting; for, in all given cases, concrete factors are present which must be known and studied before any sound opinion can be expressed. But certain broad natural principles are of course applicable with reference to soil and situation, organic and inorganic dangers, and co-t of production, such as have previously been referred to. It is well worthy of our attention that in Germany, where Sylviculture is much better understood and practised than in Britain, broad-leaved trees have always been rejroduced to a far greater extent naturally than artificially; and that with regard to conifers, natural regeneration and suwing are being far more practised now than was the case 20 or 25 years ago. There it has been found as a practical fact that in plantations the young trees exhibit a marked tendency towards forked growth, and that in other respects the cuality of the timber is not so grood as in crops formed by seed-shedding or sowing. On this matter the evidence of so eminent an authority on Sylviculture as Professor Gayer of Munich is worthy of consideration; and it is as follows : ${ }^{1}$ -

"But that the rapid initial development of many plantations considerably aftects the quality of the timber produced in comparison with that yielded by crops formed by means of sowing, and that consequently the timber of the former is less able to withstand the attacks of fungi later on, is no longer a matter of doubt or question.

"It must, however, be expressly stated that the youthful development of timbercrops can afford no reliable indication for the future quality of the mature fall. Expectations, anticipations, and suppositions in this respect have no justification; for the rhole matter depends most essentially on the later treatment of the crops (whether formed by sowing or by planting) during the operations of thinning out."

The editor's opinion by no means coincides with the author's in this matter ; for unless any special circumstances of soil and climate point to the desirability of planting, then the best financial prosition and the most farourable conditions for the young timber-erops are, on the whole, to be ohtained by sowing in preference to planting.

For further information as to the methods of sowing adopted with regard to each species of forest-tree, the student may be referred to the editor's British Forest Trees, 1893. 
Season for Planting.-O O pinions have sometimes been expressed that the months of March and April are the only proper season of the year atlapted for planting operations; yet in many cases autumn planting is really preterable. The months of November and December are perhaps best for the planting of broad-leaved species of trees, and February, March, and April for the planting out of coniferous sprecies. If the ground intended to be planted be naturally dry, both broad-leaved and coniferous species may be transplanted in the months of October, November, and December; but if naturally wet, or if the drains have only recently been made, then it is better to delay the operation till the spring months.

Healthy plants may be transplanted at any season of the year; but it is only in accordance with the laws of vegetable physiology that the least disturbance in the organism should take place in autumn, just after the completion of the active period of vegetation, or in early spring, just before its commencement. And, as has previously been remarked with reference to such disturbance (see p. 466), it is reduced when large balls of earth are used, so as to minimire the interference with the nomal balance between imbibition of foud-supllies and water, and transpiration and assimilation in the foliage. When the balls of earth are proportionately large, the planting operations may even be carried out in summer if necessary; but, on account of financial reasons, operations should be confined either to the spring or autumn. At these seasons the temperature of soil and atmosphere are not so low as to damage the plants during the operation, nor is the climate so dry as to injure them by excessive transpiration. But in favour of spring planting it may be said that almost immediately after the transplanting the young plants throw out their new roots and establish themselves on the whole more easily; whereas, if planted before then, they are more likely to be lifted by frost during winter, or to have their hold on the ground loosened slightly by high winds.

On the Continent spring planting is the rule, and autumn planting the exception. When there is so much work of this nature to be done that some of it must be performed in autumn, then the operations are carried out on soils not liable to be lifted, and with species which flush their foliage early in spring, like Larch, Elm, and Chestnut.

Where planting operations are not carried on extensively, it may be an easy matter to delay work till a certain time in the year, as the private opinion or convenience of the person intrusted with the work may suggest to him; though where 300 or 400 acres are intended to be laid down in wood in one season, it is always found necessary to take advantage of the whole season from the mirldle of October till April, whenever the weather will permit, in order to have the work all done lefore the growth of the plants begins, which is generally about the middle of April. Those who advocate planting in the spring months only may say that when the operations are to be executed upon an extensive scale, a greater number of persons may be em- 
ployed, so as to have the work done in the shorter time; but in most districts the number of gond hands that can be put on in order to have the planting of a piece of ground puickly accomplished is often practically limited.

Every experienced planter who has had occasion to employ a considerable number of men, in order to get through his work as fast as possible, is aware of the difficulty there is in getting a large number of lahourers, from any neighloourhood, properly cualified to conduct the operation well, and as it ought to be done. Common country labourers are seldom acquainted with planting operations, and require at least more than a week's practice before they can be safely intrusted to carry out the work properly. When a number of inexperienced men are brought together to plant, the work is always hadly done, and consequently is seldom attended with satisfactory success in the end. In planting extensively, therefore, it is preferable to perform a part of the work in autumn, to prolong the season of operations, and to do the work in a proper manner with a limited number of experienced men.

In planting-up extensive areas with a few good hands at disposal, it is not necessary, or even advisable, to begin at one end or sicle of the plantation, and to proceed regularly over the whole area. On almost every large piece of ground laid out for an extensive new plantation, there is generally a variety of soils and situations; and of this variety of soils and situations advantage should always be taken. When the weather is fine and open, the men may be set to plant upon the most exposed sides or parts of the ground; and when the weather is cold or wet, they may be told off to plant upon the most sheltered parts. Again, in the case of frost coming on, they may be put to other works, such as thiming, making new road d de, which can easily be undertaken during hard weather. This will keep the workmen in constant employment.

By conducting planting operations in the above manner, ten experienced hands will do far more work in four months than twenty inexperienced men in two montlis; and, what is of nure impurtance, the work by the few hands will be mituch better done, and prove far more satisfactory in the end. A very good common-sense rule is to plant dry ground with an open subsoil in antumn, either with liroakleaved sprecies, P'ines, or Firs, and to plant ground naturally cold in the subsoil in spring: also to plant dry, light, and opren-buttoned lands in wet weather, and to confine to dry weather operations on ground naturally cold in the subsoil. Any planter who may go to work upon these principles will find the results beneficial.

Even when planting operations are confined to the early spring, a commencement should of course be made with species of trees like Larch, Bireh, Elm, and 
Chestnut, which break out early into leaf; and the warmer exposures should be planted up before the colder hollows or northern exposures are operated upon. As activity of vegetation is not stimulated so early on these latter situations, there is no necessity for their being planted up so soon as the other warmer localities. The deciduous trees on the whole flush their new foliage earlier than the evergreen conifers; and this point deserves practical attention, as well as the fact that Pine, Spruce, and Silver Fir have a somewhat greater fower of estahlishing themselves when they have already begm to flush their new foliage, than is possessed by the majority of other species of trees. And so far as individual species are concerned, the older the material used for planting, the more nearly should the actual operation coincide with the most favourable season, dc.-i.e., just before the opening of the buds in spring.

As a rule, it is better to confine operations in autumn to deciduous species, and to plant out all the evergreen conifers only in spring; for the latter are more apt to be shaken by winds during the winter.

Methods of Planting.-In the planting of young forest-trees, three different methods are in practice among foresters. The first is that of pitting; the second is that of notching, either with the common spade or the planting mattock; and the third is that of tumping or planting on mounds.

1. Pit-planting should be employed for all broad-leaved species of trees, for two years' transplanted Larch and Pine, and for three years' transplanted Spruce or Silver Firs. The pits are made with the common spade, at various distances, from about 4 to $16 \mathrm{ft}$., as the case may be. That is to say, if the whole of the area operated on is intended to be planted with deciduous species, and with two years' transplanted Spruce or Pine, then the whole ground will need to be pitted to the distance required, care being, however, taken to make the pits for the hardwoods larger than those intended for the conifers. In order to do the work properly, all the pits for the hardwoods should be made first, say $15 \mathrm{in}$. on the side of the square, and 14 in. deep; then, having the pits made at these distances, say, of $16 \mathrm{ft}$. from pit to pit, make those for the Firs and Pine 9 in. on the side of the square and $10 \mathrm{in}$. deep, and just as close one to another as may be considered sufficient for the nature of the ground, or say 4 ft. over all. If, after having the pits made for deciduous species upon a piece of ground, it is found advisable to plant up with one year's transplanted Pine, then no more pits will require to be made there; for it is not necessary to be at the expense of making pits for any Pine plants which have been schooled for less than two years.

In the making of such pits as are above described, the work may often be given out by contract, the contractor being bound to cut off the upper turf as thinly as possible, and to lay it on one side of the intended pit; and in taking out the soil in the act of making the pit, he lays it upon the opposite side, which comes to be of great 
advantage in the act of planting. Where the soil is hard in the pit, the pick must be used to open it up to the desired depth. I'its for hroad-leaved species, made to the dimensions alrearly named, generally cost about 1s. 6il. per hundrerl, where there are no large stones or rorts of old trees, or from 2s. to $2 \mathrm{~s}$. fid. per himulred where these do occur; those for Pine cost about 1s. per hundred in the former case, and about $1 \mathrm{~s} .6 \mathrm{~d}$. in the latter.

In the case of planting a piece of ground among old roots, the remains of former trees, the pits should be made at least sir months previous to their being used. By thus having the soil in the pits exposed for a few months to the weathering influence of the atmosphere, it is rendered much more suitable for planting operations.

The manner of planting the young trees in those pits must be regulated according to the situation of the ground to he planted. If the situation be low and sheltered, only one plant should be put into the centre of each pit. And when once the plant has heen brought into proper position, the layer of turf taken from the top of the pit should be divided equally into two, and replaced closely upon the earth again, with the grass side uppermost. But if the situation lee rather exposed, then a plant may be put in each of the corner's of the pit; and by so doing it is kept firm in its place, through finding support against the sides of the pit. This latter methoul should always be practised when the plants are apt to be blown about by winds and storms. In planting in such pits, great care is necessary to see that the plants are made perfectly firm in the new soil of the hollow. But in order to attain security, no tramping or treading with the feet should be allowed until the whole of the earth has been put in. If the planter begin to beat the earth upon the roots of the young transplant while they are only half covered with soil, he is almost sure to do them injury. When once all the roots are well corered with soil, and the pit filled up, then a good firm tramping with the feet is necessary, in order to keep the plant properly in its place until its roots take hold of the soil. After the earth has been all put into the pit and made firm, the turf should be bedded over the whole as closely as possible, and male firm, in order to keep ont the drought.

It is, however, only necessary to plant in pits those trees which are of rather large size, such as broatl-leared species, Larch, Firs, and l'ines, that have been schooled for two years or more. Transplants of tender age or size, having smaller roots, only require to he plantecl in the natural surface-soil, which is generally free and open to the roots of all small plants.

In Germany, on most classes of soil for which pit-planting is considered preferable, the work is usually carried out by means of conical or circular spades, which are also used for lifting the transplants out of the nurseries 
(usinally close at hand; for, in sylvicultural operations conducted on a financial basis, it is found very much cheaper to raise the plants than to purchase them from nurserymen), so that the balls of earth fit in exactly

Fig. Iog. into the pits or holes made for their reception. By this

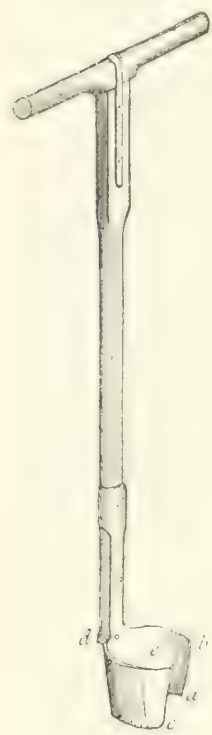
means the disturbance is minimised, and there is much less danger of the plants being moved by wind before they succeed in establishing themselves firmly in their new and permanent home.

There are many such instruments in use throughout the Continent (see Figs. 109, 110); but in general utility none of them surpasses Heyer's cylindrical spade, which was first introduced to the notice of planters in Scotland by the editor in 1876 in the following words : ${ }^{1}$

"This little instrument, if not already in use in Scotland, is worthy of introduction. The cylindrical spade (Fig. 109) is from 30 to $38 \mathrm{in}$. in height; the handle of wood is fastened by iron bands to the wooden stalk, the lower part is of iron. The lower diameter of the cylindrical sheath varies from $1 \frac{1}{2}$ to 5 in., but 3 may be taken as the average; the upper diameter is a few lines more, and the height is usually equal to the diameter. The stem of the young plant being allowed to pass through the opening $c a$, so as to come in the middle of the circle, the instrument is forced into the soil up to $d$, where a small iron plate prevents its further progress. One side, $c e$, is sharpened, the other remaining blunt, so that there is little danger of the

Heycr's Cylindri. cal Spade for planting work,

Fig. Iто.

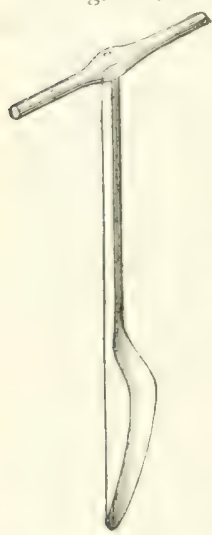

Cylindrical Nur sery Spade for lifting trans. plants. workman cutting his fingers in getting out the ball of earth. The whole is turned by means of the handle, and then drawn out, plant and earth remaining in the cylinder owing to friction. By placing the hand across $b d$, inverting the instrument, and, if requisite, applying a slight pressure from above with the thumb, the cylinder of earth falls gently into the hand. The holes into which the plants are to be brought are prepared with similar instruments of the same dimensions, and are thus rather larger than the balls of earth; but both having been slightly compressed during the operation, the first shower of rain (after planting out) corrects this. On inserting the balls, the workman (or boy) presses them down firmly with his thumbs, so as to facilitate their adhesion to the surrounding soil. A lad or a woman can with a eircular spade of 2 in. diameter plant 700 or 800 seedlings per diem, including carrying them a short distance from the nursery. For dry loose sand, or for very wet soils, this instrument is not intender ; such soils are not cohesive enough to form the balls of earth."

2. Notching. - The method of planting termed notching or slitting is done with the common spade or the planting-mattock. It is the practice most commonly in use for the planting of all small naked seedlings, such as two years' seedlings, or one year's transplanted Pine or Larch. The great point to attend to in this system of planting is to see that the cut or notch be properly closed about the young plant after it is inserted: this should be done by the planter using the heel of his shoe in beat- 
ing the cut all quite close again. The system of notching-in flants with the planting-mattock is done upon the same principle as that by the spade, and is generally practised upon a thin hard surface, where the latter could not be used conveniently.

Planting by the system of notching is carried out by a man and a boy, and may be explained as follows: The operator, with his spade, makes two deep cuts upon the turf, crossing at right angles exactly where the plant is to be put in (Fig. 111). He next inserts his spade across one of the ends of the four rars, as at ", which may be about 5 or 6 in. from the centre, this insertion of the spade being made on the side next himself. When the spade is inserted at $a$, he bends the handle or head of the spade towards himself, and nearly to the ground. At this stage of the operation the turf will open in the centre of the cross in four equal parts, but most from the point $a$; and at this instant the boy inserts his plant at the point $a$, where the spade intersects

Fig. IIr.

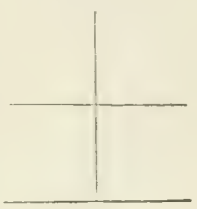
the ray from the centre. Immediately on inserting the plant he will draw it to the centre, while the planter will retain his spade for a moment until the boy has the roots rightly adjusted after passing them through the cut. As soon as this is done the operator raises up the handle of his spade, letting the earth and turf down upon the roots of the plant; he then makes all the cuts close and compact about it by tramping with the forefoot first, and then with the heel. If the cuts do not close tightly, as is sometimes the case when the sod is of a hard benty nature, a little piece of thin turf may be taken from the open space and placed over the cut, in order to keep out the drought; and this also gets tramper in with the foot. When the situation to be planted by notehing is upon a sloping brae, the operator should stand with his back up the hill and his face looking down. By doing so, he inserts his spade for the opening of the turf at right angles with the rise of the ground upon the upper side; and in this case the water coming along the surface is intercepted by the cuts, and retained for the adrantage of the young trees. Another point to attend to in the putting out of young trees by notehing is to see that they are not inserted too deeply, for this is an error in planting which very often talkes place. In oriler to aroid this error, so detrimental to the health of the plints, the boy should be instructed to hold the young tree between his forefinger and thumb, just about $1 \mathrm{in}$. above where the earth has been formerly. When he puts it into the ent, he should hold it firmly ly that part until the turf falls down into its plices and if he finds that the turf, when down, is much above the points of his finger and thumb, he must pull it up a little, so as to have these resting upon the surface 
of the turf. By attending to this precaution, the young trees will have a better chance of succeeding well. The boys are frequently left to make the plants firm in their place; but this should never be allowed by any man who wishes to do anything like his duty to his employer. The forester in charge must therefore see that the men employed on the work of planting should be made accomntable for the planting out of the young plants in a proper mamer, and not the boys.

For light descriptions of soil there are some German methods of planting very closely allied to notching in their principle. They are all based on applying pressure to the soil so as to bring it in close connection with the roots; hence they are not applicable on binding land, as that would be apt to flatten the root-system of the small naked plants, which are alone used in this way. The following is one of the best of these for ordinary purposes. The frinciple and method will easily be seen from the accompanying illustrations (see Fig. 112). In this the planting-stick may either be an iron instru-

Fig. II2.

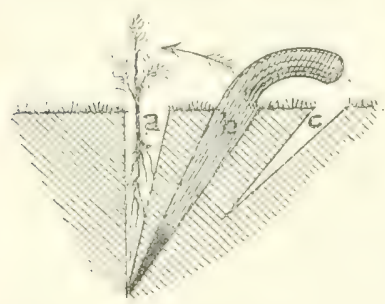

The Planting-stick. ment or simply a crooked bit of wood shod with iron at the tip, about 3 to 4 in. broad at the top, and 1 to $2 \mathrm{in}$. broad at the point. The first insertion $(a)$ into the soil is at right angles to form the bed for the plant; the next is as in the figure (b), and takes place, with simultaneous pressure in the direction from $b$ to $a$ so as to fix the seedling, when the plant has already been brought into place. In order that the roots may lie properly, the plant is inserted deeply into the hole, and then pulled up into its true position, so as to prevent it becoming twisted. A third pressure with the instrument $(c)$ is made in order to close up the aperture at $b$. The whole work can be easily done by one man, woman, or child. This is an extremely cheap method. In order that the naked seedlings may not be exposed to drought, the roots are kept well moistened by being mulched or steeped in a loamy solution when given out to the planter.

This method of planting is very easy to learn. The chief point to be insisted on is that the plant should be inserted well into the first opening; then it must be shaken slightly, and drawn up to the required height.

3. Tumping or Planting on Mounds.-In this method the roots of the plant are brought above the level of the soil, in place of being put in below it. It is a form of planting that is practically only in application on very damp soils, prone to rank growth of grass and other weeds, or on land having an unfavourable subsoil, which it is not convenient to trench or plough up. It is not likely ever to acquire any very extensive practical application, for it is rather a costly method. And if drainage works be executed, planting operations will usually be more successful, and not in the long-run more expensive, by means of simpler methods.

The soil has to be scraped together and arranged in a mound, of greater or less height according to the circumstances of each case. When the plant is 
brought into position, and the earth has been well placerl around its roots, the whole is turfed over with the grass cut away from the sprot necupied by the mound (see Fig. 11:3). From the great amount of manipulation recuirer, it can easily be understood that this method is somewhat expensive.

Some combinations of all the above methods can take place, as may be readily understood, without any detailed descriptions, from the following illustrations (see Figs. 114 to 116). Thus, in the first of these (Fig. 11t), a combination of pitting and tumping is exhibited, in which the earth lonsened from the pit is formed into a mound with a hollow encircling it, so as to retain

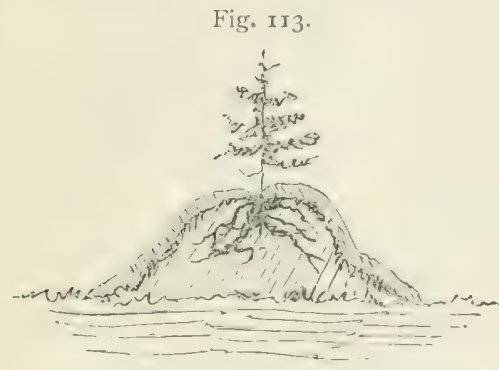

Ordinary method of Tumping with naked plants.

Fig. 115 .

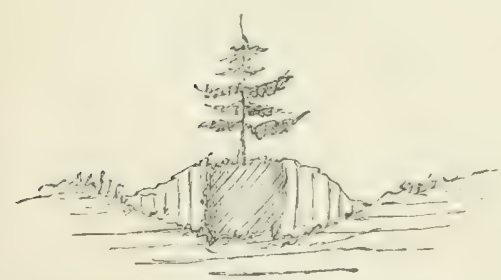

Combination of Pitting and Tumping with balls of earth.

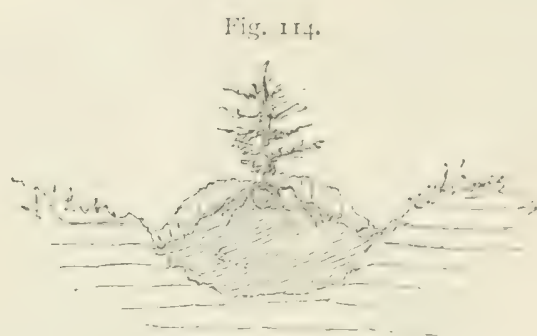

Combination of Pitting and Tumping with naked plants.

Fig. II6.

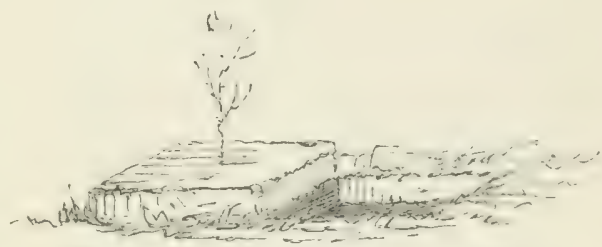

Combination of Notching and Tumping with naked plants.

rainfall: this method is adopted in Germany on very dry soils. A similar method is exhibited in the next illustration (Fig. 115), showing how large transplants hollowed out of the nursery-beds may he male into mound plants in shallow pits-a system said to yield good results in the Black Forest when old grass-lands, in situations exposed to late frosts, are being planted up.

The remaining illustration (Fig. 116) exhibits a combination of notching and tumping employed on old grazing-land and moist land overewown with weeds. The sod of turf is turned back, so that its upper surface comes to lie on the face of the ground; and then on this raised sod, of about 12 to $16 \mathrm{in.}$ syuare, the plant is noteheel in hy the ortinary method with the planting-stick or by means of a henvy notehing-iron (Fig. 117) havings a longs stalli, and weighing from 16 to $22 \mathrm{lb}$. It consequently requires a strong man to work it with both hands; whilst a boy inserts the plants in the manner alrewly described ats to the use of the planting-stick. The great point in planting with this instrument is to prevent any racant space being left near the base of the roots of the plant. It is therefore necessary for the man to pull the top of the instru- 
ment towards himself when the plant has been inserted, shaken slightly, and dram up to the position it should occupy in the ground. By this jerk he closes the lower earth against the deeper rootlets; and Fir. in - then by pressing the handle of the notching-iron towards

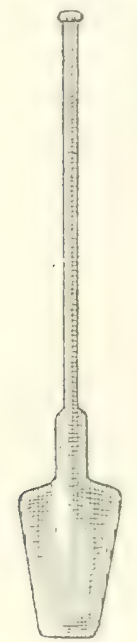

Heavy Grubbing-inon used for Notching. the plant, the upper portion of the root-system becomes firmly fixed in the soil. A repetition of the pressure at a little distance helps to bind the soil, and to prevent a deep pocket being left for the lodgment of water.

Of course there is here a decided tendency towards pressing the roots into an abnormally flat shape not natural to young plants; hence the method is only applicable to very light soils. Under such conditions it is, along with notching by means of the planting-stick, one of the most rapid and the cheapest methods. Where, however, small plants can be put out by means of Heyer's cylindrical spades, involving only small balls of earth round the roots, no method of planting can well be cheaper; and by the adoption of the latter method there is an easy solution of one of the great problems of planting on soils of medium consistency-viz., how to plant up large areas of land, in a short space of time, and at a comparatively small outlay, so as to obtain satisfactory results.

Trimming of Plants.-Whenever plants are transplanted a certain amount of disturbance is caused throughout the organism; and in order to balance the derangement which takes place in the root-system, or imlibatory prortion of the plant, a corresponding trimming of the crown is requisite in order to curtail the demands of the foliage for food-supplies, and more especially for water for the purposes of transpiration. Now it is self-evident that the larger the class of transplant, the more likely is damage to

Figr. IIC.

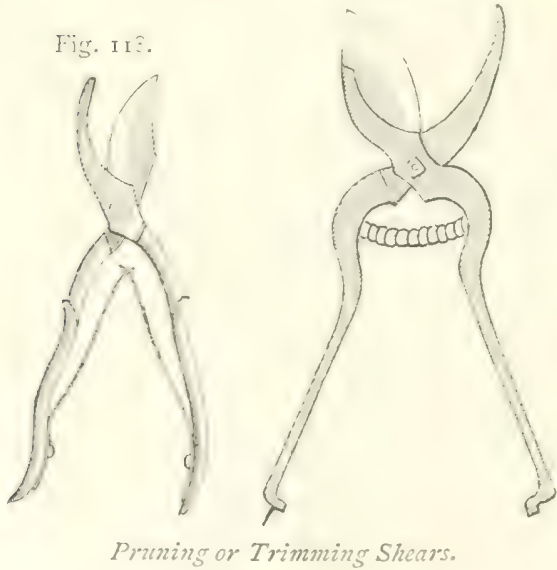
occur to the roots; and consequently the greater is the need of adjusting the rate of transpiration to the capacity of imbibition. All such deliberately inflicted injuries are, however, to a greater or less extent a drag on the normal development of the plants; hence, whenever possible, the use of small material and of simple methods of planting is advisable in preference to larger transplants and costlier methods of planting. But as transplants must, from the nature of the rank growth on many classes of land, often be used, a certain amount of trimming can hardly be avoided in the interests of the initial growth of the young plantations. And when the plant: have in the nursery-beds formed long straggling rootlets, and these are not cut away by the use of the cylindrical 
spade in lifting them from the beds, then some of the rosts may require to be cut hack, as well as the twigs of the crown. For such trimming operations on young plants the use of garden-shears is strongly to lie recommenterl (see Figs. 11s and 119). The trimming should take place either in late autumn or in early spring; and care must be taken never to injure the leading-shoot.

Hints concerning Planting.-In plinting on bare rocky soil, the work may often be performed by means of the planting-nattock (Fig. 120). The handle of this instrument is generally made about $36 \mathrm{in.}$ long, and of a piece of good Ash-wood. The.lip or cutting end, $a$, is about $4 \frac{1}{2}$ in. broad, and somewhat sharp; and the length of the one side, from the face to the eye, is about 12 in. The other side, instead of heing broad and sharp, is male to taper to a point, as in the common pick (see b). In using this implement for the purpose of planting upon thin, stony, or rocky ground, where the spade could not be used to advantage, the operator takes it into his hand in the same manner as he would do a common pick, and first pares off a thin part of the turf with the broad end $a$, exactly on the spot

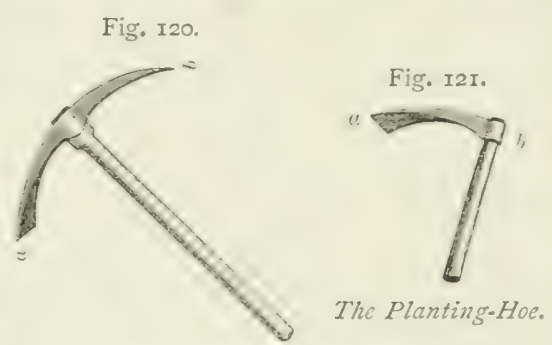

The Planting-Mattock.

where he intends to plant a tree. Having taken off a sod of turf about 6 in. square, he next with the pick-end lonsens the soil to the depth of ahout 8 in., bringing up at the same time to the surface any stones that might interfere with the planting of the tree. In this mamner any number of men may he employed, care always being taken to lieep to the specified distances as nearly as circumstances will permit. In generul, every two men employed with the plantingmattock are followed by a hoy or man having the trees in an apron, which he plants in the spots prepared. In planting with small seedlings, he uses an implement called the planting-hoe (Fin. 121). The iron part of this implement, from " to $b$, is generally almut $9 \mathrm{in}$. long. The lip or sharp end at $a$ is made about $4 \mathrm{in}$. broad, and is not so sharp as the lip of the mattock, as it has to be used in the earth; the handle may be about $15 \mathrm{inn}$ long. The person who is intrusted with the planting of the seenllings in the spots previonsly preparen? by the men with the mattocks, carries his plints in an apron hefore him. In using the planting-hoe, he leeeps it in his right hame, and digs it into each spot; and by pulling it, when in, a little torrards himself, he makes a suficient opening at the back of it to holl the roots of the young tree, which he puts in with his left hand, inserting the roots very carefully. As soon as the roots are proprerly in-

VOL. I. 
serterl, he withelaws the instrument, taking care at the same time not to disturb the plant in its position. When the implement is out, he gives the earth, upon the side of the hole next to him, a push with its lip, in order to bring the loose earth into the hole about the roots of the newly inserted plant; and a finish is given by tramping and making the plant firm in its place. In this manner three men will put out up to 2000 plants a-day.

This is very much the same as the German planting-stick (Fig. 112); but the latter instrument seems somewhat simpler and more handy.

On very bare or rocky surfaces, it is not always possible to get as much earth in a certain spot as will properly cover the roots of small seedling plants. Where this is the case, it is a better plan at once to sow the seed of the trees; indeed this is the only way of getting young trees to grow in certain districts. This plan has been adopted in some parts of the West Highlands of Scotland, and has been attended with good success.

Trees, of almost every common variety, may sometimes be seen growing upon old walls, or in any chink of a stone where the seed has only got a small portion of earthy lime or other decomposed matter to vegetate in; and in this position they may attain considerable dimensions, so as even to rend into pieces the wall in which they have got a footing. Similarly, in the crevices of rocks trees of very large dimensions may sometimes be found growing, which indicates that, where a young tree can only obtain a very slight footing for fixing its roots, it can often establish itself securely. Many bare rocky parts of our country might easily, under proper managenent in growing the seeds of forest-trees upon them, he made very productive and valuable, not only as a shelter to the surrounding country, but as yiclding a profitable crop of timber. The Oak, the Ash, and the Birch, for eximple, are all well adapted for this purpose, and might often be made to vield very fair returns as copluice - the Oak and Ash in moderately exposed, and the Birch in high and exposed, parts of the comntry.

The first crops on such land might hold out no immediate promise of remumerativenes; ; hut if proper species of trees were sown, the productive capacity of the soil might be greatly enhanced through the formation of humus, and by the protection of the land against insolation and the drying eflects of wind. In such localities crops of Spruce raised from seed develop a large root-system, which protects the woods against windfall. For first crops, in reclaiming exposed rocky tracts, the editor would suggrest Spruce, Mountain-Pine, and Larch to be sown experimentally.

Where sowing operations are carried out on poor, thin, rocky soil, the seed is not so apt as otherwise to be destroyed by mice, lirels, and other vermin, which are in the habit of frequenting more favoured spots for the sake of cover and shelter. 
In growing trees from seed in such situations, it is necessary to keep the patches clear of weeds for the first two years.

In the planting of coniferous species, care should be taken not to put them in too deep; for in this respect most of them are sensitive, and fail to establish themselves in a rapid and satisfactory manner.

In planting trees in pits, the planters should always be very careful to see that the best portion of the soil is put next the roots of the plants. If this point be not attended to, the suceess will not he equal to what it might be. They should also bear particularly in mind to chop down and pulverise with the sparte all soil which is laid close to the roots. If merely put in about them in lumps, vacuities will be left, which will probably cause water to lodse there and increase danger from frost; whereas, when the soil is made firm and small, it grets in about the tender roots, prevents the lodgment of superflusus moisture, and decreases the danger of the soil being lifted by frost.

Where pitting is performed upon a sloping piece of ground, such as the side of a hill, the earth, as it is taken out of the pit, should be put to the under side, and close upon the edge; and when the plants are placed in the pits, the good soil upon the upper edge of the pit should be broken well down with the sparle, and put in about the roots of the young trees. The soil which was taken out of the pit is still left lying upon the under side, in order the better to protect the roots from drought and to retain moisture alout them: it thus forms, when the tree is planted, a bowl in which a little moisture can be retained in its descent down the hill.

These depressions also tend to collect dead foliage; and this, on decomposing, fertilises the soil, and tends to enhance its productive capacity.

Fig. 122 illustrates this sort of pitting: a represents the earth taken out of the pit; $b$ the tree stanling in the pit which has been filled up with earth by reducing the bank behind as at $d$; whilst the original slope of the ground is indicated by the line from $c$ to $e$.

Spruce, although not indigenous to this country, will do well when planted in a high exposed situation, and may eren attilin very good dimensions if sheltered by other more hardy trees, such as the l'ine and Larch. Every planter, therefore, desirums of protucing a variety of trees in any high part of the country, may plant Spruce so as to raise timber of good and useful size, if the soil be not too light. For light soil, Pines of varions species will probably yieli more profitable results. 
In planting trees in ravines and steep hollow parts, the distance between the plints should not be measured according to the slope of the mound, but in the manner represented in Fig. 12:), drawn to the scale of an eighth of an inch to a foot. The line $a b$ represents a sloping bank to be planted with

Fig. 123.

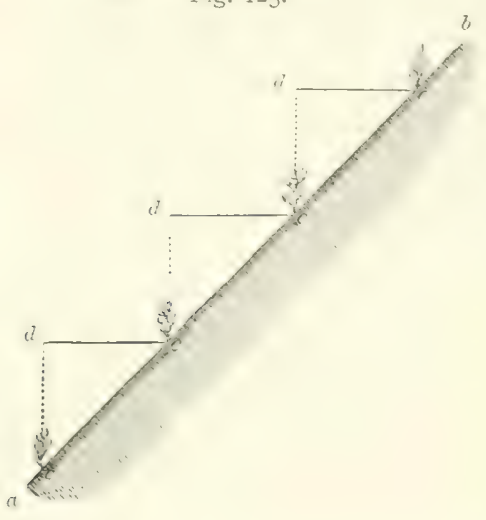
forest-trees at $4 \mathrm{ft}$. apart; the places of which are shown in the figure at $c, c, c, c$. By measuring upon the line $a b$ with an eighthof-an-inch scale, it will be at once seen that the distance between each tree from $c$ to $c$ is $6 \mathrm{ft}$. If the plants be put in at $4 \mathrm{ft}$. by $4 \mathrm{ft}$. along the slope, then the trees would really have a lateral growing-space of only about $2 \frac{1}{2} \mathrm{ft}$. instead of $4 \mathrm{ft}$. In taking distances for planting trees in a case of this nature, the operator must always keep his measure-stick, if he use one, in the position pointed out in the figure by the line from $c$ to $d$. Or, in other words, he must, when taking a measurement for planting another tree, set the one end of his measurestick at the bottom of the last tree planted; keeping it level, he then lets fall a perpendicular from the other end for the place where the next tree is to be planted, as shown by the dotted line from $d$ to $c$.

This seems to presume that the planters will work continuously downwards from above, then upwards from below. It would, of course, be a great saving of time and of energy to plant in horizontal lines, which should previously be marked out by the forester or plantation overseer.

Density of Plantations.--Every private proprietor of land, ir planting a portion of it with trees, has usually in view-

1. The deriving of the greatest possible clear or net revenue from the land under a crop of wood, without diminishing its productive capacity.

2. The most economical way of attaining this end; and,

3. The quickest possible way of producing both shelter and revenue from the land planted.

This third point is of course practically included in the second.

Forest lands are naturally divisible into three distinct classes(1) sheltered and low-lying: (2) moderately sheltered and lww-lying: and (:3) hinh-lying and much exposed. Each of these classes of land itemands particular attention, in order to come to a sound conclusion as to the proper distance for planting trees. 
1. With regard to the distance at which young plants should be put out in a sheltered and low-lying situation, every one is aware that trees will in such a situation orow more freely without any artificial means being used to protect then, than they would were the same species to be flanted in an exposed part. The artificial methor used liy experienced planters for the protection of young trees growing upon an exposed part is to plant them pretty closely together, so that they may som aftorl shelter to one another. Hence, in a sheltered part of the country, they may be planter at any rlistance consistent with future good management and profit; and this must be regulated according to the demand for the various sizes of wood required in the neighbourhood. Talse, for exaniple, the case of two estates, both situated similarly in a low-lying and sheltered part of the country, but the one in a neighlourhood where small wond is much in demand, and the other where no such wood could be suld to advantage. In the case of the former proprietor, whose estate is situated in a neighbourhood where small trees or thinnings are much in demand, it would not be wisdom in him to plant at such wide distances that he could not thin out any of his plantations till his trees become nearly of timber size. The plants might therefore be closely planted at $3,3 \frac{1}{2}$, or $4 \mathrm{ft}$. apart.

Again, in the case of the proprietor whose estate is situated in a neighbourhood where no small wood can be sold to advantage, it would not be wise of him to plant his trees so closely as the other proprietor, seeing that he cannot get any of the small thinnings sold as they may have to be taken out in order to give the others room. All the preliminary operations of tending would therefore be weedings and cleanings going to swell the costs of the plantation; whereas the thinnings can only be said to begin when the returns obtained on their clisposal cover the cost of the operation, or vield a tangible monetary profit. Undoubtedly it will be best for him to plant at such distances that the weedings and clearings are reduced to a minimum, without interfering with the development of the plants, until they attain a size fit for useful purposes in the neighbourhood hefore the thimnings can begin. In these two comprarisons the author lrelieres the whole secret as to distance in planting in sheltered localities to lie. In such situations they might he planted at 4 to $5 \mathrm{ft}$. apart, as at this distance, tree from tree, they will be able to stand together till such a time as they will be, when cut clown, fit for most country purposes, without doing injury to one another.

2. Again, laying aside every local consideration as to the sale of the thimnings, trees growing upon what may he termed moderately low-lying and sheltered parts of the country, or in a situation between sheltered and exposed, nught to be planted more closely 
than those in a sheltered locality, both on account of the general health of the trees individually, and of the plantation as a whole. In order to make up for the shelter possessed by trees in a naturally sheltered site, those in a less protected part require to be planted so closely as to produce shelter to one another artificially, and that to as great an extent as the nature of the site may demand. In such situations, again, he would advise planting at $3 \mathrm{ft}$. to $4 \mathrm{ft}$. apart. At distances much wider than $4 \mathrm{ft}$., the young trees will hardly thrive well : they would probably be much checked by exposure and want of due shelter.

3. In all situations which may be termed high-lying and exposed, or very exposed, no young trees should be planted more widely than $3 \frac{1}{2} \mathrm{ft}$, whether the weedings, clearings, and first thimnings may meet with a ready market or not. The great point to be aimed at, in the growing of timber in such situations, is to produce shelter as quickly as possible among the trees themselves; and this can only be done by planting rather closely at the outset. Even although a portion of the trees should be cut out (weeded and cleared) as they become too close, and allowed to lie as useless and unsold, no objection should be made. They will have answered their purpose, namely, that of producing artificial shelter for a time, and of developing the plantation as a whole much more healthily and quickly than could have been done without them.

These considerations comprise, in the opinion of the author, the whole art of judging as to the distance at which trees should be planted in any given locality of country. This distance will in all casses he regulated by the demand for timber in the neighhourhood, whether that may be for small or large, or both together, and at the same time by the site of the ground to be planted. If the situation be sheltered, the trees may be planted more thinly, as local circumstances may demand; and if it be exposed, for the sake of the general and future health of the plantation the trees must be planted closely, in order to produce artificial shelter.

He therefore recommends generally, that on low-lying and naturally sheltered parts of the country broad-leaved species of trees should be planted at $15 \mathrm{ft}$. apart, and made up with nurses to $5 \mathrm{ft}$. over all; that on moderately sheltered parts they should be plinted at $12 \mathrm{ft}$. apart, and made up with nurses to $4 \mathrm{ft}$. over all; and that on lighth-lying and exposed parts l'ine and Larch only should be planted, and at distances varying from $3 \frac{1}{2}$ to $4 \mathrm{ft}$., as the case may be.

The Question of Density in Plantations is one of the weakest points in British Forestry. It is no exaggeration to say that there is a most lamentable want of knowledge on the subject. It is entirely owing to the want of knowledge in the past that the most of our coniferous woods are so rough-stemmed 
and knotty as to be shut out of use for Government work unless specially passed for the purpose. Such a restriction has never been applied to timber imported from the Continent, where the woods are managed on rational principles, so as to form long, clean boles, free from branches and knots.

About 20 years ago it was the practice to have the woods very open. Thus Campibell Walker, in his Reprent on Englisk and Scoteh Forests, 187:in speaking of the Scone woods, says:-

"Mr M'Corquodale lays it down as a rule that the arerage distance between trees in a plantation should be one-thirc their height. Thus, if trees average $30 \mathrm{ft}$. high, they should stand $10 \mathrm{ft}$. apart, and so on."

This is no doubt an excellent rule of thumb for Arboriculture; but for Sylviculture it is entirely inapllicable, as being meconomical and inconsistent with those financial considerations which should form the basis of all forest operations throughout Britain.

The author's opinion, expressed in the preceding paragraphs, is already a step in the right direction; but it has no true scientific foundation. It is guided almost solely by financial considerations as to the time at which thinnings can be made, so as to yield an early return from the initial costs of formation of the plantation. It overlooks the fundamental fact that the density of the plantation, and the weedings and cleanings that are usually necessary, at more or less of outlay, before thinnings can yield any returns, and the thinnings themselves, are all factors and operations that should he undertaken witl the express intention of producing a mature crop of timber of the highest financial value, in the shortest space of time, and in the most economical manner.

The true sylvicultural object in making lantations of different density has mainly reference to the time at which the young crop should form close canoly in order to utilise the productive capacity of the soil to its fullest extent, and in the most economical manner. ${ }^{1}$ Sylvicultural experience in Germany-and they have the advantage over us of understanding and of practising Forestry on scientific principles there-has shown "that under ordinary average circumstances the plants should be able to form canopy in about 5 years' time, and that the necessary individual growing-space should be fairly well assured to each plant until between the 10th and 15th year. . . . 3- to 5-year-old Spruce, Silver Fir, and Oak should not be planted more than 40 in. apart.".

Soil and Situation of course exert great influence in the matter of fixing the density. On all lands of an inferior nature, that are apt to become heated, or wherever the conditions are unfavourable to the development of the joung crop, planting should be closer than under more favourable conditions.

The Species of Tree is also of great importance; for light-demanding kinds, like Larch or Scots Pine, cannot thrive if planted so close as shadebearing species. And, again, Silver Firs, that are slow in beginning to shoot upwarls, require to be more closely planted than other limds of trees which are of more rapid development in their early stages of growth.

1 A fuller consicleration of the principles involved will be found in the editor's Studics in Forcstry, 1894, chapter viii., pp. 15S-17s.

- Gayer, op. cit., p. 354. 
The Size of the Plants is of course also one of the main factors; for young naked seedlings must be put out closer than stout transplants.

The Market for Thinnings certainly deserves attention. But this should be treated as a subordinate matter only, and not as one of the factors primarily determining the density of the plantation.

The Costs of Formation also deserve consideration; for the greater the density, the higher is the cost of planting up land. This factor is of course moderated by the use of small material, and the choice of simple methods of notching and the like on land farourable to the latter.

The gist of great sylvicultural experience, which we shall do well to weigh and test, is contained in the following extract from Gayer : ${ }^{1}$ -

"In general, the experience won in planting wide has not been farourable; and in many localities, in order to reduce the cultural costs, sylviculturists have gone so far as to plant shade-bearing kinds of trees even at distances of $7 \frac{1}{2}$ to $10 \mathrm{ft}$. apart. Wide planting is only judicious when it concerns light-demanding species like Ash, MIaple, Sycamore, Elm, Lime, and Larch, which are of rapid growth, and which are being put out as large transplants of 6 to $8 \mathrm{ft}$. in height; but otherwise close planting deserves the preference. Whilst the absolute density of plantations must depend in each concrete case on all the various factors of influence, the arerage results of experience prove that, in general, the distances at which plants should be put out in squares range as follows :-

For Shade-learing Specics and the Oak.

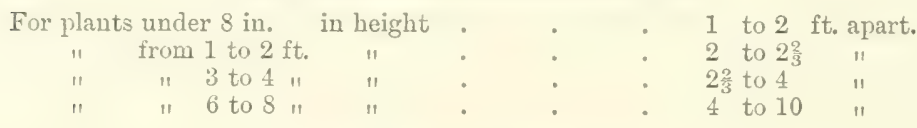

\section{For Light-demanding Spccics.}

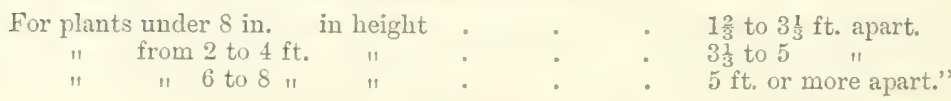

Conduct of Planting Operations.-In all planting olerations the overseer should be a man who has a fair amount of practical knowledge. Unless he has had experience upon an extensive scale, he will not be able to judge for himself in any extraordinary contingency. A man who is allowed to undertake planting operations without proper practical training is generally put out by every change of the weather, and then does not know how to proceed. In such extremities he seeks the advice of others, who very probably are as innorant in the matter as le is himselt. Hence an inexperienced man is liable to take injudicious advice, and then the whole work goes wrong; time is lost, the work is badly done, and, in the end, failure may be the result. This state of things often happens in planting operations. For the guidance of those, therefore, who may not have himl much experience, a few simple instructions may here he laid down as to the best method of procedure in the carrying out of extensive planting operations. 
All the land intended for the growing of timler-crops should lie drained or otherwise prepared for planting, as has already heen explained in chapter vi. Care must he taken to ensure that the clrains have had sufficient time to act upon the land, that pits for the largersized plants have been opened a sufficient length of time to ensure that the soil taken out of them has heen improved ly the weather before commencing to plant, and that any other operations have been performed which are likely to contribute: towards success. When all the necessary preparations have heen carried vut, the person who is to take the management of the work must, before commencing oprerations, duly consider the nature of the situation in which he is about to plant. Suppose, for example, that it may be an-extensive piece of moorland containing several varieties of soil. In this case, he should first begin upon one side of the ground, and make notes as to the kinds and quantities of trees he will require for each particular part. Thus, for instance, it may be naturally divided into the following classes of land:-

1. Thin heathy ground, with high exposure.

2. Good loamy soil, upon a slope.

3. Moss $2 \mathrm{ft}$. deep, resting upon clay.

4. Deep moss, but well dried.

5. Strong clayey soil, upon a level.

6. Light sandy soil, resting upon rock.

7. Bare rocky parts, and here and there good dry loam.

Having ascertained the different extent of each class of soil, either ly actual survey or hy estimate, the forester should next put up a pin, with a number upon it, in the centre of each compartment, and enter a corresponding number in his note-book, with, for eximlle, the following details:-

No. 1. Twenty-seven imperial acres of thin heathy ground, to be planted with Scots Pine, Austrian Pine, Spruce, Donghis Fir, Sitka Spruec, and Larch, one year transplanted, of each an equal number, and at $4 \mathrm{ft}$. apart.

No. 2. Ten acres of good loamy soil, upon a sheltered slope, to be planted with 193 Oak and 193 Ash to the acre, and made up to $4 \mathrm{ft}$. with smaller Beech and Sycamore, of each an equal number.

No. 3. Twelve acres of moss, $2 \mathrm{ft}$. deep, resting upon clay, to be planted with 193 Oak and 193 Ash per acre, and made up to $4 \mathrm{ft}$. with Spruce and Nordmann's Fir,

No. 4. Twenty-four acres of deep moss, well dried, to be all planted with 2-sear tramsplanted Scots Pine and Spruce, sitka sprmee, and Donglas Fir, at 4 it. apart,

${ }^{1}$ It is an advantage of Heyer's cylindrical spade, and of similar implements for planting, that the balls of earth fit into the holes made for their reception. Hence the preliminary operations can take place at any time, when convenient, or even simultaneously if desired. 
of each an equal number, excepting 3 acres in the centre, which cannot conveniently be drained, and which must be planted entirely with Alders, at $4 \mathrm{ft}$. apart.

No. 5. Thirty acres of strong clayey loam, upon a level, to be planted with 1210 Oaks to the acre, and made up with Sycamore and Beech, to $4 \mathrm{ft}$. apart over all.

No. 6. Seventeen acres of light sandy soil, resting upon rock, to be planted with 302 Scots Pine and 302 Larch, $18 \mathrm{in}$. high, to the acre, and made up to $4 \mathrm{ft}$. over all with 1-year transplanted Austrian and Corsican Pines, of each an equal number.

No. 7. Forty-three acres of bare rocky ground, with here and there spots of good loamy soil, to the extent of 6 acres in all. The bare rocky ground to be planted with 2-year seedling Mountain Pine, Larch, and Scots Pines, of each an equal number to the acre, and making them stand $3 \mathrm{ft}$. plant from plant. The good loamy soil to be planted with Ash, at $12 \mathrm{ft}$. apart, and made up with Douglas Fir, Menzies Spruce, and Beech, to $4 \mathrm{ft}$. over all.

It should be noted that it is often preferable, having consideration to variations in the soil, to introduce the better classes of trees in patches here and there, rather than scattered equally over the whole area.

Now, supposing the forester to have gone over the land, and to have marked down in his note-book the different natures of the soil and the kinds of plants that he considers will be most likely to thrive there, he must next calculate the number of each kind of tree he will require to have brought forward for the planting of each of these different classes of land. In order to assist him in this calculation, the following table will be found useful :-

TAble showixg the Number of Plants required per Imperial Acre, FROMI 1 TO 30 FT. APART.

\begin{tabular}{|c|c|c|c|c|c|}
\hline Distance. & Imperial acre. & Distance. & Imperial acre. & Distance. & Imperial acre. \\
\hline $\begin{array}{l}\text { Ft. } \\
1 \\
1 \frac{1}{2} \\
2 \\
2 \frac{1}{2} \\
3 \\
3 \frac{1}{2} \\
4 \\
4 \frac{1}{2} \\
5 \\
5 \frac{1}{2} \\
6 \\
6 \frac{1}{2} \\
7 \\
7 \frac{1}{2} \\
8\end{array}$ & $\begin{array}{r}\text { Numbers. } \\
43,560 \\
19,360 \\
10,890 \\
6,970 \\
4,840 \\
3,556 \\
2,722 \\
2,151 \\
1,742 \\
1,440 \\
1,210 \\
1,031 \\
889 \\
774 \\
680\end{array}$ & $\begin{array}{l}\text { Ft. } \\
8 \frac{1}{2} \\
9 \\
9 \frac{1}{2} \\
10 \\
10 \frac{1}{2} \\
11 \\
11 \frac{1}{2} \\
12 \\
12 \frac{1}{2} \\
13 \\
13 \frac{1}{2} \\
14 \\
14 \frac{1}{2} \\
15 \\
15 \frac{1}{2}\end{array}$ & $\begin{array}{c}\text { Numbers. } \\
603 \\
537 \\
482 \\
435 \\
395 \\
360 \\
329 \\
302 \\
270 \\
257 \\
239 \\
222 \\
207 \\
193 \\
181\end{array}$ & $\begin{array}{l}\text { Ft. } \\
16 \\
16 \frac{1}{2} \\
17 \\
17 \frac{1}{2} \\
18 \\
18 \frac{1}{2} \\
19 \\
19 \frac{1}{2} \\
20 \\
22 \\
24 \\
26 \\
28 \\
30 \\
32\end{array}$ & $\begin{array}{c}\text { Numbers. } \\
170 \\
164 \\
150 \\
142 \\
134 \\
127 \\
120 \\
114 \\
108 \\
90 \\
75 \\
64 \\
55 \\
48 \\
42\end{array}$ \\
\hline
\end{tabular}


In the above case the calculation drawn up by him would be as follows:-

STATEMENT of the Numbers and Kinds of Young Trees rereired to

Plant the different Compartaments in - Platitation, upon the

Estate of - 1894.

\begin{tabular}{|c|c|c|c|c|c|c|c|c|c|c|c|c|c|c|c|}
\hline 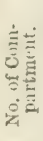 & 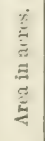 & 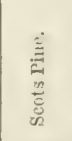 & 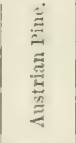 & 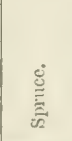 & 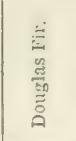 & 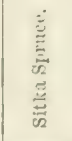 & 至 & हैं & 远 & ¿ूँ & 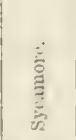 & 苞 & 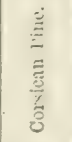 & 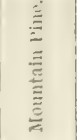 & 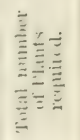 \\
\hline 1 & 27 & 12,249 & 12,249 & 12,249 & 12,249 & 12,249 & 12,249 & .. & .. & .. & . & .. & $\cdots$ & .. & 73,494 \\
\hline 2 & 10 & .. & .. & .. & . & .. & .. & 1930 & 1930 & 11,680 & $11,6 s 0$ & $\therefore$ & .. & .. & $2 \bar{\tau}, 220$ \\
\hline 3 & 12 & .. & .. & .. & .. & .. & .. & 2316 & 2316 & 14,016 & 14,010 & .. & .. & .. & 32,664 \\
\hline 4 & 24 & 14,290 & .. & 14,290 & 14,291 & 14,291 & .. & . & .. & .. & .. & 8166 & .. & .. & $65,32 S$ \\
\hline 5 & 30 & .. & .. & .. & .. & .. & .. & 3630 & .. & 39,015 & 39,015 & .. & .. & . & $S 1, \in 60$ \\
\hline 6 & 17 & 5,134 & 18,003 & .. & .. & .. & 5,134 & .. & .. & .. & .. & .. & $1 \$, 003$ & .. & $40,-274$ \\
\hline 7 & 43 & 59,694 & .. & .. & 4,840 & 4,810 & 59,693 & .. & 1812 & 4,840 & .. & .. & .. & 59,693 & 105,412 \\
\hline & 163 & 91,367 & 30,252 & 26,539 & 31,390 & 31,390 & 77,070 & 7576 & $605 \mathrm{~S}$ & 69,551 & $61, \pi 11$ & 8106 & 18,003 & 59,693 & 522,052 \\
\hline
\end{tabular}

It is hardly necessary to give any explanation of the above statement. Upon looking back to the particular's concerning the second compartment, as they were supposed to be noted on the ground, it will he seen that it contains ten acres, which number is stated in the second column from the left hand in the above table. Next, it was to be planted with 193. Oaks and 193 Ash to the acre. Now, if these numbers be multiplied by 10 , for the number of acres, this gives 1930 Oaks and 1930 Ash for the whole district; and these figures are accordingly entered under Oak and Ash in the statement. But the plantation is to be made up to $4 \mathrm{ft}$. with a mixture of equal numlers of smaller Beech and Sycamore. Now, taking the talle of distances to hand, it will he found that, in order to plant one imperial acre with trees at $4 \mathrm{ft}$. apart, 2722 are required; but as $386 \mathrm{Oak}$ and Ash already go to the acre, this quantity must be deducted from the 27.2.9. Consequently $2: 3: 36$ Beech and Sycamore remain to lie planted as a matrix; and as these ruling species are to lue mixed in equal numbers, just exactly the half of the last number, or 1168 of each, will be needed for every acre. And as there are ten acres of gromul to plant in this instance, the total number of Beech and of Sycanore required will the 11,680, which must acerorlingly be entered in the statement. In the same mamner the number of pliants requisite for each of the other districts is determinerl; and in the summing up of the whole it will be at once seen that, in order to plant the whole 16:3 acres, the forester will require to hring forwari 
to the ground $52,2,052$ plants of the various kinds and requisite sizes stated in their respective places.

When these preliminary steps have been taken, the forester must next arrange for the requisite number of plants to he hrought forward and sherghed in their respective compartments - i.e, lodged temporarily in the soil, if the nursery be too far off to have the plants transported simply as required. Great care is requisite in bringing forward the youry plants to see that it is done during open weather, and when there is a little moisture if possible; and if the plants are to be brought far from the nurseries, all their roots should be covered during the journey, in order to prevent the air from having any bad drying effect upon them. As soon as the cart arrives, a deep dry part of the ground must be chosen for sheughing or laying them in. This requires to be done in a very cautious manner, care being taken not to employ too many hands on the work at once. If this point be not carefully attended to, there will be a great chance of failure in the results of the work. It may be remarked here, however, that the plants need not be all brought forward at one time, but only as many as may be wanted for planting one or two compartments; for if they are all lifted at once from the nursery and sheughed on the area to be planted up, then they might, in the case of bad weather coming on, have to lie so long as to get injured in the sheugh. In the present instance the sheughing is merely referred to in order to illustrate how it should he gone about, whenever necessary.

Wherever large sylvicultural operations are contemplated, financial considerations demand that the plants should be grown in nurseries by the forester. Forestry cannot be practised on the soundest financial principles when large sums have to be paid to nurserymen for plants. On extensive woodland extates there ought always to he a permanent nursery for schooling plants; and besides that, where planting operations are likely to be conducted in the course of two or three years, temporary nurseries can easily be formed here and there in convenient localities, so as to have a good supply of plants available.

This method is not only much cheaper, but it creates less disturbance in the plants than when they have to be transported for considerable distance;, either on carts or otherwise.

In shenghing the young trees, a trench should be dug deep enough to hold the roots easily; and the turf and earth which are then taken out should be put upon that side of it which is meant to be the outside when the work is done. On having this earth levelled along the back or outside of the opening, if the broad-leaved trees are intended to be put in first, this may be done without loosening the bundles (for it is presumed that the plants are tied up in bundles), as they are not apt to spoil although they lie some time in the ground in a crowded state; but if the plants are Firs or Pines, then 
the bundles should he opeened out, and the plants spread out upon the side of the trench, but not more than 2 in. thick. When the whole length of the trench is filled with the plants, whether deciduous on coniferous, the finest of the earth from the next trench shonld he put on their roots, and made up with a sufficient quantity of soil so as to corer the roots of all the plants laid in, as well as to make another opening large enough for another row. When the roots are thus sufficiently covered, the whole should be trodden down slightly in order to keep out frost. After this has been done, any fine earth in the hottom of the trench which is to receive the next row should he filled into the open parts about the necks of the plants in the line put in, so that no spaces may be left for the air to get down to the roots. After re-levelling the surface of fresh earth which is put ahove the roots, the front of the new trench may be lined off and filled up as before. Many planters are very careless alout this part of the work, and sheugh in the plants in a very casual sort of manner; lut the plants should he as carefully put into the earth as if they were to remain in the sheugh for months. Should frost set in, and should snow follow, then the plants may lie in the shengh for perhaps a couple of months. When the weather breaks, if such plants be made use of for planting operations, a large proportion of them will most probably die. Such a mamner of going to work would not only be discreditable to any forester, but also ruinous to the proprietor.

And in the same manner all the plants belonging to the other compartments should also be sheughed in a piece of dry soil.

The editor begs to point out that all this unnecessary expense, risk, and trouble arises simply in consequence of the custom in Britain of plants being bought from nurserymen, in place of being reared either in temporary nurseries on the area planted up, or in a permanent nursery conveniently situated near some central point on the estate. In all countries where Sylviculture is practised on rational principles, the owners of woodlands cultivate their own seedling crops in nurseries.

The young trees having been all brought forward and sheughed in their respective places, the superintenclent of operations must next consider the number of men he may require for carrying out the actual work of planting. In this case he had much better stedect a few good hands, and have the work done properly, than wather together a number of labourers, who have perhaps never planted a tree before, and who may very likely be regardless as to how the work be done, provided they receive their daily wages.

If useful instruments like Heyer's cylindrical sprades (Fig. 10!9) he used, the most ignorant hands-men, women, or children-ean do the work just as well as the most intelligent workmen. To make a hole in the ground with an 
instrument, for a hoy to fill up with a ball of earth practically of the same size, reyuires no knowledge that cannot be accuired thoroughly in a few minutes, even by a very ignorant person.

Say, for example, that the planting is to be commenced about the 1st of February, and that the forester, on account of having other flantations to make the same season, is anxious to have the plantation in question-that is, the 163 acres referred to above-finished in the course of four weeks. There are thus 163 acres to be planted in four weeks; but at that season of year it is more than likely that a fortion of the time will consist of broken and bad weather. In order, therefore, to have the work finished if possible by the time specified, instead of calculating that it is to be done in twenty-four days, he must deduct a portion, and say that the work is to be done in eighteen days. He will thus have 479,375 plants to put into the ground in eighteen days. By the system of notching, he may generally calculate that a man in a short winter day, working from eight in the morning to four in the afternoon, and allowing one hour for rest, should plant one thousand young trees with ease, and at the same time do his work well. If a man be much hurried at his work, he cannot do it well: the forester should, therefore, not hurry his nem unreasonably, but should only make them give a fair day's work, and then it will be much better done than otherwise. As the whole is to be completed during the month of February, when the men, instead of working from eight to four, can work from seven to five, each man will be able, with the assistance of a boy, to plant 1300 liants if experienced in the work; but if inexperienced, the hands may perhaps not plant over half that number. Now, if the total number of trees to be planted, 522,052 , be divided by 1300 , the number that a man can plant in a day, it will be found that the whole task will represent about 402 working days. But if twenty men be employed, they will plant 26,000 in one day; so that twenty men should finish the work in about twenty days.

As, however, all the planting that has to be done in pits will take much longer than notching, special calculations will have to he male. Say, for example, that of the alove $52.2,052$ plants, 450,000 can be noteheel, whilst the remaining 72,052 must be planted in pits, and that the latter can only proceed at the rate of 500 per man per day, then the actual number of days' labour required will be-

$$
\begin{gathered}
450,000 \\
1300
\end{gathered}+\frac{72,052}{500}=316+144=490 \text { days. }
$$

It will therefore take 10 men 49 working days, 20 men $24 \frac{1}{2}$ days, 30 men $16 !$ days, or 35 men 14 days, to complete the work; hence, arrangements must be made accordingly. 
After making a calculation of this nature, the forester should, when the men begin work, keep a note of the number of the trees planted during the first day or two, and comprare the work actually done with his previons estimate. Ily doing so, he will ascertain how far the estimate is likely to be correct, and will acerringly be able to put on nore men, if necessary, in oriter to complete the operations within a given time.

Now, supposing that the forester has all his men ready to commence work, that he has given them orders to meet him on the gromnd at a certain time, and that he intencls to commence by planting No. 1 , being 27 acres of thin heathy soil, not adapted for the growing of broal-leaved species, to be planted with Scots I'ine and Larch, $t \mathrm{ft}$. apart, one year transplanted, of each sort an equal number. (Jn the morning appointed he should be on the ground before any of his men are collected. For, if he be a man of an indolent habit in the morning, the men will very likely prove the same; consequently the work will not go on in a prosperous manner, and there will he small hopes of getting through it in time.

When all the gang is collected and ready to begin work, he will arrange the work to he done during the day. If it have the appearance of being fine weather, he may put the men to plant upon the most exposed parts of the grounds; but, otherwise, he should begin operations upon the most sheltered parts. He should come proviled with three or four poles, such as farmers gencrally use for strainhtening and measuring off their furrows; aud while it is still thark and the men are collecting, he should pace offi, upon one sicle of the ground to be planted for the day, the proper breadth for the men to he employed upon. At the end of that distance from the outside, he should put up one of his poles as a guide for the immermost man to go ly in the act of planting; and in the same manner he will mark off the whole length of the ground by one or two more poles hefore the men commence.

The poles being set to the breadth required, he should next see that each of his men has provided himself with a boy or a girl for lhanding him the youmg plants, and that each of these attendants hats brought a strong apron for holding the latter, so as to protect their roots from the wind, as well as to lieep them together while he talises out one at a time with his right hand. He should also examine the sort of spacles the men hitve lrought to work with. For the purpose of notching, a half-worn common ganden-spate is a rery useful implement, and more especially when it has a blate of about $s$ to $9 \mathrm{in.}$ in lengtl. In all notching operations, therefore, wery man should be told to bring along with him such a spacle as alove described; for experience shows that the man who uses a new one camnot plant 
nearly so well, or so rapidly, as he would do with a half - worn, sharp-edged tool. However, those who may not be satisfied with using old spades will find in any nurseryman's warehouse an excellent implement, the planting-spade, made specially for plantation purposes. These planting-spades are of the same form as a common garden-spade, but are smaller in the blacle. They have the shears, or that iron part which clasps the wooden handle, made stronger than in the common garlen-spade, in order to resist the more certainly the strong pressure which is sometimes put upon the handle in the act of notching upon the tough turf.

The corresponding instrument in Germany, the notching-iron (see Fig. 117), is made entirely of iron, except the top-handle. But in many cases there is simply an iron knob in place of any cross-piece at the top-end.

Having satisfied himself on these points, the forester should next cause some trustworthy old man to take charge of the plants that have been sheughed, and his duty will be to give out to the boys the different species of plants as they are required. This must not be permitted to the lads themselves, as they would most likely remove the earth from the roots of the plants when they came to take away a quantity; aml, hesilles, they might make mistakes as to the quantity required to be taken at one time. The boys should be instructed to go to this old man whenever they require plants, and to bring with them in their aprons each time about 50 Larch and 50 Scots Pine, with their roots laid inwards. That is to say, the old man will take 50 plants of Larch and place them in the boy's apron, say upon the left side, with their tops out and their roots inwards, and he will also take 50 Scots Pine and place them in a similar position upon the right side of the apron. This precaution is necessary, in order to protect the roots from the winds and drought. It is not necessary that the man should count every plant he puts out; but if he count a few times, he will very soon be able to give the boys about the desired number, care being taken to give about an equal number of each kind of plant.

When the men, with their attendants carrying the plants, are all ranged in a line upon the edge of the ground to be planted, so that their hacks are triwards the plantation-ground and their faces towards the fence or boundary from which, they are to start, and each man has been given his breadth to plant, the forester should take a spade and show then how he wishes the planting to take place. He should also explain the manner of keeping the proper distance between each two consecutive plants, and must at the same time show the boys how to put the plant into the notch when it is opened by the man, as has previously been described. 
He should now see that his men go to work according to the instructions given them, while he also exercises sharp supervision to see that they make the hoys insert Larch and Scots I'ine alternately into the notehes.

As has previously been explained by the editor, it is often preferable to mix the species in small patches, rather than in a stencil-like, regular, and forced manner, irrespective of variations in the quality of the soil. It is only in the former case that the fullest advantages of mixerl planting can prosibly be obtained. More especially is this the case with regard to two species like Larch and Scots Pine, whose natural requirements as to nutrients, and whose accommodative power on soil not exactly favourable to them, are vastly different.

The men may now go on briskly with their work, the forester keeping a sharp look-out behind them, to see that they do the work according to the directions given. If there be any new hamb among them, he will, of course, have to pay most attention to them; whilst he can leave more to themselves those whom he knows to be well acquainted with the work. He must go backwards and forwards among the planters, minutely examining the work, and seeing that it is being conducted properly. When the least fault is observable, it ought to be checked at once, and the fault laid to the person who did it; and if he persist in doing the same thing over and over again, the better way is to pay him off' at once, rather than run the risk of having the work badly done. An example will thus be made among the men, showing them that the orders of the forester must not be trifled with. Every cut made with the spade in the act of planting a tree should be firmly closed, in orler to prevent the lodsment of water, and to obviate increase of danger from frost.

When any boy has his supply of plants nearly finished, he will give these to the man whose assistant he is, and run for a fresh supply while the man is planting them. As the supply of plants is generally not far off, and as the old man is ready to give them out at once, a boy may be back with a fresh supply before the man has the few remaining plants notched in. Some planters hate one hy serving the others with plants, but this methor is open to the olljection that the roots are more exposed to drought.

When the planters have arrived at the other end of the ground laid off for them by the poles, the forester will, from the pole at which they ended, measure off another space of the same description as the first, and cause the men to fall in upon it, and plant backwards another breadth of land, ending in a line with where they previously commenced. In order that the men may not be delayed, he should have the land measured off previous to their finishing the first piece, and should make the pole at which the men end the list to be

VOL. I. 
removed, and the first to begin at again. By going to work in this manner, he can always be on the spot to see his men fall into their proper places again upon the new land; and thus the planters will cross and recross the ground until they have the district finished. When there may be any odd corners to finish, upon which the whole number of men could not be profitably employed at once, the forester should cause a few of his most trustworthy hands to complete the work, and carry off the others himself to commence upon another compartment.

Whenever the day may turn out wet, the men should only be allowed to work as long as the ground is not saturated with rainthat is to say, as long as the young plants can be placed firmly in the ground. As soon, however, as the earth fails to set properly around the plants, orders should be given to drop work. Upon dry ground, however, this state of things will seldom occur.

Now, supposing that the planting of compartment No. 1 has been finished, and that the forester wishes to go on with work in the next compartment, No. 2. This consists of 10 acres of good loam upon a sheltered slope, and is to be planted with 193 Oaks and 193 Ash to the imperial acre-i.e., each species in squares of $15 \times 15 \mathrm{ft}$., and then to be filled up with smaller Beech and Sycamore to the distance of $4 \mathrm{ft}$. over all-i.e., to a total of 2722 per acre. Here it is understond that the pits have been all made a considerable time previous to the actual planting, and that it is now intended to plant, beginning with the Oak and Ash. As stronger transplants will be used for these two species, the boys will not be able to carry so many plants as they previously did in the case of the smaller I'ines and Larch; hence about half the previous number, or about 50 in all, will be a fair load. It is best to plant out the Oak first of all in squares of $15 \mathrm{ft} . \times 15 \mathrm{ft}$, and then to plant the Ash in the middle of these squares, so that they will also be at $15 \mathrm{ft} . \times 15 \mathrm{ft}$. A difficulty will now face the forester, for he will find that with double squares of $15 \times 15$, giving 386 plants per acre, he will not be able to place the remaining 2336 plants per acre conveniently at $4 \mathrm{ft} . \times 4 \mathrm{ft}$. all over the land, and will therefore have to adopt $3 \frac{3}{4} \mathrm{ft} . \times 3 \frac{3}{4} \mathrm{ft}$. for convenience in filling up with the Beech and Sycamore. It will be evident that, in order to use a $4 \mathrm{ft} . \times 4 \mathrm{ft}$. scale for filling up, he should, in the first instance, have calculated the Oak and Ash at double squares of $16 \mathrm{ft} \times 16 \mathrm{ft}$, , or else have ordered a sufficient number of Beech and Sycanore for making up to the number of 3112 plants per acre, at $3 \frac{3}{4} \times 3 \frac{3}{4} \mathrm{ft}$. He can easily help himself out of the difficulty ly using all the Beech and Sycamore at $3 \frac{3}{4} \mathrm{ft}$. apart, and then either getting more plants or filling up the blanks with any convenient species easily obtainable and suitable for the soil. 
This is again a case in which the advantages of the Continental method of planting in patches, and not with any stencil-like regnlarity over the whole area, are distinctly evident. For the Oak and the Beech can thrive on the somewhat drier patches of sril, whilst $A$ sh and sycannere will undoul,tedly thrive best on the moister land. The bulk of the ()ak should therefore be jut out on what appears to be the hetter and drier land, and filled up, with Beech chiefly; and the bulk of the Ash should be planted on the moister grouml, and filled up with Sycanore chiefly; whilst on the remainder of the comprartment the mixture may be more general, according to the number of plants of each kind still at disposal.

In the above case the editor has deliberately varied the data, so as to show how the forester must learn to help himself in any difficulty, or when a mistake has been made either hy himself or others. The utility of any forester is in great measure proportional to his power of extricating himself from difficulties that must arise now and again. Such mistakes do occur; and if there are temporary nurseries close at hand, or if a permanent nursery is maintained on the estate, a fresh supply of the most suitable plants can easily be oljtained on the shortest notice.

In the act of planting in the pits, if the situation be exposed, the plant should not be put in the centre of the pit, but rather in one corner of it (Fig 124, a), so as to obviate the bad effects arising from the wind shaking young plants before they establish themselves. In the former position the young plant has two firm sides to rest upon instead of the open soil all around it, as is the case when it is planted in the centre, as at $b$; but in the latter position it has food-supplies more easily available, and can develop its root-system more equally

Fig. 124. all round. These are matters of detail that must be decided by the forester according to the given circumstances of each concrete case; for no hard-and-fast rules are alplicalule in planting operations. Where the situation is sheltered, planting is advisable in the centre of the pit; but otherwise it may le recommented to insert the plant at the corner opposite to the direction of the prevailing strong winds in spring. Whatever position, however, may be resolved on, the boy holds the plant in its place until the man with his spade fills in all the loose earth taken out of the pit; whilst the loy licepis moving the plant slightly up and down until he finds the earth heary ahout its roots. When the whole earth is in, the man should take hold of the plant, and julge if it is too deep'; if so, he should pull it up a little, anul then with his feet make the soil firm ahout the roots of the newly inserted plint. As it is understood that in forming the pits the turf, when taken off, has been divided into two equal parts, the man will next talie the divided sod and place it, grass undermost, mon the surface of the pit, with 
the plant in the centre, and make it quite firm and close about the same. The earth upon it should then be pared off, and put with care upon the joining all round, the whole then receiving a firm treading down with the feet.

And in a somewhat similar manner all the other compartments will be taken in hand, each being completed before a move is made to the adjoining compartment, and a commencement being made with the large transplants before the work of filling up with smaller transplants or seedlings is undertaken.

Planting in Mountainous Tracts.-In making plantations on what may properly be termed mountainous parts of the country, say at elevations ranging from 1000 to nearly $2000 \mathrm{ft}$. above the level of the sea, they should always have a very much larger area than plantations on a lower-lying tract of land. Unless planted in large masses so as to afford shelter for themselves, however, the individual crops fail to attain any considerable value. As a rule, the higherlying the site of a plantation is, the larger it ought to be, so as more certainly to secure the advantages of artificial shelter in proportion as the means of natural shelter are wanting. The want of attention to this very essential point in dealing with plantations in very highlying or mountainous parts of the country is the cause of many of the existing wools throughout such districts heing found of so very little value to their proprietors. In the Highlands of Scotland, as well as in many parts of the northern counties of England, plantations extending to only a few acres in each case may be found on sites fully $1500 \mathrm{ft}$. above the sea-level; hence the result is that the crops are stunted and comparatively worthless, whether as shelter to their neighbourhoods or for producing timber profitably. Had these plantations been made to extend over 300 or 400 acres in each case, their crops would probably have been very much more valuable to their proprietors in every respect. And had they been made still larger in extent, they most likely would have been even more valualle: for the value of plantations in mountainous districts senerally increases more or less proportionately with their acreage.

When the extent of a plantation in a mountainous district has been fixed upon, the first points to attend to are the draining of all parts of the land that are found either wet or retentive in the subcril, and the soil-preparation generally. There is, generally speaking, far too little attention paid to this very important point by most planters at the present day. The great majority are satisfied with making a few open cuts on absolutely wet spots, and think that for the purpose of growing a crop of trees, it is unnecessary to spend money on land which, often erroneonsly, they consider naturally poor. This is one of the many great mistakes that ol,tains in British fores- 
try at the present day. But as the matter has been fully thresherl out in chapter vi., there is no reason for here even recapitulating the advantages of soil-preparation. No farmer of intelligence would now expend labour and means on land without first secing that it was thoroughly drained and prepared for the lest growth of crops. And yet proprietors of woollands still go on in the old way, planting crops of trees on land without preparing it first of all, although, withont more or less preparation, it is naturally unsuited for the liest and most profitable development of trees. Hence the many unsatisfactory crops of young trees now to be seen all over the country.

On all mountainous districts soil-preparation is perhaps more necessary than on lower-lying parts; for, in situations that are naturally cold, the land requires to be made warm in order to stimulate the vegetative energy of trees in our cool, damp climate. In preparing land for planting on all very high-lying districts, therefore, it should be horne in mind that much of the future success of the crop will often depend upon how this soil-preparation is carried out. If infficiently performed, the crop will often be unsatisfactory; but, if thoroughly done, it may contribute very greatly towards the financial success of the sylvicultural operations.

The nature of the soil and of the surface-herbage should next be considered, with a view to judging what kinds and sizes of plants ought to be used. In all probability, however, it will be found most advantageous, on such a high-lying part of the country as we are now supposing we have to deal with, to ylant coniferons species only, as the cultivation of hroad-leared trees is on the whole less profitalle in such localities.

A large choice, however, remains open, from Pines, Larch, Spruce, Douglas or Red Fir, Menzies or Sitka Siruce, Noble Fir, and other exotics, which have proved themselves hardy in this climate, and hold out fair jromise of producing good, useful timber in large quantities. The adrantages of forming mixed woods should also be kept in view.

The sizes of the plants to be used must in each case be regulated to a certain extent by the nature and strength of the herbage growing on the surface. On the lower-lying parts of the land embraced, there will most likely le hollows and that purtions on which the herbage is grass with ferns intermixed. On such tracts both grass and ferms are likely to grow to considerable strength in the summer time: and

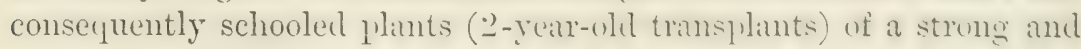
somewhat tall description may have to he used, in order to aroid the danger of having them choked by the weeds. For seedlings that have heen transplanted, even for one year only, pits will usually have to be made, as it would be unsafe to plant young trees of any con- 
siderable size ly the common system of notching. The pits for these may be made to the breadth of a common spade on the side of the square, and at least $10 \mathrm{in}$. deep; and in making them, attention should be paid to loosening the earth in the bottom of each pit with a pick, after it is hollowed to the desired depth. The pits for this class of plants should be all made at least three months previous to the time of planting, in order that the soil thrown out and the earth on the sides and bottoms of the pits may have become ameliorated by the action of the weather before it is put to the roots of the plants.

Under such circumstances it becomes a question whether tumping or mound-planting may not be preferable, - that is to say, cheaper, and as likely to prove successful. For, in tumping, smaller plants can be notched in at less expense ; and if they can only be protected against the rank growth of weeds by being thus raised up, then smaller plants establish themselves more readily than larger transplants. And in such cases, where a home nursery is close at hand, excellent results can be obtained at a moderate cost by the use of large cylindrical spades (see Figs. 109, 110).

The condition of the herbage on the surface of the parts lying next above these lowest levels will now have to be taken into account before deciding as to the size of plants to be used on them. The herbage may be heath, or it may be of a grassy description, according to the nature of the soil; but in either case, from its being at a higher elevation and probably on a poorer quality of land than that on the lower-lying prits, it is not likely to attain nearly the same strength in summer. Consequently a smaller size of plants may well be used on these parts,-say, for example, yearling seedlings that have been schooled for another year in the nursery. As these are of small size, varying from about $3 \mathrm{in}$. in the case of Spruce, or $4 \mathrm{in}$. for Scots Pine, up to $9 \mathrm{in}$. high in the case of Larch, they may be all planted by the common system of notching.

With regard to the highest-lying portions of any tract to be planted up in a mountainous district, the herbage is generally of a very short description, and for the most part consists of heather or short wiry mountain grass. And here the soil is for the most part so poor and thin that no tree will thrive so well on it as the Scots Pine; hence this species should mostly be cultivated on those tracts, with other species sparsely mixed, in order to see how they thrive. In such localities yearling seerlings schooled for another year generally answer best; for they are always well supplied with roots in proportion to the size of their tops, and if properly put into the ground rarely fail (1) estal,ish themselves well even in lofty situations, provided always that the plantation is of large extent, and that the plants are put in closely. This class of plants may be planted by the common system 
of notching, or with the planting-iron, as is gencrally done in the planting of high-lying districts in Scotland.

In tracts that are really classifialle as mountainous, it is usually advisable to raise the crops from seed, and to reproduce existing woods by the method of natural regeneration. Say, for example, that mixed seed of Scots Pine and Spruce be sown, and come up as a seedling crop, then other species whose seed is dearer and less plentiful, like Larch, Donglas fir, Menzies Simuce, dre, may be introduced here and there by planting, wherever considered suitalle.

In planting on mountainous districts, no plants should be used but such as have been reared on exposed and airy sites, and on lank that is of only average quality. Plants taken from rich gromnd in sheltered nurseries never succed well when planted out on mountainous districts. Hence, for planting on mountain-land, the nurseries should be on land of about the average quality, and should he situated as near to the plantation as can conveniently be arranged; and this fact should be kept in view, as otherwise much loss and disappointment may ensue.

If the nursery soil be much better in quality than the land to be planted up, then, owing to the greater difficulty in obtaining the food-sulply that they have hitherto been accustomed tn, the plants wilt for a long time before establishing themselves properly in their permanent home.

But if the nursery-soil be of poor quality, then the initial development of the plants, or what might be termed their constitutional ritality, is low, and they are naturally sluggish in establishing themselves on being disturhed l,y removal from the nursery.

Planting on Hillsides and on the Higher Uplands.-The hillytracts of Britain, say those of from 500 to $1000 \mathrm{ft}$. above the level of the sea, embrace a large extent of the country, chiefly throughout the southern and midland counties of Scotland, the northern counties of England, and Wales. Their soil is for the most prart of a light description, well adapted to the healthy growth of all the coniferous trees; while the surface is unlulating, presenting varied aspects within comparatively small areas. Here the soil is generally of a richer nature than obtains on higher-lying districts, and in consequence of this the natural herhage is ustually of a grassy character, with comparatively little heath and heather.

The soils and sitnation cmbraced uncer this class are particularly farourable to the development of most species of coniferous trees, whether Pines, Larches, Spruces, Silver-Firs, \&c.; whilst on the lower-lying parts of many of the districts, the land is often very suitable to the cultivation of woodland crops of Oals, Beech, Ash, Llm, Maple, Sycamore, and other broad-lenved species. 
In planting on such parts of the country, the plantations do not recuire to lie made nearly so large as is advisable on the more distinctly mountainous tracts; for artificial shelter is not so necessary for the health of the crops. In planting on all moderately elevated parts of the comntry, therefore, the individual plantations may be made of any convenient extent, according to the purpose intended; but it is well to bear in mind that on the higher land, and in the more exposed localities, the roods should be made more extensive and compact than on the lower tracts with sheltered positions.

Supposing, for example, that an area of 200 acres has been marked off for a plantation on a site averaging about $700 \mathrm{ft}$. above the level of the sea, and that this has been done in summer or in early autumn, whilst the proprietor is residing on his estate.

The land should first of all be broken up in the autumn and frepared for the reception of the timber-crops in the following spring; for, whether the necessary works consist of drainage or of other soil-preparation, or of both, it is essential that at least a winter's period be given so as to allow of the sinking or the weathering of the soil to be accomplished in a more or less thorough manner, without entailing the land lying unproductive during the period of active vegetation, when loss of increment would be occasioned, and the soil might become overgrown with rank weeds.

As the herbage on the surface of land situated at an elevation of $700 \mathrm{ft}$. is, generally speaking, of a strong-growing nature in summer, the plants used must here again be proportionally strong; for were only small plants used, the grass and other rank growth would choke them, and probably kill off many of them during the very first year after planting. In planting on such land, therefore, the broad-leaved species should be placed out on all the better portions of the land situated on the lower parts. The more valuable species like Oak and Ash may be put out as sturdy transplants of about $2 \mathrm{ft}$. high, and about 8 to $10 \mathrm{ft}$. apart; whilst the intervening spaces may be filled up with Beech, Maple, and Sycamore, so as to make the final distance from plant to plant not more than $4 \mathrm{ft}$. over all. Should nurses be desired to stimulate the plantation to more rapid growth in height, Larch and Pine may be used in such proportions as may be considered most judicious on taking the nature of the land and everything in connection with the case into consideration.

On all land of such description the editor would recommend the method of mixing in small patches, as being the only natural system of utilising to the fullest extent the latent productive capacity of the soil. The admixture of Larch and Pine with Beech and Sycamore will tend to the production of finer timber than can usually be grown in woods consisting of coniferous species only. 
In such situations, if the growth of weeds be not vigorous, or if tumping be arlopted, smaller plants may le userl than will otherwise be necessary; for large plants often fail to establish themselves well when planted by the notching systenn. IBut, wherever the nse of larger transplants has leen decided upon, these pits should be freprared at the proper distances for the reception of the plants; and care should be taken to see that the base of the pit is well loosenerl with the pick, so as to aerate the soil.

Under all ordinary circumstances it is preferable to regenerate existing woods in such localities by the method of natural reproduction under parent trees, and to plant up the blanks that are found to exist, after the clearance of the parent standards, with the species most suitable for the soil and for the object of the proprietor.

An important point in connection with pit-planting is to allow the pits to lie open for at least three months, so as to permit the soil thrown out of them to become weathered before it be returned and put about the roots of the young trees. This is a matter generally by far too little attended to; for young trees, that have leen planterl in pits immediately on their being opened, are usually considerably longer in establishing themselves than when the earth has heen exposed for a consideral,le time before it is put to the roots of the plants.

It may here be remarked that, in dealing with plantations on molerately elevated parts of the country, the herhace nuay not always be found of such a strong character as to necessitate the plinting of the trees in pits; for some parts of it may be found to consist of heath or of very short grass, dc., \&c. On all such parts, then, where the herbage is short and the site compratively high-lying, the plants may he planted by the common system of nothing; or the method of throwing back a sod of turf and notching on to the top of this little tump or mound may be employed, as has previously been described.

Wherever the soil-covering of herbage is of a dry nature, especially in the case of heather or gorse, the land should be burned over carefully, so as to retard the growth of weeds, and at the same time to manure the land to a certain extent by the mineral ash thus returned to the soil. That the fire should be kept well in hand, of course stands to reason.

Notching operations with small plants can then often be carried out successfully, which otherwise might have failed throngh the fints leing orershadowed and choked.

Planting on Low-lying Tracts.-In plinting on whit mily he termed low-lying parts of the country, - that is to say, on plains or uplands under 500 feet in elevation above the sea,- there is not, generally speaking, the same degree of natural drainage in opera- 
tion that olstains in higher-lying tracts, where the land is generally undulating and hilly. Hence, if the land have any tendency to be cold and wet in the subsoil, the drainage must be carefully attemeded to, especially on the flatter and hollow-lying portions; otherwise the crop on such parts will be apt to prove less satisfactory thim it might easily be made.

On such land mixed crops of broad-leaved trees may be planted, each species leing put out on the kind of soil which seems to suit its natural requirements. Such mixed plantations may be formed either in small patches of each kind of tree separately, or else with all the species intermixed individually, according as the circumstances of the case or the object of the planter may suggest. And when nurses for these are required, owing to danger from late frosts, Larch, Pine, Birch, or all of these, may be interspersed individually. But the choice of species is in this case mostly dependent on the nature of the land, and the prospect of a good sale for thinnings as the nurses come to be removed, when no longer required to promote the development of the main crop.

It may be remarked that these nurses are only a means to an end, and that end is the development of the main crop. If nurses be left too long, in the hope of thereby yielding more remunerative thinnings, then the wellbeing of the more valuable portion of the crop is jeopardised in an unnecessary and uneconomical manner.

When good, strong, loamy land of this class, and of about 200 or 250 feet in elevation, has been thoronghly drained or otherwise prepared for planting, during the previous antumn the kinds of trees to he planted must be fixed upon, as well as the most economical method of forming the young crop. If the tract be low-lying and moist, then the probability is that the herbage must be very strong in the summer time; hence plants of large size may have to be used. Again, if stout transplants are used, then they, or the more important species at least, may have to be planted in pits, miness the Continental method of tumping, by turning back the turf-sod, and notching in through it, can be adopited. But, in the case of the smaller plants used for filling in, this maty often le armanged so as to effect a considerable saving in the costs of formation of the plantation.

Where there is a strong growth of weeds like raspberry, bramble, foxglove, St John's wort, and the like, the broad-leaved species forming the permanent crop may have to he of sizes ranging between 3 and $4 \mathrm{ft}$. high; while, if nurses be requisite, Larch transplants ranging from 24 to $30 \mathrm{in}$., or Pines of about $12 \mathrm{in}$. high, will have to be used. These may be planted at such distances apart as the nature of each given case may suggest. 
Where existing woods are approaching maturity on this class of land, natural regeneration is simple and safe. But if once the land he clearenl of the crop, the soil soon becomes overrun with a very rank growth of weerls, which necessitates hich costs of planting, often withont attaining anything like equally goou results. Whenever the principal spereses in questirn has been regenerated, other species can be intermixed in fratches or inclivilually, as seems most advantageous.

During the course of the autumn, the pits for the young trees should all be made, in order that the soil taken out of them, as well as on their sides and bases, may be improved by the action of the weather before it is returned on the roots of the plants. The pits for the hardwoods should be made from 12 to $15 \mathrm{in}$. on the side of the square, and those for the nurses about $S$ or 9 in.; and the sril at the base of the pit should be well loosened with the pick.

In planting on uplands between 300 and $500 \mathrm{ft}$. in elevation, with what may be termed an open and airy exposure, and a deep, open, and naturally dry soil, many of the newer conifere-such as Fied or Douglas Fir, Sitka or Menzies Spruce, and Resinons or Red Pine-may be planted out as permanent crops along with Scots, Austrian, and Corsican Pines, Larch, Spruce, and Silver Fir. In planting crops of the newer conifere on parts of plantations exposent to late frosts, the Larch should always be.used as nurses to them. Although usually of more rapid growth at first, it does not injure their development by overshadowing them heavily, as is so often the case when evergreen Pines or Firs shoot ahead in growth.

The districts of the country embraced under this head are of all others the best adapted for the growth of a wide range of species, whether of broad-leaved or coniferons genera. On the lower-lying tracts, where the soil is generally of a heavy and strong nature, deciduons trees of all kinds attain their quickest growth and their largest and most valuable dimensions: while, on the higher-lying stretches of upland, where the soil is generally of a lighter and drier character, most of the deciluous species and all the coniferous treeseven those that may be considered somewhat tender on higher-lying sites-find soils and exposures faromahle to the attainment of their best dimensions and their highest rate of increment.

Planting of Waste Lands.- Cunder this term are inclucled all such tracts of country as are either too high-lying for protitalle asticulture in their present unsheltered state, or of too poor and umpromising a character to be remunerative to the farmer or the grazier. These two classes of waste lands comprise linge tracts of soil which are at present mproductive, but which might easily be brought under sylrieultural oceupation, with sreat nltimate benefit both to their owners and to the community at large. 
Enterprises of this sort should not be rashly entered into; but, when once sound opinions have been taken, and the matter can be proved to be of nationaleconomic advantage, then the task should be begun and performed in a worthy manner. Within the short space of almost one month three questions have been asked in the House of Commons concerning the planting up of waste mentands in the Highlands of Scotland (see 11\%. S:- s:3). Wherever such land can be shown to give any remuneration for the first crop of timber, it is certain to pay much better under future crops, provided the managiement be rational; and land that may not pay for the first crop will be so improved under woodland covering as to pay better during succeeding crops. The only serious consideration is that with regard to any probable increase of rainfall in districts that are already apt to suffer from too much rain rather than from danger of drought; and this point can only be settled by a careful study of all the physical factors in each individual case.

Of the class of waste lands which are too high-lying for profitable agricultural occupation in their present exposed condition, there is a large extent in the north of Scotland, in the north of England, in Wales, and in the north and west of Ireland. In all these parts of the country there are extensive tracts of land on which the natural herbage is generally poor from long deterioration of the soil and exposure to storm; and from such tracts only a very small rental can be obtained in their present unsheltered state. The land on the parts referred to is not generally so poor in its natural constituents as to prevent its cultivation being profitable. But its altitude and its general exprosure to stoms have hitherto prevented farners embarking capital on its improvement, as, without shelter, this would not yield a remunerative return; and therefore, paying only a nominal rent to the proprietor, they use it as pasturage for sheep only, or for cattle of an inferior description. Now, were these high-lying districts judiciously clothed with plantations, so as to produce shelter and thus innove the physical conditions of the adjoining land, excellent farming might be possible on them, or good root-crops might be raised for the rearing of first-class cattle; and a higher return, independent of the value of the plantations as timber-crops, might be indirectly obtained by the proprietors from their estates.

In many other countries besides Britain there are extensive stretches of land similarly unfaromahly situated, and froducing in their present exposed and unsheltered state only a poor herbage, on which the better class of farm animals cannot be maintained. In all such cases, however, the judicious formation of plantations spread over them is all that is necessary in order to render the waste lands more valuable from an economic point of view.

Another class of waste lands consists of those that are of too poor and unpromising a character to ensure their cultivation being remunerative to the farmer. Such tracts usually consist of poor 
and generally sandy wastes, situated on the lower-lying larts of a country. In Britain there is but little of this class now left; for within the last fifty years it has been nearly all reclaimed by agriculturists, and has often been made highly remunerative. Lut in many other countries, and especially in Australia, South Africa, Canada, and the United States, there are very extensive tracts, yiellling only a coarse and indifferent pasture, or prorlucing nerely a few stunted trees here and there. The poverty of the existing crops on such barren tracts does not arise from the land being defuctive in latent productive capacity for sylvicultural or agricultural crops, l, st from its being unprotected against the exhausting and deteriorating influences of stu and wind.

Here also is a great field for improvement by Sylviculture, not only from an agricultural point of view, but also from a clinnatic and national-economic standpoint; for were these extensive plains clutherl with plantations here and there, the climate would soon become moister and cooler, and rainfall would prolably increase, and with these advantages the land would certainly become productive.

Practical examples of this may be quoted in the case of parts of the Tiussian steppes, which were planted up about (j0 year's ago, and in the great sylvicultural achievement, the reboisement of the Landes near Bordeaux. Vast tracts of poor deteriorated soil, with a subsoil of moorpan, throughout Northern Germany have during the last 20 years been reclaimed hy the sul woilplough and planted up, to the great advantage both of the National Forest Department and of the neighbouring peasantry (compare notes on lyp. 4 ; and (1;0).

Planting near the Sea-Coast. - On most landed properties lying near the coast it is often found difficult to get plantations to thrive within the blasting influence of the sea-breeze. The following mode of procedure may, however, be adopted with a fair prospect of success.

Having lined off a belt of land, not less than 200 yards in breadth, along the tract of coast to be planted up, it should be fenced in, with a stone dyke if possilhle, upon the sille next the sea, whence the most biting winds usually come. This stone dyke should usually le about $6 \mathrm{ft}$. in height; but if stones for this purpose cannot be got conveniently, a turf dyke of about $4 \mathrm{ft}$. in height may be erected instead, and on the top of this a wire fence formecl of $: 3 \mathrm{it}$. in height. The wire fence should be closely wattled with branches of Spruce, or of any other tree or shrub which may he found most conrenient, as the object is to secure a fence of abunt $7 \mathrm{ft}$. in total height, for the purpose of breaking the force of the sea-breeze, and thus sheltering the young trees to be planted inside. Tpon all headlands jutting out into the sea, the line of fence should be made to talke 
a bold convex bend in the same direction, thereby increasing the seneral wilth of the plantation. While the protection-wall is being erected, all wet parts of the land should be drained, or trenched, "r wherwise prepared, fur planting operations. These preliminary works onght to be carried out during the autumn; whilst the work of planting up should be performed during the month of April following, as experience has shown this to be the best time of the year for planting on land lying along the sea-shore. Pits shomkl be made for the reception of the young trees at least three months previous to the time of beginning planting; and these should be formed about $3 \mathrm{ft}$. apart over all.

For such planting operations the use of large cylindrical spades is advantageous, unless the soil be too dry and light for the balls of earth to hold well together.

The kinds of trees most suitable for this class of planting inclucle the Sycamore, the Maple, the Beech, the Black Pines (Austrian and Corsican), the Maritime Pine, and the Cluster Pine, and probally also the Sitka or Menzies Siruce, the Tancourer Island Pine, and the sea-coast or Pacific variety of the Red or Douglas Fir. Close planting is essential to success; the distance between the plants should not exceed at most $3 \mathrm{ft}$. by $3 \mathrm{ft}$. (4840 per acre).

It is of course intelligible that on such tracts only sturdy plants can be profitably utilised; hence those transplants will be most likely to establish themselves rapidly and successfully that have been already schooled in more than one nursery-bed, and have consequently a compact, fibrous root-system, which can be easily lifted by a large cylindrical spade, and replanted in a hole formed by the same or any other spade of similar size and shape.

The broad-leaved species will not come away rapidly. Many of thern will, in the case of pit-planting, even die down to the gromul during the second year after being planted. But the proprietor and the forester must not he at all cliscouraged upon this account: for it is (quite natural that the roung plinnts should do so, as they must suffer considerably by being at once transplanted from a nursery to the open wround upon the sea-coast. In orler to strengthen the growth of such young deciduous plants as show indication of wilting bally nfter they have heen in the ground for one year, they should be cut flush with the surface of the soil in the early spring, and they will then send out strong young shoots of a hardy nature. By this tine the conifers should be heginning to shoot alsead in growtl, so as to afford some shelter to the ground. If the land be not of a mature suited to the healthy growth of deciduous species, it will be hetter to plant the ground all over with conifers alone. Though the 
Beech, Maple, and Sycamore all stand the sea-lreeze well, yet if the soil be very light and mossy, or very yorr and thin, as often occurs along the sea-shore, they have not much chance of ol,taining arlerquate food-supplies during the first time of planting. Many conifers, on the other hand, and more especially l'ines, not only make comparatively slight demands on the land for foorl-supplies, lut are at the same time remarkably accommodative on soils not furourable to their natural requirements as to food and moisture. They can therefore often thrive and flourish upon poor, light, sandy soil.

If the fence be made of sufficient height to produce a proper degree of shelter to the young plants, they will make fair progress, and in a few years will be found to form canopy; and some years later thinning may be commenced. On poor land of this description, all the operations of thiming should be carried out gradually and frequently, in order to obviate any dissipation of vital encrey in an individual struggle between the trees for light, and warmth, and growing-space-in fact, for the very essentials of life.

But, at the same time, the thinning operations should invariably be so light as not to break or interrunt the leaf-canopy; for that would expose the soil to the exhansting effects of sun and wind, would dissipate l,y evaporation the small supply of soil-moisture, and would blow abont the dead foliage, in place of giving it a fair chance of decomposing and forming humus for the amelioration of the land and the enlancement of its productive capacity. For the regeneration of timber-crops on such situations, natural reproduction in small patehes is recommended, in order to aroid hreaking up the canney to any great extent, and thus exposing the soil to the inimical action of sun and wind.

It must not be expected that the conifers will rise high or make fine-looking, tall trees, at any rate whilst the first crop is on the ground. But, if they receive careful attention in the way of tenting, they may, after assuming a very bushy habit for the first 10 to 15 years, ultimately develop into fair timber-trees. Trees that inmeriately begin to rise high in such a situation would be at once beaten down by the gales from the sea; but if their root-systems become thoroughly established, and spread themselves before they make strong leading-shoots, then they soon form a good shelter to ererything else near them.

In other words, growth in height cammot talie liace vigorously until after canopy has been formed for several years, and the productive capacity is beginning to be enhanced by shacke, protection of soil-moisture, and the formation of humus. Hence close planting is a very important means of assisting in the development of the plantation; and thone methods of planting deserve the preference which offer the formation of canopy in the slurtest time-i.e., 
which admit of the greatest density of the plantation, without any undue outlay for material and work.

When once such an outer belt of shelter-wood has been formed, and has succeeded in faily establishing itself, other plantations may more eisily be formed behind them, owing to the shelter they afford. In making plantations inside of the belt of shelter-wood, any kinds of trees suitable for the land may be used; for the soil should now be well screened from the blasting influence of the sea-breeze, and may therefore be dealt with in the usual way, according as the nature of the land in each case may require.

The advantages of such a belt of shelter-wood along the coast are immense, both from a sylvicultural and an agricultural point of view; for its ameliorating influence places the whole of the property in the position of an estate situated sereral miles inland. Hence thriving plantations of all other kinds of trees can more easily be reared on it; while agriculture can at the same time be more profitably pursued than where the land lies open to the breeze.

In planting within the influence of the sea, although the species of trees already maned should usually be the principal linds put out, yet, by way of variety, many other trees may be mixed along with them, for the sake of arboricultural or resthetic effect. Thus, the Common Yew, the Evergreen Oak, the Turkey Oak, the Pear-tree, the Dwarf Pine, the Elder, the Mountain Ash, the Service-tree, the Huntingdon and the Bedford Willows, and the Abele and Ontario Poplars, may all form part of the mixed crop. If a proper density of canopy be maintained, there should be no underwood; but where the proprietor wishes to treat the plantations arboriculturally, and not on a purely sylvicultural method, the underwood may consist of the Common Broom and Furze, together with Sea Buckthorn, Guelderrose, Common Hawthorn, Scots-rose, the Snowberry, the Common Mahonia, and Privet. All of these succeed more or less in situations under the influence of the sea-breeze; but of course they should be used only on the more sheltered parts, where variety and effect may be an object. We may also remark, that of all the plants named as suitahle for underwool here, the Sea Buckthorn is the harliest, and may safely be used on the most exposed points.

The Barberry often grows freely and rapidly on land of this description; but it should be cut out persistently if the woods are in the vicinity of arable land, as it forms the host of the fungus Puccinia graminis Pers., which causes rust in wheat. It nourishes the Ecidium berberidis Pers., which has a change of generation with Uredo linearis, and with its winter-form Puccinia graminis (Hess, Forstschutz, vol. ii., 1890, p. 168).

The following brief description of the method adopted in planting up the 
Tolkham sanclhills on the Earl of Leicester's Norfolk extate may he brith of interest and of use :-

Planting on the Coast of Norfolk. ${ }^{1}$ - Holkhau Simrlhills were malit-

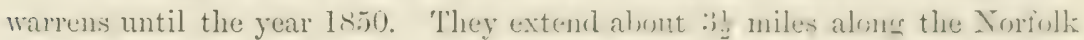
coast, are from 5 to 25 chains wide, and are bounded by the German Ocean on the north, and on the south by rich pasture-land reclaimed from the sea, dating as far back as 1660, when the first enclosure was made. These lills are held together by the Psamma arenaria, a plant having a strong creeping perennial root, with many tubers at the joints about the size of a pea. It is plinted and encouraged on the Norfolk const to aid in fixing the and aqain-t the action of the wind and tides, which it does in a remarkable manner; whilst the marrum, or hent-grass, is considered of so much importance that there are severe laws to prohibit its being destroyed. The sea lyme-grass (Elymus arencrius), a strong, rough, glaucous plant, common on sandy shores, is also frequent here, and answers the same purpose as the bent in fixing the sand.

About forty years ago small experiments were made with the Black Pines and the Common Scots Pine, which were thoroughly protected from rabbits; but no great amount of success was anticipated, as the soil was almost pure sand. At the end of the first season the plants were all alive, had made shoots of 1 or $2 \mathrm{in.}$, and seemed healthy; the second year they did so much better that attention was drawn to their success, and arrangements were at once made to shoot off the rabbits, and to plant a small portion of the hills annually till the whole was brought under wood.

The east end of the hills, nearly 2 miles in length, which was only partly planted previous to 1875 , is now a thriving plantation, not only forming a shelter for the acljoining pasture, but ensiderably enlancing the leauty of the landscape; and the trees are doing much better than might have heen expecterl.

In 1877 the plants had in many cases established themselves well, though the tops of the Corsican Pine were much injured by the northerly winds and blowing sands. The tops of the hills were about this time planted up, frincipally with Black Pines. When these heran to estalshin themselver, the Corsican Pines, which were cut by wind, began to improre; and by 1882 a very decided improvement was visible. Since then, owing to the progress the plantations made, they have been considerably extended.

The proportions in which the plants are lised are:-

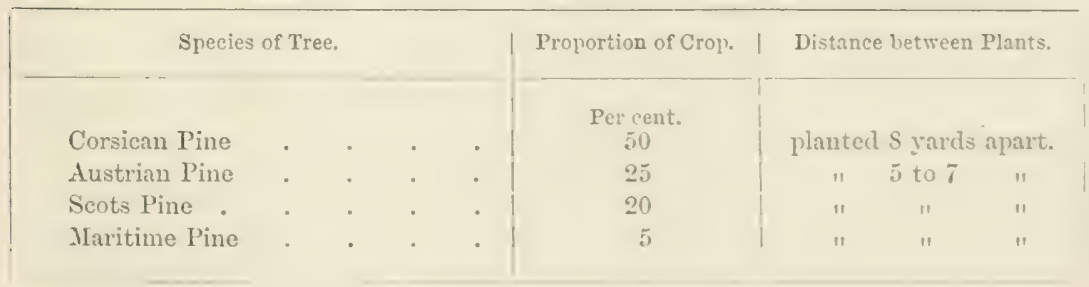

As the plantations are omamental (arboricultural), and are not planted for profit (sylvicultural), these distances have been fixed so as to gire plenty

1 See article in The Transactions of the Royal Scottish Arboricultural Socicty, 1593, P. 350 .

VOL. I. 
of room for the trees dereloping their laterals. The Austrian and the Maritime l'ines, being on the higher and more exposed situations, and fully exposed to every stom from the (ieman Ocean, are planted 5) to 7 yards apart; lience they caminot posilbly make the same growth as the Corsican Pines, which are more sheltered. Many of the latter are now full of health, 30 to $35 \mathrm{ft}$. high, and with lateral branches covering an area equal to a circle of 8 yards in diameter. The Scots and Austrian Pines are making a proportionate growth.

In addressing the Prussian Minister of Agriculture on the subject, Prof. Wagner recommended Lathyrus sylvestris, a strong perennial-rooted surecies of the Everlasting-Pea tribe, for cultivation throughout the immense tracts of barren sandhills along the coast of Northern Germany, and rointed out that it would form a far better means of bringing these vast wastes under profitable and permanent cultivation than the planting of Pine and Spruce. Little faith was put in that statement, however, until its correctness had been proved by private experiments on a large scale. The latter were conducted for many years and at heavy expense, on sandhills where sylvicultural crops of Pine and Spruce had been tried, but had failed owing to the majority of the young trees being partly smothered or uprooted by the ever-shifting sand, whilst the survivors were vegetating so weakly that the experiments were tantamount to failure. But now a flock of sheep is kept on the Lathymus fodder grown on the identical sandhills where six years ago not a blade of grass could be seen.

In all calculations relative to reclamation or improvement of land by means of planting, it must be distinctly borne in mind that the first crop of timber cannot possibly be equal in quality to the succeeding crops, if the first crop be properly managed. Under judicious management of the first crop, the productive capracity of the land will be greatly enhanced; and this will not be of the nature of any unearned increment, but will be purchased by a part of the original outlay in establishing the first crop (see notes on 11 . 6 and 605 ).

Planting on Mossy Land.-Muss or peat-soil consists in general of decayed vegetable matter, which has accumulated in a flat or hollow part having an impervious subsoil, usually of plastic clay. When left to itself, a tract of mossy land is always laden with stagnant water, which cannot escape downwards in consequence of the impervious nature of the stratum whereon it lies. The water contained in the moss - soil can escape only by evaporation from the surfice; hence it is evident that the soil of dripping peat-hags must at all times be cold as compared with other land lying upon an open or porous subsoil. In consequence of this cold nature of the soil, valuable woods are never to be found growing upon unreclaimed mosis-land, hut only a few stunted Pine, Birch, Willow, and Alder, with an cren more unproductive soil-covering of heath, heather, and romble grasses and hog-plants. Moss-land, even after heing dried hy chainage, is usually at first of a dull and inert claracter, and not apt to rroduce good crojs mutil the soil becomes of an earthy nature later 
on; but then it is often characterised ly great fertility. This inertness is the more oliserval,le in such moss-lands as are furely of a humose character, and without any consideralle mixture of inorsanic matter, such as the classes of land lnown ly the nane of flow or soaly moss, or dripping peat.

Two different descriptions of moss-land may he rlistinguished, according as it contains less or more of inorganic matter, or is of a purely humose character; and these differences are very important from a sylvicultural point of view.

In hringing moss-land unter timber-crops, the first proint to he attended to is its drainage; for hefore this the thoroughly accrmplished no other work can be undertaken. The draining of moss-Iand is performed in the usual way by open trenches (see $1.5: 3 t, t$ sey.) ; but with this exception, that the drains should in all cases le made alsout one-third deeper than the depth they are intended to remain at permanently. Thus, if it he wished to have the trenches to remain at the depth of $4 \mathrm{ft}$. after they have heen opener, then they will have to be made about $5 \mathrm{ft}$. $6 \mathrm{in}$. deep in the first instance. This is necessary on account of the great sulsidence that always takes place in moss-land after the water is removed from it hy drainage; indeed, in the case of very light flow-moss, the subsidence may even amount to nearly one-half of the original depth of the drains. In draining moss-land for planting with trees, if the moss is not over $6 \mathrm{ft}$. deep, it will he found advantageous to open out the trenches to the sulisoil; as only then can the land he made jerfectly dry, and suitable for the healthy growth of trees. To drain moss-lind proprerly for sylvicultural cropss, the trenches should he open to the depth of from 5 to $6 \mathrm{ft}$. in the first place, in order to make allowance for sulsidence, and they should be dug at distances not wiler than $35 \mathrm{ft}$. aprart. If, however, the moss be shallow, as often hapnens, the drains need not le mate so deep. For example, if the moss lue found only about $3 \mathrm{ft}$. deep un the average, then, in order to secure an average depth of $t \mathrm{ft}$. for the drains after the moss had subsided, they would require to the opened to the depth of $5 \mathrm{ft}$. in the first instance, thus allowing $1 \mathrm{ft}$. for sulsidence in the moss on the surface; and so on with any other depth of moss, always allowing one-third of its depth for sulsidence.

In all cases moss-land should lie from twelve to eighteen months moler the cleansing action of the drains, as there are generally ingredients (like humic, geic, and uhnie acids, dic) lodking in land of this description which are found injurious to the health of young flants, and which require to be removed before planting can be sucessfully undertaken on it. This is a point which should never le lost sight of in dealing with the afforestation of moss-lands. Many young ylantations of large extent, formed inmediately after the drainage had lieen 
jerformed, have completely failed owing to this point having heen nerglectert: while the second planting thereby necessitated, thongh done mnly two years after, was perfectly sucessful, simply from the mo:s haring become cleansed of the bad ingredients which harl lodged in it, and which had been drained off before the second crop was planted.

German experience on the subject varies somewhat from the above method. Thus Burckhardt (op. cit., p. 561) says of the moors on the great North German Plain :-

"Every moorland drainage-scheme should be begun early and continued gradually to its completion; hence 5 or 10 years, or even more, may be required, according to circumstances. For the trenches can never be dug at once to the depth that they should eventually have. By gradual shrinkage the moor settles itself and gains in density ; whilst in other cases the trenches are closed up by the soft mossy soil, or nasty fissures are formed, or outlay of one sort or another is occasioned. As a rule, soft, boggy moors should only be drained to a depth of $2 \mathrm{ft}$. to begin with."

The question, as to how the drainage of extensive moors in mountainous districts may affect the climate of any locality, is of particular interest with regard to the Highlands of Scotland. Large and extensive experience on the subject is nowhere available; but the following extract (Ramann, Forstliche Jintenkunde und stendortslehre, 1893, p. 400) represents the opinion of a sylvicultural specialist on the matter:-

"In general there will be no reason, especially in mountainous tracts with copious summer precipitations, to be too apprehensive about the drainage of marshy land at high elevations. It is proverbial that such moors are like sponges, which refresh with their moisture the thirsty neighbouring lands in time of drought. This sounds exceedingly well ; but it is exceedingly doubtful if it be true. Often enough mountain-moors are more injurious than useful to the surrounding land, owing to their low temperature and their strong evaporation. And it must be recollected that these moors are, almost without exception, old forest-lands that have become unproductive and swampy."

Such is also the case in the Scottish Highlands. For they originally bore a woodland covering, of Scots Pine chiefly; but the 24,000 men employed during the reign of Edward I. by John of Ghent, in burning the woods, destroyed most of them, and the private interests of landlords completed the work of destruction towards the close of the past, and during the present, century.

Burckhardt's opinion on this particular subject-and it is the opinion of one of the greatest of German sylviculturists-is worthy of consideration. It is as follows (op. cit., p. 568):-

"Mountain-moors especially offer a difficult problem for solution; and the question whether or not they may be planted up so as to yield a continuously profitable sylvicultural crop has not yet been satisfactorily and finally answered."

Planting operations on moss-land have no special difficulties to contend with; hence notching in with the planting-stick (see Fig. 112) is ts be recommended as cheap and effective. Hags of dripling peat, even after they have been well dried by draining, will not grow hard- 
woods to any advantage, with the exception of Ash, which will dro well in moss as a coppice; Suruce Fir and Secots P'ine, however, both thrive fairly well on mossy land, the Spruce heing introduced in largest numbers wherever the situation is shelterer. In a mossy soil, plants of any description never establish thenselves quickly: hence new plantations make very little progress for the first few years from the tine of planting, owing to the humose soil being inert and rlull, until it becomes of a more earthy nature.

In planting up moss-land haring a consideralle protion of sandy or earthy inorganic matter in it, I'nplars, Willows, Birch, and Alier may be used, of the usual kinds grown for timber, together with Spruce and Silver Firs, and the Scots, Anstrian, Corsicin, and Cluster I'ines, all of which will succeed. These shonld he plinterl at distances not wider than $4 \mathrm{ft}$; and of course they can be mixed in such proprortions as may lie considered most suitahle to the circumstances of each given case. As a rule, the chief species should be that whose requirements are hest satisfied by the nature of the snil and the sitnittion; and practically this can only be determiner after due consideration of each individual case. Even crops of excellent Oak timber may sometimes be met with upon a mossy surface-soil resting ul m clay, when the land has been well drained, and the moss has subsided, so as to permit of the roots finding their way down into the clay, whence they could derive mineral nourishment. ¿ 'pon a soil of this description, Larch and Scots Pine also thrive well.

As Burckhardt remarks (op. cit., p. 568) :-

"When, on moorland soils, we see almost all kinds of trees thriving in some places, and especially when we see Oak, Birch, Spruce, Silver Fir, and Pine growing satisfactorily, whilst in other places accommodating species, like Scots Pine and Birch, only produce dwarfish crops, the explauations are in some cases to be sought in the varying nature of moorland soil, and in others in the method of treatment adopted; but both of these matters demand great attention.'

Where the more expensive method of pitting is adopted, the plints ought to be of fairly large size; but if the area be notched up with the planting-stick, or if the situation he at all exposent, then smaller plants should he nsed. I'oplans and Willows ahout $: 0 \mathrm{ing}$. high, and Firs and lines from 6 to 9 in., ought to suftice for must lucalities, unless the growth of weeds becomes very rank and luxurious.

Even then, the cheap and simple method of notching on tumpls may still remove any necessity for the more expensive pitting with contlier material.

If the moss be not over $3 \mathrm{ft}$. deep, Oak, Ash, Elm, and Birch maty be used with finir success, as these kinds generally thrive well when once their roots get down into the subsiil; still, as a sylricultural crop on moss-land, softwoods and conifers will usually be found 
the most remunerative. The Birch, Elm, and Oak thrive well on thin moss resting on a substratum of clay; hence, where variety is an olject in the crop, these may be introduced in small patches here and there within a matrix of conifers.

As the most profitable crop on sandy moss, in a high-lying situation, there is no tree that will usually render a better account of itself than the Sicots Pine. Ample proof of this exists in many parts of the north of Scotland and the north of England, and especially in many of the natural forests in the districts of Braemar, Abernethy, Duthal, Iothienurchus, Glemmore, and others. In these localities there are large tracts of moss-land containing a considerable portion of sand, on which the Scots Pine has attained very fair dimensions.

In planting on moss of a purely humose character, Scots Pine and Spruce should be the chief species used; and more recent exotics, like Red or Douglas Fir, and Sitka or Menzies Spruce, may be introduced experimentally, though only to such an extent that their loss would not interrupt the leaf-canopy of the crop materially. Silver Fir, Oak, aud some other hardwood kinds, sometimes do well where the moss is so thin that their roots can reach down to the subsoil before they attain any considerable age; but where it is so deep as to prevent the roots getting down to the subsoil, they soon become stunted and unhealthy, and die off prematurely. Hence in all cases the nature of the tree-crop must be suited to the depth and general condition of the moss or moorland being operated upon.

From the foregoing statements relative to the growth of various trees upon moss-land, it will appear that Scots l'ine, Spruce, Silver Firs, Willows, I'oplar's, Alders, and Birch are entitled' to most consideration in the planting up of moorlands. This statement must, however, only be taken with the qualification that, if the situation be rery high-lying and exposed, silver Fir and spruce, Willows, Poplars, and Alders will not do well. Under such circumstances, Scots Pine and Birch would be more suitable, as lieing hardy and adapted for a high situation. It may be observed, further, that the Austrian, the Corsican, and the Cluster I'ines, as also the deciduous species named, should not be planted out upon moss-land, excepting where it is in comparatively low-lying localities or on only moderately elevated situations.

Coppice for Powder-Wood.-This is a branch of Forestry generally too little attended to. And this is the more remarkable when the value of wood suitable for powder manufacturers is considered, and also the large extent of waste-land in the country which might, with sircat advantige to its owners, he made to yield crops suitable for this furpine. Indeed, in the north of scotland, and in the northern counties of Fingland, there are large tracts of high - lying ground at present 
yielding only a stunted and inprofitalje herbage, which, were they planted with plants suitable for the manufacture of powder, miglit be made to yield handsone rentals. As this class of wood-produce does not require to be of large dimensions, it could lie the more easily reared in ligh-lying districts of the country, and might easily be conveyed thence to the places where it was to be used.

It is, perhaps, not generally known that a large supply of the wood used in this comintry for the manufacture of the finer kinds of powder for small-arms and fowling-pieces is imported from lielgium and Germany. The wood which is chiefly utilised for this purrose

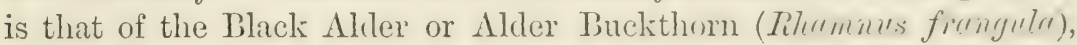
a shrub found to be extremely easy of cultivation in most kinds of soils; and as it brings from $£ 10$ to $£ 14$ a-ton, in the peden strets, in the British market, it is certainly worth the attention of limeled proprietors to cultivate it as a part of their woodland crops. ${ }^{1}$ It ought to be humiliating to us as a great nation that the main supply of wood suited to the manufacture of the finer linds of powder for small-arms has to be brought from foreign countries, seeing that we might so easily grow it ourselves as a profitable crop in the econony of our landed estates.

In addition to the Alder Buckthorn, the Alder, and the Beech, the other linds of trees and shrubs whose wook may be utilised for the manufacture of powder comprise various kinds of Dogwood (Cornus), Willows of various species, Birch, Hazel, Momntain-Ash, and Wild Cherry.

When properly formed and managed, colpuice-ronts composed of these species may often be found to prove very profitalile as woolland crops. In growing these kinds for a supply of powder-wool, each should be planted in patches lyy itself, rather than mixel with the other linds; for each species has its peculiar property, and therefore its own value with the powder-manufacturer. Once fairly establishecl on a piece of ground, all these linds prodnce heary crops of shoots and yield a large retum per acre, more particularly the Alder. The shoots should be all treated as copprice in rearing them for a sulply of powder-wood; and they may he cut over', striphed of their hark, and sold to the powder-mantiacturer at any stige of their growth, as large wood is never wanted for the purpose of powiter-maling.

1 The market is no longer so remunerative as formerly, ns is explained in the following extract from the editor's British Forcst Trecs, 1893, p. 340 :-

"Black Alder was formerly rather prized for the preparation of charcoal for porrder; but of recent years Alder and Beechwood have been more generally used for this purpose, the former being solely used for the manufacture of smokeless powder. Where it occurs in any quantity, it yields pea and bean sticks where Spruce and Silver Fir poles are not axailable, also good sticks for umbrellas, walking-sticks, and similar petty purposes. . . . When it is coppiced with a rotation of 3 to 6 years, it shoots freely from the stool." 
Indeed, when the shoots are compratively small, a higher price is given for them than for larger rods; for in the young state of the shoots the powder made from them is finer than when made from older and larger growths.

The Black Alder (Rhammus) is the most valuable of the species named, as it is used for making the very finest kinds of powder. The Dogwoods come next in value; whilst Birch, Hazel, and Alder follow in the order naned. The Mountain-Ash and the Wild Cherry are only of comparatively little quality; and Willows rank even lower for the purposes of powder-making, although they are all in use, however, for making different qualities of powder.

Softroods have also a special and more recent value over hardwoods for utilisation as wood-puly, for laprer-manufacture, an industry which is practically at present confined to the continent of Europe.

But it would seem to offer very fair prospects for moist land in the Highlands of Scotland, as it not only promises quick returns for money laid out in reclaiming and planting, but also would fall within the Sylva cadua, which are of such importance from the point of view of entailed estateholders under Scots law (see chapter i., p. 73).

Planting of Scrub-lands. - It often happens that land to be planted is much overgrown with broom, furze, hazel, and various other kinds of brushwood; and wherever any of these are found to prevail, they should be removed by grubbing them out by the roots with the mattock, or by trenching, if necessary, before planting. Broom and furze are, generally speaking, easily got rid of by grubbing them up with the common mattock. But Hazel and other strong-rooted kinds of plants are more difficult to deal with; and it is usually found necessary to trench the ground occupied by them in order to get them entirely removed.

In clearing broom and furze from a piece of land before planting trees upon it, the best way is to give out by contract the work of grubbing them, either at so much per acre or at so much for the whole, according to the extent and character of the scrub to be removed, but binding the contractor to take out every plant by the roots. Work of this kind may be contracted for at various prices, according to the closeness and strength of the plants to be dealt with. Patchy crops may be grubbed out at 20s. per acre, while in other cases it may cost 70 s. per acre; but in the latter case there will probably be a close crop of very strong furze. On the average, however, such work may be arranged for at about 40 s. per acre, inchnding the luming of the brushwood on the ground. In contracting fur work of this kind, the forestur requires to look carefully after the contractor, to see that he takes out all the plants by the root. When 
this class of work is carelessly performed, and a laree fronortion of the plants is only cut over under the surface, the roots left in the ground throw up another strong (cole of whins during the following year; and this soon forms as strong a crop as before. Hence work of this nature requires the careful attention of the forester.

In dealing with the removal of Hazel and of similar stront-ronterl 1)lants, however, the case is dillerent: it is always fomm nece-nary to use both the spade and the mattock in order to root them out properly. Where the plants are few in number, and have large clear spaces between them, it will le found the easiest and chealest plim to dig out each pint seprarately, and to fill "1, the lowle inmenliately. Wherever the plants form rather a close crop, or nearly so, on the ground, the cheapest and most satisfactory way is to trench the ground all over, so far as it is occupied by the scrub or brushwood. This trenching need not le of a deep character, but only just enough to enable the contractor for the work-for it should usually lue done by contract-to get sufficiently deep to take out every plant by the roots. From $1 \mathrm{ft}$. to $1.5 \mathrm{in}$. will be found a sufficient depth of trench to remove the roots of most kinds of brushwood of this description. Land may he trenched and cleared in this wily, after having strong stocks of Hazel and Birch standing at an average distance of $9 \mathrm{ft}$. apart, for about $£ 7$ an acre. This sum, however, does not include the cost of removing the roots fron the land after trenching, as this can be done by the proprietor's own workmen apart from the contract.

In planting up land that has just been cleared of broom or furze by the use of the mattock, the youmg plants may be put in either l,y pitting or notching, according as the nature of the situation to be operated on is of a momntainoms, moderately elevated, or low-lying situation; and these specifie classes of land have already been treated of elsewhere in the present chapter.

In the case of an exposed piece of land having been trenched for a crop of young trees, it should never be planted immediately: for the loose and very open chameter of the land, hefore the turf henins to settle and decompose, exposes it to the eflects of dromght to such an extent as to prove injurious to a large proportion of the crop. If the trenching be ferformed in the antumn, however, the limet may lie safely planted in the spring following.

This precaution is not so necessary in the case of trenched land on a sheltered part, as here the plants are nut nearly so lialle to be injured by winds blowing them about.

In all cases of planting on trenched land, larger plants may be notched in than is advisable on untrenehed land: for, in woil that hats been thoronghly opened up and aerited hy trenching. the roots of 
comparatively large plants establish themselves much more easily and rapidly thin on land that has undergone no special preparation. The size of the plants that can be most advantageously used must in all cases, however, be regulated by the nature of the soil and of the situation.

Where there is a strong growth of heather, juniper, whins, and the like, burning of these during late summer is often very advantageous before beginning the work of trenching in autumn. And at the same time the mineralashes yielded by the scrubby growth of brushwood acts as manure for the enrichment of the soil. Wherever such firing of gorse or heather is to take place extensively, it should be conducted on a well-considered plan; and of course measures must be taken to prevent the spread of the fire into any neighbouring plantations, or beyond the area to be operated upon.

Replanting of Woodlands. - Many hold the opinion that a crop' of trees will not succeed satisfactorily on land that had been formerly under a crop of the same sort of trees, and on which they had become matured; and the reason invariably given for this is, that the former crop had exhausted the land of the proper food for a second of the same kind. In the author's opinion the statement is, generally speaking, true, with respect to the growth of any kinds of trees planted on lands not adapted to their healthy development; while it is in error when applied to the growth of the same kinds planted on lands in all respects adapted to their healthy development. It is from not considering the question from both of these points of view that false conclusions have been arrived at on the subject.

That such a question should be raised at all, indicates the low level of sylvicultural knowledge in this country. In natural forests crop succeeds crop; and when changes take place, they can easily be accounted for by the relation of the different species towards light and shade, frost, \&c., or by the power of the seed of certain light-winged species lying dormant (like Birch) for many years, and asserting themselves whenever they have favourable supplies of light. By these means the changes noted by Evelyn (see p. 520) are logically and satisfactorily accounted for. The researches of Continental sylvicultural chemists-Ebermayer, Wollny, Ramann, and others-prove that there is practically no danger of any species of high-timber crop exhausting any given mineral food-constituent from the soil, so long as the crop is managed with due regard to the maintenance of a normal density of canopy for the protection of the soil against the effects of sun and wind, and so long as the dead foliage is retained on the soil for the formation of humus.

The student will find a résumé of the latest information on the subject of the demands of the varions kinds of trees for food-supplies (see 1. 332) in the editor's Studies in Forestry, 1894, chapter iv. (see also chaps. ii. and iii. of the present work).

Where soil and situation are suitable for any given species of tree, and the crols have been and are still properly managed, the latter may be regenerated 
either naturally or artificially; but where crops have been grnwn in localities not naturally favourable to them, then of course difficulties of more than the nistal nature will be attendant on regeneration, whether natural or artificial. Ancl in the latter case the less stited the soil and situation are for the given species, the greater will be the difficulty in regenerating the crops.

For example, on the low-lying tracts and the talble-lands of the south generally, apart from the hilly and mountainous districts of the country, it is seldom found, except under peculiar circumstances, that Larch and Pine yield any great ont-tum of timber in a sound state when planted as a crop on land that had heen hefore occupierl by trees of the same sorts; while, on the granite districts of the north, there are large tracts that have produced a second, and even a third crop of the one or the other of these trees, each successive crop seeming as healthy as the one before it had been.

Larch and Scots Pine are light-demanding trees. Now, if the woods have not been mderplanted when the crops begin to thin themselves and can no longer protect the productivity of the soil in a satisfactory manner, then of course the soil gradually becomes deteriorated, reseneration becomes more difficult, and the productive capacity of the land sinks.

But, on richer and more fertile granite soils, an underwood will in most cases spring up of trees and shruls which can thrive with less light on such good land than they would require on poorer soil containing smaller amounts of nutrients in an easily available form.

The facts recorded by the author agree with the observations of the editor; but the deductions therefrom vary essentially; as alreatly indicated.

In the natural P'ine-forests of Strathspey and Braeminr, crop has succeeded cropl probably for thousands of years; and still those growing there at the present clay seem to produce as good, and healthy, and large stems as any of those found lying in the mosses, which are the remains of crops that had stood and mrown on the same land many centuries ago. And notwithstanding all the successive cropis of sicots Pine that have grown in these forests, whenever any portion is sufficiently cleared of old trees to admit of air and light reaching the soil, a crop of young and healthy seedlings rises up thickly all over. This indicates that successive cropls of the sane tree will arow each as healthily and as lixuriantly as its predecessor on the same piece of land,-provided always that the kinds used are planted in the soil maturally adapted to the species of tree in yuestion, and that the crops are maintained in gool canopy. The conclusion to be drawn from this is, therefore, that in order to grow trees mon any piece of land, it is only necessary to to the work on the prineiples that nature has pointed out to us-vize, to plinnt species of trees whose nomal requirements can be satisfied by the given soil and situltion, and to maintain such nomal density of canouy throughout all stages as will 
suffice to frutect the productive calracity of the soil without crowding the plantations so as to interfere with their healthy growth and greatest financial economy.

Any attempt to show that a rotation of timber crop may be beneficial, or even necessary, as in the case of agricultural crops, must exhibit want of knowledge of sylvicultural chemistry. Evergreen coniferous crops in particular, if properly managed, leave the land much richer in nutrients in an arailable form than when the land was originally planted with them; and woil which has been allowed to hecome temporarily exhausted by badly managed broad-leaved crops may be recuperated by one crop of evergreen conifers, so as to become suitable once more for the growth of deciduous trees. But mismanagement is in such cases the sole cause of the necessity for any change of crop. This has nothing to do with the demands of the trees for one particular kind of food in greater quantities than a properly protected soil can yield in continuity.

In the great natural forests of America successive crops of the finest of timber have been and are still being raised, under the same natural law. There, where Nature has had her own way without any interference from man; the crops of past ages are lying rotting in all stages of decomposition; while matured and young trees of the same linds form the crop now growing on the soil. And wherever a clearing has been made by the winds, young seedlings of the same kinds as the parent trees rise quickly up in their places, all as healthy as the older trees of the crop, and likely to attain equal dimensions of timber. But in every case each kind of tree has its own peculiar site and soil: the Pines occupy the dry and gravelly ridges; the broad-leaved trees luxuriate in the rich, loamy, and clayey lands; while the Larch and Arborvitæ thrive best in cool damp hollows.

It is the neglect of applying to Forestry this sort of knowledge that is the cause of failures in planting generally, whether the land may have been formerly under a crop of trees or not. Larch may be planted after Larch, Pine after Pine, and broad-leaved species after broal-leaved species, in all cases where the land is naturally adapted to their healthy growth, and where rational treatment is accorded to the growing crop.

It may therefore be infurred from the foregoing remarks that no particular course of preparation is necessary on land in order to ensure the healthy growth of a crop of young trees on it after the cleatrance of a previous crop of timber, provided always that the princilles which nature has pointel out are attended to in dealing with it.

But at the time of regeneration a certain amount of soil-preparatinn nay le necessiry either for the reception of the seed in the case "if natural reprouluction or sowing, or for the speedy establishment of the young plants in the case of artificial reproduction by means of 
planting. This more especially holds goorl with resuect to snch land as has borne a crop of old timber, anil on which a large guantity wi decayer vegetable matter rests which must be thromghly araterl before it can decompose and humify normally.

In artificially reproducing crops of I'ines, Sprnce, and Silver IFir: it is often necessary to grul, out the old stumps left in the gromnd, so as to prevent lodgment for lreetles; lat otherwise any leaving of the land fallow is simply a waste of prorluctivity and a deliberate exposure of the soil to the deteriorating influences of sun and wint.

The former wasteful plan of Scottish foresters in allowing land to lie unproductive for a period of four years after clearing the mature crop, and grubbing up the stumps, and preparing the soil, was not believed in by some of them, as the following extract from Campbell Walker's Report on English and Scotch Forests, 1872, shows:-

"As already stated, Mr MICOrquodale (Scone Forests) does not consider it impossible to replant land from which a crop of timber has been recently removed, and does not agree with IIr Grant Thompson (Strathspey Forests), that it is necessary to wait until the natural herbage or vegetation returns; but he does consider that, in order to plant successfully, special treatment is necessary.

"He appears to have given the matter much attention, and has arrived at the conclusion that it is the beetle, and the beetle only, which interferes with the growth of young trees planted on land recently cleared of conifers. He has contributed several papers on the subject to the Scottish Arboricultural Societs, and tried rarious methods for overcoming the difficulty, arriving at last at the following, which he has now no hesitation in recommending: Allow the land to lie entirely waste for one year, excluding all cattle and sheep, in order to allow grass, \&c., to grow. Then burn it when dry, and plant out by the double-notching system.

"This plan should not cost more than 15s. per acre, all told; and the saring by not allowing the land to lie waste for a number of years, as in Strathspey, is rery considerable."

In the author's opinion, a change of crop is often absolutely necessary on woodland in order to ensure entire success in replinting it. Thus, where a crop of Oak has been grown on very light and therefore unsuitable land, a crop of Larch and P'ine will sncecenl admirably; and where a crop of Larch has heen grown to maturity on land of a heavy description, hardwoods will succeed well.

In the editor's opinion, when once species of trees have been selected that are suitable to the soil or situation, no rotation of crop is necessary except it be prompted by financial considerations. Sylvicultural experience eomuluter on the Continent on a very much more extensive seale than in britain, and ly a much more highly educated boly of men than British foresters are at the present time, has provel the correctness of this riew. But if plantations be formed of insuflicient density to bewin with, and he allowed to grow up with a arowing-space beyond the absolute reyurements of the individual trees for healthy growth and development, then the woods must he considered to the mismanaged from the sylvicultural point of riers; and in roods that are mismanaged, rotation of the crop may often become necessary. 
Hedgerow Timber. ${ }^{1}$-At the present time, when so much necessity exists for the most thorough agricultural utilisation of arable lanul, many are crying out vehemently against hedgerow timlier, and declaring that all hedgerow timber-trees are injurious to the raising of plentiful and healthy crops in the fields upon the edges of which they are planted. And that this is true to a certain extent camnot be denied. But that hedgerow trees are injurious to the crops in the adjoining fields cannot so much be attributed to the presence of the trees themselves as to bad management in growing them ; for if anything, however useful in itself when properly managed, he allowed to orerstep due order and balance, it becomes an evil instead of a good. This is just the condition of a great many hedgerow trees, particularly in England, at the present day. In many cases the kinds of trees have not been adapted to the nature of the soil, hence they spread too much; and in most cases the trees have been entirely left to nature, instead of being trained up with the view of doing good as shelter to the adjoining fields. They have thus often become injurious; have been allowed to spread out their branches widely upon all sides; have been irregularly and most injudiciously planted; have been topped and mutilated, and made to auswer any purpose but that of doing good to the farmer. In short, hedgerow timber at the present day is a part of Arboriculture that is least understood; and yet its proper management is of the greatest importance both to the proprietor and the farmer. Hedgerow trees, when trained up and managed upon right principles, instead of being a nuisance to farmers, become of first-rate importance in all well-cultivated districts; and instead of impoverishing the land, they become a source of fertility to it. But although the former may often be said to be the general state of things relative to hedgerow trees, there are nevertheless many fine examples of their being well managed; and in such cases, farmers say that they are very much benefited by the shelter produced by the trees, and would not upon any account part with them.

The physical fact remains indisputable that all portions of the crops lying to the west, north, and east of the hedgerow trees do not get full and abundant supplies of light and warmth from the monning, noonday, and afternoon sun. No matter how fertile any land may be, it is the light and the warmth of the

I The editor's opinion on the matter of hedgerow timber has been previously expressed (see p. 511). Hedgerow trees rob the agricultural land of its productive capacity ; whilst the timber itself is not of such good technical quality as might be produced in properly managed woods on true forest soil on the higher uplands, and in hilly and mountainous tracts.

For the benefit of the student, it may here be remarked that an essay on IIcdgerou and Ficld Timber will be found in the Trans. Scot. Arbor. Socy., vol. xi., part ini., 1887, pp. $550-561$. 
sun that furnish the energy for calling the productivity into account. Now, herlgerow timber mechanically intercepts the light and warmtl of the smin; hence it directly prejurlices the productive capacity of all land falling within the length of its sharlow. If any one be sceptical ahout this, let him make unprejudiced and mbiassed olservations during the ripening of the wrain next summer. Let him also weigh a few ears of grain taken from near the north side of the trees, and contrast the result with that yielded hy srain, from the same field, that has been sown and has grown in the full enjoyment of light and warmth, and of the sun's life-giving energy.

The planting of hedgerow trees is generally done with a threefold view,-(1) of raising useful timber in the country, without occupying much brealth of land exclusively for that purpose ; (2) for the production of shelter for stock and crops in the adjoining fields; and (3) for resthetic effect.

Now, all these three objects can be attained without any injury whatever being done to the agricultural produce of the country. In some districts, both in England and Scotland, where attention has of late been paid to the pruming of hedgerow trees, much grool has arisen from their influence. In all cases, trees planted in hedgerows are freely exposed to the air; consequently the natural habit of trees under such circumstances is towards ramification. Inut if the forester apply his knowledge and practical skill to trees unler these circumstances, he can, by the timely use of his knife, check this rambling habit; and it is in a great measure from the want of this aplication of timely pruning that a large proportion of the existing lielgerow trees are now of so little value as timber, and so minous to the fields. That shelter has been produced to the fields from the existence of trees about them is evident; but then the amount of good which has been done in this respect has heen orerbalanced by the shade they have cast upon both sides from the spread of their branches, causing a deficiency in the actual crop upon the shadel parts. Thus it cannot be said that much real good has arisen from the presence of hedgerow trees of the older class.

This approaches to the editor's view. But he must insist on the fact that pruning is only a mitigation of the evil, and that the evils of orer-shalowing must remain so long as the trees are planted out in hedgerows.

The total clearance of hedgerow timber would be a death-blow to the beauty of English rural seenery; but Arborieulture differs from sylvieulture in not being trammelled by financial and economic considerations.

That they are an ornament to the comntry, and the chief beauty of rural seenery, is undeniable. But the farmer, who hats his rent to raise off the land, feels no pleasure when he looks upon the trees in his hedgerows, and is aware of their doing him much dimatge. $\mathrm{He}$ 
simply hecones desirous of having them removed, in order that he may have the land now occupied by them brought into more profitable cultivation.

In travelling through some parts of England, one is particularly struck with the mamer in which the majority of the leedgerow trees have been planted. They have often been put out mpon raised banks of earth, with sometimes a deep ditch on each side, at other times with a ditch upon the one side and a dyke upon the other. Frequently, too, this bank of earth is overgrown with thorns, brambles, and other weedls, miking altogether, with the broad-spreading trees, a formidable mass of very considerable extent. This is the state of things that farmers complain of. Now, in order to grow hedgerow trees upon right principles, the trees in this state should be taken out, tiles put into the ditches on each side in order to convert them into proper drains, the bank levelled down over them, the ground trenched, and a recuisite quantity of lime put into it in order to decompose all the old roots the more quickly. If this were done in the spring months, the ground so dealt with should be well manured and put under green crop; and in the autumn a hedge of Thorns or Beech should le planted in one continuous straight line upon the surface, putting in a young tree at every 12 yards for hedgerow timber. In renewing the fences in this manner, any alteration could be made that might be considered an improvement upon the old style, such as omitting the renewal of some of the fences altogether, and consequently unlarying the fields so fir as might be considered necessary; and in carrying out such improvements, the direction of the line of many of the present fences could be altered so as to suit the wishes of the proprietor.

A great error has been made with regard to the raising of hedgerow timber in planting those sorts of trees which are of a spreading hal it, and are not easily liept within due hounds. If hedgerow timber be considered desirable, then the following are the only linds of trees which should be planted in the neighbourhood of fields: Oakk, English Elm, Sycanore, Maple, Birch, Sweet-Chestnut, Black Italian Poplar, and, in some situations, the Cracking Willow. These are all trees more or less of an upright habit, and such as, by the timely use of the pruning-knife, can be easily kept within due lateral bounds. The Ash is often found growing as a hedgerow tree; but it ought to be planted very sparingly under such circumstances. When standing alone and exposed to light and air, its top is extremely liable to branch off into large limbs; and, what is even worse, the rovt- of the . L sh are of all other trees the most searching upon land, which they impoverish very much.

The Beech is another tree frequently found growing out of place 


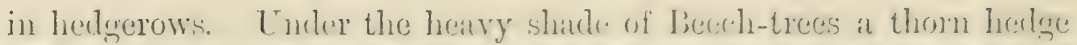
will not prosper; and neither grass nor main ean thrive muler the sharlow of its dense foliage. 'These prejurlicial eflects are enhanced by its ramifying habit when standing alone; and this can hardly be alpreciably altered by puning. Anwher chatacteriotic of the Beech is that, when growing in a free enen sitnation, it is always fomel leaning to the sheltered side; that is to say, if - the prevailing winds of the district be from the west, the tree will be extrenely har of hanches upon that side, and over-heavy upon the "nposite side,-ann ollinuity which is of course particularly out of place in hedgerow timber.

The Spruce, Fir, and Pine tribes are all trees of an upright habit; but they are not adapted for standing allone. They always thrive beit when congregated together. Iiesider, the rorts of these trees run too shallow for growing upon the borders of fielils, where the plomeng must have free access "1] to their very stems. Hence no coniferous species of trees should be planted out along hedgerows.

The training up of the young trees for plinting in herlgerows is a matter of the greatest importance, and should be carefully attended to. Trees of the kinds that hive heen abuve recommended for hedgerows should all be raisent in the nursery for the purpose: this shonit be done hy every propuretur. They should also be frepuently transplanted in the schooling-herts, in order to secure every plint being well furnished with healthy fibrous roots. The transplants should be pruned and trained into an upright shape, eacle with a single lealer only while in the nursery-ground; and the size of the young trees should be from 6 to $8 \mathrm{ft}$. when they are transplanted. If trees for herlgerows are planted of sizes much almere this, they do not estallish themselves so well ; for they are more alt to ramify than to grow in height, and that is a tendency which is, of course, to be avoided.

When once the hedgerow-fence has been formed with thorns, and spaces have been left in it at intervals of 12 yards for the young hedgerow trees, these should be selected according to the nature of the soil. And upun hoth hedere and trees leing fikinterl, a fence or paling should be put up on each side if there are to be cartle in the fiehls; whilst the sulserguent temeling of the herlge must receive the attention elsewhere indicaterl (vol, ii. 1'1) $11-25)$. These hedges, when at their full size, should never be more than $3 \mathrm{ft}$. in diameter at the base. As the trees grow up, they shombl be regularly pruned, so that each of them may have a clean stem of from 10 to $15 \mathrm{ft}$. high, in order to allow the hedge under their crown to have free exposure to light and air. And as the crowns of the trees increatse in breatth, the hranches should he well shortened in, so that, when the trees have arrived at 30 years of age, their side branches may extend only a few feet upon each side of the fence. In order

VOL. I. 
to keep them in this state, they should have their branches shortened in every two or three years; and even when they have attained full size, they should not be allowed to extend over the hedge more than $S$ or $10 \mathrm{ft}$. upon each side. The whole art of growing hedgerow trees consists in having these things properly attended to.

This system possesses many advantages over the older method.

Under the old system of growing hedge-fences and hedgerow trees, there was generally from 8 to $15 \mathrm{ft}$. of land wasted upon the boundary of every field; whereas by the method above recommended, and which is being practised in some districts of Britain, only $3 \mathrm{ft}$. in breadth, at most, is occupied by the fence or hedge. And as the trees are not allowed to grow beyond a certain breadth, their shade does not so materially injure the crop, even when seed is sown close in to the side of the hedge; whilst, as the hedges are never allowed to grow above $4 \frac{1}{2} \mathrm{ft}$. high, and the trees are kept clear of branches on their stems for at least $10 \mathrm{ft}$. up, a free current of air is allowed to pass everywhere, keeping both the hedge and crop upon the land in a healthy state.

A $10 \mathrm{ft}$. gap between the top of the hedge and the base of the crown would tend very seriously to ammihilate the shelter which is said to be the great advantage yielded by hedgerow timber - apart from its admitted great resthetic beauty.

The trees, when treated in the manner above recommended, in consequence of being so much kept in upon the side branches, soon become tall, and form fine trunks of timber. In order to gain this end quickly, the top of each tree should have the lead from the very first, and no side branch should be allowed to gain strength upon it.

This system of growing trees in the form of hedgerows is, however, adapted only to level and low-lying parts of the country, and not to hilly and exposed tracts; for on the latter trees require to be grown in masses, in order to produce shelter both to themselves and to the neighbouring fields.

Cost of Planting.--In calculating the expenses likely to be incurred in the laying down of a piece of land under a crop of young forest-trees, the proprietor has to consider, first, the nature of the figure in which he may intend to lay out his plantation. On the form or figure of a plantation much of the expense of fencing it depends; and as this item very frequently forms in Britain a considerable proportion of the entire cost, it will be proper here to show the circumstances which, when attended to, lessen this expense.

When a proprietor intends to plant a piece of land upon his estate, say to the extent of 50 acres, he cannot exactly calculate the sum that may be remuired for fencing until he hats litid ont and actually measured the line of plantation, unless lie shall fix upon a rectilinear figure. 
In order to lay out a plantation of 50 acres in extent in the form of strips of 4 chains or $S S$ yards broad, the proprietor would require to erect 5676 lineal yards of fence to enclose it; and supposing the fence need in the enelosing of this plantation in the form of strips to be stone dyke, costing 1s. 6 d. per yard, then the whole expenses of fencing, in this instance, would amount to $£ 425,14 \mathrm{~s}$.- equal to $\mathfrak{L} 8,10$ s. 3d. per imperial acre upon the land enclosed.

But supposing that, instead of laying out the 50 acres in the form of strips, the proprietor wished to lay ont the sane curantity of land in the form of a regular square, then the side of a square that would contain 50 acres will be 490 yards; consequently the four sides added together will amount to 1960 lineal yards, which wrould be the extent of fencing required, instead of 5676 as in the first instance, although the same quantity of gromul is enclosed in both cases. Supposing, as before, the 1960 yards to be stone dyke, at 1s. 6ol. per yatrd, the whole expense of fencing the 50 acres contained in a square would be only $£ 147$, or $£ 2,17 \mathrm{~s} .9$ d. for each acre of the land enclosed. Now, this at once indicates the atvantage of forming all plantations in a solid compract form when fencing is necessary, in order to minimise the outlay. And by the cheaper method a much more valuable plantation is raised, an art from any other consideration connected with the mere fencing.

The above examples prove that the expense of fencing ground for new plantations can only be estimated when the land has been surveyed and mapped. The two following instances exhibit the maximum and minimum cost in the whole of the author's experience of fencing :-

1. For small plantations on home ground with broad-leaved trees, enclosed by wire fence $4 \mathrm{ft}$. high:-

To average expense of lencing, per acre, with wire fence, 76 yards at $1 \mathrm{~s}$. $6 \mathrm{~d}$.

To 100 yards of open drains, at 2d. per yard

To 1800 pits, at $1 \mathrm{~s}$. per 100 .

To 200 broanl-leaver trees, at 30s. per 1000

To 1600 Larch, at 20 s. per 1000

To four days of a man planting an acre, at 3 s.

\begin{tabular}{rrr}
$£ 5$ & 14 & 0 \\
0 & 16 & 8 \\
0 & 18 & 0 \\
0 & 6 & 0 \\
1 & 12 & 0 \\
0 & 12 & 0 \\
\hline & 12 & 18 \\
\hline
\end{tabular}

2. For an enclosure of 500 acres of moorland with Pines and Larch enclosed by wire fence:-

To average expense of fencing, per acre, with wire fence, 20 yards at $1 \mathrm{~s}$.

To 100 yards of drains, at $2 d$. per yard

'T'o 1200 Pines, at 5s. per 1000

'To 1200 Larch, at 10s. per 1000

To three days planting, at $3 \mathrm{~s}$. 
When plantations are made of small extent, the expense of fencing comes to a relatively very high figure per acre, as is shown in the case of the first example; while the larger they are made, the less it is per acre, as shown in the second example, in which the entire cost on the acre for fencing is only $20 \mathrm{~s}$. It may further be stated that in planting in some mountainous parts of the country, where the enclosures are mate very large, the expense of fencing is compratively small per acre, in some cases not costing over 5s. per acre. On this branch of the work, therefore, as may be noted from these examples, much of the expernse of British planting depends, and this is mainly regulated by the size of the enclosure.

The great Continental forests are not enclosed in any artificial manner, except in the case of immense deer-parks, round which a "Gitter," or $7 \mathrm{ft}$. high paling of wood or wire, is erected, in order to keep the deer from straying.

It is worthy of notice here that the expense of fencing the enclosures is often far greater than the costs of planting. In the first example given, the actual planting cost $£ 3,8$ s. ont of a total of $£ 9,18$ s. 8 d. per acre; while in the second example it is only $£ 1,7 \mathrm{~s}$. out of a total of $£ 3,3 \mathrm{~s} .8 \mathrm{~d}$. Hence, under the present system in Britain, the greater part of the expense of laying down land under flantations is often incurred for fencing and draining the enclosures.

The following costs of cultural operations in Bavaria may be of interest, and perhaps also of use to foresters in Britain (Gayer's Waldbau, 1889, p. 597):-

A man's wage is calculated at 1s. 9d. per diem.

A woman's " " $1 \mathrm{~s}, 2 \frac{1}{2} \mathrm{~d}$. "

The cost of a 2 -horsed cart is $9 \mathrm{~s}$.

" 1 " $1 \mathrm{~s}, 6 \mathrm{~d}$.

1. Cost of forming Nurseries-

(a) Preparing compost-heaps

(b) Earth-work-consisting of turning oxer the soil twice (in summer and the following spring) with the spade to a depth of 12 to $16 \mathrm{in.}$, clearing the soil of roots, knocking out the earth from the turf-sods, burning the roots and turf, and spreading the ashes orer the whole soil, preparing the soil with the iron rake, laying it out into squares, and forming the beds and the paths between them

2. Sowing the Seed in the Nurseriesi.e., strewing the becls with searched compost, pressing in the rills with sowing-boards, and sowing the sced carefully, covering up with compostearth and turf-ashes, and turning over the soil of old seedling-beds .
$£ 0 \quad 1 \quad \& \quad$ to $\mathfrak{L}_{0} \quad 2 \quad 0$ per 36 cubic ft.

$714 \quad 0$ to $8 \quad 0 \quad 0$ per acre.

$216 \quad 0$ to 3000 per ncre. 
3. Schooling or Transplanting 1- or 2 year-old scedlings from the seedbeds into the nursery - lines, and strewing compost over the beds at the end of June

1. Planting out yenrling Pines, Oak, Nkler; 2-year-old Isech, Spruce, Maple, Sy. cannore, Alder, Ask ; 3-year-old Silver Fir, s.c., without balls of earth, from the seed-berls to open grassy" land by means of the small eylindrical spade, and applying compost to them.

Planting alone, without any application of compost-earth

Planting, with application of compost, on very strong and binding lank, hard to work.

5. Planting as above on very grassy land, and including the preparation of the soil in the previous autumn, by means of turning back the socls of turf in pieces of $18 \mathrm{in.} \times 10 \mathrm{in}$.

Planting as above on strong ancl binding land, difficult to work, and apt to damage the planting implements

1i. Planting of transplants 2 to $3 \mathrm{ft}$. high and with balls of earth, including transport from the nursery and soilpreparation in the previous autumn

7. Planting broarl-leaved transplants of 3.3 to $5 \mathrm{ft}$. high - especially $\Lambda$ sh, Elm, Maples, in Willow and P'oplar coppices - without balls of earth, and including soil-preparation in autumn and transport from the nurseries

S. Planting cuttings of Willow and Poplar in trenclies $1 \mathrm{ft}$. (lecp) and 40 in. apart, to form coppice; this includes cutting the slips in February, sheughing them till required, preparing the trenches, and eovering the slips with earth

?. Sowing seed on soil from which the stumps have been grubbed up

10. Sowing in Rills after preparing the soil in strips $2 \mathrm{ft}$. broad and $4 \mathrm{ft}$. apart

11. Ditching. Forming main drains $6 \mathrm{ft}$. broad at top, $1 \mathrm{ft}$. broad below, and 40 in. deep

Forming side-clrains 16 in, wilc at top, $10 \mathrm{in}$. wide below, and 16 to $20 \mathrm{in}$. (lecp
É 20 to to 2 i jer 1000 .

$\begin{array}{llllllll}0 & 4 & 0 & \text { to } & 0 & i & i j & \text { per } 1000 .\end{array}$

0 ; 1) per 1000 .

080 to 0 9 9 per 1000.

$0 \quad 8 \quad 0$ to $0 \quad 10$ o per 1000 .

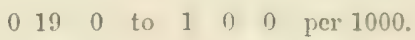

0140 to $01 \&$ o per 1000 .

1 1) 0 to 150 ก 1000.

0170 to 10 () per acre.

038 to 040 per acre.

$\begin{array}{lllllll}0 & 16 & 0 & \text { to } & 1 & 1 & \text { per acre. }\end{array}$

020 per 40 rumning $\mathrm{ft}$.

ก 1 ) per $\$ 0$ ruming $\mathrm{ft}$. 


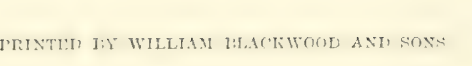




\section{BO0KS FoR FORESTERS.}

\section{TIIE BOOK OF THE LANDEI) ESTATE.}

Contaning Directions for the Maxagement and 1)evelotalest

of the Resoulcres of LANivid Property.

By ROBER'T E. BROTVN, Factor and Estate $\Lambda$ gent.

Royal octavo, with Illustrations, 21s.

\section{THE LARCH:}

A Practical Treatise on its Culture and Geveiral Managejent.

\section{By CHTISTOPHER YOUNG MICHE, Forester, Cullen House.}

With Illustrations of Remarkable Trees.

New and Cheaper Edition, with an Introductory Chapter

on the L.Arch Disease.

Crown 8vo, 5s.

"Within its pages he will fiml more information upon the best modes of treatment and culture of the larch tree, whether in the nursery or plantation, than in any otlier book extant in the English language." - Journal of F'orestry.

"' 1'ho work is a most valuable addition to our standard literature on arboriculture. The lover of trees will find the book full of curious and interesting material; while to owners and managers of woodlands the volume must prove of the highest practical ntility." - Lanil Journal.

\section{TIE PRACTICE OF FORESTRY.}

By the SAME AuTinol.

With Illustrations. Crown 8vo, 6s.

"A thoroughly prictical and sensible work......The author gives much excellent alvice, the rosult of practical knowledgo and careful study."-Moming I'ost.

"This is a manual of practice of the very best kind, as gool in its way as "The Lareh,' by the samo intelligent, observant, experienced forester."-Fichl.

"He gives information founded on long practice on almost erery point connected with the subject."-Jourual of IIorticulturc.

"A book of an eminently practical nature,...... dealing with evident ability with every question that is likely to meet the forester in his laily work."--Siolsman. 


\section{B00KS FOR AGRICULTURISTS.}

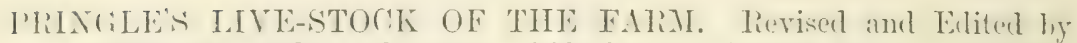
JAMES MACDONALD, Secretary, Highland and Agricultural Society of Scotland. Third and Cheaper Edition. Crown Sro, 7s. 6d.

"The general subject of food and feeding is dealt with from the most modem point of view. The varieties, loreeding, and general management of cattle, sheep; farm-horses, pigs, ant poultry are all discussed in a thoroughly practical way, and few farmers would fail to find here sound and useful hints that would well pay for the perusal of the book." -Daily News.

"This is the third edition of a work the value and anthority of which have long been recognised by the stock-raising community....... The chapters devoted to the treatment and rearing of cattle give very valuable instruction and information, which those who make the production of beef their special object will find it to their advantage to study." - Dorset County Chronicle.

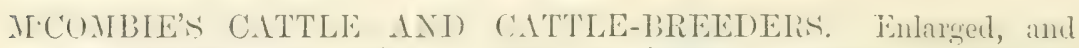
with Memoir of the Author by JAMES MACDONALD, Secretary, Highland and Agricultural Society of Scotland. New Edition. Crown 8vo, 3s. 6d,

"Much as we enjoy the first part of the book, which is mainly a record of tracling incidents, the lints on breeding and care of cattle are most useful. The student will do well to carefully study this section of the book; every sentence being the result of practical experience, is thoroughly reliable."-Ficld.

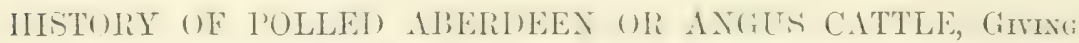
an Account of the Origin, Improvement, and Charactemistics of the Breed. By JAMIES MACDONALD and JAMES SINCLAIR, Editor of 'The Live-Stock Jourual.' Illustrated with numerous Animal P'ortraits. Large crown Svo, 12s. 6d.

"This is a book for cattle-breeders to buy and to study." - Ficld.

'THE STOCK-OWNER'S GUIDE. A Handy Medical Treatise for etert Man who owns an Ox or Cow. By G. S. HeATLEY, M.R.C.V.S. Crown 8ro, 4s. 6d.

"A work that will prove of the highest service to stock-owners. The arrangement is admirable, and the various diseases are described in clear and simple language."-F'armers' Giazetle.

\section{THE WILD RABBIT IN A NEW ASPECT; or, RabBIT-TVarmENS} THAT PAY. A record of recent Experiments conducted on the Estate of the Right Hon. the EARL of Wharncliffe at Wortley Hall. By J. SIMPSON. Small crown 8 vo, 5s.

"MIr Simpson's book will be found of great value......It is literally packed with interesting knowledge, all gleaned at first hand, and calculated to be of great interest to any one starting a rabbit-firm." - Pall s Mall Gazette. post.

"A sound practical guide to the treatment of rabbits and rabbit-warrens."-Morning "This is a valuable book, and should be in the hands of all who are interested in farming and sport."-Shooting Times.

\section{THE HANDY BOOK OF BEES, AND THEIR PROFITABLE} MANAGEMEN'T. By Ą, PETTIGREW. Fifth Edition, Enlarged. Crown 8vo, 3s.6d.

"The author of this volume is evidently a practical man, and knows a great deal more about bees and their habits than most of the bee-keepers in England; indeed, he may be said to be a very master in the art of bee mysteries."-Bell's Life in London.

"We recommend lis book to all who wish to spread a linowledge of this useful art among their neighbours and friends."-Land and Water. 




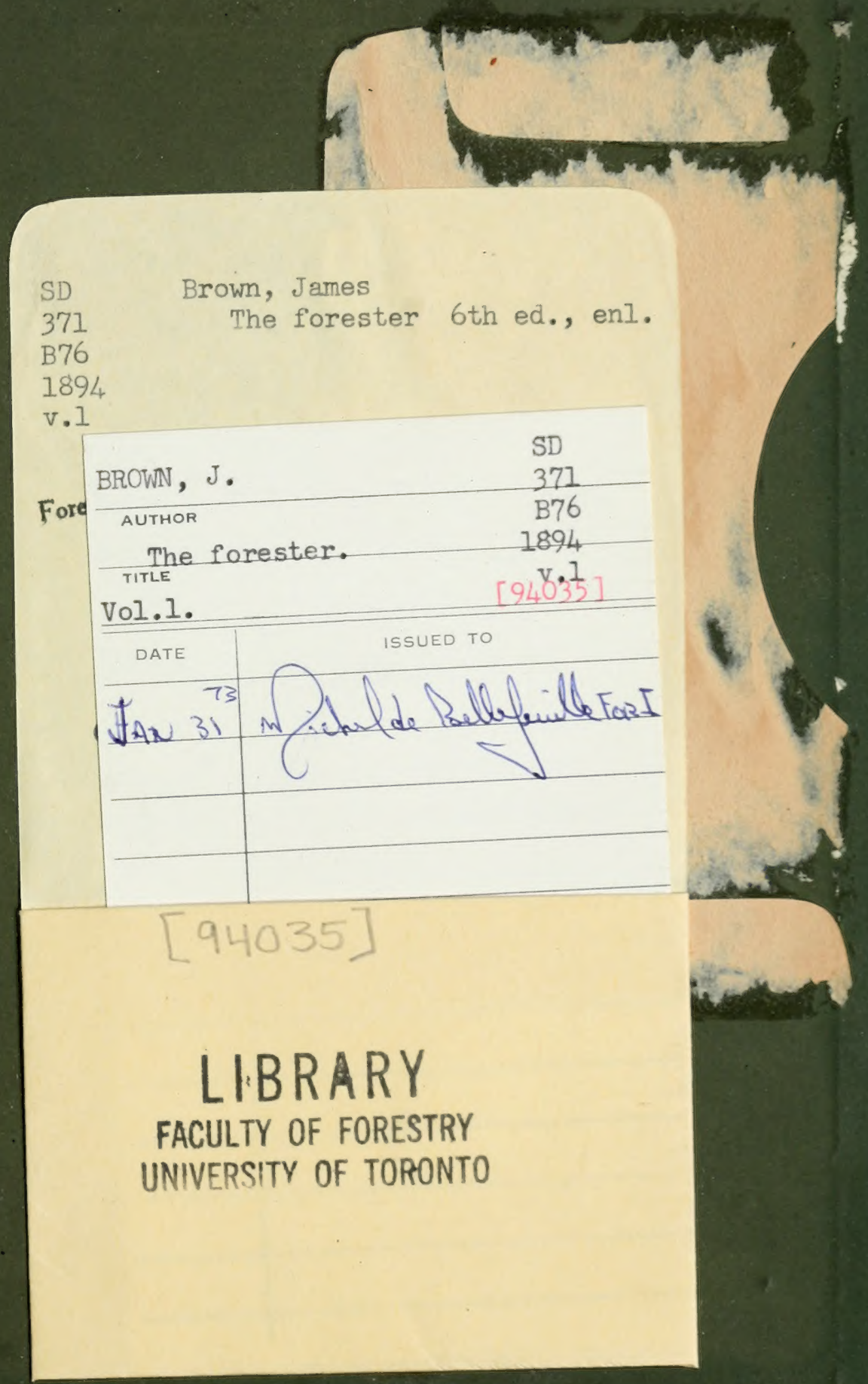



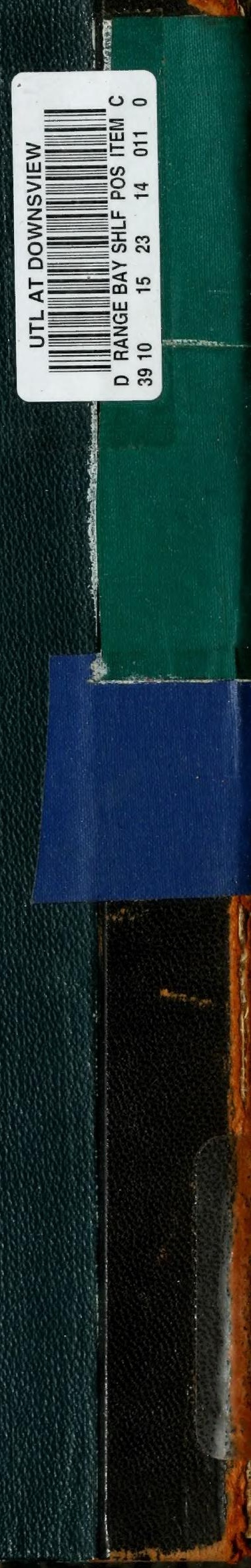